Study of the thermal stratification in PWR reactors and the PTS (pressurized thermal shock) phenomenon ADOLFO ROMERO HAMERS 



\title{
POLITECHNIC UNIVERSITY OF VALENCIA
}

Energy Engineering Institute

Department of Chemical and Nuclear engineering

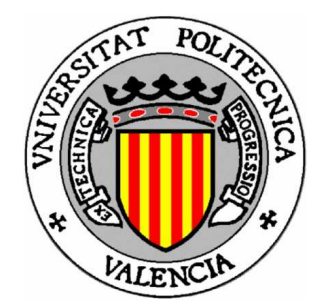

\section{STUDY OF THE THERMAL STRATIFICATION IN PWR REACTORS AND THE PTS (PRESSURIZED THERMAL SHOCK) PHENOMENON}

\section{DOCTORAL THESIS}

\author{
ADOLFO ROMERO HAMERS \\ INDUSTRIAL ENGINEER
}

By the University Jaume I of Castellón

Supervisors:

\author{
Dr. José Luís Muñoz-Cobo González \\ Universidad Politécnica de Valencia \\ Dr. Sergio Chiva Vicent \\ Universidad Jaume I de Castellón
}

Valencia, Febrero 2014 


\section{Collection Doctoral Thesis}

(c) Adolfo Romero Hamers

(c) 2014, of the present edition: Editorial Universitat Politècnica de València Telf.: 963877012 / www.lalibreria.upv.es

ISBN: 978-84-9048-235-3 (printed version)

Any unauthorized copying, distribution, marketing, editing, and in general any other exploitation, for whatever reason, of this piece of work or any part thereof, is strictly prohibited without the authors' expressed and written permission. 


\section{REMARKS}

A fluid is any body whose parts yield to any force impressed on it, and by yielding, are easily moved among themselves.

Sir Isaac Newton, from Section V, Book II of the Principia, 1687.

Numerical precision is the very soul of science.

Sir D'Arcy Wentworth Thompson, Scottish biologist and natural scientist, 1917.

Music is the pleasure the human mind experiences from counting without being aware that it is counting

Gottfried Wilhelm Leibniz, 1646-1716 

I dedicate this work to my parents, to my sister, and to my uncle. 



\section{ACKNOWLEDGEMENTS}

Quiero expresar mi agradecimiento a D. José Luís Muñoz-Cobo González por darme la oportunidad de haber estado este tiempo a su lado en el departamento de Ingeniería Química y Nuclear de la Universidad Politécnica de Valencia, y por todo lo aprendido en este periodo, así como su ayuda y apoyo a la hora de realizar esta tesis.

Quiero mostrar mi agradecimiento también a D. Sergio Chiva Vicent por el apoyo y consejo en ciertos momentos de dificultad durante el desarrollo de este trabajo.

También quiero agradecer aquí a Clara Segarra su apoyo durante este último tramo de la tesis. 



\begin{abstract}
In the event of hypothetical accident scenarios in PWR, emergency strategies have to be mapped out, in order to guarantee the reliable removal of decay heat from the reactor core, also in case of component breakdown. One essential passive heat removal mechanism is the reflux condensation cooling mode. This mode can appear for instance during a small break loss-of-coolant-accident (LOCA) or because of loss of residual heat removal (RHR) system during mid loop operation at plant outage after the reactor shutdown.
\end{abstract}

In the scenario of a loss-of-coolant-accident (LOCA), which is caused by the leakage at any location in the primary circuit, it is considered that the reactor will be depressurized and vaporization will take place, thereby creating steam in the PWR primary side. Should this lead to "reflux condensation", which may be a favourable event progression, the generated steam will flow to the steam generator through the hot leg.

This steam will condense in the steam generator and the condensate will flow back through the hot leg to the reactor, resulting in countercurrent steam/water flow. In some scenarios, the success of core cooling depends on the behaviour of this countercurrent flow.

Over several decades, a number of experimental and theoretical studies of countercurrent gas-liquid two-phase flow have been carried out to understand the fundamental aspect of the flooding mechanism and to prove practical knowledge for the safety design of nuclear reactors. Starting from the pioneering paper of Wallis (1961), extensive CCFL data have been accumulated from experimental studies dealing with a diverse array of conditions A one-dimensional two field model was developed in order to predict the countercurrent steam and liquid flow that results under certain conditions in the cold leg of a PWR when a SBLOCA (small break loss of coolant accident) in the hot leg is produced.

The countercurrent developed model is able to predict the pressure, temperature and velocity distributions for both phases. This computer code predicts this scenario by solving the mass, momentum and energy conservation equations for the liquid and for the steam separately, and they are linked by evaluating the interfacial condensation and heat transfer, 
the steam wall condensation and heat transfer, and the interfacial friction as the closure relations.

The convective terms which appear in the discretization of the mass and energy conservation equations, were evaluated using the ULTIMATE-SOU (second order upwinding) method. For the momentum equation convective terms the ULTIMATEQUICKEST method was used.

The steam-water countercurrent developed code has been validated using some experimental data extracted from some previously published articles about the direct condensation phenomenon for stratified two-phase flow and experimental data from the LAOKOON experimental facility at the Technical University of Munich. 


\section{RESUMEN}

En el hipotético escenario de un suceso que ocasione un accidente en un PWR (reactor de agua a presión), se han de establecer las estrategias de emergencia a seguir con el fin de garantizar la evacuación del calor residual del núcleo del reactor, así como en el caso de una hipotética rotura de aun componente.

Un mecanismo pasivo esencial de extracción del calor es el modo de refrigeración por reflujo de condensado. Este modo puede aparecer durante un pequeño LOCA (Loss Of Coolant Accident) o por una pérdida del sistema de extracción de calor durante operación de medio lazo tras una parada del reactor. En el escenario de un LOCA, el cual está causado por una pérdida de refrigerante en algún lugar del circuito primario, se considera que se producirá la despresurización del primario y la consecuente vaporización de parte del fluido presente en las ramas del primario, lo cual generará vapor en el circuito primario.

Esto nos conducirá al fenómeno del reflujo de condensado. El vapor generado fluirá a través de la rama caliente hacia el primario de los generadores de vapor. Éste vapor condensará en las paredes de los tubos en U de los generadores y volverá hacia la rama caliente resultando en el fenómeno de flujo bifásico liquido/vapor en contracorriente. En ciertos escenarios la correcta refrigeración del núcleo depende del comportamiento de este flujo e contracorriente.

Durante varias décadas se han realizado diversos estudios teóricos y experimentales del fenómeno del flujo bifásico liquido/vapor en contracorriente con el fin de entender el mecanismo del reflujo y con el fin de obtener conocimiento práctico para asegurar la seguridad de las centrales nucleares. Partiendo del artículo pionero de Wallis (1961), se han acumulado extensos datos sobre el CCFL (countercurrent flow limit) para un amplio abanico de condiciones de flujo.

Se ha desarrollado un modelo numérico de flujo bifásico líquido/vapor en contracorriente con el fin de predecir los perfiles de presión, temperatura y velocidad de ambas fases. Éste código predice la distribución de las principales variables físicas en este escenario resolviendo numéricamente las ecuaciones de conservación de masa, momento y energía 
por separado, y acoplándolas a través de las llamadas condiciones de salto o de cierre. Estas condiciones son la fricción interfacial, la condensación en la pared de la zona de vapor y la condensación y transferencia de calor en la interfase.

Los términos convectivos que aparecen en las ecuaciones de conservación de la masa y de la energía han sido evaluados usando el método ULTIMATE-SOU (second order upwinding). Para los términos convectivos de la ecuación de conservación del momento se ha utilizado el método QUICKEST en combinación con la estrategia ULTIMATE.

El código bifásico liquido/vapor en contracorriente que se ha desarrollado ha sido validado haciendo uso de datos publicados en diferentes artículos relacionados en revistas internacionales sobre condensación directa, y haciendo uso de datos obtenidos en la instalación experimental LAOKOON en la Universidad técnica de Munich. 


\section{RESUM}

En l'hipotètic escenari d'un succés que ocasione un accident en un PWR (reactor d'aigua a pressió), s'han d'establir estratègies d'emergència a seguir amb la finalitat de garantir l'evacuació del calor residual del nucli del reactor, així com en el cas de l'hipotètic trencament de algún component.

Un mecanisme passiu especial d’extracció de la calor és el mode de refrigeració per reflux de condensat. Aquest mode pot aparèixer durant un menut LOCA (Loss Of coolant Accident) o per una pèrdua del sistema d'extracció de calor durant l'operació en mig llaç darrere d'una parada del reactor. A l'escenari d'un LOCA, el qual està causat per una pèrdua de refrigerant en algun lloc del circuit primari, es considera que produeix la despressurització del primari i la conseqüent vaporització de part del fluid present en les branques del primari, el qual produirà vapor en el circuit primari.

Açò ens portarà al fenomen del reflux de condesat. El vapor generat fluirà a través de la branca calenta cap al primari dels generadors de vapor. Aquest vapor condensarà en les parets dels tubs en $\mathrm{U}$ dels generadors de vapor i tornarà cap a la branca calenta resultant en el fenomen del flux bifàsic líquid/vapor a contracorrent. En certs escenaris la correcta refrigeració del nucli depèn del comportament d’aquest flux a contracorrent.

Durant varies dècades s'han realitzat diversos estudis teòrics y experimentals del fenomen del flux bifàsic líquid/vapor a contracorrent amb la finalitat d’entendre el mecanisme del reflux i obtindre el coneixement pràctic per assegurar la seguretat de les centrals nuclears. Partint de l'article pioner de Wallis (1961), s’han acumulat extenses dades sobre el CCFL (countercurrent flow limit) per a un ampli ventall de condicions de flux.

S ’ ha desenvolupat un model numèric de flux bifàsic líquid/vapor a contracorrent amb la finalitat de predir els perfils de pressió, temperatura i velocitat de les dues fases. Aquest codi prediu la distribució de les principals variables físiques en aquest escenari resolent les equacions de conservació de massa, moment i d’energia per separat i acoplant-les a través de les anomenades condicions de salt o de tancament. Aquestes condicions són la fricció 
interfacial, la condensació en la paret de la zona de vapor, i la condensació i transferència de calor a l'interfase.

Els termes convectius que apareixen en les equacions de conservació de la massa i de l'energia han estat avaluats usant el mètode ULTIMATE-SOU (second order upwinding). Per al càlcul dels termes convectius de l'ecuació del moment s'ha utilitzat el mètode QUICKEST en combinació amb l'estratègia ULTIMATE.

El codi bifàsic liquid/vapor a contracorrent que s'ha desenvolupat ha sigut validat fent ús de dades publicades en diferents articles relacionats en diverses revistes internacionals sobre condensació directa, i fent ús de dades obtengudes en la instal.lació experimental LAOKOON en la Universitat tècnica de Munich. 


\section{NOMENCLATURE}

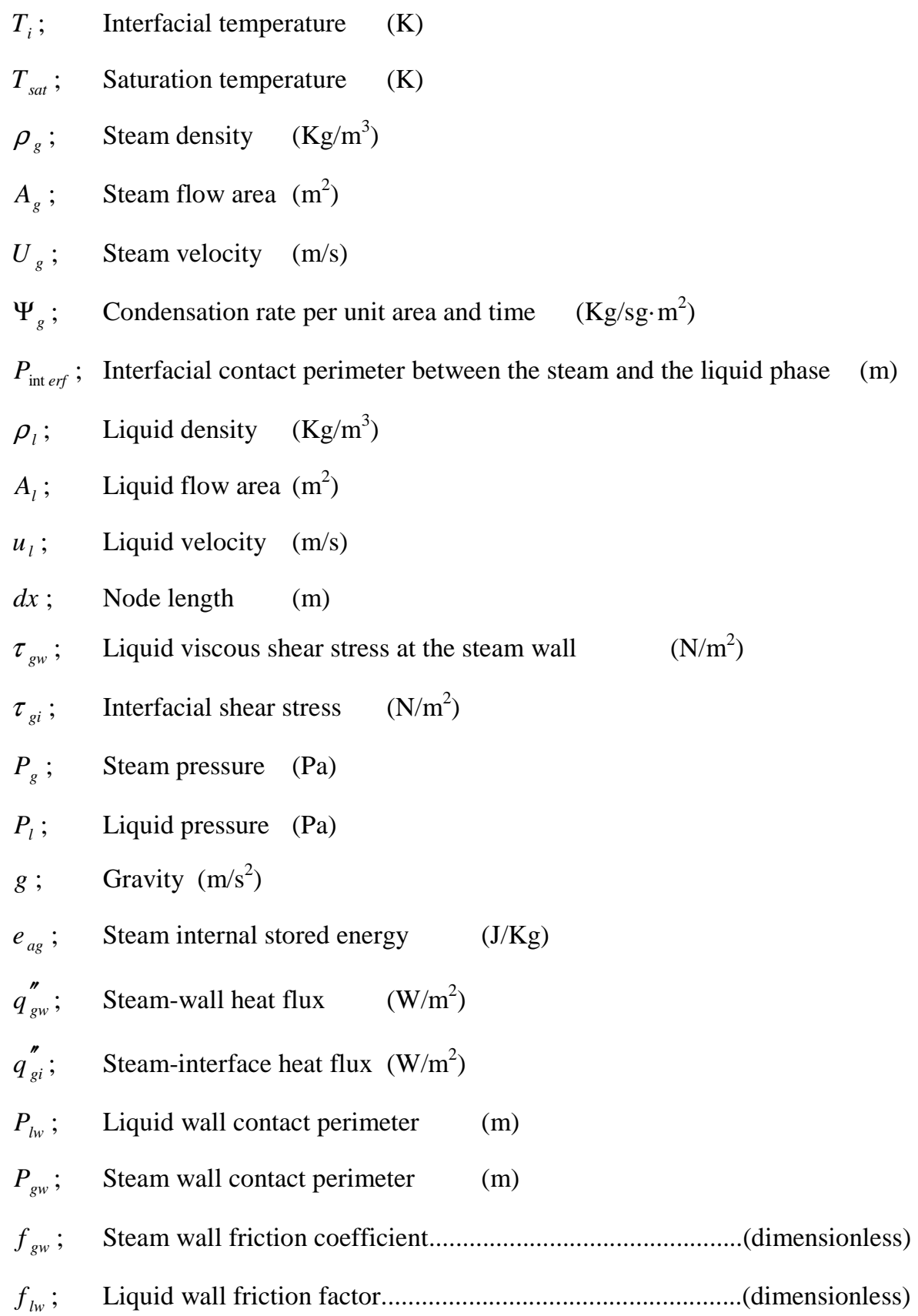


$f_{g i} ; \quad$ Interfacial friction factor. (dimensionless)

$\Phi_{g} ; \quad$ Condensation mass during one time step in one cell $(\mathrm{Kg})$

$\Phi_{g w} ;$ Condensation mass during one time step in one cell at the steam wall $\left(\mathrm{K}_{\mathrm{g}}\right)$

$Q_{l i} ; \quad$ Liquid interfacial heat transfer during one time step in one cell $\quad(\mathrm{J})$

$Q_{g i} ; \quad$ Steam interfacial heat transfer during one time step in one cell $\quad$ (J)

$T_{g} ; \quad$ Steam temperature $\quad(\mathrm{K})$

$T_{l} ; \quad$ Liquid temperature $\quad(\mathrm{K})$

$T_{\text {sati }} ; \quad$ Interface temperature $\quad(\mathrm{K})$

$h_{a} ; \quad$ Convective heat transfer coefficient to the exterior $\left(\mathrm{W} / \mathrm{m}^{2} \mathrm{~K}\right)$

$\delta ; \quad$ Thickness of the condensate film (m)

th; Pipe wall thickness (m)

$R ; \quad$ Pipe radius $\quad(\mathrm{m})$

$\theta_{g} ; \quad$ Steam area angle $(\mathrm{rad})$

$r_{1} ; \quad$ Outer radius $\quad(\mathrm{m})$

$r_{2} ; \quad$ Inner radius $\quad(\mathrm{m})$

$T_{i g} ; \quad$ Steam wall interfacial temperature (K)

$\theta_{l} ; \quad$ Liquid area angle $\quad(\mathrm{rad})$

$T_{w l} ; \quad$ Liquid wall temperature $(\mathrm{K})$

$T_{w g} ; \quad$ Steam wall temperature $(\mathrm{K})$

$T_{a} ; \quad$ Exterior temperature $\quad(\mathrm{K})$

$R_{l} ; \quad$ Liquid wall thermal resistance $\quad(\mathrm{K} / \mathrm{W})$

$R_{g} ; \quad$ Steam wall thermal resistance $\quad(\mathrm{K} / \mathrm{W})$

$\Gamma_{k} ; \quad$ Rate of generation of the K phase per unit volume $\left(\mathrm{Kg} / \mathrm{m}^{3}\right)$

$Q_{w l} ; \quad$ Heat transfer to the liquid wall at one time step and one cell (J)

$Q_{w g} ; \quad$ Heat transfer to the steam wall at one time step and one cell (J) 
$h_{l \text { int }} ; \quad$ Liquid interfacial convective heat transfer coefficient

$\left(\mathrm{W} / \mathrm{m}^{2} \mathrm{~K}\right)$

$h_{g \text { int }}$; Steam interfacial convective heat transfer coefficient

$\left(\mathrm{W} / \mathrm{m}^{2} \mathrm{~K}\right)$

$K_{l} ; \quad$ Liquid conductivity $\quad(\mathrm{W} / \mathrm{mK})$

$K_{g} ; \quad$ Steam conductivity $\quad(\mathrm{W} / \mathrm{mK})$

$D h_{l} ; \quad$ Liquid hydraulic diameter

(m)

$D h_{g} ; \quad$ Steam hydraulic diameter (m)

$\operatorname{Re}_{l} ; \quad$ Liquid Reynolds number... (dimensionless)

$\operatorname{Re}_{g} ; \quad$ Steam Reynolds number. (dimensionless)

$J a ; \quad J a k o b$ number... (dimensionless)

$\mathrm{Pr}_{l} ; \quad$ Liquid Prandtl number. (dimensionless)

$\mu_{l} ; \quad$ Liquid dynamic viscosity $(\mathrm{Pa} \cdot \mathrm{s})$

$\mu_{g} ; \quad$ Steam dynamic viscosity (Pa.s)

$C p_{l} ; \quad$ Liquid specific heat at constant pressure $\quad(\mathrm{J} / \mathrm{KgK})$

$h_{w_{l}} ; \quad$ Liquid wall convective heat transfer coefficient $\quad\left(\mathrm{W} / \mathrm{m}^{2} \mathrm{~K}\right)$

$h_{w_{g_{-} \text {sens }}}$;Steam wall sensible heat transfer coefficient $\quad\left(\mathrm{W} / \mathrm{m}^{2} \mathrm{~K}\right)$

$G_{r_{l}} ; \quad$ Liquid Grashof number. (dimensionless)

$G_{r_{g}} ; \quad$ Steam Grashof number.. (dimensionless)

$h_{g} ; \quad$ Steam enthalpy at the bulk $\quad(\mathrm{J} / \mathrm{Kg})$

$h_{f g} ; \quad$ Phase change latent heat $(\mathrm{J} / \mathrm{Kg})$. $(\mathrm{J} / \mathrm{Kg})$

$h_{l} ; \quad$ Liquid enthalpy at the bulk $\quad(\mathrm{J} / \mathrm{Kg})$

$N u_{l \text { int }} ;$ Liquid interface Nusselt number. (dimensionless) 


\section{KEYWORDS}

Thermal stratification, flooding, countercurrent flow, cocurrent-flow, countercurrent flow limitation, zero penetration point, pressurized thermal shock, LOCA (loss of coolant accident), high pressure injection, direct contact condensation, interfacial heat transfer, interfacial condensation, interfacial friction. 


\section{TABLE OF CONTENTS}

ACKNOWLEDGEMENTS

1.3 BRIEF INTRODUCTION TO THE PHYSICAL MATTER WE ARE DEALING WITH........................................................................ $11_{-}$

1.4 THESIS DESCRIPTION .......................................................... 1_6

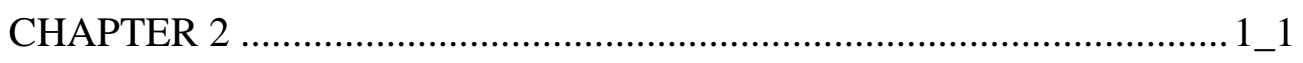

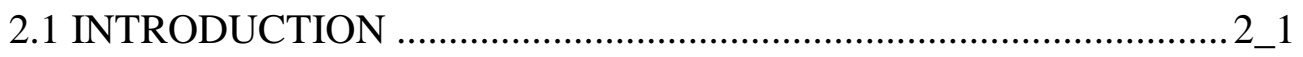

2.2 RELEVANCE OF THE THERMAL STRATIFICATION

PHENOMENON ….................................................................... $2 \_3$

2.2.1 THERMAL TRANSIENTS ................................................... 2_6

2.2.2 THERMAL STRATIFICATION................................................ 2 _6

2.3 THERMAL STRATIFICATION IN PIPES ....................................2_9

2.3.1 THERMAL STRATIFICATION IN THE PURGE LINE OF THE

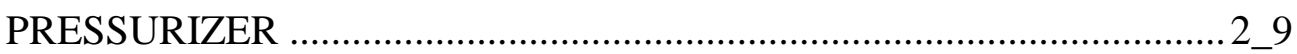


2.3.2 THERMAL STRESS IN THE SPRAY LINES ….........................2_13

2.3.3 THERMAL STRESS IN OTHER LINES ...................................2_14

2.3.3.1 SAFETY INJECTION LINES ..............................................2_14

2.3.3.2 STEAM GENERATOR FEEDWATER LINES ........................2_17

2.3.3.3 RHR SYSTEM LINE..........................................................2_18

2.4 STRATIFICATION IN THE COLD LEG DUE TO THE SAFETY

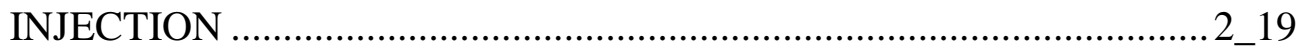

2.5 DESCRIPTION OF THE PHENOMENA THAT MAY BE INVOLVED WHEN STUDYING THE THERMAL STRATIFICATION IN THE COLD LEG

2.5.1 FROUDE NUMBER AND FLOW REGIME CLASSIFICATION 2_23

A) SUBCRITICAL FLOW $(\mathrm{Fr}<1)$ : ................................................ $2 \_25$

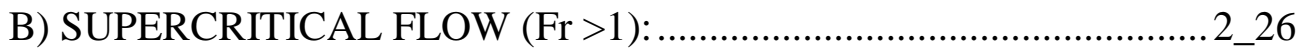

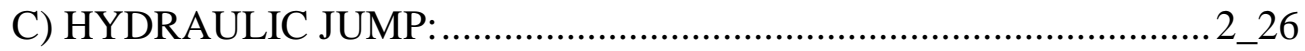

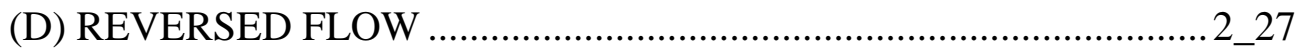

D.1 PARTIALLY REVERSED FLOW ….......................................2_28

D.2 TOTALLY REVERSED FLOW ………..................................2_28

D.3 COUNTERCURRENT FLOW LIMITATION ..............................2_29

2.6 MODELLING OF THE COUNTERCURRENT PHENOMENON BY

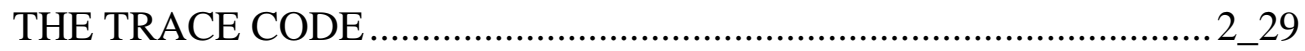

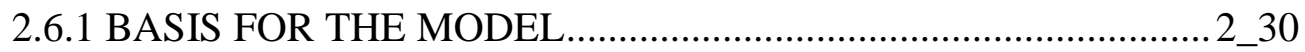

2.6.2 DIRECT CONDENSATION THEORY AND LITERATURE

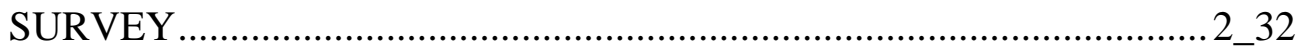

2.6.2.1 DIRECT CONTACT CONDENSATION THEORY ..................2_32

2.6.2.2 LITERATURE SURVEY ...................................................2_40

CHAPTER 3 ….............................................................................

3.1 INTRODUCTION …................................................................ 3

3.2 TEST 1.2 DESCRIPTION …..................................................... 3_2

3.2.1 EXPERIMENTAL PROCEDURE AND INITIAL CONDITIONS .3_2 
3.2.2 BOUNDARY CONDITIONS..................................................... 3 3

3.2.3 EXPERIMENT DEVELOPMENT ............................................... $3 \_3$

3.2.4 EXPERIMENTAL RESULTS..................................................... $3 \_6$

3.2.4.1 INITIAL STEADY-STATE CONDITIONS ................................... 3 6

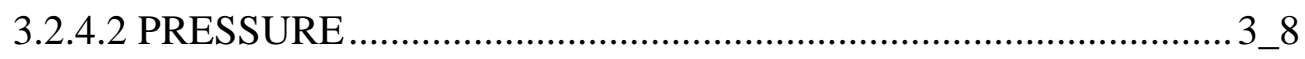

3.2.4.3 FLOWS AND LIQUID LEVELS …………………………….... 3_9

3.2.4.4 TEMPERATURE.......................................................................

3.2.4.5 ACCUMULATORS INJECTION …………………………....... 3 14

3.2.4.6 END OF THE EXPERIMENT ……………………………....... 3 15

3.3 STEADY-STATE DEMONSTRATION........................................... 15

3.3.1 STEADY-STATE RESULTS WITH THE TRACE MODEL ..........3_16

3.3.1.1 VESSEL .........................................................................

3.3.1.2 PRIMARY LOOP ........................................................ 3

3.3.1.3 PRESSURIZER ……………....................................... 19

3.3.1.4 PUMPS ................................................................. 3

3.3.1.5 STEAM GENERATORS ………………………………... $3 \_20$

3.3.1.6 ACCUMULATORS ........................................................... $3 \_23$

3.3.1.7 HIGH PRESSURE INJECTION SYSTEM ..............................3_24

3.4 RESULTS OF THE EXPERIMENT REPRODUCTION WITH THE TRACE CODE AND COMPARISON WITH THE EXPERIMENTAL

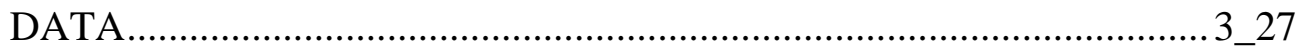

3.4.1 PRIMARY PRESSURE...............................................................

3.4.2 SECONDARY PRESSURE ………………………………...... $3 \_27$

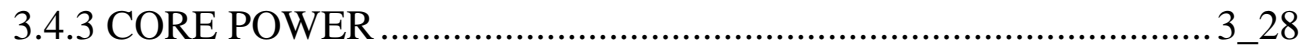

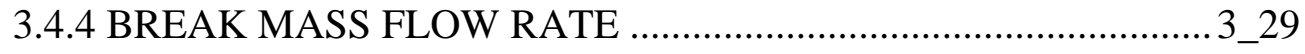

3.4.5 VOID FRACTION ................................................................... 30

3.4.6 HPI MAS FLOW RATE ................................................................. 3 3 30

3.4.7 ACCUMULATORS MASS FLOW RATE INJECTION .................3_31 
3.4.8 PRIMARY MASS FLOW RATE 3_32

3.4.9 MASS FLOW RATE THROUGH THE SAFETY AND RELIEF VALVES 3_32

3.4.10 LIQUID TEMPERATURES AT THE COLD LEG 3_33

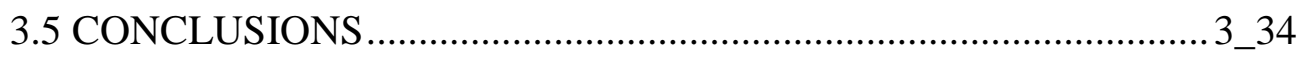

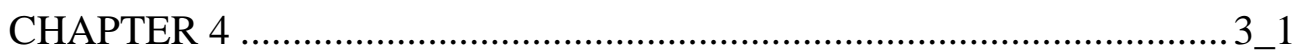

STEAM-WATER COUNTERCURRENT FLOW PHENOMENON AND

ITS MODELIZATION …………………………………………..... 3

4.1 INTRODUCTION .................................................................. 4 _1

4.2 CONSIDERATIONS OF THE MODEL ............................................ 4_2

4.3 CONSERVATION EQUATIONS .................................................... 4_3

4.3.1 LOCAL AND INSTANTANEOUS CONSERVATION EQUATIONS4_3

4.3.2 3D AVERAGED CONSERVATION EQUATIONS ......................... 4_6

4.3.3 1D AVERAGED CONSERVATION EQUATIONS ........................ 4_15

4.4 DISCRETIZATION OF THE EQUATIONS ………………………... 4_23

4.4.1 GRID DESCRIPTION ................................................................ 4_25

4.4.2 DISCRETIZATION OF THE MASS CONSERVATION

EQUATION …………............................................................... 4_25

4.4.3 DISCRETIZATION OF THE MOMENTUM CONSERVATION

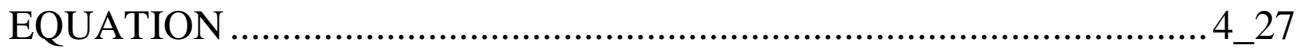

4.4.4 DISCRETIZATION OF THE ENERGY EQUATION .................... 4_31

4.5 CLOSURE OR CONSTITUTIVE EQUATIONS …………………..... 4 _33

4.5.1 INTERFACIAL AND WALL FRICTION ....................................... 4_34

4.5.2 STEAM MASS CONDENSATION ……………………………... 4 _36

4.5.2.1 INTERFACIAL CONDENSATION ............................................ 4 _36

4.5.2.2 STEAM WALL CONDENSATION ............................................ 4 _37

4.5.3 INTERFACIAL HEAT TRANSFER ............................................. 4 _38

4.6 HEAT TRANSFER TO THE WALL ............................................... 4 _40 
4.6.1 LIQUID WALL HEAT TRANSFER ......................................... 4 _40

4.6.2 STEAM WALL HEAT TRANSFER ......................................... 4 _42

4.6.3 WALL TEMPERATURES AND LUMPED THERMAL

RESISTANCE COEFFICIENT .....................................................4_45

4.6.3.1 LIQUID PHASE ............................................................... 4 _46

4.6.3.2 STEAM PHASE .......................................................... 4 _48

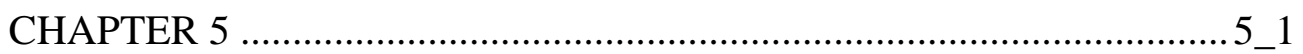

NUMERICAL RESOLUTION AND STRUCTURE OF THE CC

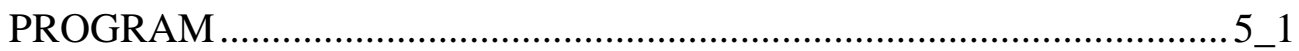

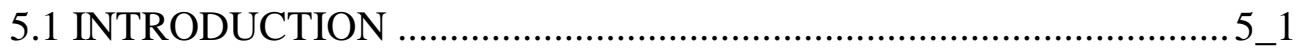

5.2 SEMI-IMPLICIT RESOLUTION OF THE MOMENTUM

EQUATION

5.3 IMPLICIT RESOLUTION OF THE MASS AND ENERGY

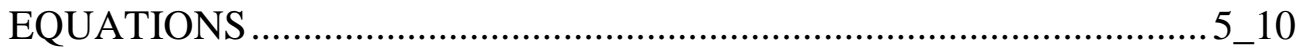

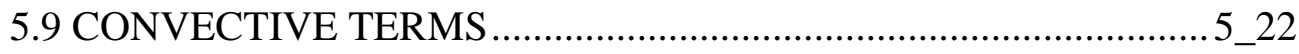

5.10 CONVERGENCE ALGORITHM FOR THE BIPHASIC SYSTEM

AND EQUATIONS LINKAGE .....................................................5_23

5.11 GEOMETRICAL VARIABLES UPDATING ..............................5_25

5.12 DESIGN AND IMPLEMENTATION OF THE CC CODE.............5_27

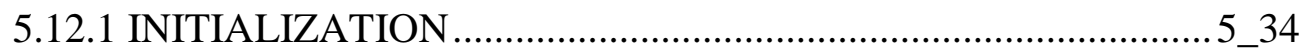

5.12.2 VEFICV AND VEFICL SUBROUTINES .................................5_37

5.12.3 VIMPV AND VIMPL SUBROUTINES ....................................5_38

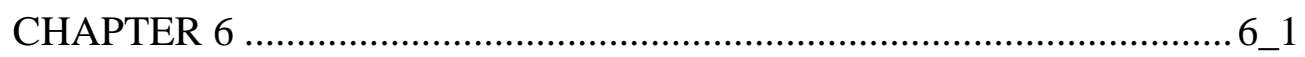

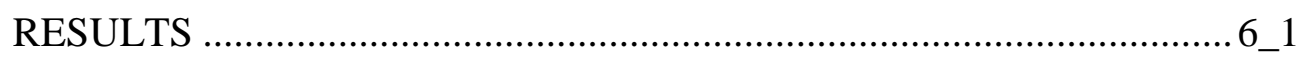

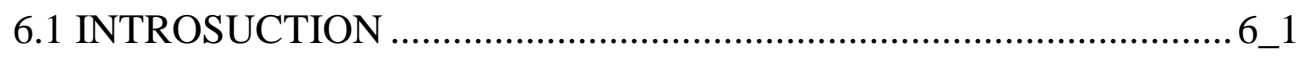

6.2 CC CODE VALIDATION ........................................................... $6 \_2$

6.3 VALIDATION 1 ...................................................................... $6 \_3$

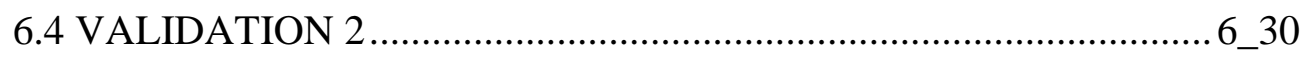

6.4 VALIDATION 3 ................................................................. 6 _ 39 


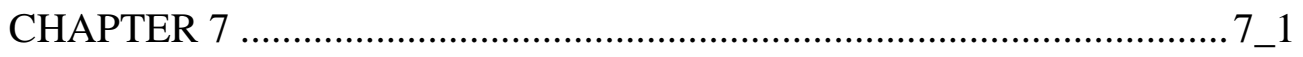

CONCLUSIONS AND FUTURE WORK ............................................ 7 _1

7.1 CONCLUSIONS ...................................................................

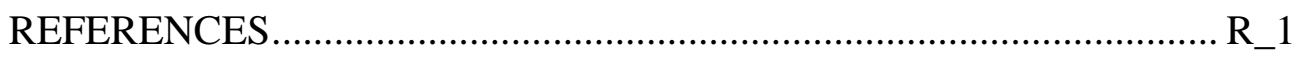

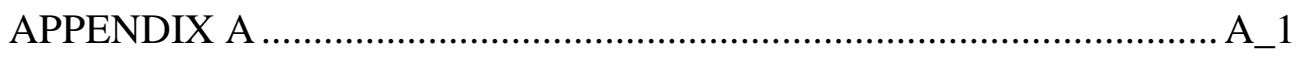

A.1 INTRODUCTION ....................................................................... A_1

A.2 CHARACTERISTIC OF MULTIPHASE FLOW .............................. A_3

A.3 CLASSIFICATION OF TWO-PHASE FLOW ................................. A_4

A.4 LOCAL AND INSTANTANEOUS CONSERVATION

EQUATIONS ................................................................................ A_

A.5 CONSERVATION EQUATIONS AVERAGING .......................... A_10

A.5.1 VOLUMETRIC AVERAGING OF THE INSTANT AND LOCAL CONSERVATION EQUATIONS ................................................... A_13

A.6 THE CONSERVATION EQUATIONS AVERAGING AND THEIR JUMP CONDITIONS ….............................................................. A_15

A.6.1 THE MASS CONSERVATION EQUATION AVERAGING AND its JUMP CONDITION A_16

A.6.2 THE MOMENTUM CONSERVATION EQUATION AVERAGING AND ITS JUMP CONDITION.

A.6.3 THE ENERGY CONSERVATION EQUATION AVERAGING AND ITS JUMP CONDITION....................................................... A_21

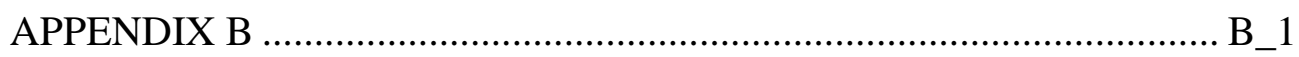

CALCULATION OF THE CONVECTIVE TERMS OF THE

CONSERVATION EQUATIONS ...................................................... B_1

B.1 CONVECTIVE TERMS ............................................................. B_1

B.2 FIRST ORDER UPWINDING (fou) ............................................ B_1

B.3 SECOND ORDER UPWINDING (sou) ....................................... B_4

B.4 QUICKEST method ................................................................. B_6

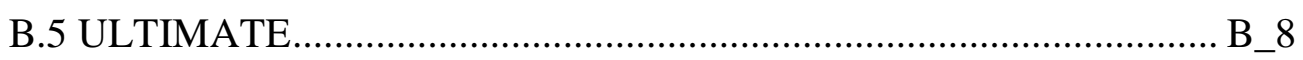




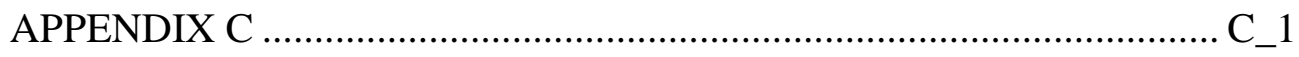

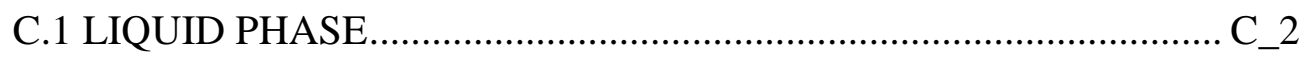

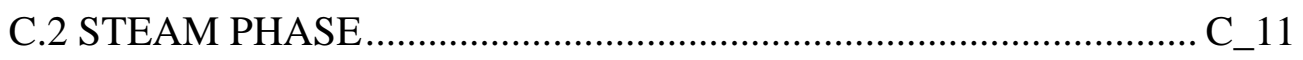

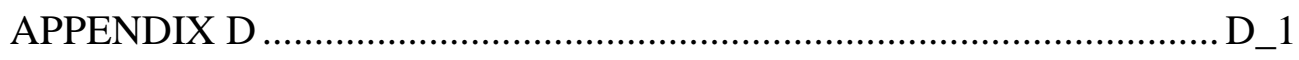

CALCULATION OF THE INTERFACIAL CONDENSATION AND ITS

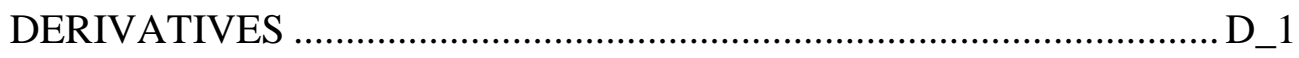

D.1 LIQUID PHASE ................................................................. D_1

D.1.1 Derivative of the LIQUID CONDENSATION WITH RESPECT TO

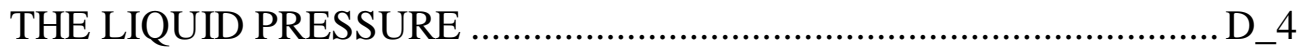

D.1.2 DERIVATIVE OF THE LIQUID CONDENSATION WITH RESPECT TO THE LIQUID PRESSURE DIFFERENCES.................... D_5

D.1.3 DERIVATIVE OF THE LIQUID CONDENSATION WITH RESPECT TO THE LIQUID TEMPERATURE.................................... D_5

D.2 STEAM PHASE...................................................................... D

D.2.1 DERIVATIVE OF THE STEAM CONDENSATION DERIVATIVE WITH RESPECT TO THE STEAM PRESSURE.................................... D_9

D.1.2 DERIVATIVE OF THE STEAM CONDENSATION WITH RESPECT TO THE STEAM PRESSURE DIFFERENCES.................. D_11

D.1.3 DERIVATIVE OF THE STEAM CONDENSATION WITH RESPECT TO THE STEAM TEMPERATURE ................................... D_11

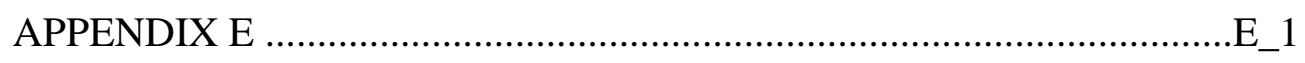

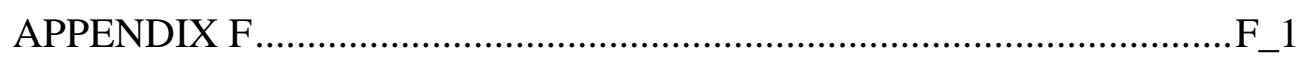

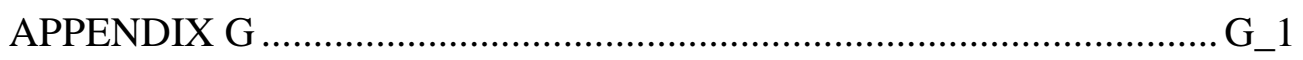




\section{LIST OF FIGURES}

Figure 1.1 PWR piping configuration and reflux condensation flow paths. .....................1_4 Figure 1.2. Terminologies in countercurrent gas-liquid two-phase flow in a model of PWR hot leg presented by Deendarlianto et al. (2008)............................................................ 6 Figure 2.1 Effect of the thermal stratification on the pipe deformation ...........................2_7 Figure 2.2 Axial thermal tensions profiles originated by two different levels of thermal

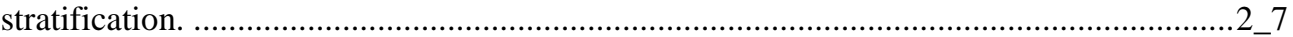

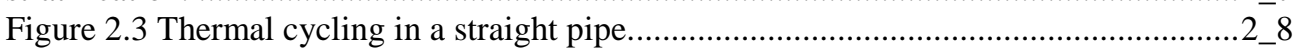
Figure 2.4 Thermal cycling in an elbow.................................................................2_8

Figure 2.5 Striping

Figure 2.6. Thermal stratification in the purge line of the pressurizer due to the flow through itself.

Figure 2.7 Layout of a purge pressurizer line of a Westinghouse plant .........................2_10 Figure 2.8. Thermocouple and displacement transducer locations at the YGN Korean plant

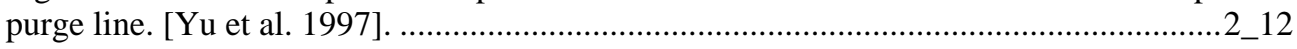

Figure 2.9 Circular temperatures distribution in an outgoing purge flow at the YGN plant

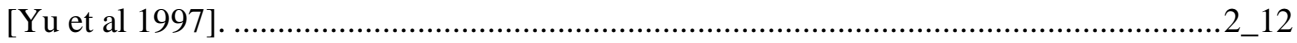
Figure 2.10 Different working conditions at the pressurizer spray line. ........................2_13 Figure 2.11 Pressurizer spray lines arrangement at the Grhonde plant. .........................2_14 Figure 2.12 Interaction between the turbulent flow in the main pipe and the stagnant coolant at the branch.

Figure 2.13 Crack produced in 1987 in the Farley 2 reactor. The crack is situated in the welding between the elbow and the pipe. It was $120^{\circ}$ circumferentially extended at the inner face and had a $25 \mathrm{~mm}$ length at the outer surface. ...........................................2_16 Figure 2.14 Crack produced in 1988 in the Tianghe 1 reactor. The crack is situated in the elbow with an internal length of $89 \mathrm{~mm}$ and a exterior one of $41 \mathrm{~mm}$..........................2_16 Figure 2.15 Crack produced in 1977 in the Oconee 2 reactor. The crack was situated in the welding and was extended circumferentially $360^{\circ}$ at the inner face and $77^{\circ}$ at the outer face.

Figure 2.16 Leakage flow interaction effect with RCS turbulence and its influence on the thermal stratification.

Figure 2.17 Schematic representation of the steam generator feed water line in Doel 3/4 plant......................................................................................................... 2_ 18 Figure 2.18 Crack situation in the Genkai 1 plant......................................................2_19 Figure 2.19 Thermal stratification regions in the primary of a PWR reactor as Reyes

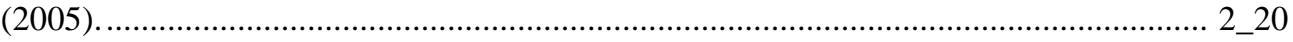
Figure 2.20 Comparison of the Reyes and Theophanous criteria for the beginning of the thermal stratification in the cold leg...........................................................................2_21 Figure 2.21 Safety injection and stratification in the cold leg during a PTS...................2_22 Figure 2.22 Liquid Froude number in countercurrent stratified flow.............................2_24 
Figure 2.23 Subcritical countercurrent flow............................................................2_25

Figure 2.24 Supercritical countercurrent flow...........................................................2_26

Figure 2.25 Hydraulic jump in horizontal countercurrent flow..................................2_27

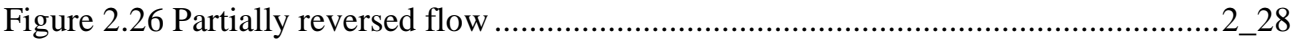

Figure 2.27 Totally reversed flow ......................................................................2_29

Fig. 2.28 Flow pattern in horizontal flow...................................................................2_34

Fig. 2.29 Two-phase flow patterns in horizontal tubes: (a) Condensation with high liquid

loading; (b) condensation with low liquid loading...............................................2_34

Figure 2.30 Flow pattern map for horizontal flow (Baker 1954) .....................................2_35

Figure 2.31 Two-phase flow regime map of Mandhane et al. (1974) ..............................2_36

Fig. 2.32 Liquid film temperatures as functions of the inlet steam flow rate ...................2_41

Figure 3.1 Break Configuration ........................................................................ $3 \_3$

Figure 3.2 Break unity scheme ............................................................................ $3 \_3$

Figure 3.3 Power decay curve ................................................................................... 3 _ 5

Figure 3.4 Pumps rotational speed coastdown .......................................................

Figure 3.5 Primary and secondary pressures ...........................................................

Figure 3.6 HPI mass flow rate.......................................................................... $3 \_9$

Figure 3.7 Pressurizer level ...................................................................................... $3_{-} 10$

Figure 3.8 Primary system mass flow rate. Loop A ...................................................... $3_{-} 10$

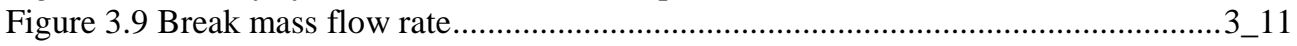

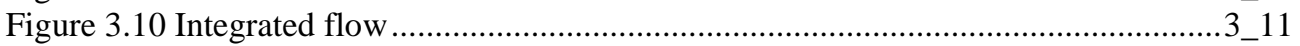

Figure 3.11 Hot legs levels........................................................................................ $3_{-} 12$

Figure 3.12 Secondary liquid level of both loops....................................................... $3 \_12$

Figure 3.13 Injected mass flow rate by the auxiliary feedwater system........................... 13

Figure 3.14 Cold leg temperature in the loop with pressurizer ....................................... 3 _ 13

Figure 3.15 Cold leg temperature in the loop without pressurizer .................................. 3 14

Figure 3.16 Mass flow rate injected by the accumulator................................................ $3 \_15$

Figure 3.17 Core power........................................................................................... 3 _ 17

Figure 3.18 Downcomer to upper head bypass flow, measured in different points. ..........3_17

Figure 3.19 Hot leg liquid temperature .......................................................................

Figure 3.20 Cold leg liquid temperature. .................................................................... $3 \_18$

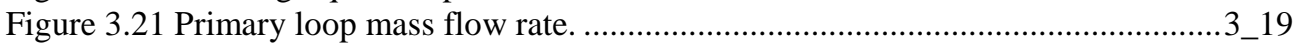

Figure 3.22 Primary system pressure ..................................................................... $3_{-} 19$

Figure 3.23 Pumps rotational speed $(\mathrm{rad} / \mathrm{s})$................................................................. $3 \_20$

Figure 3.24 Pressure in the secondary side of the steam generators. ............................. 3_21

Figure 3.26 Steam mass flow rate versus time at steady-state conditions........................ 3_21

Figure 3.27 Main feedwater system flow...................................................................... $3 \_22$

Figure 3.28 Main feedwater temperature. ............................................................... 3 _22

Figure 3.29 Auxiliary feedwater temperature. ............................................................ $3 \_23$

Figure 3.30 Accumulators pressure........................................................................... $3 \_23$

Figure 3.31 Accumulators temperature ....................................................................... $3 \_24$

Figure 3.32 High pressure injection system mass flow rate.......................................... $3 \_25$

Figure 3.33 HPI liquid temperature for the transient of the experiment $1.2 \ldots \ldots \ldots \ldots \ldots \ldots \ldots . . . . . . .25$

Figure 3.34 Primary side pressure evolution ............................................................ $3 \_27$

Figure 3.35 Secondary pressure ............................................................................ $3 \_28$

Figure 3.36 Core Power ....................................................................................... $3 \_29$ 
Figure 3.37 Break mass flow rate.

Figure 3.38 Void fraction versus time computed with the TRACE code at the hot leg position where the break occurs

Figure 3.39 HPI flow rate injection...................................................................... $3 \_31$

Figure 3.40 Accumulators mass flow rate .............................................................. $3 \_31$

Figure 3.41 Primary loop A mass flow rate ................................................................. 3 _ 32

Figure 3.42 Experimental and calculated with TRACE mass flow rates through the safety

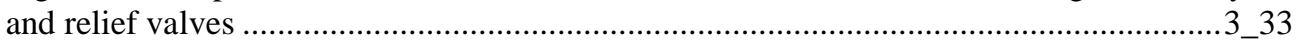

Figure 3.43 Liquid temperature at an axial cut of the cold leg ....................................... 3 _34

Figure 4.1 Cold leg physical phenomena during the stratification ................................... $4 \_1$

Figure 4.2 Unitary vectors $\hat{n}_{g}$ and $\hat{n}_{l}$ in an arbitrary point of the liquid-steam interface....4_4

Figure 4.3. Occupied volume by phase $\mathrm{k}$ at the time instant $\mathrm{t}$ in the volume element $V \ldots 4 \_7$

Figure 4.4 Countercurrent separated flow ....................................................................4_ 15

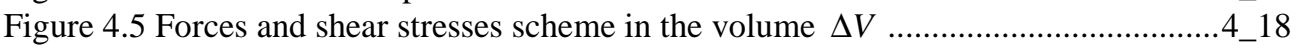

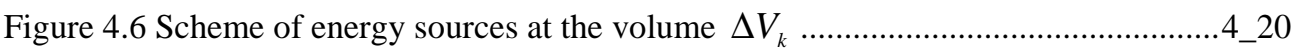

Figure 4.7 Grid for the problem ............................................................................. $4 \_25$

Figure 4.8 Scheme o the shear stresses for the liquid and for the steam .........................4_35

Figure 4.9 Heat transfer resistances scheme for the liquid wall .....................................4_41

Figure 4.10 Heat transfer resistances scheme for the steam wall ...................................4_43

Equation (120). Mean condensation heat transfer coefficient .........................................4_44

Figure 4.11 Iterative procedure for finding the liquid wall temperature .........................4_47

Figure 5.1 Representation of the explicit scheme .....................................................5_ 4

Figure 5.2 Representation of the implicit scheme ..................................................5_5

Figure 5.3 Newton-Raphson geometric scheme........................................................5_12

Figure 5.4 Iteration for solving the steam phase field ................................................5_24

Figure 5.5 Iteration for solving the liquid phase field ..................................................5_24

Figure 5.6 Pipe nodalization and liquid area scheme ..............................................5_26

Figure 5.7 Flow diagram of the subroutine VEFIC .....................................................5_38

Figure $6.1 \mathrm{CC}$ code boundary conditions configuration..................................................6_3

Figure 6.2 Schematic of the experimental apparatus of the Kyoun-Won Lee et al. [134]

experiments .........................................................................................................6_5

Figure 6.3 Experimental data plotted in the Mandhane's flow pattern map of the experiments performed by Kyung-Won Lee a, et al. 2006 [134] .....................................6_6

Figure 6.4 Bulk water temperatures along the flow stream of the experiments performed by

Kyung-Won Lee a, et al. 2006 [134].

6_7

Figure 6.5 Effects of the steam flow rate on the interfacial condensation heat transfer at the experiments performed by Kyung-Won Lee a, et al. 2006 [134] ......................................6_7

Graph 6.6 Liquid bulk temperature distribution for the smooth 1 conditions ....................6_9

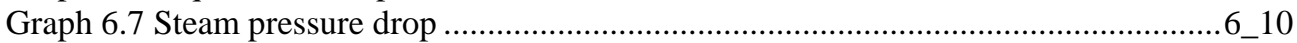

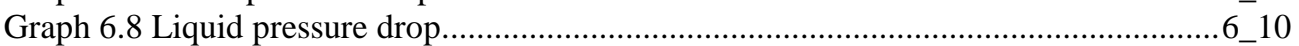

Graph 6.9 Maximum of the mass function ................................................................... $6 \_10$

Graph 6.10 Maximum of the energy function .............................................................6_10

Graph 6.11 Steam pressure distribution .......................................................................

Graph 6.12 Liquid pressure distribution................................................................. $6 \_11$

Graph 6.13 Void fraction distribution .................................................................... $6 \_12$ 


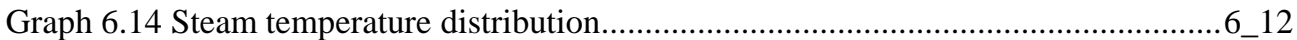

Graph 6.15 Liquid temperature distribution ............................................................. $6 \_12$

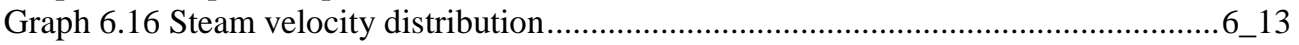

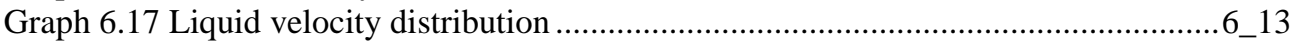

Graph 6.18 Interfacial heat transferred by cell distribution...........................................6_13

Graph 6.19 Liquid condensation rate .....................................................................6_13

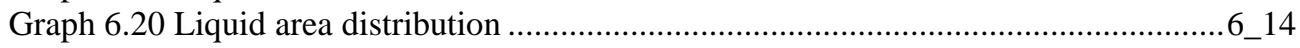

Graph 6.21 Steam mass flow rate distribution ........................................................ 6

Figure 6.22 Liquid bulk temperature distribution for the smooth 2 conditions.................6_15

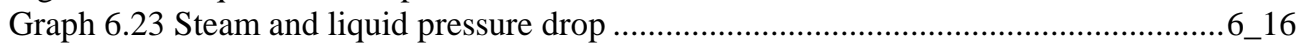

Graph 6.23 Maximum of the mass equations ................................................................6_16

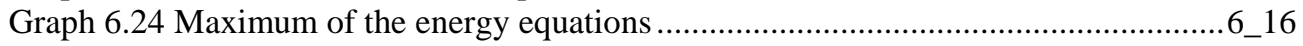

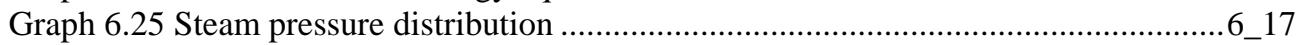

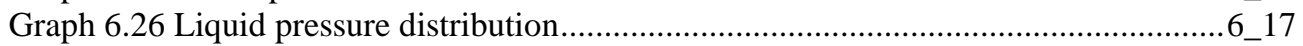

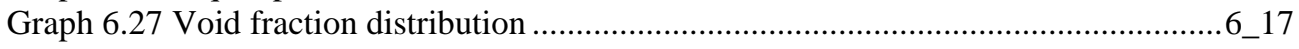

Graph 6.28 Steam temperature distribution............................................................ 6 18

Graph 6.29 Liquid temperature distribution ............................................................ $6 \_18$

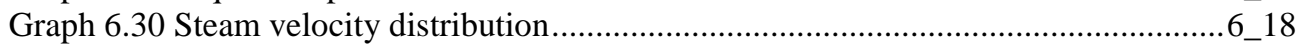

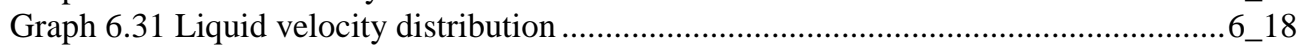

Graph 6.32 Interfacial heat transfer distribution ...................................................... 6

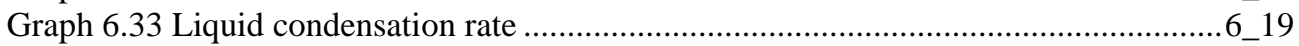

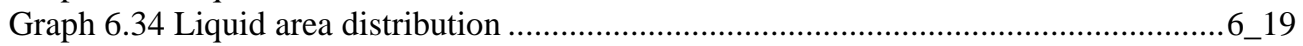

Graph 6.35 Steam mass flow rate distribution ..........................................................6_19

Figure 6.36 Liquid bulk temperature distribution for the wavy 1 conditions...................6_21

Graph 6.37 Steam pressure drop ..............................................................................6_22

Graph 6.38 Liquid pressure drop................................................................................6_22

Graph 6.39 Maximum of mass function.....................................................................6_22

Graph 6.40 Maximum of energy function..................................................................6_22

Graph 6.41 Steam pressure distribution ......................................................................6_23

Graph 6.42 Liquid pressure distribution...................................................................6_23

Graph 6.43 Void fraction distribution ......................................................................6_23

Graph 6.44 Steam temperature distribution............................................................. $6 \_24$

Graph 6.45 Liquid temperature distribution ..............................................................24

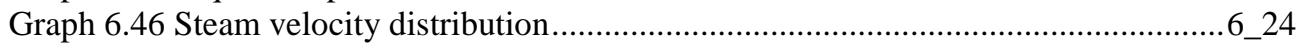

Graph 6.47 Liquid velocity distribution ...................................................................24

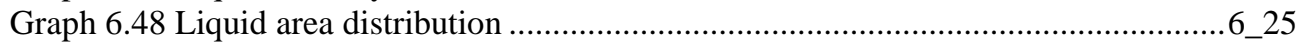

Graph 6.49 Steam mass flow rate distribution ..........................................................6_25

Figure 6.50 Liquid bulk temperature distribution for the wavy 2 conditions ..................6_26

Graph 6.51 Steam pressure drop ........................................................................6_27

Graph 6.52 Liquid pressure drop...................................................................6_27

Graph 6.53 Maximum of mass function...................................................................6_27

Graph 6.54 Maximum of energy function..................................................................6_27

Graph 6.55 Steam pressure distribution .....................................................................6_28

Graph 6.56 Liquid pressure distribution.............................................................. 6 28

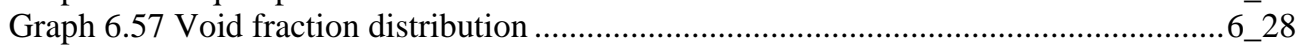

Graph 6.58 Steam temperature distribution................................................................6_28 
Graph 6.59 Liquid temperature distribution........................................................... 6 28

Graph 6.60 Steam velocity distribution.................................................................6_29

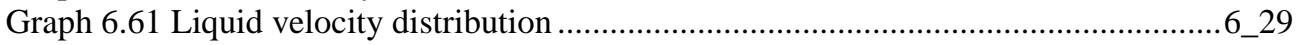

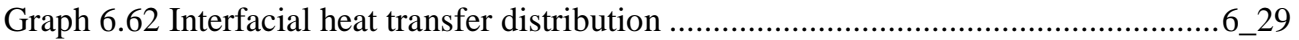

Graph 6.63 Liquid condensation rate .....................................................................29

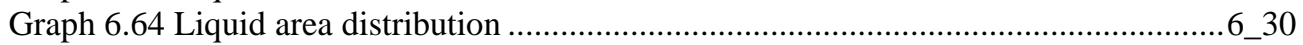

Graph 6.65 Steam mass flow rate distribution ............................................................6_30

Figure 6.65 Schematic of the experiment............................................................. $6 \_31$

Figure 6.66 Axial steam and condensation mass rate profiles as a function of inlet steam

mass flow rate .................................................................................................6_ 32

Figure 6.67 Axial local heat transfer coefficient profile as a function of the steam mass flow

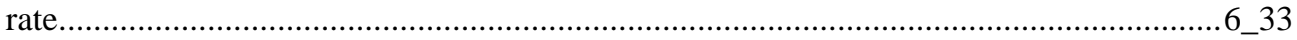

Figure 6.68 Typical axial steam pressure profiles as a function of the inlet steam mass flow

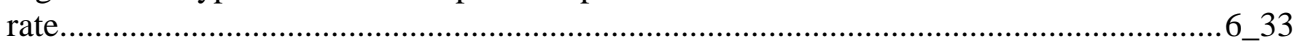

Graph 6.69 Steam mass flow distribution .......................................................... $6 \_35$

Graph 6.70 Steam mass flow rate distribution ...................................................... 6 _36

Graph 6.71 Steam mass flow rate distribution ......................................................... $6 \_37$

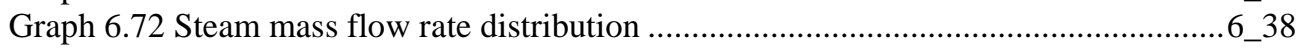

Graph 6.73 Steam mass flow rate distribution ..............................................................6_38

Figure 6.74 Geometry for the CFD simulations, (a) Cocurrent flow (b) Countercurrent

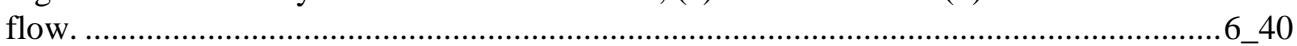

Graph 6.75 Comparison of the water temperature between the LAOKOON test and the

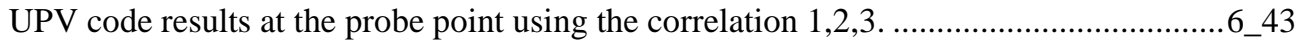

Graph 6.79 Comparison of the water temperature between the LAOKOON test and the

UPV code results at the probe point using correlations 1-3 .........................................6_46

Graph 6.86 Comparison of the water temperature between the LAOKOON test and the

UPV code results at the probe point using the correlations $1-5$.....................................6_49

Graph 6.86 Comparison of the water temperature between the LAOKOON test and the

UPV code results at the probe point using the correlations 1 and 2 ...............................6_52

Figure A.1 Classification of two-phase flow .............................................................. A_6

Figure A.1 Unitary vectors $\hat{n}_{g}$ and $\hat{n}_{l}$ in an arbitrary point of the liquid-steam interface..A_8

Figure A.2. Occupied volume by phase $\mathrm{k}$ at the time instant $\mathrm{t}$ in the volume element $\forall$.A_11

Figure A.3 Control volume where a volume $V_{k}(\vec{r}, t)$ for the phase $\mathrm{k}$ is included. The

volume is limited by the planes ...............................................................................

Figure B.1 Space-time gridding showing the convective characteristics inside the left face

of the cell I of a finite volume........................................................................... B_2

Figure B.2 Gridding for $\phi^{n}(\xi)$ constant at each cell i.................................................. B_3

Figure B.3 Second order upwinding......................................................................... B_5

Figure B.4 Third order interpolation .................................................................. B_ 7

Figure B.5 Value of the normalized nodes in the case of monotonic behaviour .............. B_ 10

Figure B.6 Definition of the upstream, downstream and centred nodes,......................... B_10

depending on the velocity sign ............................................................................. B_ 10

Figure B.7 Universal limitator diagram border.................................................... B_13

Figure E.1 Temperature distributions during film condensation on a vertical plate ........... $\mathrm{E}_{-} 1$

Figure E.2. Model of laminar film condensation on a vertical plate ................................. E_2 
Figure E.3. Axial cut of the pipe. Configuration of the problem.

E_4

Figure E.4. Momentum balance at an elementary volume of the condensate film of the wall 4

Equation (E.18). Condensate liquid velocity profile ..................................................... E_ 8

Equation (E.20). Mass condensation rate …............................................................. E_9

Equation (E.24) For the condensate film thickness .................................................... E_9

Figure E.5 Elementary volume for the condensate falling film..................................... E_ 10

Equation (E.33). Local heat transfer coefficient ......................................................... E_12

Equation (E.43). Reynolds number in the approach.............................................. E_14

Equation (E.47). Mean condensation heat transfer coefficient........................................ E_15

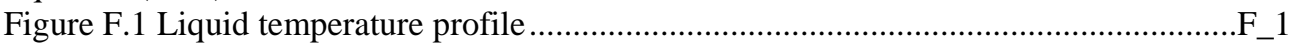

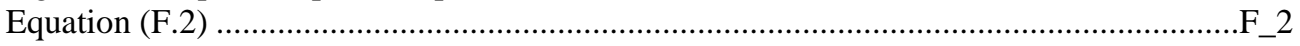

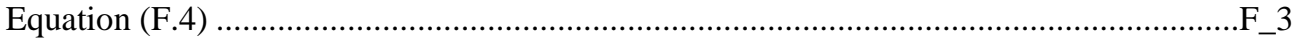

Figure (F.2). Liquid temperature profile at different points ......................................... ${ }_{-} 4$

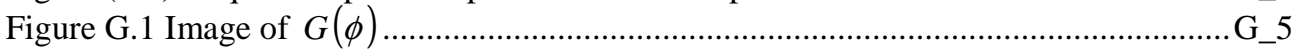




\section{LIST OF TABLES}

Table 3.1 Actuation logic specifications and setpoints ....................................................

Table 3.2 Table with the initial steady-state conditions .............................................

Table 3.3: Initial steady-state conditions....................................................................

Table 3.4 Comparison of the test 1.2 results ............................................................. $3 \_26$

Table 4.1 Resume of the 1D averaged conservation equations ......................................4_22

Table 6.1 Test matrix of the experiments ................................................................6_6

Table 6.2 Smooth conditions at the Kyung-Won Lee a et al. 2006 [134] experiments .......6_8

Table 6.3 Boundary conditions for the SMOOTH 1 case .................................................6_ 8

Table 6.4 Boundary conditions for the SMOOTH 2 case ............................................6_14

Table 6.4 Wavy conditions at the Kyung-Won Lee a et al. 2006 [134] experiments........6_19

Table 6.5 Boundary conditions for the WAVY 1 case .....................................................6_20

Table 6.6 Boundary conditions for the WAVY 2 case ..................................................6_25

Table 6.7 Boundary conditions for Lim and Tankin (1984) experiments on direct

condensation for cocurrent flow [37] ................................................................ $6 \_34$

Table 6.8 Main geometrical variable values...............................................................6_40

Table 6.9 Flow Regime parameters: high Reynolds number of steam, Cocurrent flow....6_41

Table 6.10 Mean water temperature comparison between the LAOKOON experiments and

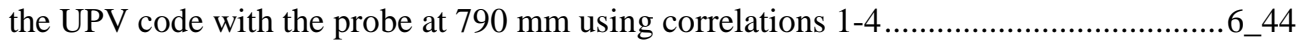

Table 6.11 Flow Regime parameters: low Reynolds number of steam, Cocurrent flow ...6_44

Table 6.12 Mean water temperature comparison between the LAOKOON experiments and

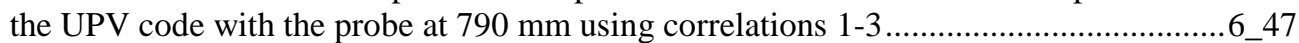

Table 6.13 Flow Regime parameters: low Reynolds number of steam, countercurrent flow

6_47

Table 6.14 Mean water temperature comparison between the LAOKOON experiments and the UPV code at the probe $790 \mathrm{~mm}$............................................................................6_50

Table 6.15 Flow Regime parameters: low Reynolds number of steam, countercurrent flow

6_50

Table 6.16 Mean water temperature comparison between the LAOKOON experiments and the UPV code at the probe $790 \mathrm{~mm}$...........................................................................6_52

Table A.1 Equivalence terms of the generalized conservation equation ......................... 14 


\section{CHAPTER 1}

\section{INTRODUCTION}

\subsection{MOTIVATION}

The present work was originated from a CSN (Nuclear Society Council) proposal on the application of the study "Analysis and simulation of the experiments PKL/OECD and ROSA OECD (Organization for Economic Co-operation and Development)" to nuclear plants.

The main objective of the above project is to investigate various safety-related issues in the experimental programs PKL and ROSA. Our concern in this work is the analysis of test 1.2, a small break at the lower part of the hot leg leading to a small break LOCA scenario and the consequent actuation of the safety systems.

This global project also attempts to assure and maintain the capacity of both international as well as national groups of experts to analyze this kind of events in the case of their occurrence in Spanish nuclear plants.

Under a small break LOCA scenario, the primary side of a nuclear plant suffers a strong depressurization. Due to the security actuations and the physical phenomena which undergo in this scenario, like the reflux due to the condensation at the primary side of the $U$ tubes of the Steam Generators, and the steam income to the cold leg from the downcomer of the vessel, a countercurrent steam-water flow at the cold leg might happen. This can lead to a thermal stratification at cold leg liquid layer due to the low velocities of the liquid and the cold liquid injection by the HPI (high pressure injection) systems, which can cause a pipe crack at the cold leg due to the different dilatations of the steel of the pipe which are dependant on the temperature.

In light water nuclear power plants the thermal stratification can occur in some pipes, normally during the plant start-ups and shutdowns. Because of the temperature dependence 
of the steel dilatation coefficients, thermal stratification induces axial and tangential tensions at different pipe locations that may eventually break them.

\subsection{OBJECTIVES}

In this work a more deep and detailed study of the thermal stratification which is produced under certain circumstances in a nuclear plant, and its associated phenomenon like the PTS (Pressurized Thermal Shock) will be made, in order to give to the thermal-hydraulic code TRACE a higher capability when simulating this phenomenon.

For achieving this goal, a pseudo 2D thermal-hydraulic steam-water countercurrent flow code was developed in order to mathematically simulate all the phenomena which are involved into this scenario.

Therefore, a computer program in FORTRAN was developed for modelling this steam/water countercurrent flow in the cold leg. This program will be used in future to provide the thermal-hydraulic codes like TRACE with a better tool for simulating this kind of phenomena.

\subsection{BRIEF INTRODUCTION TO THE PHYSICAL MATTER WE ARE DEALING WITH}

We firstly need to be situated at the problem which we are facing. In this way, we might say that a Nuclear Power plant works by transferring heat from a primary coolant (pressurized water at about $15 \mathrm{MPa}$ ) to a secondary coolant (pressurized water/steam at about $7 \mathrm{MPa}$ ) at the Steam generators in a pressurized water reactor (PWR).

The primary coolant water is heated in the core and passes through the steam generators, where it transfers heat to the secondary coolant water to generate steam. The steam then drives a turbine that turns an electric generator. Steam is condensed and returns to the steam generator as feedwater. Hot leg pipes connect the reactor pressure vessel (RPV) and the steam generator (SG), and consist of a combination of horizontal sections, single or multiple elbows, and inclined or vertical sections depending on the manufacturer of the reactor. 
In the event of hypothetical accident scenarios in PWRs, emergency strategies have to be mapped out, in order to guarantee the reliable removal of decay heat from the reactor core, also in case of component breakdown. One essential passive heat removal mechanism is the reflux condensation cooling mode. This mode can appear for instance during a small break loss-of-coolant-accident (LOCA) or because of loss of residual heat removal (RHR) system during mid loop operation at plant outage after the reactor shutdown. In the scenario of a loss-of-coolant-accident (LOCA), which is caused by the leakage at any location in the primary circuit, it is considered that the reactor will be depressurized and vaporization will take place, thereby creating steam in the PWR primary side. Should this lead to "reflux condensation", which may be a favourable event progression, the generated steam will flow to the steam generator through the hot leg. This steam will condense in the steam generator and the condensate will flow back through the hot leg to the reactor, resulting in countercurrent steam/water flow. In some scenarios, the success of core cooling depends on the behaviour of this countercurrent flow.

When a liquid and a steam flow in a horizontal tube, they may be distributed in the tube in a variety of different configurations. At the 1940's, flow visualization experiments were carried out to record the various configurations in which gas and liquid may flow together. Observations of liquid-steam distribution are generally classified by the observers into separate "flow-regimes". Bergelin and Gazley (1949) [6] reported five different flow regimes in horizontal tubes. Later, Baker (1954) [8] classified horizontal two-phase flows into seven flow regimes. Although the classification of two-phase flows into flow regimes is somewhat subjective, a certain typical pattern has been observed by most researchers. Dobson (1994) [88] compiled a list of most typical flow regimes reported in the literature for condensing horizontal flow.

The stratified countercurrent flow of steam and condensate is only stable for certain ranges of steam and water mass flow rates. For a given condensate flow rate, if the steam mass flow rate increases to a certain value, a portion of the condensate will exhibit a partial flow reversal and will be entrained by the steam in the opposite flow direction towards the steam generator. This phenomenon is known as countercurrent flow limitation (CCFL) or the onset of "flooding". In case of an additional increase of the steam flow, the condensate is completely blocked and the reflux condensation cooling mode ends. In this situation the 
cooling of the reactor core from the hot leg is impossible, but may be continued by coolant drained through the cold leg to the downcomer. The countercurrent flow in the hot leg under reflux condensation conditions is illustrated in Figure 1.1.

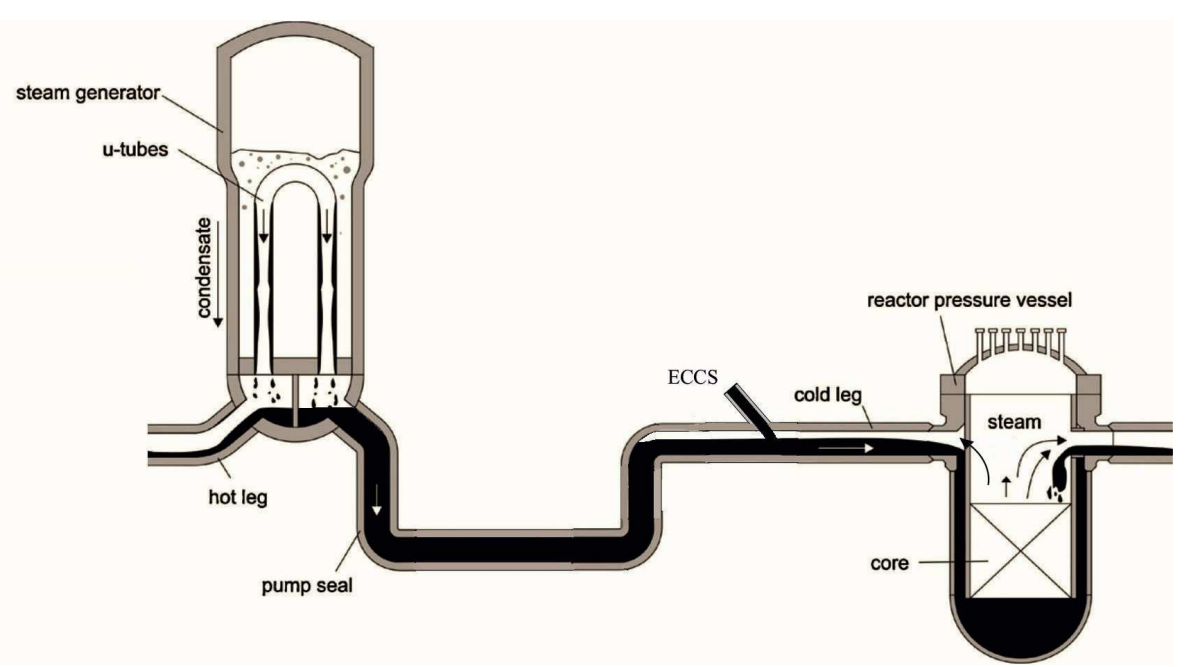

Figure 1.1 PWR piping configuration and reflux condensation flow paths.

Over several decades, a number of experimental and theoretical studies of countercurrent gas-liquid two-phase flow have been carried out to understand the fundamental aspect of the flooding mechanism and to prove practical knowledge for the safety design of nuclear reactors. Starting from the pioneering paper of Wallis (1961) [9], extensive CCFL data have been accumulated from experimental studies dealing with a diverse array of conditions. The accumulated data have led to the development of both empirical correlations and analytical models. Bankoff and Lee (1986) [43] reviewed the flooding research in vertical and inclined channels. They presented a summary of the several important parameters on flooding and the available flooding models. They also suggested that more careful experimentation on the parametric dependence is required to investigate the important parameters. Krishnan (1987) performed a review of the two-phase countercurrent flow in upright pipe elbows as an analogy of the CANDU reactor feeder pipes (hot leg pipe). A total of 4 research papers that were available in the year of 1986 (Siddique et al., Wan and 
Krishnan, Wan, and Ardron and Banerjee) are included in his review papers. Krishnan compared the onset of flooding data obtained from the experimental and the numerical studies proposed by those authors, and discussed the possible sources of the unexpected results which were revealed from the above researches.

Finally he recommended that new experiments are also needed to provide information on the mechanism of flooding. The points above highlight the importance of knowing the current status of research in this field to better identify the direction of future research.

\section{BASIC TERMINOLOGIES}

The basic definitions in countercurrent air-water two-phase flow have been given by Celata et al. (1989). Those include the terminologies of the onset of flooding and zero penetration point. For the case of the countercurrent flow in a model PWR hot leg, the detail terminologies and flow regime have been given by Deendarlianto et al. (2008), and only the main features are presented here. In their experimental work, the liquid flow rate was kept constant, and the air flow rate was increased and decreased in small increments and decrements respectively. Air-water data in a particular test section are used for illustrative purposes. The trends and values will differ for steam-water data under PWR hot leg conditions. Two tanks were used to simulate the reactor pressure vessel (RPV) simulator and the steam generator (SG) separator in the actual German PWR. In the experiment, the air was injected in the RPV simulator and flowed through the test section to the SG separator, from which it was released to the atmosphere. The water from the feed water pump was injected in the SG separator, from where it could flow in countercurrent mode to the air flow through the test section to the RPV simulator.

For small gas flow rate, the liquid film flows countercurrently with the gas phase in the hot leg channel. The pressure difference inside the test section is still low, and slightly increases with the air mass flow rate. This regime is defined as the stable countercurrent flow. As the gas flow rate $\left(m_{G}\right)$ is gradually increased, thus, there is a maximum gas flow rate at which the down-flowing water mass flow rate $\left(\dot{m}_{L}-D\right)$ in reactor pressure vessel is equal to the inlet water mass flow rate. This point is defined as the onset of flooding or countercurrent flow limitation (CCFL) as shown in Figure 1.2. With further increasing of the air mass flow rate, the water mass flow rate $\left(m_{L-D}\right)$ flow into the RPV simulator is 
close to zero. This point corresponds to the zero liquid penetration (ZP). The region between the CCFL and ZP is defined as partial delivery region. In turn, when the gas flow rate is decreased, a point is reached where a fully countercurrent gas-liquid two-phase flow is established. This is known as the deflooding point. "Scaling" in general encompasses all differences existing between a real full-size industrial plant and a corresponding experimental facility.

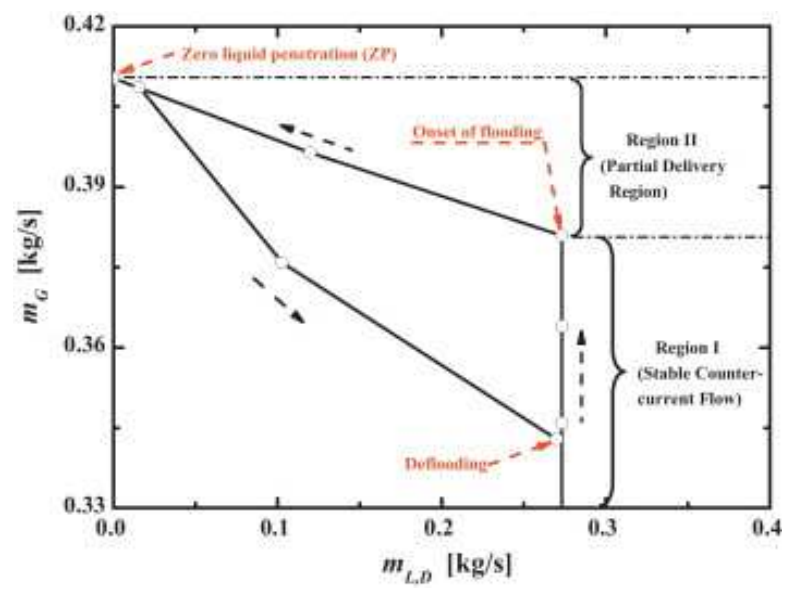

Figure 1.2. Terminologies in countercurrent gas-liquid two-phase flow in a model of PWR hot leg presented by Deendarlianto et al. (2008).

\subsection{THESIS DESCRIPTION}

This Thesis is organized in 7 chapters, in which all the work done in order to achieve all the objectives previously named is described.

A short introduction of the matter and a general overview of the thesis are made in the first chapter.

In Chapter 2 the state of the art of the thermal stratification and PTS is described. All the physical phenomena like the direct contact condensation, which are involved in the thermal stratification scenario that we are studying in this thesis, are also described. 
In Chapter 3 the test 1.2 and its results are described in order to give the reader a general overview of the experimental data obtained in the LSTF facility by the JAEA (Japanese Atomic energy Agency). Afterwards, the steady-state demonstration is presented and, finally, the results of the simulation of the test 1.2 with the TRACE code are also presented. In Chapter 4 all the conservation equations, physical phenomena and discretizations that we need for physically simulate this scenario that we are studying are presented 


\section{CHAPTER 2}

\section{STATE OF THE ART AND BIBLIOGRAPHIC REVIEW OF THE COUNTERCURRENT FLOW AND THE THERMAL STRATIFICATION IN LIGHT WATER NUCLEAR REACTORS}

\subsection{INTRODUCTION}

Research on Pressurized Thermal Shock (PTS) events is of interest in view of their impact on both plant operation and nuclear reactor safety issues. The PTS analysis is required to assure the integrity of the Reactor Pressure Vessel (RPV) throughout the reactor life. An important part of this analysis is the thermal-hydraulic analysis calculations to determine the pressure and temperature fields acting on the cold leg and especially on the RPV which are then used as input parameters for further structural calculations. Several scenarios that describe what could occur in Small Break Loss Of Coolant Accidents (SB-LOCA) result in an Emergency Core Cooling (ECC) water injection into the cold leg of a Pressurized Water Reactor (PWR). The cold water mixes there with the hot coolant, which is present in the primary circuit. The mixture flows to the downcomer where further mixing of the fluids takes place. Single-phase as well as two-phase PTS situations have to be considered. In case of two-phase PTS situations the water level in the RPV has dropped down to or below the height position of the cold leg nozzle, which leads to a partially filled or totally uncovered cold leg. Pressurized Thermal Shock implies the occurrence of thermal loads on the Reactor Pressure Vessel wall. In order to predict thermal gradients in the structural components of the Reactor Pressure Vessel (RPV) wall, knowledge of transient temperature distribution in the downcomer is needed. The prediction of the temperature distribution requires reliable Computational Fluid Dynamic simulations. 
The thermal stratification phenomenon consists on the physical separation of the cold and hot water layers in pipes, pools or tanks, where the hot layer occupies the upper portion of the pipe or tank and the cold layer the lower one. Both layers are separated by a boundary layer at an intermediate temperature. Despite being mass and energy exchange phenomenon through this boundary layer, it appears that the mean temperature of both layers suffers little changes [Beniussa 1999, Braschel 1984].

In light water nuclear plants in general thermal stratification can occur in their pipes, basically during start-up and shutdown processes. The pipes where this thermal stratification has been found to occur are:

- Feed water lines.

- Spray lines.

- Pressurizer purge lines in PWR reactors.

However, thermal stratification can also occur in pipes that have been isolated because of valves shutdown and were later reopened and injected with fluid at lower velocity and higher temperature.

In this case it has been observed that thermal stratification in these pipes occurs [López Zamora 2002], due to the accumulation of the lower temperature fluid at the lower part of the pipe, and that the higher temperature fluid injected flows through the higher part of the pipe, just if the velocity is small, increasing thermal mixing with the velocity [Grebner 1995].

Thermal stratification in tanks and pools appear mostly in the pressure suppression pools of the new generation of passive reactors due to the discharge of steam and non-condensable gases from the containment passive safety condensers [Hart et al. 1999, Auban et al. 2007]. In this case thermal stratification appears because the injected steam is generally hotter that the pool water.

Thermal stratification also forms upon fluid injection of water into the vessel from the ECCS system, because the temperature of the water income from the safety injection is much lower than the one already existing in the vessel. In this case whether or not thermal stratification does occur depends on the complex mixing phenomenon happening inside the 
vessel. Recently these phenomena have started to be experimentally studied and with CFD codes as CFX and FLUENT [Toppila 2007].

The importance of thermal stratification on plant safety issues is related to the generation of both axial and tangential tensions in the steel pipes and the reactor vessel leading to structural damage [Blumer et al. 1987].

Another important kind of thermal stratification related to PWR nuclear reactors safety is the PTS (Pressurized thermal shock). This phenomenon occurs when the vessel's wall of a PWR reactor is suddenly exposed to a low temperature water and high pressure while performing safety injection into the cold leg during a LOCA accident. In this situation the HPI (high pressure injection) that enters the cold leg produces:

Steam condensation and flow stratification if the pipe is filled with steam.

Thermal stratification if the cold leg is filled with hot water. In this case the coolant from the cold leg forms a cold water plume in the downcomer. This plume increases its size in the downcomer due to thermal diffusion and convection. The wall-to-vessel heat transfer to the plume, have significant effect to the thermal shock generated upon the wall [Lele et al. 2002, Theophanous et al. 1984].

\subsection{RELEVANCE OF THE THERMAL STRATIFICATION PHENOMENON}

During the 80's some unexpected thermal stratification events were observed in nuclear plant pipes; however their impact on thermal loads and mechanical systems tensions were not accounted for in nuclear plants design [Schmidt, 2003; Dahlberg, 2007]. This situation changed suddenly when in November, 1987 an increase of radioactivity was detected in the Farley 2 (USA) reactor that was assumed due to a crack in the pipe of the core emergency cooling system.

This accident made the NRC consider issuing the newsletter 88-08 "Thermal stresses in piping connected to reactor coolant systems". Supplements 1 and 2 were issued after a similar event happened in the Tihange 1 plant. Supplement 3 was issued in response to the event happened in the Japanese plant Genkai 1. 
Due to the interest in thermal stratification in nuclear plants safety we include below the objectives of these newsletters:

NRC newsletter Number 88-08 from the 22nd of June of 1988 [NRC 88-08, 1988].

“ The objective of this newsletter is to require to whom have licenses to operate with PWR Nuclear plants for: (1) To revise their cooling systems in order to identify every pipe no isolated connected to them that could be subject to thermal distributions which would produce thermal tensions. (2) Take actions in order to ensure that the identified pipes won't be subjected to unacceptable thermal tensions".

NRC newsletter Number 88-08 supplement $n^{\circ} 1$ from the 24th of June of 1988 [NRC 88-08 SI, 1988].

"The objective of this supplement is: (1) provide preliminary information about an event in Tihange 1 which appears to be similar to the one in Tihange. (2) Emphasize in the necessity to examine the pipes no isolated and connected to the cooling system of the reactor to ensure that there are no indications to be cracks or defect. There are no new requirements in this supplement".

NRC newsletter Number 88-08 supplement $n^{\circ} 2$ from the 4th of August of 1988 [NRC 88$08 \mathrm{~S} 2,1988]$.

"This supplement emphasize in the necessity to make ultrasonic tests carried out by skilled personnel to detect cracks in the steel pipes. There are no new requirements included in this supplement".

NRC newsletter Number 88-08 supplement $n^{\circ} 3$ from the 4th of April of 1989 [NRC 88-08 S3, 1989].

“ The purpose of this supplement is: (1) provide information about a thermal stratification event in no isolated pipes connected to the primary system appeared in a foreign reactor and similar to the event of the 9th of December of 1987 in Farley - 2, (2) Emphasize to the receivers of this newsletter about the need to carry out enough revisions of their primary systems in order to identify every pipe, connected to them, no isolated, that could have an unacceptable thermal stratification,(3) Emphasize in the necessity to examine the pipes on 
isolated and connected to the cooling system of the reactor to ensure that there are no indications to be cracks or defect. There are no new requirements in this supplement".

New safety concerns appeared connected to thermal tensions due to stratification at the Trojan plant pressurizer purge line. This event led to a new NRC, 88-11 newsletter entitled "Thermal stratification in the purge line of the pressurizer".

NRC newsletter Number 88-11 from the 20th of December of 1989 [NRC 88-11, 1988].

"The purpose of this Newsletter is: (1) Ask from the receivers to establish and implement a program to confirm the integrity of the pressurizer line if thermal stratification is observed, (2) Ask from the receivers to inform about the actions carried out to solve this matter".

When talking about the thermal stratification phenomenon we often refer to the cyclic temperature stratification phenomenon that can appear in the pipes of a light water reactor, in which the height of separation or interface between regions with different temperature varies with time. It can also vary with time the length of the stratified portion of the pipe, usually called thermal cycling.

This phenomenon is related with:

Thermal stratification.

The penetration of vortex in tees, closed legs and leakages in valves.

Mixing in tees.

This phenomenon is related with thermal loads happening in the nuclear plants and it can lead to thermal stress in the components putting in danger the plant's safety. These loads can be due to thermal transients, thermal stratification or turbulent mixing.

Thermal stratification can also appear in those systems with the structural and operational plant dynamic conditions shown below:

Horizontal pipes.

Water sources at different temperatures.

Slow flow conditions that avoids the two flows which are at different temperatures from mixing. 
It is to be noted that those conditions are present and have to be accounted for in the safety analysis of the systems listed below:

- Incoming feed water in the steam generators of the PWR.

- Incoming feed water to the vessel of the BWR reactors.

- Feed water lines in BWR reactors.

- Purge lines of the PWR reactors.

- Spray lines of the PWR reactors.

- Safety injection in the cold leg of PWR.

\subsubsection{THERMAL TRANSIENTS}

Although most plant components are designed to bear with the low cycling thermal stress there is a transient that can produce quick temperature variations.

This transient is generated by the sudden injection of a high flux of either cold or hot water into both horizontal and vertical pipes resulting into high temperature changes and the production of damaging thermal shocks.

\subsubsection{THERMAL STRATIFICATION}

It is assumed that a fluid is thermally stratified when some layers at different temperatures appear. As a change in temperature results in a change in the water density, the colder water (higher density) flows to the lower part of the recipient or pipe and the hotter one to the upper part. The thermal stratification can be classified into the categories given below:

- Global thermal stratification

Global thermal stratification appears when flow conditions change, in a large horizontal section of the pipe, from stratified to not stratified, and then again to stratified. Stratification will make the pipe to curve (Figure 2.1), resulting in loads to its supporters, elbows, and nozzles. 


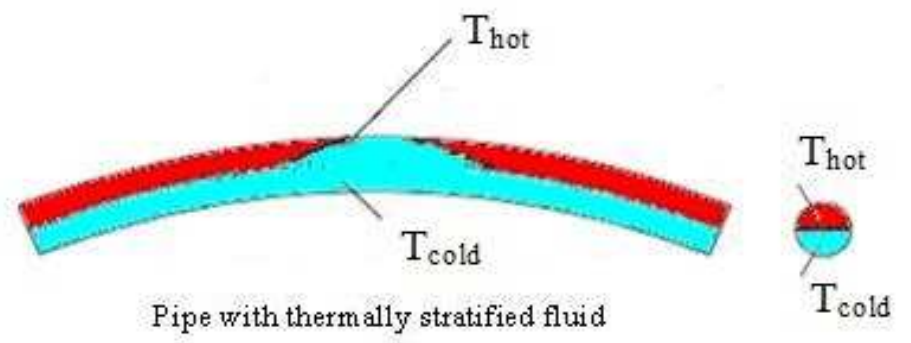

Figure 2.1 Effect of the thermal stratification on the pipe deformation

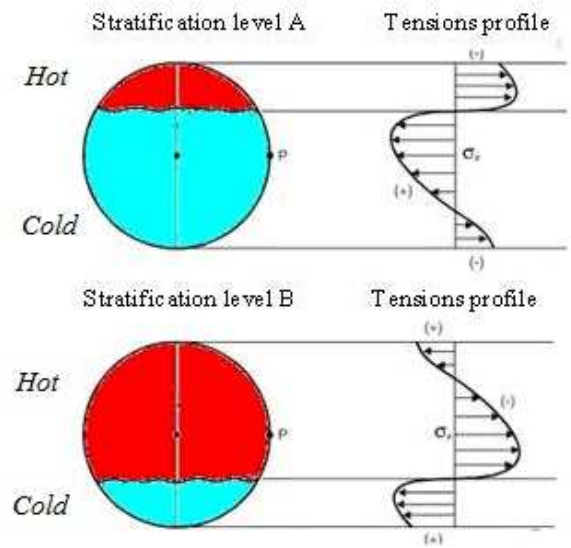

Figure 2.2 Axial thermal tensions profiles originated by two different levels of thermal stratification.

- Cyclic thermal stratification

Cyclic thermal stratification is produced in horizontal pipes by large cyclic changes in the height of the hot-cold interface. The cycling can result into pipe cracking by thermal stress (Figure 2.2).

- Turbulent penetration with thermal cycling

Turbulent penetration with thermal cycling appears when the length of the stratified portion changes with time periodically. A typical example is when the main pipe turbulence enters a secondary pipe with stagnant water and thermally stratified. Turbulent penetration 
fluctuates with time and produces the axial cycling of the interface. This kind of stratification is normally associated with a loss of flow in valves (Figure 2.3). It can also be produced in vertical sections and the cycling in the elbow (Figure 2.4).

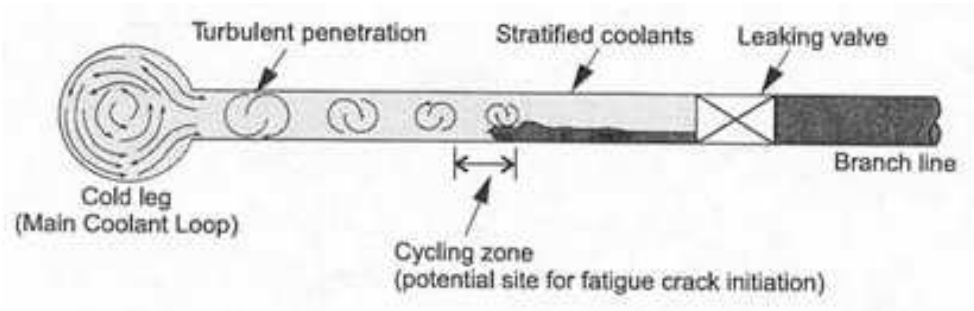

Figure 2.3 Thermal cycling in a straight pipe.

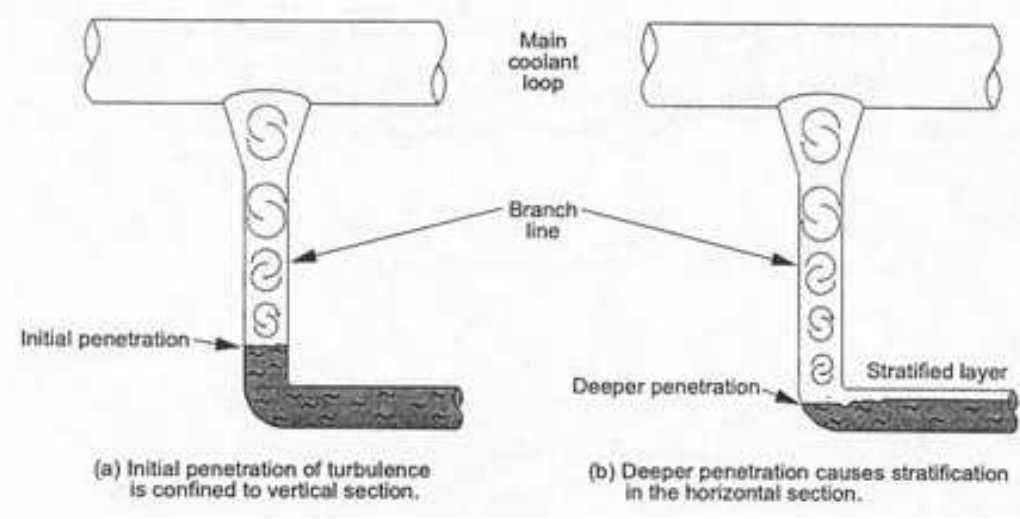

Figure 2.4 Thermal cycling in an elbow.

- "Striping"

The stratification can also be associated with high frequency temperature variations. In this case it's called striping. The striping can be seen as a quick variation of the position of the interface (Figure 2.5).

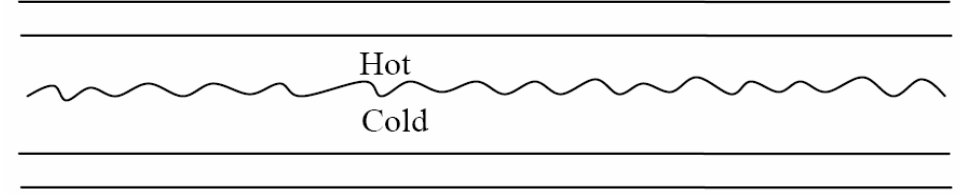

Figure 2.5 Striping 


\subsection{THERMAL STRATIFICATION IN PIPES}

In this section several kinds of thermal stratification scenarios will be presented and

discussed:

- Purge line of a PWR pressurizer.

- Spray lines.

- Other lines.

\subsubsection{THERMAL STRATIFICATION IN THE PURGE LINE OF THE PRESSURIZER}

A typical part where thermal stratification takes part in Light water reactors is the purge line that connects the pressurizer with the primary hot leg.

Thermal stratification arises from the influx of hot water from the pressurizer to the hot leg impacting on the lower water temperature exiting in the intermediate purge line. The larger temperature differences do happen during the start-up and shutdown of the plant. The temperature difference between the fluid in the pressurizer and the one flowing through the hot leg can reach $180^{\circ} \mathrm{C}$ during the start-up process. During the shutdown process the difference is lower and in normal operation it is between $20^{\circ} \mathrm{C}$ and $40^{\circ} \mathrm{C}$. Figure 2.6 shows the thermal stratification produced by an outgoing flow from the purge line of the pressurizer, which is hotter than the fluid flowing through this line and connected to the hot leg.

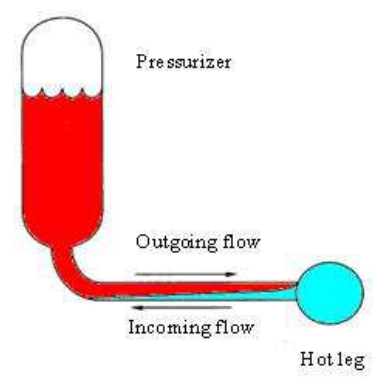

Figure 2.6. Thermal stratification in the purge line of the pressurizer due to the flow 


\section{through itself.}

The flow stratification in the pipe originates a temperature distribution in the cross section of the metallic pipe that results into local mechanical tensions.

A very important aspect to take into account is the geometry and the layout of the line of the pressurizer purge. These pipes normally have a diameter between 250 and $400 \mathrm{~mm}$ and big lengths (more than $20 \mathrm{~m}$ ) between the hot leg and the pressurizer. This line normally has a small vertical length at the exit of the pressurizer that changes to horizontal, having several elbows before entering the hot leg, see Figure 2.7.

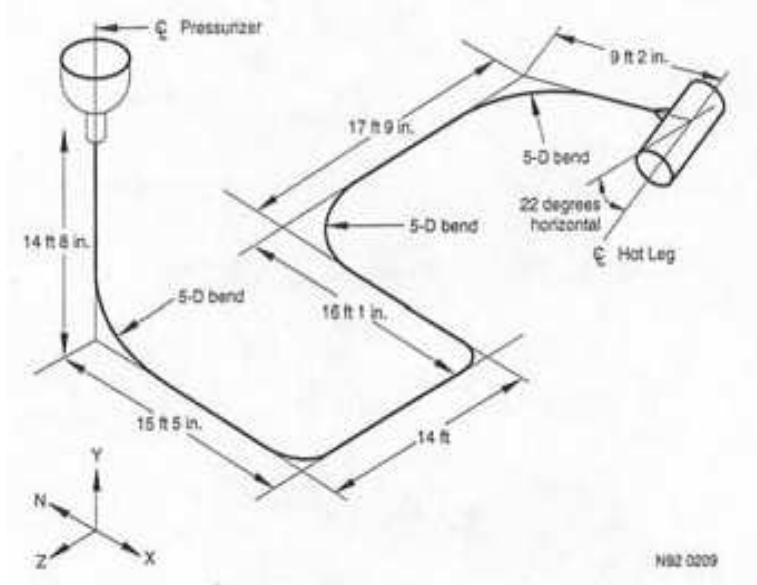

Figure 2.7 Layout of a purge pressurizer line of a Westinghouse plant

In September 1987, the temperature differences between the upper and lower part of the purge of the Muelheim-Kaerlich plant were measured. In some cases they reached $180{ }^{\circ} \mathrm{C}$ $\left(325^{\circ} \mathrm{F}\right)$. High temperature differences were also measured at the San Onofre plant (units 2 and 3) [Riccardella, 1992].

Also thermal stratification dynamics induced damaging motion displacements at the Trojan plant purge line resulting into permanent line deformations.

In view the above observations Newsletter 88-11 was issued on December 1988 by the NRC specifying purge line thermal stratification calculation requirements to operate PWR reactors. 
Recently measured thermal stratification effects at the Paks Hungary VVER-440 plant purge line have been calculated by the ANSYS-CFX code (Boros et al. 2007). Three months long measurements showed that during the plant's normal operation periodic stratification is produced at the purge line with a 45 minutes period, in line with the operation of the pressurizer heaters. However during this normal operation interval, the maximum temperatures difference between the hot and the cold layer was of $30{ }^{\circ} \mathrm{C}$, showing the absence of any critical stresses during normal operation of the plant. By the way, the temperature monitoring system installed in the pipes of the plant, detected the existence of stable thermal stratification during the start-up and heating period of the plant. During this period, the maximum differences between the cold and hot layers were from $130{ }^{\circ} \mathrm{C}$ to $140{ }^{\circ} \mathrm{C}$.

A description of the measurements made by (Yu et al. (1997) \} at the YGN Korean plant purge line will be presented in this subsection. The pressurizer purge line was provided with temperature sensors placed at the upper and lower parts of the pipe into the five positions from A1 to A5 as well as with thermocouples at positions B1 to B4 as shown in Figure 2.8. Moreover for the purpose of measuring three-dimensional mechanical displacements, lineal displacement transducers (LVDT) were installed at the L1, L2 and L3 as also shown in Figure 2.8.

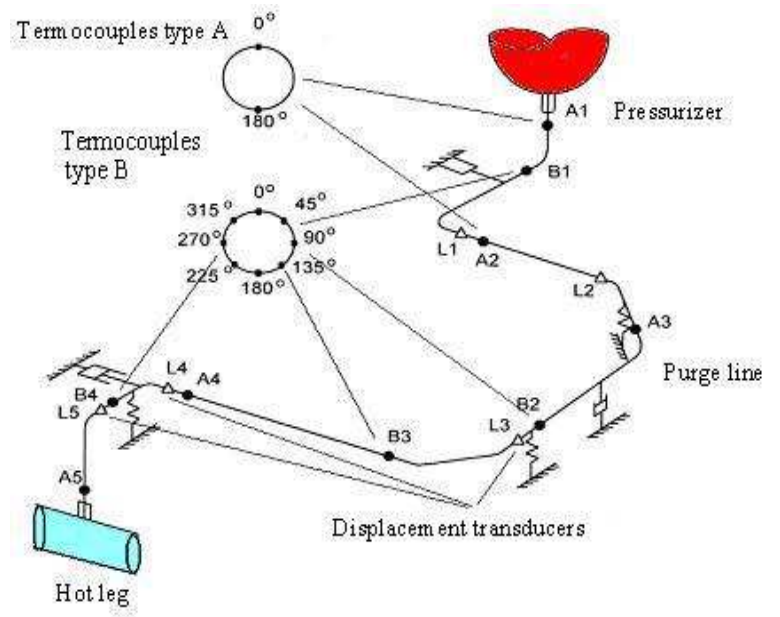

Figure 2.8. Thermocouple and displacement transducer locations at the YGN Korean plant purge line. [Yu et al. 1997]. 
The measurements did reveal that the purge line flow stratifies during start-up and remains stratified with more or less intensity at all of the operation phases of the plant. Temperature differences between the higher and the lower part of the purge line have been associated to level changes in the pressurizer.

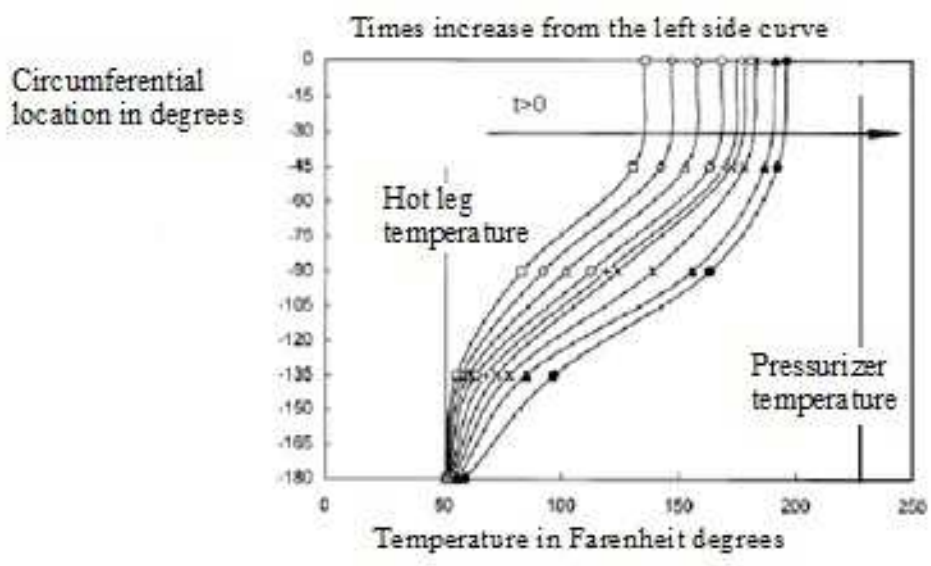

Figure 2.9 Circular temperatures distribution in an outgoing purge flow at the YGN plant [Yu et al 1997].

Let's focus on that when the $\mathrm{T}$ value in $180{ }^{\circ} \mathrm{C}$ corresponds to the lowest part of the pipe, then we have a temperature in this position very close to the one in the hot leg. Also this temperature does not change very much with time. In the upper part of the pipe the temperature increases with time because of the flow from the upper part of the pressurizer that is at a higher temperature.

\subsubsection{THERMAL STRESS IN THE SPRAY LINES}

Thermal stratification in spray lines was observed in 1984 at start-up operation following the same lines of evolution as in the case of purge lines. However pressurizer spray lines need special attention at both start-up and shutdown as these lines can present different conditions of operation, as shown in Figure 2.10.

Figure 2.11 shows the results of temperature measurements at the German Grohnde plant four spray lines where thermal stratification was observed [Metzner, 1998]. 

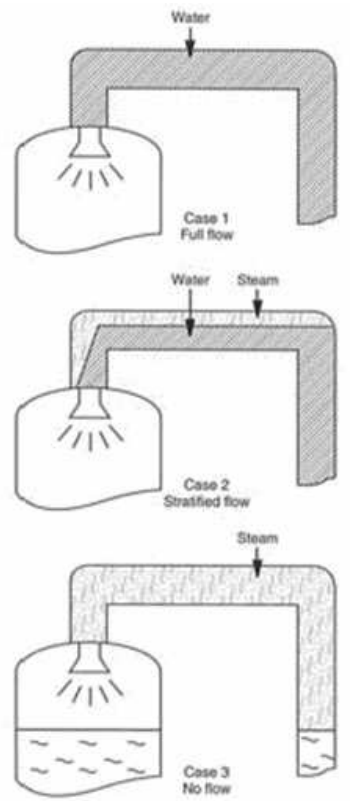

Figure 2.10 Different working conditions at the pressurizer spray line.

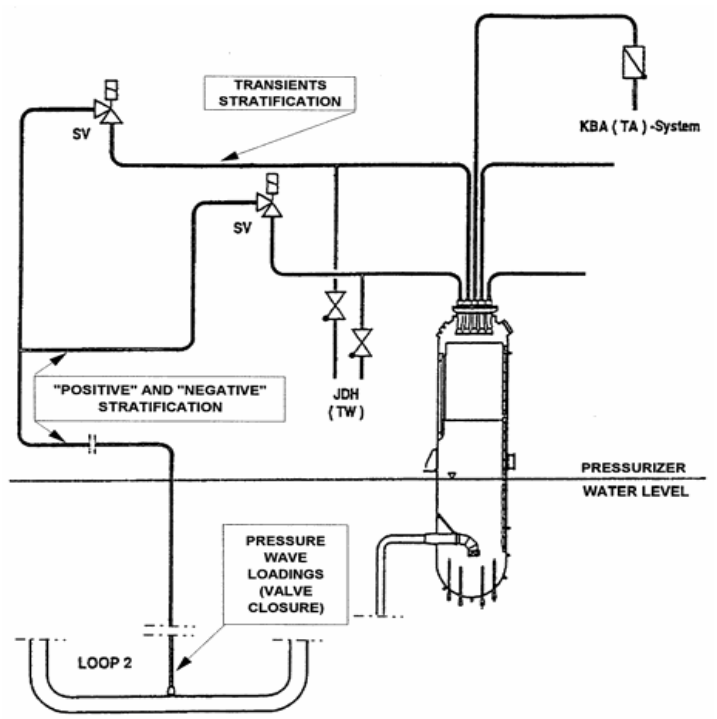

Figure 2.11 Pressurizer spray lines arrangement at the Grhonde plant. 


\subsubsection{THERMAL STRESS IN OTHER LINES}

Nuclear power plants contain a large variety of pipes and ramifications (injection systems, residual heat extraction, small diameter pipes, etc) and nozzles that can be damaged by thermal stresses arising from operationally induced transients and their consequent thermal shock phenomena. Turbulent penetration and thermal cycling has been known, since the eighties, to result into pipe cracking.

\subsubsection{SAFETY INJECTION LINES}

Figure 2.12 illustrates the production of stratification at the safety injection line upon the influx of hot leg turbulence. The turbulence intensity decreases exponentially as it penetrates in the leg, however the temperature remains practically constant along some diameters length and later it decreases. The length of the penetration does depend on both main pipe flow velocity and on the pipe layout. For instance the length of penetration in a branch of a PWR plant containing stagnant coolant is between 15 and 25 diameters of the branch. The turbulent penetration does interact with the existing stratified layers resulting into stratified flow conditions.

Under some specific conditions, the range of the perturbation usually fluctuates around some values resulting into thermal cycling phenomena.

Stratified flow can also be produced by leaky valves. 


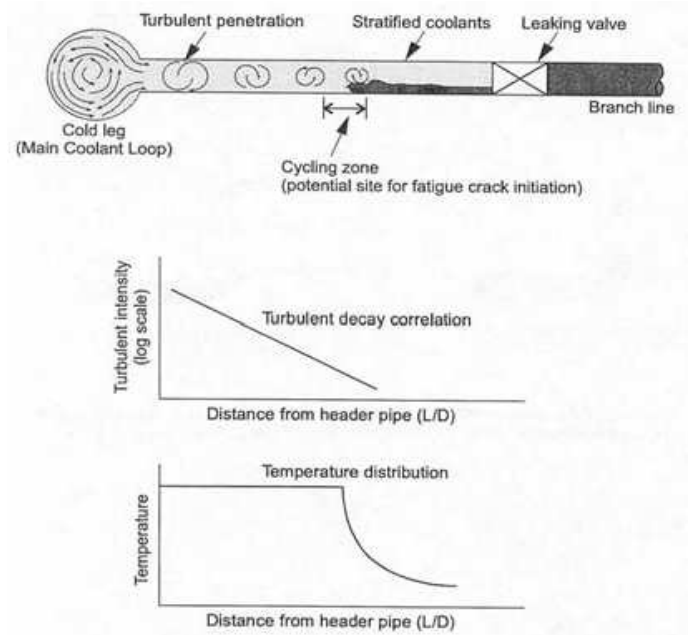

Figure 2.12 Interaction between the turbulent flow in the main pipe and the stagnant coolant at the branch.

Pipe lines cracking induced by turbulence was first reported to appear in 1982 at the Crystal River plant. Since this first case, several more were reported to occur at a variety of sites: Farley 2, Tihange 1, Oconee. In Figures 2.13, 2.14, and 2.15 layouts of the points where these cracks were produced are shown.

Otherwise it is interesting to note that Nakamori y Hanzawa made an experiment to simulate the safety injection line with the conditions that the Farley plant had when the leakage was detected [Nakamori, 1995]. In this experiment the existence of stratification and the temperature cycling close to the cracks was negligible. Facing this situation, the NRC concluded that while not having consistent results with the Farley and Tianghe cracks, and all the phenomenology involved, it will not be completely sure that these analytical models are correct. For this reason the Farley and Tianghe incidents must be used as reference cases to prove that the analytical models are appropriate [Lund, 1998]. 


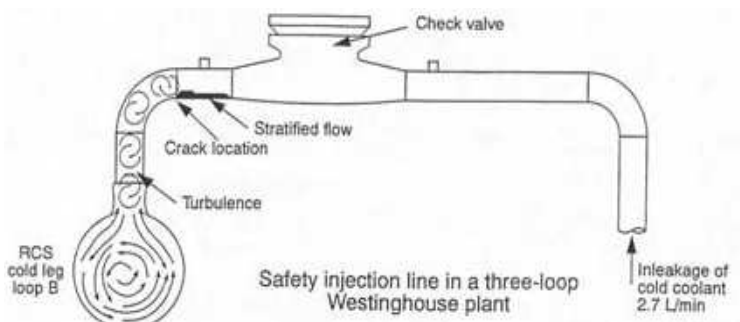

Figure 2.13 Crack produced in 1987 in the Farley 2 reactor. The crack is situated in the welding between the elbow and the pipe. It was $120^{\circ}$ circumferentially extended at the inner face and had a $25 \mathrm{~mm}$ length at the outer surface.

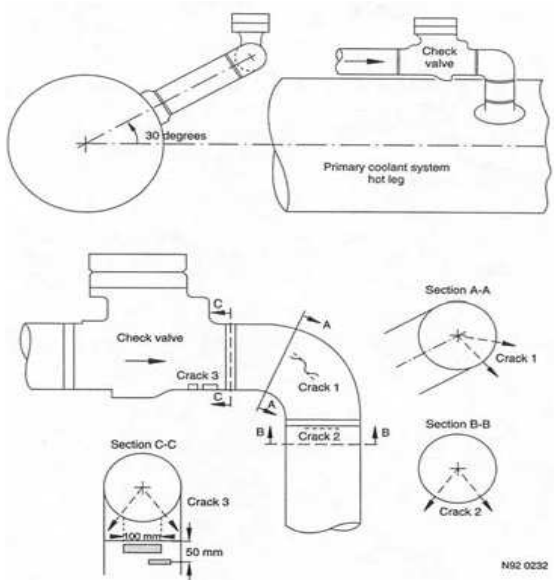

Figure 2.14 Crack produced in 1988 in the Tianghe 1 reactor. The crack is situated in the elbow with an internal length of $89 \mathrm{~mm}$ and a exterior one of $41 \mathrm{~mm}$.

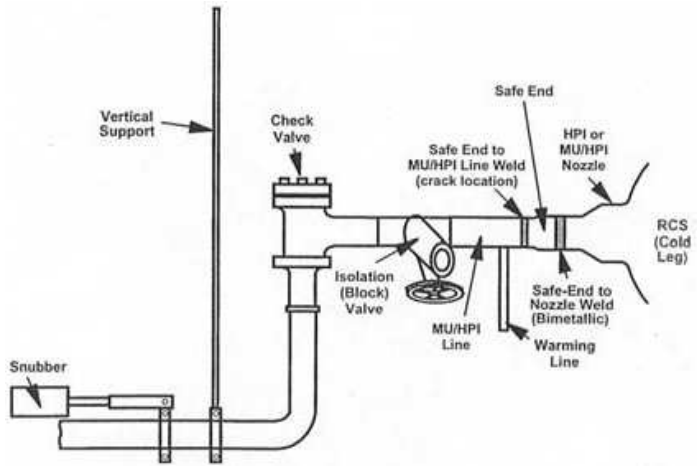

Figure 2.15 Crack produced in 1977 in the Oconee 2 reactor. The crack was situated in the welding and was extended circumferentially $360^{\circ}$ at the inner face and $77^{\circ}$ at the outer face. 
Resuming, the leakage through some valves to the cooling system of the reactor from external high pressure water sources resulted in cracks and afterwards to leakages in the cooling system pipes. We should look for the origin of these cracks in the incoming fluid from the leakages of the high pressure cold water source that stratifies with the hot fluid at the exit of this one. In this pipe exists a discharging pipe that communicates with one of the loops of the cooling system of the reactor through an elbow. The cold incoming fluid interacts with the turbulence from the cooling system of the reactor. Therefore depending on the mixing level reached which will depend on the grade of turbulence we will have more or less thermal stratification in this elbow. This will origin cracks with time in the welding used to join the elbow with the pipe as shown in Figure 2.16.

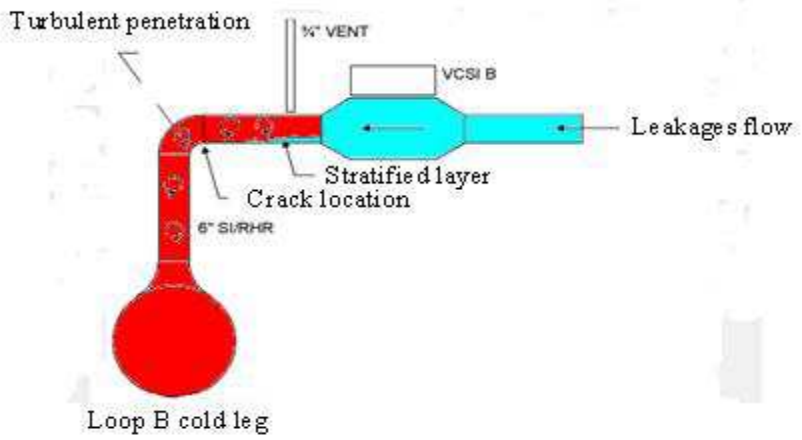

Figure 2.16 Leakage flow interaction effect with RCS turbulence and its influence on the thermal stratification.

\subsubsection{STEAM GENERATOR FEEDWATER LINES}

When operating at low cold feed water flows, it is possible that hot fluid from the steam generator to flow back to this pipe. In this case thermal stratification can be produced, and can result in thermal tensions, what can result in cracks in the welds, as happened in several unities of USA (Cook 2 (1978), Sequoyah (1992), Diablo Canyon (1992). In 1979 the NCR issued a newsletter IE 79-13 "Cracking in feedwater system piping".

In the Doel 3/4 (Belgium) temperature measurements were made in these lines and the existence of this reverse flow that results in a stratification as shown in Figure 2.17 was revealed De Smet, 1998]. 


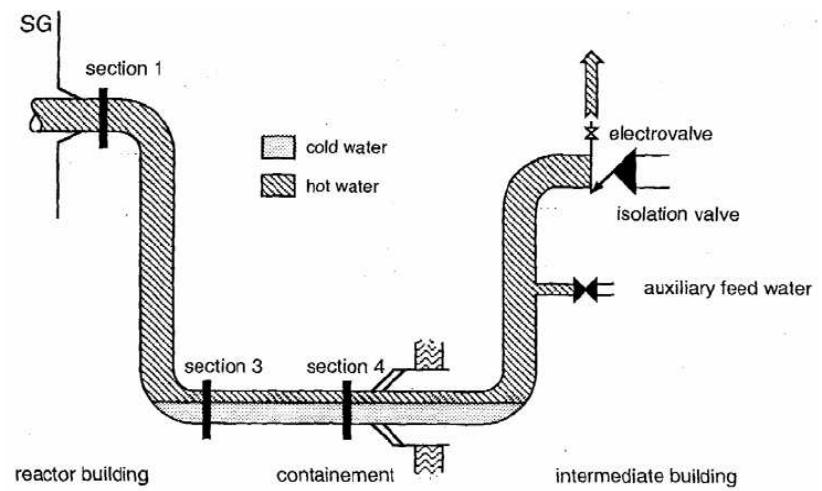

Figure 2.17 Schematic representation of the steam generator feed water line in Doel 3/4 plant.

\subsubsection{RHR SYSTEM LINE}

In the Genkai 1 plant a crack was produced in the RHR system line (Residual heat removal). The crack position is shown Figure 2.18.

In order to investigate the cause of this event, an experiment was made by the Mitsubishi Heavy Industries. It was concluded form this research that the crack in the welding was caused by the temperatures cycling by the thermal stratification, which fluctuated as the leakage flow of the valve changes [Shirahama, 1998].
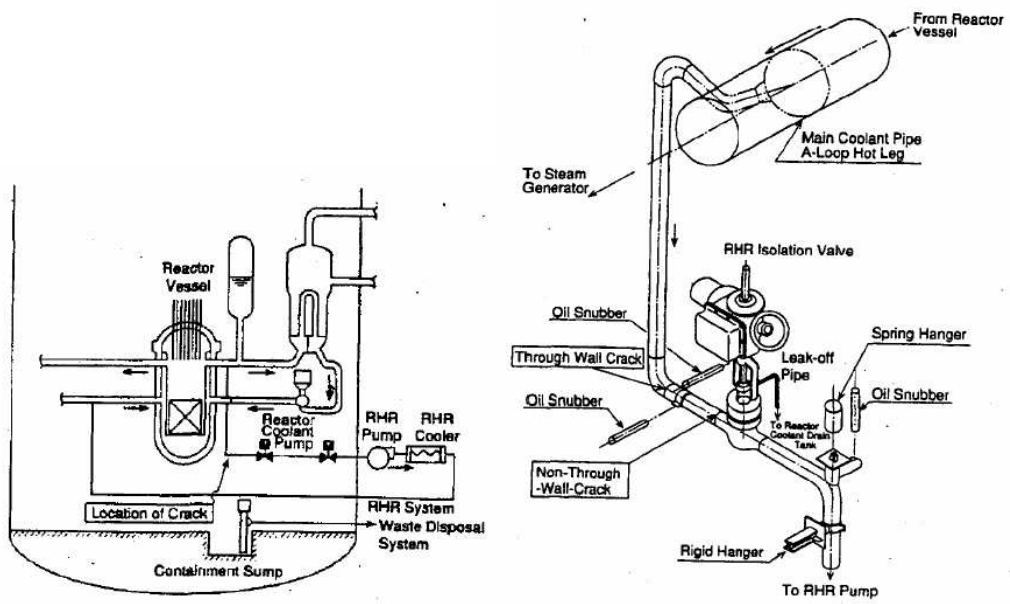

Figure 2.18 Crack situation in the Genkai 1 plant. 


\subsection{STRATIFICATION IN THE COLD LEG DUE TO THE SAFETY INJECTION}

There exists a phenomenon in the nuclear literature called PTS (Pressurized Thermal Shock), which may occur during safety injection HPI (high pressure injection) in the PWR reactors through the cold leg. It is related to the thermal stratification phenomenon.

If the mass flow rate in the primary is significant, then the cold water from the HPI system mixes with the hot water flowing through the cold leg. However, when the mass flux flowing through the leg is small, the cold water injected gets stratified in the loop and creates a cold water plume in the downcomer, which may originate thermal tensions in the vessel.

Thence it is really interesting to study the conditions under which the loss of natural circulation flow during the actuation of the safety injection systems (ECCS) occur, resulting that the flow circulating through the loop is important due to the fact that the existence of the same, tends to keep the flow in the primary well mixed, reducing or avoiding the impact of the PTS.

Figure 2.19 shows the different regions of a PWR where the thermal stratification produced by the safety injection (HPI) in the cold leg can happen.

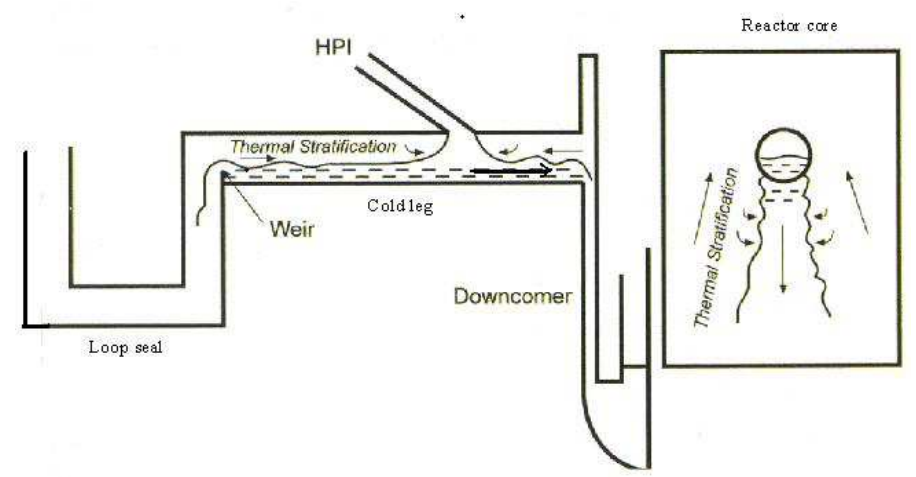

Figure 2.19 Thermal stratification regions in the primary of a PWR reactor as Reyes (2005). 
In order to find out under what conditions a good mixing or thermal stratification in the cold leg of a PWR reactor is produced when cold water is injected by the high pressure safety injection (HPI), Theofanus et al. (1984) correlated with success the conditions under which natural circulation was established, and arrived to the following criterion:

$$
F r_{H P I / L}=\left[1+\frac{Q_{L}}{Q_{H P I}}\right]^{-7 / 5}
$$

where $\mathrm{Q}_{\mathrm{L}}$ is the flow circulating through the cold leg; $\mathrm{Q}_{\mathrm{HPI}}$ is the flow through the safety injection nozzle and $\mathrm{Fr}_{\mathrm{HPI} / \mathrm{CL}}$ is a modified Froude ${ }^{1}$ number defined as follows:

$$
F r_{H P I / C L}=\frac{Q_{H P I}}{A_{L}\left[g D_{L} \frac{\rho_{H P I}-\rho_{L}}{\rho_{H P I}}\right]^{1 / 2}}
$$

where, $A_{L}$ y $D_{L}$ are the cross section and the cold leg diameter respectively; $g$ is the gravity acceleration; $\rho_{H P I}$ and $\rho_{L}$ are the fluid densities at the injection nozzle conditions and at the hot leg conditions.

Equation 2.2 defines the separation border between the well mixing flow and the stratified one, for the geometry in Figure 2.21. Afterwards Reyes (2001) developed a similar criterion to Equation 2.1 by making a Hydraulic jump analysis. The criterion obtained with this methodology was:

$$
F r_{H P I / L}=\left[1+\frac{\rho_{L} Q_{H P I}}{\rho_{H P I} Q_{L}}\right]^{-1 / 2}\left[1+\frac{Q_{L}}{Q_{H P I}}\right]^{-3 / 2}
$$

The criteria given by Equations 2.1 and 2.3 are similar except when the relation between the flows $\mathrm{Q}_{\mathrm{L}} / \mathrm{Q}_{\mathrm{HPI}}$ is smaller than 1, differing each time more until this relation gets close to 0 . The curves obtained with both criteria are represented in Figure 2.22, for the conditions of the experiments carried out in the CREARE 1/5 facility [Fanning et al 1983].

\footnotetext{
${ }^{1}$ The Froude number expresses the relation between the inertial forces and the gravitational forces. When we are under stratified conditions, the gravitational forces that actuate are the buoyancy ones.
} 


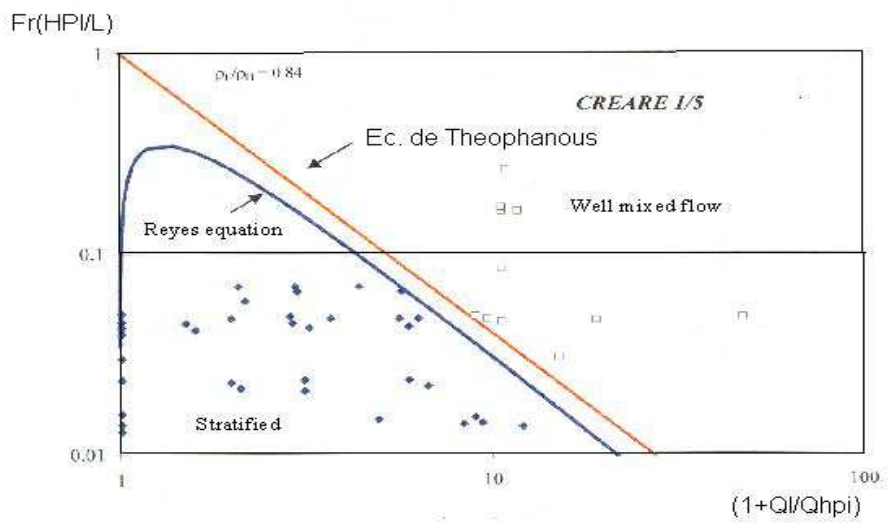

Figure 2.20 Comparison of the Reyes and Theophanous criteria for the beginning of the thermal stratification in the cold leg.

There are two plumes formed as can be observed in Figure 2.21; the first one is in the nozzle discharging zone of the high pressure injection (HPI), and the second one is in the downcomer due to the cold leg coming from the safety injection. The study of these plumes has been made by Reyes [2005]. Let's focus the fact that the cold water of the first plume is divided into two flows, one flowing to the recirculation pump and another one flowing to the downcomer which as falls through it forms the second plume studied by Reyes.

The previous criteria tells us that after the loss of natural circulation in the loop, when $\mathrm{Q}_{\mathrm{L}}=0$, the flow in the cold leg stratifies thermally. The fluid coming from the safety injection enters by the upper part of the pipe creating a column or plume that falls to the bottom of the pipe.

As is indicated in Figure 2.21, this plume scatters in both directions, towards the pump and towards the downcomer, but the lock of the loop seal prevents the flow to go in this direction unless it overflows, what forces the water to create a small pool and then it flows to the downcomer, where the cold water that enters through the cold leg forms a plume again as it is observed in Figure 2.21. 


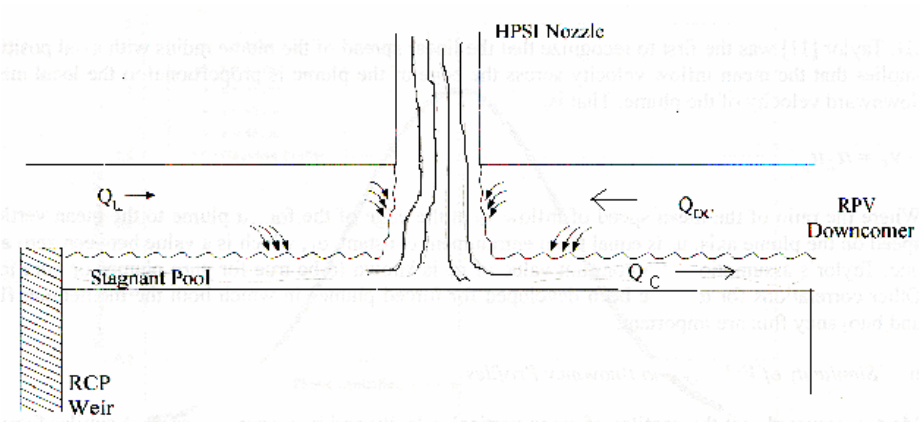

Figure 2.21 Safety injection and stratification in the cold leg during a PTS.

\subsection{DESCRIPTION OF THE PHENOMENA THAT MAY BE INVOLVED WHEN STUDYING THE THERMAL STRATIFICATION IN THE COLD LEG}

The problem which we will study in the following chapters is the steam-water biphasic countercurrent flow in the cold leg due to a LOCA (loss of coolant accident), and the corresponding further actions in order which guarantee the reliable removal of decay heat from the reactor core. During this scenario, it may result into a stratified flow at the cold leg due to its depressurization.

The physical phenomena which may concern to this situation are:

- Interfacial heat transfer and condensation.

- Interfacial and with the walls friction.

- To the walls heat transfer at the liquid phase, and the heat transfer and condensation at the walls of the steam phase.

- Hydraulic jump.

In the present work we haven't study the hydraulic jump which may occur if some factors concur. 


\subsubsection{FROUDE NUMBER AND FLOW REGIME CLASSIFICATION}

In order to describe and classify flow phenomena that can appear in an stratified flow, we must introduce some definitions:

The local Froude number of a liquid film at the position in a horizontal channel of length 1 is defined as:

$$
F_{r_{x}}=\frac{u_{l}(x)}{\sqrt{g y(x)}}
$$

where, $\mathrm{x}$ is any position in the channel $\in[0,1], \mathrm{g}$ is the gravity acceleration, $\mathrm{u}_{\mathrm{L}}(\mathrm{x})$ is the mean liquid velocity and $\mathrm{y}(\mathrm{x})$ is the liquid depth at the $\mathrm{x}$ position.

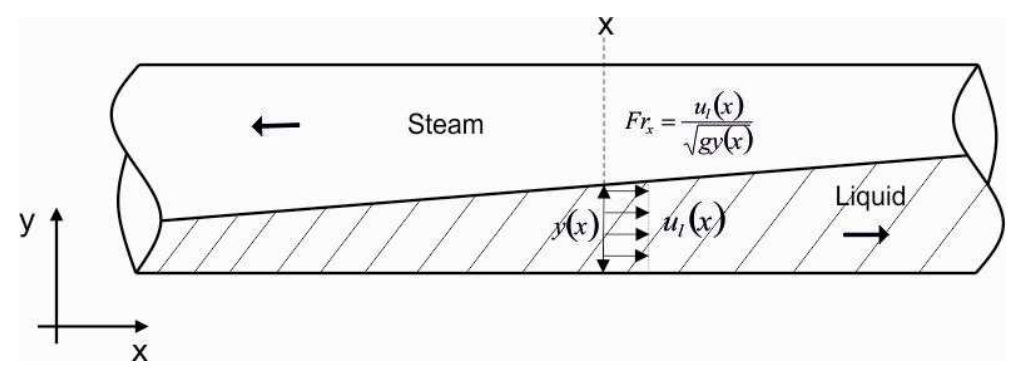

Figure 2.22 Liquid Froude number in countercurrent stratified flow.

The Froude number is a dimensionless number which represents the ratio of the inertial to gravitational forces.

The inertial forces $F_{a}$ are expressed as:

$$
F_{a}=m_{F} a=m_{F} \frac{u}{t}=m_{F} \frac{u}{\delta / u}=\frac{m_{F} u^{2}}{\delta}
$$

where $m_{F}$ is the mass of the fluid, a is the acceleration, $\mathrm{t}$ is the time, $\mathrm{u}$ is the velocity and $\delta$ is the characteristic length. 
The gravitational force is expressed as:

$$
F_{g}=m_{F} g
$$

So, the ratio can be expressed as:

$$
\frac{F_{a}}{F_{g}}=\frac{m_{F} u^{2}}{\delta m_{F} g}=\frac{u^{2}}{g \delta}
$$

It can be seen that the Froude number is just the square root of this expression if the liquid depth y is chosen as the characteristic length $\delta$.

We can say that the Froude number is a ratio between the liquid velocity and the celerity of an elementary gravity wave:

$$
F r_{x}=\frac{u_{l}(x)}{c(x)}
$$

According to this definition we can lead to some interesting conclusions when classifying flow regimes. Hence, depending on the Froude number we have the following flow regimes for our horizontal countercurrent stratified flow:

\section{A) SUBCRITICAL FLOW (FR $<1)$ :}

The flow is subcritical when, for a channel of section $S$, the Froude number is less than 1 . In a subcritical flow, the mean velocity is relatively low although a subcritical flow always accelerates in the direction of the flow, as we can see in Figure 2.23. The liquid depth decreases progressively in the flow direction, and therefore, the liquid velocity increases downstream. In a subcritical flor gravitational forces are dominant. 


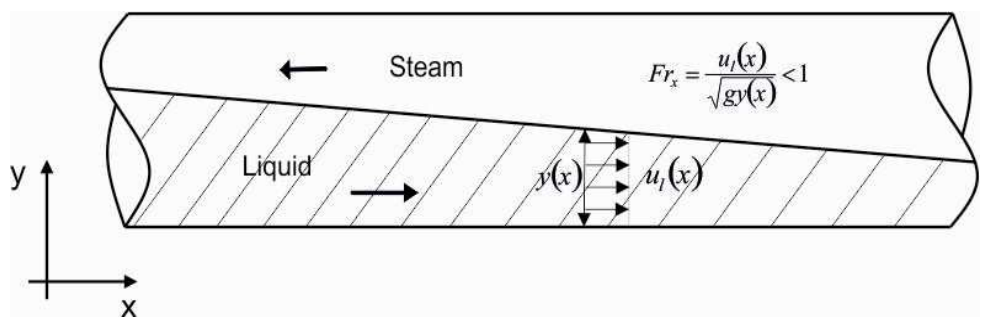

Figure 2.23 Subcritical countercurrent flow.

If the Froude number is less than unity, the celerity of an elementary gravity wave is higher than the velocity of the flow. So, surface waves can travel faster than the flow it-self, and this wave can propagate upstream against the flow and upstream areas are in hydraulic communication with downstream areas. This means that in a subcritical flow, any disturbance influences the upstream conditions, so that surface wave can propagate either upstream or downnstream.

\section{B) SUPERCRITICAL FLOW (FR >1):}

The flow is supercritical in a channel if the Froude number is higher than unity. In a supercritical flow, the mean velocity is relatively high and the inertial term is dominant. However, a supercritical flow always decelerates in the direction of the flow and the liquid depth increases progressively in the downstream direction (Figure 2.24).

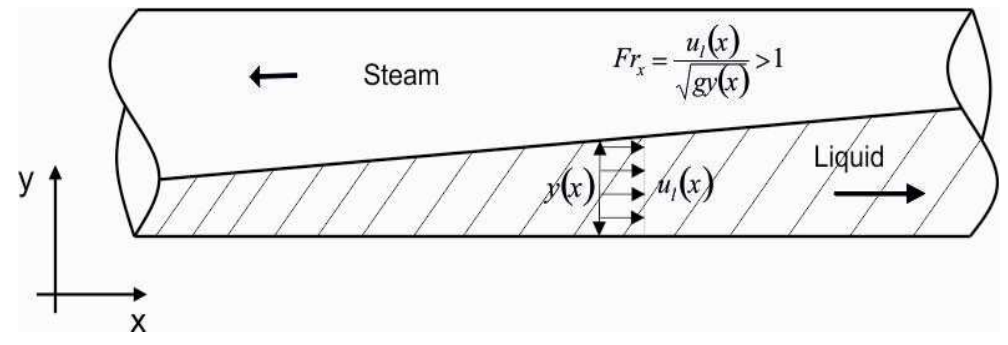

Figure 2.24 Supercritical countercurrent flow 
In a supercritical flow, only the supercritical waves can be observed, and they propagate always in the flow direction and generate a typical oblique interference pattern with small amplitudes and small wavelengths. Large amplitude waves which propagate upstream are not possible in a supercritical flow, since the velocity of the flow is greater than the celerity of an elementary gravity wave. So, upstream areas of the channel are not in hydraulic communication with the downstream areas.

\section{C) HYDRAULIC JUMP:}

The hydraulic jump is by definition, the transition from supercritical to subcritical flow (Figure 2.25). Therefore the hydraulic jump means a sudden increase in the liquid depth at a certain position of the channel and hence, a change in the type of waves of the flow.

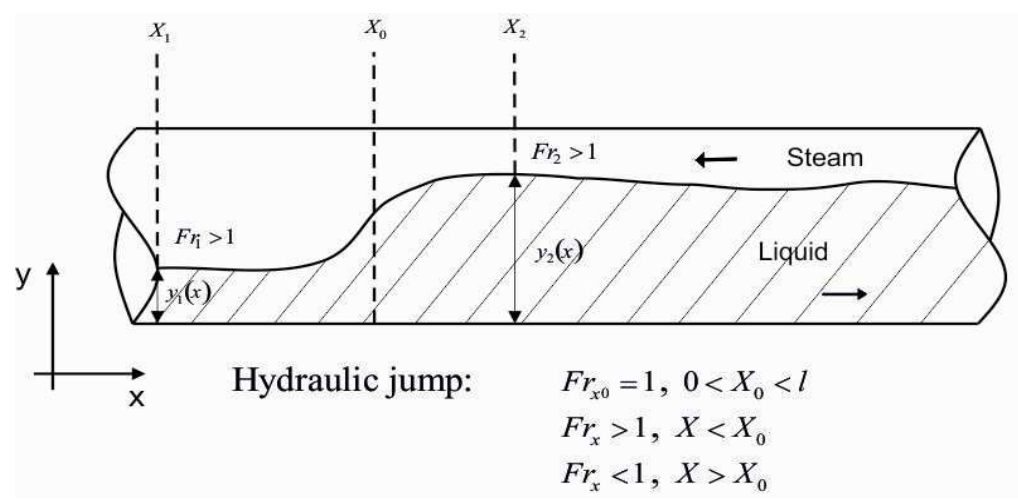

Figure 2.25 Hydraulic jump in horizontal countercurrent flow.

We should notice something in the previous definitions. Since subcritical and supercritical flow are defined in relation to a natural wave velocity, they are closely analogous to subsonic and supersonic flow respectively, which are defined in terms of the natural velocity of a small amplitude compression wave in a gas (velocity of sound). Therefore, the supercritical waves in a liquid flow may be analogous to the supersonic waves in gas flows, as there is a parallelism between the Froude number for incompressible flow and the Match number for compressible flow. So, the hydraulic jump corresponds to the shock front in gas dynamics. 


\section{(D) REVERSED FLOW}

In horizontal, stratified countercurrent flow of gas and liquid, a limit can be reached when the liquid flows partially in the gas direction, and therefore, liquid flow at its initial direction is reduced. A breakdown of the stable countercurrent stratified two-phase flow occurred. This phenomenon is often called flooding in the literature. Since flooding defines the flow conditions, for which the liquid begins to flow, partially or totally, in the gas direction, the terms reversed flow and flow reversal will be defined below. The onset of flow reversal defines the maximum rate at which both liquid and steam can flow countercurrently. A further increase of the gas flow rate leads to instabilities and the countercurrent flow can not be sustained as a stratified flow.

We have then two types of reversed flow depending on the quantity of liquid that is carried over by the gas: partially reversed or totally reversed flow.

\section{D.1 PARTIALLY REVERSED FLOW}

For high gas velocities, part of the liquid starts to flow in the gas direction, while the rest of the liquid remains flowing in the initial direction (Figure 2.26). This phenomenon is referred to as partially reversed flow.

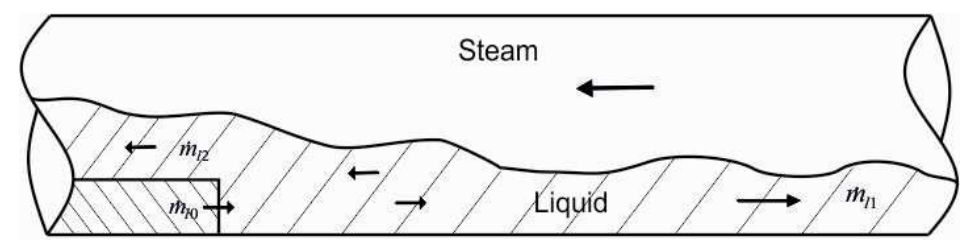

Figure 2.26 Partially reversed flow

When partially reversed flow occurs, a part of the initial liquid mass flow rate $\dot{m}_{L 0}$ flows backwards driven by the gas. So, we can say that $0<\dot{m}_{L 1}<\dot{m}_{L 0}$, where $\dot{m}_{L 1}$ is the mass flow fraction that flows backwards, and as we see in Figure 2.26, $\dot{m}_{L 2}$ is the mass flow 
fraction that keeps flowing in the same direction. Hence, it is useful to define the following ratio:

$$
b=\frac{\dot{m}_{L 2}}{\dot{m}_{L 0}}, \text { where obviously } 0 \leq b \leq 1
$$

\section{D.2 TOTALLY REVERSED FLOW}

For much higher velocities, the entire liquid is carried over by the gas. This flow regime is defined as totally reversed flow. In reactors applications, a totally reversed flow is often referred to as zero liquid penetration point. It is essential to avoid the occurrence of such a flow regime, since if this point is reached, the reactor core refrigeration during the transient cannot be guarantied.

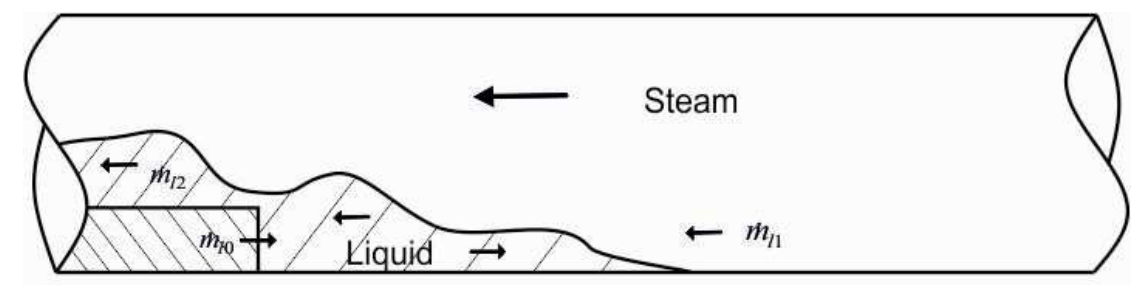

Figure 2.27 Totally reversed flow

While a partially reversed flow corresponds to values for $\mathrm{b}$ of $0 \leq b \leq 1$, the value of $\mathrm{b}=1$ corresponds to the totally reversed flow.

\section{D.3 COUNTERCURRENT FLOW LIMITATION}

Flow reversal represents a natural boundary limit of countercurrent flow, beyond which flow limiting mechanisms play a predominant role. Once reversed flow has set in, it is impossible to increase the liquid delivery into the downcomer by increasing the liquid supply. The liquid level increases considerably due to turbulence and air entrainment caused by the onset of reversed flow. The flow path available for the gas can reduce significantly or even be totally blocked by liquid slugs. This leads to an immediate increase in pressure what results in a limitation of the liquid delivery rate, even if the liquid mass 
flow rate is increased. This mechanism which limits the liquid delivery rate is often called Countercurrent Flow Limitation (CCFL).

\subsection{MODELLING OF THE COUNTERCURRENT PHENOMENON BY THE TRACE CODE}

A special model exists in the TRACE code that allows the user to invoke characteristic CCFL correlations at specific locations of the 3D VESSEL component or in a 1D vertical component. This capability exists in the axial direction in the 3D VESSEL component.

Countercurrent flow and CCFL can occur at any location in the reactor system.

For instance, in the case of a reflux-condensation transient associated with a small-break LOCA, countercurrent flow is predicted to exist in the hot leg and in the entrance to the steam-generator inlet plenum. In the VESSEL, CCFL can occur during blowdown as ECC liquid is attempting to fill the downcomer. During reflood, CCFL can occur at the tie plate, where the upstream flow of steam prevents or limits the fallback of liquid. This is especially important for those systems that employ upper-plenum ECC injection.

Excluding mass transfer, the accurate prediction of the flow rates is dependent primarily on the interfacial drag between the phases (which is itself dependent on the accurate prediction of the flow regime). In a given flow system, CCFL usually occurs at a flow area restriction. Typically, without the use of the CCFL model, the code predicts the complete turnaround point (zero liquid delivery), but over predicts the amount of liquid flow downstream in the region of countercurrent flow. To improve the prediction in the countercurrent region, we added a special CCFL model to the 3D VESSEL and to the vertical 1D components.

\subsubsection{BASIS FOR THE MODEL}

The TRAC CCFL model is designed to provide the user with an alternative method for calculating countercurrent flow in geometrically complex reactor hardware. This model allows the user to input the characteristic flooding curve parameters for a specific geometry applied at a particular location in the vessel. Typically, these parameters have been 
developed from experimental data for the geometry of interest or for hardware of at least similar dimensions. Bankoff has shown that the data correlate well with the relationship:

$$
H_{g}^{1 / 2}+M_{B} H_{l}^{1 / 2}=C_{B}
$$

where $H_{g}$ is the dimensionless gas flux, $H_{l}$ is the dimensionless liquid delivery, $C_{B}$ is the abscissa intercept, and $M_{B}$ is the slope. $H_{g}$

This relationship is used in the CCFL model because it allows the user to implement either the Wallis scaling (diameter dependence), Kutateladze scaling (surface-tension dependence), or a combination of the two. This is done by defining as follows a variable length scale in the determination of the dimensionless flux:

$$
\begin{aligned}
& H_{K}=j_{k}\left(\frac{\rho_{k}}{g w \Delta \rho}\right)^{1 / 2} \\
& w=D^{1-E} L^{E} \\
& L=\left(\frac{\sigma}{g \Delta \rho}\right)^{1 / 2}
\end{aligned}
$$

where:

$$
\begin{array}{ll}
k & \text { refers to the phase (gas or liquid). } \\
j & \text { is the superficial velocity. } \\
D & \text { is the diameter of the holes. } \\
g & \text { is the gravitational constant. } \\
\sigma & \text { is the surface tension. } \\
\rho & \text { is the density. } \\
\Delta \rho & \text { is the difference between the phase densities. } \\
E & \text { is an interpolation constant between } 0 \text { and } 1 .
\end{array}
$$

Note that for $E=0$, the correlation reverts to the Wallis scaling, and for $E=1$, reverts to the Kutateladze scaling. For $E$ between 0 and 1, the user can input the scaling proposed by 
Bankoff. This scaling can be calculated for tie-plate geometry even if no experimental data are available based on the critical wave number, $k_{c}=2 \pi / t_{p}$, so that:

$$
E=\tanh \left(\eta k_{c} D\right)
$$

where $\eta$ is the ratio of the area of the holes to the area of the tie plate and $t_{p}$ is the thickness of the tie plate. Also, Bankoff developed a correlation for $C_{B}$ based on the Bond number $L^{*}=n \pi D(g \Delta \rho / \sigma)^{1 / 2}$, so that:

$$
C_{B}=1.07+4.33 e-3 L^{*} \text { for } L^{*} \leq 200
$$

and

$$
C_{B}=1.94 \text { for } L>200
$$

where $\mathrm{n}$ is the number of holes.

\subsubsection{DIRECT CONDENSATION THEORY AND LITERATURE SURVEY}

This point will be divided into two main parts. In the first one, the reader will be introduced to the direct condensation phenomenon and into the basic principles, concepts, variables and main relations, in order to get a better overview.

In the second part a literature survey of the direct condensation phenomenon will be presented.

The direct contact condensation is a very important phenomenon, which is directly related to the problem of the thermal stratification in a horizontal stratified two-phase flow that we are facing. 


\subsubsection{DIRECT CONTACT CONDENSATION THEORY}

Some basic concepts and their definitions will be presented:

Condensation: Condensation is the change of the physical state of matter from gaseous phase into liquid phase.

Saturation temperature: The saturation temperature is the temperature for a corresponding saturation pressure at which a liquid boils into its vapour phase.

Direct contact heat transfer: Direct contact heat transfer can occur whenever two substances at different temperatures touch each other physically.

Direct contact condensation: Direct contact condensation is called when water steam condensates over sub-cooled liquid water free surfaces.

Filmwise condensation: It is called filmwise condensation when a continuous condensate film wets a surface, at a temperature below the saturation temperature.

Dropwise condensation: If the condensate does not wet all the surface and forms discrete droplets, then it is called dropwise condensation.

Sensible heat: Sensible heat is heat exchanged by a body or thermodynamic system that has as its sole effect a change of temperature.

Latent heat: Latent heat is the heat released or absorbed by a body or a thermodynamic system during a constant-temperature process. A typical example is a change of state of matter, meaning a phase transition. The term was introduced around 1762 by Joseph Black.

Flow regime: A range of stream flows having similar bed forms, flow resistance, and means of transporting sediment.

The flow type which we are focusing on in this work is the countercurrent horizontal flow. The flow regime patterns for horizontal flow are shown in Figure 2.28. 


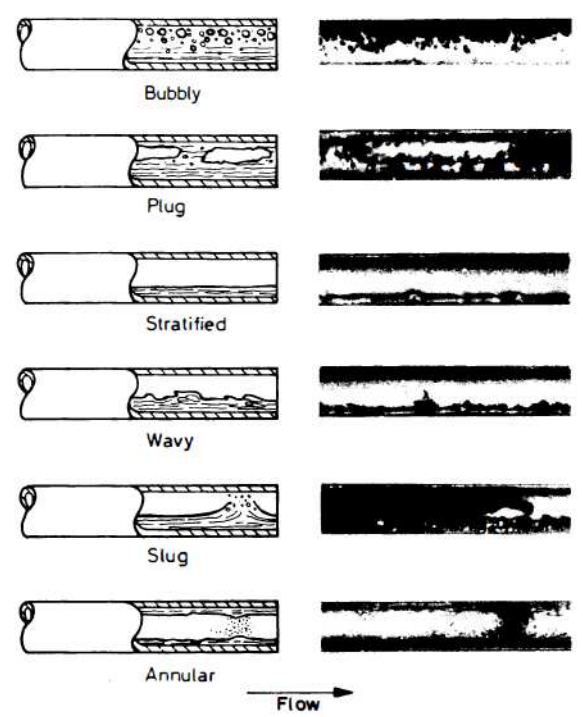

Fig. 2.28 Flow pattern in horizontal flow.

The two-phase flow patterns for condensation in horizontal tubes are illustrated in Figure 2.29 as the condensation phenomenon is being treated in this Chapter.

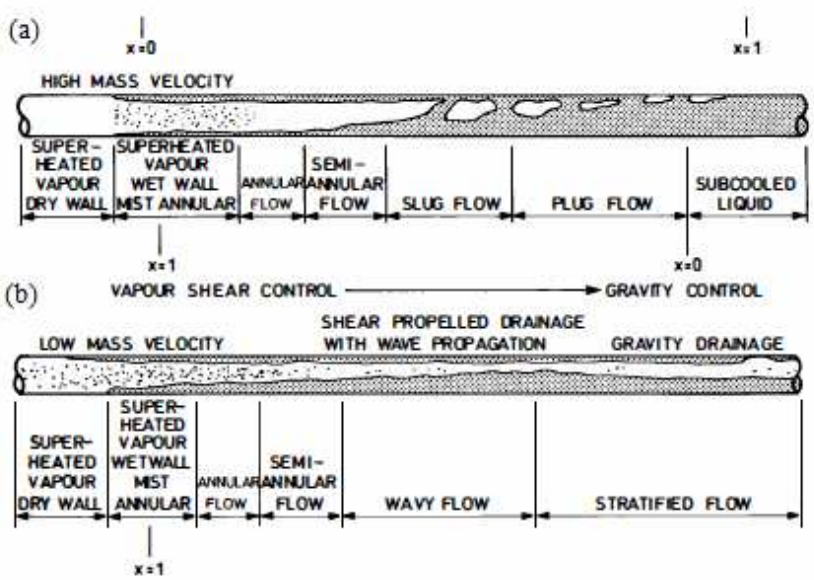

Fig. 2.29 Two-phase flow patterns in horizontal tubes: (a) Condensation with high liquid loading; (b) condensation with low liquid loading. 
One flow pattern that is widely used in petrochemical industry (Baker, 1954) is shown in Figure 2.30.

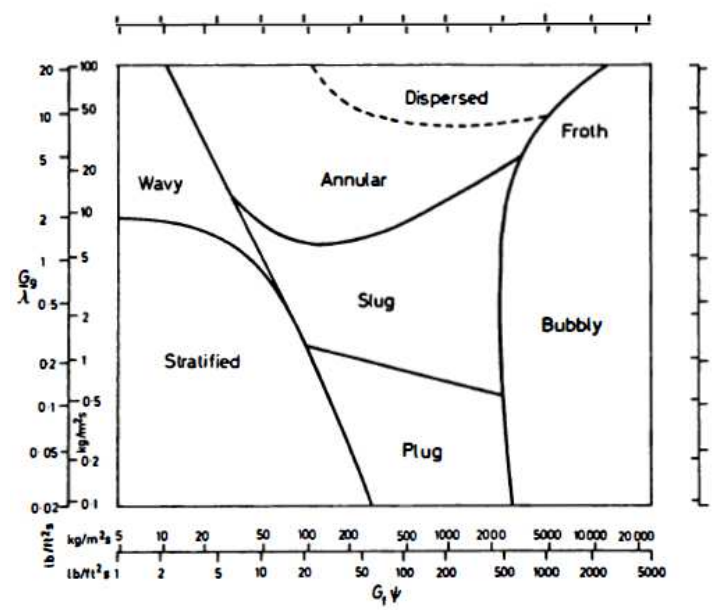

Figure 2.30 Flow pattern map for horizontal flow (Baker 1954).

The flow regime as a function of the superficial mass velocities $\left(G_{g}, G_{l}\right)$ of the liquid and steam phases respectively is shown in Figure 2.30. The factors $\lambda$ and $\psi$ are given by the following relationships:

$$
\lambda=\left[\left(\frac{\rho_{g}}{\rho_{A}}\right)\left(\frac{\rho_{f}}{\rho_{w}}\right)\right]^{1 / 2}, \psi=\left(\frac{\sigma_{w}}{\sigma}\right)\left[\left(\frac{\mu_{f}}{\mu_{w}}\right)\left(\frac{\rho_{w}}{\rho_{f}}\right)^{2}\right]^{1 / 3}
$$

The subscripts $\mathrm{A}$ and $\mathrm{W}$ refer to the values of the physical properties for air and water respectively at atmospheric pressure and temperature.

Another relevant flow regime map for the flow of an air/water mixture in a horizontal, 2.5 centimeter diameter pipe at $25^{\circ} \mathrm{C}$ and 1 bar is the Mandhane et al. (1974) map shown below: 


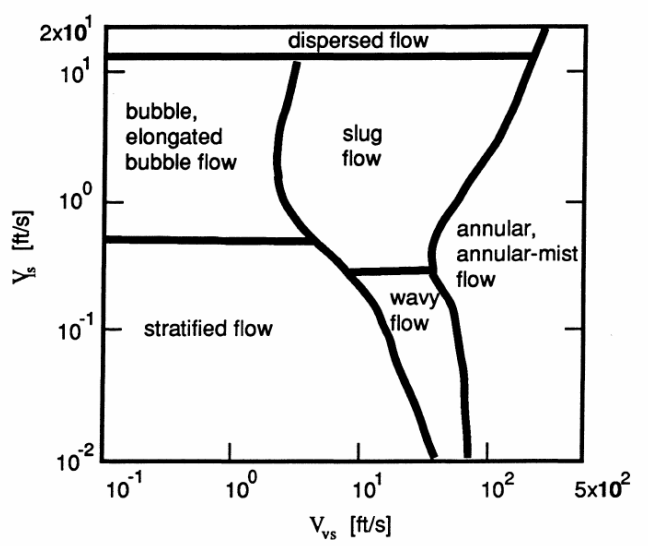

Figure 2.31 Two-phase flow regime map of Mandhane et al. (1974)

Heat transfer coefficient: The heat transfer coefficient, in thermodynamics and in mechanical and chemical engineering, is used in calculating the heat transfer, typically by convection or phase transition between a fluid and a solid, or between a vapour and a fluid on its surface.

Since, the phenomenon which we are dealing with is the direct contact condensation, the heat transfer coefficient, can be modeled through the Nusselt number. Hence, the Nusselt number for interfacial condensation between steam and a liquid layer since we are trying to study the stratified steam-water flow, can be modeled as a function of some different dimensionless numbers.

These correlations are obtained from different experiments and presented in some papers in different international scientific journals. They are usually presented as a function of dimensionless numbers like, Nusselt number ( $\mathrm{Nu}$ ), Prandtl number (Pr), Reynolds number (Re), Grashoff number (Gr), Froude number (Fr), Jakob number (Ja) and Stanton number (St).

Once we get a correlation and, under certain conditions, we can calculate the heat transferred between the steam and the liquid phases. Since, this heat is inversely proportional to the mass condensation rate; we can hence calculate the mass condensation rate using the following equation: 


$$
\dot{m}_{c}=\frac{\dot{q}_{\text {int erface }}}{i_{g}-i_{f}}
$$

where;

$i_{g}-i_{f} ;$ latent heat $(\mathrm{KJ} / \mathrm{Kg})$

$\dot{q}_{\text {int erface }} ;$ heat transferred between the steam and the liquid at the interface $(\mathrm{KJ} / \mathrm{s})$.

We will in general have an equation as the one below:

$$
N u_{\text {cond }}=c_{1} \operatorname{Re}_{l}{ }^{c_{2}} \operatorname{Re}_{g}{ }^{c 3} \mathrm{Ja}^{c 4} \operatorname{Pr}_{l}{ }^{c 5} \mathrm{Fr}_{l}{ }^{c 6} \mathrm{St}^{c_{7}} \mathrm{Gr}{ }^{c 8}
$$

Where, the coefficients from $\mathrm{c} 1$ to $\mathrm{c} 8$ have to be correlated with experimental data. Now below, these dimensionless numbers will be defined:

Nusselt number:

It is a dimensionless number and, Named after Wilhelm Nusselt, is the ratio of convective to conductive heat transfer across (normal to) the boundary (surface) within a fluid. The conductive component is measured under the same conditions as the heat convection but with a (hypothetically) stagnant (or motionless) fluid.

$$
N_{u_{l}}=\frac{h L}{k_{l}}
$$

where:

$L$; Characteristic length

$k_{l}$; Thermal conductivity of the fluid

$h$; Convective heat transfer coefficient.

Reynolds number: 
The Reynolds number $(\mathrm{Re})$ is a dimensionless number that gives a measure of the ratio of inertial forces to viscous forces and consequently quantifies the relative importance of these two types of forces for given flow conditions. Reynolds numbers frequently arise when performing dimensional analysis of fluid dynamics problems, and as such can be used to determine dynamic similitude between different experimental cases.

$$
\operatorname{Re}=\frac{\rho u L}{\mu}=\frac{u L}{v}
$$

where,

$\rho$; Density $\left(\mathrm{Kg} / \mathrm{m}^{3}\right)$

$\mu$; Dynamic viscosity $(\mathrm{Pa} \cdot \mathrm{s})$

$v$; Kinematic viscosity $\left(\mathrm{m}^{2} / \mathrm{s}\right)$.

Jakob number:

It is a dimensionless number which is used in phase change heat transfer calculations. It is defined below:

$$
J a=\frac{C p_{l}\left(T_{s a t}-T_{l}\right)}{h_{f g}}
$$

where,

$C p_{l}$; Specific heat of the liquid phase $\left(\mathrm{KJ} / \mathrm{Kg}^{\circ} \mathrm{K}\right)$

$T_{\text {sat }} ;$ Saturation temperature

$T_{l} ; \quad$ Liquid temperature

$h_{f g} ; \quad$ Phase change enthalpy $(\mathrm{KJ} / \mathrm{Kg})$.

Prandtl number:

The Prandtl number is a dimensionless number which evaluates the ratio of momentum diffusivity (kinematic viscosity) to thermal diffusivity. It was named after the German physicist Ludwig Prandtl.

It is defined as: 


$$
\operatorname{Pr}=\frac{v}{\alpha}=\frac{C p \mu}{k}
$$

where;

$C p ; \quad$ Specific heat $\left(\mathrm{KJ} / \mathrm{Kg}^{\mathrm{o}} \mathrm{K}\right)$

$\mu ; \quad$ Dynamic viscosity $(\mathrm{Pa} \cdot \mathrm{s})$

$k ; \quad$ Thermal conductivity $\left(\mathrm{KJ} / \mathrm{m}^{\circ} \mathrm{K}\right)$.

Froude number:

Named after William Froude, the Froude number is a dimensionless number defined as the ratio of a characteristic velocity to a gravitational wave velocity. It is defined for horizontal stratified flow as:

$$
F r=\frac{u}{\sqrt{g y}}
$$

where;

$u ;$ Velocity $(\mathrm{m} / \mathrm{s})$

$g$; Gravitational acceleration $\left(\mathrm{m} / \mathrm{s}^{2}\right)$

$y$; Liquid depth (m).

\section{Stanton number:}

The Stanton number, St, is a dimensionless number that measures the ratio of heat transferred into a fluid to the thermal capacity of fluid. It is defined as:

$$
S t=\frac{h}{C p \rho V}
$$

where,

$h$; $\quad$ Convection heat transfer $\left(\mathrm{Kw} / \mathrm{m}^{2 \mathrm{o}} \mathrm{K}\right)$ 
$C p ; \quad$ Specific heat $\left(\mathrm{KJ} / \mathrm{Kg}^{\mathrm{o}} \mathrm{K}\right)$

$\rho ; \quad$ Density $\left(\mathrm{Kg} / \mathrm{m}^{3}\right)$

$V$; Velocity of the fluid $(\mathrm{m} / \mathrm{s})$.

Grashof number:

The Grashof number is a dimensionless number in fluid dynamics and heat transfer which approximates the ratio of the buoyancy to viscous force acting on a fluid. It frequently arises in the study of situations involving natural convection. It was named after the German engineer Franz Grashof.

It is defined as:

$$
G r=\frac{g \beta\left(T_{s a t}-T_{\infty}\right) D^{3}}{v^{2}}
$$

where,

$g ; \quad$ Gravitational acceleration $\left(\mathrm{m} / \mathrm{s}^{2}\right)$

$\beta ; \quad$ Volumetric thermal expansion coefficient $\left(1 /{ }^{\circ} \mathrm{K}\right)$

$T_{\text {sat }} ; \quad$ Saturation temperature

$T_{\infty} ; \quad$ Bulk temperature $(\mathrm{K})$

$D ; \quad$ Hydraulic diameter (m)

$v ; \quad$ Kinematic viscosity $\left(\mathrm{m}^{2} / \mathrm{s}\right)$.

\subsubsection{LITERATURE SURVEY}

A literature survey will be presented in this point in order to give an overview of which experiments related with the direct condensation phenomenon have been made in the past, under which conditions, and what is the actual situation of this knowledge.

The first experimental study of the stratified steam-water flow that I found in the literature was performed in 1981, by Segev, A.; Flanigan, L.J.; Kurth, R.E.; Collier, R.P. 
- Reference: Segev, A; Flanigan, LJ; Kurth, RE; Collier, RP 1981. Experimental study of countercurrent steam condensation. Journal of heat transfer transactions of the Asme 103 (2), 307-311.

Some different correlations can be found in this article for the interfacial heat transfer, which depend on the experimental conditions and geometrical configuration. The case of countercurrent steam-water flow was studied for three different slopes of the channel $(0.5$, 17 and 45 degrees).
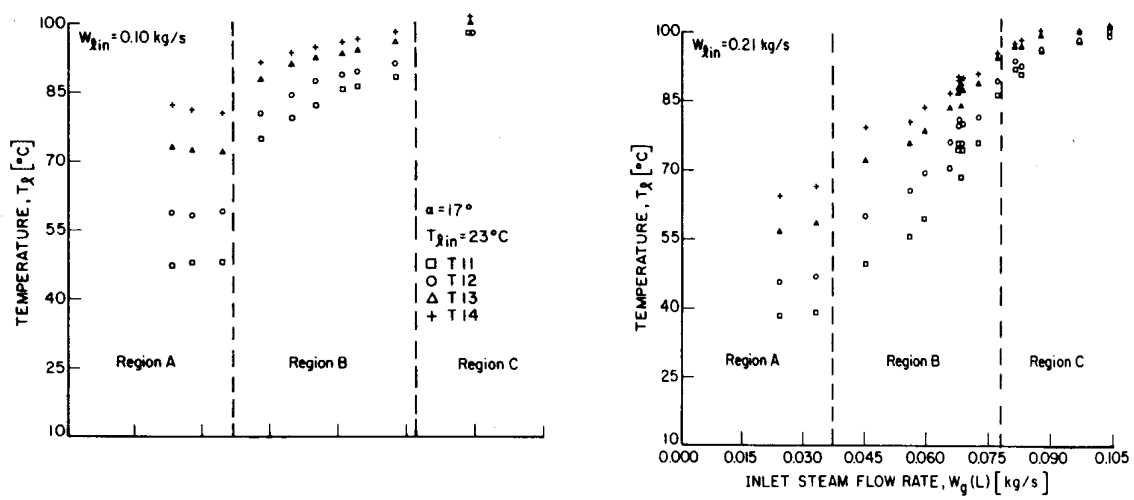

Fig. 2.32 Liquid film temperatures as functions of the inlet steam flow rate

Region A:

$$
N u l \text { int }=8.5 e-4 \operatorname{Re}_{l}{ }^{0.85} \operatorname{Re}_{g}{ }^{0.25} \operatorname{Pr}_{l}{ }^{0.5}
$$

Region B:

$$
N u_{l \text { int }}=1.16 e-3 \operatorname{Re}_{l}{ }^{0.87} \operatorname{Re}_{g}{ }^{0.28} \operatorname{Pr}_{l}{ }^{0.05}
$$

Region C:

$$
N u l \text { int }=5.79 e-4 \operatorname{Re}_{l}{ }^{1.08} \operatorname{Re}_{g}{ }^{0.016} \operatorname{Pr}_{l}{ }^{2.0}
$$

As a conclusion of this article it is said that the general behaviour in the 17 and 45 degree was similar to the behaviour of the 0.5 degree inclination, even though the films in the latter 
where much thicker. However the results in the horizontal positions were more sensitive to variations in steam flow rate since wave action was propagated further along the horizontal films compared to the inclined films.

In 1984, I.S. Lim, R.S. Tankin, M.C. Yuen, published a paper with the results of an experiment for cocurrent steam/water flow.

- Reference: I.S. Lim, R.S. Tankin, M.C. Yuen 1984. Condensation measurement of horizontal cocurrent steam/water flow. ASME J. Heat Transfer, 106 (1984), pp. 425-432.

The facility geometry was a rectangular channel with $6.35 \mathrm{~cm}$ high, $30.48 \mathrm{~cm}$ wide and $160.1 \mathrm{~cm}$ long. Different measurements where made for different steam mass flows, liquid inlet temperatures and mass flows. The experiment was performed at atmospheric pressure. Two interfacial surface configurations for the liquid were performed depending on the boundary conditions. They are smooth and wavy interface. Obviously for the wavy interface, we might have more area, more heat transfer, and hence, more condensation.

Finally we resume two correlations for the data sets, one for smooth and another for wavy interface:

Smooth interface:

$$
N u_{l \text { int }}=0.534 \operatorname{Re}_{l}{ }^{0.09} \operatorname{Re}_{g}{ }^{0.58} \operatorname{Pr}_{l}{ }^{0.3}
$$

Wavy interface:

$$
N u_{l \text { int }}=0.0291 \operatorname{Re}_{l}^{0.42} \operatorname{Re}_{g}{ }^{0.58} \operatorname{Pr}_{l}{ }^{0.3}
$$

In 1985, H.J. Kim, S.C. Lee, S.G. Bankoff published a paper with the results of an experiment for countercurrent steam/water flow. 
- Reference: H.J. Kim, S.C. Lee, S.G. Bankoff 1985.Heat transfer and interfacial drag in countercurrent steam-water stratified flow. Int. J. Multiphase Flow, 11 (1985), pp. 593606.

The interfacial friction and the condensation heat and mass transfer for a countercurrent steam/water flow are studied in this paper. As we see in the correlation below, the Reynolds number of the steam has been replaced by the Froude number to take into account the thickness of the gas and liquid layers. The obtained correlation is:

$$
N u_{l \text { int }}=0.966 \operatorname{Re}_{l}^{0.98} \operatorname{Pr}_{l}^{0.95} \mathrm{Fr}^{0.8}
$$

In 2000, I.C. Chu, S.O. Yu, M.H. Chun 2000 published a paper with the results of an experiment for countercurrent steam/water flow.

- Reference: I.C. Chu, S.O. Yu, M.H. Chun 2000. Interfacial condensation heat transfer for countercurrent steam-water stratified flow in a circular pipe. J. Korean Nucl. Soc., 32 (2) (2000), pp. 142-156.

An experimental study of steam condensation on a subcooled thick water layer in a countercurrent stratified flow was made in this paper.

Two correlations were obtained. The difference between them is that the Prandtl number in the first one was substituted by the Jakob number in order to take into account the subcooling in the water layer.

$$
\begin{aligned}
& N u_{l \text { int }}=7.96 e-7 \operatorname{Re}_{l}{ }^{1.31} \operatorname{Re}_{g}{ }^{0.51} \operatorname{Pr}_{l}{ }^{1.19} \\
& N u_{l \text { int }}=7.13 e-9 \operatorname{Re}_{l}{ }^{1.32} \operatorname{Re}_{g}{ }^{0.53} J a^{1.21}
\end{aligned}
$$

In 2006 Kyung-Won Lee, In-Cheol Chu, Seon-Oh Yu, Hee Cheon published a paper with the results of an experiment for countercurrent steam/water flow. 
- Reference: Kyung-Won Lee, In-Cheol Chu, Seon-Oh Yu, Hee Cheon No 2006. Interfacial condensation for countercurrent steam-water stratified wavy flow in a horizontal circular pipe. International journal of Heat and mass Transfer 49, 3121-3129.

A countercurrent steam/water flow experiment can be found in this paper, which was made in order to study the interfacial condensation. A correlation was obtained from making a least-square fit of the experimental data, which is shown below:

$$
N u_{l \text { int }}=1.2 e-7 \operatorname{Re}_{l}{ }^{0.59} \operatorname{Re}_{g}{ }^{1.2} J a^{0.82}
$$

This correlation is obtained for a wavy interface and applicable ranges of:

$j_{g}>2.5 \mathrm{~m} / \mathrm{s}$

$4000<\operatorname{Re}_{l}<14000$

$12000<\operatorname{Re}_{g}<23000$

$43.5<J a<180$.

In 2009 Hyun-Sik Park a, Sung-Won Choi b, Hee Cheon No, published a paper with the results of an experiment for countercurrent steam/water flow.

- Reference: Hyun-Sik Park a, Sung-Won Choi b, Hee Cheon No, 2009. Direct-contact condensation of pure steam on cocurrent and countercurrent stratified liquid flow in a circular pipe. International Journal of Heat and Mass Transfer 52, 1112-1122.

The direct-contact condensation for a steam/water countercurrent and for cocurrent flow at atmospheric pressure, and for a circular pipe was studied in this paper. The correlation which was obtained and which is shown in this paper is the following one:

$$
N u_{l \text { int }}=9.66 e-4 \cdot \operatorname{Re}_{l}{ }^{0.98} \cdot \mathrm{Fr}_{g}{ }^{0.8} \cdot \operatorname{Pr}_{l}{ }^{0.95}
$$




\section{CHAPTER 3}

\section{ANALYSIS WITH TRACE CODE OF ROSA TEST 1.2: SMALL LOCA IN THE HOT-LEG WITH HPI AND ACCUMULATOR ACTUATION}

\subsection{INTRODUCTION}

The analysis of the experiment ROSA 1.2 with the TRACE code was assigned to the "thermal-hydraulic and nuclear engineering group" of the Polytechnic University of Valencia. This test was performed in the nuclear safety research centre of the Japan Atomic Energy Agency in the large scale test facility (LSTF) on May 17, 2007.

The test ROSA 1.2 consists of a $1 \%$ small break LOCA in the hot leg B of the LSTF facility. The orifice has a hydraulic diameter of $10.1 \mathrm{~mm}$, and is located in the bottom of the pipe. The orifice is connected to the blow-down system through a pipe of higher hydraulic diameter. The actuation of the high pressure injection system (HPIS) is activated automatically with a delay of 12 seconds when the pressure falls below 12.27 MPa. The accumulator injection is activated when the pressure falls below 4.51 MPa. The cold water injected into the cold legs by the ECCS mixes with the hot primary coolant and stratifies in the pipe flowing back toward the downcomer of the pressure vessel. Because of the injected water being cooler than the one already in the cold leg, it doesn't completely mix with the fluid of the cold leg and accumulates at the bottom of the pipe by forming a cold layer that moves towards the downcomer. However the upper part contains fluid at higher temperature that is normally in form of steam during the transient progress. This steam partially condenses on the lower boundary layer interface, and some local pressure variations can occur that may create unstable flow oscillations that in turn promote thermal mixing. Such multidimensional and non-equilibrium flow phenomena are of concern for pressurized thermal shock (PTS). 
The goal of test series 1 was to obtain the multidimensional temperature distribution in the cold leg and the vessel downcomer during the ECCS injection for verification of computer codes and models. In test 1.2 the break was located at the bottom of the hot leg B, in such a way that actuates since practically the beginning of the transient, and later at 2537 seconds from the start of the test, and at the time instant when the pressure in the primary falls below $4.51 \mathrm{MPa}$, the accumulator injection system is actuated.

This chapter is organized as follows; first the test itself is described, i.e. the initial conditions, the boundary conditions, and hence, we will display the graphs of the data set measurements in the test 1.2 experiment.

Afterwards the steady-state case obtained with the TRACE code is demonstrated, and finally, we will compare the results of the test 1.2 obtained with the simulation with the TRACE code with the experimental data.

\subsection{TEST 1.2 DESCRIPTION}

The test 1.2 is described in this point. The experimental procedure is explained, the initial and boundary conditions are presented ad the main variable graphs are displayed.

\subsubsection{EXPERIMENTAL PROCEDURE AND INITIAL CONDITIONS}

The preparation procedures are similar to those of the experiments performed previously in this facility, which is described next:

- The primary is empty before reconfigure the facility for the experiment, and the measure systems are reconfigured.

- The primary is filled with demineralised water, and the air is injected by vacuum pumps connected to the head of the pressurizer and to the exit of it until the value of $735 \mathrm{mmHg}$ of pressure is reached.

- The steam is generated using electric heaters in the accumulation tanks to purge the air while the vacuum pumps are working. The injection continues during 60 minutes until the temperature of the gas reaches the saturation temperature. 
- The primary pressure is completed with the demineralised water injection, until $18 \mathrm{MPa}$ with the help of the HPI pump.

- The primary system is depressurized and the liquid level in the pressurizer is decreased.

- The gamma ray densimeter and the conductance measurer are calibrated again while the primary fills with water.

- For the heating of the primary, in the core or in the pressurizer heaters, electrical heaters are used simulating the fuel rods.

The initial conditions of the primary system are maintained during 60 minutes, to stabilize the thermal system in the LSTF, including the metallic structures.

The data Collection starts 6 minutes before the beginning of the experiment. The end of the experiment will be done when the core power turns off and the valve closes.

\subsubsection{BOUNDARY CONDITIONS}

Figures 3.1 and 3.2 show the break unit. This break is simulated with a $10.1 \mathrm{~mm}$ inner orifice diameter at the bottom of the hot leg, where a vertical pipe was mounted, which has a valve that simulates the break. In this unit a Venturi flowmeter (FE-570-BU) was installed. The inner diameter of the pipe is $60 \mathrm{~mm}$ with a length of $506.8 \mathrm{~mm}$.

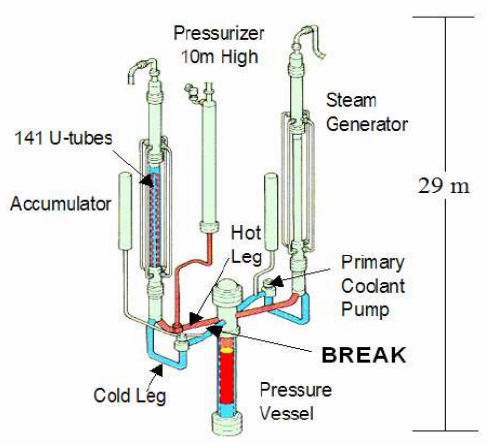

Figure 3.1 Break Configuration

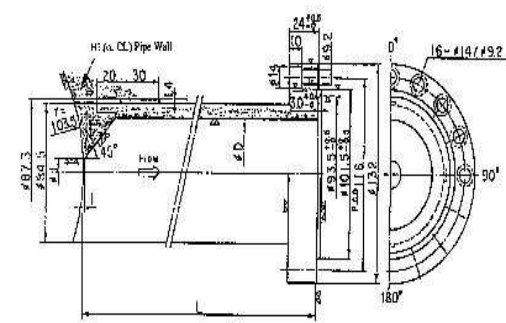

Figure 3.2 Break unity scheme 


\subsubsection{EXPERIMENT DEVELOPMENT}

The chronology of the test 1-2 events of the OECD/NEA ROSA is indicated next:

- The SCRAM signal is actuated when the pressure falls below 12.97 MPa, after which the main steam valve is closed and the feedwater in the secondary is turned off.

- The safety injection signal is actuated when pressure falls below 12.27 MPa.

- The high pressure injection is actuated with a delay of $12 \mathrm{~s}$.

- At 303s, the pumps stop with the corresponding coastdown curves.

- The accumulator is actuated at $2537 \mathrm{~s}$ when the set point signal turns on, and stops actuating at $4696 \mathrm{~s}$.

Table 3.1 shows the experiment actuation logic. The experiment starts at the moment when the break unity valve opens, what happens at $0 \mathrm{~s}$. At the same time the pumps rotational speed rises up to $161.8 \mathrm{rad} / \mathrm{s}$, for a better pressure and temperature simulation in transients of reference PWR reactors.

Table 3.1 Actuation logic specifications and setpoints

\begin{tabular}{|c|c|}
\hline Event & Condition \\
\hline Break & Zero time \\
\hline SCRAM signal generation & Primary pressure $=12,97 \mathrm{MPa}$ \\
\hline Start of the power decay curve & $\begin{array}{l}\text { SCRAM signal or liquid level in PRZ } \\
<2,3 \mathrm{~m}\end{array}$ \\
\hline $\begin{array}{l}\text { Start of the coastdown of the } \\
\text { pumps }\end{array}$ & SCRAM signal \\
\hline Turbine valves closure & SCRAM signal \\
\hline End of the main feedwater system & SCRAM signal \\
\hline Heaters turning off & SCRAM signal \\
\hline Injection signal generation & Injection signal \\
\hline $\begin{array}{l}\text { Start of the high pressure injection } \\
\text { system }\end{array}$ & Injection signal $+12 \mathrm{sg}$ \\
\hline Start of the accumulators system & Primary pressure $=4,51 \mathrm{MPa}$ \\
\hline
\end{tabular}


The initial power of the core is $10 \mathrm{MW}$, corresponding to the $14 \%$ of the nominal power volumetrically scaled at $1 / 48$ of the reference PWR (3423 MWt). The SCRAM signal actuates when the primary system pressure falls below $12.97 \mathrm{MPa}$.

Figure 3.3 shows the core power decay after the SCRAM signal, based on calculations considering the decay heat and the accumulated heat on the fuel rods. The core power is maintained at $10 \mathrm{MW}$ during the following $18 \mathrm{~s}$ after the SCRAM signal actuates, and then the core power decay starts, so that the typical PWR reactor temperatures are obtained. Equally Figure 3.3 shows the evolution of the pumps rotational speed after the SCRAM signal actuation.

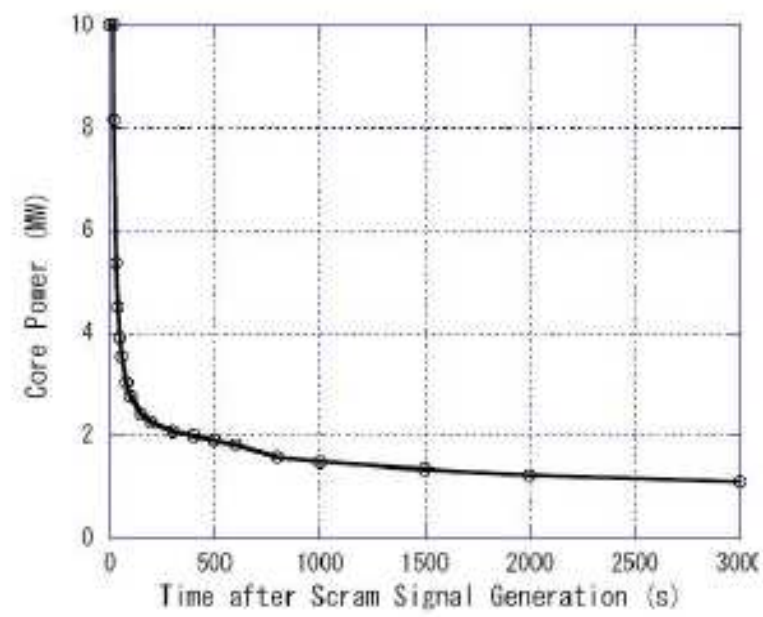

Figure 3.3 Power decay curve

The secondary pressure was rised up to $8.0 \mathrm{MPa}$, and as the secondary temperature also increases, the primary-secondary heat transfer is reduced. The steam generators liquid level is maintained over the $\mathrm{U}$ tubes.

The opening and closing pressure setpoints of the secondary side relief valves are, 8,03 and $7,82 \mathrm{MPa}$ respectively. The flow area of the relief valves is simulated using an orifice of 
$16.2 \mathrm{~mm}$ inner diameter to provide a steam flow of $2.8 \mathrm{~kg} / \mathrm{s}$ when the secondary pressure is 8.0 MPa.

The proportional heaters of the pressurizer are used to adjust the pressure, while the support ones help to mitigate the system heat losses. The proportional and the support heaters power are, as the initial steady-state conditions, 3.9 and $33.9 \mathrm{KW}$ respectively.

After the break, they are incremented up to 8.5 and $88.2 \mathrm{KW}$. The proportional heaters are turned off after the SCRAM signal if the liquid level falls below $2.3 \mathrm{~m}$.

Many regions of the LSTF are equipped with proportional heaters in order to mitigate losses to the ambient.

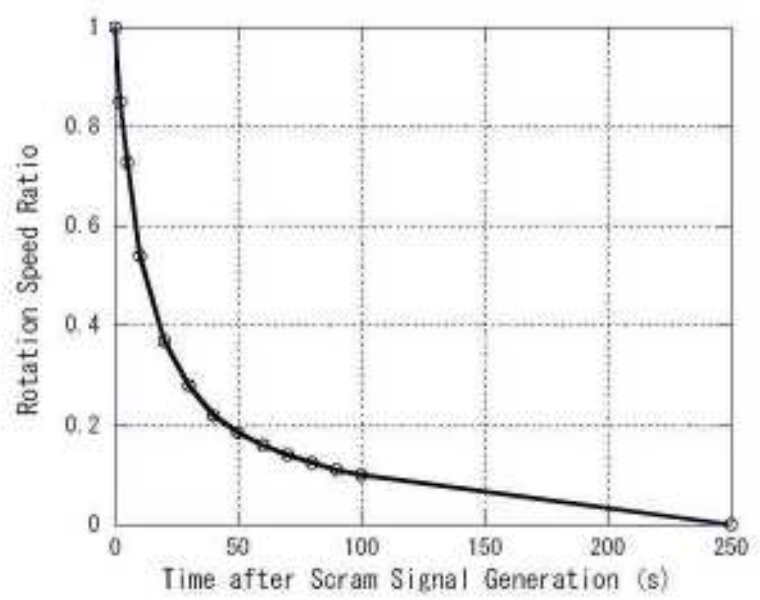

Figure 3.4 Pumps rotational speed coastdown

\subsubsection{EXPERIMENTAL RESULTS}

The initial steady-state operating conditions prior to the experiment are shown in Table 3.2.

In the following points we will show the graphs for the main physical variables evolution. 


\subsubsection{INITIAL STEADY-STATE CONDITIONS}

The data shown in Table 3.2, were obtained before the start of the experiment, and correspond with the LSTF facility steady-state for these conditions.

Table 3.2 Table with the initial steady-state conditions

\begin{tabular}{|c|c|c|}
\hline Component & $\begin{array}{l}\text { Specified (loop } \\
\text { with/without PZR) }\end{array}$ & $\begin{array}{l}\text { Measured (loop } \\
\text { with/without PZR) }\end{array}$ \\
\hline \multicolumn{3}{|l|}{ Vessel } \\
\hline Core power (MW) & $10,0+/-0,07$ & 10.10 \\
\hline $\begin{array}{l}\text { Downcomer to upper head of the } \\
\text { Vessel bypass }(\%)\end{array}$ & 0,3 & No measured \\
\hline \multicolumn{3}{|l|}{ Primary loop } \\
\hline Hot leg liquid temperature $(\mathrm{K})$ & $598,1+/-2,75$ & $598,2 / 597,9$ \\
\hline Cold leg liquid temperature $(\mathrm{K})$ & $562,4+/-2,75$ & $563,2 / 563,0$ \\
\hline Mass flow rate ( $\mathrm{Kg} / \mathrm{s}$ for each loop) & $24,3+/-1,25$ & $24,63 / 24,33$ \\
\hline $\begin{array}{l}\text { Downcomer to upper head mass flow } \\
\text { rate }(\mathrm{kg} / \mathrm{s} / \text { loop) }\end{array}$ & $0,049+/-0,01$ & $0,048 / 0,044$ \\
\hline \multicolumn{3}{|l|}{ Pressurizer (PZR) } \\
\hline Pressure $(\mathrm{MPa})$ & $15,5+/-0,108$ & 15,52 \\
\hline Liquid level (m) & $7,2+/-0,25$ & 7,28 \\
\hline \multicolumn{3}{|l|}{ Steam Generator } \\
\hline Secondary pressure (MPa) & $7,3+/-0,054$ & $7,31 / 7,32$ \\
\hline Secondary liquid level (m) & $10,3+/-0,38$ & $10,25 / 10,23$ \\
\hline Steam mass flow $(\mathrm{kg} / \mathrm{s})$ & $2,74+/-0,10$ & $2,66 / 2,58$ \\
\hline Main feedwater mass flow $(\mathrm{kg} / \mathrm{s})$ & $2,74+/-0,05$ & $2,75 / 2,62$ \\
\hline Main feedwater temperature $(\mathrm{K})$ & $495,2+/-2,63$ & $495,7 / 494,9$ \\
\hline Auxiliary feedwater temperature $(\mathrm{K})$ & $310+/-2,37$ & 309,3 \\
\hline \multicolumn{3}{|l|}{ Accumulators } \\
\hline Pressure (MPa) & $4,51+/-0,054$ & $4,49 / 4,50$ \\
\hline Temperature (K) & $320+/-2,3 / 2,4$ & $321,5 / 321,3$ \\
\hline Liquid level over the base of the tank & $6,80+/-0,12 / 0$ & $156,70 / 6,72$ \\
\hline
\end{tabular}




\begin{tabular}{|l|l|l|}
\hline Low pressure injection system & & \\
\hline Pressure $(\mathrm{MPa})$ & $1,24+/-0,108$ & 1,20 \\
\hline Temperature $(\mathrm{K})$ & $310+/-2,63$ & 309,9 \\
\hline
\end{tabular}

\subsubsection{PRESSURE}

Figure 3.10 compares the primary and the secondary system pressure evolution. The primary system pressure starts to decay at the first instant, simultaneously with the break. The Scram signal is generated at $49 \mathrm{~s}$ when the primary pressure falls below $12.97 \mathrm{MPa}$.

This signal provokes the shut down of the main isolation valves and the start of the pumps rotational speed decay. The secondary pressure fluctuates between 8,03 y 7,82 MPa due to the relief valves opening and closing cycle from $1000 \mathrm{~s}$, being the moment when it starts to decay due to the heat losses to the exterior through the lagging. The safety injection signal starts at $77 \mathrm{~s}$ due to the primary system pressure decay below $12.27 \mathrm{MPa}$.

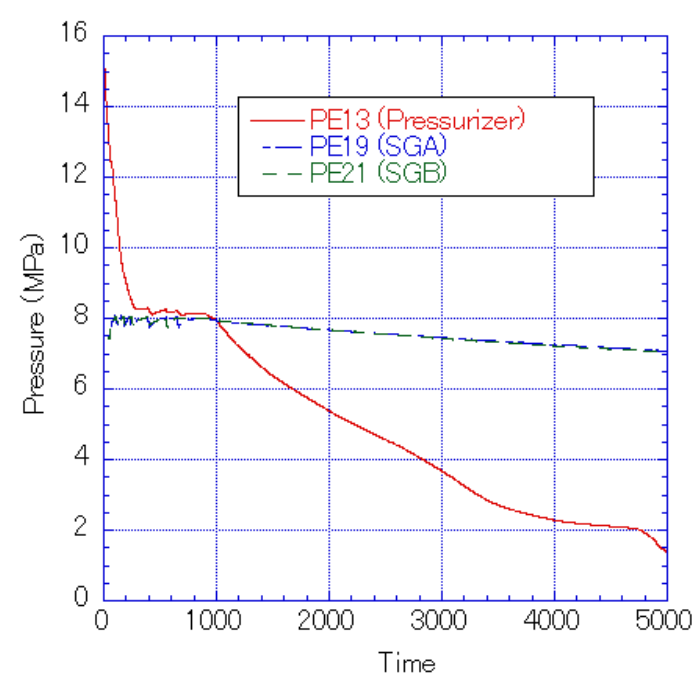

Figure 3.5 Primary and secondary pressures

The accumulators system starts around $2537 \mathrm{~s}$, when the primary system pressure falls below 4.51 $\mathrm{MPa}$. As from this moment the accumulators injection actuates depending on 
the pressure differences between the accumulator and the injection point. Figure 3.6 shows the cooling flow rate injected by the accumulators.

Around the time $1000 \mathrm{~s}$ the secondary pressure starts to decay due to the change in the natural circulation conditions as it is illustrated in Figure 3.5. The cooling discharge by the accumulators is completed when finishing the test.

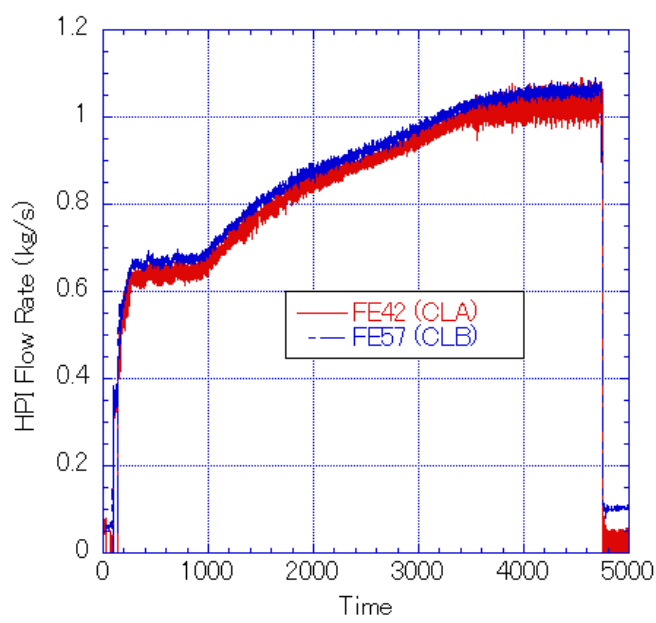

Figure 3.6 HPI mass flow rate

\subsubsection{FLOWS AND LIQUID LEVELS}

The cooling inventory distribution in the primary system and in the secondary was calculated using different pressure values, cooling density and temperature.

The liquid level in the pressurizer starts decreasing immediately after the break happens, and it empties around the $90 \mathrm{~s}$ (Figure 3.7).

Figure 3.8 shows the mass flow rate in the primary system measured in the pump, using a Venturi. Natural circulation starts at $350 \mathrm{~s}$ of the experiment when the pumps are completely stopped. The natural circulation oscillates once the accumulators injections happen. 


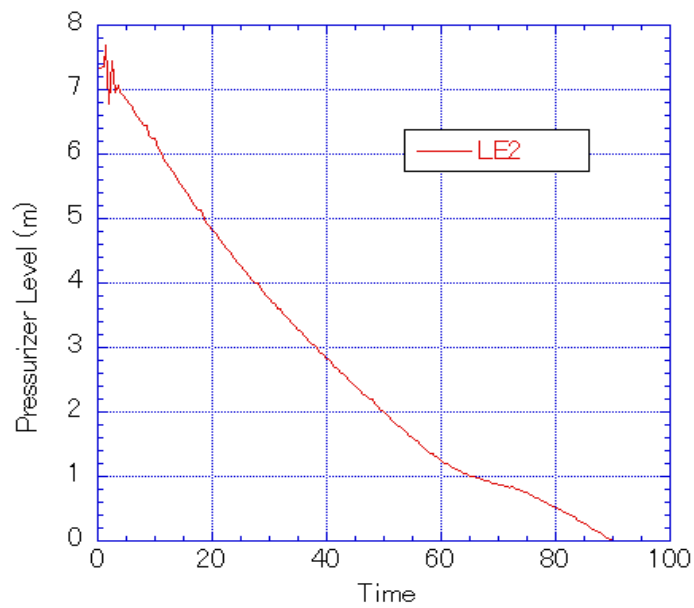

Figure 3.7 Pressurizer level

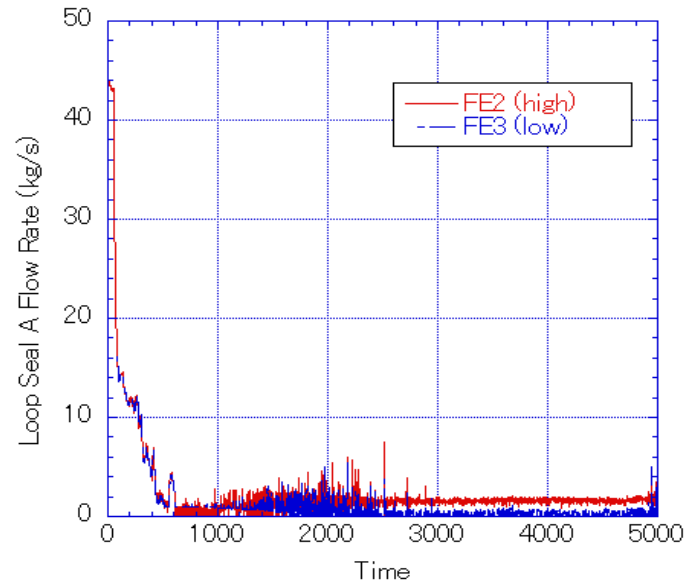

Figure 3.8 Primary system mass flow rate. Loop A

The measured data in the Venturi, of the loss of coolant in the break are shown in Figure 3.14. However, in Figure 3.15 the integrated in time mass flow in the break is displayed, namely, the total of coolant lost in the experiment with the time.

The collapsed liquid levels in the upper plenum, core and downcomer, decrease at $50 \mathrm{~s}$, not being recovered, but in the upper plenum where it is somehow recovered. 


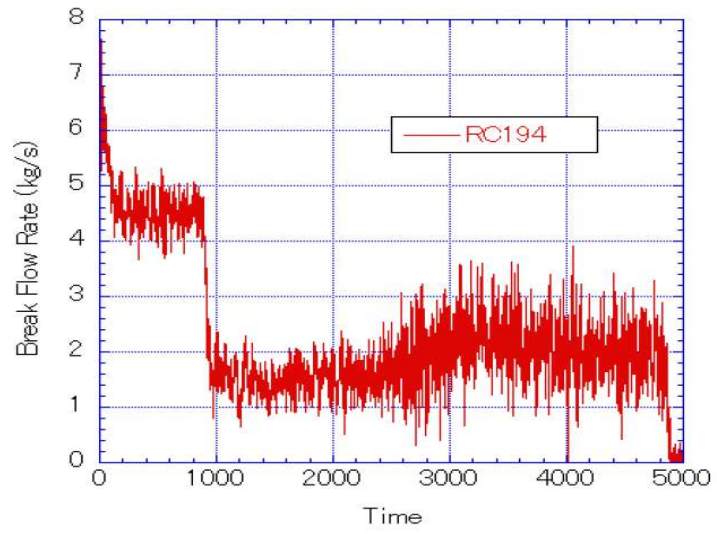

Figure 3.9 Break mass flow rate

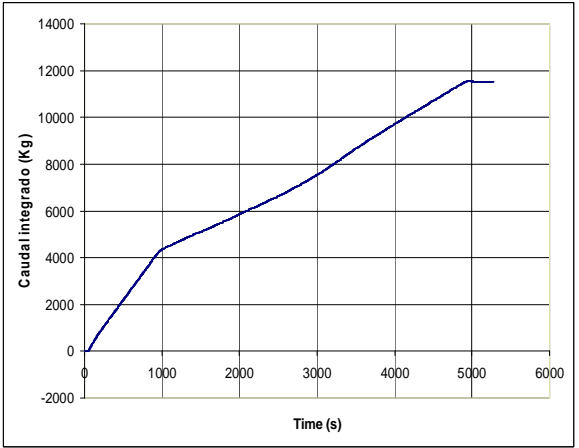

Figure 3.10 Integrated flow

The natural circulation continues until the end of the experiment. The liquid level of the cold and hot legs start recovering due to the injection of the accumulators, so incrementing the natural circulation, which could become mono-phase.

The liquid level in the hot legs, which were obtained with a gamma ray densimeter, can be appreciated in Figure 3.11. 


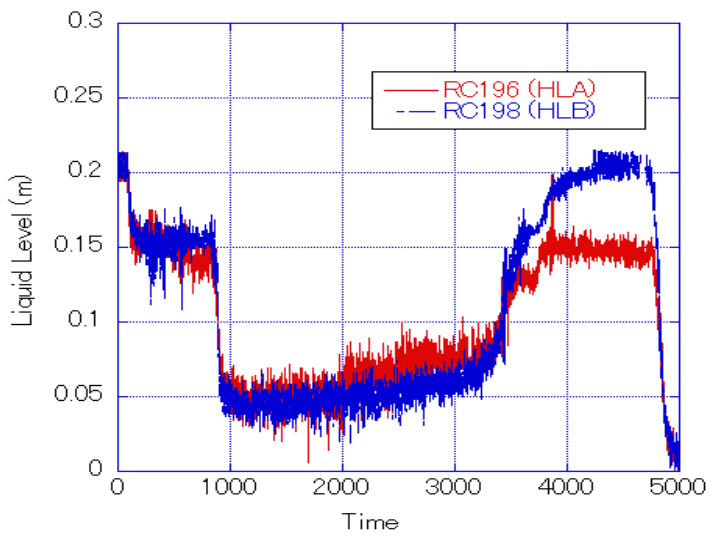

Figure 3.11 Hot legs levels

In Figures 3.12 and 3.13 the liquid level of the secondary side of the steam generator and the system mass flow rate of the auxiliary feedwater respectively are displayed.

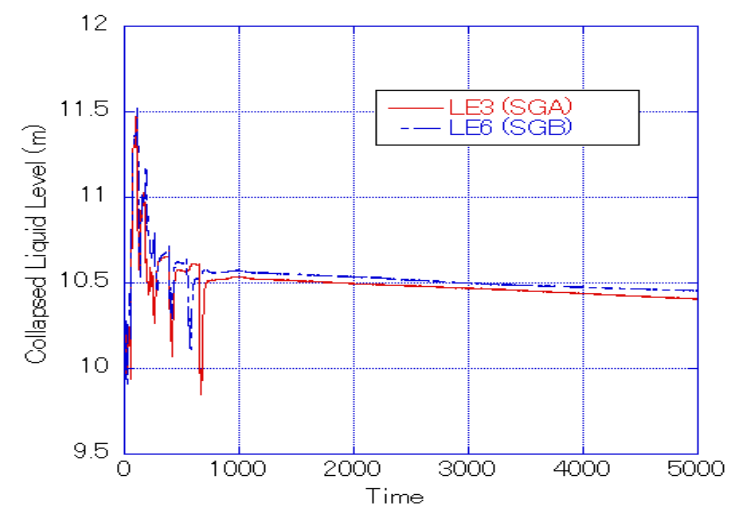

Figure 3.12 Secondary liquid level of both loops 


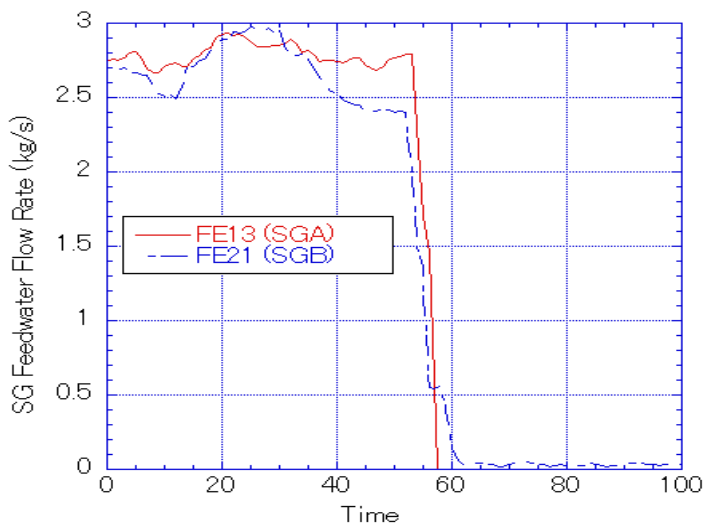

Figure 3.13 Injected mass flow rate by the auxiliary feedwater system

The liquid level of the steam generators remains at $12 \mathrm{~m}$, at the higher part of the $\mathrm{U}$ tubes. The liquid level in the secondary of the steam generator descends mildly during the experiment.

\subsubsection{TEMPERATURE}

The objective of the test 1.2 is to make a study of the thermal stratification under certain conditions. In Figure 3.14 this stratification is observed. Because of different thermocouples placed at different heights inside the cold leg there are differences in temperatures.

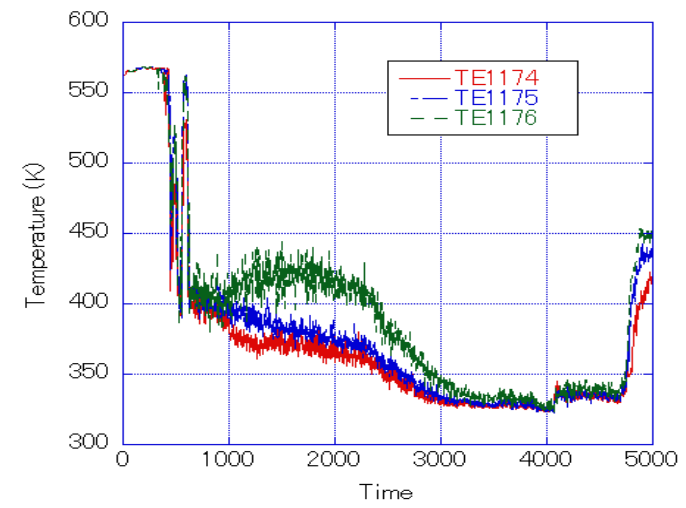

Figure 3.14 Cold leg temperature in the loop with pressurizer 
The thermal stratification in the loop B can be appreciated in Figures 3.14 and 3.15. It can be observed that there is a vertical temperature gradient in the pipe which remains with time. We can also observe that the temperature distribution and evolution is different in the loop with pressurizer than in the one without pressurizer.

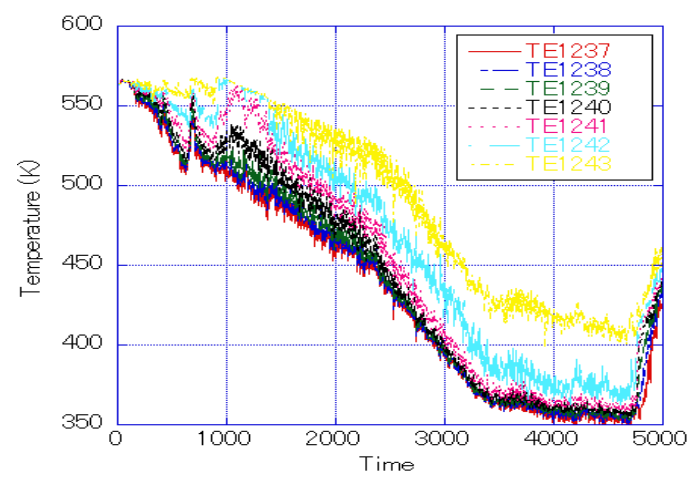

Figure 3.15 Cold leg temperature in the loop without pressurizer

\subsubsection{ACCUMULATORS INJECTION}

The total quantity of nitrogen in the accumulators tanks is $1800 \mathrm{~mol}$.

The gaseous phase pressure in these tanks starts to descend simultaneously with the injection of water, and continues descending until the injection is completed.

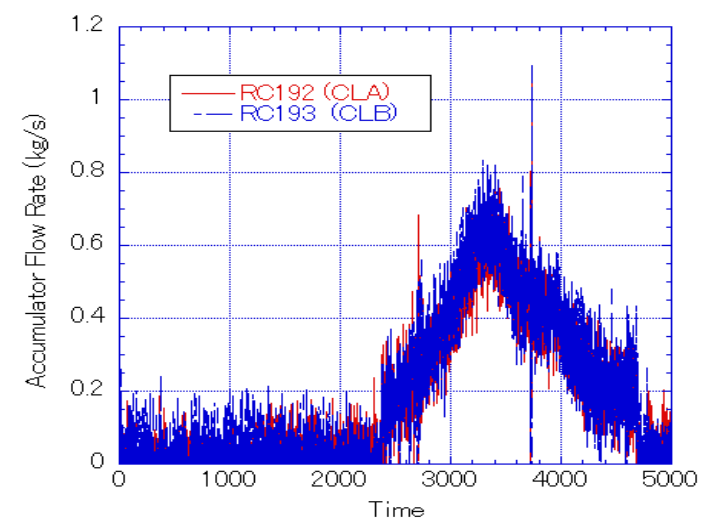

Figure 3.16 Mass flow rate injected by the accumulator 
The temperature of the gas in both tanks, vary during the coolant injection as a function of the injection flow. This temperature decreases due to the adiabatic expansion during the long injection and is recovered by coolant and the walls of the tanks heating when the injection flow decreases.

\subsubsection{END OF THE EXPERIMENT}

The experiment concludes by closing the valve that simulates the break at $4696 \mathrm{~s}$.

\subsection{STEADY-STATE DEMONSTRATION}

The present chapter is dedicated to the verification of the results obtained for the steadystate case of the TRACE model for the LSTF facility. For this case we compare the results obtained with the developed TRACE model with the experimental ones provided by the JAEA, which are the starting point of the experiment.

Table 3.3: Initial steady-state conditions

\begin{tabular}{|c|c|c|c|}
\hline Component & $\begin{array}{l}\text { Tag name } \\
(\operatorname{loop} \mathrm{A} / \mathrm{B})\end{array}$ & Specified & $\begin{array}{l}\text { Measured } \\
(\operatorname{loop} A / B)\end{array}$ \\
\hline \multicolumn{4}{|l|}{ Pressure vessel } \\
\hline Core power (MW) & WE270A-T & 10.0 & 10.1 \\
\hline \multicolumn{4}{|l|}{ Primary loop } \\
\hline $\begin{array}{l}\text { Hot leg fluid temperature } \\
(\mathrm{K})\end{array}$ & $\begin{array}{l}\text { TE020C-HLA } \\
\text { /TE160C-HLB }\end{array}$ & 598.0 & $597.2 / 596.9$ \\
\hline $\begin{array}{l}\text { Cold leg fluid } \\
\text { temperature }(\mathrm{K})\end{array}$ & $\begin{array}{l}\text { TE070C-CLA } \\
\text { /TE210C-CLB }\end{array}$ & 562.0 & $563.1 / 563.0$ \\
\hline $\begin{array}{l}\text { Mass flow rate }(\mathrm{Kg} / \mathrm{s} / \\
\text { loop) }\end{array}$ & $\begin{array}{l}\text { FE020A-LSA/ } \\
\text { FE160A-LSB }\end{array}$ & 24.3 & $25.38 / 25.37$ \\
\hline $\begin{array}{l}\text { Pump rotational speed } \\
\text { (rev/s) }\end{array}$ & $\begin{array}{l}\text { FE010-HLA/ FE150- } \\
\text { HLB }\end{array}$ & 13.3 & $13.9 / 13.9$ \\
\hline \multicolumn{4}{|l|}{ Pressurizer } \\
\hline Pressure (MPa) & PE300A-PR & 15.5 & 15.54 \\
\hline Liquid level (m) & LE280-PR & 7.2 & 7.34 \\
\hline
\end{tabular}




\begin{tabular}{|l|l|l|l|}
\hline $\begin{array}{l}\text { Secondary-side pressure } \\
(\mathrm{MPa})\end{array}$ & $\begin{array}{l}\text { PE430-SGA/ PE450- } \\
\text { SGB }\end{array}$ & 7.3 & $7.32 / 7.33$ \\
\hline $\begin{array}{l}\text { Secondary-side liquid } \\
\text { level (m) }\end{array}$ & $\begin{array}{l}\text { LE4330-SGA/ } \\
\text { LE450-SGB }\end{array}$ & 10.3 & $10.26 / 10.23$ \\
\hline $\begin{array}{l}\text { Steam mass flow rate } \\
\text { (Kg/s) }\end{array}$ & $\begin{array}{l}\text { FE440-SGA/ FE480- } \\
\text { SGB }\end{array}$ & 2.74 & $2.68 / 2.61$ \\
\hline $\begin{array}{l}\text { Main feedwater flow rate } \\
\text { (Kg/s) }\end{array}$ & $\begin{array}{l}\text { FE430-SGA/ FE470- } \\
\text { SGB }\end{array}$ & 2.74 & $2.75 / 2.65$ \\
\hline $\begin{array}{l}\text { Main feedwater } \\
\text { temperature (K) }\end{array}$ & $\begin{array}{l}\text { TE430-SGA/ TE470- } \\
\text { SGB }\end{array}$ & 495.2 & $496.3 / 495.5$ \\
\hline ECCS water tank & TE660-ACC & 320.0 & 321.3 \\
\hline $\begin{array}{l}\text { Accumulator A water } \\
\text { tank temp. }(\mathrm{K})\end{array}$ & TE700-ACH & 320.0 & 321.9 \\
\hline $\begin{array}{l}\text { Accumulator B water } \\
\text { tank temp. (K) }\end{array}$ & TE800-RWST & 310.0 & 309.8 \\
\hline HPI water temp. (K) & & & \\
\hline
\end{tabular}

\subsubsection{STEADY-STATE RESULTS WITH THE TRACE MODEL}

We will display now all the graphs of the main plant variables for a steady-state and we will comment the results.

\subsubsection{VESSEL}

The core power of the facility is given by the component power-250, and it is constant, with a value of $10 \mathrm{MW}$ until some incident happens. As it is displayed in Figure 3.17, the core power with the TRACE code is constant at steady-state conditions. 


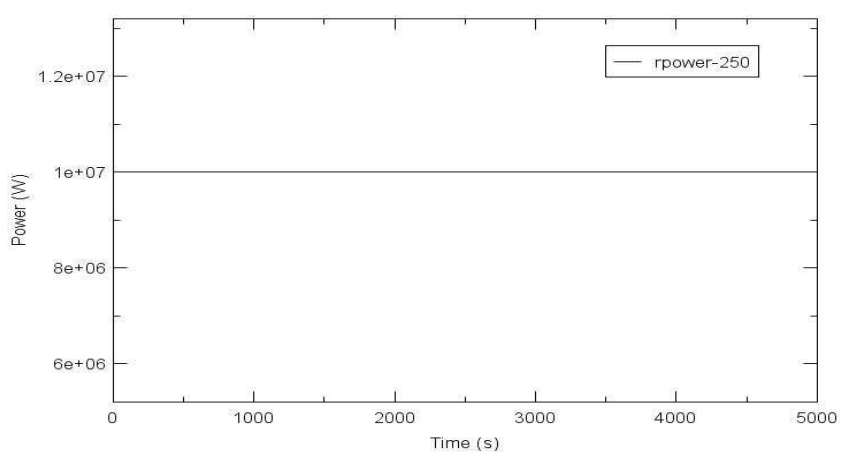

Figure 3.17 Core power

In Figure 3.18 the mass flow rate through the core bypass, at different nodes, i.e. the flow that gets to the upper head without passing through the core channels is shown.

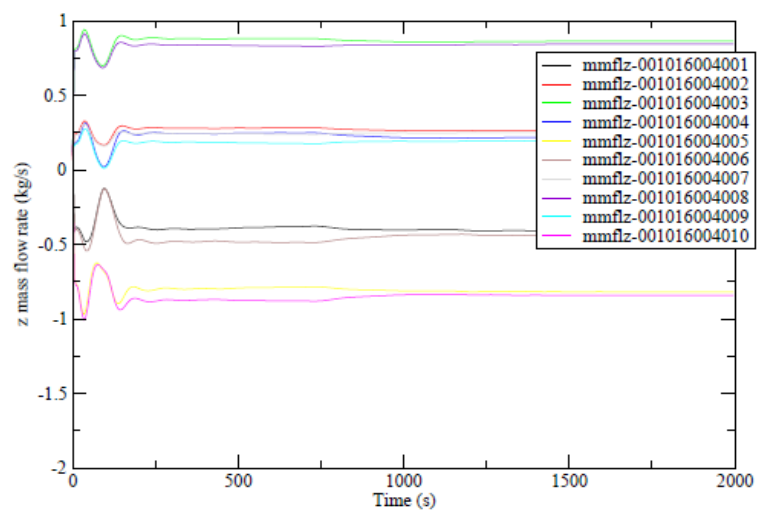

Figure 3.18 Downcomer to upper head bypass flow, measured in different points.

\subsubsection{PRIMARY LOOP}

The results obtained in the stationary case in both loops for the primary system will be shown in this section.

The hot leg liquid temperature (Figure 3.19) is stabilized around $598.9 \mathrm{~K}$ in both loops, this value is a bit higher that the one which we were looking for $(598.1 \mathrm{~K})$, but it is a reasonably valid result when we compare with the measured one of $598.2 \mathrm{~K}$. 


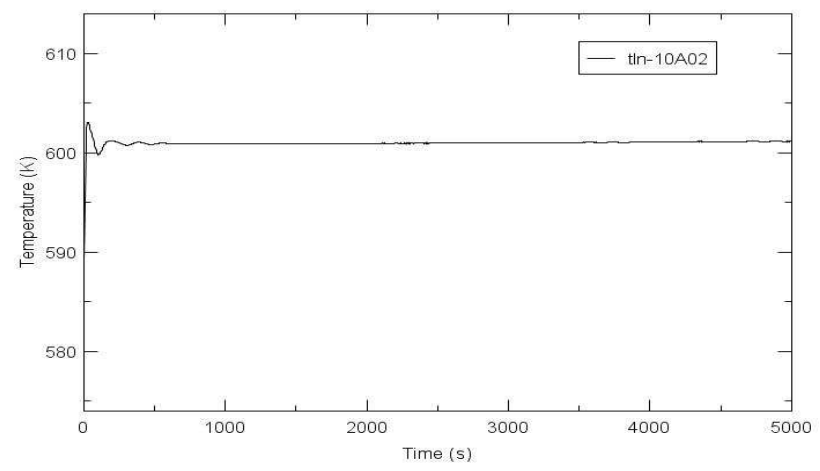

Figure 3.19 Hot leg liquid temperature

For the liquid temperature in the cold legs (Figure 3.20), both calculated values attain to a stationary value of $561.9 \mathrm{~K}$, a bit lower than the desired value $(562.4 \mathrm{~K})$, however, we are inside the uncertainty interval of $+/-2,75 \mathrm{~K}$ around this value.

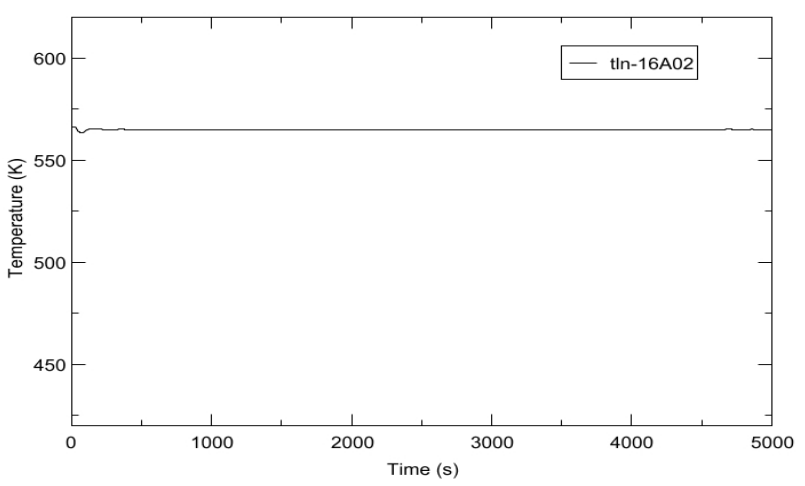

Figure 3.20 Cold leg liquid temperature.

In Figures 3.19 and 3.20 can be seen as both temperatures deviate from its objective value. This is because of the primary system liquid temperature control which has been introduced in the model and which makes the mean legs temperature to be as closest to the half of the sum of the objective values $(580.25 \mathrm{~K})$.

The primary system mass flow rate (Figure 3.21) is determined by the rotational speed and heights of the pumps (components Pump 14/24). In this way, as the initial liquid velocity in the thermal-hydraulic components of the primary is null, it takes some time to attain the 
flow value at which the steam becomes stationary, which is 23.8 and $23.7 \mathrm{Kg} / \mathrm{s}$ in loops A and $\mathrm{B}$, respectively. The specified value for the plant steady-state is $24.3 \mathrm{Kg} / \mathrm{s}$.

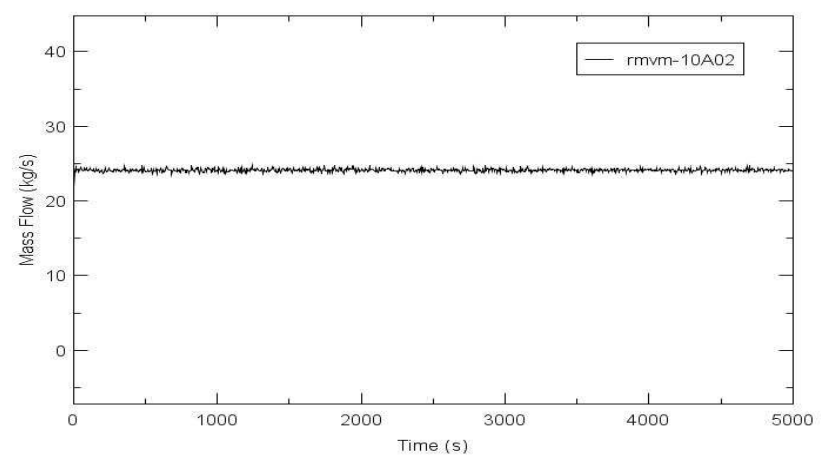

Figure 3.21 Primary loop mass flow rate.

\subsubsection{PRESSURIZER}

The pressurizer takes the value for the primary pressure from the cells located at the bottom of it, that as we can observe in Figure 3.22 remains stable at a value of $15.4 \mathrm{MPa}$, which is a very close to the desired one (15.5 MPa).

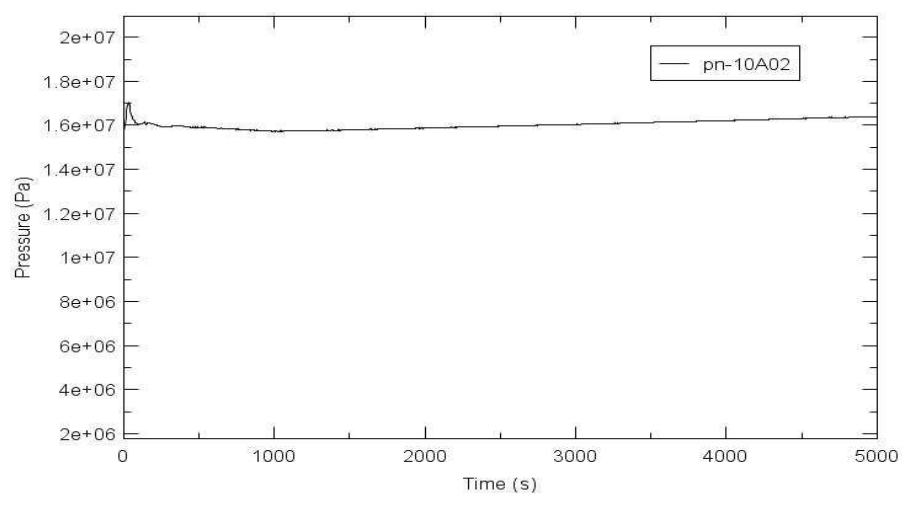

Figure 3.22 Primary system pressure 


\subsubsection{PUMPS}

The main pumps in the LSTF facility are modeled with the TRACE components Pump-14 and Pump-24. The initial steady-state rotational speed is 13.3 revolutions/second as it is shown in Table 3.3. This is equivalent to $87.5 \mathrm{rad} / \mathrm{s}$. In the TRACE pumps model we need to introduce the rotational speed in $\mathrm{rad} / \mathrm{s}$ units, so we introduced the value of $87.5 \mathrm{rad} / \mathrm{s}$ for both pumps, as can be observed in Figure 3.23.

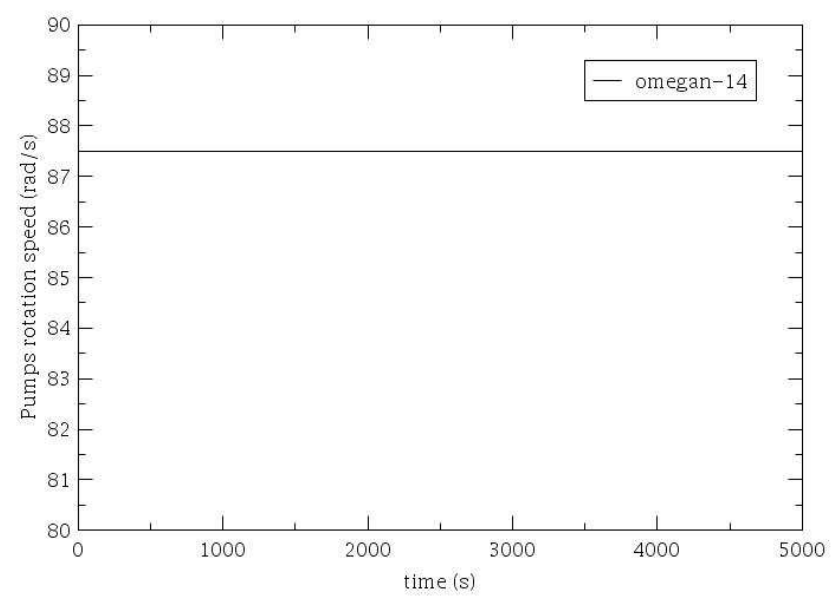

Figure 3.23 Pumps rotational speed (rad/s)

We can observe in the previous displayed figures that the pumps rotational speed with the TRACE code for the steady-state condition is exactly the same as the specified value of $87.5 \mathrm{rad} / \mathrm{s}$ given in table 3.3 .

\subsubsection{STEAM GENERATORS}

The secondary side pressure (Riser) of the steam generators, should have an objective value of 7.3 $\mathrm{MPa}$, for a better simulation of the heat transfer between the primary and the secondary side. It can be observed in Figure 3.24 that we attain a stationary value of 7.18 MPa for loops A and B. 


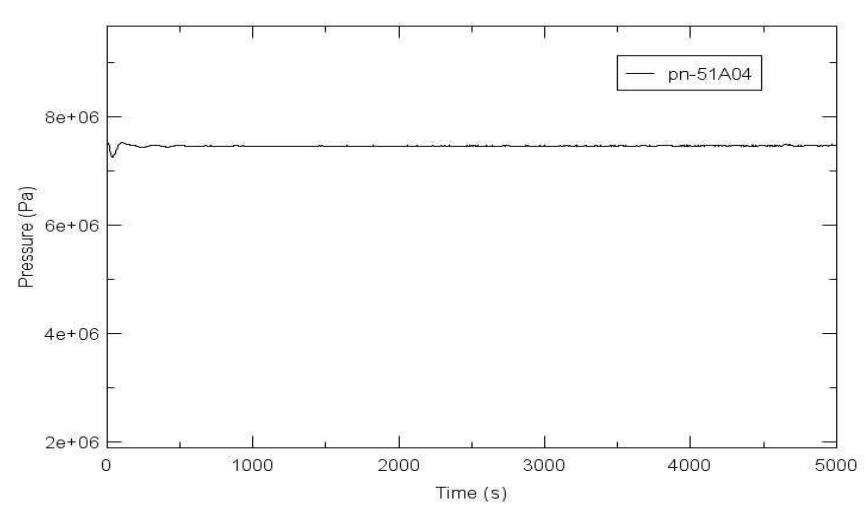

Figure 3.24 Pressure in the secondary side of the steam generators.

In Figure 3.25 the steam mass flow rate through the main steam valve at the steam generator is displayed. This value is approximately $2.76 \mathrm{Kg} / \mathrm{s}$ for loop A and $2.74 \mathrm{Kg} / \mathrm{s}$ for loop B. These values stabilize at the specified steady-state values of the LSTF facility as observed in Table 3.3 .

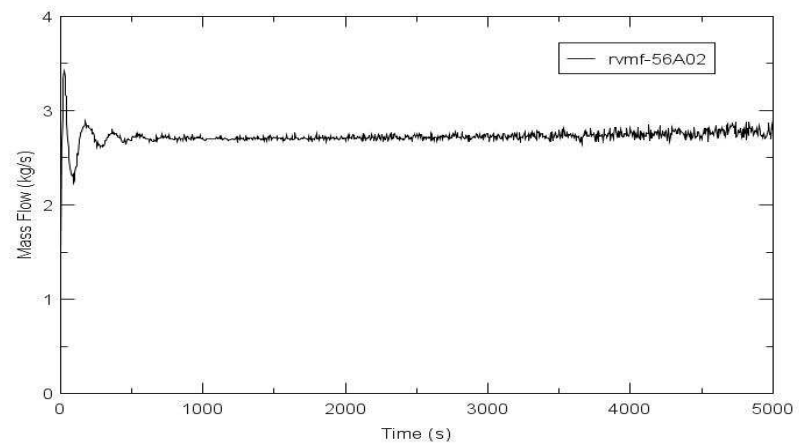

Figure 3.26 Steam mass flow rate versus time at steady-state conditions.

We can observe the main feedwater flow rate in Figure 3.27, which stabilizes at the same value for the main steam mass flow rate, so that the system is stable and all the mass flow rate coming in from the feedwater system, goes out through the main steam valve. 


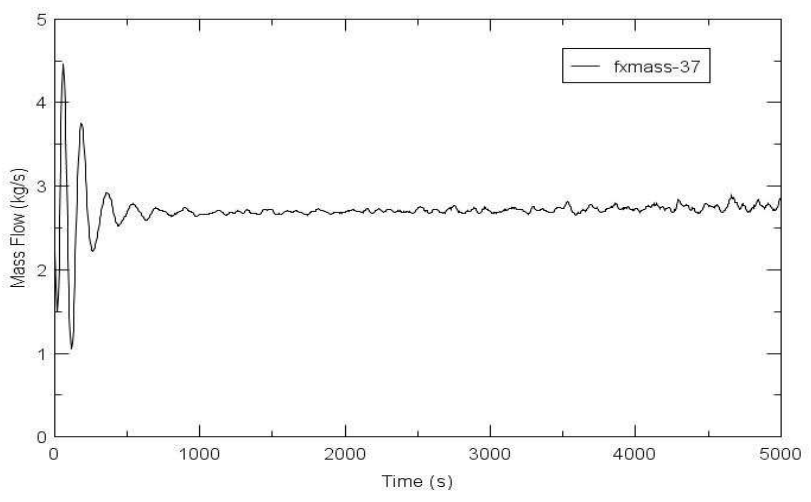

Figure 3.27 Main feedwater system flow.

We can observe that the feedwater temperature is constant as it is defined in Figure 3.28, which is, $495.2 \mathrm{~K}$.

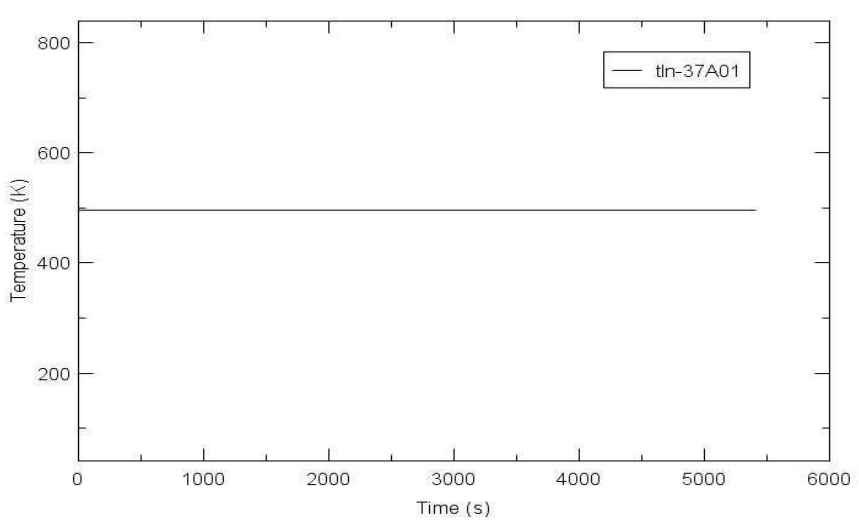

Figure 3.28 Main feedwater temperature.

The auxiliary feedwater temperature, as it can be appreciated in Figure 3.29 is $310.0 \mathrm{~K}$. 


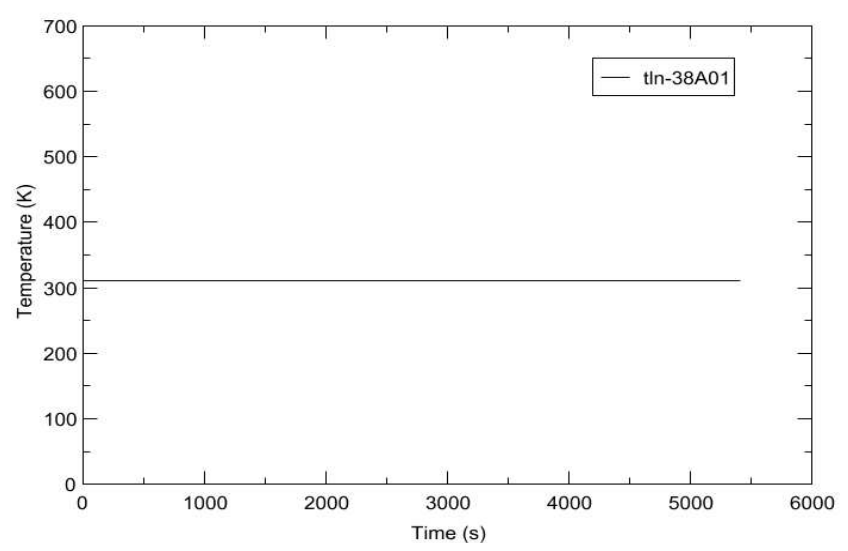

Figure 3.29 Auxiliary feedwater temperature.

\subsubsection{ACCUMULATORS}

The accumulators are an isolated system until the moment when they are turned on, therefore its pressure is maintained constant during the stationary.

The pressure of the accumulators which was obtained during the TRACE simulation for the steady-state case, having a specified pressure value of $3.51 \mathrm{MPa}$ is shown in Figure 3.30.

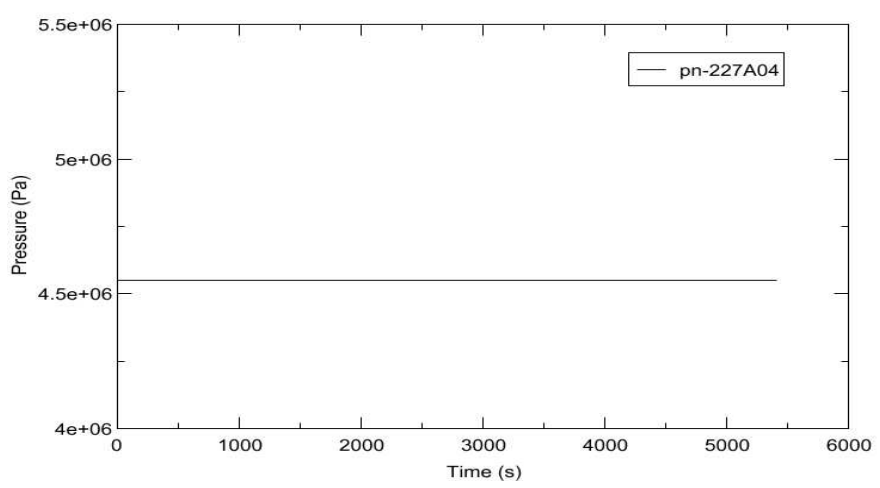

Figure 3.30 Accumulators pressure.

So as the pressure, the temperature of the accumulators is shown in Figure 3.31. It remains constant in the value given at the beginning, until the system starts to inject. It has an initial value of $320 \mathrm{~K}$. 


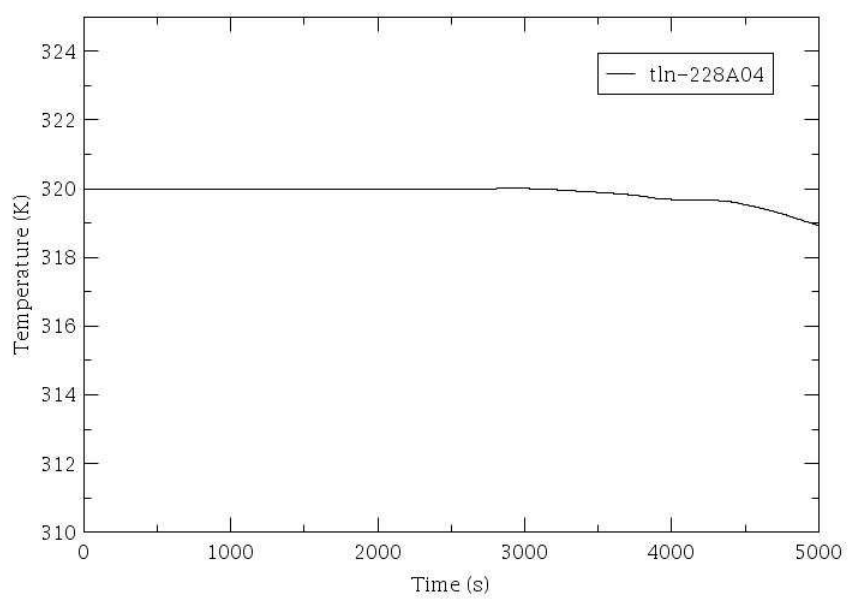

Figure 3.31 Accumulators temperature

\subsubsection{HIGH PRESSURE INJECTION SYSTEM}

Like all the other systems which are modeled with Fill components, the high pressure injection system mass flow rate has been defined with a table. In this table we have the system pressure as the input variable, and the outcome of the table is the HPI mass flow rate.

The HPI mass flow rate vs time is displayed in Figure 3.32. We can see here the mass flow rate evolution with time, according to the pressure table shown in the released information by the JAEA (Japanese Atomic energy Agency) for this test. 


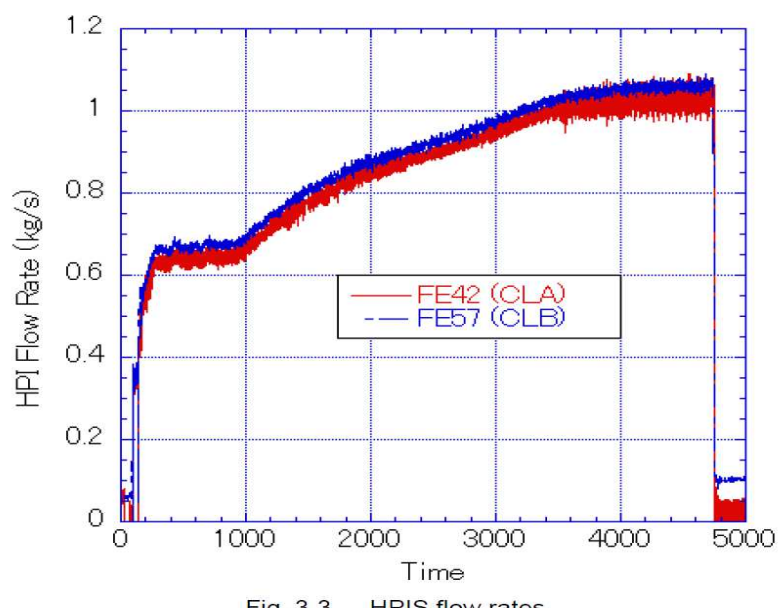

Figure 3.32 High pressure injection system mass flow rate.

For the liquid injection temperature of the HPI, as it has been displayed in the following figure, we have a constant value which was specified in Table 3.3.

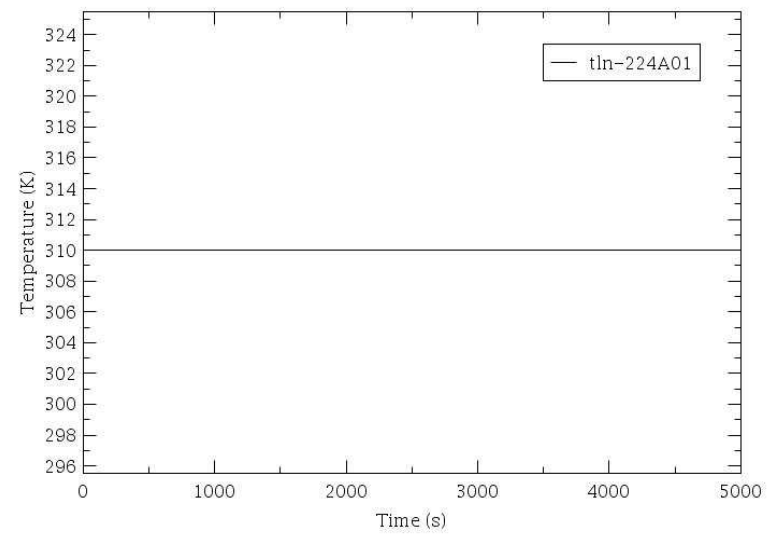

Figure 3.33 HPI liquid temperature for the transient of the experiment 1.2

The results obtained with the TRACE code at steady-state conditions are very close to the ones provided by the Japanese agency (JAEA) for the execution of the case, as is shown in Table 3.4. 
Table 3.4 Comparison of the test 1.2 results

\begin{tabular}{|c|c|c|c|}
\hline Component & Specified & $\begin{array}{l}\text { Measured } \\
(\operatorname{loop} A / B)\end{array}$ & TRACE Model \\
\hline \multicolumn{4}{|l|}{ Pressure vessel } \\
\hline Core power (MW) & 10.0 & 10.1 & 10.10 \\
\hline \multicolumn{4}{|l|}{ Primary loop } \\
\hline $\begin{array}{l}\text { Hot leg fluid temperature } \\
(\mathrm{K})\end{array}$ & 598.0 & $597.2 / 596.9$ & 598,9 \\
\hline $\begin{array}{l}\text { Cold leg fluid temperature } \\
(\mathrm{K})\end{array}$ & 562.0 & $563.1 / 563.0$ & 561,9 \\
\hline $\begin{array}{l}\text { Mass flow rate }(\mathrm{Kg} / \mathrm{s} / \\
\text { loop) }\end{array}$ & 24.3 & $25.38 / 25.37$ & $23,85 / 23,72$ \\
\hline $\begin{array}{l}\text { Pump rotational speed } \\
\text { (rev/s) }\end{array}$ & 13.3 & $13.9 / 13.9$ & 13.3 \\
\hline \multicolumn{4}{|l|}{ Pressurizer } \\
\hline Pressure (MPa) & 15.5 & 15.54 & 15,43 \\
\hline Liquid level (m) & 7.2 & 7.34 & 7,50 \\
\hline \multicolumn{4}{|l|}{ Steam generator } \\
\hline $\begin{array}{l}\text { Secondary-side pressure } \\
(\mathrm{MPa})\end{array}$ & 7.3 & $7.32 / 7.33$ & 7,18 \\
\hline $\begin{array}{l}\text { Secondary-side liquid } \\
\text { level (m) }\end{array}$ & 10.3 & $10.26 / 10.23$ & 10,31 \\
\hline $\begin{array}{l}\text { Steam mass flow rate } \\
(\mathrm{Kg} / \mathrm{s})\end{array}$ & 2.74 & $2.68 / 2.61$ & 2.70 \\
\hline $\begin{array}{l}\text { Main feedwater flow rate } \\
(\mathrm{Kg} / \mathrm{s})\end{array}$ & 2.74 & $2.75 / 2.65$ & $2,76 / 2,74$ \\
\hline $\begin{array}{l}\text { Main feedwater } \\
\text { temperature }(K)\end{array}$ & 495.2 & $496.3 / 495.5$ & 495,2 \\
\hline \multicolumn{4}{|l|}{ ECCS water tank } \\
\hline $\begin{array}{l}\text { Accumulator } \mathrm{A} / \mathrm{B} \text { water } \\
\text { tank pressure }(\mathrm{MPa})\end{array}$ & 4,51 & 4,52 & 4,54 \\
\hline $\begin{array}{l}\text { Accumulator } \mathrm{A} / \mathrm{B} \text { water } \\
\text { tank temp. }(\mathrm{K})\end{array}$ & 320.0 & 321.9 & 320 \\
\hline HPI water temp. (K) & 310.0 & 309.8 & 310 \\
\hline
\end{tabular}




\subsection{RESULTS OF THE EXPERIMENT REPRODUCTION WITH THE TRACE CODE AND COMPARISON WITH THE \\ EXPERIMENTAL DATA}

In this section we will show the evolution of the main variables, obtained in the simulation of the experiment 1.2 with the TRACE code, and the interpretation.

The graphs show the experimental curve of the results of the experiment conducted at the ROSA/LSTF facility, provided by the Japanese agency JAEA, and the data obtained for the same variable with the thermal-hydraulic code TRACE, in the Nuclear and Chemical engineering department at the Polytechnic University of Valencia.

\subsubsection{PRIMARY PRESSURE}

The decrease of the primary system pressure, due to the break in the hot leg, is very similar to the experimental one as can be observed in Figure 3.34. This implies that the scram signals and the safety injections at times and with mass flow rates are produced very close to the experimental values.

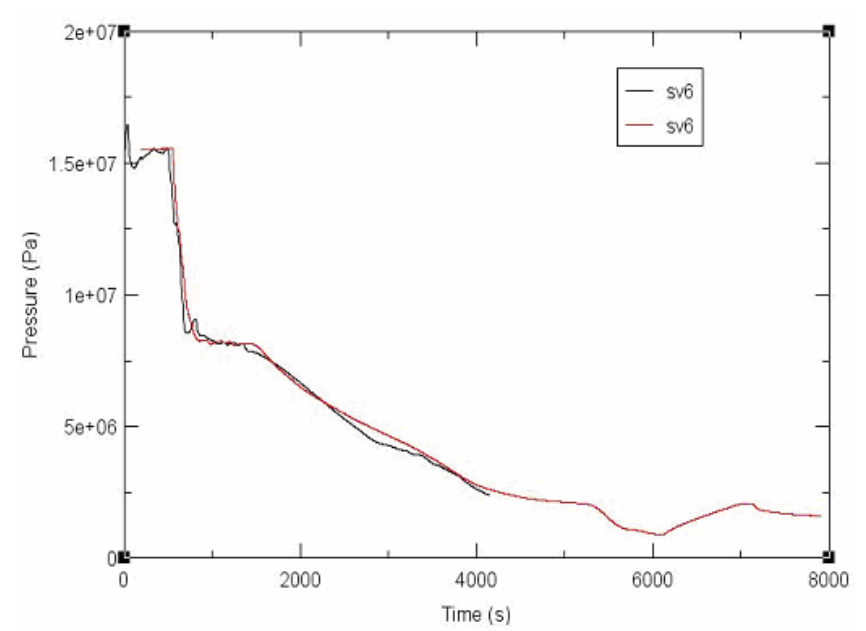

Figure 3.34 Primary side pressure evolution 


\subsubsection{SECONDARY PRESSURE}

Concerning the pressure in the secondary side of both loops (Figure 3.35), we notice the cycling of the relief valves of the steam lines to maintain the secondary pressure below 8.03 $\mathrm{MPa}$, what was also performed in the real experiment. Therefore, the secondary pressure really follows the behaviour observed in the experiment.

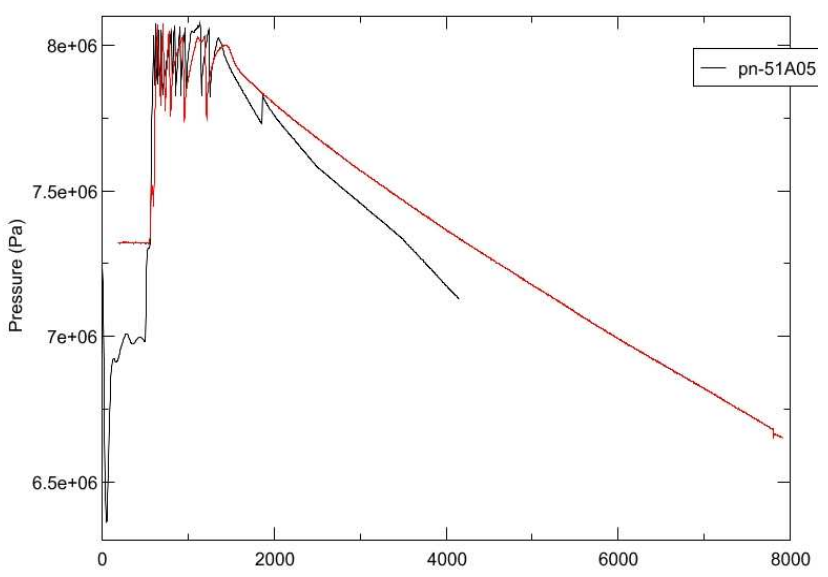

Figure 3.35 Secondary pressure

There is only something that we should mention here, and this is that the secondary pressure decay as we can observe in Figure 3.35 is a bit faster than the experimental one. This might be caused by a not completely perfect simulation of the heat released to the surroundings from the secondary side of the steam generator.

\subsubsection{CORE POWER}

The decay of the core power is absolutely identical to the experimental one. We can assume here that the point kinetic model that has been introduced in the TRACE model gives accurate response for the core power, as we observe in Figure 3.36. 


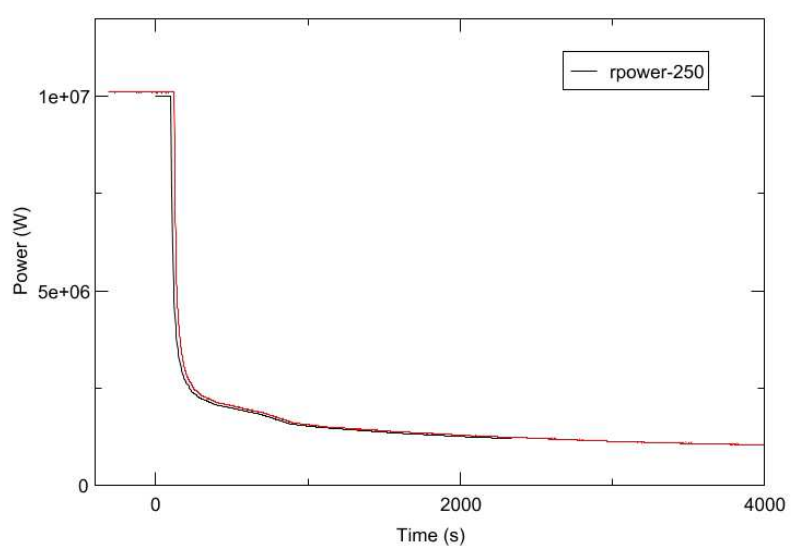

Figure 3.36 Core Power

\subsubsection{BREAK MASS FLOW RATE}

In Figure 3.37 we have displayed the mass flow rate through the break. We can observe here that the TRACE results follow very closely the experimental ones, so we can assume that we have correctly modelled the break flow area, discharge loss coefficients and all the dimensions related with the break line.

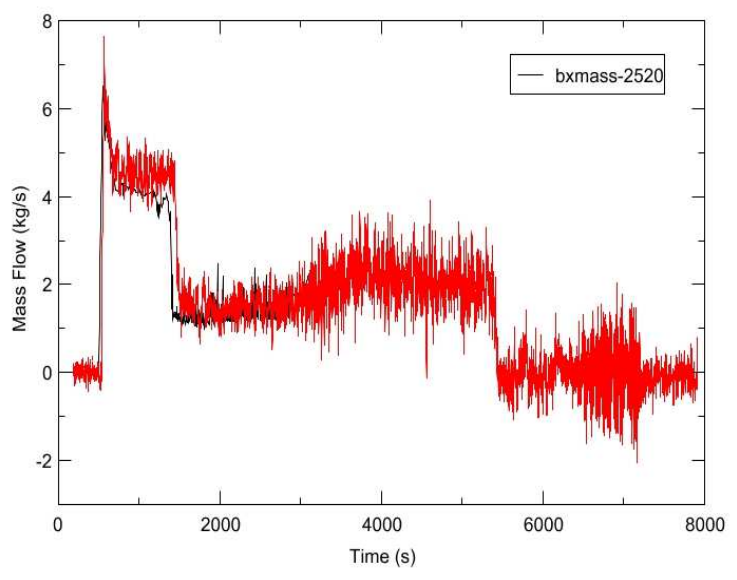

Figure 3.37 Break mass flow rate 


\subsubsection{VOID FRACTION}

The void fraction evolution in the hot leg, at the position where the break occurs, is displayed in Figure 3.38.

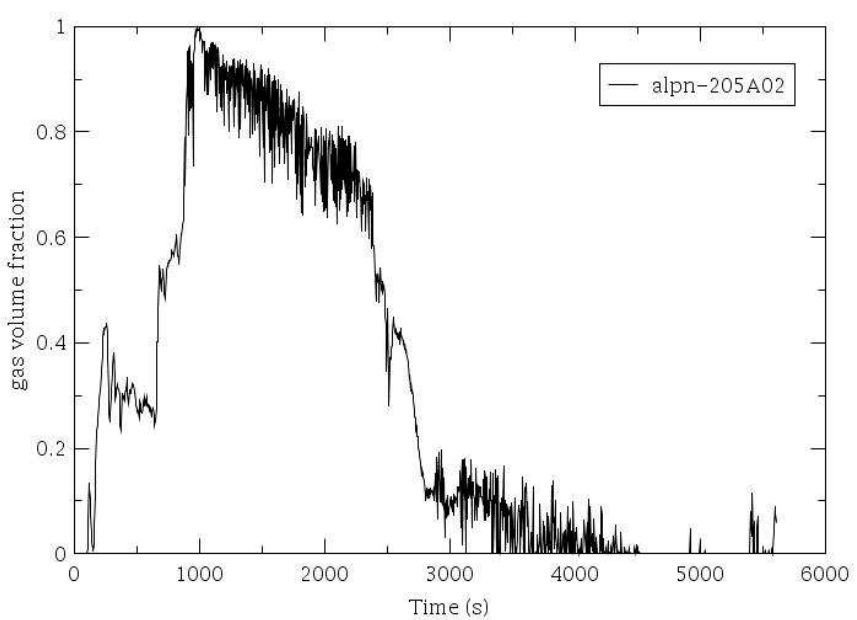

Figure 3.38 Void fraction versus time computed with the TRACE code at the hot leg position where the break occurs

As can be observed, the pipe is practically filled with steam, i.e. the liquid level becomes practically zero, at about 1000 seconds. Since the HPI is actuating, in the cold leg, and the pumps are turned off, the hot leg fills back with water coming from the U tubes. Since the primary pressure rapidly decays, this allows the hot leg to refill with water, otherwise it would keep on releasing fluid through the break at a higher mass flow rate and the void fraction would remain close to 1 (i.e. all steam).

\subsubsection{HPI MAS FLOW RATE}

In Figure 3.39 can observed the HPI mass flow rate injection to the cold leg. The red one is the TRACE value, and the black one the experimental one at the ROSA facility. Both graphs are very similar, and hence we are correctly modelling the HPI injection to the cold leg. 


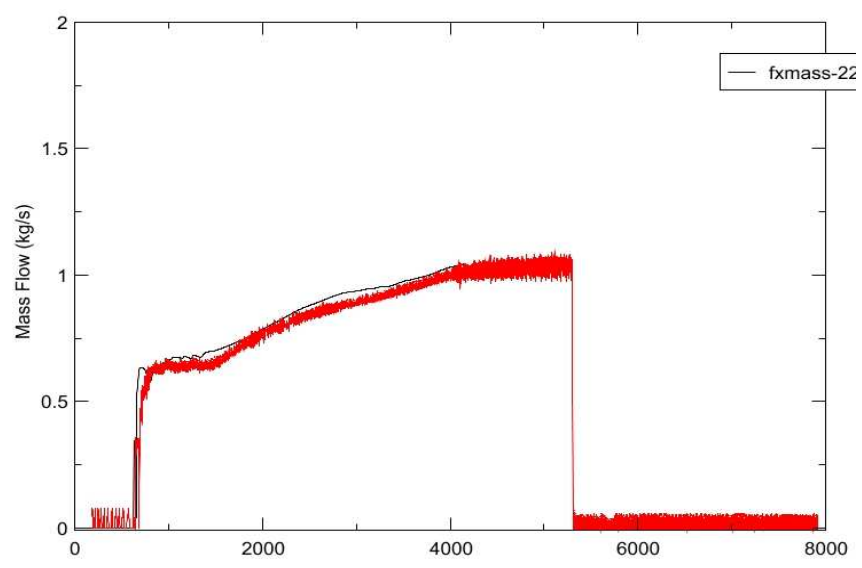

Figure 3.39 HPI flow rate injection

\subsubsection{ACCUMULATORS MASS FLOW RATE INJECTION}

In Figure 3.40 it is displayed the accumulators mass flow rate injection. We observe that the Trace values (red) are very similar and have the same behaviour as the experimental ones (black).

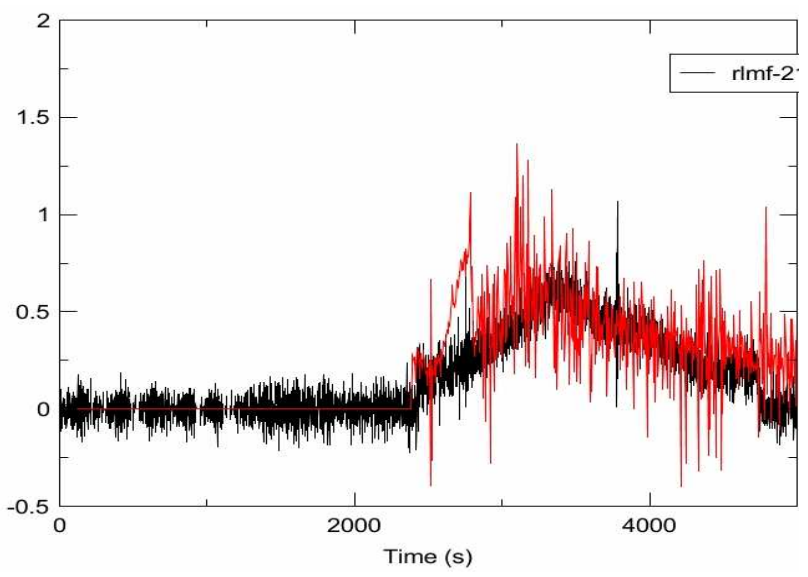

Figure 3.40 Accumulators mass flow rate 


\subsubsection{PRIMARY MASS FLOW RATE}

In Figure 3.41 it is displayed the mass flow rate through the loop A. We can observe that it is very similar to the experimental data.

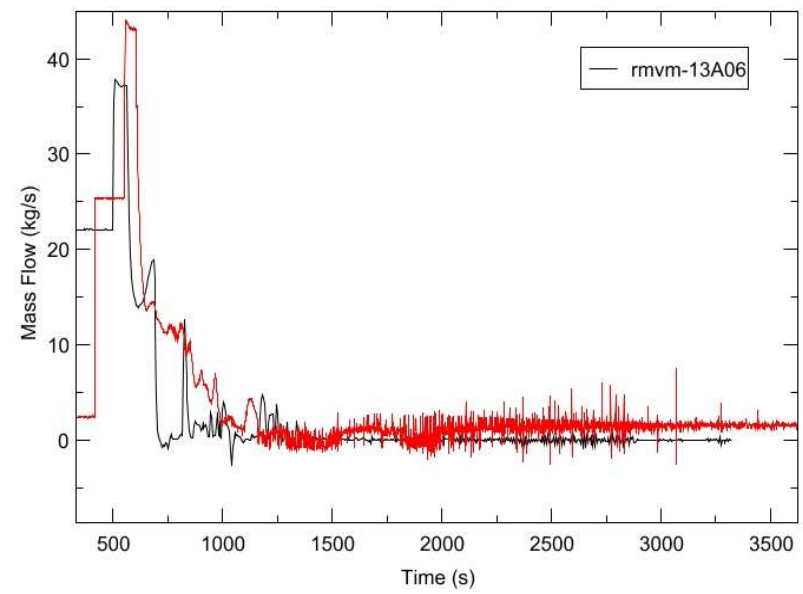

Figure 3.41 Primary loop A mass flow rate

\subsubsection{MASS FLOW RATE THROUGH THE SAFETY AND RELIEF} VALVES

In Figure 3.42 the mass flow rate through the safety and relief valves in the TRACE code compared to the experimental values is displayed. 


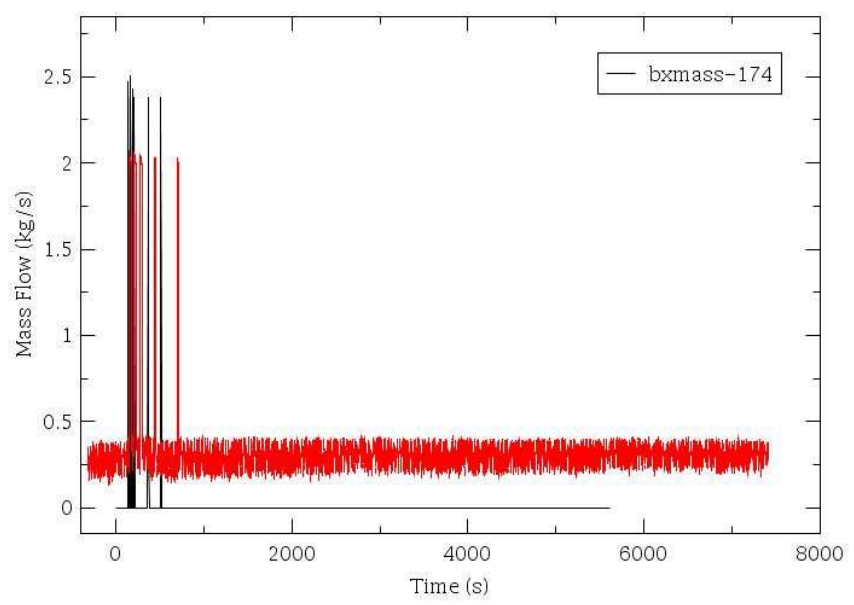

Figure 3.42 Experimental and calculated with TRACE mass flow rates through the safety and relief valves

\subsubsection{LIQUID TEMPERATURES AT THE COLD LEG}

In Figure 3.43 the thermal stratification at the cold leg with time is displayed. This is the main issue we are dealing with in this thesis, since this was the genesis and starting point for it. It can be observed in Figure 3.43 that the liquid temperature in the cold leg becomes axially stratified from the very first instants of the start of the experiment.

As the cold leg becomes partially filled with water and there is steam coming from the downcomer of the vessel, and flowing countercurrently, we thought it would be a good research issue to study this scenario going on here. The main outcome of this study would be a computer program which solves all the required equations to predict this scenario in the cold leg in order to, in future, provide the TRACE code with a tool for a better capability to predict the evolution of the physical variables that play a main role in this phenomenon. 


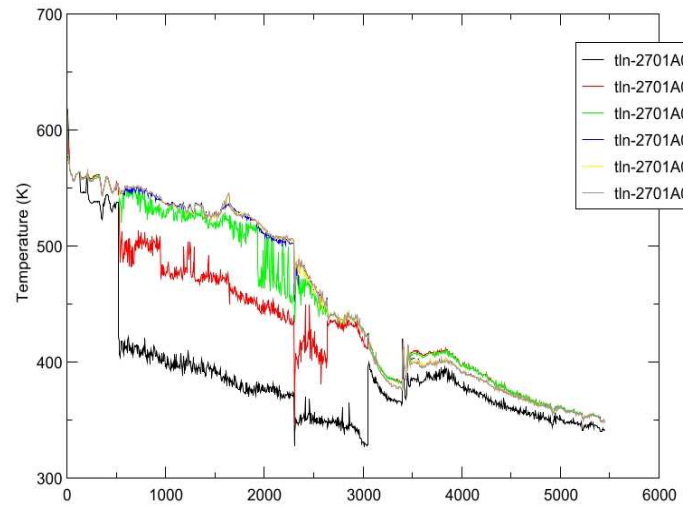

Figure 3.43 Liquid temperature at an axial cut of the cold leg

\subsection{CONCLUSIONS}

The reference steady-state situation was first obtained with the TRACE code using the same initial boundary conditions of the LSTF facility for this experiment. Some improvement in the nodalization of the plant model has been performed in order to consider some LSTF specifications. The TRACE results are close to the experimental ones at steadystate.

For this transient the ability of TRACE to correctly predict the fluid regime in the hot leg is very important. At the beginning of the transient the fluid is discharged through the break located at the bottom of the hot leg. This fluid is in liquid state and as a consequence the mass flow rate discharged through the break is very high, and the pressure drop very high during the first seconds of the transient until the beginning of the HPI injection. This behaviour is predicted very well by the TRACE code. Later, the flow at the hot leg becomes biphasic with low void fraction, and the mass flow rate discharged through the break is still high because the TRACE off-take model considers the fact that at the bottom of the hot leg we have liquid. Finally, the flow in the hot leg becomes biphasic with high void fraction and we discharge mainly steam through the break. In this test the contraction of the fluid vein during the steam discharge has an important influence on the depressurization rate during the steam flow regime. A contraction factor of 0.6 has been considered only during the steam regime in order to take this fact into account. The TRACE 
code predicts very well the change of regime from biphasic to practically single-phase steam that takes place between time 900 seconds and time 1000 seconds.

The injection of the HPIS in the cold leg produces a significant thermal stratification in this pipe that attains the value of $100^{\circ} \mathrm{C}$. TRACE code predicts well the average temperature in the cold leg, especially in the loop seal. However, some of the complex 3D thermal stratification phenomena that take place in the cold leg during the HPIS injection cannot be reproduced with a $1 \mathrm{D}$ model as the one used to represent the cold leg in the TRACE code. As a consequence the liquid temperatures predicted by TRACE in the downcomer that match well the experimental data during the first 900 seconds start to separate from the experimental ones at this point of time.

The evolution with time of the rest of variables as the pressure in the primary system, mass flow rate through the break, pressure in the secondary, and mass flow rate through the primary are all of them well predicted by the TRACE code along the transient. The pressure in the secondary is well predicted, for instance the maximum pressure attained in the secondary and the cycling of the safety and relief valves are well predicted by the TRACE code. It is also well predicted by TRACE the depressurization rate in the secondary.

The mass flow rates through the safety and relief valves are a little bit smaller about 0.25 $\mathrm{Kg} / \mathrm{s}$ than in the experiment, but Figure 3.47 shows that when the safety and relief valves are closed the experimental values have a small mass flow rate through the valves, equal to $0.25 \mathrm{Kg} / \mathrm{s}$. So the $2.5 \mathrm{Kg} / \mathrm{s}$ predicted by TRACE for the mass flow rate through the SR valves seems to be correct. The opening and closing times of the SR valves are a bit displaced with respect to the experimental ones. 


\section{CHAPTER 4}

\section{STEAM-WATER COUNTERCURRENT FLOW PHENOMENON AND ITS MODELIZATION}

\subsection{INTRODUCTION}

In this chapter our mathematical modelling of a PWR reactor hot or cold leg for the steam/water countercurrent flow study is presented.

In light water nuclear plants, countercurrent flow and thermal stratification can occur in some pipes, mainly during the startup and shutdown. However, in our case we will study the scenario of an accident of the small LOCA type.

Since we are studying this LOCA type scenario, and we aim to study a specific period of time during this accident, we suppose that a steam/water countercurrent and stratified flow is taking place.

In Figure 4.1 a graphic scheme where all the physical phenomena which are taking place and which we are modelling is illustrated:

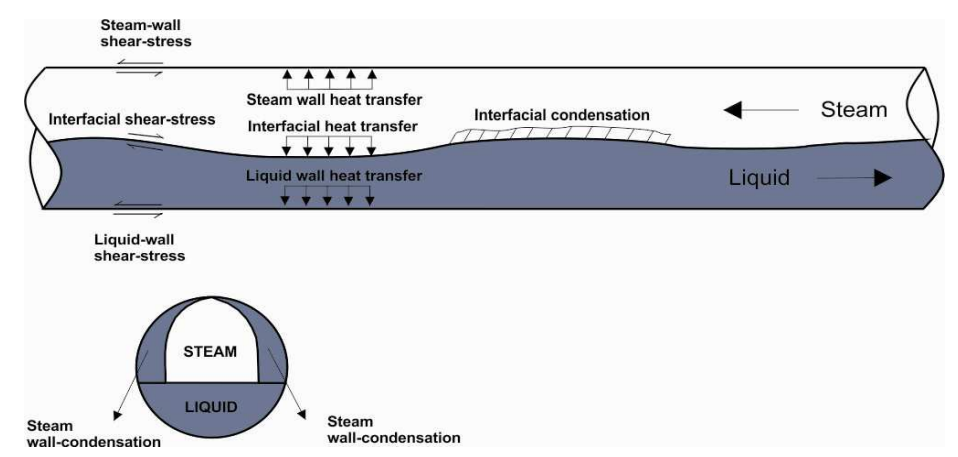

Figure 4.1 Cold leg physical phenomena during the stratification 
The model hypothesis as well as the equations used for the modelling of our problem will be presented. The mathematical model consists of six conservation equations which are; the mass, momentum and energy conservation equations for each phase. Apart from these conservation equations for each phase, we have some equations which will be later explained, and which are called jump conditions or closure relations. These relations connect the steam and liquid conservation equations. These jump relations consist of some mathematical equations which assure that the physical discontinuities at the interface, which correspond to the interfacial phenomena that can be seen in Figure 4.1, are accomplished when solving our problem.

There are presented the considerations which were made prior to solving our countercurrent problem in the next point. Then we present and explain how the conservation equations and the jump conditions are obtained. Also all the additional phenomena which have been taken into account and calculated in our code, like the heat transfer to the walls and the different frictions, are described.

Thereafter the discretization of the differential equations is presented.

\subsection{CONSIDERATIONS OF THE MODEL}

The main considerations for this model are:

It is a one-dimensional model. Both phases interchange mass and energy through the interface which is supposed to be at the saturation temperature $T_{i}=T_{\text {sat }}(P)$, while the steam can be superheated or not, and the liquid is sub-cooled.

The pressure drops are different for each phase, since liquid and steam are stratified and flowing countercurrently.

Both phases are assumed to be stratified, and the condensation process takes place at the interface at saturation conditions.

Steam can condense also on the tube walls. 


\subsection{CONSERVATION EQUATIONS}

In this section the conservation equations which have been implemented in the code are deduced. These equations are then used to solve the steam-water countercurrent flow in the hot or cold leg of a PWR reactor. Since the model is 1D, it won't have the capability to predict axial temperature profiles at the liquid layer. However depending on the interfacial and the wall temperature, below the interface, a liquid temperature profile will be assumed. Proceeding in this way, we will achieve an estimation of the thermal stratification in the pipes.

\subsubsection{LOCAL AND INSTANTANEOUS CONSERVATION EQUATIONS}

The conservation equations are the starting point for biphasic systems analysis. These equations are presented for each phase separately and in Cartesian geometry.

We start here by presenting the conservation equations applied to an infinitesimal volume and at an instant of time. These are the governing equations for a viscous fluid flow (in our case, biphasic flow), and they are called local and instantaneous conservation equations. They are expressed in general by using the subscript $\mathrm{k}$, which represents the liquid $(\mathrm{k}=\mathrm{l})$, or the steam $(\mathrm{k}=\mathrm{g})$.

\section{$>\quad$ MASS CONSERVATION EQUATION}

$$
\frac{\partial \rho_{k}}{\partial t}+\vec{\nabla} \cdot\left(\rho_{k} \vec{u}_{k}\right)=0 \quad \mathrm{k}=1, \mathrm{~g}
$$

where $\rho_{k}$ is the density of the phase $\mathrm{k}$, and $\vec{u}_{k}$ is the velocity of the phase $\mathrm{k}$ in the time instant $\mathrm{t}$ and in the considered point.

Since Equation 4.1 is a local and instantaneous equation for each phase at a given point and it is only applicable to open domains in space, there is no mass generation rate per unit volume. 
What we have just said means that Equation 4.1 is applicable to each phase just up to the interface. Therefore, at the interface, the density, velocity, and energy suffer an abrupt change and it is necessary to specify conservation equations in order to mathematically simulate these singularities at the interface. These equations are called the jump conditions.

We need to introduce here the concept of interface. The interface is an imaginary surface between the steam and liquid phases through which the phases interchange mass, momentum and energy. By supposing that the interface $A_{I}$ between the steam and the water phases moves with a velocity $\vec{u}_{i}$, which depends on the considered time instant and position, then the mass flow from one phase to the interface, must equal the mass flow from the interface to the other phase. This conservation equation at the interface is expressed as follows:

$$
\sum_{k=l, g} \rho_{k}\left(\vec{u}_{k}-\vec{u}_{i}\right) \cdot \hat{n}_{k}=0
$$

Let's notice that the unitary vectors $\hat{n}_{g}$ and $\hat{n}_{l}$ point out to opposite directions for the liquid and steam phases.
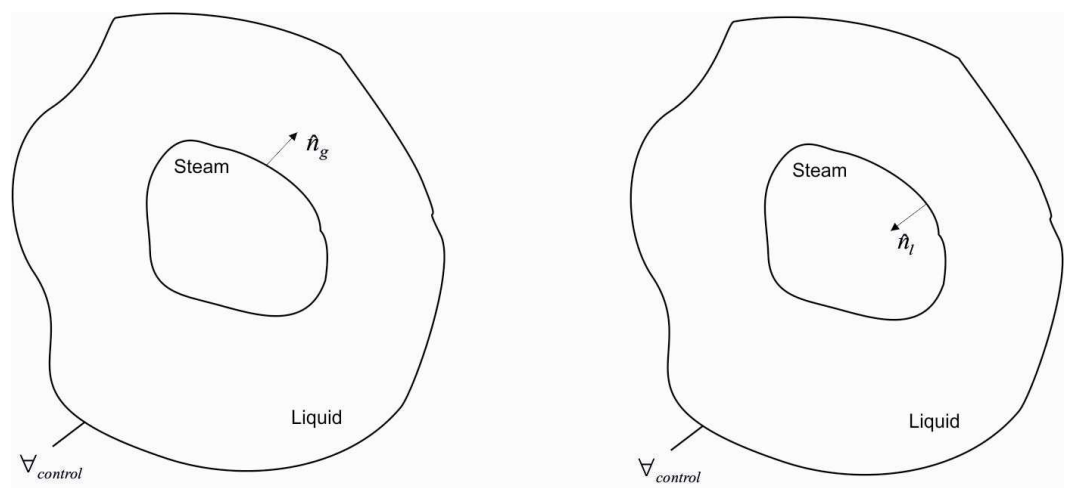

Figure 4.2 Unitary vectors $\hat{n}_{g}$ and $\hat{n}_{l}$ in an arbitrary point of the liquid-steam interface 


\section{MOMENTUM CONSERVATION EQUATION}

$$
\frac{\partial\left(\rho_{k} \vec{u}_{k}\right)}{\partial t}+\vec{\nabla} \cdot\left(\rho_{k} \vec{u}_{k} \vec{u}_{k}\right)=\rho_{k} \vec{g}+\vec{\nabla} \cdot \vec{T}_{k}
$$

where $\rho_{k} \vec{g}$ is the momentum source due to gravity, and $\vec{T}_{k}$ is the stress tensor due to pressure and the shear stress due to the viscous tension, i.e.:

$$
\vec{T}_{k}=-p \vec{I}+\vec{\tau}_{k}
$$

where $\vec{\tau}_{k}$ is the viscous shear stress tensor of the phase $\mathrm{k}$, where the tension $\vec{t}\left(\hat{n}_{k}\right)$ in an arbitrary point of the interface with unit vector $\hat{n}_{k}$ is given by:

$$
\vec{t}\left(\hat{n}_{k}\right)=\hat{n}_{k} \cdot \vec{T}_{k}=-p_{k} \hat{n}_{k}+\hat{n}_{k} \cdot \vec{\tau}_{k}
$$

In this case, the jump conditions consist of supposing that in every point of the interface, the momentum flow rate from one phase to the interface equals the momentum flow rate from the interface to the other phase plus the exerted tensions by the phases at both sides of the interface. This condition can be expressed as follows:

$$
-\sum_{k=l, g} \rho_{k} \vec{u}_{k}\left(\vec{u}_{k}-\vec{u}_{i}\right) \cdot \hat{n}_{k}+\sum_{k=l, g} \hat{n}_{k} \cdot \vec{T}_{k}=0
$$

Basically, this means that when integrating the overall interfacial area, the momentum rate that one phase loses goes to the other.

\section{ENERGY CONSERVATION EQUATION}

$$
\frac{\partial\left(\rho_{k} e_{k}\right)}{\partial t}+\vec{\nabla} \cdot\left(\rho_{k} e_{k} \vec{u}_{k}\right)=-\vec{\nabla} \cdot \vec{q}_{k}^{\prime \prime}+\vec{\nabla} \cdot \vec{T}_{k} \cdot u_{k}+\rho_{k} \vec{g} \cdot \vec{u}_{k}+\dot{q}_{k}^{\prime \prime \prime}
$$


where, $\vec{q}_{k}^{\prime \prime}$ is the heat flux received or released through the boundary surfaces, $\vec{\nabla} \cdot \vec{T}_{k} \cdot u_{k}$ is the rate of work done by the pressure and viscous forces, $\rho_{k} \vec{g} \cdot \vec{u}_{k}$ is the rate of work done by the gravity forces, and $\dot{q}_{k}^{\prime \prime \prime}$ is the generated heat rate inside the volume.

Let's remember that the stored energy per unit mass $(J / K g)$ is given by:

$$
e_{k}=e_{k}^{\prime}+\frac{1}{2} u_{k}^{2}+g z
$$

where $e_{k}^{\prime}$ is the internal specific energy.

In this case, the jump conditions express the fact that the energy transported by convection and the work done, through the interface, that wins or loses one phase equals the energy that the other phase loses or wins respectively. This can be expressed as follows:

$$
-\sum_{k=l, g} \vec{q}_{k}^{\prime \prime} \cdot \hat{n}_{k}+\sum_{k=l, g} \vec{t}\left(\hat{n}_{k}\right) \cdot \vec{u}_{k}-\sum_{k=l, g} e_{k} \rho_{k}\left(\vec{u}_{k}-\vec{u}_{i}\right) \cdot \hat{n}_{k}=0
$$

where $\vec{t}\left(\hat{n}_{k}\right)$ is the stress vector as defined in Hetsroni's book, page I-9, see Equation (4.5).

\subsubsection{D AVERAGED CONSERVATION EQUATIONS}

Now well, the equations that all the thermal-hydraulic codes use, and which we are going to use in this thesis, are always time and space averaged equations. In these equations, a double space and time average (Ishii 1975) or a space average and an "ensemble average" (Banerjee 1980) is performed on the local and instantaneous equations. The mathematical development of the time and space averaging is fully explained in Appendix G.

We are introducing here a few definitions before continuing.

Let's suppose that we have a volume $V$ with two phases, as is shown in Figure 4.3. 


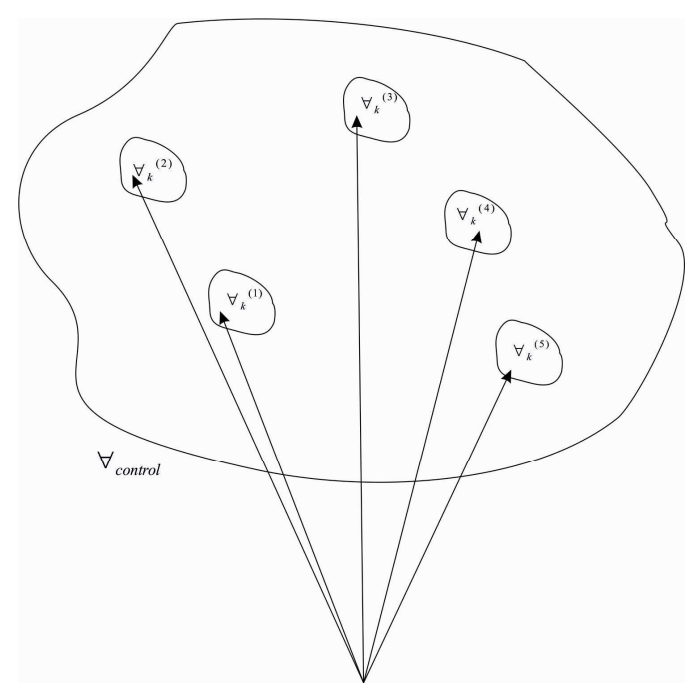

Figure 4.3. Occupied volume by phase $k$ at the time instant $t$ in the volume element $V$

Now, let's consider the characteristic function for the phase k, defined as follows:

$$
X_{k}(\vec{r}, t)=\mid \begin{array}{lll}
1 & \text { if } & \vec{r} \in k \\
0 & \text { if } & \vec{r} \notin k
\end{array}
$$

We define the mean volumetric fraction for the phase $\mathrm{k}$, in the volume $V$, centered at $\vec{r}$

$$
\left\langle\alpha_{k}(\vec{r}, t)\right\rangle=\frac{1}{V} \int_{V} X_{k}(\vec{r}, t) d V=\frac{1}{V} \int_{V_{k}} \int_{(\vec{r}, t)} d V=\frac{V_{k}(\vec{r}, t)}{V}
$$

where the symbol \langle\rangle represents the space averaging of a variable.

Now well, the volume fraction also changes with time. That's why we define the time averaging of the magnitude (4.11) as:

$$
\overline{\left\langle\alpha_{k}(\vec{r}, t)\right\rangle}=\frac{1}{T} \int_{T}\left\langle\alpha_{k}(\vec{r}, t)\right\rangle d t
$$

where the symbol - represents the time averaging of a variable, and $\mathrm{T}$ is a time interval centered in t, i.e.: 


$$
\left[t-\frac{T}{2}, t+\frac{T}{2}\right]
$$

This averaging leads us to the so called macroscopic equations, which are presented next. In these equations all the magnitudes are averaged magnitudes. For the sake of simplicity we have omitted the averaging symbol in the conservation equations.

\section{MASS CONSERVATION EQUATION}

Here the time and space averaged mass conservation equation is presented:

$$
\underbrace{\frac{\partial\left(\alpha_{k} \rho_{k}\right)}{\partial t}}_{1}+\underbrace{\vec{\nabla} \cdot\left(\rho_{k} \alpha_{k} \vec{u}_{k}\right)}_{2}=\underbrace{\Gamma_{k}}_{3} \quad \mathrm{k}=\mathrm{l}, \mathrm{g}
$$

where $\alpha_{k}$ is the averaged volume fraction of the $\mathrm{k}$ phase, $\rho_{k}$ is the density of the phase $\mathrm{k}$, $\vec{u}_{k}$ is the velocity of the phase, and:

1) $\frac{\partial\left(\alpha_{k} \rho_{k}\right)}{\partial t}$ : Is the rate of change of the stored mass per unit volume in an arbitrary position and time instant of the domain.

2) $\vec{\nabla} \cdot\left(\rho_{k} \alpha_{k} \vec{u}_{k}\right):$ Is the mass flow rate through the fluid element faces.

3) $\Gamma_{k}$ : Is the mass generation rate per unit volume for the phase $\mathrm{k}$ that can be positive or negative.

In the further conservation equations, when separating the conservation equations for each phase, we will use the following definitions of volume fraction: 
- Steam volume fraction:

$$
\left\langle\alpha_{g}\right\rangle=\alpha
$$

- Liquid volume fraction:

$$
\left\langle\alpha_{l}\right\rangle=1-\left\langle\alpha_{g}\right\rangle=1-\alpha
$$

where we say that $\alpha$ is the steam volume fraction and hence, $1-\alpha$ is the liquid volume fraction.

Finally, by inserting the previous definitions in Equation (4.14), the averaged mass conservation equations used in the thermal-hydraulic codes for both phases are:

\section{$\underline{\text { Liquid phase }}$}

$$
\frac{\partial\left((1-\alpha) \rho_{l}\right)}{\partial t}+\vec{\nabla} \cdot\left(\rho_{l}(1-\alpha) \vec{u}_{l}\right)=\Gamma_{l}
$$

Steam phase

$$
\frac{\partial\left(\alpha \rho_{g}\right)}{\partial t}+\vec{\nabla} \cdot\left(\rho_{g} \alpha \vec{u}_{g}\right)=\Gamma_{g}
$$

being $\Gamma_{g}$ the steam generation rate per unit volume at point $\vec{r}$.

As it is explained in Appendix G, the mass jump condition can be expressed as:

$$
\Gamma_{g}=-\Gamma_{l}
$$

Hence, Equations (4.17) and (4.18) can be combined in one single equation, where the mass conservation for the total mass is given by: 


$$
\frac{\partial\left(\alpha \rho_{g}+(1-\alpha) \rho_{l}\right)}{\partial t}+\vec{\nabla} \cdot\left(\alpha \rho_{g}+\rho_{l}(1-\alpha) \vec{u}_{l}\right)=0
$$

\section{MOMENTUM CONSERVATION EQUATION}

Here the time and space averaged momentum conservation equation is presented:

$\underbrace{\frac{\partial\left(\alpha_{k} \rho_{k} \vec{u}_{k}\right)}{\partial t}}_{1}+\underbrace{\vec{\nabla} \cdot\left(\alpha_{k} \rho_{k} \vec{u}_{k} \vec{u}_{k}\right)}_{2}+\underbrace{\alpha_{k} \vec{\nabla} P}_{3}-\underbrace{\vec{\nabla} \cdot \alpha_{k} \vec{k}_{k}^{T}}_{4}-\underbrace{\alpha_{k} \rho_{k} \vec{g}}_{5}=\underbrace{\vec{F}_{k i}}_{6}+\underbrace{\vec{F}_{k w}}_{7}+\underbrace{\Gamma_{k} \vec{u}_{k i}}_{8}$

where $\alpha_{k}$ is the averaged volume fraction of the k phase, $\rho_{k}$ is the density of the phase k, $\vec{u}_{k}$ is the velocity of the phase $\mathrm{k}, \vec{\tau}_{k}{ }^{T}$ is the Reynolds viscous shear stress tensor for the $\mathrm{k}$ phase, and:

1) $\frac{\partial\left(\alpha_{k} \rho_{k} \vec{u}_{k}\right)}{\partial t}$ : Is the rate of change of the stored momentum per unit volume in an arbitrary position and time instant of the domain.

2) $\vec{\nabla} \cdot\left(\alpha_{k} \rho_{k} \vec{u}_{k} \vec{u}_{k}\right):$ Is the momentum flow rate through the fluid element faces.

3) $\alpha_{k} \vec{\nabla} P$ : Pressure drop in the element of fluid.

4) $\vec{\nabla} \cdot \alpha_{k} \vec{\tau}_{k}{ }^{T}$ : This term is the rate of change of the momentum per unit volume due to the viscous shear stress.

5) $\alpha_{k} \rho_{k} \vec{g}$ : Is the rate of change of the momentum per unit volume due to the gravity forces.

6) $\vec{F}_{k i}$ : Is the rate of change of the momentum per unit volume due to the friction between phases $\vec{F}_{k i}$. 
This term is produced due to the fact that the liquid and the steam move at different velocities, what produces a frictional shear stress that causes the steam to be slowed down by the liquid and the liquid dragged by the steam since the steam velocity is higher than the liquid one, and inversely if the liquid velocity is higher than the steam one.

$$
\vec{F}_{k i}=\frac{1}{V} \int_{A_{I}} \vec{\tau}_{k} \cdot \hat{n}_{k} d S
$$

7) $\vec{F}_{k w}$ : Is the rate of change of the momentum per unit volume due to the friction with the walls $\vec{F}_{k w}$.

$$
\vec{F}_{k w}=\frac{1}{V} \int_{A_{k w}} \vec{\tau}_{k} \cdot \hat{n}_{k} d S
$$

8) $\Gamma_{k} \vec{u}_{k i}$ is the rate of change of the momentum per unit volume due to the momentum interchanged due to the phase change.

$$
\Gamma_{k} \vec{u}_{k i}=-\frac{1}{V} \int_{A_{I}} \rho_{k} \vec{u}_{k}\left(\vec{u}_{k}-\vec{u}_{i}\right) \cdot \hat{n}_{k} d S
$$

where $\Gamma_{k}$ is the mass generation rate per unit volume of the phase $\mathrm{k}$, and $\vec{u}_{k i}$ the velocity of the phase $\mathrm{k}$ at the interface.

The integration of the jump condition all along the interfacial area, leads us to the following expression:

$$
\vec{F}_{g i}=-\vec{F}_{l i}
$$

In the momentum conservation equation and also in the following energy conservation equation, we are assuming that $P_{k}=P$. This yields the pressure to be the same for both phases. This is because we are supposing that we have a homogeneous flow, i.e. we are analyzing a volume where the phases are mixed and, where we have volumetric weighted properties for every phase. However this assumption is not true for stratified flow.

Finally, the averaged 3D mass conservation equations normally used in thermal-hydraulic codes are: 
$\underline{\text { Liquid phase }}$

$$
\begin{aligned}
\frac{\partial}{\partial t} \vec{u}_{l}+\vec{u}_{l} \cdot \vec{\nabla} \vec{u}_{l}=-\frac{1}{\rho_{l}} \vec{\nabla} p & +\frac{c_{i}}{(1-\alpha) \rho_{l}}\left(\vec{u}_{g}-\vec{u}_{l}\right)\left|\vec{u}_{g}-\vec{u}_{l}\right| \\
& -\frac{\Gamma_{g}^{-}}{(1-\alpha) \rho_{l}}\left(\vec{u}_{g}-\vec{u}_{l}\right)-\frac{c_{w l}}{(1-\alpha) \rho_{l}} \vec{u}_{l}\left|\vec{u}_{l}\right|+\vec{g}
\end{aligned}
$$

$\underline{\text { Steam phase }}$

$$
\begin{aligned}
\frac{\partial}{\partial t} \vec{u}_{g}+\vec{u}_{g} \cdot \vec{\nabla} \vec{u}_{g}=-\frac{1}{\rho_{g}} \vec{\nabla} p-\frac{c_{i}}{\alpha \rho_{g}}\left(\vec{u}_{g}-\vec{u}_{l}\right)\left|\vec{u}_{g}-\vec{u}_{l}\right| \\
-\frac{\Gamma_{g}^{+}}{\alpha \rho_{g}}\left(\vec{u}_{g}-\vec{u}_{l}\right)-\frac{c_{w g}}{\alpha \rho_{g}} \vec{u}_{g}\left|\vec{u}_{g}\right|+\vec{g}
\end{aligned}
$$

where:

$$
\begin{aligned}
& \Gamma_{g}^{+}=\max \left[\Gamma_{g}, 0\right] \\
& \Gamma_{g}^{-}=\min \left[-\Gamma_{g}, 0\right]
\end{aligned}
$$

\section{$>\quad$ ENERGY CONSERVATION EQUATION}

Here the time and space averaged energy conservation equation is presented:

$$
\underbrace{\frac{\partial\left(\alpha_{k} \rho_{k} e_{k}\right)}{\partial t}}_{1}+\underbrace{\vec{\nabla} \cdot\left(\alpha_{k} \rho_{k} e_{k} \vec{u}_{k}\right)}_{2}=-\underbrace{P \frac{\partial}{\partial t} \alpha_{k}}_{3}-\underbrace{P \vec{\nabla} \cdot\left(\alpha_{k} \vec{u}_{k}\right)}_{4}+\underbrace{\Gamma_{k}\left(e_{k i}+\frac{P_{k}}{\rho_{k}}\right)}_{5}+\underbrace{\dot{q}_{i k}}_{6}
$$




$$
+\underbrace{\dot{q}_{w k}}_{7}+\underbrace{\alpha_{k} \dot{q}_{k}^{\prime \prime \prime}}_{8}
$$

where $e_{k}$ is the stored energy per unit mass in the fluid element, and:

1) $\frac{\partial\left(\alpha_{k} \rho_{k} e_{k}\right)}{\partial t}$; is the stored energy rate of change per unit volume $\left(\mathrm{J}^{\mathrm{sm}} \mathrm{sm}^{3}\right)$ in an arbitrary position and time instant of the domain.

2) $\vec{\nabla} \cdot\left(\alpha_{k} \rho_{k} e_{k} \vec{u}_{k}\right)$ : This term when integrated over V, is the energy flow rate through the fluid element faces.

3) $-P \frac{\partial}{\partial t} \alpha_{k}$ : Is the loss of energy per unit volume due to phase expansion.

4) $-P \vec{\nabla} \cdot\left(\alpha_{k} u_{k}\right):$ Is the work done by the pressure due to expansion.

5) $\Gamma_{k}\left(e_{k i}+\frac{P_{k}}{\rho_{k}}\right)$ : Is the variation of stored energy due to mass transfer between phases.

6) $\dot{q}_{i k}$ : Is the rate of heat per unit volume interchanged between the interface and the phase $\mathrm{k}$.

7) $\dot{q}_{w k}$ : Is the rate of heat per unit volume interchanged between the phase $\mathrm{k}$ and the walls.

8) $\alpha_{k} \dot{q}_{k}^{\prime \prime \prime}$ : Volumetric source of energy in the fluid element.

By integrating the jump condition of the energy equation with respect to the interfacial area $A_{I}$ contained in the fluid element volume (neglecting the work done by the viscous forces) we get:

$$
-\int_{A_{I}}\left(\vec{q}_{l}^{\prime \prime} \cdot \hat{n}_{l}+\vec{q}_{g}^{\prime \prime} \cdot \hat{n}_{g}\right) d S-\int_{A_{I}}\left(h_{o g} \dot{m}_{g}+h_{o l} \dot{m}_{l}\right) d S=0
$$

where: 


$$
\begin{aligned}
& \dot{m}_{k}=\rho_{k}\left(\vec{u}_{k}-\vec{u}_{i}\right) \cdot \hat{n}_{k} \\
& h_{o k}=e_{k}+P / \rho_{k}
\end{aligned}
$$

Thence we can write the jump condition equation as follows:

$$
\left(\dot{q}_{l i}^{\prime \prime}+\dot{q}_{g i}^{\prime \prime}\right) \frac{A_{I}}{V}+h_{o l i} \Gamma_{l}+h_{o g i} \Gamma_{g}=0
$$

By using in Equation (4.26) the mass jump condition, i.e. $\Gamma_{g}=-\Gamma_{l}$ we can say that:

$$
\Gamma_{g}=-\frac{\left(\dot{q}_{l i}^{\prime \prime}+\dot{q}_{g i}^{\prime \prime}\right) A_{I}}{\left(h_{o g i}-h_{o l i}\right) V}
$$

Finally, in order to obtain the $3 \mathrm{D}$ energy conservation equations for the internal energy, we subtract from (4.30), the kinetic energy equation. This last equation is obtained multiplying each momentum component equation by $u_{k j}$ and summing up the three resulting equations.

After some calculus it is obtained:

Liquid phase

$$
\begin{array}{r}
\frac{\partial\left((1-\alpha) \rho_{l} e_{l}^{\prime}\right)}{\partial t}+\vec{\nabla} \cdot\left((1-\alpha) \rho_{l} e_{l}^{\prime} \vec{u}_{l}\right)=-P_{l} \frac{\partial}{\partial t}(1-\alpha)-P \vec{\nabla} \cdot\left((1-\alpha) \vec{u}_{l}\right) \\
+\dot{q}_{w l}+\dot{q}_{i l}+\dot{q}_{d l}+\Gamma_{l} h_{l i}^{\prime}
\end{array}
$$

$\underline{\text { Steam phase }}$

$\frac{\partial\left(\alpha \rho_{g} e_{g}^{\prime}\right)}{\partial t}+\vec{\nabla} \cdot\left(\alpha \rho_{g} e_{g l}^{\prime} \vec{u}_{g}\right)=-P_{g} \frac{\partial}{\partial t} \alpha-P \vec{\nabla} \cdot\left(\alpha \vec{u}_{g}\right)+\dot{q}_{w g}+\dot{q}_{i g}+\dot{q}_{d g}+\Gamma_{g} h_{g i}^{\prime}$ 


\subsubsection{D AVERAGED CONSERVATION EQUATIONS}

Since our code is a 1D code, we must first obtain the averaged 1D equations from the previous 3D averaged equations. We can find this development at the "Handbook of multiphase systems by Ged Hetsroni ", or in the book "Thermo-fluid dynamics of twophase flow" by Mamoru Ishii.

\section{$>\quad$ MASS CONSERVATION EQUATION}

We assume both phases as separated as we can see in the next figure, where we show an $\Delta V$ of the pipe with cross sectional area $A(x)$ :

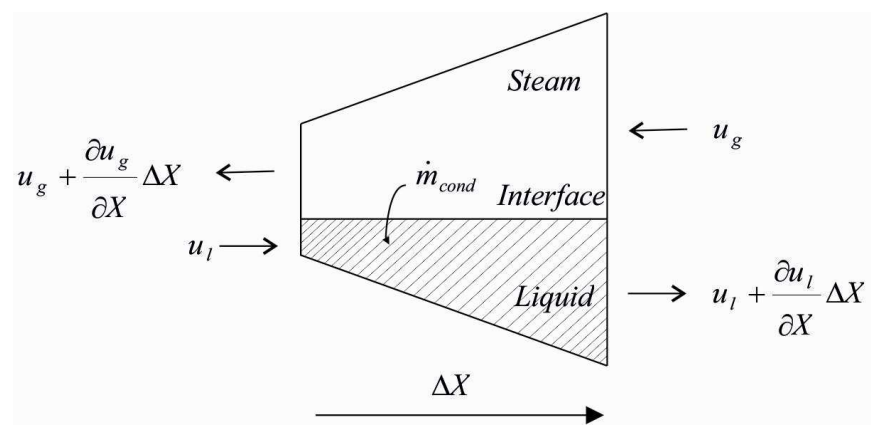

Figure 4.4 Countercurrent separated flow

Then, we apply the continuity equation for the k phase at the volume $\Delta V_{k}$ as follows:

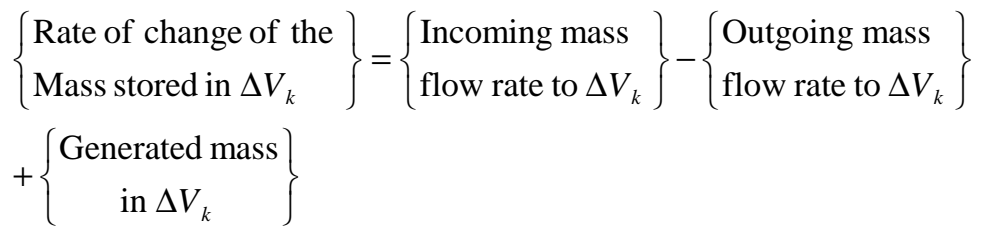

where $\Delta V_{k}$ is the occupied volume by the $\mathrm{k}$ phase.

Steam phase: 


$$
\frac{\partial\left(\rho_{g} \alpha A(x)\right)}{\partial t}+\frac{\partial}{\partial x}\left(\rho_{g} \alpha A(x) u_{g}\right)=\Gamma_{g} A(x)
$$

where $\mathrm{t}$ is the time (s), $A(x)$ is the cross sectional area of the pipe $\left(m^{2}\right), \rho_{\mathrm{g}}$ is the steam density $\left(\mathrm{Kg} / \mathrm{m}^{3}\right), u_{g}$ is the steam velocity $(\mathrm{m} / \mathrm{s}), \Gamma_{\mathrm{g}}$ is the condensation rate per unit volume $\left(\mathrm{Kg}_{\mathrm{g}} \mathrm{sm}^{3}\right)$. The $\mathrm{g}$ subscript refers to the steam phase, and $\mathrm{x}$ represents the $\mathrm{x}$ direction which corresponds with the axis of the pipe.

Liquid phase:

$$
\frac{\partial\left(\rho_{l}(1-\alpha) A(x)\right)}{\partial t}+\frac{\partial}{\partial x}\left(\rho_{l}(1-\alpha) A(x) u_{l}\right)=\Gamma_{l} A(x)
$$

where $\mathrm{t}$ is the time $(s), \mathrm{A}$ is the cross sectional area of the pipe $\left(m^{2}\right), \rho_{\mathrm{l}}$ is the liquid density $\left(\mathrm{Kg} / \mathrm{m}^{3}\right), u_{l}$ is the liquid velocity $(\mathrm{m} / \mathrm{s}), \Gamma_{l}$ is the liquid mass generation rate per unit volume $\left(\mathrm{Kg} / \mathrm{sm}^{3}\right)$.

The equations (4.38) and (4.39) assume the jump condition.

$$
-\int_{A I} \rho_{g}\left(\vec{u}_{g}-\vec{u}_{i}\right) d A_{I} \cdot \hat{n}_{g}-\int_{A I} \rho_{l}\left(\vec{u}_{l}-\vec{u}_{i}\right) d A_{I} \cdot \hat{n}_{l}=0
$$

where $A_{I}$ is the interfacial area in the volume $\Delta V$.

i.e. the mass flow rate lost by one phase is won by the other.

Let's introduce now some definitions: 


$$
\dot{m}_{g i}=\int_{A_{I}} \rho_{g}\left(\vec{u}_{g}-\vec{u}_{i}\right) \cdot \hat{n}_{g} d A
$$

Is the steam mass flow rate crossing the interface. Notice that $\dot{m}_{g i}$ is positive when there is condensation, and negative when there is evaporation. Therefore the condensation rate at the interface is defined as $m_{\text {condgi }}=\dot{m}_{g i}$. Now the evaporation rate per unit volume is defined to have a positive sign when we have evaporation, so we write taking into account (4.41):

$$
\Gamma_{g}=-\frac{1}{V} \dot{m}_{g i}=-\dot{m}_{g i}^{\prime \prime} a_{I}^{\prime \prime \prime}
$$

Notice that $\Gamma_{g}$ is negative when there is condensation. This means that the vapour phase loses steam.

where, $a_{I}^{\prime \prime \prime}$ is the interfacial area concentration $\left(\mathrm{m}^{-1}\right)$ in the considered volume, and is defined as follows:

$$
a_{I}^{\prime \prime \prime}=\frac{A_{I}}{V}=\frac{P_{\text {int } e r f} \Delta x}{A(x) \Delta x}=\frac{P_{\text {int } e r f}}{A(x)}\left[m^{-1}\right]
$$

Now, we must say that the condensation mass flow rate that is simulated in our CC code, includes the steam condensation at the interface, and also the steam condensation at the wall of the pipe where there is only steam phase due to having a separated flow.

$$
\dot{m}_{g}=-\Gamma_{g} V=\dot{m}_{g i}+\dot{m}_{g w}
$$

where $\dot{m}_{g i}$ is the steam condensation at the liquid/steam interface, and $\dot{m}_{g w}$ is the steam condensation or evaporation at the steam pipe wall.

As we already said, the jump condition in the continuity equation means that:

$$
\Gamma_{g}=-\Gamma_{l}
$$

where, $\Gamma_{g}$ is the steam condensation rate per unit volume $\left(\mathrm{Kg} / \mathrm{sm}{ }^{3}\right)$, and $\Gamma_{l}$ is the liquid mass generation rate per unit volume $\left(\mathrm{Kg}_{\mathrm{sm}}{ }^{3}\right)$. 


\section{MOMENTUM CONSERVATION EQUATION}

A scheme of the forces and shear stresses that are actuating in the volume $\Delta V$ is shown in Figure 4.5.

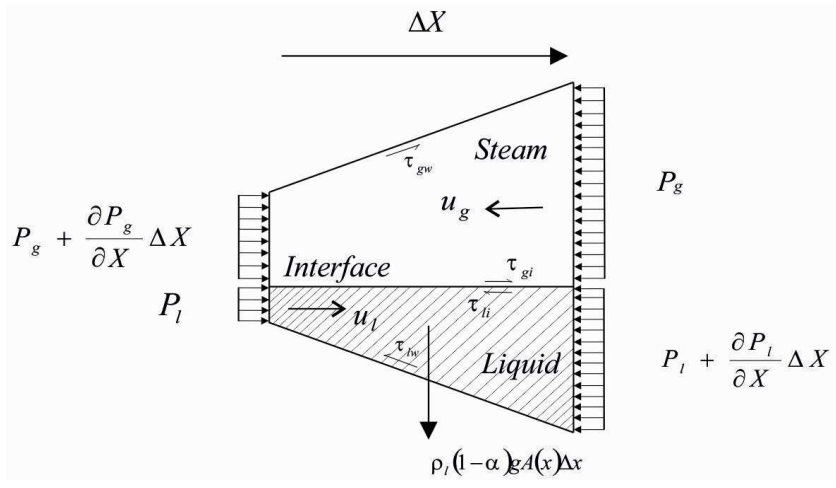

Figure 4.5 Forces and shear stresses scheme in the volume $\Delta V$

We apply the momentum conservation for the k phase, to the $\Delta V_{k}$ volume as follows:

$\left\{\begin{array}{l}\text { Rate of change of the } \\ \text { Momentum stored in } \Delta V_{k}\end{array}\right\}=\left\{\begin{array}{l}\text { Rate of incoming momentum } \\ \text { to } \Delta V_{k} \text { through the } \Delta V_{k} \text { contour }\end{array}\right\}$

$-\left\{\begin{array}{l}\text { Rate of outgoing momentum } \\ \text { from } \Delta V_{k} \text { through the } \Delta V_{k} \text { contour }\end{array}\right\}+\left\{\begin{array}{l}\text { Sum of forces that act on the } \\ \text { volume element } \Delta V_{k}\end{array}\right\}$

Next we define the friction stresses of the steam and liquid with the walls:

$$
\tau_{g w}=\frac{1}{2} f_{g} \rho_{g} u_{g}\left|u_{g}\right| \text { and } \tau_{l w}=\frac{1}{2} f_{l} \rho_{g} u_{l}\left|u_{l}\right|
$$

The interfacial stresses are defined by the expressions:

$$
\tau_{g i}=\frac{1}{2} f_{i} \rho_{g}\left(u_{g}-u_{l}\right)_{i}\left|u_{g}-u_{l}\right|_{i} \text { and } \tau_{g i}=-\tau_{l i}
$$

Concerning the liquid we notice that for the wall we have, $\vec{\tau}_{l w}=-\tau_{l w} \widehat{e}_{x}$, with $\tau_{l w}>0$, and since $u_{l}>0$, this term contributes to decelerate the liquid. The term of the interfacial shear stress is, $\vec{\tau}_{l i}=-\tau_{l i} \hat{e}_{x}$, with $\tau_{l i}>0$ and also contributes to decelerate the liquid. 
Steam phase:

$$
\begin{gathered}
\frac{\partial\left(\rho_{g} u_{g} \alpha A(x)\right)}{\partial t}=-\frac{\left(\rho_{g} u_{g}{ }^{2} \alpha A(x)\right)}{\partial x}-\tau_{g w} P_{g w}-\tau_{g i} P_{g i}-\alpha A(x) \frac{\partial P_{g}}{\partial x}+\Gamma_{g} A(x)\left[u_{k}\right] \\
+\rho_{g} g \alpha A(x) \cos \theta
\end{gathered}
$$

where, the variable $\tau_{g w}$ represents the steam viscous shear stress at the wall defined previously, $\tau_{g i}$ represents the interfacial shear stress at the interface steam-liquid that tends to slow down the steam, $P_{g}$ is the pressure of the steam, $\mathrm{A}_{\mathrm{g}}$ is the steam transversal area, $\mathrm{g}$ is the gravity acceleration and $\Gamma_{\mathrm{g}}$ is the condensation rate per unit volume $\left(\mathrm{Kg} / \mathrm{sm}^{3}\right)$.

Due to that the pipe is horizontal, $\theta=90$, the gravity force doesn't act in this direction and the momentum equation results into the following one:

$$
\frac{\partial\left(\rho_{g} u_{g} \alpha A(x)\right)}{\partial t}=-\frac{\partial\left(\rho_{g} u_{g}{ }^{2} \alpha A(x)\right)}{\partial x}-\tau_{g w} P_{g w}-\tau_{g i} P_{g i}-\alpha A(x) \frac{\partial P_{g}}{\partial x}+\Gamma_{g} A(x)\left[u_{k}\right]
$$

where;

$$
\Gamma_{g} A(x)\left[u_{k}\right]=\left\{\begin{array}{llc}
\Gamma_{g} A(x) u_{l} & \text { if } & \Gamma_{g}>0 \\
\Gamma_{g} A(x) u_{g} & \text { if } & \Gamma_{g}<0
\end{array}\right.
$$

Liquid phase:

As in the steam phase, the gravity term doesn't appear because we are considering a horizontal pipe.

$$
\begin{array}{r}
\frac{\partial\left(\rho_{l} u_{l}(1-\alpha) A(x)\right)}{\partial t}=-\frac{\partial\left(\rho_{l} u_{l}{ }^{2}(1-\alpha) A(x)\right)}{\partial x}+\tau_{l w} P_{l w}+\tau_{g i} P_{g i} \\
-(1-\alpha) A(x) \frac{\partial P_{l}}{\partial x}+\Gamma_{l} A(x)\left[u_{k}\right]
\end{array}
$$


where:

$$
\Gamma_{l} A(x)\left[u_{k}\right]=\left\{\begin{array}{llc}
\Gamma_{l} A(x) u_{l} & \text { if } & \Gamma_{g}<0 \\
\Gamma_{l} A(x) u_{g} & \text { if } & \Gamma_{g}>0
\end{array}\right.
$$

\section{ENERGY CONSERVATION EQUATION}

The energy conservation equation is applied to the control volume shown in Figure 4.6:

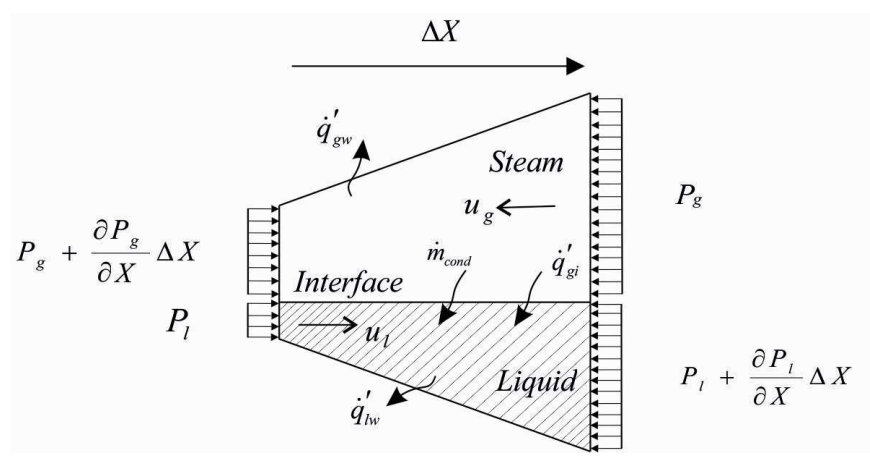

Figure 4.6 Scheme of energy sources at the volume $\Delta V_{k}$

$\left\{\begin{array}{l}\text { Rate of change of the } \\ \text { Energy stored in } \Delta V_{k}\end{array}\right\}=\left\{\begin{array}{l}\text { Rate of total energy incoming } \\ \text { to } \Delta V_{k} \text { through the } \Delta V_{k} \text { contour }\end{array}\right\}-$

$\left\{\begin{array}{l}\text { Rate of total energy outgoing } \\ \text { from } \Delta V_{k} \text { through the } \Delta V_{k} \text { contour }\end{array}\right\}+\left\{\begin{array}{l}\text { Heat rate received } \\ \text { through the interface }\end{array}\right\}$

$+\left\{\begin{array}{l}\text { Energy received through the interface in the } \\ \text { condensation process per unit time in } \Delta \mathrm{V}_{\mathrm{k}}\end{array}\right\}$

$+\left\{\begin{array}{l}\text { Heat rate through the } \\ \text { walls }\end{array}\right\}-\left\{\begin{array}{l}\text { Work performed per unit } \\ \text { time during expansion in } \Delta \mathrm{V}_{\mathrm{k}}\end{array}\right\}$ 
Steam phase:

$$
\begin{aligned}
\frac{\partial}{\partial t}\left(\rho_{g} e_{a g} \alpha A(x)\right)=-\frac{\partial}{\partial x}\left(\rho_{g} u_{g} e_{a g} \alpha A(x)\right)-P_{g} \frac{\partial}{\partial x}\left(u_{g} \alpha A(x)\right)+\dot{q}_{g w}^{\prime}+\dot{q}_{g i}^{\prime} \\
-P_{g} \frac{\partial(\alpha A(x))}{\partial t}+\Gamma_{g} A(x) h_{g i}
\end{aligned}
$$

where $e_{a g}(J / K g)$ is the internal energy stored in the steam, $\dot{q}_{g w}^{\prime}$ is the heat removed from steam through the walls $(W / m), \dot{q}_{g i}^{\prime}$ is the heat removed from the steam through the interface $(W / m), \quad P_{g w}$ is the contact perimeter steam-wall $(m)$, and $P_{\text {int } e r f}$ is the interfacial steam-liquid perimeter $(m)$.

Liquid phase:

$$
\begin{aligned}
\frac{\partial}{\partial t}\left(\rho_{l} e_{a l}(1-\alpha) A(x)\right)=\frac{-\partial}{\partial x}\left(\rho_{l} u_{l} e_{a l}(1-\alpha) A(x)\right)-P_{l} \frac{\partial}{\partial x}\left(u_{l}(1-\alpha) A(x)\right) \\
+\dot{q}_{l w}^{\prime}+\dot{q}_{l i}^{\prime}-P_{l} \frac{\partial((1-\alpha) A(x))}{\partial t}+\Gamma_{l} A(x) h_{l i}
\end{aligned}
$$

Considering the energy equation, we can truly say that the interchanged energy in the interface is conserved. This means that the energy interchange through the interface surface is zero, what can be expressed as follows:

$$
-\int_{A I} \rho_{g}\left(\vec{u}_{g}-\vec{u}_{I}\right) \cdot \hat{n}_{g} h_{g i} d A-\int_{A I} \rho_{l}\left(\vec{u}_{l}-\vec{u}_{I}\right) \cdot \hat{n}_{l} h_{l i} d A-\int_{A I} \vec{q}_{g}^{\prime \prime} \cdot \hat{n}_{g} d A-\int_{A I} \vec{q}_{l}^{\prime \prime} \cdot \hat{n}_{l} d A=0
$$

From this expression and taking note of the definitions of $\Gamma_{\mathrm{g}}$ and $\Gamma_{\mathrm{l}}$, and the equality $\Gamma_{g}=-\Gamma_{l}$, we get an expression to obtain $\Gamma_{\mathrm{g}}$ : 


$$
\Gamma_{g}\left(\frac{K_{g}}{s \cdot m^{3}}\right)=-\frac{\dot{q}_{l i}^{\prime \prime}+\dot{q}_{g i}^{\prime \prime}}{\left\langle h_{g i}-h_{l i}\right\rangle} \frac{A_{I}}{V}=-\frac{\dot{q}_{l i}^{\prime \prime}+\dot{q}_{g i}^{\prime \prime}}{h_{f g}} a_{I}^{\prime \prime \prime}
$$

We present in Table 4.1 a resume of the 1D averaged conservation equations for each phase:

Table 4.1 Resume of the 1D averaged conservation equations MASS CONSERVATION EQUATIONS

Liquid phase:

$$
\frac{\partial\left(\rho_{l}(1-\alpha) A(x)\right)}{\partial t}+\frac{\partial}{\partial x}\left(\rho_{l}(1-\alpha) A(x) u_{l}\right)=\Gamma_{l} A(x)
$$

Steam phase:

$$
\frac{\partial\left(\rho_{g} \alpha A(x)\right)}{\partial t}+\frac{\partial}{\partial x}\left(\rho_{g} \alpha A(x) u_{g}\right)=\Gamma_{g} A(x)
$$

\section{MOMENTUM CONSERVATION EQUATIONS}

Liquid phase:

$$
\begin{gathered}
\frac{\partial\left(\rho_{l} u_{l}(1-\alpha) A(x)\right)}{\partial t}=-\frac{\partial\left(\rho_{l} u_{l}^{2}(1-\alpha) A(x)\right)}{\partial x}-\tau_{l w} P_{l w}-\tau_{g i} P_{g i} \\
-(1-\alpha) A(x) \frac{\partial P_{l}}{\partial x}+\Gamma_{l} A(x)\left[u_{k}\right]
\end{gathered}
$$

Steam phase:

$$
\begin{gathered}
\frac{\partial\left(\rho_{g} u_{g} \alpha A(x)\right)}{\partial t}=-\frac{\partial\left(\rho_{g} u_{g}{ }^{2} \alpha A(x)\right)}{\partial x}-\tau_{g w} P_{g w}-\tau_{g i} P_{g i}-\alpha A(x) \frac{\partial P_{g}}{\partial x} \\
+\Gamma_{g} A(x)\left[u_{k}\right]
\end{gathered}
$$

ENERGY CONSERVATION EQUATIONS 
Liquid phase:

$$
\begin{gathered}
\frac{\partial}{\partial t}\left(\rho_{l} e_{a l}(1-\alpha) A(x)\right)=\frac{-\partial}{\partial x}\left(\rho_{l} u_{l} e_{a l}(1-\alpha) A(x)\right)-P_{l} \frac{\partial}{\partial x}\left(u_{l}(1-\alpha) A(x)\right) \\
+\dot{q}_{l w}^{\prime}+\dot{q}_{l i}^{\prime}-P_{l} \frac{\partial((1-\alpha) A(x))}{\partial t}+\Gamma_{l} A(x) h_{l i}
\end{gathered}
$$

Steam phase:

$$
\begin{aligned}
\frac{\partial}{\partial t}\left(\rho_{g} e_{a g} \alpha A(x)\right)=- & \frac{\partial}{\partial x}\left(\rho_{g} u_{g} e_{a g} \alpha A(x)\right)-P_{g} \frac{\partial}{\partial x}\left(u_{g} \alpha A(x)\right)+\dot{q}_{g w}^{\prime}+\dot{q}_{g i}^{\prime} \\
& -P_{g} \frac{\partial(\alpha A(x))}{\partial t}+\Gamma_{g} A(x) h_{g i}
\end{aligned}
$$

\subsection{DISCRETIZATION OF THE EQUATIONS}

Once we have obtained the differential equations for our problem, they have been discretized in order to transform them from a differential equation into an algebraic equation whose unknown variables in our case are: $u_{l}, u_{g}, P_{l}, P_{g}, T_{l}, T_{g}$.

We might say at this point that we will have two different systems of equations, one for each phase, with three equations (mass, momentum and energy), for each one. They will be solved separately and they are coupled through the interfacial heat, the condensate mass and the interfacial friction.

The discretization of the differential equations can be made by two methods; explicit and implicit. In the explicit methods the value of the unknown variables matrix at the new time step are calculated from the variables at the previous time step. The advantage of this method is that the solution is obtained with a minimum number of arithmetic operations at each time step. However this advantage is affected by the stability and convergence conditions which impose severe restrictions to the maximum time step to choose.

The implicit methods normally have pentadiagonal, tridiagonal or bidiagonal unknown variables matrices. As we will later see, the $\mathrm{CC}$ code solves a tridiagonal matrix. The advantage of this type of discretization method is that it has no time step limitation. 
In our CC model we will solve the mass and energy equations with an implicit method and the momentum equation with a semi-implicit one. We will do a velocity correction by the pressure variations, so the method to solve the problem in semi-implicit and its main restriction is the courant limit:

$$
\text { Courant }=\frac{u \Delta t}{\Delta x} \leq 1
$$

In order to discretize the equations a finite control volume has been used. This technique was introduced by Mc Donald in 1971 and Mc Cormack and Paullay in 1972 in order to solve the Euler equations. In this technique the conservation equations are directly discretized in a determined physical space. Figure 4.7 shows the finite volume used in the discretization. Now we will describe the grid made for the discretization.

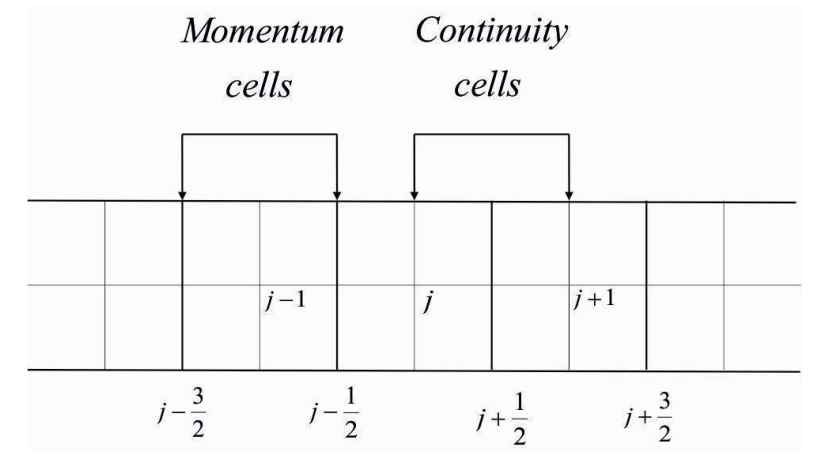

Figure 4.7 Grid for the problem

\subsubsection{GRID DESCRIPTION}

The space domain has been divided in small parts shown in Figure 4.6 (continuous lines). Those domains are the ones where the conservation equations are discretized, and the variable values are calculated in the centre of them. The velocities are calculated at the faces of the cells. This is the reason why it is needed to construct an auxiliary grid and to displace it from the other (the discontinuous lines). So we have one grid for the mass and energy equations (continuity cells) and another for the momentum equation (momentum cells). 


\subsubsection{DISCRETIZATION OF THE MASS CONSERVATION EQUATION}

To discretize the mass conservation equation we integrate the Equation (4.38) in the volume $\Delta V_{k}$ shown in Figure 4.3. We must remark that when discretizing all the gas and liquid areas i.e. $A_{g}=\alpha A$ and $A_{l}=(1-\alpha) A$, both the continuity cell and the momentum cell ones are discretized explicitly.

Steam phase:

We integrate the steam mass conservation equation with respect to the time between the time steps $t$ and $t+\Delta t$, and it is also integrated with respect to the $\mathrm{X}$ coordinate that represents the length of the continuity cell, between the coordinates $X_{j-1 / 2}$ and $X_{j+1 / 2}$.

$$
\int_{t}^{t+\Delta t} \int_{j-1 / 2}^{j+1 / 2} \frac{\partial\left(\rho_{g} \alpha A(x)\right)}{\partial t} d t d x+\int_{t}^{t+\Delta t} \int_{j-1 / 2} \frac{\partial}{\partial x}\left(\rho_{g} \alpha A(x) u_{g}\right) d t d x=\int_{t}^{t+\Delta t} \int_{j-1 / 2}^{j+1 / 2} \Gamma_{g} A(x) d t d x
$$

The superscripts $t$ and $t+\Delta t$ indicate that the variables are calculated at the time steps $t$ and $t+\Delta t$ respectively.

Let's analyze each term separately:

For this first term we assume that the variables $\rho_{g}$ and $A_{g}$, are at the control volume we are integrating, constant and equal to the value in the centre of the continuity cell. The area is supposed as constant for the considered time step, so, it appears as a constant, and its value is updated at the end of each time step. This assumption for the value of the area will also be made in all the further integrations.

$$
\int_{t}^{t+\Delta t} \int_{j-1 / 2}^{j+1 / 2} \frac{\partial\left(\rho_{g} A_{g}(x)\right)}{\partial t} d t d x=\int_{t}^{t+\Delta t} \frac{\partial\left(\rho_{g} A_{g}\right)_{j}}{\partial t} \Delta x d t=\left[\left(\rho_{g}\right)_{j}^{t+\Delta t}-\left(\rho_{g}\right)_{j}^{t}\right] A_{g_{j}}{ }_{j}^{t} \Delta x
$$


In this second term, we have the convective fluxes at the faces of the continuity cell.

So we notice that we need to evaluate the value of $\rho_{g}, A_{g}$ and $u_{g}$ at the faces of the cell.

The convective term when it is discretized yields:

$$
\int_{t}^{t+\Delta t} \int_{j-1 / 2}^{j+1 / 2} \frac{\partial}{\partial x}\left(\rho_{g} u_{g} A_{g}(x)\right) d t d x=\left[\left(\left(\rho_{g} A_{g}\right)^{t} u_{g}{ }^{t+\Delta t}\right)_{j+1 / 2}-\left(\left(\rho_{g} A_{g}\right)^{t} u_{g}{ }^{t+\Delta t}\right)_{j-1 / 2}\right] \Delta t
$$

Now we are going to integrate the condensation rate term. We suppose the condensation rate as constant in all the cell and equal to the value at the centre of it. We have the same for the value of the interfacial perimeter.

One thing that we must notice here is that the condensation term is discretized implicitly. For the semi-implicit resolution of the momentum conservation equation as we will see at sections 5.2 and 5.4 for the liquid and the steam phases respectively, the condensation term is considered as explicit, otherwise we couldn't have cleared up the corresponding velocity at $\mathrm{t}+\Delta \mathrm{t}$.

$$
\int_{t}^{t+\Delta t} \int_{j-1 / 2}^{j+1 / 2} \Gamma_{g} A(x) d t d x=\Phi_{g}{ }_{j}^{t+\Delta t}
$$

Finally we get the following algebraic expression:

$$
\begin{array}{r}
{\left[\left(\rho_{g}\right)_{j}^{t+\Delta t}-\left(\rho_{g}\right)_{j}^{t}\right] A_{g_{j}}{ }_{j} \Delta x=-\left[\left(\left(\rho_{g} A_{g}\right)^{t} u_{g}{ }^{t+\Delta t}\right)_{j+1 / 2}-\left(\left(\rho_{g} A_{g}\right)^{t} u_{g}{ }^{t+\Delta t}\right)_{j-1 / 2}\right] \Delta t} \\
+\Phi_{g_{j}}{ }^{t+\Delta t}
\end{array}
$$

Liquid phase:

Analogously for the liquid phase, we get:

$$
\begin{aligned}
\left\lfloor\left(\rho_{l}\right)_{j}^{t+\Delta t}-\left(\rho_{l}\right)_{j}^{t}\right\rfloor A_{l j}^{t} \Delta x=-\left\lfloor\left(\left(\rho_{l} A_{l}\right)^{t} u_{l}^{t+\Delta t}\right)_{j+1 / 2}-\left(\left(\rho_{l} A_{l}\right)^{t} u_{l}{ }^{t+\Delta t}\right)_{j-1 / 2}\right\rfloor \Delta t & \\
& +\Phi_{l j}{ }^{t+\Delta t}
\end{aligned}
$$




\subsubsection{DISCRETIZATION OF THE MOMENTUM CONSERVATION EQUATION}

The momentum equation is integrated similarly to the mass equation one, but we must observe that the momentum cell is displaced with respect to the continuity one. So what we have is that the limits of this cell will be $j$ and $j+1$.

Steam phase:

We integrate the steam momentum conservation equation with respect to the time between the steps $t$ and $t+\Delta t$, and it is also integrated with respect to the $\mathrm{X}$ coordinate that represents the length of the momentum cell between the nodes $X_{j}$ and $X_{j-1}$.

$$
\begin{aligned}
\int_{t}^{t+\Delta t} \int_{j-1}^{j} \frac{\partial\left(\rho_{g} u_{g} \alpha A(x)\right)}{\partial t} d t d x=\int_{t}^{t+\Delta t} \int_{j-1}^{j} & {\left[-\frac{\left(\rho_{g} u_{g}{ }^{2} \alpha A(x)\right)}{\partial x}-\tau_{g w} P_{g w}-\tau_{g i} P_{g i}\right.} \\
& \left.-\alpha A(x) \frac{\partial P_{g}}{\partial x}+\Gamma_{g} A(x)\left[u_{k}\right]\right] d t d x
\end{aligned}
$$

Let's analyze each term separately:

When discretizing the rate of momentum change, we estimate the value of the variables $\rho_{g}, u_{g}, A_{g}$ as constant in the considered control volume, and equal to the value at the centre of the momentum cell.

$$
\int_{t}^{t+\Delta t} \int_{j-1}^{j} \frac{\partial}{\partial t}\left(\rho_{g} u_{g} A_{g}\right) d t d x=\left[\left(\rho_{g} u_{g} A_{g}\right)_{j-1 / 2}^{t+\Delta t}-\left(\rho_{g} u_{g} A_{g}\right)_{j-1 / 2}^{t+\Delta t}\right] \Delta x
$$

For the convective momentum through the faces of the momentum cell, we get the values at $j$ and $j+1$ as follows:

$$
\int_{t}^{t+\Delta t} \int_{j-1}^{j}-\frac{\partial}{\partial x}\left(\rho_{g} u_{g}^{2} A_{g}\right) d t d x=-\left[\left(\rho_{g} u_{g}^{2} A_{g}\right)_{j}^{t}-\left(\rho_{g} u_{g}^{2} A_{g}\right)_{j-1}^{t}\right] \Delta t
$$


Now we integrate the viscous shear stress at the wall and at the interface. We consider the friction factor and the perimeter as constant in the momentum cell and equal to the value at $j-1 / 2$.

$$
\begin{aligned}
& \int_{t}^{t+\Delta t} \int_{j-1}^{j} \tau_{g w} P_{g w} d t d x=\frac{1}{2}\left(\rho_{g} P_{g w} f_{g w}\right)_{j-1 / 2}^{t} u_{g_{j-1 / 2}}{ }^{t+\Delta t}\left|u_{g_{j-1 / 2}}{ }^{t}\right| \Delta x \Delta t \\
& \int_{t}^{t+\Delta t} \int_{j-1}^{j} \tau_{g i} P_{g i} d t d x=\left(\frac{1}{2} \rho_{g}\left(u_{g_{j-1 / 2}}-u_{l j-1 / 2}\right)\left|u_{g_{j-1 / 2}}-u_{l j-1 / 2}\right| P_{\text {int erf }} f_{l i}\right)_{j-1 / 2}^{t} \Delta x \Delta t
\end{aligned}
$$

We have to make a distinction here. The momentum interchange between phases depends on the relative velocity.

In our main case, in which we are trying to study the countercurrent flow, the steam flows countercurrently to the liquid, and for solving the equations, we consider the liquid velocity in the downstream direction to be positive, and when solving the steam equations we consider the steam velocity to be positive too in the downstream direction for the steam, which is, opposite to the liquid downstream direction. So, the contribution to the steam momentum by the liquid is:

$$
\int_{t}^{t+\Delta t} \int_{j-1}^{j} \tau_{g i} P_{g i} d t d x=\left(\frac{1}{2} \rho_{g}\left(u_{l_{j-1 / 2}}-u_{g_{j-1 / 2}}\right)\left|u_{l_{j-1 / 2}}-u_{g_{j-1 / 2}}\right| P_{\text {int erf }} f_{l i}\right)_{j-1 / 2}^{t} \Delta x \Delta t
$$

This term diminishes the amount of countercurrent flow momentum of the steam.

When flowing cocurrently, the steam condensation adds momentum to the liquid phase, and when flowing countercurrently, the steam condensation takes momentum from the liquid.

Now we have the pressure gradient term. As we are integrating in the momentum cell, we get the pressure difference between $j$ and $j-1$. 
$\int_{t}^{t+\Delta t} \int_{j-1}^{j}-\frac{\partial P_{g}}{\partial x} A_{g}(x) d t d x=-\left(P_{g_{j}}-P_{g_{j-1}}\right)^{t} A_{g_{j-1 / 2}} \Delta t$

We can see that the pressure gradient is discretized explicitly, because the momentum equation is solved with a semi-implicit method.

The last term is the integration of the momentum change due to the interfacial condensation. We have the value of the condensation rate at the centre of the cell, so, at $j-1 / 2$;

$$
\int_{t}^{t+\Delta t} \int_{j-1}^{j} \Gamma_{g} A(x)\left[u_{k}\right] d t d x=\Phi_{g_{j-1 / 2}}^{t+\Delta t} u_{g_{j-1 / 2}}^{t}
$$

We substituted $\left[u_{k}\right]$ by $u_{g}$ since we are assuming here that condensation is taking place. In this case $\Gamma_{g}\left[u_{k}\right]=\Gamma_{g} u_{g}$ with $\Gamma_{g}<0$ and $u_{g}<0$.

Here we have the term $\Phi_{g}$, which is negative as we will see in Appendix B. As the steam velocity is negative in the $\mathrm{x}$ direction, the whole term is positive what means that the steam condensation takes negative momentum from the steam.

Finally we get the following algebraic expression:

$$
\begin{aligned}
& {\left[\left(\rho_{g} u_{g} A_{g}\right)_{j-1 / 2}^{t+\Delta t}-\left(\rho_{g} u_{g} A_{g}\right)_{j-1 / 2}^{t}\right] \Delta x=-\left[\left(\rho_{g} u_{g}{ }^{2} A_{g}\right)_{j}^{t}-\left(\rho_{g} u_{g}{ }^{2} A_{g}\right)_{j-1}^{t}\right] \Delta t} \\
& -\frac{1}{2}\left(\rho_{g} P_{g w} f_{g w}\right)_{j-1 / 2}^{t} u_{g_{j-1 / 2}}+\Delta t u_{g_{j-1 / 2}} \mid \Delta x \Delta t \\
& \left(\frac{1}{2} \rho_{g}\left(u_{g_{j-1 / 2}}-u_{l j-1 / 2}\right)\left|u_{g_{j-1 / 2}}-u_{l j-1 / 2}\right| P_{\text {int erf }} f_{g i}\right)_{j-1 / 2}^{t} \Delta x \Delta t-\left(P_{g_{j}}-P_{g_{j-1}}\right)^{t} A_{g_{j-1 / 2}}^{t} \Delta t \\
& +\Phi_{g_{j-1 / 2}}{ }^{t+\Delta t} u_{g_{j-1 / 2}}
\end{aligned}
$$

Liquid phase:

Analogously for the liquid phase, we get: 


$$
\begin{gathered}
{\left[\left(\rho_{l} u_{l} A_{l}\right)_{j-1 / 2}^{t+\Delta t}-\left(\rho_{l} u_{l} A_{l}\right)_{j-1 / 2}^{t}\right] \Delta x=-\left[\left(\rho_{l} u_{l}^{2} A_{l}\right)_{j}^{t}-\left(\rho_{l} u_{l}^{2} A_{l}\right)_{j-1}^{t}\right] \Delta t} \\
-\left[\frac{1}{2}\left(\rho_{l} P_{l w} f_{l w}\right)_{j-1 / 2}^{t} u_{l j-1 / 2}^{t+\Delta t}\left|u_{l j-1 / 2}^{t}\right|\right] \Delta x \Delta t \\
-\left[\left(\frac{1}{2} \rho_{g}\left(u_{l j-1 / 2}-u_{g}{ }_{j-1 / 2}\right)\left|u_{l j-1 / 2}-u_{g j-1 / 2}\right| P_{\text {int } e r f} f_{l i}\right)_{j-1 / 2}^{t}\right] \Delta x \Delta t \\
\quad-\left(P_{l_{j}}-P_{l j-1}\right)^{t} A_{l j-1 / 2}^{t} \Delta t+\Phi_{l j-1 / 2}^{t+\Delta t} u_{g_{j-1 / 2}}^{t}
\end{gathered}
$$

We must note here that, in the interfacial momentum term for the liquid phase, we have here the steam density. This is because this term has to be the same one for both phases, and actuating as opposed to the corresponding phase flow.

\subsubsection{DISCRETIZATION OF THE ENERGY EQUATION}

To discretize the energy conservation equation we integrate Equations (4.52) and (4.53) in the volume $\Delta V_{k}$ shown in Figure 4.5. The cell in which we integrate these equations is the continuity cell.

\section{Steam phase:}

We integrate the steam energy conservation equation with respect to the time between the steps $t$ and $t+\Delta t$, and it is also integrated with respect to the $\mathrm{X}$ coordinate that represents the length of the continuity cell between the nodes $X_{j-1 / 2}$ and $X_{j+1 / 2}$.

$$
\begin{aligned}
\int_{t}^{t+\Delta t} \int_{j-1 / 2}^{j+1 / 2} \frac{\partial}{\partial t}\left(\rho_{g} e_{a g} \alpha A(x)\right) d x d t & =\int_{t}^{t+\Delta t} \int_{j-1 / 2}^{j+1 / 2}\left[\frac{-\partial}{\partial x}\left(\rho_{g} u_{g} e_{a g} \alpha A(x)\right)-P_{g} \frac{\partial}{\partial x}\left(u_{g} \alpha A(x)\right)\right. \\
& \left.-P_{g w} \dot{q}_{g w}^{\prime}-P_{g i} \dot{q}_{g i}^{\prime}-P_{g} \frac{\partial(\alpha A(x))}{\partial t}+\Gamma_{g} A(x) h_{g i}\right] d x d t
\end{aligned}
$$

So we get: 
Now we will analyze each term separately:

In the first term we suppose that the values of the variables $\rho_{g}, e_{a g}$ and $A_{g}$ are constant and equal to the value at the centre of the cell in the considered control volume:

$$
\int_{t}^{t+\Delta t} \int_{j-1 / 2}^{j+1 / 2} \frac{\partial}{\partial t}\left(\rho_{g} e_{a g} \alpha A(x)\right) d x d t=\left[\left(\rho_{g} e_{a g}\right)_{j}^{t+\Delta t}-\left(\rho_{g} e_{a g}\right)_{j}^{t}\right] A_{g_{j}}{ }_{j} \Delta x
$$

The convective term is discretized semi-implicitly as we can see below:

$$
\begin{aligned}
\int_{t}^{t+\Delta t} \int_{j-1 / 2}^{j+1 / 2}-\frac{\partial}{\partial x}\left(\rho_{g} u_{g} e_{a g} \alpha\right. & A(x)) d x d t= \\
- & {\left[\left(\left(\rho_{g} e_{a g} A_{g}\right)^{t} u_{g}{ }^{t+\Delta t}\right)_{j+1 / 2}-\left(\left(\rho_{g} e_{a g} A_{g}\right)^{t} u_{g}{ }^{t+\Delta t}\right)_{j-1 / 2}\right] \Delta t }
\end{aligned}
$$

The following term represents the time variation of the steam expansion in the continuity volume. We integrate it implicitly:

$$
\int_{t}^{t+\Delta t} \int_{j-1 / 2}^{j+1 / 2}-P_{g} \frac{\partial}{\partial x}\left(u_{g} \alpha A(x)\right) d x d t=-P_{g_{j}}{ }^{t+\Delta t}\left[\left(u_{g}{ }^{t+\Delta t} A_{g}{ }^{t}\right)_{j+1 / 2}-\left(u_{g}{ }^{t+\Delta t} A_{g}{ }^{t}\right)_{j-1 / 2}\right] \Delta t
$$

Now we will discretize the heat transfer to the wall and the interfacial one. As we see we will integrate these terms implicitly:

$$
\begin{aligned}
& \int_{t}^{t+\Delta t} \int_{j-1 / 2} P_{g w} q_{g w}^{\prime \prime+1 / 2} d x d t=\left(q_{g w}^{\prime \prime}\right)_{j}^{t+\Delta t} A_{g w}{ }_{j}^{t} \Delta t=\left(Q_{g w}\right)_{j}^{t+\Delta t} \\
& \int_{t}^{t+\Delta t} \int_{j-1 / 2}^{j+1 / 2} P_{g i} q_{g i}^{\prime \prime} d x d t=\left(q_{g i}^{\prime \prime}\right)_{j}^{t+\Delta t} A_{g i}{ }_{j}{ }_{j} \Delta t=\left(Q_{g i}\right)_{j}^{t+\Delta t}
\end{aligned}
$$

We will discretize now the energy loss term due to the condensation, so, because of the phase change of the steam:

$$
\int_{t}^{t+\Delta t} \int_{j-1 / 2}^{j+1 / 2} \Gamma_{g} A(x) h_{g} d x d t=\left(\Phi_{g}\right)_{j}^{t+\Delta t} h_{g_{j}}{ }^{t+\Delta t}
$$


The last term is the change of the steam energy due to the change of the volume. As the variation of the liquid or steam volume does not vary very much for one time step in the countercurrent cases that we are studying, this term is equaled to zero

The value of the areas and the rest of geometrical variables will be updated at the end of each time step.

In the case of a big increase of the liquid area as in the case of having a HPI (high pressure injection) in the middle of the pipe, as in the test 1.2 of the ROSA facility, we cannot make this term zero, and we have to take into account the area as another unknown variable in the iterative process.

$$
\int_{t}^{t+\Delta t} \int_{j-1 / 2}^{j+1 / 2}-P_{g} \frac{\partial}{\partial t}(\alpha A(x)) d x d t=P_{g_{j}}{ }^{t+\Delta t}\left(A_{g_{j}}{ }^{t+\Delta t}-A_{g_{j}}{ }^{t}\right) \Delta x=0
$$

Finally we get the following algebraic expression:

$$
\begin{aligned}
& {\left[\left(\rho_{g} e_{a g}\right)_{j}^{t+\Delta t}-\left(\rho_{g} e_{a g}\right)_{j}^{t}\right] A_{g}{ }_{j}^{t} \Delta x} \\
& +\left[\left(\left(\rho_{g} e_{a g} A_{g}\right)^{t} u_{g}{ }^{t+\Delta t}\right)_{j+1 / 2}-\left(\left(\rho_{g} e_{a g} A_{g}\right)^{t} u_{g}{ }^{t+\Delta t}\right)_{j-1 / 2}\right] \Delta t \\
& \quad+P_{g j}{ }^{t+\Delta t}\left[\left(u_{g}{ }^{t+\Delta t} A_{g}{ }^{t}\right)_{j+1 / 2}-\left(u_{g}{ }^{t+\Delta t} A_{g}{ }^{t}\right)_{j-1 / 2}\right] \Delta t-\left(Q_{g i}\right)_{j}^{t+\Delta t}-\left(Q_{g w}\right)_{j}^{t+\Delta t}=\left(\Phi_{g}\right)_{j}^{t+\Delta t} h_{g}{ }_{j}{ }^{t+\Delta t}
\end{aligned}
$$

\section{Liquid phase:}

Analogously for the liquid phase, we get:

$$
\begin{aligned}
& {\left[\left(\rho_{l} e_{a l}\right)_{j}^{t+\Delta t}-\left(\rho_{l} e_{a l}\right)_{j}^{t}\right] A_{l j}^{t} \Delta x} \\
& +\left[\left(\left(\rho_{l} e_{a l} A_{l}\right)^{t} u_{l}{ }^{t+\Delta t}\right)_{j+1 / 2}-\left(\left(\rho_{l} e_{a l} A_{l}\right)^{t} u_{l}{ }^{t+\Delta t}\right)_{j-1 / 2}\right] \Delta t \\
& +P_{l j}^{t+\Delta t}\left[\left(u_{l}{ }^{t+\Delta t} A_{l}{ }^{t}\right)_{j+1 / 2}-\left(u_{l}{ }^{t+\Delta t} A_{l}{ }^{t}\right)_{j-1 / 2}\right] \Delta t-\left(Q_{l i}\right)_{j}^{t+\Delta t}-\left(Q_{l w}\right)_{j}^{t+\Delta t}=\left(\Phi_{l}\right)_{j}^{t+\Delta t} h_{g_{j}}{ }^{t+\Delta t}
\end{aligned}
$$




\subsection{CLOSURE OR CONSTITUTIVE EQUATIONS}

As we saw before, the general conservation equations are those called local and instantaneous conservation equations. Due to the fact that the contour between phases changes with time, we necessarily have to do a time and space averaging in order to obtain the final 1D equations that we will use. In this thesis we necessarily will lose information that has to be compensated with additional relations at the contours of the phases so as on the inside. Those relations are called closure or constitutive relations and they naturally appear in multi-phase flows theory.

The main constitutive relations in our $\mathrm{CC}$ model are the interfacial heat transfer, the interfacial mass transfer and the interfacial friction.

\subsubsection{INTERFACIAL AND WALL FRICTION}

We will firstly define the expressions for the wall viscous shear stress for both phases, and the viscous shear stress for the interface with the liquid and steam phases. In order to have the proper signs for the interface with these equations we set:

$$
\begin{gathered}
\tau_{g w}=\frac{1}{2} \rho_{g} u_{g}\left|u_{g}\right| f_{g w}, \tau_{l w}=\frac{1}{2} \rho_{l} u_{l}\left|u_{l}\right| f_{l w} \\
\tau_{g i}=\frac{1}{2} \rho_{g i}\left(u_{g}-u_{l}\right)\left|u_{g}-u_{l}\right| f_{g i} \\
\tau_{g i}=-\tau_{l i}
\end{gathered}
$$

In order to evaluate those expressions when discretizing the momentum equation, we need the value for the friction factor coefficients for each phase and the interface. The discretized viscous shear stresses are:

$$
\vec{\tau}_{g w j-1 / 2}=-\tau_{g w j-1 / 2} \hat{e}_{x}=-\frac{1}{2}\left(\rho_{g} f_{g w}\right)_{j-1 / 2}^{t} u_{g_{j-1 / 2}}{ }^{t+\Delta t}\left|u_{g_{j-1 / 2}}{ }^{t}\right| \hat{e}_{x}
$$

We can observe in Figure 4.7 that the steam shear stress with the wall is positive in $\mathrm{x}$ direction, and since the steam is flowing countercurrently, it will take momentum from the steam as it flows downstream. 


$$
\vec{\tau}_{l w j-1 / 2}=-\tau_{l w j-1 / 2} \hat{e}_{x}=-\frac{1}{2}\left(\rho_{l} f_{l w}\right)_{j-1 / 2}^{t} u_{l j-1 / 2}^{t+\Delta t}\left|u_{l j-1 / 2}^{t}\right| \hat{e}_{x}
$$

We can observe in Figure 4.7 that the liquid shear stress with the wall is negative in $\mathrm{x}$ direction, and since the liquid is flowing to the $\mathrm{x}$ direction, hence, it will take momentum from the liquid as it flows downstream.

$$
\vec{\tau}_{g i j-1 / 2}=-\tau_{g i j-1 / 2} \hat{e}_{x}=-\frac{1}{2}\left(\rho_{g} f_{g i}\right)_{j-1 / 2}^{t}\left(u_{g_{j-1 / 2}}-u_{j j-1 / 2}\right)\left|u_{g_{j-1 / 2}}-u_{l j-1 / 2}\right| \hat{e}_{x}
$$

We can observe in Figure 4.7 that the steam interfacial shear stress is positive in $\mathrm{x}$ direction, and since the steam is flowing countercurrently, it will take momentum from the steam as it flows downstream.

$$
\vec{\tau}_{l i j-1 / 2}=-\tau_{l i j-1 / 2} \hat{e}_{x}=-\frac{1}{2}\left(\rho_{g} f_{g i}\right)_{j-1 / 2}^{t}\left(u_{l_{j-1 / 2}}-u_{g_{j-1 / 2}}\right)\left|u_{l j-1 / 2}-u_{g_{j-1 / 2}}\right| \hat{e}_{x}(4.9
$$

We can observe in Figure 4.8 that the liquid interfacial shear stress is negative in $\mathrm{x}$ direction, and since the liquid is flowing with the $\mathrm{x}$ direction, hence, it will take momentum from the liquid as it flows downstream.

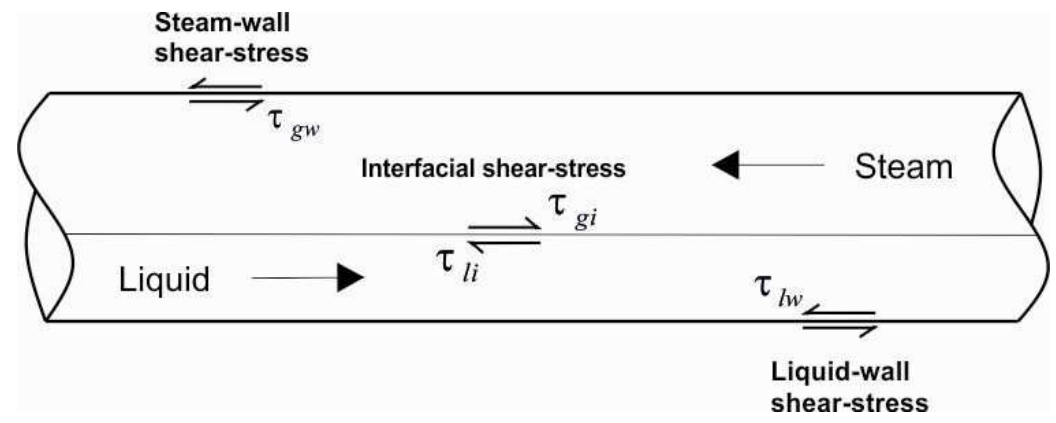

Figure 4.8 Scheme o the shear stresses for the liquid and for the steam 
We can find several different definitions of the friction factor. We will use the most commons, which use the Reynolds number. So we can have two different expressions depending on the Reynolds value, and hence, the flow regime:

\section{Wall friction factor:}

For laminar regime we will use:

$$
f_{k w}=\frac{64}{\operatorname{Re}_{k}} \quad \operatorname{Re}_{k}<2300
$$

If we have a turbulent regime flow, we use the Blasius [1] equation:

$$
f_{k w}=0.079 \operatorname{Re}_{k}^{-0.25} \quad \operatorname{Re}_{k}>2300
$$

Interfacial friction factor:

For the interfacial friction factor we will use, among the correlations we can find in the literature, the Kim et al. 1985 [38] correlation:

$$
f_{k i}=0.14 \cdot 10^{-5} \operatorname{Re}{ }_{L}+0.021
$$

This correlation was developed specifically for steam-water countercurrent flow in a duct. This friction factor is obtained from pressure losses, and hence, the corresponding fanning friction factor in order to obtain the interfacial shear stress is:

$$
f_{k i}=\frac{0.14 \cdot 10^{-5} \operatorname{Re}{ }_{L}+0.021}{4}
$$

\subsubsection{STEAM MASS CONDENSATION}

In the $\mathrm{CC}$ code there has been simulated as the interfacial condensation as the steam condensation at the steam wall.

We define $\Phi_{g}$ as the condensation mass for one cell and one time step $(\mathrm{Kg})$. 


$$
\Phi_{g}(K g)=\Gamma_{g}\left(\frac{K g}{s m^{3}}\right) A\left(m^{2}\right) \Delta x(m) \Delta t\left(s_{g}\right)
$$

From now on, we will express with the term $\Phi_{g}$ the condensation at the liquid-steam interface, and the condensation at the wall, i.e.:

$$
\Phi_{g}=\Phi_{i g}+\Phi_{\text {gwall }}
$$

\subsubsection{INTERFACIAL CONDENSATION}

As it was deduced by making an energy balance at the interface, the mass transfer between phases will be calculated and implemented as can be seen in the following equation:

$$
\begin{gathered}
\Phi_{i g}\left(K_{g}\right)=-\frac{Q_{l i}+Q_{g i}}{h_{g i}-h_{l i}} \\
\Phi_{i g}=-\Phi_{i l}
\end{gathered}
$$

where $Q_{l i}, Q_{g i}$ are the heat transfer $(J)$ interchanged with the interface, for the liquid $\left(Q_{l i}\right)$, and for the steam $\left(Q_{g i}\right)$ during one time step inside one cell, $h_{g i}$ is the steam enthalpy ( $J / K g)$ and $h_{l i}$ is the saturated liquid enthalpy ( $J / K g$ ).

Here we can observe as the interfacial condensation during one time step is inversely proportional to the latent heat, this is, to the released heat when phase changes from steam to liquid, and directly proportional to the heat transferred between phases.

In order to calculate this interfacial heat transfer, we consider an interface between phases, which we consider to be at the saturated temperature at the steam pressure. So, the steam and the liquid interchange heat with this interface at the saturation temperature.

$$
Q_{l i}(J)=\dot{q}_{l i}^{\prime \prime}\left(\frac{J}{s m^{2}}\right) A_{I}\left(m^{2}\right) \Delta t\left(s_{g}\right)
$$




$$
Q_{g i}(J)=\dot{q}_{g i}^{\prime \prime}\left(\frac{J}{s m^{2}}\right) A_{I}\left(m^{2}\right) \Delta t\left(s_{g}\right)
$$

Therefore, when discretizing, the term $\Phi_{i g}$ it is calculated to give us the interchanged mass between phases in $\mathrm{Kg}$.

In Appendix D, it is explained the calculation of the mass condensation at the interface and its derivatives, which will be needed, to solve the system of equations (mass and energy) which is explained in Chapter 5.

\subsubsection{STEAM WALL CONDENSATION}

In Appendix E it is explained with more detail how it has been calculated the condensation at the pipe wall.

However, the steam mass condensation at the wall is directly proportional to the interchanged heat with the wall, and inversely proportional to the latent heat.

$$
\Phi_{\text {gwall }}\left(K_{g}\right)=\frac{Q_{g w}}{h_{g i}-h_{l i}}
$$

where $Q_{g w}$ is the heat interchanged ( $J$ ) with the pipe wall, $h_{g i}$ is the steam enthalpy $(\mathrm{J} / \mathrm{Kg})$ and $\mathrm{h}_{\mathrm{li}}$ is the saturated liquid enthalpy $(\mathrm{J} / \mathrm{Kg})$.

$$
Q_{g w}(J)=P_{\text {int erf }} \Delta x \Delta t \bar{h}\left(T_{w v}-T_{\text {satv }}\right)
$$

where $T_{\text {satv }}$ is the saturation temperature at the steam pressure, and $T_{w v}$ is the wall

temperature, $\bar{h}$ is the condensation heat transfer coefficient at the pipe walls explained in Appendix C.

\subsubsection{INTERFACIAL HEAT TRANSFER}

When solving the equations system, we need the interfacial heat transfer to evaluate the coefficients of the matrix to be solved. We also need the derivatives of the heat transfer with respect to the pressure, temperature and the pressure differences for each phase. 
As we saw in the previous point, we have two interfacial heat transfers. One represents the heat interchange between the interface and the steam bulk, and another between the interface and the liquid bulk.

The expression for the liquid interfacial heat transfer is as follows:

$$
Q_{l i}=A_{i} h_{l \text { int }}\left(T_{\text {sati }}-T_{l}\right) \Delta t(\mathrm{~J})
$$

The expression for the steam interfacial heat transfer is as follows:

$$
Q_{g i}=A_{i} h_{g \text { int }}\left(T_{\text {sati }}-T_{g}\right) \Delta t(\mathrm{~J})
$$

$T_{g}$ is the steam temperature $(\mathrm{K})$ at the corresponding pressure, $T_{l}$ the liquid temperature ( $K$ ) in the centre of the node, $T_{\text {sati }}$ is the interface temperature which is saturated at the steam pressure.

Different correlations will be used for calculating the interfacial heat transfer for the liquid and the steam.

The well known Dittus-Boelter correlation [112] willl be used for calculating the heat transfer from the steam to the interface as a turbulent flow and a forced convection heat transfer mode for the steam is supposed:

$$
\mathrm{h}_{\text {gint }}=\frac{\mathrm{K}_{\mathrm{g}}}{\mathrm{D}_{\mathrm{hg}}} \mathrm{Nu}_{\mathrm{gint}}=\frac{\mathrm{K}_{\mathrm{g}}}{\mathrm{D}_{\mathrm{hg}}} 0.023 \operatorname{Re}_{\mathrm{g}}{ }^{0.8} \operatorname{Pr}_{\mathrm{g}}{ }^{0.4}
$$

Different correlations will be used for calculating the heat transfer from the liquid to the interface, which have the following pattern:

$$
\mathrm{h}_{\text {lint }}=\frac{\mathrm{K}_{1}}{\mathrm{D}_{\mathrm{hl}}} \mathrm{Nu}_{\text {lint }}=\frac{\mathrm{K}_{1}}{\mathrm{D}_{\mathrm{hl}}} \mathrm{c}_{1} \operatorname{Re}_{1}{ }^{\mathrm{c}_{2}} \operatorname{Re}_{\mathrm{g}}{ }^{\mathrm{c}_{3}} \mathrm{Ja}^{\mathrm{c}_{4}} \operatorname{Pr}_{1}{ }^{\mathrm{c}_{5}}
$$

where $h_{\text {int }}$ is the liquid interfacial heat transfer coefficient $\left(\mathrm{W} /{ }^{\circ} \mathrm{Km}^{2}\right), h_{g \text { int }}$ is the steam interfacial heat transfer coefficient $\left(\mathrm{W} /{ }^{\circ} \mathrm{Km}^{2}\right), \mathrm{K}_{\mathrm{l}}$ is the liquid conductivity $\left(\mathrm{W} /{ }^{\mathrm{o}} \mathrm{Km}^{2}\right.$ ), $\mathrm{K}_{\mathrm{g}}$ is the conductivity of the steam $\left(\mathrm{W} /{ }^{\circ} \mathrm{Km}\right), \mathrm{Dh}_{1}$ is the liquid hydraulic diameter $(m)$, $\mathrm{Dh}_{\mathrm{g}}$ is the steam hydraulic diameter $(m)$, Re is the Reynolds number, Ja is the Jakob number, and Pr is Prandtl number. 
For the interfacial heat transfer from the liquid to the interface, we can use different correlations, where $\mathrm{c} 1, \mathrm{c} 2, \mathrm{c} 3, \mathrm{c} 4, \mathrm{c} 5$, are different constants which change depending on the flow regime we are studying, the pipe inclination, etc.

We show the definitions for these dimensionless numbers below:

$$
\begin{array}{ll}
\operatorname{Re}_{k}=\left(\frac{\rho_{k} u_{k} D_{h k}}{\mu_{k}}\right), & \text { for each k phase } \\
J a=\left(\frac{C p_{l} \rho_{l}\left(T_{g}-T_{l}\right)}{\rho_{g} h_{f g}}\right) & \\
\operatorname{Pr}_{k}=\left(\frac{C p_{k} \mu_{k}}{C_{k}}\right) & \text { for each k phase }
\end{array}
$$

In Appendix $\mathrm{C}$, it is explained how the interfacial heat transfer for each node, and the derivatives that we need in order to solve the system of equations are calculated, as we will explain in Chapter 6.

\subsection{HEAT TRANSFER TO THE WALL}

When solving the equations system, we need the heat transfer to the wall to evaluate the coefficients of the matrix to be solved. We also need the derivatives of the heat transfer with respect to the pressure, temperature and the pressure differences for each phase.

As the phenomenon is different at the steam wall than at the liquid wall, due to the condensation, we are going to explain them separately.

\subsubsection{LIQUID WALL HEAT TRANSFER}

The expression for the heat transferred with the wall at the liquid phase is as follows:

$$
\mathrm{Q}_{\mathrm{lw}}=\mathrm{A}_{\mathrm{lw}} \mathrm{h}_{\mathrm{lw}}\left(\mathrm{T}_{\mathrm{lw}}-\mathrm{T}_{\mathrm{lm}}\right) \Delta \mathrm{t}
$$


where, $A_{l w}$ is the area of the liquid in contact with the wall, $h_{l w}$ is the convective heat transfer coefficient, $T_{l w}$ is the temperature of the wall in contact with the liquid, and $T_{l m}$ is the mean liquid temperature at the bulk.

For calculating the convection to the wall, two different correlations will be used. The Dittus-Boelter and the Grashof one. When solving the liquid-wall heat transfer the one that gives the higher value will be taken.

$$
\left\{\begin{array}{rlr}
\mathrm{h}_{\mathrm{lw}}=\mathrm{h}_{\mathrm{DB}}=\frac{\mathrm{K}_{1}}{\mathrm{D}_{\mathrm{hl}}} \mathrm{Nu}_{\mathrm{DB}}=\frac{\mathrm{K}_{1}}{\mathrm{D}_{\mathrm{hl}}} 0.023 \mathrm{Re}_{1}{ }^{0.8} \operatorname{Pr}_{1}^{0.4} & \text { Dittus-Boelter } \\
\mathrm{h}_{\mathrm{lw}}=\mathrm{h}_{\mathrm{Gr}}=\frac{\mathrm{K}_{1}}{\mathrm{D}_{\mathrm{hl}}} \mathrm{Nu}_{\mathrm{Gr}}=\frac{\mathrm{K}_{1}}{\mathrm{D}_{\mathrm{hl}}} 0.59 \mathrm{Gr}_{1}^{0.25} \operatorname{Pr}_{1}^{0.25} & \text { Grashof } \\
\operatorname{Re}_{l}=\left(\frac{\rho_{l} u_{l} D_{h l}}{\mu_{l}}\right) & \\
\operatorname{Pr}_{l}=\frac{C p_{l} \mu_{l}}{K_{l}} & 9.81 \beta_{l}\left(T_{l j}^{t+\Delta t}-T_{l w j}{ }^{t+\Delta t}\right) \rho_{l}^{2} D_{h l}^{3} \\
\mu_{l}^{2}
\end{array}\right.
$$

In Figure 4.9 the thermal resistances that we have at the liquid wall are presented: 


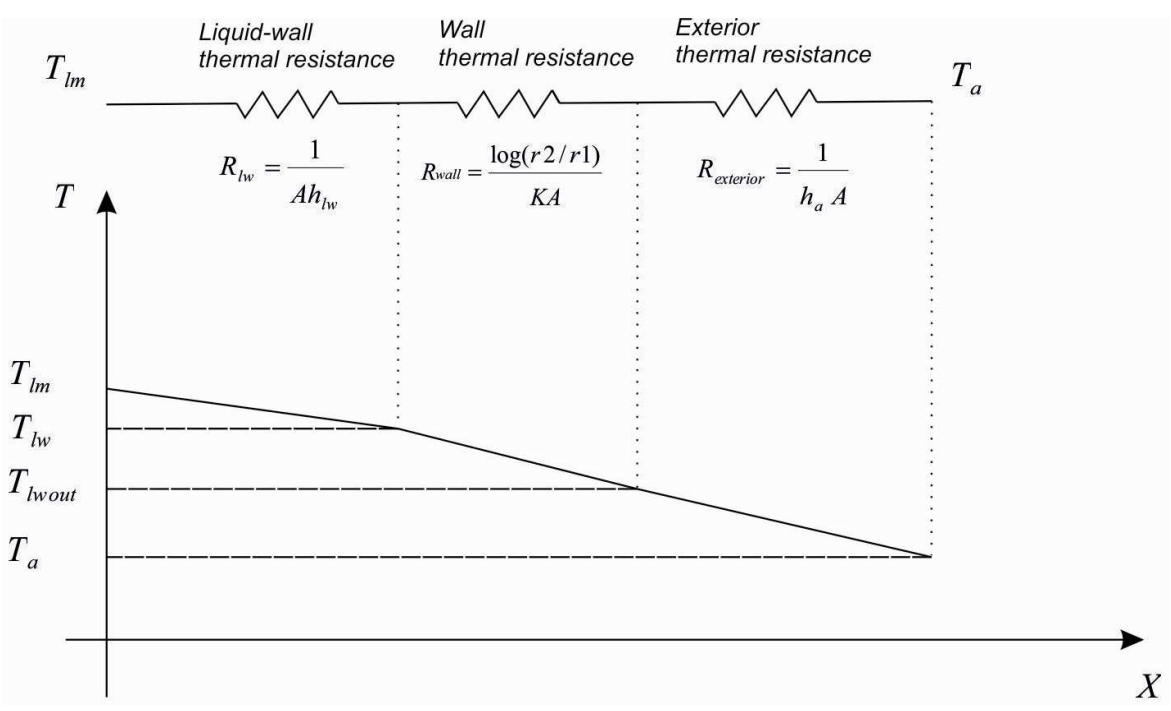

Figure 4.9 Heat transfer resistances scheme for the liquid wall

$$
R_{l}\left(\frac{K}{W}\right)=\frac{1}{\theta_{l} R d x h_{w l}}+\frac{\ln \left(r_{2} / r_{1}\right)}{\theta_{l} K_{w} d x}+\frac{1}{\theta_{l}\left(R+t_{h}\right) h_{a} d x}
$$

where, $h_{l w}$ is the convective heat transfer coefficient $\left(W / m^{2} K\right)$ for each phase, $h_{a}$ is the convective heat transfer coefficient $\left(W / \mathrm{m}^{2} K\right)$ for the exterior, $\theta_{k}$ is the phase angle at this $\mathrm{dx}(\mathrm{rad}), \mathrm{R}$ is the pipe radius $(m), K_{w}$ is the wall conductivity, $t_{h}$ is the wall thickness, and $r_{1}$ and $r_{2}$ are, the inner and outer radius respectively.

\subsubsection{STEAM WALL HEAT TRANSFER}

The expression for the heat transferred with the wall at the steam phase is as follows:

$$
\mathrm{Q}_{\mathrm{wg}}=\mathrm{A}_{\mathrm{wg}}\left(\mathrm{h}_{\mathrm{wg} \_ \text {sens }}+\mathrm{h}_{\mathrm{wg} \_ \text {cond }}\right)\left(\mathrm{T}_{\mathrm{ig}}-\mathrm{T}_{\mathrm{gm}}\right) \Delta \mathrm{t}
$$


where, $A_{g w}$ is the area of the steam in contact with the wall, $h_{w g_{-} s e n s}$ is the convective heat transfer coefficient, $h_{w g_{-} \text {cond }}$ is the condensation heat transfer coefficient at the steam-wall zone, $T_{i g}$ is the temperature at the interface between the steam and the condensate film and $T_{g m}$ is the mean steam temperature at the bulk.

The heat transfer equation for the steam phase is somehow different to the liquid phase due to having condensation at the wall. Then, we have a different way of transmitting the heat. So, we have two parallel processes at the condensate film boundary layer to the steam, which are, convection and condensation, as can be observed in Figure 4.10:

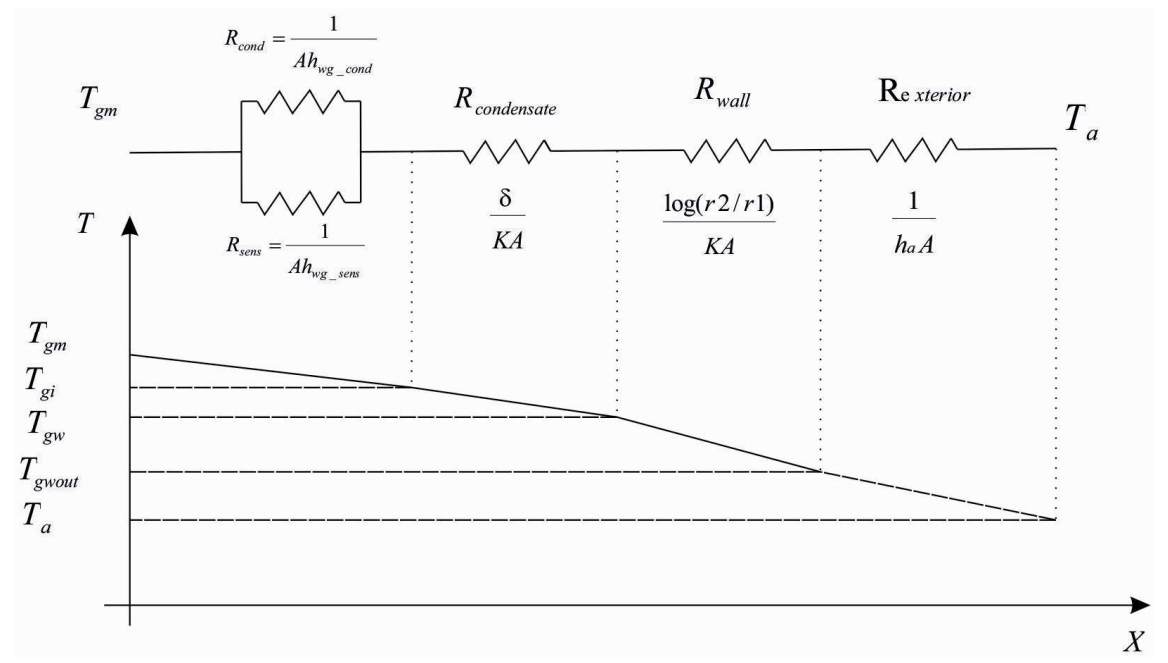

Figure 4.10 Heat transfer resistances scheme for the steam wall

As we can observe in Figure 4.9, we have different thermal resistances. We first have two parallel thermal processes, which are the sensible heat due to convection to the condensate film, and the condensation term.

In order to calculate the convective heat transfer to the wall (sensible heat), we will use two different correlations. The Dittus-Boelter, and the Grashof one. We will take the one that gives us the higher value. 


$$
\begin{cases}h_{w g_{-} \text {sens }}=h_{D B}=\frac{K_{g}}{D_{h g}} N u_{D B}=\frac{K_{g}}{D_{h g}} 0.023 \operatorname{Re}_{g}{ }^{0.8} \operatorname{Pr}_{g}{ }^{0.4} & \text { Dittus-Boelter } \\ h_{w g_{-} \text {sens }}=h_{G r}=\frac{K_{g}}{D_{h g}} N u_{G r}=\frac{K_{g}}{D_{h g}} 0.59 G r_{g}{ }^{0.25} \operatorname{Pr}_{g}^{0.25} & \text { Grashof }\end{cases}
$$

where the dimensionless numbers are defined as:

$$
\begin{aligned}
& \operatorname{Re}_{g}=\left(\frac{\rho_{g} u_{g} D_{h g}}{\mu_{g}}\right) \\
& \operatorname{Pr}_{g}=\frac{C p_{g} \mu_{g}}{K_{g}} \\
& G r_{g}=\frac{9.81 \beta_{g}\left(T_{g_{j}}{ }^{t+\Delta t}-T_{g w_{j}}{ }^{t+\Delta t}\right) \rho_{g}{ }^{2} D_{h g}{ }^{3}}{\mu_{g}{ }^{2}}
\end{aligned}
$$

For the condensation heat transfer coefficient, we will use a self-deducted equation which we obtained from making a mass and energy balance at the steam fraction wall, which is:

$$
\bar{h}\left(\theta_{i}\right)=\frac{B^{1 / 4} K_{l}}{A^{1 / 4}} \frac{1}{\theta_{l}} \int_{0}^{\theta_{i}} \frac{\operatorname{sen}^{1 / 3}(\theta)}{(F(\theta))^{1 / 4}}\left(1-\frac{3}{8} \frac{A^{1 / 4}(F(\theta))^{1 / 4}}{R B^{1 / 4} \operatorname{sen}^{1 / 3}(\theta)}\right)^{1 / 3} d \theta
$$

Equation (123). Mean condensation heat transfer coefficient

In Appendix $\mathrm{C}$ it is explained how the condensation mean wall heat transfer coefficient for the steam is calculated, and the derivatives that we need to solve the system of equations, as we will explain in Chapter 5.

We hence have three different thermal resistances at the steam wall. These resistances are: 
$R_{\text {condensate }}$ :

It represents the thermal resistance due to the conduction heat transfer through the condensate film at the steam wall.

As we know, $\dot{q}^{\prime \prime}\left(W / m^{2}\right)=-K \vec{\nabla} T$ (Fourier law). So, in the radial direction, we can approximate this as; $\dot{q}(W)=-K A \frac{\Delta T}{\delta}$, where $\delta$ is the thickness of the condensate film. The thermal resistance for the condensate film will be:

$$
R_{\text {condensate }}=\frac{\Delta T(K)}{\dot{q}(W)}=\frac{\delta}{K A}
$$

$R_{\text {wall }}$ :

This thermal resistance represents the conduction heat transfer through the wall as it is obtained for a cylindrical pipe wall:

$$
R_{\text {wall }}=\frac{\log (r 2 / r 1)}{K A}
$$

Rexterior :

This thermal resistance represents the convection heat transfer to the exterior. As we already know, $\dot{q}=-h \cdot A \cdot \Delta T$, and hence, the thermal resistance is:

$$
R_{\text {exterior }}=\frac{\Delta T(K)}{\dot{q}(W)}=\frac{1}{h_{a} A}
$$

Finally we get the wall global thermal resistance for this dx piece of pipe. The expression is as follows:

$$
R_{g}\left(\frac{K}{W}\right)=\frac{1}{\theta_{g} R d x\left(h_{w g_{-} \text {sens }}+h_{w g_{-} \text {cond }}\right)}+\frac{\delta}{K_{l} \theta_{g} R d x}+\frac{\ln \left(r_{2} / r_{1}\right)}{\theta_{g} K_{w} d x}+\frac{1}{\theta_{g}\left(R+t_{h}\right) h_{a} d x}
$$


At the next point, it is explained how it is iterated in order to get the interfacial temperature at the condensate film boundary limit and thus the steam wall heat transfer is calculated with the following equation:

$$
Q_{w g}=A_{w g}\left(h_{w g_{-} \text {sens }}+h_{w g_{-} \text {cond }}\right)\left(T_{i g}-T_{g m}\right) \Delta t
$$

\subsubsection{WALL TEMPERATURES AND LUMPED THERMAL RESISTANCE COEFFICIENT}

In order to calculate the heat transfer to the walls, it is necessary to determine the wall temperatures. The reason is, because the convection heat transfer coefficients (for sensible heat or condensation) depend on the phases properties, and these properties depend on the phases temperatures, which depend on the heat transfer to the walls. So, every variable is dependant on the others as a loop. Hence, the only way for solving this is by means of an iteration process, and reaching a converged value for the wall temperatures and thermal resistance coefficient.

As in the previous point, the liquid and steam are explained separately.

\subsubsection{LIQUID PHASE}

Firstly, we need the value for the convective heat transfer coefficient to the wall $h_{w k}$. This will be the one as we said in the previous point. This is, we take the higher value between the Dittus-Boelter and the Grashof one.

$$
h_{l w}\left(\frac{W}{m^{2} K}\right)
$$

Secondly, we need the thermal resistance for this dx piece of pipe. It is as follows: 


$$
R_{l}\left(\frac{K}{W}\right)=\frac{1}{\theta_{l} R d x h_{w l}}+\frac{\ln \left(r_{2} / r_{1}\right)}{\theta_{l} K_{w} d x}+\frac{1}{\theta_{l}\left(R+t_{h}\right) h_{a} d x}
$$

where, $h_{l w}$ is the convective heat transfer coefficient $\left(W / m^{2} K\right)$ for each phase, $h_{a}$ is the convective heat transfer coefficient $\left(W / m^{2} K\right.$ ) for the exterior, $\theta_{k}$ is the phase angle at this $\mathrm{dx}(\mathrm{rad}), \mathrm{R}$ is the pipe radius $(m), K_{k}$ is the phase conductivity, $t_{h}$ is the wall thickness, and $r_{1}$ and $r_{2}$ are, the inner and outer radius respectively.

In order to make an iterative process we first make an energy balance at the wall as follows:

$$
d \dot{q}_{l w}=h_{l w}\left(T_{l m}-T_{l w}\right) P_{l} d x=\frac{T_{l m}-T_{a}}{R_{l}}
$$

From this energy balance, we can iterate and obtain the liquid wall temperature.

A flow chart of the iterative procedure is shown in Figure 4.11: 


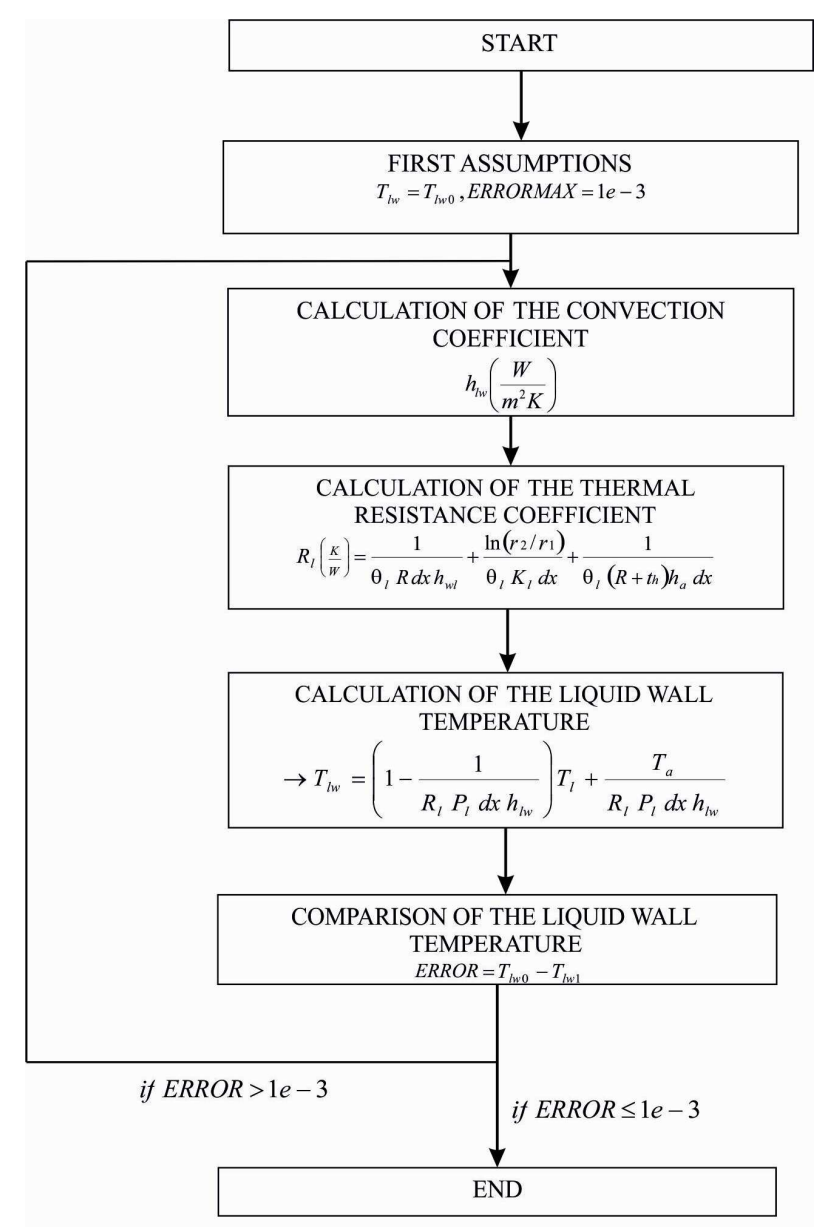

Figure 4.11 Iterative procedure for finding the liquid wall temperature

In words;

First, we assume a wall temperature. Then the terms $h_{k w}$ and $R_{k}$ are calculated. From Equation (4.128) we get a new value for the wall temperature:

$$
\rightarrow T_{l w}=\left(1-\frac{1}{R_{l} P_{l} d x h_{l w}}\right) T_{l m}+\frac{T_{a}}{R_{l} P_{l} d x h_{l w}}
$$

Now the obtained value is compared with the assumed one and, in case of being bigger, we take this new value as the wall temperature and then we go back to the first step. 
This iterative process is continued till we reach a converged value for the wall temperature and the thermal resistance coefficient.

\subsubsection{STEAM PHASE}

For the steam phase, the procedure is exactly the same. The difference is that, the heat transfer coefficient at the wall changes due to the wall condensation.

So we have;

$$
R_{g}\left(\frac{K}{W}\right)=\frac{1}{\theta_{g} R d x\left(h_{w g_{-} \text {sens }}+h_{w g_{-} \text {cond }}\right)}+\frac{\delta}{K_{l} \theta_{g} R d x}+\frac{\ln \left(r_{2} / r_{1}\right)}{\theta_{g} K_{w} d x}+\frac{1}{\theta_{g}\left(R+t_{h}\right) h_{a} d x}
$$

Then, the energy balance gives us:

$$
d \dot{q}_{w g}=\left(h_{w g_{-} \text {sens }}+h_{w g_{-} \text {cond }}\right)\left(T_{g m}-T_{g i}\right) P_{l} d x=\frac{T_{g m}-T_{a}}{R_{g}}
$$

So, clearing the wall temperature value from Equation 4.131, we obtain:

$\rightarrow T_{g i}=\left(1-\frac{1}{R_{g} P_{g} d x\left(h_{w g_{-} \text {sens }}+h_{w g_{-} \text {cond }}\right)}\right) T_{g m}+\frac{T_{a}}{R_{g} P_{g} d x\left(h_{w g_{-} \text {sens }}+h_{w g_{-} \text {cond }}\right)}$ 


\section{CONSERVATION EQUATIONS DISCRETIZATION RESUME}

\section{Mass conservation equation:}

Steam phase

$$
\left[\left(\rho_{g}\right)_{j}^{t+\Delta t}-\left(\rho_{g}\right)_{j}^{t}\right] A_{g_{j}}{ }_{j}^{t} \Delta x+\left[\left(\left(\rho_{g} A_{g}\right)^{t} u_{g}{ }^{t+\Delta t}\right)_{j+1 / 2}-\left(\left(\rho_{g} A_{g}\right)^{t} u_{g}{ }^{t+\Delta t}\right)_{j-1 / 2}\right] \Delta t=\Phi_{g_{j}}{ }_{j}+\Delta t
$$

Liquid phase

$$
\left\lfloor\left(\rho_{l}\right)_{j}^{t+\Delta t}-\left(\rho_{l}\right)_{j}^{t}\right\rfloor A_{l j}^{t} \Delta x+\left\lfloor\left(\left(\rho_{l} A_{l}\right)^{t} u_{l}^{t+\Delta t}\right)_{j+1 / 2}-\left(\left(\rho_{l} A_{l}\right)^{t} u_{l}^{l+\Delta t}\right)_{j-1 / 2}\right\rfloor \Delta t=\Phi_{l j}^{l+\Delta t}
$$

\section{Energy conservation equation:}

Steam phase

$$
\begin{aligned}
& {\left[\left(\rho_{g} e_{a g}\right)_{j}^{t+\Delta t}-\left(\rho_{g} e_{a g}\right)_{j}^{t}\right] A_{g_{j}}{ }^{t} \Delta x=-\left[\left(\left(\rho_{g} e_{a g} A_{g}\right)^{t} u_{g}{ }^{t+\Delta t}\right)_{j+1 / 2}-\left(\left(\rho_{g} e_{a g} A_{g}\right)^{t} u_{g}{ }^{t+\Delta t}\right)_{j-1 / 2}\right] \Delta t-P_{g_{j}}{ }^{t+\Delta t}\left[\left(u_{g}{ }^{t+\Delta t} A_{g}{ }^{t}\right)_{j+1 / 2}-\left(u_{g}{ }^{t+\Delta t} A_{g}{ }^{t}\right)_{j-1 / 2}\right] \Delta t} \\
& \quad+\left(Q_{g i}\right)_{j}^{t+\Delta t}+\left(Q_{g w}\right)_{j}^{t+\Delta t}+\left(\Phi_{g}\right)_{j}^{t+\Delta t} h_{g i}{ }^{t+\Delta t}
\end{aligned}
$$

Liquid phase

$$
\left[\left(\rho_{l} e_{a l}\right)_{j}^{t+\Delta t}-\left(\rho_{l} e_{a l}\right)_{j}^{t}\right] A_{l j}^{t} \Delta x=-\left[\left(\left(\rho_{l} e_{a l} A_{l}\right)^{t} u_{l}^{t+\Delta t}\right)_{j+1 / 2}-\left(\left(\rho_{l} e_{a l} A_{l}\right)^{t} u_{l}^{t+\Delta t}\right)_{j-1 / 2}\right] \Delta t-P_{l j}^{t+\Delta t}\left[\left(u_{l}^{t+\Delta t} A_{l}{ }_{l}^{t}\right)_{j+1 / 2}-\left(u_{l}{ }^{t+\Delta t} A_{l}{ }^{t}\right)_{j-1 / 2}\right] \Delta t
$$




$$
+\left(Q_{l i}\right)_{j}^{l+\Delta t}+\left(Q_{l w}\right)_{j}^{t+\Delta t}+\left(\Phi_{l}\right)_{j}^{t+\Delta t} h_{l i j}^{i+\Delta t}
$$

\section{Momentum conservation equation:}

$\underline{\text { Steam phase }}$

$$
\begin{gathered}
{\left[\left(\rho_{g} u_{g} A_{g}\right)_{j-1 / 2}^{t+\Delta t}-\left(\rho_{g} u_{g} A_{g}\right){ }_{j-1 / 2}^{t}\right] \Delta x=-\left[\left(\rho_{g} u_{g}{ }^{2} A_{g}\right){ }_{j}^{t}-\left(\rho_{g} u_{g}{ }^{2} A_{g}\right){ }_{j-1}^{t}\right] \Delta t-\frac{1}{2}\left(\rho_{g} P_{g w} f_{g w}\right)_{j-1 / 2}^{t} u_{g_{j-1 / 2}}^{t+\Delta t}\left|u_{g_{j-1 / 2}}{ }^{t}\right| \Delta x \Delta t} \\
-\left(\frac{1}{2} \rho_{g}\left(u_{g_{j-1 / 2}}-u_{l j-1 / 2}\right)\left|u_{g_{j-1 / 2}}-u_{l j-1 / 2}\right| P_{\text {int } e r f} f_{g i}\right)_{j-1 / 2}^{t} \Delta x \Delta t-\left(P_{g_{j}}-P_{g_{j-1}}\right)^{t} A_{g_{j-1 / 2}}^{t} \Delta t+\Phi_{g_{j-1 / 2}}^{t} u_{g_{j-1 / 2}}^{t}
\end{gathered}
$$

\section{Liquid phase}

$$
\begin{aligned}
& {\left[\left(\rho_{l} u_{l} A_{l}\right)_{j-1 / 2}^{t+\Delta t}-\left(\rho_{l} u_{l} A_{l}\right)_{j-1 / 2}^{t}\right] \Delta x=-\left[\left(\rho_{l} u_{l}^{2} A_{l}\right)_{j}^{t}-\left(\rho_{l} u_{l}^{2} A_{l}\right)_{j-1}^{t}\right] \Delta t-\frac{1}{2}\left(\rho_{l} P_{l w} f_{l w}\right)_{j-1 / 2}^{t} u_{l j-1 / 2}^{t+\Delta t}\left|u_{l j-1 / 2}^{t}\right| \Delta x \Delta t} \\
& -\left(\frac{1}{2} \rho_{g}\left(u_{l j-1 / 2}-u_{g j-1 / 2}\right)\left|u_{l j-1 / 2}-u_{g_{j-1 / 2}}\right| P_{\text {int erf }} f_{l i}\right)_{j-1 / 2}^{t} \Delta x \Delta t-\left(P_{l j}-P_{l j-1}\right)^{t} A_{l j-1 / 2}^{t} \Delta t+\Phi_{l j-1 / 2}^{t} u_{g}^{t}{ }_{j-1 / 2}^{t}
\end{aligned}
$$




\section{CHAPTER 5}

\section{NUMERICAL RESOLUTION AND STRUCTURE OF THE CC PROGRAM}

\subsection{INTRODUCTION}

This chapter presents the numerical resolution of the discretized mass, momentum and energy conservation equations, and the incorporation of high precision schemes to the general method using limitators. The interpolation method FOU (first order Upwinding) has been applied for the calculation of the convective term. In order to evaluate the convective terms of the momentum equation we used the QUICKEST (Quadratic Upstream Interpolation for Convective Kinematics with Estimated Streaming Terms) method. Both methods have been incorporated using a TVD (Total Variation Diminution) scheme called ULTIMATE, developed by Leonard [B.P.Leonard].

The manner how we are going to find a solution to our problem is by solving two systems of three equations for each phase separately which are weakly coupled mainly through the areas for each phase and the interfacial terms. Due to having liquid and steam flowing countercurrently, we will have two different pressure distributions, two velocity distributions, and two temperature distributions, one for each phase.

We have to remark that the way the countercurrent system is being solved is by solving the 1D mass, momentum and energy equations for each phase separately. The liquid and steam fields have to be coupled in order to correctly model the interfacial discontinuities as we explained in Chapter 4. Hence, to correctly predict the liquid and steam velocity, temperature and pressure fields, we couple both systems by calculating the interfacial heat transfer from the steam to the liquid, the interfacial mass transfer through the interface, and the interfacial friction between phases. 
Another remarkable point we must notice, is that since the steam and the liquid are flowing countercurrently, the pressure drops are opposite for the liquid and for the steam. This is that the liquid pressure decreases in the liquid downstream direction, and the steam in the opposite direction, since it flows countercurrently.

The method that we will follow to solve each system of equations is the SIMPLE (SemiImplicit Method for Pressure Linked Equations) method, as proposed by Suhas V. Patankar and Spalding in "Numerical heat Transfer and fluid flow", 1972. This method consists of semi-implicitly solve the momentum equation, and then implicitly solve, the mass and energy equations, making actualizations of the pressure, temperature and velocity for each iteration.

As it appears in the Patankar book, the important operations, in order of their executions are:

1. Guess the pressure field $\mathrm{p}^{*}$.

2. Solve the momentum equation to obtain $\mathrm{u}^{*}$.

3. Solve the p' equation.

4. Calculate the new $\mathrm{p}$, by adding $\mathrm{p}$ ' to $\mathrm{p}$.

5. Calculate $\mathrm{u}$ from its starred value using the velocity correction formulas.

6. Solve the discretized equation for other variables (temperature in our case).

7. Treat the corrected pressure $\mathrm{p}$ as a new guessed pressure $\mathrm{p}^{*}$, return to step 2 and repeat the whole procedure until a converged solution is obtained.

This is basically the procedure which is performed in our code in order to solve the conservation equations. In point 5.2 we explain how we are solving the momentum equation in order to obtain a new velocity profile for each phase. In point 5.3 we explain how the energy and mass equations are numerically solved in order to obtain the pressure corrections, and thence, the new profiles for the velocity, pressure and temperature for each phase. 
When solving a differential equation, there are two methods which can be used. These methods are an explicit method and an implicit method.

Depending on how we make the discretization of the equation, the method would be one or the other.

\section{Explicit method}

Here it will be explained what an explicit method consists on. When solving a partial differential equation, we substitute the derivatives by their algebraic differences. We can approximate these derivates with these differences in several ways. One would be by approximating them using the values of the variables at the actual time step. So, we would have an explicit scheme since, we would only have one unknown value, and the rest would be evaluated at the actual time step and hence, known.

For example, when solving:

$$
\frac{\partial U}{\partial t}=\frac{\partial^{2} U}{\partial x^{2}}
$$

We would have a discretization like:

$$
\frac{u_{i, j+1}-u_{i, j}}{k}=\frac{u_{i+1, j}-2 u_{i, j}+u_{i-1, j}}{h^{2}}
$$

where the index $\mathrm{i}$ denotes the spatial discretization and the index $\mathrm{j}$ denotes the time discretization; being $\mathrm{h}$ the space step and $\mathrm{k}$ the time step.

An example is illustrated in Figure 5.1 for showing a better comprehension. 


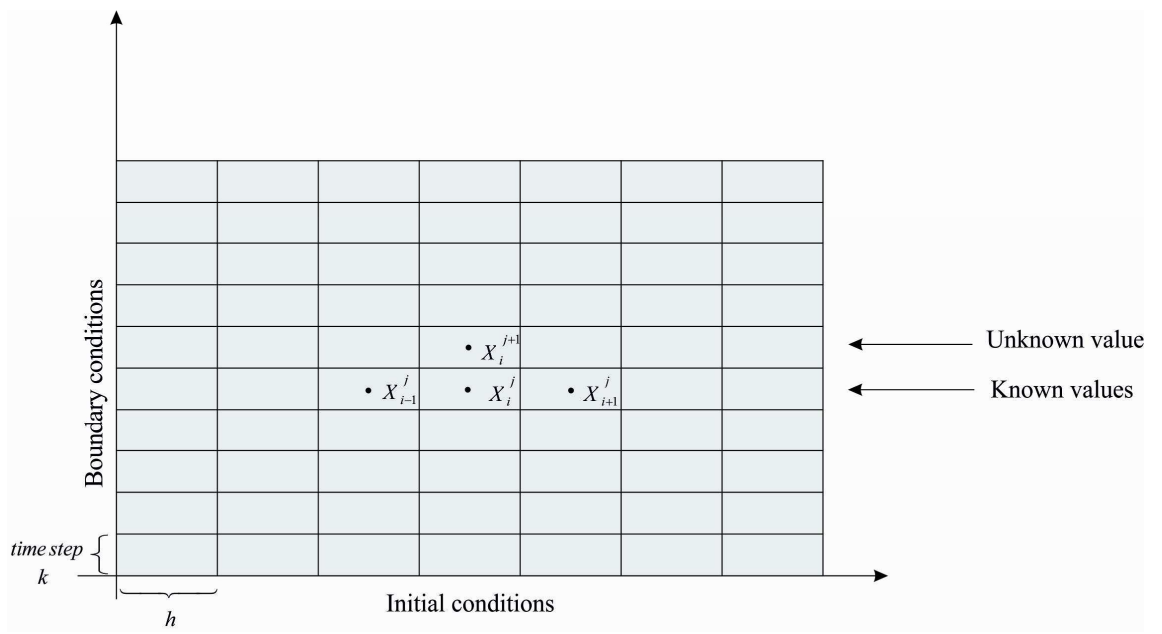

Figure 5.1 Representation of the explicit scheme

\section{Implicit method}

A partial differential equation can also be solved by substituting the derivatives by differences at the time step $i+1$, and hence, we have a discretized scheme where the value we are looking for depends on the values at the actual time step, which are known, and on the neighbour values which are unknown.

For example, when solving:

$$
\frac{\partial U}{\partial t}=\frac{\partial^{2} U}{\partial x^{2}}
$$

We would have a discretization like:

$$
\frac{u_{i, j+1}-u_{i, j}}{k}=\frac{1}{2}\left\{\frac{u_{i+1, j+1}-2 u_{i, j+1}+u_{i-1, j+1}}{h^{2}} \pm \frac{u_{i+1, j}-2 u_{i, j}+u_{i-1, j}}{h^{2}}\right\}
$$

An example for showing a better comprehension is illustrated in figure 5.2. 


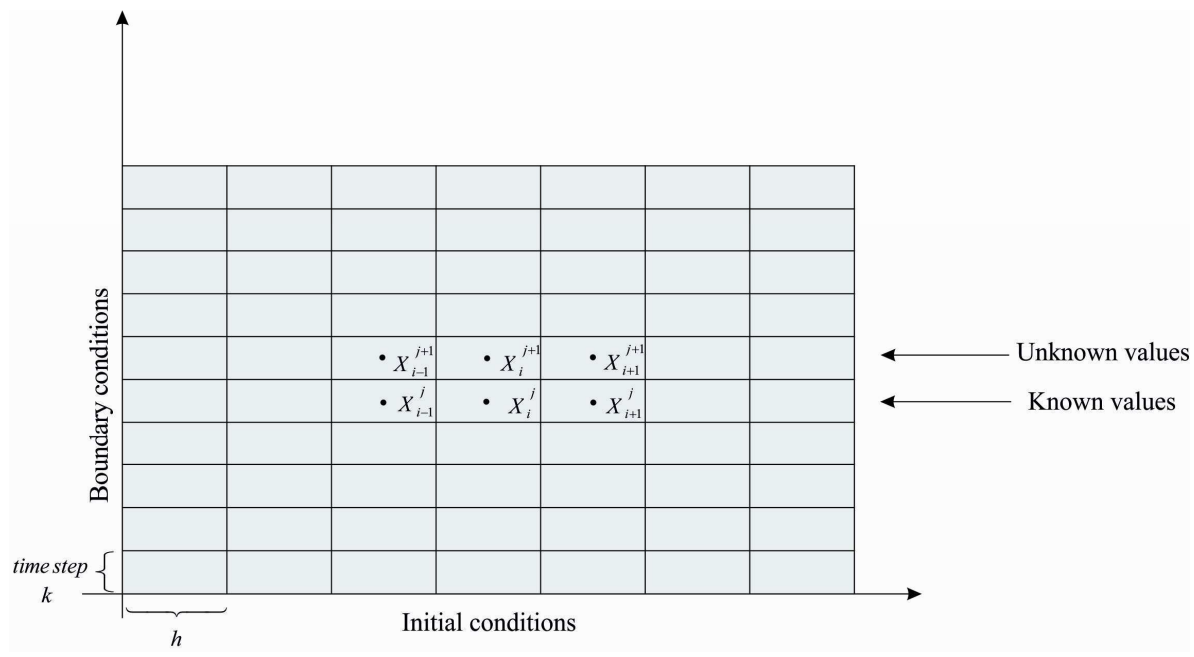

Figure 5.2 Representation of the implicit scheme

The explicit and implicit schemes have different behaviours when solving them. An explicit method is strongly restricted by the Courant number:

$$
C=\frac{u \Delta t}{\Delta x}<1
$$

In order to relax the explicit restrictions, a semi-implicit method is used when solving the momentum conservation equation in the SIMPLE method, as we will see in point 5.2.

The implicit schemes are more stable, and this is because the mass and energy equations are solved by using an implicit scheme, as we will see in point 5.3.

In order to numerically solve the conservation equations, we need first to define some functions where, all the terms are put in one hand side and so, every function is set to zero. These functions come from the mass conservation equations for the liquid and the steam $(4.13,4.14)$, the momentum conservation equation for the liquid and the steam $(4.22,4.23)$ and the energy conservation equation for the liquid and for the steam $(4.32,4.33)$.

We define here three functions; $F_{k 1}, F_{k 2}, F_{k 3}$, for the mass, energy and momentum respectively for each phase $\mathrm{k}(\mathrm{k}=\mathrm{l}, \mathrm{g})$, which we will solve in order to get the solution for $u_{k}, T_{k}, P_{k}$. 
Mass conservation equation:

$$
\begin{gathered}
F_{k 1}=\left\lfloor\left(\rho_{k}\right)_{j}^{t+\Delta t}-\left(\rho_{k}\right)_{j}^{t}\right\rfloor A_{l j}{ }_{j} \Delta x+\left[\left(\left(\rho_{k} A_{k}\right)^{t} u_{k}{ }^{t+\Delta t}\right)_{j+1 / 2}-\left(\left(\rho_{k} A_{k}\right)^{t} u_{k}{ }^{t+\Delta t}\right)_{j-1 / 2}\right\rfloor \Delta t \\
-\Phi_{k j}{ }^{t+\Delta t}=0
\end{gathered}
$$

$>$ Energy conservation equation:

$F_{k 2}=$

$$
\begin{aligned}
& \left\lfloor\left(\rho_{k} e_{a k} A_{k}\right)_{j}^{t+\Delta t}-\left(\rho_{k} e_{a k} A_{k}\right)_{j}^{t}\right\rfloor \Delta x \\
& +\left\lfloor\left(\left(\rho_{k} e_{a k} A_{k}\right)^{t} u_{k}{ }^{t+\Delta t}\right)_{j+1 / 2}-\left(\left(\rho_{k} e_{a k} A_{k}\right)^{t} u_{k}{ }^{t+\Delta t}\right)_{j-1 / 2}\right\rfloor \Delta t \\
& +P_{k j}^{t+\Delta t}\left[\left(u_{k}{ }^{t+\Delta t} A_{k}{ }^{t}\right)_{j+1 / 2}-\left(u_{k}{ }^{t+\Delta t} A_{k}{ }^{t}\right)_{j-1 / 2}\right\rfloor \Delta t \\
& -\left(Q_{k i}\right)_{j}^{t+\Delta t}-\left(Q_{k w}\right)_{j}^{t+\Delta t}-\left(\Phi_{k}\right)_{j}^{t+\Delta t} h_{k j}{ }^{t+\Delta t}=0 \quad \mathrm{k}=1, \mathrm{~g}
\end{aligned}
$$

\section{$\underline{\text { Momentum conservation equation: }}$}

$F_{k 3}=$

$$
\begin{aligned}
& \left\lfloor\left(\rho_{k} u_{k} A_{k}\right)_{j-1 / 2}^{t+\Delta t}-\left(\rho_{k} u_{k} A\right)_{j-1 / 2}^{t}\right\rfloor \Delta x \\
& +\left[\left(\rho_{k} u_{k}^{2} A_{k}\right)_{j}^{t}-\left(\rho_{k} u_{l}^{2} A_{k}\right)_{j-1}^{t}\right] \Delta t \\
& +\frac{1}{2}\left(\rho_{k} P_{k w} f_{k w}\right)_{j-1 / 2}^{t} u_{k j-1 / 2}^{t+\Delta t}\left|u_{k j-1 / 2}^{t}\right| \Delta x \Delta t \\
& +\left(\frac{1}{2} \rho_{g}\left(u_{g_{j-1 / 2}}-u_{l j-1 / 2}\right)\left|u_{g_{j-1 / 2}}-u_{l_{j-1 / 2}}\right| P_{\text {int } e r f} f_{i}\right)_{j-1 / 2}^{t} \Delta x \Delta t \\
& +\left(P_{k j}-P_{k j-1}\right)^{t} A_{k_{j-1 / 2}}^{t} \Delta t-\Phi_{k j-1 / 2}^{t} u_{g_{j-1 / 2}}^{t}=0 \quad \mathrm{k}=1, \mathrm{~g}
\end{aligned}
$$

In the momentum equation there are some terms where the subscript is not $\mathrm{k}$ and it is $\mathrm{g}$ or $\mathrm{l}$. These terms are; 
- The interfacial friction; the steam density it is considered for calculating the interfacial friction term. Then we have the relative velocity between the steam and the liquid, which is the source of interfacial friction.

- The momentum transfer due to the interfacial condensation. It is evaluated as the mass generation of the phase $\mathrm{k}$ multiplied by the steam velocity, because the steam is the phase which is condensing and losing momentum due to phase change.

\subsection{SEMI-IMPLICIT RESOLUTION OF THE MOMENTUM EQUATION}

As can be seen in Chapter 4, the momentum equation was discretized semi-implicitly. Every time step and in the Newton-Raphson iteration procedure, the obtained velocities are also updated due to the changes that the new pressure distributions induce.

We are trying here to solve the momentum equation and obtain a new velocity profile. Since the momentum cell is displaced from the continuity one, and by making a reformulation of the method by Raithby [W.J. Minkowycz], we must guarantee that the continuity equation is accomplished in the momentum cells, as it is accomplished in the continuity cells too. This is because the mass fluxes that appear in the momentum equation must be known.

In order to assure this condition in the momentum cells, the mass conservation equation is discretized in a momentum cell. Hence, we obtain a mass conservation equation, where the convective terms are taken at the faces of the momentum cells, i.e. the centres of the continuity cells.

$$
\begin{aligned}
& F_{k 1}= \\
& \left\lfloor\left(\rho_{k}\right)_{j-1 / 2}^{t+\Delta t}-\left(\rho_{k}\right)_{j-1 / 2}^{t}\right\rfloor A_{k j-1 / 2}^{t} \Delta x+\left\lfloor\left(\left(\rho_{k} A_{k}\right)^{t} u_{k}{ }^{t+\Delta t}\right)_{j}-\left(\left(\rho_{k} A_{k}\right)^{t} u_{k}{ }^{t+\Delta t}\right)_{j-1}\right\rfloor \Delta t \\
& -\Phi_{k j-1 / 2}^{t}=0 \quad \mathrm{k}=1, \mathrm{~g}
\end{aligned}
$$

The first step we have to do in order to follow the SIMPLE method is to guess a pressure field. This is made in our code by establishing initial conditions for each phase. The second step is to get the velocity at the time step $n+1$ from the momentum equation. 
In order to being able to treat both equations together, we multiply the mass conservation equation $\left(F_{k 1}\right)$ by $u_{k j-1 / 2}^{t+\Delta t}$ (implicit velocity of the phase $\mathrm{k}$, at the centre of the momentum cell). This is made so that the resulting equation has momentum units, and we can operate this equation jointly with the momentum conservation function $F_{k 3}$.

$$
\begin{gathered}
u_{k j-1 / 2}^{t+\Delta t} F_{k 1}=\left[\left(\rho_{k}\right)_{j-1 / 2}^{t+\Delta t}-\left(\rho_{k}\right)_{j-1 / 2}^{t}\right] A_{k j-1 / 2}^{t} u_{k j-1 / 2}^{t+\Delta t} \Delta x \\
+\left[\left(\left(\rho_{k} A_{k}\right)^{t} u_{k}{ }^{t+\Delta t}\right)_{j}-\left.\left(\left(\rho_{k} A_{k}\right)^{t} u_{k}{ }^{t+\Delta t}\right)_{j-1}\right|_{k_{j-1 / 2}} ^{t+\Delta t} \Delta t-\Phi_{k j-1 / 2}^{t} u_{k j-1 / 2}^{t+\Delta t}=0\right. \\
\mathrm{k}=1, \mathrm{~g}
\end{gathered}
$$

As we already said, $F_{k 1}$ equals zero, and hence, $u_{k j-1 / 2}^{t+\Delta t} F_{k 1}$, equals zero too.

We now make the next subtraction; $u_{k j-1 / 2}^{t+\Delta t} F_{k 1}-F_{k 3}=0$. This makes the momentum equation to accomplish the continuity equation too in the momentum cell.

We can observe in the discretization of the momentum equation in the Chapter 4 , that the convective term is estimated at $t+\Delta t$, which is multiplied by the velocity again in $t+\Delta t$ in different faces. So we approximate; $u_{k j}{ }^{t+\Delta t} \cdot u_{k j}{ }^{t+\Delta t} \approx u_{k j}{ }^{t} \cdot u_{k j}{ }^{t+\Delta t}$, and we take the velocity in $t+\Delta t$ as the velocity in $t$. Hence, we have the following equation:

$$
\begin{aligned}
& u_{k j-1 / 2}^{t+\Delta t} F_{k 1}-F_{k 3}= \\
& -\left(\rho_{k} A_{k}\right)_{j-1 / 2}^{t} u_{k j-1 / 2}^{t+\Delta t} \Delta x+\left(\rho_{k} u_{k} A_{k}\right)_{j}^{t} u_{k j-1 / 2}^{t+\Delta t} \Delta t \\
& -\left(\rho_{k} u_{k} A_{k}\right)_{j-1}^{t} u_{k j-1 / 2}^{t+\Delta t} \Delta t-\Phi_{k j-1 / 2}^{t} u_{k j-1 / 2}^{t+\Delta t} \\
& +\left(\rho_{k} u_{k} A_{k}\right)_{j-1 / 2}^{t} \Delta x-\left(\rho_{k} u_{k}^{2} A_{k}\right)_{j}^{t} \Delta t+\left(\rho_{k} u_{k}{ }^{2} A_{k}\right)_{j-1}^{t} \Delta t \\
& -\frac{1}{2}\left(\rho_{k} P_{k w} f_{k w}\right)_{j-1 / 2}^{t} u_{k j-1 / 2}^{t+\Delta t}\left|u_{k j-1 / 2}^{t}\right| \Delta t \Delta x
\end{aligned}
$$




$$
\begin{aligned}
& -\left(\frac{1}{2} \rho_{g}\left(u_{g_{j-1 / 2}}-u_{l_{j-1 / 2}}\right)\left|u_{g_{j-1 / 2}}-u_{l_{j-1 / 2}}\right| P_{\text {int } e r f} f_{l i}\right)_{j-1 / 2}^{t} \Delta x \Delta t \\
& -\left(P_{k_{j}}-P_{k_{j-1}}\right)^{t} A_{k_{j-1 / 2}}^{t} \Delta t+\Phi_{k_{j}{ }_{j}} u_{g_{j-1 / 2}}{ }^{t}=0 \quad \mathrm{k}=\mathrm{l}, \mathrm{g}
\end{aligned}
$$

We obtain here an equation where the explicit velocity appears here to be a constant, so we can directly clear the implicit velocity at $t+\Delta t$ as follows:

$$
u_{k j-1 / 2}^{t+\Delta t}=\frac{A}{B}
$$

where we define $\mathrm{A}$ and $\mathrm{B}$ as:

$$
\begin{gathered}
A=\left(\rho_{k} u_{k} A_{k}\right)_{j-1 / 2}^{t} \Delta x-\left(\rho_{k} u_{k}{ }^{2} A_{k}\right)_{j}^{t} \Delta t+\left(\rho_{k} u_{k}{ }^{2} A_{k}\right)_{j-1}^{t} \Delta t \\
-\left(\frac{1}{2} \rho_{g}\left(u_{g_{j-1 / 2}}-u_{l j-1 / 2}\right)\left|u_{g_{j-1 / 2}}-u_{l_{j-1 / 2}}\right| P_{\text {int } e^{\prime}} f_{k i}\right)_{j-1 / 2}^{t} \Delta x \Delta t \\
-\left(P_{k_{j}}-P_{k j-1}\right)^{t} A_{k j-1 / 2} \Delta t+\Phi_{k j-1 / 2}^{t} u_{g}{ }_{j-1 / 2}^{t}
\end{gathered}
$$

and:

$$
\begin{aligned}
B=\left(\rho_{k} A_{k}\right)_{j-1 / 2}^{t} \Delta x-\left(\rho_{k} u_{k} A_{k}\right)^{t}{ }_{j} \Delta t+\left(\rho_{k} u_{k} A_{k}\right)^{t}{ }_{j-1} \Delta t+\Phi_{k j-1 / 2}^{t} & \\
& +\frac{1}{2}\left(\rho_{k} P_{k w} f_{k w}\right)_{j-1 / 2}^{t}\left|u_{k j-1 / 2}^{t}\right| \Delta t \Delta x
\end{aligned}
$$

The velocity that is calculated in the Equation (5.12) is not the ultimate one for this time step, since it depends on the pressure corrections and is updated every iteration of the Newton-Raphson procedure explained in point 5.3. 
We also need the derivative of the velocity with respect to the pressures difference, for the later updating of the velocity and temperature when solving the mass and energy equations as we will explain in the point 5.3.

We can obtain the derivative of the velocity in the momentum face with respect to the pressures difference by deriving the Equation (5.12) with respect to the pressures difference between the adjacent nodes. As we can observe in Equation (5.13), the only term that depends on the pressure difference is the pressure gradient term in the momentum equation. So we get that this derivative is:

$$
\frac{\partial u_{k j-1 / 2}^{t+\Delta t}}{\partial\left(P_{k_{j}}-P_{k j-1}\right)}=\frac{-A_{k j-1 / 2}{ }^{t} \Delta t}{B}
$$

\subsection{IMPLICIT RESOLUTION OF THE MASS AND ENERGY EQUATIONS}

The next step is to solve the discretized mass and energy equations, in order to determine the variable values that we still need. The solution of this system of equations will give us the value for $P_{k_{j}}^{t+\Delta t}$ and $T_{k j}{ }_{k}^{t+\Delta t}$ in the centre of the continuity grid. We shall say that in the mass and energy equations we have the velocities in the faces of the continuity cell, but these velocities depend on the pressures difference at the centres of the continuity cells. The SIMPLE method of Patankar works by solving the conservation equations obtaining the velocity field at the faces by solving the pressures difference at the adjacent nodes, since the velocities directly depend on the pressures difference. When solving this equations there will appear the convective fluxes at the faces of the continuity cells, and hence we will need the velocities in these faces. These velocities used in the actual time step are the ones we already calculated in the previous point when solving the momentum equation at the centre of the momentum cells, which coincides with the faces of the continuity cells. At each iteration, we obtain a temperature and pressure fields, and then, since we used the velocity field obtained from the momentum equation as we explained in the point 5.2 for solving the mass and energy equations, we need to update the velocity field after doing another iteration. This is done each and every iteration as is explained at the end of this point. 
This fact leads us to the following system of algebraic equations for each node of the continuity grid:

$$
\begin{gathered}
F_{m}\left[P_{k j}^{t+\Delta t}, T_{k j}^{t+\Delta t},\left(P_{k j}^{t+\Delta t}-P_{k j-1}^{t+\Delta t}\right),\left(P_{k j+1}^{t+\Delta t}-P_{k j}^{t+\Delta t}\right)\right]=0 \\
m=1,2
\end{gathered}
$$

Therefore, we have, for each node, two algebraic equations, two unknowns evaluated at the centre of the cell and two pressures evaluated at the neighbor nodes. This system is nonlinear due to the fact that the velocity field is dependant on the pressure and temperature fields, and at the same time this pressure field is dependant on the velocity field and the temperature field. So, all the variables are interrelated, and it cannot be solved directly, but by an iterative procedure. Hence, we will solve it iteratively using the Newton-Raphson method.

We will explain here first how the Newton-Raphson method works for a single 1D equation.

If we are trying to solve the equation $f(x)=0$ and we cannot obtain the exact solution $\bar{x}$ just an approximation $x_{n}$ so as $\bar{x}=x_{n}+h$ we will get:

$$
f(\bar{x}) \approx f\left(x_{n}\right)+h \cdot f^{\prime}\left(x_{n}\right) \Rightarrow h \approx-\frac{f\left(x_{n}\right)}{f^{\prime}\left(x_{n}\right)}
$$

so that;

$$
\bar{x} \approx x_{n}-\frac{f\left(x_{n}\right)}{f^{\prime}\left(x_{n}\right)}
$$

We get so, the so called Newton-Raphson formula:

$$
x_{n+1} \approx x_{n}-\frac{f\left(x_{n}\right)}{f^{\prime}\left(x_{n}\right)}
$$


If we construct, by using the Newton-Raphson formula, the succession $\left(x_{n}\right)$ and it converges, we will have that $\lim x_{n}=\bar{x}$, since by applying limits in (5.19):

$$
\lim x_{n+1}=\lim x_{n}-\frac{f\left(\lim x_{n}\right)}{f^{\prime}\left(\lim x_{n}\right)} \Rightarrow f\left(\lim x_{n}\right)=0
$$

always if $f^{\prime}\left(\lim x_{n}\right) \neq 0$, what is accomplished if we demand that the function has one unique root in the interval $[a, b]$.

In Figure 5.3 a geometric scheme of how the Newton-Raphson method works is shown:

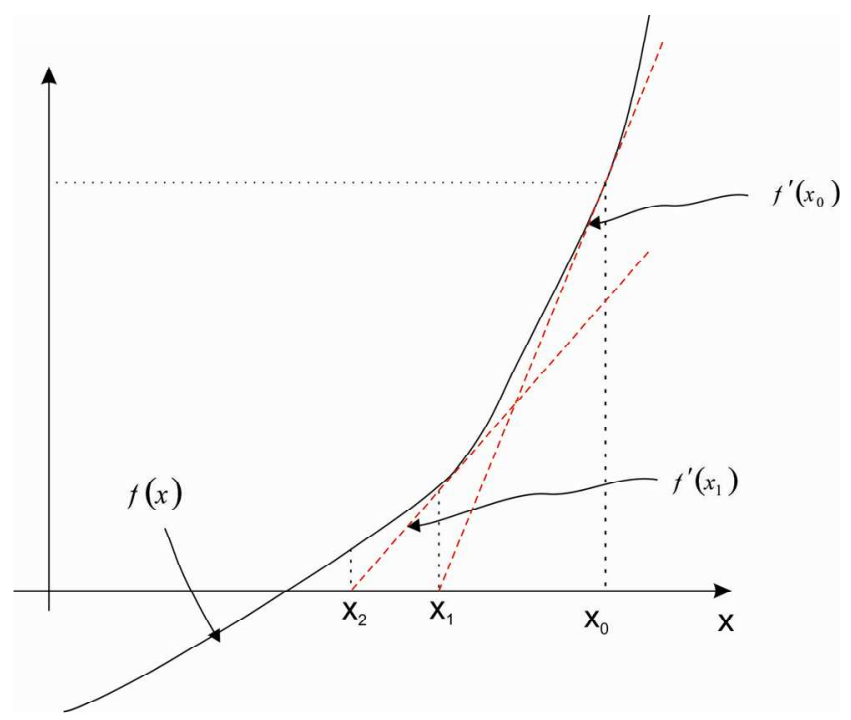

Figure 5.3 Newton-Raphson geometric scheme

In the Newton-Raphson method we get more approximated to the root by the calculation of the derivatives. We can obtain the linearized system of equation that we need by making a Taylor approximation of the system of conservation functions in the same way as for a single equation. We cut this development at the first derivative, so we get the following system of algebraic equations for each phase k: 


$$
\vec{F}_{k}\left(\vec{X}_{k}+\partial \vec{X}_{k}\right)=0=\vec{F}_{\text {ln }}\left(\vec{X}_{k}\right)+\vec{F}_{k n}^{\prime}\left(\vec{X}_{k}\right) \partial \vec{X}_{k}
$$

This can be expressed in terms of the Jacobian:

$$
\sum_{p=1}^{4} J_{k m p} \delta X_{p}=-F_{k m}\left(\vec{X}_{k}\right) \quad \mathrm{m}=1,2
$$

where:

$$
\begin{gathered}
\left(\vec{X}_{k}\right)=\left[P_{k j}^{t+\Delta t}, T_{k j}^{t+\Delta t},\left(P_{k j}^{t+\Delta t}-P_{k j-1}^{t+\Delta t}\right),\left(P_{k j+1}^{t+\Delta t}-P_{k j}{ }^{t+\Delta t}\right)\right] \\
\delta X_{p}=X_{p}^{r+1}-X_{p}^{r}
\end{gathered}
$$

$J_{k m p}$ are the Jacobian matrix elements for phase k, which are given by:

$$
J_{k m p}=\left[\frac{\partial F_{k m}}{\partial X_{p}}\right]
$$

We calculate the terms of the Jacobians matrix:

$$
\begin{aligned}
& J_{k m 1}=A_{k}(m, 1)=\frac{\partial F_{k m j}}{\partial P_{k j}} \quad \mathrm{~m}=1,2 \\
& J_{k m 2}=A_{k}(m, 2)=\frac{\partial F_{k m j}}{\partial T_{l j}} \quad \mathrm{~m}=1,2 \\
& J_{k m 3}=-A_{k}(m, 3)=-\frac{\partial F_{k m j}}{\partial\left(P_{k j}-P_{k j-1}\right)} \quad \mathrm{m}=1,2 \\
& J_{k m 4}=-A_{k}(m, 4)=-\frac{\partial F_{k m j}}{\partial\left(P_{k j+1}-P_{k j}\right)}, \quad \mathrm{m}=1,2
\end{aligned}
$$


Finally, from 5.13, we obtain the following system:

$$
\begin{aligned}
& {\left[\begin{array}{cc}
\frac{\partial F_{k 1}}{\partial P_{k j}^{t+\Delta t}} & \frac{\partial F_{k 1}}{\partial T_{k j}^{t+\Delta t}} \\
\frac{\partial F_{k 2}}{\partial P_{k j}^{t+\Delta t}} & \frac{\partial F_{k 2}}{\partial T_{k j}^{t+\Delta t}}
\end{array}\right]\left[\begin{array}{l}
\delta P_{k} \\
\delta T_{k}
\end{array}\right]=} \\
& {\left[\begin{array}{l}
-F_{k 1} \\
-F_{k 2}
\end{array}\right]+\delta\left(P_{k_{j}}-P_{k j-1}\right) \cdot\left[\begin{array}{c}
-\frac{\partial F_{k 1}}{\partial\left(P_{k_{j}}-P_{k_{j-1}}\right)} \\
-\frac{\partial F_{k 2}}{\partial\left(P_{k_{j}}-P_{k_{j-1}}\right)}
\end{array}\right]+\delta\left(P_{k_{j}}-P_{k_{j-1}}\right) \cdot\left[\begin{array}{c}
-\frac{\partial F_{k 1}}{\partial\left(P_{k j+1}-P_{k j}\right)} \\
-\frac{\partial F_{k 2}}{\partial\left(P_{k j+1}-P_{k j}\right)}
\end{array}\right]}
\end{aligned}
$$

We can also express it as follows on account of definitions 5.25 to 5.28:

$$
\begin{aligned}
& {\left[\begin{array}{ll}
A_{k}(1,1) & A_{k}(1,2) \\
A_{k}(2,1) & A_{k}(2,2)
\end{array}\right]\left[\begin{array}{l}
\delta P_{k} \\
\delta T_{k}
\end{array}\right]=} \\
& {\left[\begin{array}{l}
A_{k}(1,5) \\
A_{k}(2,5)
\end{array}\right]+\delta\left(P_{k j}-P_{k j-1}\right) \cdot\left[\begin{array}{l}
A_{k}(1,3) \\
A_{k}(2,3)
\end{array}\right]+\delta\left(P_{l j}-P_{l j-1}\right) \cdot\left[\begin{array}{l}
A_{k}(1,4) \\
A_{k}(2,4)
\end{array}\right] }
\end{aligned}
$$

Firstly the terms at the left hand side of the equation, i.e. $A_{k}(1,1), A_{k}(1,2)$, $A_{k}(2,1), A_{k}(2,2)$ are calculated:

We calculate the partial derivatives of the mass conservation equation with respect to the liquid pressure and temperature. 


$$
\begin{aligned}
& A_{k}(1,1)=\frac{\partial F_{k 1}}{\partial P_{k j}^{t+\Delta t}}=A_{j}^{t} \Delta x \frac{\partial \rho_{k j}^{t+\Delta t}}{\partial P_{k j}^{t+\Delta t}}-\frac{\partial \Phi_{k j}^{t+\Delta t}}{\partial P_{k j}^{t+\Delta t}} \\
& A_{k}(1,2)=\frac{\partial F_{k 1}}{\partial T_{k j}{ }_{j}^{t+\Delta t}}=A_{j}^{t} \Delta x \frac{\partial \rho_{k j}{ }^{t+\Delta t}}{\partial T_{k j}{ }^{t+\Delta t}}-\frac{\partial \Phi_{k j}{ }^{t+\Delta t}}{\partial T_{k j}{ }^{t+\Delta t}}
\end{aligned}
$$

We calculate now the derivatives of the energy conservation equation with respect to the liquid pressure and temperature:

$$
\begin{aligned}
& A_{k}(2,1)=\frac{\partial F_{k 2}}{\partial P_{k j}{ }^{t+\Delta t}}=\rho_{k j}{ }^{t+\Delta t} A_{k j}{ }^{t} \frac{\partial e_{a l j}{ }^{t+\Delta t}}{\partial P_{k_{j}}{ }^{t+\Delta t}} \Delta x+e_{a k j}{ }^{t+\Delta t} A_{k j}{ }^{t} \frac{\partial \rho_{k j}{ }^{t+\Delta t}}{\partial P_{k j}{ }^{t+\Delta t}} \Delta x \\
& +\left[\left(u_{k}{ }^{t+\Delta t} A_{k}{ }^{t}\right)_{j+1 / 2}-\left(u_{k}{ }^{t+\Delta t} A_{k}{ }^{t}\right)_{j-1 / 2}\right] \Delta t-\frac{\partial Q_{w k}{ }^{t+\Delta t}}{\partial P_{k j}^{t+\Delta t}} \Delta t-\frac{\partial Q_{i k}{ }^{t+\Delta t}}{\partial P_{k j}{ }^{t+\Delta t}} \Delta t \\
& -\frac{\partial \Phi_{k j}^{t+\Delta t}}{\partial P_{k j}^{t+\Delta t}} h_{k j}^{t+\Delta t}-\Phi_{k j}^{t+\Delta t} \frac{\partial h_{k j}^{t+\Delta t}}{\partial P_{k j}^{t+\Delta t}} \\
& A_{k}(2,2)=\frac{\partial F_{k 2}}{\partial T_{k j}^{t+\Delta t}}=\rho_{k j}{ }_{k j}^{t+\Delta t} \frac{\partial e_{a k j}{ }^{t+\Delta t}}{\partial T_{k j}{ }^{t+\Delta t}} A_{k j}^{t} \Delta x+e_{a k j}{ }^{t+\Delta t} \frac{\partial \rho_{k j}{ }^{t+\Delta t}}{\partial T_{k j}{ }^{t+\Delta t}} A_{k j}{ }^{t} \Delta x \\
& -\frac{\partial Q_{w k}{ }^{t+\Delta t}}{\partial T_{k j}{ }^{t+\Delta t}} \Delta t-\frac{\partial Q_{i k}{ }^{t+\Delta t}}{\partial T_{k j}{ }^{t+\Delta t}} \Delta t-\frac{\partial \Phi_{k_{j}}{ }^{t+\Delta t}}{\partial T_{k j}{ }^{t+\Delta t}} h_{k j}{ }^{t+\Delta t}-\Phi_{k j}{ }^{t+\Delta t} \frac{\partial h_{k_{j}}{ }^{t+\Delta t}}{\partial T_{k j}{ }^{t+\Delta t}}
\end{aligned}
$$

These coefficients that we just defined represent the elements of the Jacobian matrix, and hence, the derivatives of the mass and energy functions with respect to the phase pressure and the phase temperature.

When we derivate with respect to the pressure the mass equation we see that the variables that can be derived are, the phase density $\rho_{k}$, and the mass transfer to the phase $\Phi_{k}$. The derivative of the mass transfer is explained in more detail in Appendix B. 
When we derivate with respect to the pressure the energy equation, we see that the variables that can be derived are, the stored energy $e_{a k}$, the phase density $\rho_{k}$, the heat transfer to the walls $Q_{w k}$, the interfacial heat transfer $Q_{i k}$, and the work done by the volume expansion.

For the derivatives of the mass and energy functions with respect to the pressure and temperature, we have the same terms, with the only difference that for the energy function derivative, we don't have the term of the derivative of the volume expansion work because it is not dependant on the temperature.

Now we are going to define the terms $A_{k}(1,5), A_{k}(2,5)$.

The term $A_{k}(1,5)$, represent the minus of the mass conservation function evaluated at the actual time step $(\mathrm{t})$, so we have:

$$
\begin{aligned}
& A_{k}(1,5)=-F_{k 1}= \\
& \quad-\left[\left(\rho_{k}\right)_{j}^{t+\Delta t}-\left(\rho_{k}\right)_{j}^{t}\right] A_{k j}^{t} \Delta x-\left[\left(\left(\rho_{k} A_{k}\right)^{t} u_{k}{ }^{t+\Delta t}\right)_{j+1 / 2}-\left(\left(\rho_{k} A_{k}\right)^{t} u_{k}{ }^{t+\Delta t}\right)_{j-1 / 2}\right] \Delta t+\Phi_{k j}{ }^{t+\Delta t}
\end{aligned}
$$

We might mention here, that the mass conservation equation is discretized implicitly, due to that the Newton-Raphson method is based on the calculation of the derivatives to reach the converged solution, and so, the condensation rate that here appears is also implicit, i.e. in $\mathrm{t}+\Delta \mathrm{t}$. This affects to the terms that appear in the coefficients $A_{k}(1,1), A_{k}(2,2)$, which are derivate with respect to $P_{k j}^{t+\Delta t}$ and $T_{k j}^{t+\Delta t}$.

The term $A_{k}(2,5)$, represent the minus of the energy conservation function evaluated at the actual time step $(\mathrm{t})$, so we have the following expression:

$$
\begin{aligned}
& A_{k}(2,5)=-F_{k 2}= \\
& -\left\lfloor\left(\rho_{k} e_{a k}\right)_{j}^{t+\Delta t}-\left(\rho_{k} e_{a k}\right)_{j}^{t}\right\rfloor A_{k j}^{t} \Delta x-\left[\left(\left(\rho_{k} e_{a k} A_{k}\right)^{t} u_{k}{ }^{t+\Delta t}\right)_{j+1 / 2}-\left(\left(\rho_{k} e_{a k} A_{k}\right)^{t} u_{k}{ }^{t+\Delta t}\right)_{j-1 / 2}\right\rfloor \Delta t \\
& -P_{k j}^{t+\Delta t}\left\lfloor\left(u_{k}{ }^{t+\Delta t} A_{k}{ }^{t}\right)_{j+1 / 2}-\left(u_{k}{ }^{t+\Delta t} A_{k}{ }^{t}\right)_{j-1 / 2}\right\rfloor \Delta t+\left(Q_{i k}\right)_{j}^{t+\Delta t}+\left(Q_{w k}\right)_{j}^{t+\Delta t}+\left(\Phi_{k}\right)_{j}^{t+\Delta t} h_{k j}^{t+\Delta t}
\end{aligned}
$$


We continue with the derivatives with respect to the pressures difference between the considered node and the upstream one $j\left(P_{k j}^{t+\Delta t}-P_{k j-1}^{t+\Delta t}\right)$ :

$$
\begin{aligned}
& A_{k}(1,3)=-\frac{\partial F_{k 1}}{\partial\left(P_{k_{j}}-P_{k_{j-1}}\right)}=\rho_{k_{j-1 / 2}}^{t} \frac{\partial u_{k j-1 / 2}^{t+\Delta t}}{\partial\left(P_{k_{j}}-P_{k_{j-1}}\right)} A_{k j-1 / 2}^{t} \Delta t+\frac{\partial \Phi_{k j}{ }^{t+\Delta t}}{\partial\left(P_{k_{j}}-P_{k_{j-1}}\right)} \\
& A_{k}(2,3)=-\frac{\partial F_{k 2}}{\partial\left(P_{k j}-P_{k j-1}\right)}=\rho_{k j-1 / 2}^{t} \frac{\partial u_{k j-1 / 2}^{t+\Delta t}}{\partial\left(P_{k j}-P_{k j-1}\right)} e_{a k j-1 / 2}^{t} A_{k j-1 / 2}^{t} \Delta t+ \\
& +P_{k j}^{t+\Delta t} \frac{\partial u_{k j-1 / 2}^{t+\Delta t}}{\partial\left(P_{k_{j}}-P_{k_{j-1}}\right)} A_{k_{j-1 / 2}}^{t} \Delta t+\frac{\partial Q_{i k j}{ }^{t+\Delta t}}{\partial\left(P_{k_{j}}-P_{k_{j-1}}\right)}+\frac{\partial\left(\left(\Phi_{k}\right)_{j}^{t+\Delta t} h_{k j}{ }^{t+\Delta t}\right)}{\partial\left(P_{k_{j}}-P_{k_{j-1}}\right)}+\frac{\partial Q_{w k j}{ }^{t+\Delta t}}{\partial\left(P_{k_{j}}-P_{k_{j-1}}\right)}
\end{aligned}
$$

As we can see, the terms that are derivated in the mass conservation equation are the convective terms where the velocity in the faces appears, and the mass generation term, which has this velocity inside its definition too.

In the energy function, and when deriving with respect to the pressures difference, we have the convective term too, the term due to the volume expansion, the derivate of the interfacial heat transfer, and the derivate of the mass generation which is explained in detail in Appendix B.

Now we will obtain the derivatives with respect to the pressures difference between the downstream node and the considered one $j,\left(P_{k_{j+1}}^{t+\Delta t}-P_{k_{j}}^{t+\Delta t}\right)$ :

$$
\begin{aligned}
& A_{k}(1,4)=-\frac{\partial F_{k 1}}{\partial\left(P_{k_{j+1}}-P_{k_{j}}\right)}=-\rho_{k_{j+1 / 2}}^{t} \frac{\partial{u_{k j+1 / 2}}^{t+\Delta t}}{\partial\left(P_{k_{j+1}}-P_{k_{j}}\right)} A_{k_{j+1 / 2}}^{t} \Delta t+\frac{\partial \Phi_{k j}{ }^{t+\Delta t}}{\partial\left(P_{k_{j+1}}-P_{k_{j}}\right)} \\
& A_{k}(2,4)=-\frac{\partial F_{k 2}}{\partial\left(P_{k_{j+1}}-P_{l j}\right)}=-\rho_{k_{j+1 / 2}}^{t} \frac{\partial{u_{k j+1 / 2}}^{t+\Delta t}}{\partial\left(P_{k_{j+1}}-P_{k j}\right)} e_{a l j+1 / 2}^{t} A_{k_{j+1 / 2}}^{t} \Delta t
\end{aligned}
$$


$-P_{k j}^{t+\Delta t} \frac{\partial u_{k j+1 / 2}^{t+\Delta t}}{\partial\left(P_{k_{j+1}}-P_{k j}\right)} A_{k j+1 / 2}^{t} \Delta t+\frac{\partial Q_{i k j}^{t+\Delta t}}{\partial\left(P_{k_{j+1}}-P_{k_{j}}\right)}+\frac{\partial\left(\left(\Phi_{k}\right)_{j}^{t+\Delta t} h_{k j}{ }^{t+\Delta t}\right)}{\partial\left(P_{k_{j+1}}-P_{k_{j}}\right)}+\frac{\partial Q_{w k j}{ }^{t+\Delta t}}{\partial\left(P_{k_{j+1}}-P_{k_{j}}\right)}$

When deriving with respect to the pressures difference between the downstream node and the considered one, the terms that appear are the same as in the previous pressures difference.

Now we have defined all the terms of the system of Equations (5.29).

We proceed here by clearing $\left[A_{j}\right]^{-1}$ from Equation (5.29) we get:

$$
\begin{aligned}
& {\left[\begin{array}{l}
\delta P_{k} \\
\delta T_{k}
\end{array}\right]=\left[A_{j}\right]^{-1}\left[\begin{array}{l}
-F_{k 1} \\
-F_{k 2}
\end{array}\right]+} \\
& \left.\quad+\delta\left(P_{l j}-P_{l j-1}\right)\left[A_{j}\right]^{-1}\left[-\frac{\partial F_{k 1}}{\partial\left(P_{l j}-P_{l j-1}\right)}\right]+\delta\left(P_{l j+1}-P_{l j}\right)\left[A_{j}\right]^{-1}\left[-\frac{\partial F_{k 2}}{\partial\left(P_{l j}-P_{l j-1}\right)}\right]-\frac{\partial F_{k 2}}{\partial\left(P_{l j+1}-P_{l j}\right)}\right]
\end{aligned}
$$

This can be expressed as follows:

$$
\left[\begin{array}{l}
\delta P_{k} \\
\delta T_{k}
\end{array}\right]=\vec{b}_{5 k}+\vec{b}_{3 k} \delta\left(P_{k j}-P_{k j-1}\right)+\vec{b}_{4 k} \delta\left(P_{k_{j+1}}-P_{k j}\right)
$$

where we define the vectors:

$$
\vec{b}_{5 k}=\left[A_{j}\right]^{-1}\left[\begin{array}{l}
-F_{k 1} \\
-F_{k 2}
\end{array}\right]
$$




$$
\begin{gathered}
\vec{b}_{3 k}=\left[A_{j}\right]^{-1}\left[\begin{array}{c}
-\frac{\partial F_{k 1}}{\partial\left(P_{l j}-P_{l j-1}\right)} \\
-\frac{\partial F_{k 2}}{\partial\left(P_{l j}-P_{l j-1}\right)}
\end{array}\right] \\
\vec{b}_{4 k}=\left[A_{j}\right]^{-1}\left[\begin{array}{c}
\partial F_{k 1} \\
-\frac{\partial\left(P_{l j+1}-P_{l j}\right)}{\partial\left(P_{l j+1}-P_{l j}\right)}
\end{array}\right]
\end{gathered}
$$

We get from Equation 5.42 two linear equations for each cell from here:

$$
\left\{\begin{array}{l}
\delta P_{k j}=b_{5 k}(1)+b_{3 k}(1) \delta\left(P_{k_{j}}-P_{k_{j-1}}\right)+b_{4 k}(1) \delta\left(P_{k_{j+1}}-P_{k_{j}}\right) \\
\delta T_{k j}=b_{5 k}(2)+b_{3 k}(2) \delta\left(P_{k_{j}}-P_{k_{j-1}}\right)+b_{4 k}(2) \delta\left(P_{k_{j+1}}-P_{k_{j}}\right)
\end{array}\right.
$$

In the Equation (5.44) we have $\delta P_{k}$ as a linear function of the unknowns $\delta\left(P_{k j}-P_{k j-1}\right)$ and $\delta\left(P_{k j+1}-P_{k_{j}}\right)$, and thence, we have the pressure in one cell related with the pressure in the neighbor cells for each phase.

The way we are solving this system is by solving first the Equation (5.44) for all the nodes of the continuity grid. These equations are assembled and we have a tridiagonal system of equations, with dimension NZMAX (maximum number of nodes of the discretized pipe), as we see in the next matrix: 


$$
\left[\begin{array}{cccccccccc}
J_{1} & L_{1} & 0 & . & . . & . & . & . . & . . & 0 \\
K_{2} & J_{2} & L_{2} & 0 & . . & . . & . . & . . & . . & 0 \\
0 & K_{3} & J_{3} & L_{3} & 0 & . . & . . & . . & . . & 0 \\
0 & . . & . . & . . & . . & . . & . & . . & . . & 0 \\
0 & . . & . . & . . & . . & . . & . . & . . & . . & 0 \\
0 & . . & . . & . . & . . & . & . & . . & . . & 0 \\
0 & . . & . . & . & . . & . & . & . . & . . & 0 \\
0 & . . & . . & . . & . . & & K_{N-2} & J_{N-2} & L_{N-2} & 0 \\
0 & . . & . . & . . & . . & . . & . . & K_{N-1} & J_{N-1} & L_{N-1} \\
0 & . . & . . & . . & . . & . . & . . & . . & K_{N} & J_{N}
\end{array}\right]\left[\begin{array}{c}
\delta P_{1} \\
\delta P_{2} \\
\delta P_{3} \\
. \\
. \\
. . \\
. . \\
\delta P_{N-2} \\
\delta P_{N-1} \\
\delta P_{N}
\end{array}\right]=\left[\begin{array}{c}
M_{1} \\
M_{2} \\
M_{3} \\
. \\
. \\
. . \\
. . \\
M_{N-2} \\
M_{N-1} \\
M_{N}
\end{array}\right]
$$

where the elements of the matrix for each phase are:

$$
\begin{aligned}
& K=b_{3}(1) \\
& J=b_{4}(1)-b_{3}(1)+1 \\
& L=-b_{4}(1) \\
& M=b_{5}(1)
\end{aligned}
$$

These elements are obtained in the subroutine VIMP (subroutine in charge of solving the mass and energy functions in our code) and they are stored in the common matrix. This matrix is solved in the subroutine TRIDIAG.

When assembling all equations depending on increment of the pressure in one system of linear equations, we get a tridiagonal matrix which elements are: aa, $\mathrm{b}$ and $\mathrm{c}$ of the page.

The special case of a linear system is the tridiagonality. This is that, only the elements of the main diagonal and two parallel bands are different from zero. This is a common system which occurs frequently and can be solved with a LU decomposition.

The tridiagonal matrix is solved using the subroutine TRIDIAG. This subroutine solves for the u vector with a NZMAX length, the tridiagonal system.

We have added the LAPACK libraries in order to solve the tridiagonal matrix more efficiently. So, in the VIMPL and VIMPV subroutines, we give the corresponding values to the matrix T(NZMAX,NZMAX) and H(NZMAX,1). These matrices are the input to the LAPACK libraries. 
For the resolution of the matrix, as for the liquid and steam separately, we need to multiply the inverse matrix by the vectors $\vec{b}_{5}, \vec{b}_{6}, \vec{b}_{7}$. This multiplication is made with the LU decomposition subroutines: LUDCMP, LUBKSB, obtained from the reference [William H. Press].

In order to assure the stability of the LU decomposition a partial pivoting (columns interchange) is necessary. This partial pivoting is implemented in the subroutines LUDCMP and LUKSB in our code.

The elements of the matrix to be solved are obtained from the VIMP subroutine. This subroutine calls to the subroutine LUDCMP using the following arguments: A, NLOG, NOHYS, INDX, D. The subroutine replaces the A matrix, by the LU one decomposition. NPHYS is the dimension of the matrix. In our case, NLOG and NPHYS equal two. INDX is the exit argument of the subroutine. This vector stores the permutation column affected by the partial pivoting. The argument $\mathrm{D}$ is also an exit of the subroutine LUDCMP which has the value of +1 or -1 , depending on the number of interchanged columns being even or odd.

The subroutine, in combination with the matrix LUBKSB, obtains the product of the vectors $\vec{b}$ by the matrix A. this product receives again the name of $\vec{b}$, and the matrix A disappears.

The subroutine LUBKSB is called from the subroutine VIMP with the arguments: A, NLOG, NPHYS, INDX and b3, b4 or b5 as necessary. A is the LU decomposition obtained with the subroutine LUDCMP. When we solve this system we get the new values for the vectors b3, b4 and b5. The obtained values are stored for their future utilization. The first values of the vectors correspond to the pressure increments, and they are stored in each cell for the resolution of the tridiagonal matrix as follow:

$$
\begin{aligned}
& a a_{i-e s i m}=b_{5 k}(1) \\
& b_{i-e s i m}=b_{6 k}(1)-b_{5 k}(1)+1 \\
& c_{i-e s i m}=b_{6 k}(1) \\
& r_{i-e s i m}=b_{7 k}(1)
\end{aligned}
$$


These values are stored in the common MATRIZ, and i takes the value from 1 to NZMAX. At each iteration, we calculate every $\delta P_{k j}$, and in the subroutine $\mathbf{B K S}$, we update the values of the rest of the unknowns with the calculated increments. Therefore, for the last $\mathrm{r}$ iteration we have the value for $\delta P_{k j}=P_{k j}{ }^{r+1}-P_{k j}{ }^{r}$, and so, the value for $P_{k j}{ }^{r+1}$ as the result of the $r^{\text {th }}$ Newton algorithm. Once we get the pressure values for the $r+1$ iteration, we get for the rest of unknown variables:

- From Equation (5.38), we obtain directly the new temperature values at the centre of the continuity cells, as follows:

$$
T_{k j}^{r+1}=T_{k j}^{r}+\delta T_{k j}
$$

- In order to update the velocities for the $\mathrm{r}$ iteration, we have to make use of the Equation (5.15), and since we have the derivative of the velocity with respect to the pressures difference, hence we can directly obtain the variation of the velocity due to the pressure corrections as follows:

$$
\delta u_{k j-1 / 2}^{r+1}=\frac{\partial u_{k j-1 / 2}^{t+\Delta t}}{\partial\left(P_{k_{j}}-P_{k_{j-1}}\right)} \cdot\left(\delta P_{k_{j}}-\delta P_{k_{j-1}}\right)
$$

Then:

$$
u_{k j-1 / 2}^{r+1}=u_{k j-1 / 2}^{r}+\delta u_{k j-1 / 2}^{r+1}=u_{k_{j-1 / 2}^{r}}^{r}+\frac{\partial u_{k j-1 / 2}^{t+\Delta t}}{\partial\left(P_{k_{j}}-P_{k_{j-1}}\right)} \cdot\left(\delta P_{k_{j}}-\delta P_{k_{j-1}}\right)
$$

\subsection{CONVECTIVE TERMS}

The convective terms which appear in the discretization of the mass and energy conservation equations, were evaluated using the ULTIMATE-SOU (second order 
upwinding) method. For the convective terms of the momentum equation, we are using the ULTIMATE-QUICKEST method. These methods are explained in Appendix H.

The SOU (second order upwinding) method is used in our code to calculate the convective terms of the mass and energy equations. This scheme is less diffusive than the FOU (first order upwinding), but we can have oscillations in the solution. A way of reducing these oscillations is by using the ULTIMATE strategy, which is explained in Appendix H.

In order to reduce the oscillations of the SOU method, in the momentum equations, there were developed when studying the computational fluid systems, some so called high resolution schemes with convective kinematics, being one of them the QUICKEST method.

The QUICKEST (Quadratic Upstream Interpolation for Convective Kinematics with Estimated Streaming Terms) is used in our code for evaluating the convective terms of the momentum equation.

The QUICKEST and the FOU schemes are used in our code combined with the ULTIMATE strategy.

The ULTIMATE strategy belongs to the TVD (Total Variation Diminution) schemes.

The ULTIMATE strategy is based on an explicit formulation that uses a Universal Limitator. This strategy, expressed by B.P. Leonard, has one simple universal limitator, which can be applied to a differences scheme without an order restriction. This limitator makes the oscillations vanish without affecting the exactitude of the scheme hoped for.

\subsection{CONVERGENCE ALGORITHM FOR THE BIPHASIC SYSTEM AND EQUATIONS LINKAGE}

Here it is explained the procedure that we follow in order to reach the converged solution. It has been shown in the previous points how the momentum and the mass and energy equations for one time step are solved. Now since we have a two-phase flow where the phases are flowing countercurrently and totally separated, we have to operate in a special way in order to find the solution. 
1) First there are set all the initial conditions for the steam and for the liquid phases, so as the boundary conditions.

2) The steam pressure, velocity and temperature distributions for the next time step by assuming a constant temperature and velocity fields for the liquid defined as initial conditions are calculated.

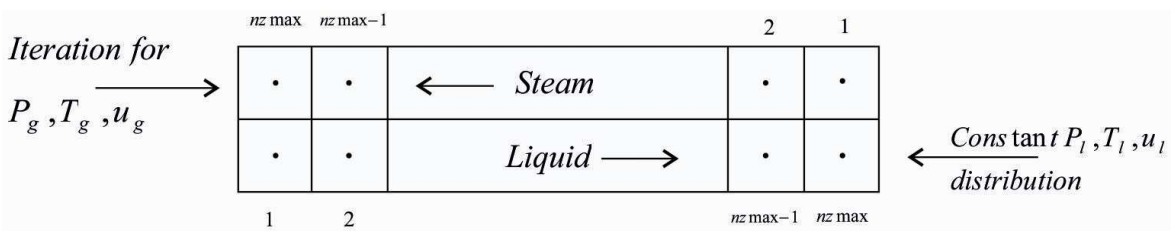

Figure 5.4 Iteration for solving the steam phase field

3) Now, a new liquid temperature and velocities distribution for the next time step by assuming a constant pressure, temperature and velocity fields are calculated for the steam previously obtained for the same time step.

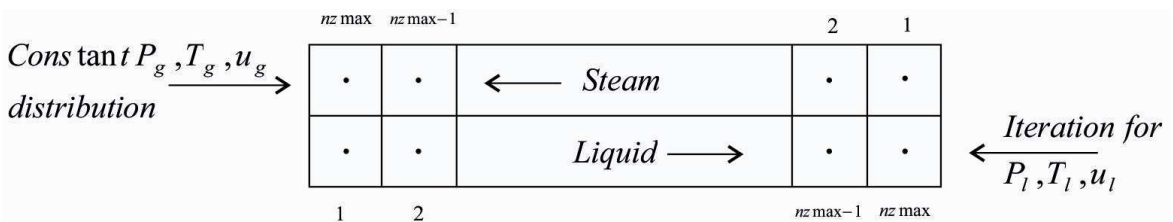

Figure 5.5 Iteration for solving the liquid phase field

4) Once iterated, the temperature and velocity vectors for the liquid and the steam are updated for the next time step with the distributions that we have previously calculated.

5) Now we jump back to step 2) with the variable distributions that we have just obtained, and we go on with this procedure until the converged solution is obtained.

Therefore we are calculating a transient with given boundary conditions, and so, we finally reach a converged solution which will give us a pressure, temperature and velocity distribution for the liquid and the steam.

As for each time step, we solve the system of equations for each phase separately, we need for each phase the temperature, and velocity distributions for the other phase in order to calculate all the dimensionless numbers and so, the mass and energy transfer between phases. In this way, when for one phase we need for example the temperature of the other 
phase, and noticing that the liquid and the steam flow countercurrently, we couple the node $i$ of the phase which we are calculating, with the NZMAX-i one of the other.

\subsection{GEOMETRICAL VARIABLES UPDATING}

For each time step, once the Newton-Raphson algorithm exists for each phase, and before step 5) and after step 4) as it is explained in the previous point, the subroutine ACTVAR is called. In this subroutine, all the unknown variables $\left(P_{l}, T_{l}, u_{l}, P_{g}, T_{g}, u_{g}\right)$ of our problem are updated to the $\mathrm{t}+1$ calculated values.

In order to solve the energy and mass equations for each phase separately, we avoided considering the void fraction in the equations and so, we considered the area constant for one time step for each phase.

In this point at the ACTVAR subroutine, and before continuing with the next time step, we need to update the geometrical variables, including the areas for each phase.

For this we force the system to accomplish the liquid area conservation equation. So, calculate the new liquid area, and then the steam area, and all the required geometrical variables for our problem. This equation is:

$$
\frac{\partial A_{l}}{\partial t}+\nabla \cdot\left(A_{l} \vec{u}_{l}\right)=\frac{\Gamma_{\text {wall }}}{\rho_{l_{-} \text {wall }} \Delta x}+\frac{\Gamma_{\text {int erface }}}{\rho_{l_{-} \text {int erface }} \Delta x}+\frac{\Gamma_{\text {injection }}}{\rho_{l_{-} \text {inyect }} \Delta x}
$$

where $\Gamma_{\text {wall }}, \Gamma_{\text {int erface }}$ and $\Gamma_{\text {injection }}$ are the different sources of liquid mass in $(\mathrm{Kg} / \mathrm{s})$. 


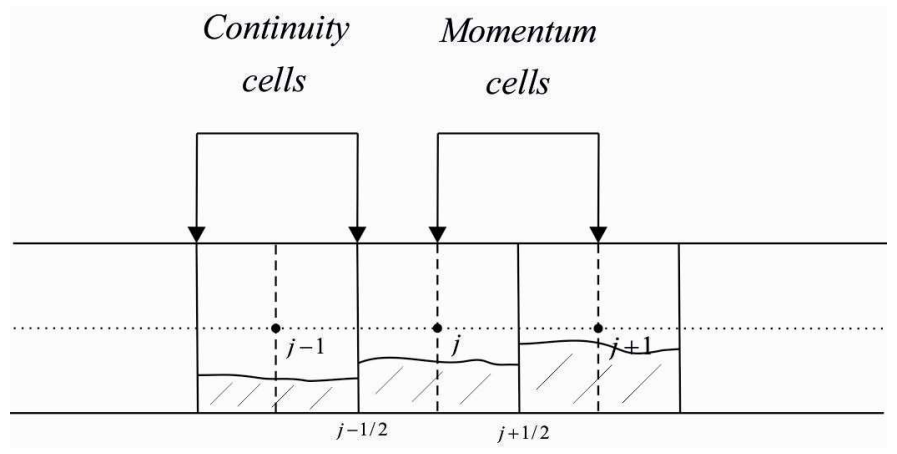

Figure 5.6 Pipe nodalization and liquid area scheme

The 1D equation for the conservation of liquid area, which is obtained from equation (5.50) is:

$$
\frac{\partial A_{l}(x, t)}{\partial t}+\frac{\partial A_{l}(x, t) u_{l}(x, t)}{\partial x}=\frac{\Gamma_{\text {wall }}(x, t)}{\rho_{l_{-} \text {wall }} \Delta x}+\frac{\Gamma_{\text {int erface }}(x, t)}{\rho_{l_{-} \text {int erface }} \Delta x}+\frac{\Gamma_{\text {injection }}(x, t)}{\rho_{l_{-} \text {inyect }} \Delta x}
$$

we will integrate now the Equation (5.51) in the $\mathrm{j}$ continuity cell, i.e. between $j-1 / 2$ and $j+1 / 2$.

$$
\begin{aligned}
\int_{j-1 / 2}^{j+1 / 2} \frac{\partial A_{l}}{\partial t} d x d t & +\int_{j-1 / 2}^{j+1 / 2} \frac{\partial A_{l}(x, t) u_{l}(x, t)}{\partial x} d x d t= \\
& \int_{j-1 / 2}^{j+1 / 2}\left[\frac{\Gamma_{\text {wall }}}{\rho_{l_{-} \text {wall }} \Delta x}+\frac{\Gamma_{\text {int erface }}}{\rho_{l_{-} \text {int erface }} \Delta x}+\frac{\Gamma_{\text {injection }}}{\rho_{l_{-} \text {inyect }} \Delta x}\right] d x d t
\end{aligned}
$$

We obtain the following discretized equation:

$$
A_{l j}^{t+\Delta t} A_{l_{j}}^{t}+\left(A_{l_{j+1 / 2}}^{t} u_{l j+1 / 2}^{t}-A_{l_{j-1 / 2}}^{t} u_{l_{j-1 / 2}^{t}}^{t}\right) \frac{\Delta t}{\Delta x}=\frac{\Gamma_{\text {wall }} \Delta t}{\rho_{l_{-} \text {wall }} \Delta x}+\frac{\Gamma_{\text {int erface }} \Delta t}{\rho_{l_{-} \text {int erface }} \Delta x}+\frac{\Gamma_{\text {injection }} \Delta t}{\rho_{l_{\text {_inyect }}} \Delta x}
$$

Clearing the value for the new liquid area value $A_{l j}^{t+\Delta t}$ :

$$
A_{l_{j}}^{t+\Delta t}=A_{l_{j}}^{t}+\left(A_{l_{j-1 / 2}}^{t} u_{l_{j-1 / 2}}^{t}-A_{l_{j+1 / 2}}^{t} u_{l_{j+1 / 2}}^{t}\right) \frac{\Delta t}{\Delta x}+\frac{\Gamma_{\text {wall }} \Delta t}{\rho_{l_{-} \text {wall }} \Delta x}+\frac{\Gamma_{\text {int erface }} \Delta t}{\rho_{l_{-} \text {int erface }} \Delta x}+\frac{\Gamma_{\text {injection }} \Delta t}{\rho_{l_{\text {_inyect }}} \Delta x}
$$


Now we get the steam phase area, as follows:

$$
A_{g_{j}}{ }^{t+\Delta t}=\pi R^{2}-A_{l j}{ }^{t+\Delta t}
$$

Now we can calculate the steam void fraction for each cell with the following equation:

$$
\alpha_{j}=\frac{A_{g_{j}}{ }^{t+\Delta t}}{\pi R^{2}}
$$

Now that we have the new values for the steam volume fraction, we can get the new values for all the geometric variables for the liquid and steam phases in every cell of the pipe, at the ACTVARPR subroutine.

It is to be said here that it would be a better solution to include in the unknown variables the liquid phase area and iterate with it. Since the duct has a constant area, and the source of mass is small for almost all of the cases it hasn't been implemented. The difficulties came up when we were trying to reproduce the case where we were taking into account the HPI injection in the middle of the pipe as it happens at the ROSA facility.

This is because in this case we have an extra addition of mass in one cell, due to the HPI (high pressure injection), and the code isn't prepared to deal with this problem called "water packing" in the literature. For a better simulation of this phenomenon we should have reprogrammed the code and included another equation, which would be the liquid area conservation equation in the iterative algorithm and modified the solution matrix and all the Jacobian coefficients which are involved.

This is something that should be continued in the future and hence, keep on improving the code by the future PHD students that will come up at the Nuclear Engineering Department at the Polytechnic university of Valencia.

\subsection{DESIGN AND IMPLEMENTATION OF THE CC CODE}

In this chapter we will describe our $\mathrm{CC}$ code and all the subroutines that form it. As we already saw in previous chapters, we need to solve the governing equations of a $1 \mathrm{D}$ 
biphasic countercurrent stratified flow. We have programmed this CC problem using the FORTRAN 90 programming language, under the tool DIGITAL VISUAL FORTRAN 2010.

We have structured the program using subroutines, which are called from the main program. The common variables which are used in the different subroutines, are stored in COMMON files which are included in the subroutine by using the sentence INCLUDE.

Following the main program flow, we firstly initialize the physical and geometrical variables, based upon the characteristics and the initial and boundary conditions of the problem. After having initialized the problem, we continue with getting a new velocity distribution, first for the steam, and then for the liquid, in the subroutines VEFICV and VEFICL.

Once we have the new velocity profile, we continue by solving the mass and energy equations for steam and liquid as we explain in Chapter 6. As we saw before, we solve this system of equations iteratively. So, we proceed to getting a new pressure, temperature and velocity distriburions of the corresponding phase by supposing constant velocities, pressure and temperature fields for the liquid phase for every iteration. Once we come out of the iterative process for the steam, we do the same with the liquid, supposing now constant the velocity, temperature and pressure fields of the steam at each iteration, as previously obtained.

The velocity fields are updated at each and every iteration as follows:

$$
\begin{aligned}
& u_{g_{j-1 / 2}^{r+1}}^{r+1}=u_{g_{j-1 / 2}}^{r}+\frac{\partial u_{g_{j-1 / 2}}^{t+\Delta t}}{\partial\left(P_{g_{j}}-P_{g_{j-1}}\right)}\left(\delta P_{g_{j}}-\delta P_{g_{j-1}}\right) \\
& u_{l j-1 / 2}^{r+1}=u_{l j-1 / 2}^{r}+\frac{\partial u_{l_{j-1 / 2}}^{t+\Delta t}}{\partial\left(P_{l_{j}}-P_{l j-1}\right)} \cdot\left(\delta P_{l_{j}}-\delta P_{l_{j-1}}\right)
\end{aligned}
$$

This process is similar to the Patankar SIMPLER method velocity pressure correction. In our problem we do this process twice, one for the steam first, and then for the liquid. 
The obtained velocity, temperature and pressure distributions are cheked to be converged in the subroutine CONVERGEV for the steam, and CONVERGEL for the liquid.

When the problem is converged, for the steam and the liquid, we continue by updating all the variables for the steam and the liquid, and then we continue for another time step.

Hereafter we show a flow chart of the CC code:

START

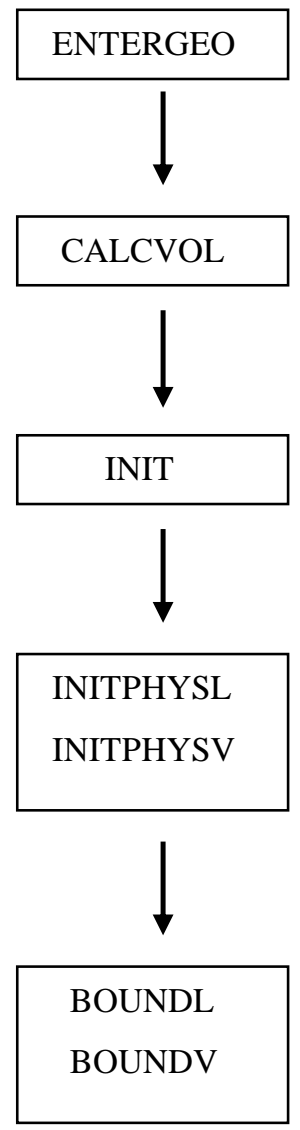

Here we enter the values of the geometric variables.

Here we calculate the rest of geometrical variables that we need (AREACV,AREACL,AREAMV, AREAML,PERMV,PERML,PINTERF ,THETAV,THETAL,DHV,DHL) .

Here we initialize the physical variables $\left(\mathrm{U}_{\mathrm{G}}, \mathrm{U}_{\mathrm{L}}, \mathrm{P}_{\mathrm{V}}, \mathrm{P}_{\mathrm{L}}, \mathrm{T}_{\mathrm{V}}, \mathrm{T}_{\mathrm{L}}\right.$, $\mathrm{U}_{\mathrm{GN}}, \mathrm{U}_{\mathrm{LN}}, \mathrm{P}_{\mathrm{VN}}, \mathrm{P}_{\mathrm{LN}}, \mathrm{T}_{\mathrm{VN}}, \mathrm{T}_{\mathrm{LN}}$, and $\left.\mathrm{C}_{1}, \mathrm{C}_{2}, \mathrm{C}_{3}, \mathrm{C}_{4}, \mathrm{C}_{5}\right)$.

Here we initialize the physical properties $\left(\mathrm{E}_{\mathrm{L}}, \mathrm{H}_{\mathrm{L}}, \mathrm{Rho}_{\mathrm{L}}, \mathrm{Cp}_{\mathrm{L}}, \mathrm{C}_{\mathrm{L}}\right.$, $\mathrm{Vis}_{\mathrm{L}}, \mathrm{Beta}_{\mathrm{L}}, \mathrm{E}_{\mathrm{V}}, \mathrm{H}_{\mathrm{V}}, \mathrm{Rho}_{\mathrm{V}}, \mathrm{Cp}_{\mathrm{V}}, \mathrm{C}_{\mathrm{V}}, \mathrm{Vi}$ $\mathrm{s}_{\mathrm{V}}$, Beta $\left._{\mathrm{V}}\right)$.

Here we initialize the boundary conditions at the inlet and outlet of the liquid and steam.

$\left(\mathrm{U}_{\text {LINT }}, \mathrm{P}_{\text {LINT }}, \mathrm{T}_{\mathrm{LBC}}, \mathrm{A}_{\mathrm{LPINT}}+\right.$ liquid physical properties,

$\mathrm{U}_{\mathrm{GINT}}, \mathrm{P}_{\mathrm{GINT}}, \mathrm{T}_{\mathrm{GBC}},+$ steam physical properties). 


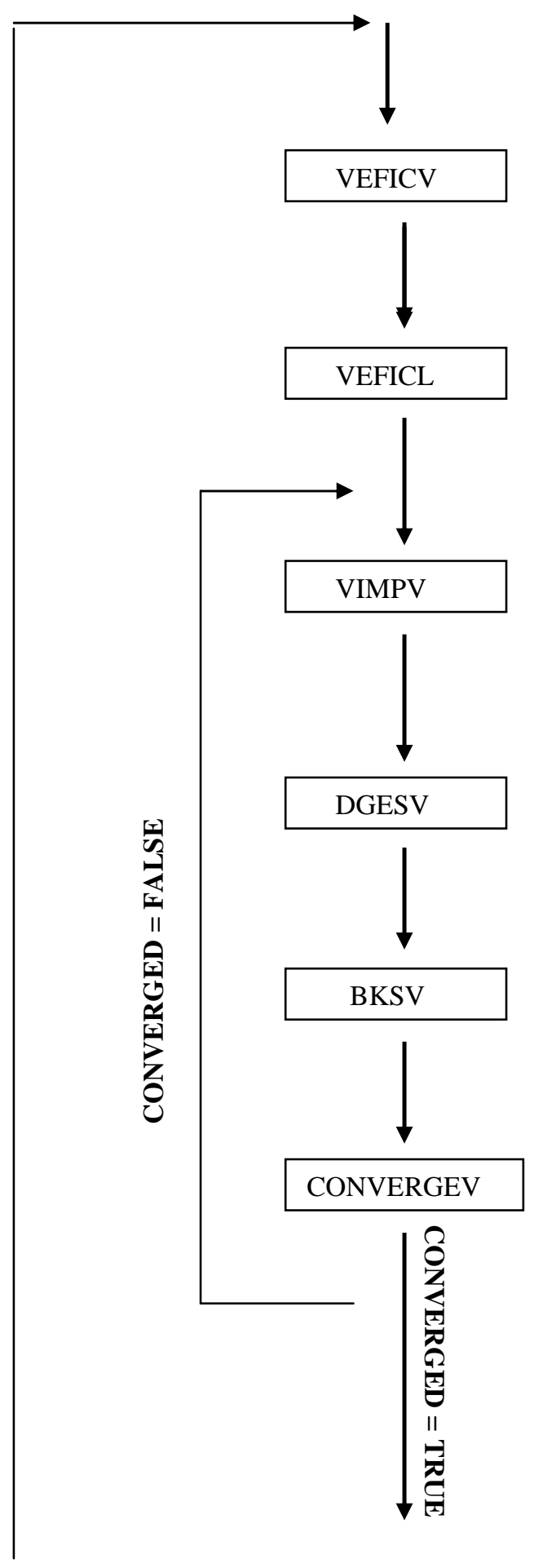

Here we solve the steam mass and momentum equations in order to get the next time step velocity profile and its derivatives, UGN, DUGDP.

Here we solve the liquid mass and momentum equations in order to get the next time step velocity profile and its derivatives, ULN, DULDP.

Here we solve the steam mass and energy equations in order to get the next time step velocity, temperature and pressure profiles

$\left.\mathrm{U}_{\mathrm{GN}}, \mathrm{T}_{\mathrm{GN}}, \mathrm{P}_{\mathrm{GN}}\right)$.

This subroutine solves the tridiagonal matrix of the mass and energy equations, with the LAPACK libraries.

This subroutine updates the velocity, temperature and pressure profiles $\mathrm{U}_{\mathrm{GN}}$, $\mathrm{T}_{\mathrm{GN}}, \mathrm{P}_{\mathrm{GN}}$, at each and every iteration, since the algorithm is looking to find the root for the system of equations.

This subroutine checks if the algorithm is converged and the root has been found for the tridiagonal matrix. 


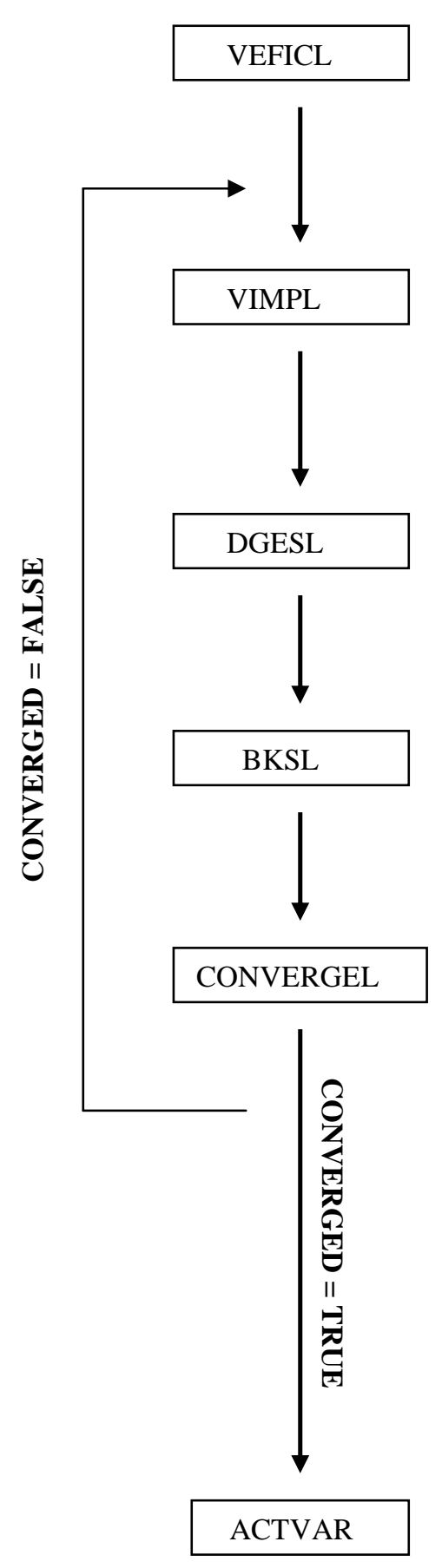

Here we solve the liquid mass and momentum equations in order to get the next time step velocity profile and its derivatives, ULN, DULDP.

Here we solve the steam mass and energy equations in order to get the next time step velocity, temperature and pressure profiles

$\left.\mathrm{U}_{\mathrm{LN}}, \mathrm{T}_{\mathrm{LN}}, \mathrm{P}_{\mathrm{LN}}\right)$.

This subroutine solves the tridiagonal matrix of the mass and energy equations, with the LAPACK libraries.

This subroutine updates the velocity, temperature and pressure profiles $\mathrm{U}_{\mathrm{LN}}$, $\mathrm{T}_{\mathrm{LN}}, \mathrm{P}_{\mathrm{LN}}$, at each and every iteration, since the algorithm is looking to find the root for the system of equations.

This subroutine checks if the algorithm is converged and the root has been found for the tridiagonal matrix.

This subroutine updates the velocity, temperature and pressure profiles for the steam and for the liquid. Also updates the geometrical variables for the next time step. 


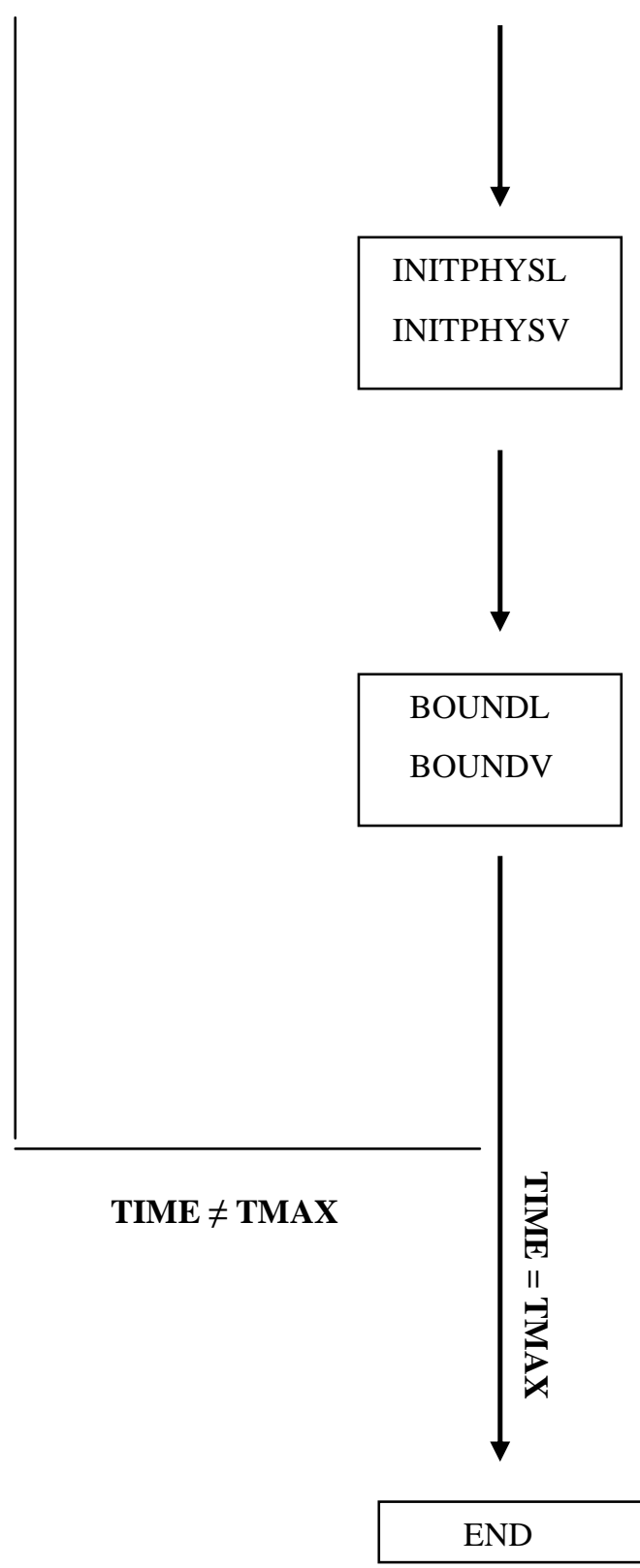

Here we initialize the physical properties $\left(\mathrm{E}_{\mathrm{L}}, \mathrm{H}_{\mathrm{L}}, \mathrm{Rho}_{\mathrm{L}}, \mathrm{Cp}_{\mathrm{L}}, \mathrm{C}_{\mathrm{L}}\right.$, Vis $_{L}$, Beta $_{L}, \mathrm{E}_{\mathrm{V}}, \mathrm{H}_{\mathrm{V}}, \mathrm{Rho}_{\mathrm{V}}, \mathrm{Cp}_{\mathrm{V}}, \mathrm{C}_{\mathrm{V}}, \mathrm{Vi}$ $\mathrm{s}_{\mathrm{V}}, \mathrm{Beta}_{\mathrm{V}}$ ) for the next time step .

Here we initialize the boundary conditions at the inlet and outlet of the liquid and steam for the next time step.

$\left(\mathrm{U}_{\text {LINT }}, \mathrm{P}_{\text {LINT }}, \mathrm{T}_{\mathrm{LBC}}, \mathrm{A}_{\text {LPINT }}+\right.$ liquid physical properties,

$\mathrm{U}_{\mathrm{GINT}}, \mathrm{P}_{\mathrm{GINT}}, \mathrm{T}_{\mathrm{GBC}},+$ steam physical properties). 


\subsubsection{INITIALIZATION}

In order to solve our problem, we firstly need to initialize all the geometrical variables, which we will need later. For this issue, we have implemented the subroutine ENTERGEO. This subroutine reads the values for the geometrical variables by reading from a file called Datostuberia. These geometrical variables are:

In case of a circular duct:

The number of nodes NZMAX.

The pipe length $\mathrm{L}$.

The pipe radius $\mathrm{R}$

The pipe thickness TH.

The isolation conductivity CONDAISL.

In case of a rectangular duct:

The number of nodes NZMAX.

The pipe length $\mathrm{L}$.

The pipe width WD

The duct Height HTH.

The pipe thickness TH.

The isolation conductivity CONDAISL.

So in the code we first call the subroutine ENTERGEO where we will get the value of DZ for each cell. Afterwards, we call the subroutine CALCVOL. In this one we get the value for the rest of geometrical variables and we store them in the common COMMGEO.

The variables that we calculate in CALCVOL are: 
The area of the continuity cells for the steam AREACV.

The area of the continuity cells for the liquid AREACL.

The area of the momentum cells for the steam AREAMV.

The area of the momentum cells for the steam AREAML.

The contact angle of the steam with the wall THETAV.

The contact angle of the liquid with the wall THETAL.

The contact perimeter of the steam PERMV.

The contact perimeter of the liquid PERML.

The interfacial contact perimeter between the steam and the liquid phases PINTERF.

The hydraulic diameter of the steam DHV.

The hydraulic diameter of the liquid DHL.

The dimension of these vectors is NZMAX +2 . The reason for this is that, when using a second order upwinding and the quickest schemes to solve our problem, we need to have two virtual cells. So, we have two more cells than the total number of cells NZMAX for the pipe length. These variables are stored in the common COMMGEO.

Now we have to set the initial conditions for the problem. This is accomplished by setting all the initial values for the variables which we will solve in the problem. So we call the subroutine INIT, which reads an already prepared file called COND, which has these initial conditions for the problem. These conditions are:

The initial steam velocity UGI.

The initial liquid velocity ULI.

The initial steam pressure PVIN.

The initial liquid pressure PLIN.

The initial steam temperature TING.

The initial liquid temperature TINL.

The initial steam wall temperature TWINV.

The initial liquid wall temperature TWINL.

The initial steam volume fraction ALPIN. 
All these variables are stored in the common COMPHYS AND COMVEL, and they have a dimension of NZMAX.

We now call the subroutine INITPHYSL and INITPHYSV, in order to initialize the thermal-hydraulic properties and the derivatives of all the variables that we will need in further calculations for the liquid and for the steam. These variables are stored in the common COMPHYS, and they have a dimension of NZMAX +2 .

Now we specify the maximum execution time for the problem TIMMAX, and the time step DELTT.

Before starting to solve our problem, the only thing left to do is to set the boundary conditions for the problem. This is done in the subroutine BCNV for the steam, and BCNL for the liquid. The reason why we have two different subroutines for the boundary conditions is because, the way that we solve our countercurrent flowing steam and liquid problem is by solving first the steam, supposing the liquid as constant in the velocity, temperature and pressure fields, then updating all the variables for the steam, and then do the same for the liquid, supposing now the steam velocity, temperature and pressure fields as constant. Then we update the variables for the liquid and now we continue with another time step.

The subroutines BCNV and BCNL, read from a file called BOUND. First the value for the variables INLET and OUTLET are read. These specify if the boundary conditions for the inlet and the outlet are a pressure condition or a velocity condition. In our case, we have a velocity condition at the inlet, and a pressure condition at the outlet.

We are going to explain now the inlet and the outlet conditions:

INLET: At the inlet we have a velocity condition, both for the steam and for the liquid. So the subroutine reads the value for the inlet velocities, temperatures and pressures for the steam and the liquid, and the steam volume fraction. We call then the subroutine PROTER to get the thermal-hydraulic properties at the inlet.

OUTLET: At the outlet, we consider a pressure condition. So the subroutine reads from the file BOUND the value for the outlet pressure. Now we call the properties subroutine to get the thermal-hydraulic properties at the virtual cell NZMAX +2 . Then we calculate the value 
for the velocity and the derivative of the velocity with respect to the pressure differences at this virtual cell NZMAX+2.

\subsubsection{VEFICV AND VEFICL SUBROUTINES}

After we have initialized the problem, we call the subroutines VEFICV (for the steam phase) and VEFICL (for the liquid phase). In these subroutines we solve the momentum equations and we get a first estimation for the steam and the liquid velocities at the time step $n+1$. This first estimation will be modified later, when solving iteratively the mass and energy equations, and obtaining a new pressure field, first for the steam and then for the liquid.

In the subroutines VEFICV and VEFICL we call the subroutines CALCGR and FRICV for the steam (VEFICV) and to CALCLR and FRICL for the liquid (VEFICL).

In the subroutines FRICV and FRICL we calculate the friction factor with the wall for the steam ad the liquid, and the interfacial friction factors between phases.

The subroutines CALCGR and CALCLR, calculate the convective terms for the momentum equation $(\alpha \rho u)$ and $(\alpha \rho u u)$ for every momentum cell of the pipe. This moment flux is calculated at the centre of each continuity cell, or what is the same, at the centre of each momentum cell. For this calculation we use a second order upwinding scheme, combined with the QUICKEST scheme and a TVD (Total variation Diminution) strategy.

These fluxes that we have calculated, are stored as FUGR(NZMAX+2) and FRGR(NZMAX+2) for the steam, and FULR(NZMAX+2) and FRLR(NZMAX+2) for the liquid, in the common COMLOC.

So, in this subroutine, and as we already explained in Chapter 6, we solve the momentum and mass equations and we get a new velocity fields for the steam and the liquid.

Now we will show the flow diagram for the subroutine VEFIC: 
Calculation of the convective flows with the subroutines CALCGR, CALCLR

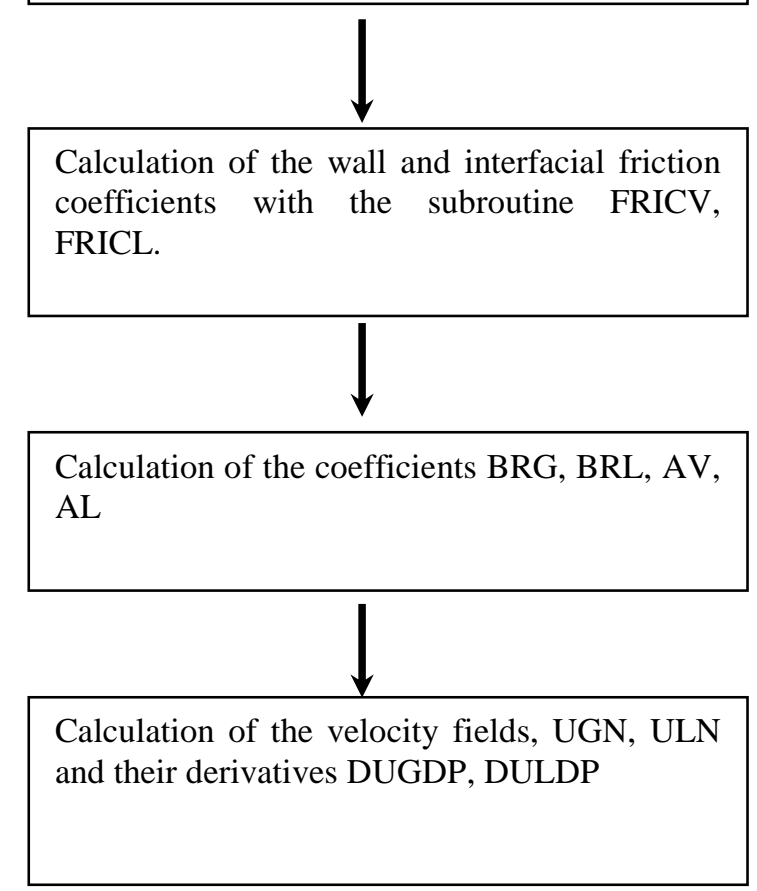

Figure 5.7 Flow diagram of the subroutine VEFIC

\subsubsection{VIMPV AND VIMPL SUBROUTINES}

We firstly need to evaluate the convective terms:

$\rho_{g} u_{g} A_{g}, \rho_{g} A_{g} \frac{\partial u_{g}}{\partial P_{g}}, \rho_{g} u_{g} e_{g} A_{g}, \rho_{g} e_{g} A_{g} \frac{\partial u_{g}}{\partial P_{g}}$, for the steam, and $\rho_{l} u_{l} A_{l}, \rho_{l} A_{l} \frac{\partial u_{l}}{\partial P_{l}}$, $\rho_{l} u_{l} e_{l} A_{l}, \rho_{l} e_{l} A_{l} \frac{\partial u_{l}}{\partial P_{l}}$. We calculate these terms in the subroutines FVAP, FLIQ, FEGN and FELN. 
In the subroutine VIMPV and VIMPL, we call the subroutines FVAP and FLIQ, where we calculate the convective terms, $\rho_{g} u_{g} A_{g}, \rho_{g} A_{g} \frac{\partial u_{g}}{\partial P_{g}}$ and $\rho_{l} u_{l} A_{l}, \rho_{l} A_{l} \frac{\partial u_{l}}{\partial P_{l}}$ respectively. Here, we have to calculate these terms at the faces of the momentum cells. How it has been already explained, it has been used an ULTIMATE-SOU strategy to get these values. This is a combination between the ULTIMATE and a second order upwinding schemes.

We calculate here the courant number using the steam or liquid velocity at the $n+1$ time step, and then we calculate the value for the indexes CENTRE, UP AND DOWN, where the up index is limited to the central one when the physical limits are exceeded. These indexes are used to calculate the convective flows and correspond to the ones explained in Appendix H. The convective terms are calculated with the ULTIMATE strategy, and stored as arrays in the common COMLOC.

In order to calculate the momentum convective terms, we use the subroutines FVAP and FLIQ. For the energy convective terms, we use the subroutines FEGN and FLIQN for the steam and the liquid respectively.

After having calculated the convective terms that we need to calculate the coefficients for the Jacobian matrix, using the subroutine VIMPV for the steam, or VIMPL for the liquid, we update the thermodynamic properties using the subroutine PROTER.

Once we have updated the thermodynamic properties, we call the subroutine GAMMAV for the steam and GAMMAL for the liquid to get the values for the condensation rate and its derivatives.

Now we call the subroutine CALORV and CALORL, where we calculate the heat transfer to the walls and the interfacial one, as the derivatives of these heats with respect to the corresponding pressure and temperature.

After this, and in the VIMPV subroutine, we call the PRESIONDEVAPOR subroutine to calculate the steam pressure associated to the liquid temperature, in order to get the limit where the steam cannot continue condensing. 
Now we calculate the coefficients of the Jacobian matrix $A(2,2)$. We invert this matrix and we multiply it by $\mathrm{A}(\mathrm{m}, 3), \mathrm{A}(\mathrm{m}, 4)$, and $\mathrm{A}(\mathrm{m}, 5)$, where $\mathrm{m}$ takes the values 1 and 2 . We do this with the subroutines LUDCMP and LUBKSB.

We evaluate now the vectors $\vec{b}_{3}, \vec{b}_{4}, \vec{b}_{5}$. With these vectors, as we explained earlier we construct the Tridiagonal matrix, which we solve to get the $\delta P_{i}$ values. Then by back substitution with Equation (5.38), we get the $\delta T_{i}$ values.

We solve the matrix with the subroutine DGESV, which is a subroutine from the LAPACK library. In order to use this subroutine, we construct a tridiagonal matrix T(nzmax,nzmax) and the independent matrix $\mathrm{H}(\mathrm{nzmax}+1,1)$.

With the solutions we have obtained we call the subroutine CONVERGEV and CONVERGEL, where we see if the solutions we get are converged. If they are converged we continue with another time step. If not, we do other iteration.

With these $\delta P_{i}$ and $\delta T_{i}$ values, we proceed updating the temperature, pressure and velocity fields and we continue with another time step. 


\section{CHAPTER 6}

\section{RESULTS}

\subsection{INTRODUCTION}

The main goal of this thesis has been to develop a pseudo 2D steam-water countercurrent biphasic code. In this chapter there are reproduced with our CC code some experimental studies made in the past, and hence validate it. In the further points, some comparative graphs with which we will prove that our CC code provides accurate results for the main physical variables are presented.

At the Polytechnic University of Valencia, an experimental facility is being set up in order to obtain experimental data which will be used to study the thermal stratification and the countercurrent flow phenomena. This facility will be used to study different thermalhydraulic phenomena, as the direct contact condensation in a steam-water countercurrent flow.

This thesis has been the starting point for all the future works which will be performed within this facility, and it has helped the work team at the UPV to clarify which will be the requirements that will be needed by the facility, and hence design it accordingly.

Since this facility hasn't been finished yet, we still don't have self experimental data sets, and hence we need to get experimental data from somewhere else in order to validate our CC code.

The manner how our CC code is being validated in this chapter is by reproducing different steam-water countercurrent flow experiments which were found through our deep research in the literature. In the next point the different experimental data source that have been used are enumerated. These are, some scientific papers which experimentally studied the countercurrent and direct condensation phenomena, and also the experimental data 
provided by the HZDR (Helmoltz Zentrum Dresden Rossendorf) obtained at the LAOCOON test facility has been reproduced.

\subsection{CODE VALIDATION}

As this study starts from the test 1.2 performed with the LSTF Japanese experimental facility, which relates to thermal stratification and countercurrent phenomena at the cold leg of a PWR nuclear reactor, we first searched at different bases as science-direct, JRC, etc. for publications related to steam-water countercurrent flow, and direct contact condensation.

A deep research has been made to find different articles in order to get more data and check the predictions made by the code developed for this thesis. In this chapter we will show different result comparisons using data obtained from different experiments. These experiments which we have used are detailed below:

- Validation 1. The CC code predictions are compared with the data obtained from the article:

Kyung-Won Lee a, In-Cheol Chu b, Seon-Oh Yu c, Hee Cheon No a, 2006 [83].

- Validation 2. The CC code predictions are compared with the data obtained from the article:

I.S. Lim, R. S. Tankin, 1984 [37].

- Validation 3. The CC code predictions are compared with the data provided by the HZDR (Helmholtz Zentrum Dresden Rossendorf). The data were an outcome from the so called, LAOCON EXPERIMENTS.

A schematic of the CC code boundary conditions configuration is shown in Figure 6.1. 


\section{Boundaryconditions}

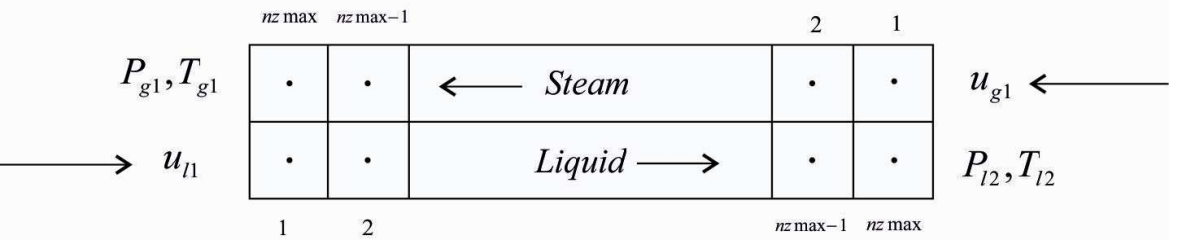

Figure 6.1 CC code boundary conditions configuration

In order to reproduce the experimental conditions of the following articles which have been used to validate our CC code, the boundary conditions that can be observed in the previous figure are set in our code.

As the liquid and steam phase are flowing countercurrently, the outlet and inlet conditions are opposite for each phase. The CC code works by establishing an outlet value for the pressure and the temperature and an inlet value for the velocity for each phase as the boundary conditions for our problem. These values are filled in a table for each case below.

\subsection{VALIDATION 1}

In this first validation, the $\mathrm{CC}$ code predictions are compared with the data obtained from the article by Kyung-Won Lee a, In-Cheol Chu b, Seon-Oh Yu c, Hee Cheon No a, 2006 [134], for the set of experimental data that appear there.

In this article, the interfacial condensation heat transfer for a steam-water countercurrent stratified wavy flow in a horizontal and circular pipe was investigated.

In contrast to the previous work of Chu et al. [I.C. Chu, S.O. Yu, M.H. Chun], 2000 [114] that investigated the interfacial condensation heat transfer in a stratified smooth flow in a horizontal pipe, this work performs experiments for steam-water stratified wavy flow, and gives comparative results.

The correlation that will be used for all the cases, both for the smooth cases and for the wavy ones, is the one that appears in the Kyoung-Won Lee et al. article [134].

The correlation that will be used is the following one: 


$$
h_{l \text { int }}=\frac{K_{l}}{D_{h l}} \cdot N u_{l \text { int }}=\frac{K_{l}}{D_{h l}} \cdot 1.2 e-7 \cdot \operatorname{Re}_{l}^{0.59} \cdot \operatorname{Re}_{g}^{1.2} \cdot J a^{0.82}
$$

This correlation was obtained by correlating the data sets obtained with the experiment of the paper of Kyoun-won Lee, and it was obtained for a wavy interface conditions.

Depending on the steam velocity the liquid layer interfacial surface can change from smooth to wavy, due to the instabilities that may happen. A deep study of the fluid instabilities has to be done in order to obtain accurate criteria to establish if instability may happen. This specific theme was studied by sir Horace Lamb In the 1879 book Hydrodynamics. In chapter IX of this book, it is studied the surface waves at a liquid layer. It was also studied by Chandrasekhar in the 1961 book Hydrodynamic and Hydromagnetic stability. More theories can be found as the ones by Jeffreys (1925, 1926), Taitel and Dukler (1976), Lin and Hanratty (1986), Barnea and Taitel (1993) and Funada and Joseph (2001).

Different criteria can be found to determine if a smooth stratified flow is stable or not, as this is the phenomenon which we are dealing with in this thesis.

The classical theory of $\mathrm{KH}$ instability of an inviscid fluid may be obtained by making $\mu_{G}=\mu_{L}=0$. After some assumptions we get to the following criterion:

$$
j^{*}>\alpha^{3 / 2}
$$

where $j^{*}=\frac{U_{G} \alpha \sqrt{\rho_{G}}}{\sqrt{g H\left(\rho_{L}-\rho_{G}\right)}}$ and $\alpha=\frac{h_{G}}{H}$ being $\mathrm{H}$ the channel height.

More recent studies achieved other criteria as the one of Taitel and Dukler (1976), who obtained the following criterion: 


$$
j^{*}>\left(1-\frac{h_{L}}{H}\right) \alpha^{3 / 2}
$$

Jeffreys $(1925,1926)$ proposed a linear ad hoc theory for the generation of water waves by wind as an alternative to the inviscid Kelvin-Helmholtz theory. The criterion was:

$$
U_{G}>\left[\frac{4 \mu_{L} g}{s U_{L}}\right]^{1 / 2}
$$

There can be found several more criteria in the literature for the transition from smooth conditions to wavy conditions.

Even though that the Kyoun-Won Lee et al. [134] correlation was developed for a wavy interface we will reproduce the smooth conditions implementing the same correlation in our code and comparing the liquid bulk temperature results.

We might say that in this article four liquid bulk temperature distributions along the pipe can be found. Two of them are for smooth conditions and two for wavy conditions. We will then try to predict these bulk liquid temperatures for these boundary conditions with our code, and compare the results with the graphs which appear in the article.

In Figure 6.2 a schematic of the experimental apparatus used to get the experimental data is shown.

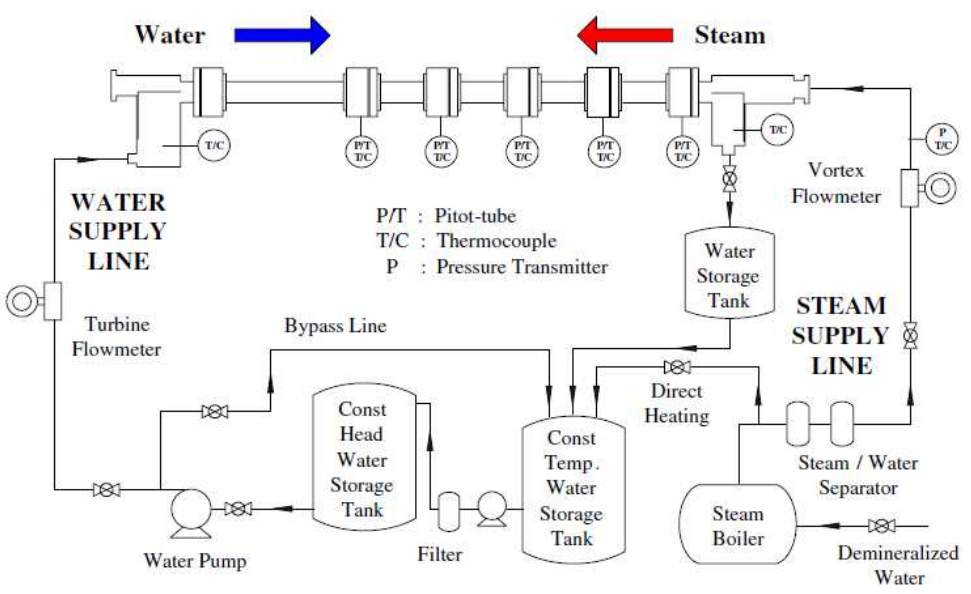

Figure 6.2 Schematic of the experimental apparatus of the Kyoun-Won Lee et al. 
[134] experiments

In the Table 6.1 it can be seen the set of experiments which were made.

\begin{tabular}{llllllll}
\hline$T_{f, \text { in }}\left({ }^{\circ} \mathrm{C}\right)$ & $T_{g, \text { in }}\left({ }^{\circ} \mathrm{C}\right)$ & $W_{f, \text { in }}(\mathrm{kg} / \mathrm{s})$ & $W_{g, \text { in }}(\mathrm{kg} / \mathrm{s})$ & $\mathrm{Re}_{f}$ & $\mathrm{Re}_{g}$ & $J a$ & $\begin{array}{l}\text { Number } \\
\text { of data }\end{array}$ \\
\hline 25 & 100 & $0.08-0.22$ & $\begin{array}{l}0.013- \\
0.019\end{array}$ & $\begin{array}{l}4000- \\
10000\end{array}$ & $\begin{array}{l}12000- \\
19000\end{array}$ & $77.9-180$ & 41 \\
& & & & & & \\
\hline 45 & 100 & $0.08-0.22$ & $0.015-$ & $4000-$ & $14000-$ & $55.2-131$ & 31 \\
& & 0.018 & 13000 & 17000 & & \\
\hline 55 & 100 & $0.08-0.22$ & $0.015-0.02$ & $4000-$ & $17000-$ & $43.5-$ & 33 \\
& & & 14000 & 23000 & 99.1 & \\
\hline \multicolumn{7}{c}{} \\
& & & & & & & \\
\hline
\end{tabular}

Table 6.1 Test matrix of the experiments

Figure 6.3 shows the experimental data plotted in the Mandhane's flow pattern map. They comment in the article that visual observations showed that the transition from the stratified smooth to the wavy flow occurred when the local steam superficial velocity was greater than about $2.5 \mathrm{~m} / \mathrm{s}$ for the range of the water superficial velocities of $0.01-0.05 \mathrm{~m} / \mathrm{s}$. The gas superficial velocities required for the transition from the smooth to the wavy interface are lower in steam-water experiments than in air-water experiments, because the interfacial shear stress in the presence of condensation is increased by the mass transfer.

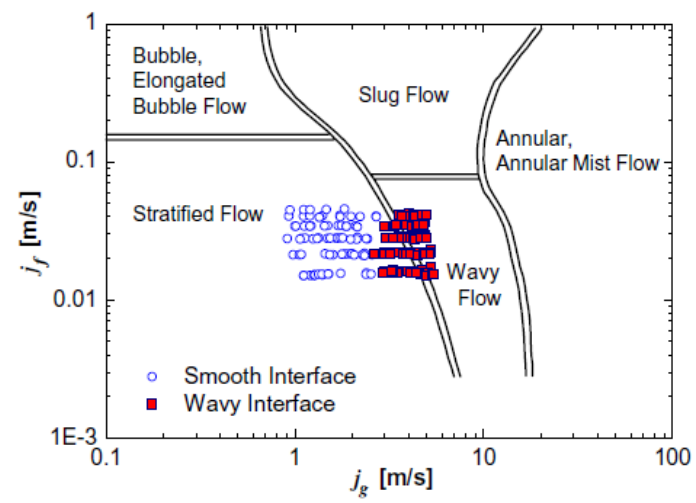

Figure 6.3 Experimental data plotted in the Mandhane's flow pattern map of the experiments performed by Kyung-Won Lee a, et al. 2006 [134] 
The water layer thicknesses were from $0.013 \mathrm{~m}$ to $0.028 \mathrm{~m}$. The ratio of the water layer thickness to pipe diameter varied from 0.155 to 0.333 , which was much greater than the ratio obtained in the previous works for a wide rectangular channel.

In Figure 6.4 the bulk liquid temperatures are shown for the smooth and wavy cases:

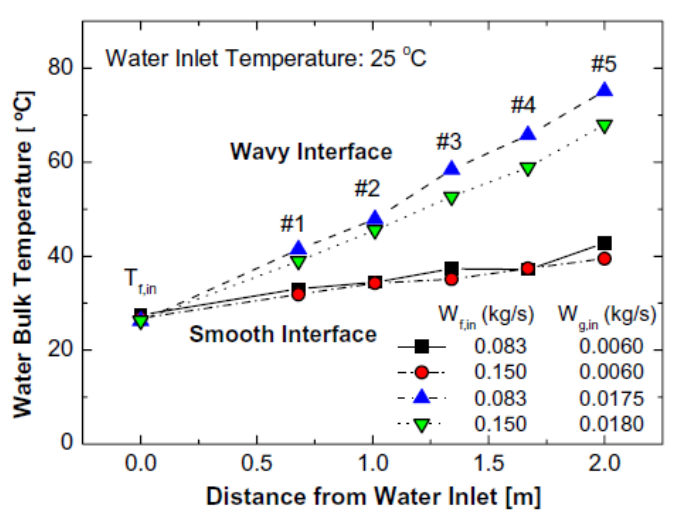

Figure 6.4 Bulk water temperatures along the flow stream of the experiments performed by Kyung-Won Lee a, et al. 2006 [134]

It can be seen as for the wavy cases, the bulk liquid temperature have a higher slope. This is because for a wavy case, the interfacial area is bigger than for a smooth case, and hence, the interfacial heat transfer and condensation rate on the interfacial surface is also bigger.

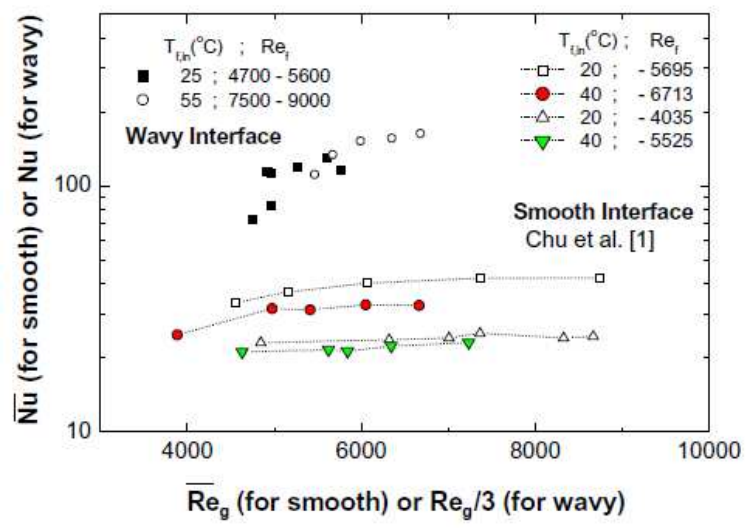

Figure 6.5 Effects of the steam flow rate on the interfacial condensation heat transfer at the experiments performed by Kyung-Won Lee a, et al. 2006 [134] 
In Figure 6.5 a map chart can be observed, where the Nusselt number is plotted as a function of the Reynolds dimensionless number. It can be observed that it is higher for a wavy interface.

\section{$\underline{\text { SMOOTH CODITIONS }}$}

For smooth conditions we have the following two boundary conditions at the Kyung-Won Lee a, et al. 2006 [134] experiments, which will be compared with the results that were obtained with our code:

Table 6.2 Smooth conditions at the Kyung-Won Lee a et al. 2006 [134] experiments

\begin{tabular}{|l|c|c|}
\hline \multicolumn{1}{|c|}{ CASE } & Smooth 1 & Smooth 2 \\
\hline Steam mass flow rate (Kg/s) & 0.006 & 0.006 \\
\hline Liquid mass flow rate $(\mathrm{Kg} / \mathrm{s})$ & 0.083 & 0.15 \\
\hline Inlet pressure $(\mathrm{Pa})$ & $1.01 \mathrm{e} 5$ & $1.01 \mathrm{e} 5$ \\
\hline Inlet Steam Temperature (K) & 373.15 & 373.15 \\
\hline Inlet liquid temperature (K) & 298.15 & 298.15 \\
\hline Pipe diameter (m) & 0.084 & 0.084 \\
\hline Pipe length (m) & 2.0 & 2.0 \\
\hline
\end{tabular}

\section{$\underline{\text { SMOOTH } 1}$}

In Table 6.3 the boundary conditions as they are set in our CC code for this first case are shown:

Table 6.3 Boundary conditions for the SMOOTH 1 case

\begin{tabular}{|c|c|c|}
\hline \multicolumn{3}{|c|}{ LIQUID PHASE } \\
\hline$u_{l 1}$ & $T_{l 2}$ & $P_{l 2}$ \\
\hline 0.101 & 298.15 & $1.01 \mathrm{e} 5$ \\
\hline \multicolumn{3}{|c|}{ STEAM PHASE } \\
\hline$u_{g 1}$ & $T_{g 2}$ & $P_{g 2}$ \\
\hline
\end{tabular}




\begin{tabular}{|l|l|l|}
\hline 2.17 & 373.15 & $1.01 \mathrm{e} 5$ \\
\hline
\end{tabular}

The liquid temperature data, presented at the Kyung-Won Lee et al. 2006 article [134] for the (smooth 1) boundary conditions, are compared with our code results for these boundary conditions in Graph 6.6.

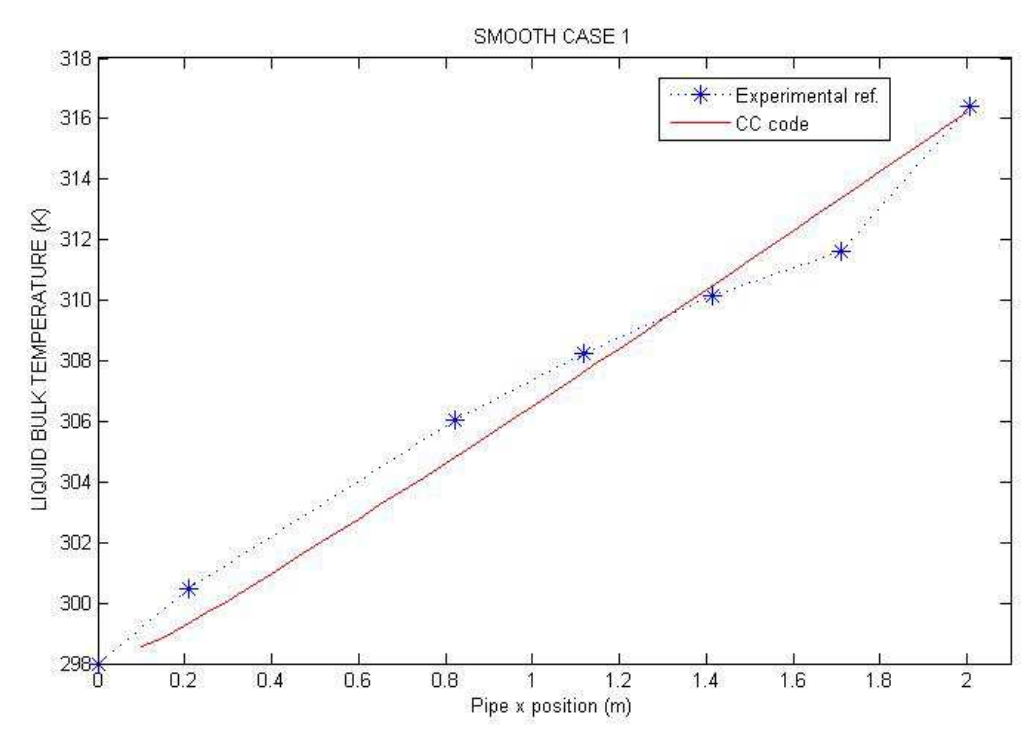

Graph 6.6 Liquid bulk temperature distribution for the smooth 1 conditions

It can be observed in this graph, as the liquid bulk temperature distribution with our CC code agrees very well with the experimental results as they appear in the article for the smooth 1 case.

It can be deduced from this graph that the results that our code provides for the liquid bulk temperature has a very similar behaviour as the experiment, since both have a very similar slope.

Therefore, we can deduce that the models which were introduced and implemented in our code as the correlation for the interfacial heat and mass transfer through the Nusselt number, the interfacial friction and the walls condensation model gives accurate results for this case. 
The next two graphs show the steam and liquid pressure drop along the pipe, for the steam and for the liquid versus time. We can see that the pressure drop oscillates and soon it converges to the final value which is of $3.7 \mathrm{~Pa}$ for the steam, and of $12.37 \mathrm{~Pa}$ for the liquid.

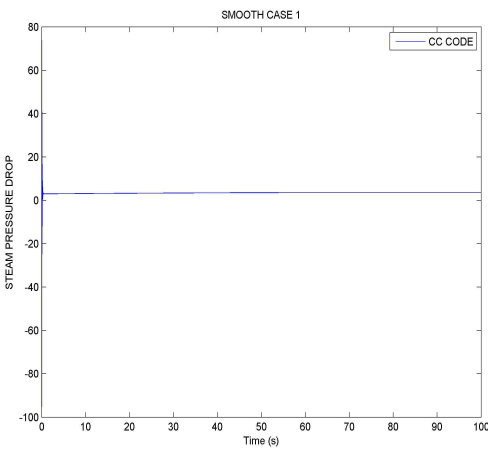

Graph 6.7 Steam pressure drop

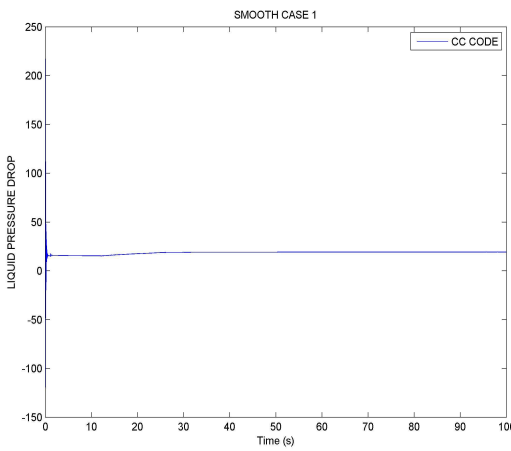

Graph 6.8 Liquid pressure drop

The next two graphs show the maximum value for the mass and the energy function for all the pipe discretization nodes. So, if this value falls down to zero, this means that the converged solution for the conservation equations has been reached. The Newton-Raphson iterative method which we are using works by searching for the roots of the non linear system of conservation equations in discretized form. So, as it can be seen in the Figures 6.9 and 6.10, the problem is completely converged at about 30 seconds. Even so, this case was kept on running until the 100 seconds to assure that the problem was converged.

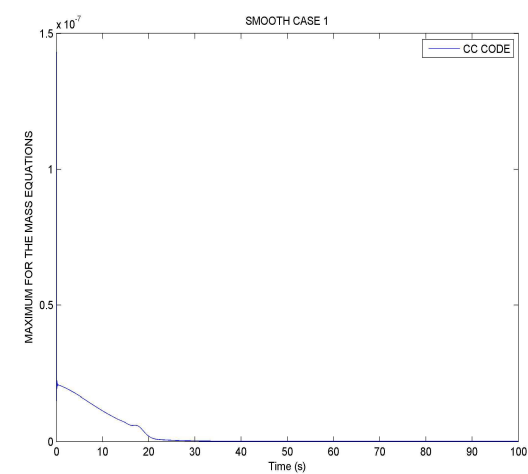

Graph 6.9 Maximum of the mass function

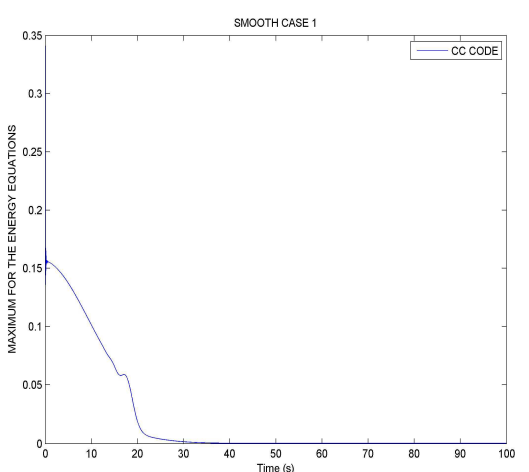

Graph 6.10 Maximum of the energy function 
In Figures 6.11 and 6.12, the steam and the liquid pressure distributions along the pipe when they are flowing countercurrently for this case are shown.

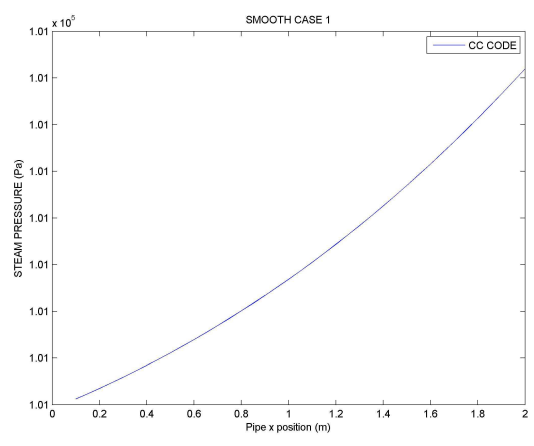

Graph 6.11 Steam pressure distribution

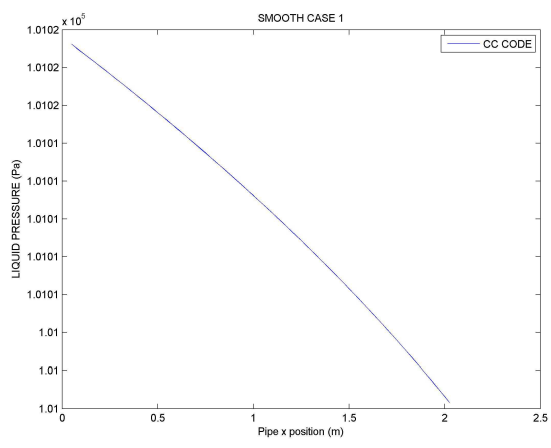

Graph 6.12 Liquid pressure distribution

As it can be observed in the previous graphs for the liquid and for the steam, the liquid and the steam pressures decrease in opposed directions. This agrees the real behaviour since they are flowing countercurrently, and it can be seen as our code is able to predict this scenario.

Every flow stream moves in the direction of a negative pressure gradient, i.e. from where pressure is higher to where is lower. So, the liquid pressure decreases in the opposite direction as the steam.

In Figure 6.13 it is displayed the void fraction distribution, and as we can see, it decreases along the pipe due to the steam condensation. 


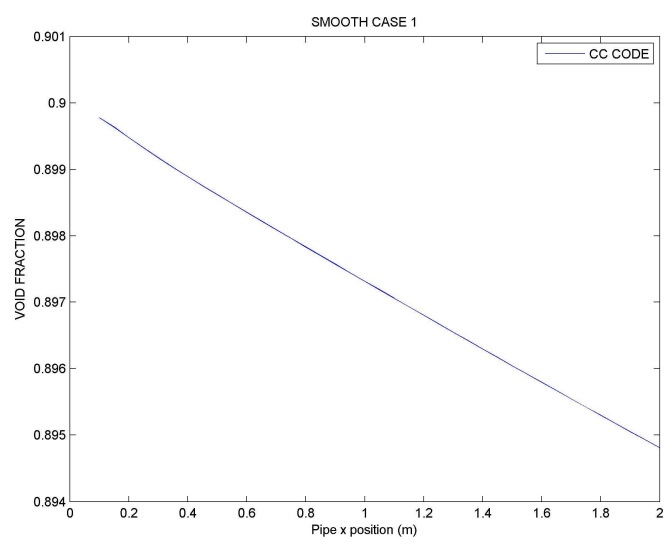

Graph 6.13 Void fraction distribution

The next two graphs show the temperature distributions for the steam and for the liquid. It can be observed that the steam temperature weakly decreases. This decrease is caused because of the steam condensation rate. As the steam flows downstream and it condensates, the vapour pressure decays and the saturation temperature also does so.

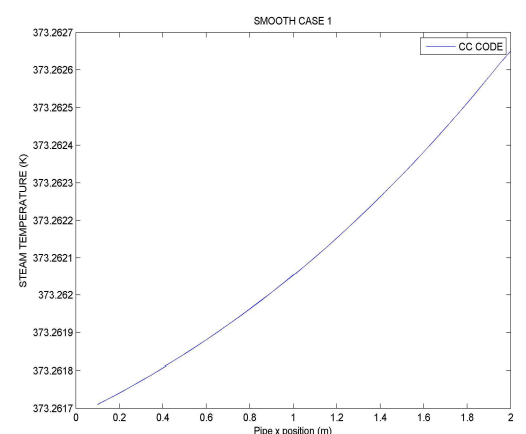

Graph 6.14 Steam temperature distribution

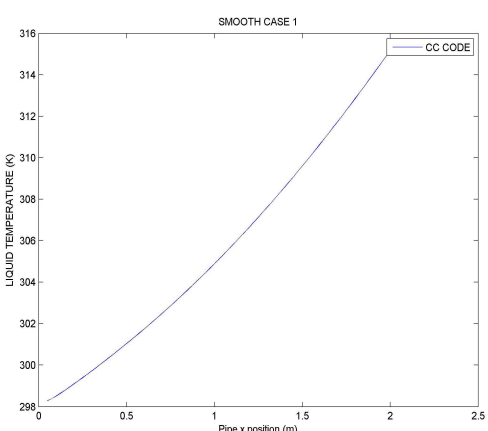

Graph 6.15 Liquid temperature distribution

The next two graphs show the steam and liquid velocity distributions. 


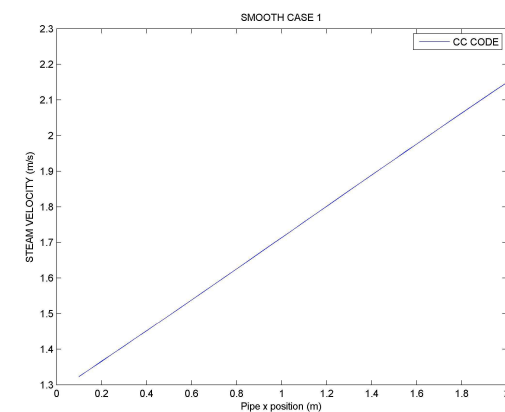

Graph 6.16 Steam velocity distribution

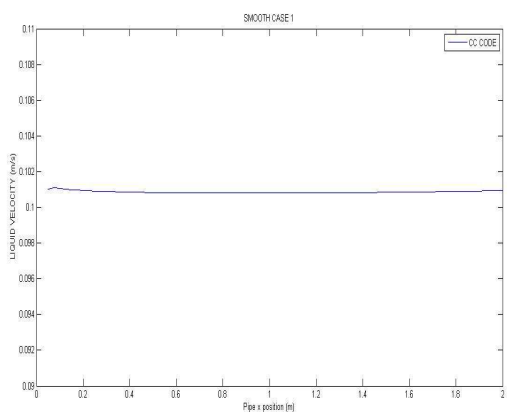

Graph 6.17 Liquid velocity distribution

It can be appreciated as the steam velocity decreases downstream. This is because of the friction with the walls and mainly due to the steam condensation.

Here below now, we show the interfacial heat transfer distribution, and the liquid condensation rate. As we can observe, they have the same shape, as the condensation rate is inversely proportional to the interfacial heat transfer.

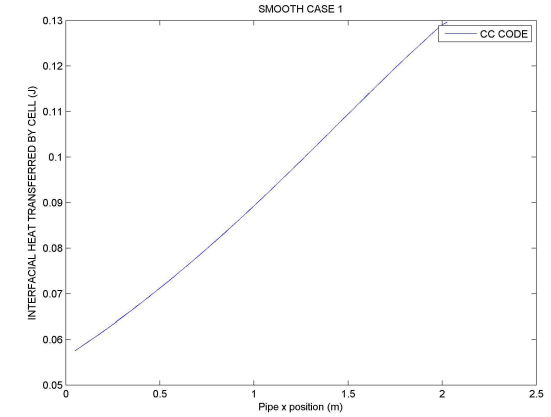

Graph 6.18 Interfacial heat transferred by cell distribution

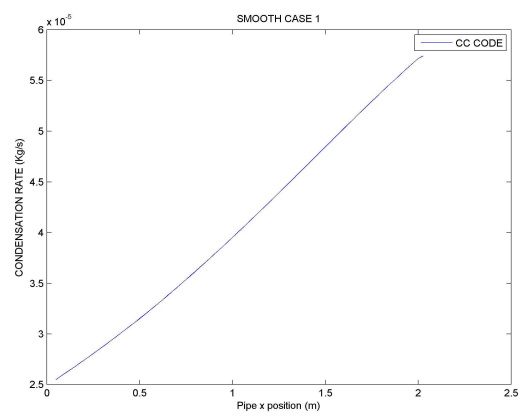

Graph 6.19 Liquid condensation rate

In the next graph, it can be observed as the liquid area increases with the direction of the liquid flow, because of the steam condensation, which increases the liquid mass along the pipe. 


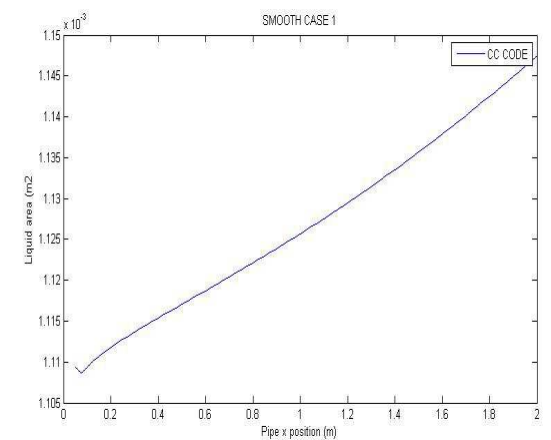

Graph 6.20 Liquid area distribution

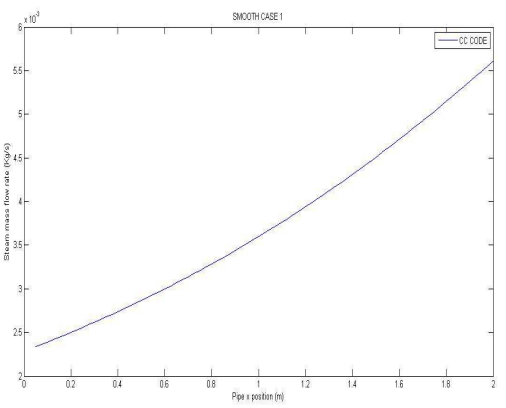

Graph 6.21 Steam mass flow rate distribution

We can see in this last graph as the steam mass flow rate decreases in the direction of the steam as it its flowing countercurrently.

\section{$\underline{\text { SMOOTH } 2}$}

In Table there the boundary conditions as they are set in our $\mathrm{CC}$ code for this case are shown:

Table 6.4 Boundary conditions for the SMOOTH 2 case

\begin{tabular}{|c|c|c|}
\hline \multicolumn{3}{|c|}{ LIQUID PHASE } \\
\hline$u_{l 1}$ & $T_{l 2}$ & $P_{l 2}$ \\
\hline 0.182 & 298.15 & $1.01 \mathrm{e} 5$ \\
\hline$u_{g 1}$ & $T_{g 2}$ & $P_{g 2}$ \\
\hline 2.17 & 373.15 & $1.01 \mathrm{e} 5$ \\
\hline
\end{tabular}

In Figure 6.22 the liquid temperature graph at the Kyung-Won Lee a, et al. 2006 [134] article for the smooth 2 boundary conditions that we have detailed in Table 6.2 is compared with our code results for this boundary conditions. 


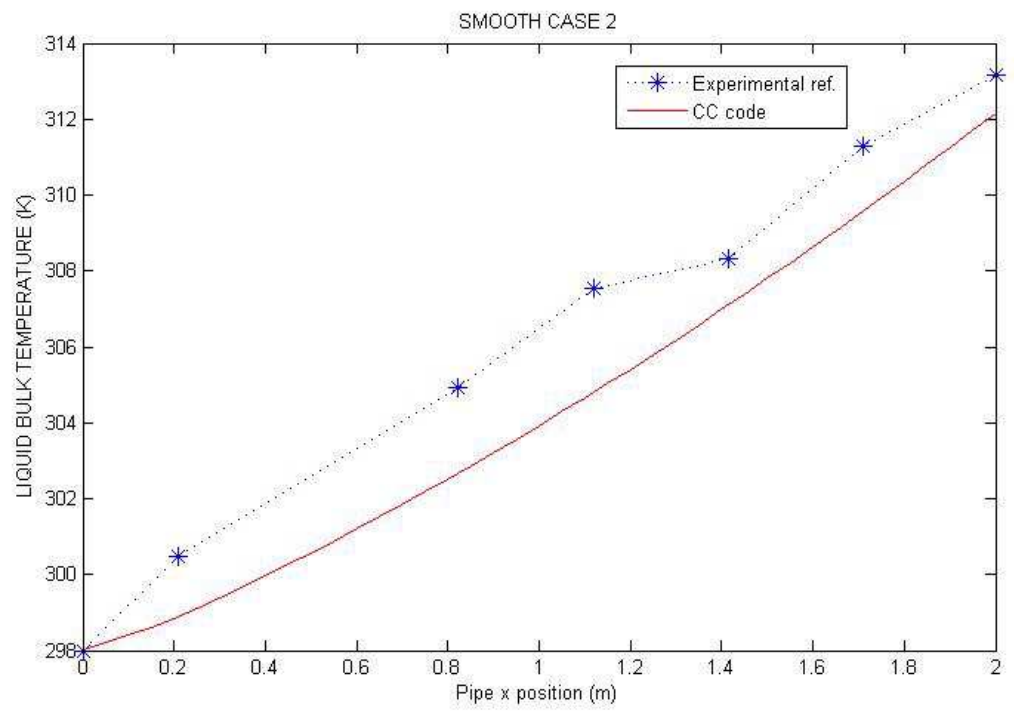

Figure 6.22 Liquid bulk temperature distribution for the smooth 2 conditions

It can be seen at this graph that the liquid temperature distribution obtained with our CC code agrees very well with experimental results as it appears in the article Kyung-Won Lee a, et al. 2006 [134]. At the final part of the pipe, the difference of the liquid temperature between the experimental results and the $\mathrm{CC}$ code ones reduces to one degree at $1.4 \mathrm{~m}$ and this difference is maintained through this final stretch the pipe.

It can be deduced from this graph that the results that our code provides for the liquid bulk temperature has a very similar behaviour as the experiment, since both have a very similar slope.

Therefore, we can deduce that the models which were introduced and implemented in our code as the correlation for the interfacial heat and mass transfer through the Nusselt number, the interfacial friction and the walls condensation model gives accurate results for this case.

The next two graphs show the steam and liquid pressure drop along the pipe, for the steam and for the liquid. We can see that the pressure drop oscillates and soon it converges to the final value which is of 4.1 $\mathrm{Pa}$ for the steam, and of $12.2 \mathrm{~Pa}$ for the liquid. 

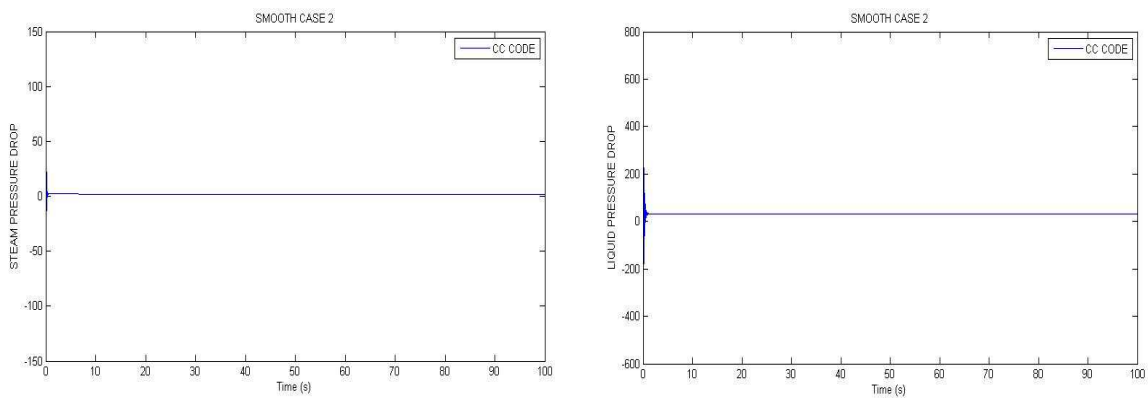

Graph 6.23 Steam and liquid pressure drop

The next two graphs show the maximum value for the mass and the energy function for all the pipe nodes. So, if this value falls down to zero, this means that the converged solution for the conservation equations has been reached. The Newton-Raphson iterative method which we are using works by searching for the roots of the non-linear system of conservation equations in discretized form.

As it can be seen in Figures 6.23 and 6.24, the problem is completely converged.

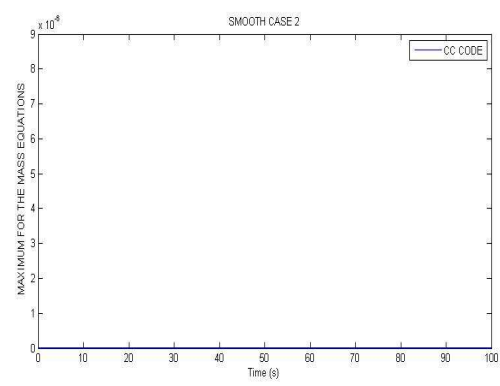

Graph 6.23 Maximum of the mass equations

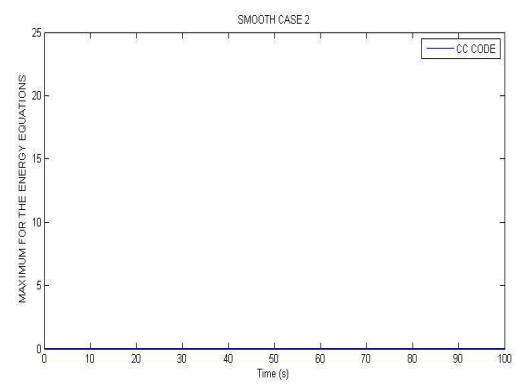

Graph 6.24 Maximum of the energy equations

Below the steam and the liquid pressure evolutions along the pipe is shown. 


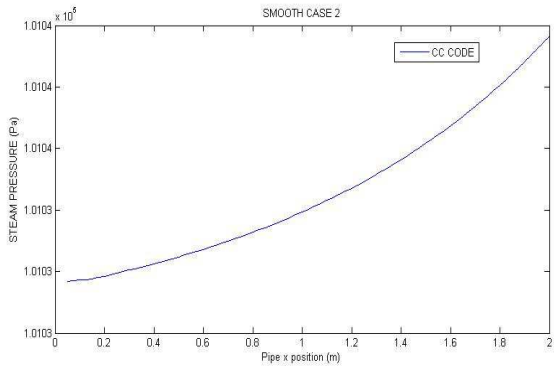

Graph 6.25 Steam pressure distribution

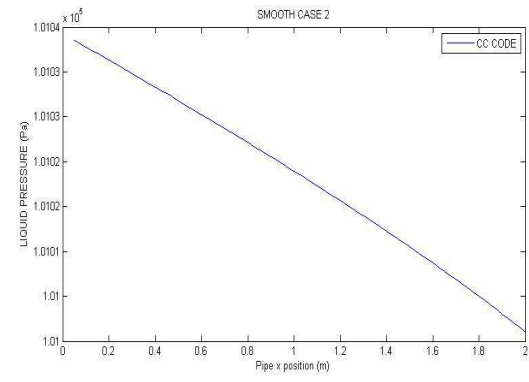

Graph 6.26 Liquid pressure distribution

It can be observed that the steam pressure diminishes from the right side (inlet of the steam) to the left side, due to the interfacial friction, the friction with the walls, and the steam condensation.

Here next, the void fraction distribution is displayed, and as it can be seen, it decreases along the pipe due to the steam condensation.

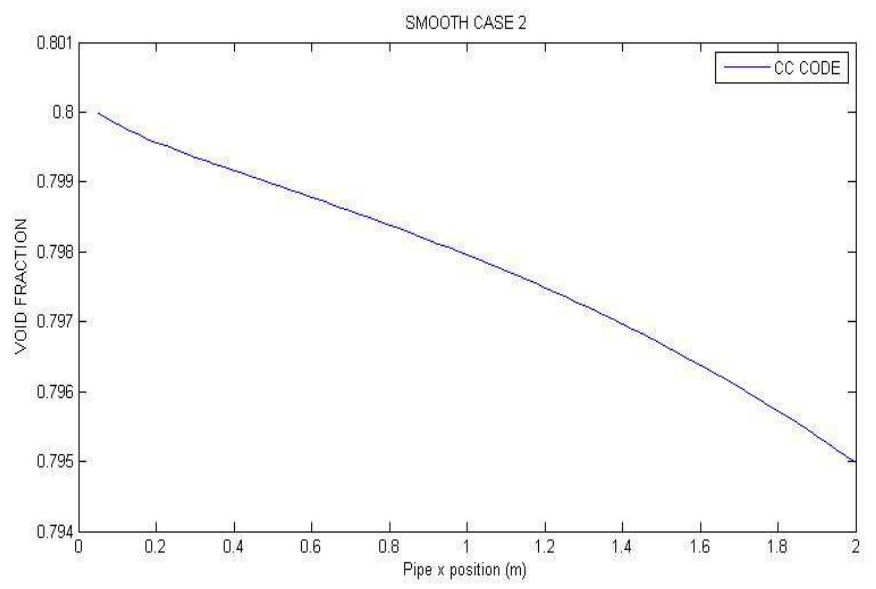

Graph 6.27 Void fraction distribution

The next two graphs show the temperature distributions for the steam and for the liquid. 


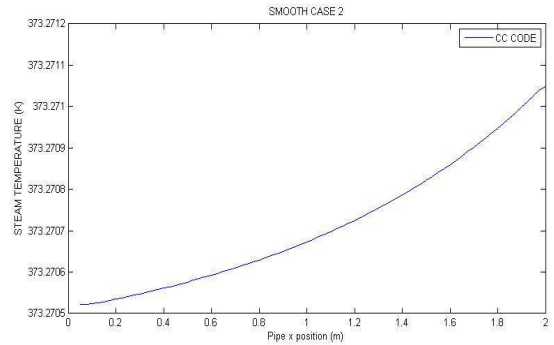

Graph 6.28 Steam temperature distribution

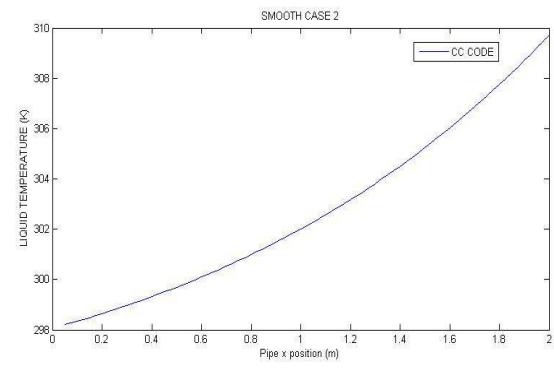

Graph 6.29 Liquid temperature distribution

The next two graphs show the temperature distributions for the steam and for the liquid. It can be seen that the steam temperature weakly decreases. This decrease is caused because of the steam condensation rate. As the steam flows downstream and it condensates, the vapour pressure decays and the saturation temperature also does so.

The next two graphs show the steam and liquid velocity distributions.

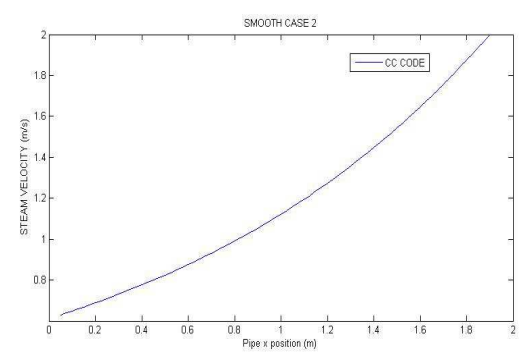

Graph 6.30 Steam velocity distribution

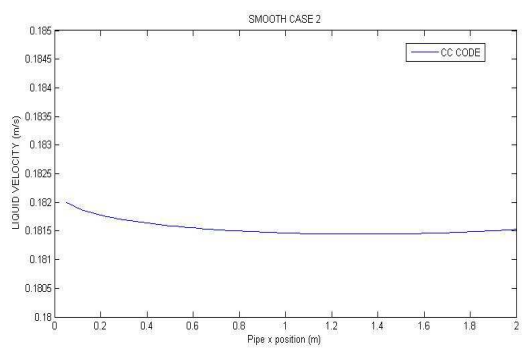

Graph 6.31 Liquid velocity distribution

Hereafter the interfacial heat transfer distribution and the liquid condensation rate are shown. As we can see they follow the same shape, as the condensation rate is inversely proportional to the interfacial heat transfer. 


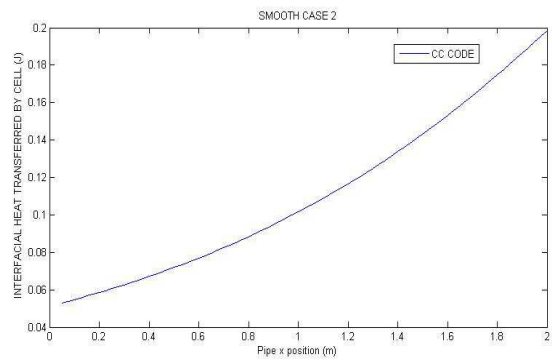

Graph 6.32 Interfacial heat transfer distribution

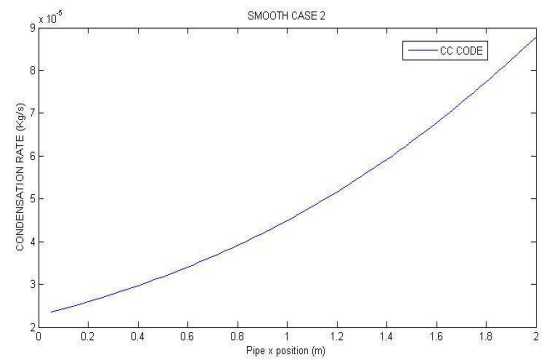

Graph 6.33 Liquid condensation rate

We point out that the increase in the liquid temperature is produced by the steam condensation along the pipe.

In the next graph, it can be seen that the liquid area increases in the direction of the liquid flow, because of the steam condensation, which increases the liquid mass along the pipe.

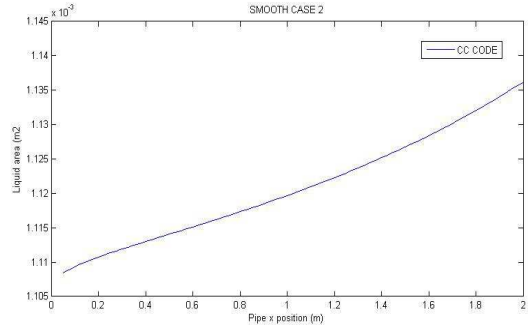

Graph 6.34 Liquid area distribution

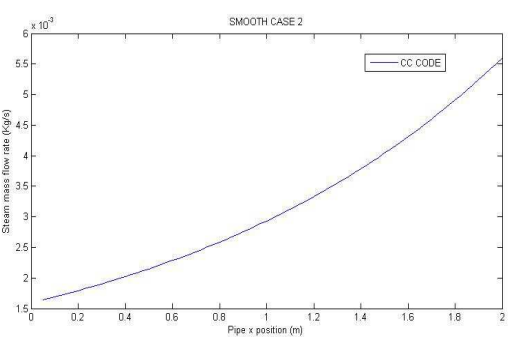

Graph 6.35 Steam mass flow rate distribution

It can be seen in Graph 6.35 as the steam mass flow rate decreases in the direction of the steam as it its flowing countercurrently.

\section{WAVY CONDITIONS}

For the wavy conditions we have the following battery of conditions:

Table 6.4 Wavy conditions at the Kyung-Won Lee a et al. 2006 [134] experiments

\begin{tabular}{|l|c|c|}
\hline \multicolumn{1}{|c|}{ CASE } & Wavy 1 & Wavy 2 \\
\hline Steam mass flow rate $(\mathrm{Kg} / \mathrm{s})$ & 0.0175 & 0.018 \\
\hline Liquid mass flow rate $(\mathrm{Kg} / \mathrm{s})$ & 0.083 & 0.15 \\
\hline
\end{tabular}




\begin{tabular}{|l|c|c|}
\hline Inlet pressure (Pa) & $1.01 \mathrm{e} 5$ & $1.01 \mathrm{e} 5$ \\
\hline Inlet Steam Temperature (K) & 373.15 & 373.15 \\
\hline Inlet liquid temperature (K) & 298.15 & 298.15 \\
\hline Pipe diameter (m) & 0.084 & 0.084 \\
\hline Pipe length (m) & 2.0 & 2.0 \\
\hline
\end{tabular}

In this case, the inlet conditions of the liquid and the steam mass flow rates, produces interfacial waves at the steam/liquid interface. These waves enhance the condensation heat transfer rate along the pipe. We denote by "wavy", the existence of waves which increase the interfacial area and hence, the steam condensation.

\section{WAVY 1}

The boundary conditions as they are set in our CC code for this case are shown in Table 6.5 :

Table 6.5 Boundary conditions for the WAVY 1 case

\begin{tabular}{|c|c|c|}
\hline \multicolumn{3}{|c|}{ LIQUID PHASE } \\
\hline$u_{l 1}$ & $T_{l 2}$ & $P_{l 2}$ \\
\hline 0.101 & 298.15 & $1.01 \mathrm{e} 5$ \\
\hline$u_{g 1}$ & STEAM PHASE \\
\hline 6.33 & $T_{g 2}$ & $P_{g 2}$ \\
\hline
\end{tabular}

Here the liquid temperature graph at the Kyung-Won Lee a et al. 2006 [134] article, for the wavy 1 boundary conditions that we have detailed in the Table 6.2 is compared with our code results for this boundary conditions. 


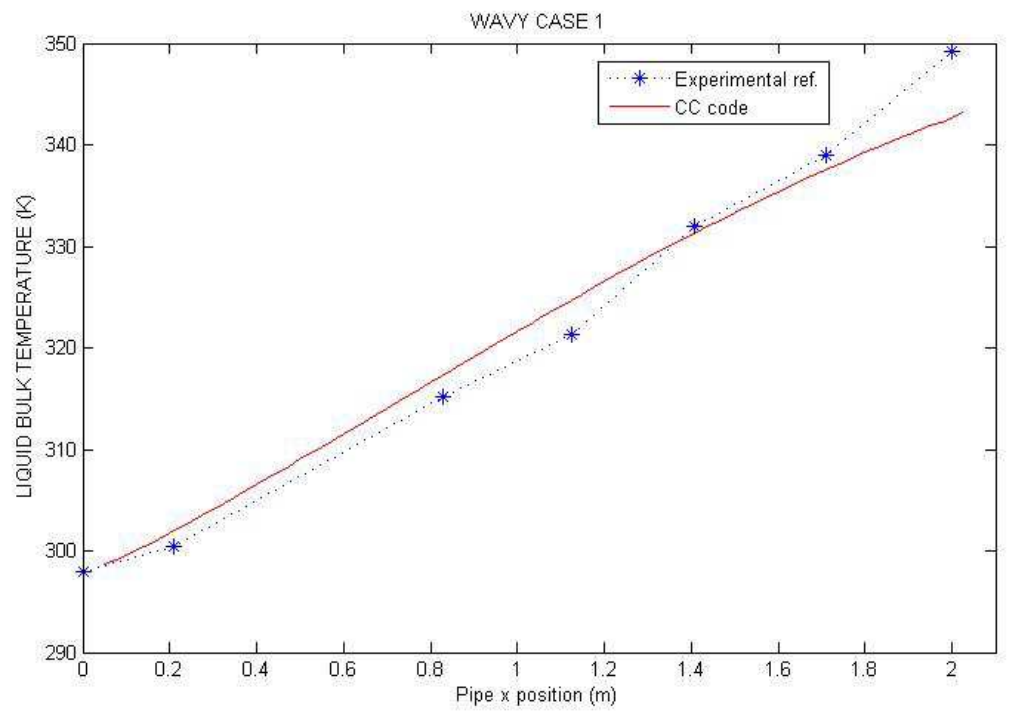

Figure 6.36 Liquid bulk temperature distribution for the wavy 1 conditions

It can be seen at this graph that the liquid temperature distribution with our $\mathrm{CC}$ code predict very well the experimental results which appears in the article of Kyung-Won Lee a, et al. 2006 [134]. Only in the last part of the pipe, the experimental liquid temperature rises up a little bit faster than our program, and so, there are around five degrees of difference at the exit of it, where both enter at $298.15 \mathrm{~K}$. The experimental curve ends with $348.7 \mathrm{~K}$, and the CC code with $343.25 \mathrm{~K}$.

It can be deduced from this graph that the results that our code provides for the liquid bulk temperature has a very similar behaviour as the experiment, since both have a very similar slope.

Therefore, we can deduce that the models which were introduced and implemented in our code as the correlation for the interfacial heat and mass transfer through the Nusselt number, the interfacial friction and the walls condensation model gives accurate results for this case.

In the next two graphs the steam and liquid pressure drop along the pipe, for the steam and for the liquid is displayed. We can see that the pressure drop oscillates and soon it 
converges to the final value which is of $10.75 \mathrm{~Pa}$ for the steam, and of $92.1 \mathrm{~Pa}$ for the liquid.

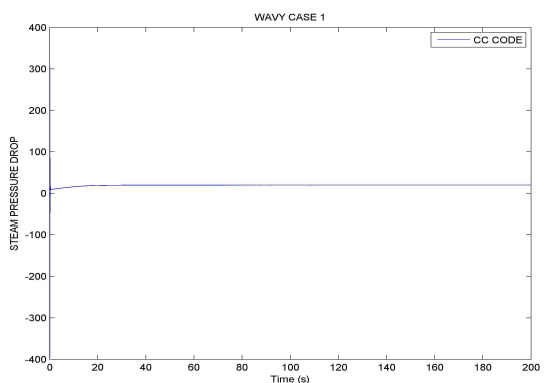

Graph 6.37 Steam pressure drop

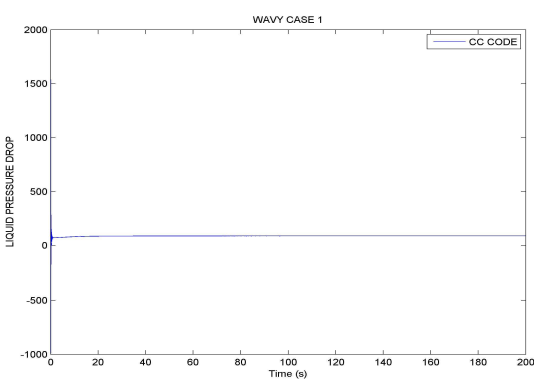

Graph 6.38 Liquid pressure drop

Now below the steam and the liquid pressure distributions along the pipe once we have attained the convergence is shown.

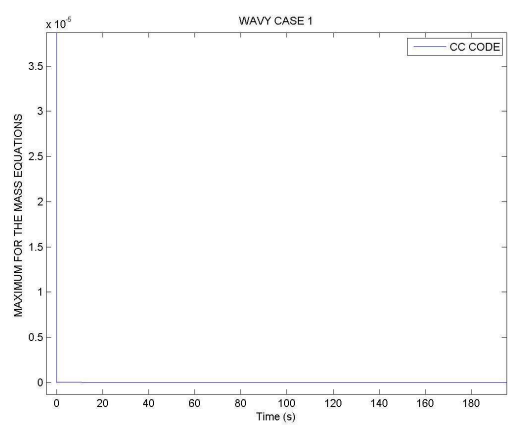

Graph 6.39 Maximum of mass function

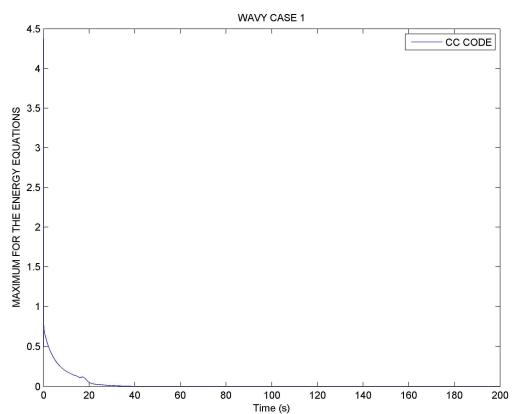

Graph 6.40 Maximum of energy function

Now below the steam and the liquid pressure evolutions along the pipe is shown. 


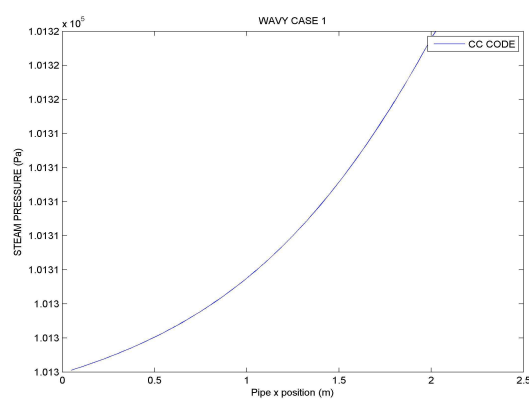

Graph 6.41 Steam pressure distribution

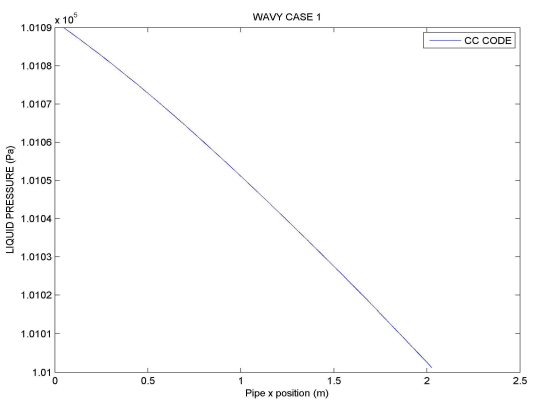

Graph 6.42 Liquid pressure distribution

Here next, we have the void fraction distribution, and as it can be seen, it decreases along the pipe due to the steam condensation.

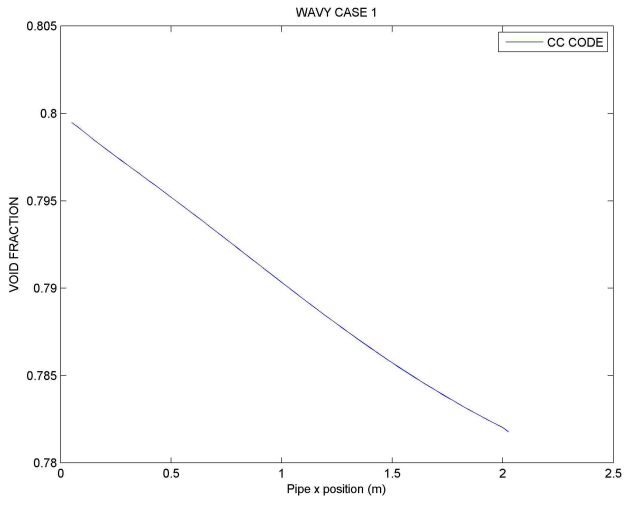

Graph 6.43 Void fraction distribution

The next two graphs show the temperature distributions for the steam and for the liquid. It is observed that the liquid temperature increases along the pipe due to the heat supplied to the liquid by the steam condensing enthalpy which includes the change of phase enthalpy. 


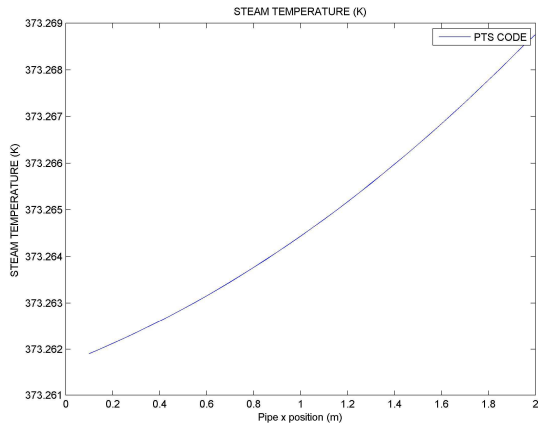

Graph 6.44 Steam temperature distribution

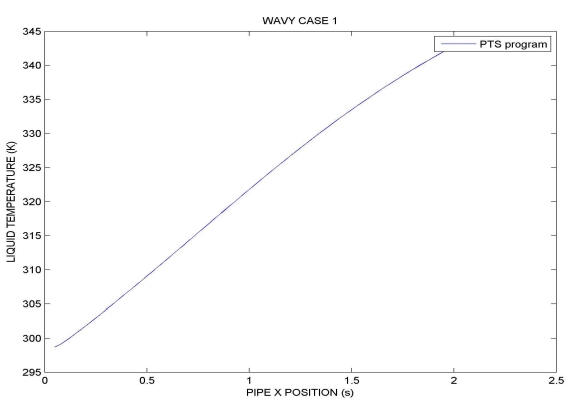

Graph 6.45 Liquid temperature distribution

The next two graphs show the steam and liquid velocity distributions.

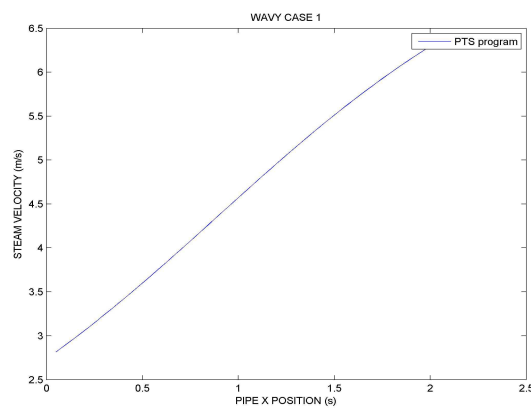

Graph 6.46 Steam velocity distribution

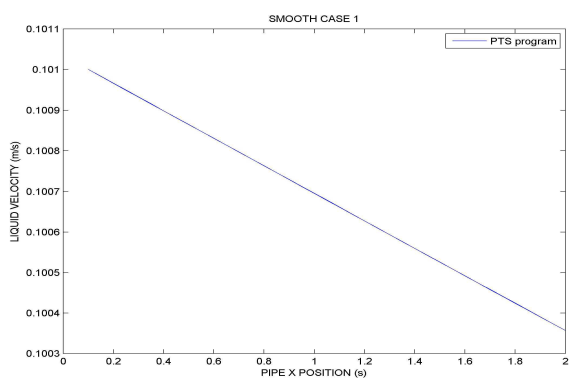

Graph 6.47 Liquid velocity distribution

In the next graph, it can be seen that the liquid area increases in the direction of the liquid flow, due to the steam condensation, which increases the liquid mass along the pipe.
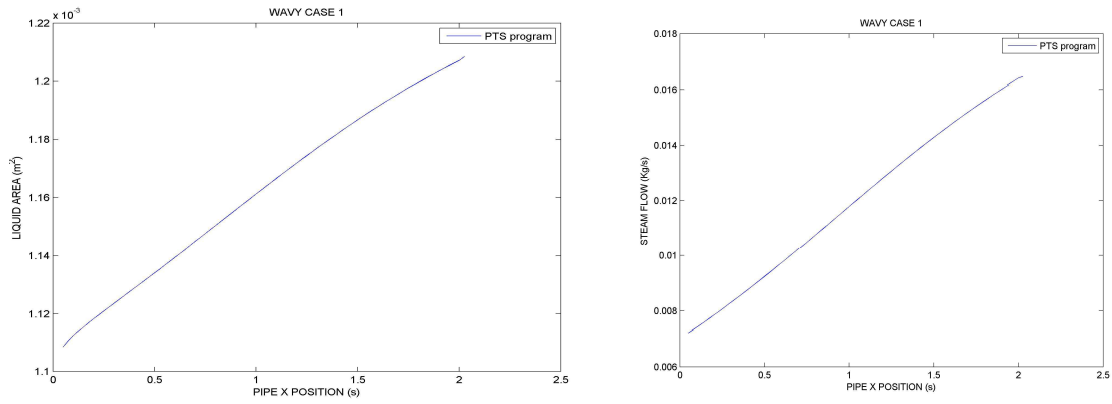


\section{Graph 6.48 Liquid area distribution}

\section{Graph 6.49 Steam mass flow rate} distribution

It can be seen in the last graph that the steam mass flow rate decreases in the direction of the steam as it its flowing countercurrently.

\section{WAVY 2}

The boundary conditions as they are set in our CC code for this case are shown in Table 6.6:

Table 6.6 Boundary conditions for the WAVY 2 case

\begin{tabular}{|c|c|c|}
\hline \multicolumn{3}{|c|}{ LIQUID PHASE } \\
\hline$u_{l 1}$ & $T_{l 2}$ & $P_{l 2}$ \\
\hline 0.182 & 298.15 & $1.01 \mathrm{e} 5$ \\
\hline$u_{g 1}$ & STEAM PHASE \\
\hline 6.52 & $T_{g 2}$ & $P_{g 2}$ \\
\hline
\end{tabular}

In Figure 6.50 the results of our CC code are compared with the experimental results by Kyung-Won Lee et al. 2006 [134], for the boundary conditions that lead to a wavy interface between the liquid and the steam. 


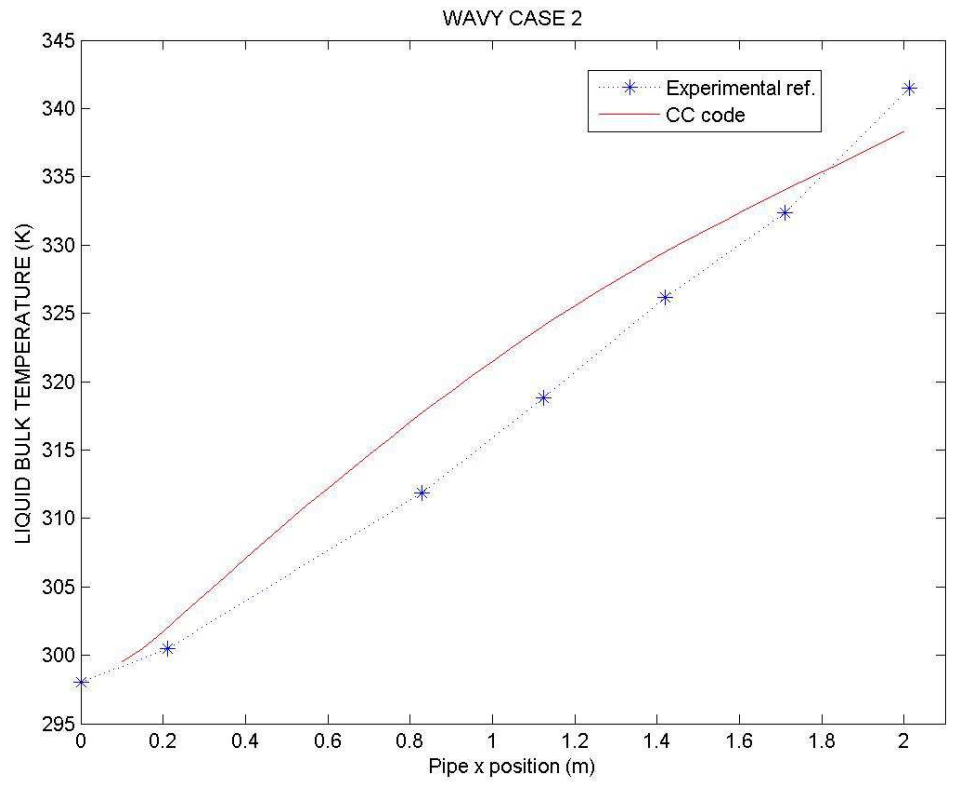

Figure 6.50 Liquid bulk temperature distribution for the wavy 2 conditions

It can be seen at this graph that the liquid temperature distribution with our CC code predicts very well the experimental results which appear in the article of Kyung-Won Lee a et al. 2006 [134]. The difference between them rises to about 7 degrees in the middle part of the pipe and then decreases to only 3 degrees in the last part of the pipe.

It can be deduced from this graph that the results that our code provides for the liquid bulk temperature has a very similar behaviour as the experiment, since both have a very similar slope.

Therefore, we can deduce that the models which were introduced and implemented in our code as the correlation for the interfacial heat and mass transfer through the Nusselt number, the interfacial friction and the walls condensation model gives accurate results for this case. 
The next two graphs show the steam and liquid pressure drop along the pipe, for the steam and for the liquid. We can see that the pressure drop oscillates and soon it converges to the final value which is of 11.6 $\mathrm{Pa}$ for the steam, and of 95.40 $\mathrm{Pa}$ for the liquid.

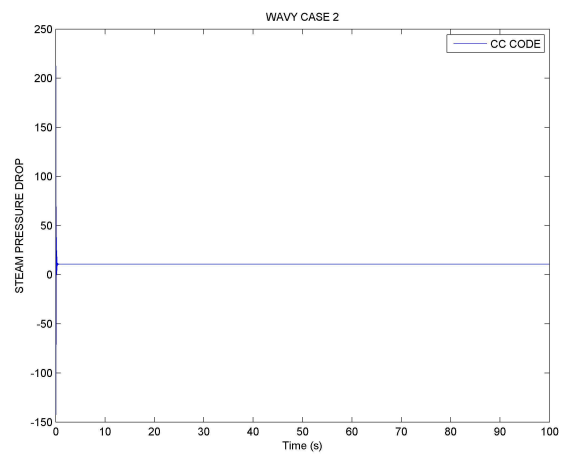

Graph 6.51 Steam pressure drop

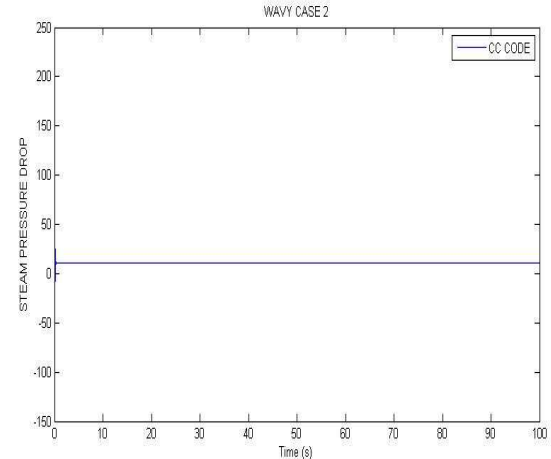

Graph 6.52 Liquid pressure drop

The next two graphs show the maximum value for the mass and the energy function for all the pipe discretization nodes. So, if this value falls to zero, it means that the converged solution for the conservation equations has been reached. The Newton-Raphson iterative method which we are using works by searching for the roots of the algebraic non-linear discretized system of equations.

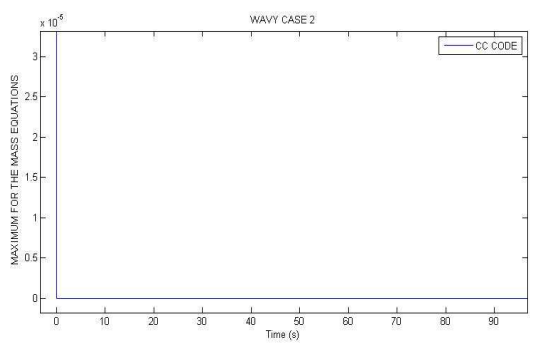

Graph 6.53 Maximum of mass function

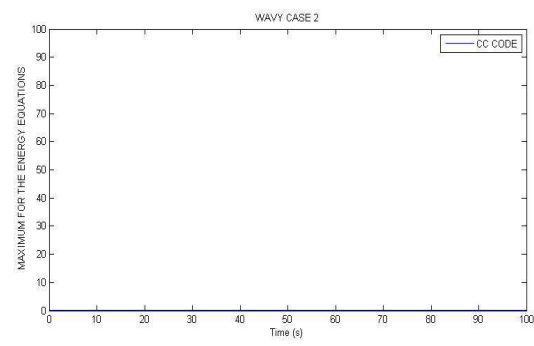

Graph 6.54 Maximum of energy function

Now below the steam and the liquid pressure distributions along the pipe is shown. 


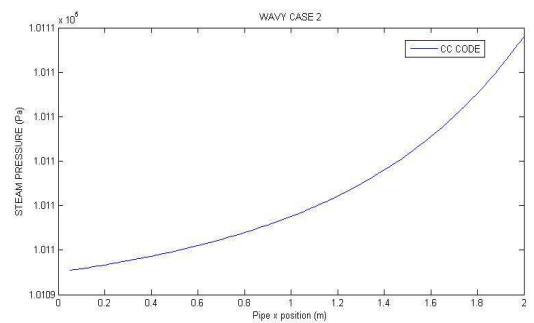

Graph 6.55 Steam pressure distribution

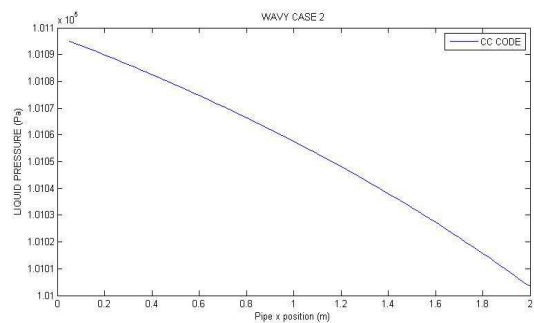

Graph 6.56 Liquid pressure distribution

Here next, we have the void fraction distribution, and as we can see, it decreases along the pipe due to the steam condensation.

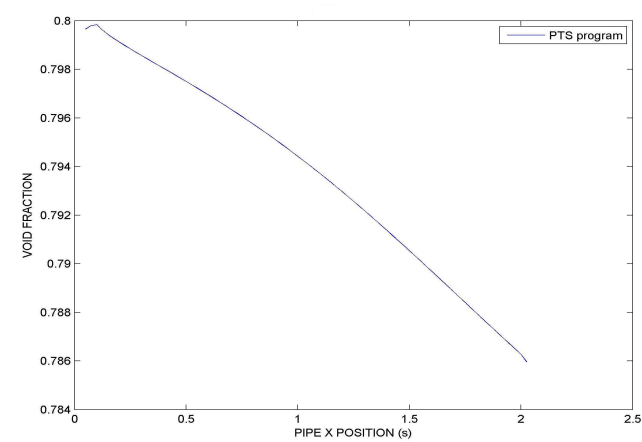

Graph 6.57 Void fraction distribution

The next two graphs show the temperature distributions for the steam and for the liquid.

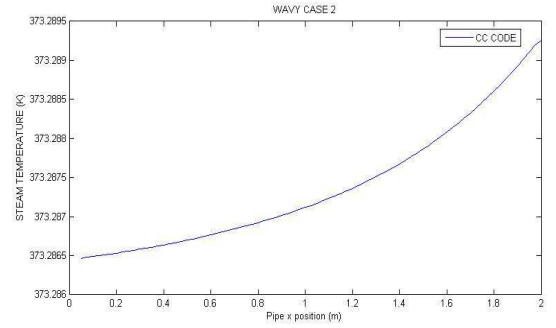

Graph 6.58 Steam temperature distribution

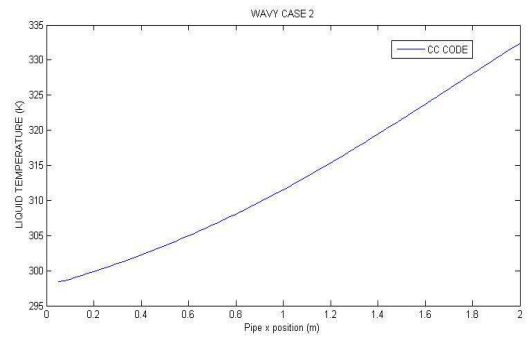

Graph 6.59 Liquid temperature distribution 
The next two graphs show the steam and liquid velocity distributions.

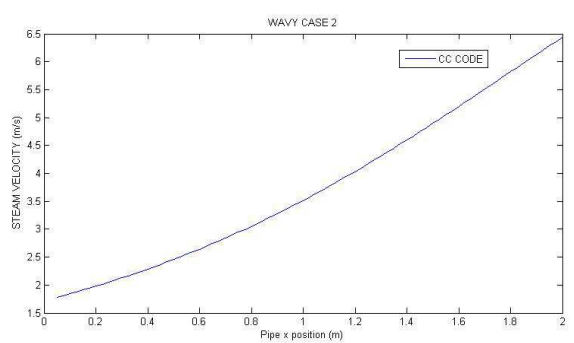

Graph 6.60 Steam velocity distribution

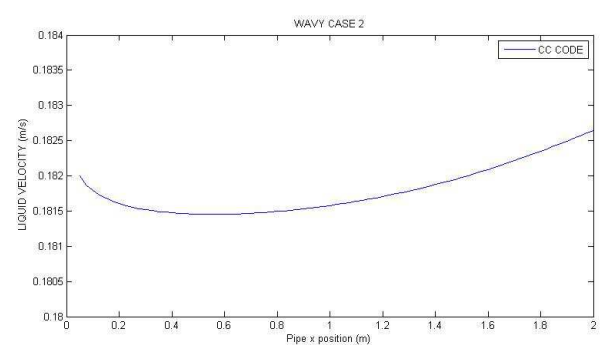

Graph 6.61 Liquid velocity distribution

Here below the interfacial heat transfer distribution, and the liquid condensation rate are shown. As we can observe they follow the same shape, as the condensation rate is inversely proportional to the interfacial heat transfer.

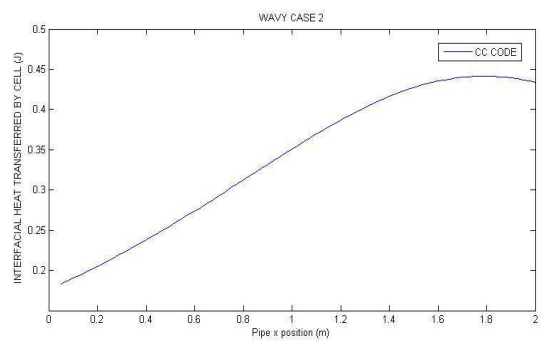

Graph 6.62 Interfacial heat transfer distribution

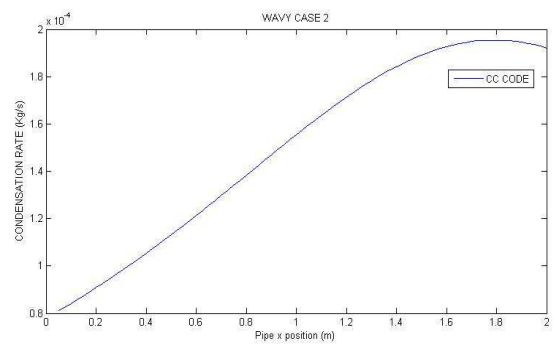

Graph 6.63 Liquid condensation rate

In the next graph, it can be observed that the liquid area increases with the direction of the liquid flow, because of the steam condensation, which increases the liquid mass along the pipe. 


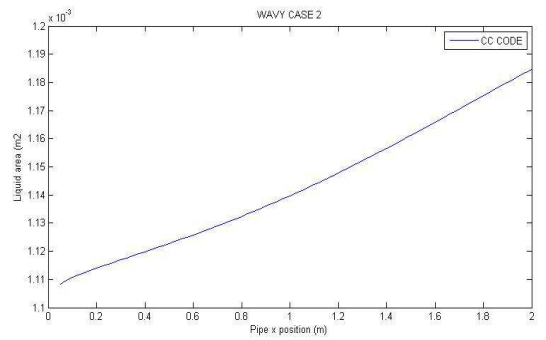

Graph 6.64 Liquid area distribution

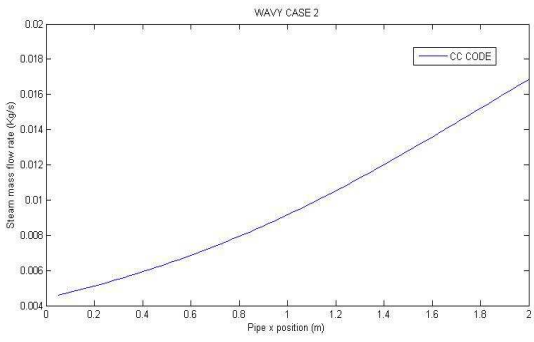

Graph 6.65 Steam mass flow rate distribution

It can be seen in this last graph that the steam mass flow rate decreases in the direction of the steam as it its flowing countercurrently.

\subsection{VALIDATION 2}

Throughout the published articles that we have revised, we found, that in 1984, I.S. Lim et al published the following paper;

I.S. Lim, R. S. Tankin, 1984. Condensation Measurement of horizontal Cocurrent Steam/Water Flow, Journal of heat transfer, 106 425-432 [37].

In this article, we have found that Lim et al. studied the cocurrent steam-water condensation in a rectangular duct. This experiment was undertaken to provide a carefully measured set of data on the condensation of steam on sub-cooled water layer in a simple system.

Our CC code has been developed firstly for simulating and predicting a countercurrent twophase flow, but since we don't have too many experimental data in order to validate it, and this article is a relevant one when dealing with the direct condensation phenomenon, we modified our code for simulating the cocurrent scenario which was performed in the Lim et al. article.

A scheme of the experimental facility is displayed in Figure 6.65. 


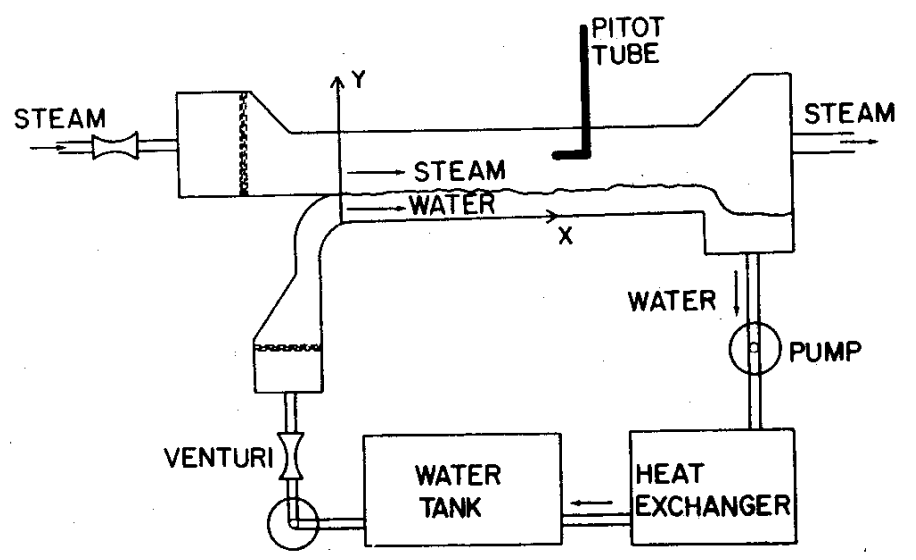

Figure 6.65 Schematic of the experiment

These authors obtained a set of data for different steam mass flow rates. So, in the next figure the steam mass flow rate and the condensation mass rate profiles as a function of the inlet mass flow rate are displayed.

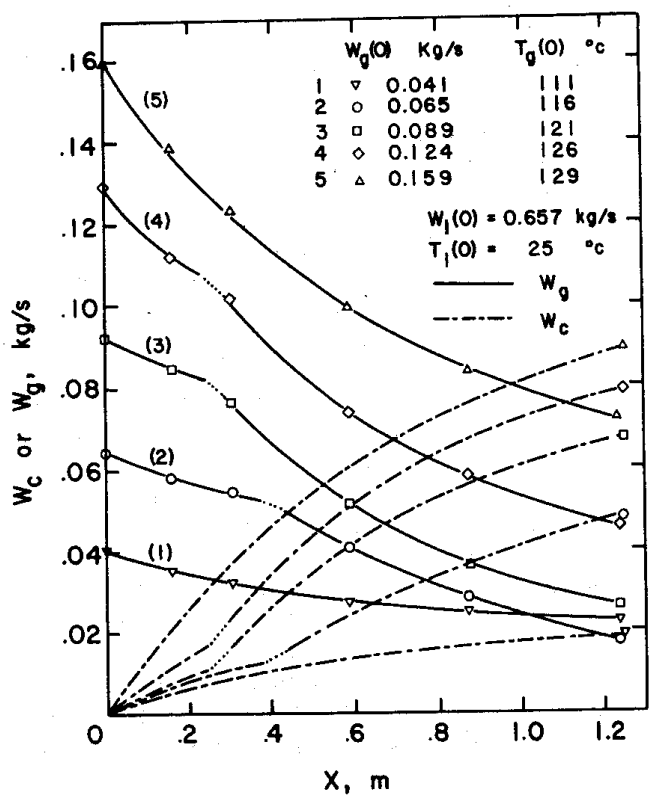

Figure 6.66 Axial steam and condensation mass rate profiles as a function of inlet steam mass flow rate 
In this experiment the steam mass flow rate was varied from $0.04 \mathrm{~kg} / \mathrm{s}$ to $0.16 \mathrm{~kg} / \mathrm{s}$ and the liquid mass flow rate from $0.2 \mathrm{~kg} / \mathrm{s}$ to $1.45 \mathrm{~kg} / \mathrm{s}$. The liquid layer heights that have been used were, $0.95,1.59$ and $2.22 \mathrm{~cm}$. The pressure at the inlet was of $0.3 \mathrm{kPa}$ above the atmospheric pressure.

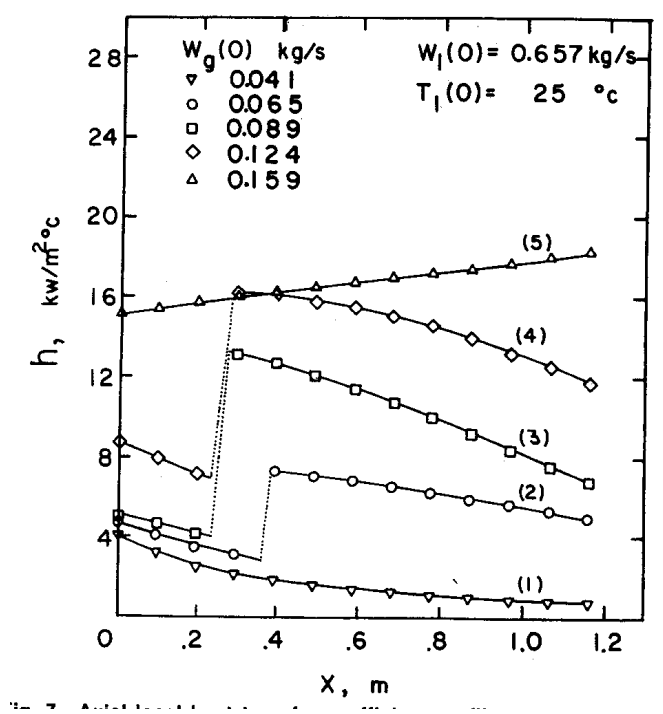

Figure 6.67 Axial local heat transfer coefficient profile as a function of the steam mass flow rate

The steam pressure was also measured, as can be seen in Figure 6.68 . 


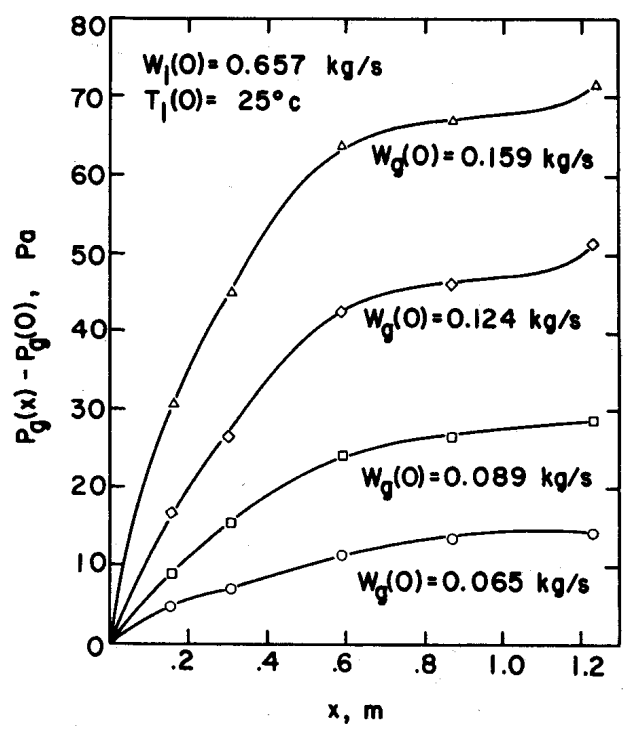

Figure 6.68 Typical axial steam pressure profiles as a function of the inlet steam mass flow rate

One of the tasks of the work performed was to correlate the experimental data on condensation mass rate characterized by Nusselt number;

$N \bar{u}=\frac{h_{c} D}{k}$, being $h_{c}$ the condensation heat transfer coefficient in terms of the dimensionless numbers; $\operatorname{Re}_{L}, \operatorname{Re}_{G}, \operatorname{Pr}_{L}$, for wavy and smooth conditions.

Those correlations are:

Smooth interface:

$$
N \bar{u}=0.534 \operatorname{Re}_{g}^{0.58} \operatorname{Re}_{l}^{0.09} \operatorname{Pr}_{l}^{0.3}
$$

Wavy interface:

$$
N \bar{u}=0.0291 \operatorname{Re}_{g}^{0.58} \operatorname{Re}_{l}^{0.42} \operatorname{Pr}_{l}^{0.3}
$$


We have then modified our $\mathrm{CC}$ code to simulate the conditions of this experiment for cocurrent flow and we have compared our results with the graphs that appear in it. Therefore, the boundary conditions that we will simulate with our CC code are:

Table 6.7 Boundary conditions for Lim and Tankin (1984) experiments on direct condensation for cocurrent flow [37]

\begin{tabular}{|l|c|c|c|c|c|}
\hline \multicolumn{1}{|c|}{ CASE } & $\mathbf{1}$ & $\mathbf{2}$ & $\mathbf{3}$ & $\mathbf{4}$ & $\mathbf{5}$ \\
\hline $\begin{array}{l}\text { Steam mass flow rate } \\
(\mathrm{Kg} / \mathrm{s})\end{array}$ & 0.041 & 0.065 & 0.089 & 0.124 & 0.159 \\
\hline $\begin{array}{l}\text { Liquid mass flow rate } \\
(\mathrm{Kg} / \mathrm{s})\end{array}$ & 0.657 & 0.657 & 0.657 & 0.657 & 0.657 \\
\hline $\begin{array}{l}\text { Inlet pressure } \\
(\text { Pa) }\end{array}$ & $1.016 \mathrm{e} 5$ & $1.016 \mathrm{e} 5$ & $1.016 \mathrm{e} 5$ & $1.016 \mathrm{e} 5$ & $1.016 \mathrm{e} 5$ \\
\hline $\begin{array}{l}\text { Inlet Steam } \\
\text { Temperature (K) }\end{array}$ & 384.15 & 389.15 & 394.15 & 399.15 & 402.15 \\
\hline $\begin{array}{l}\text { Inlet Liquid } \\
\text { Temperature (K) }\end{array}$ & 298.15 & 298.15 & 298.15 & 298.15 & 298.15 \\
\hline $\begin{array}{l}\text { Liquid layer thickness } \\
\text { (m) }\end{array}$ & 0.022 & 0.022 & 0.022 & 0.022 & 0.022 \\
\hline Pipe Width (m) & 0.3048 & 0.3048 & 0.3048 & 0.3048 & 0.3048 \\
\hline Pipe Height (m) & 0.0635 & 0.0635 & 0.0635 & 0.0635 & 0.0635 \\
\hline Pipe length (m) & 1.2 & 1.2 & 1.2 & 1.2 & 1.2 \\
\hline
\end{tabular}

\section{CASE 1}

In the case 1 , an inlet steam mass flow rate of $0.041 \mathrm{Kg} / \mathrm{s}$, and an inlet liquid mass flow rate of $0.657 \mathrm{Kg} / \mathrm{s}$ is being considered. The inlet boundary conditions are; $101600 \mathrm{~Pa}$, the inlet steam temperature is $384.15 \mathrm{~K}$, and the inlet liquid temperature is of $298.15 \mathrm{~K}$.

In the article can be seen the steam mass flow rate distribution for this case. So, the same case with the same boundary conditions is simulated with our CC code and below the comparison between our results and the experimental data is displayed: 


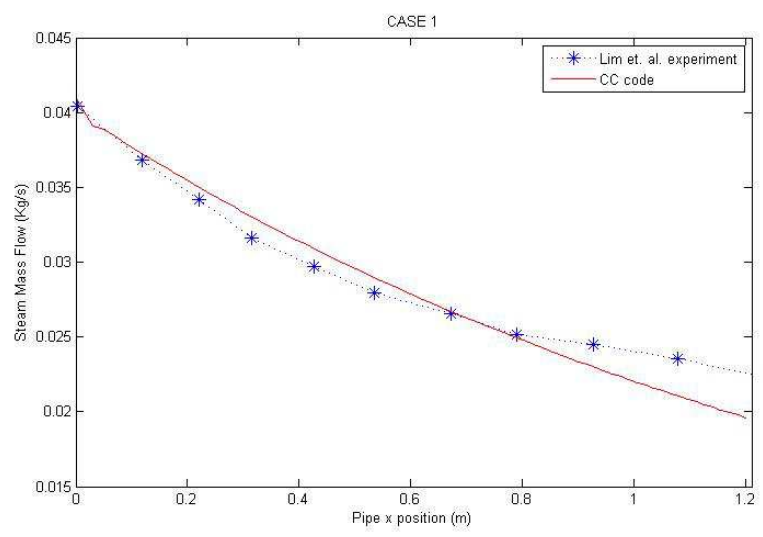

Graph 6.69 Steam mass flow distribution

It can be observed that the results we get from our $\mathrm{CC}$ code, agree pretty well with the experimental results which were published in this article.

\section{CASE 2}

In the case 2, an inlet steam mass flow of $0.065 \mathrm{Kg} / \mathrm{s}$, and an inlet liquid mass flow rate of $0.657 \mathrm{Kg} / \mathrm{s}$ is being considered. The inlet conditions are, $101600 \mathrm{~Pa}$, the inlet steam temperature is $389.15 \mathrm{~K}$, and the inlet liquid temperature is of $298.15 \mathrm{~K}$. 


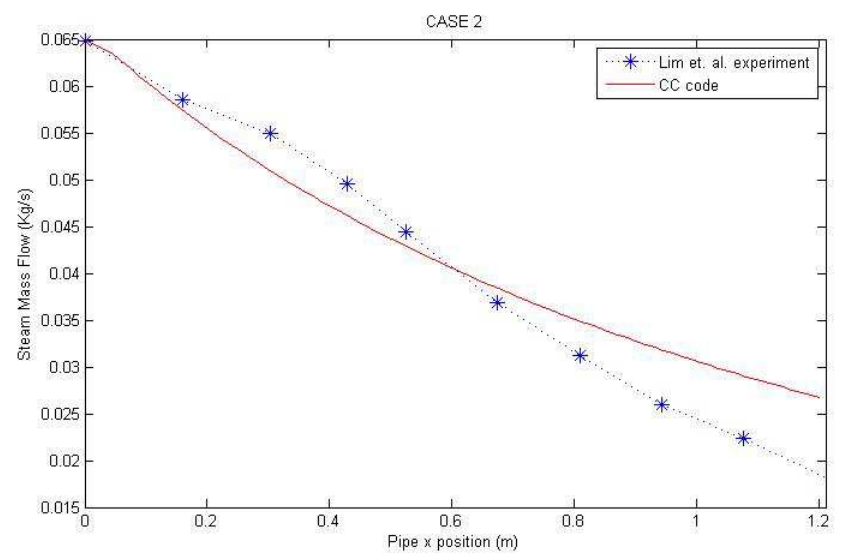

Graph 6.70 Steam mass flow rate distribution

It can be observed that the result that we get from our CC code, agree very well to the experimental results that were published in this article. At the end of the pipe maybe we move a bit away from the curve at the article, and our CC code give higher values than the experimental ones, but in the beginning our CC code gives smaller values. So, in general our CC result follows pretty well the experimental data for the case 2.

\section{CASE 3}

In the case 3, an inlet steam mass flow rate of $0.089 \mathrm{Kg} / \mathrm{s}$, and an inlet liquid mass flow rate of $0.657 \mathrm{Kg} / \mathrm{s}$ is being considered. The inlet conditions are, $101600 \mathrm{~Pa}$, the inlet steam temperature is $394.15 \mathrm{~K}$, and the inlet liquid temperature is of $298.15 \mathrm{~K}$. 


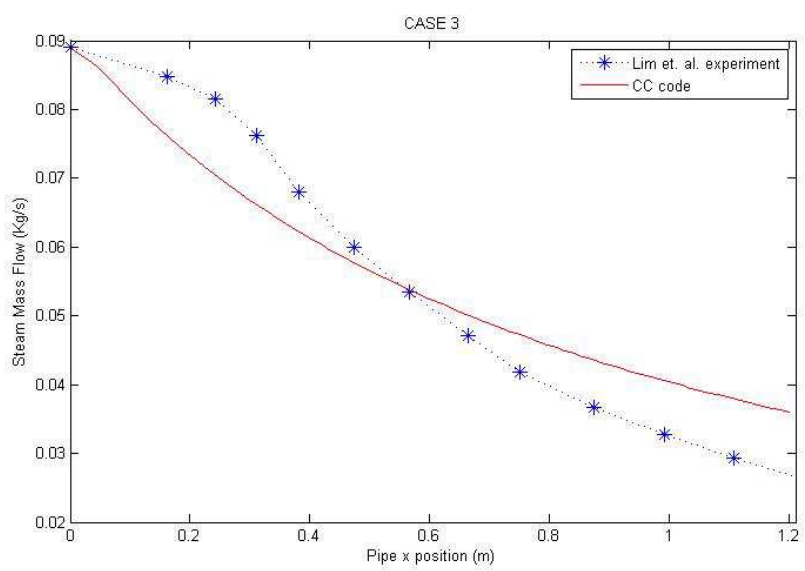

Graph 6.71 Steam mass flow rate distribution

It can be observed that the experimental results in this case follow a curve shape, and our $\mathrm{CC}$ has a more uniform shape since it doesn't change its curvature. Any way the error is small and we can say that our CC code gives also a pretty good result for these boundary conditions.

\section{CASE 4}

In the case 4 , an inlet steam mass flow rate of $0.124 \mathrm{Kg} / \mathrm{s}$, and an inlet liquid mass flow rate of $0.657 \mathrm{Kg} / \mathrm{s}$ is being considered. The inlet conditions are, $101600 \mathrm{~Pa}$ for the pressure, the inlet steam temperature is $399.15 \mathrm{~K}$, and the inlet liquid temperature is of $298.15 \mathrm{~K}$. 


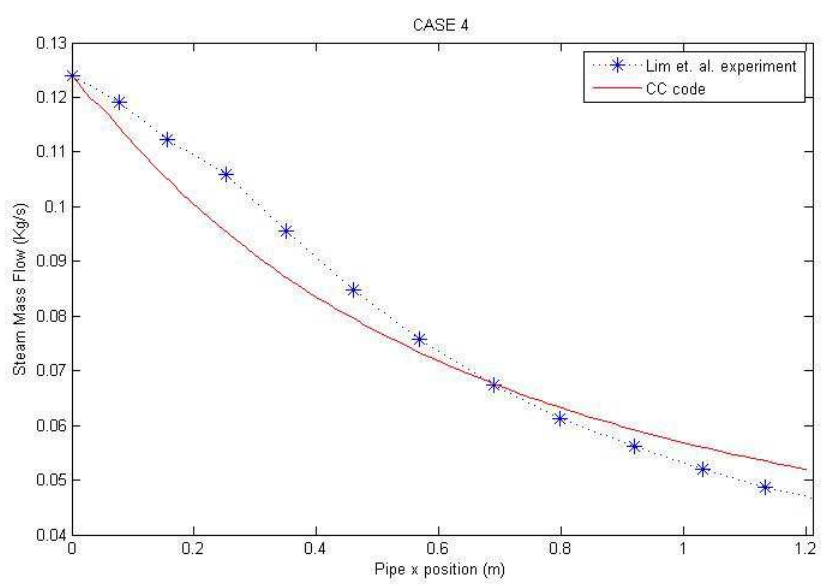

Graph 6.72 Steam mass flow rate distribution

In Graph 6.72 can be observed that the experimental graph and our CC code results for these boundary conditions agree very well with the experimental data along the pipe.

\section{CASE 5}

In the case 5 an inlet steam mass flow rate of $0.159 \mathrm{Kg} / \mathrm{s}$, and an inlet liquid mass flow rate of $0.657 \mathrm{Kg} / \mathrm{s}$ is being considered. The inlet conditions are, $101600 \mathrm{~Pa}$, the inlet steam temperature is $402.15 \mathrm{~K}$, and the inlet liquid temperature is of $298.15 \mathrm{~K}$.

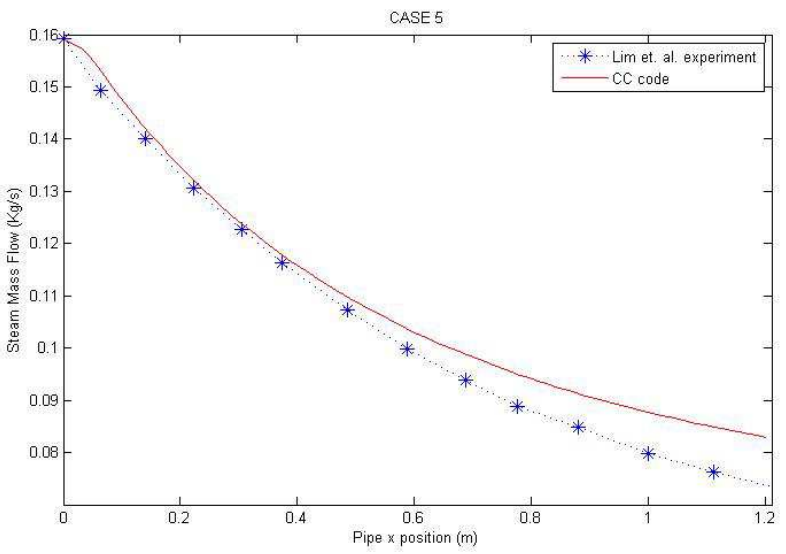

Graph 6.73 Steam mass flow rate distribution 
For these boundary conditions can be observed that the $\mathrm{CC}$ results fit really well to the experimental results.

\subsection{VALIDATION 3}

At this point, some comparative graphs using the LAOKOON experimental data will be displayed. The LAOKOON test facility belongs to the Technical University of Munich.

In the LAOKOON experiments, four cases were studied. Two of them were for cocurrent steam/water flow, and two of them were for countercurrent flow.

Cocurrent flow:

High steam Reynolds number

Low steam Reynolds number

Countercurrent flow:

High steam Reynolds number

Low steam Reynolds number

The geometry of the experimental facility is shown in Figure 6.74: 

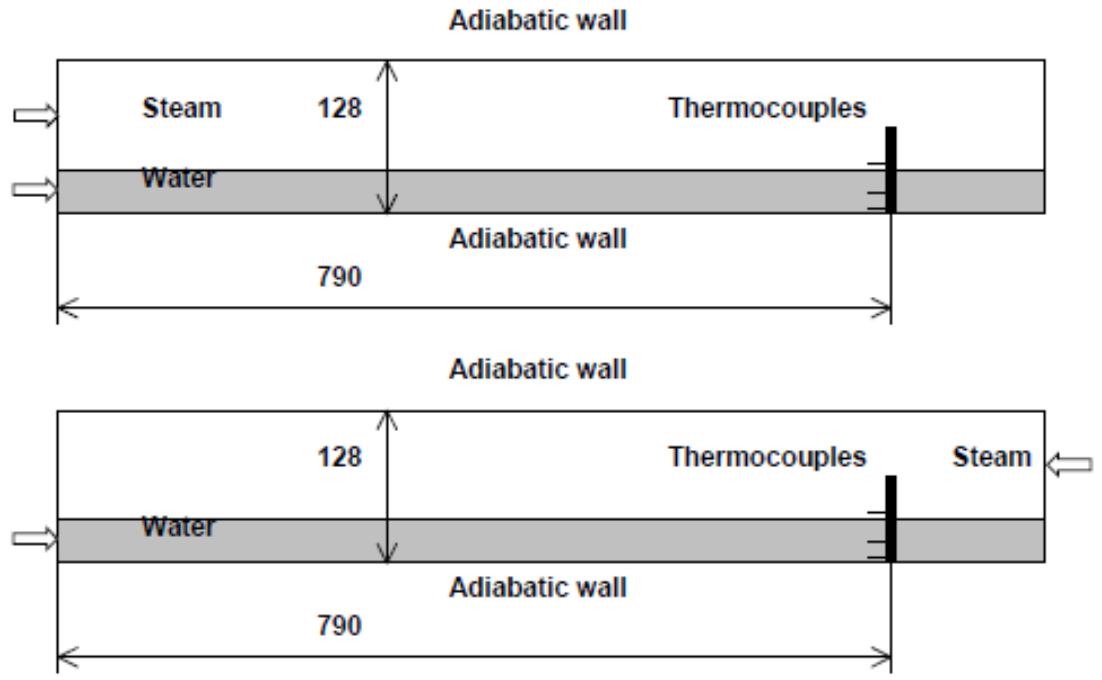

Figure 6.74 Geometry for the CFD simulations, (a) Cocurrent flow (b) Countercurrent flow.

Table 6.8 Main geometrical variable values

\begin{tabular}{|c|c|}
\hline Pipe length & $790 \mathrm{~mm}$ \\
\hline Pipe width & $30 \mathrm{~mm}$ \\
\hline Pipe height & $128 \mathrm{~mm}$ \\
\hline
\end{tabular}

One of the crucial points in the numerical simulation of this direct-contact condensation phenomenon is the correlation that it is being used and implemented in the code.

The results are very sensitive to this correlation since it is the main source of energy interchanged between the steam and the liquid phases.

In this way, some different correlations which are an outcome of several different publications on this issue in the last years will be used in order to simulate this scenario and will be compared with the LAOKOON experimental results. 
CASE 1: Cocurrent High steam Reynolds number.

Table 6.9 Flow Regime parameters: high Reynolds number of steam, Cocurrent flow

\begin{tabular}{|l|c|}
\hline Inlet flow rate velocity of water & $0.28 \mathrm{~m} / \mathrm{s}$ \\
\hline Inlet flow rate velocity of steam & $3.20 \mathrm{~m} / \mathrm{s}$ \\
\hline Inlet water temperature & $27.05^{\circ} \mathrm{C}$ \\
\hline Mean water temperature at the probe & $51.28^{\circ} \mathrm{C}$ \\
\hline Pressure & $6.97 \mathrm{bar}$ \\
\hline Height of the water layer & $31 \mathrm{~mm}$ \\
\hline
\end{tabular}

At this point the Nusselt number correlation for the interfacial heat and mass transfer between phases are the two that appear in the article by Lim, Tankin and Yuen (1984).

In this article we can find two correlations; one for a smooth interface, and another one for a wavy interface. So, our CC code will be executed with both of them and see how well the liquid bulk temperature is predicted by our code with each of them. Then another correlation from another article will be used, and finally, a self-made one will be used.

Therefore, some different correlations from different articles are checked and the results are compared with the experimental measurements.

The same procedure will be made for the four cases which are being compared.

\section{Correlation 1:}

The correlation that will be used here is the following one obtained by Lim et al. (1984) [37] for smooth conditions:

$$
h_{l \text { int }}=\frac{K_{l}}{D_{h l}} \cdot N u l \text { int }=\frac{K_{l}}{D_{h l}} \cdot 0.534 \cdot \operatorname{Re}_{l}{ }^{0.09} \cdot \operatorname{Re}_{g}{ }^{0.58} \cdot \operatorname{Pr} l^{0.3}
$$


As we can observe, the liquid Reynolds number exponent in this correlation is low here since it was correlated for the experimental data obtained for a smooth interface.

With the correlation 1 we are too far away from getting a good result for the liquid temperature. As it can be seen, we have two points for the LAOKOON test, one for the entry and another one which is the mean liquid temperature at the probe.

In blue we have the liquid temperature prediction with the correlation 1. As can be appreciated we have for this correlation a big error of about an $18 \%$.

\section{Correlation 2:}

The correlation that will be used here is the following one obtained by Lim et al. (1984) [37] for wavy conditions:

$$
h_{l \text { int }}=\frac{K_{l}}{D_{h l}} \cdot N u l \text { int }=\frac{K_{l}}{D_{h l}} \cdot 0.0291 \cdot \operatorname{Re} l^{0.42} \cdot \operatorname{Re}_{g}{ }^{0.58} \cdot \operatorname{Pr} l^{0.3}
$$

This correlation was obtained by Lim et al. (1984) for wavy interface conditions. This means that it will give higher values for the Nusselt number, and hence, a higher condensation rate.

As can be seen, the liquid temperature prediction with this correlation is even worst than the previous one, as we are having a higher condensation rate, and hence, a higher liquid temperature value at the probe.

Since this correlation was obtained for a wavy interface, the condensation is even higher than with the previous one for smooth interface. It gives higher Nusselt values, the condensation rate is higher, and hence, the liquid temperature is higher at the probe. 


\section{Correlation 3:}

As a consequence of the previous results, another correlation will be used, which has been taken from the Kim et al. 1985 [38] paper.

The correlation that will be used is the following one:

$$
h_{l \text { int }}=\frac{K_{l}}{D_{h l}} \cdot N u l_{\text {int }}=\frac{K_{l}}{D_{h l}} \cdot 3.2 \cdot 10^{-6} \cdot \operatorname{Re} l^{0.95} \cdot \operatorname{Re}_{g}{ }^{0.78} \cdot \operatorname{Pr} l^{0.95}
$$

With this correlation we have a good result since we are having a $2 \%$ of error for the liquid temperature at the probe.

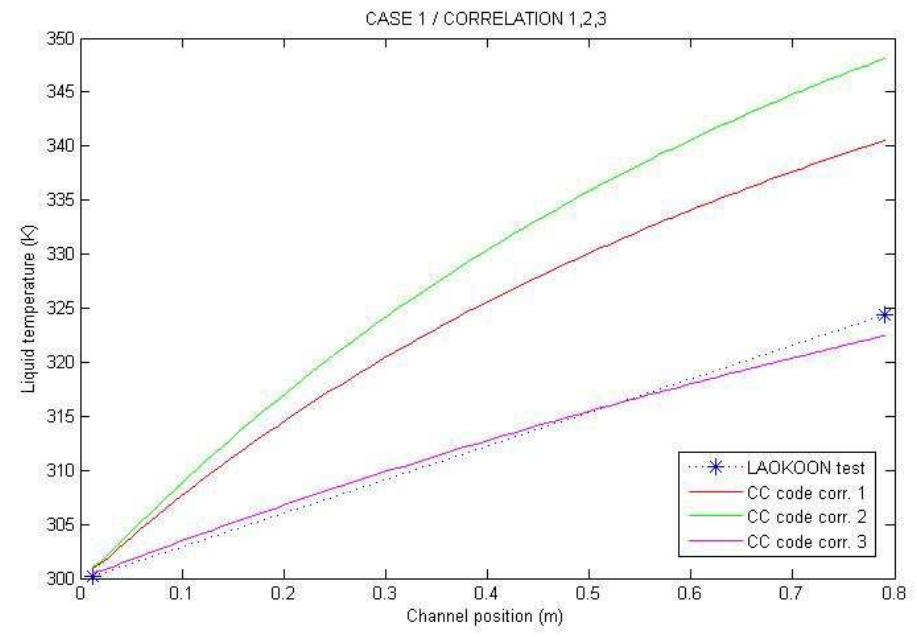

Graph 6.75 Comparison of the water temperature between the LAOKOON test and the UPV code results at the probe point using the correlation 1,2,3. 
Table 6.10 Mean water temperature comparison between the LAOKOON experiments and the UPV code with the probe at $790 \mathrm{~mm}$ using correlations 1-4

\begin{tabular}{|c|c|}
\hline & Mean water temperature at the probe $\mathbf{7 9 0} \mathbf{~ m m}$ \\
\hline LAOKOON $\left({ }^{\circ} \mathrm{K}\right)$ & 324.43 \\
\hline CC code $\left({ }^{\circ} \mathrm{K}\right)$ & 340.54 \\
\hline Correlation1 & 348.09 \\
Correlation 2 $\left({ }^{\circ} \mathrm{K}\right)$ & 322.42 \\
\hline $\begin{array}{c}\text { CC code }\left({ }^{\circ} \mathrm{K}\right) \\
\text { Correlation 3 }\end{array}$ & 324.32 \\
\hline $\begin{array}{c}\text { CC code }\left({ }^{\circ} \mathrm{K}\right) \\
\text { Correlation } 4\end{array}$ & \\
\hline
\end{tabular}

CASE 2: Cocurrent Low steam Reynolds number.

Table 6.11 Flow Regime parameters: low Reynolds number of steam, Cocurrent flow

\begin{tabular}{|l|c|}
\hline Inlet flow rate velocity of water & $0.27 \mathrm{~m} / \mathrm{s}$ \\
\hline Inlet flow rate velocity of steam & $3.39 \mathrm{~m} / \mathrm{s}$ \\
\hline Inlet water temperature & $23.43^{\circ} \mathrm{C}$ \\
\hline Mean water temperature at the probe & $39.89^{\circ} \mathrm{C}$ \\
\hline Pressure & $3.98 \mathrm{bar}$ \\
\hline Height of the water layer & $31 \mathrm{~mm}$ \\
\hline
\end{tabular}

At this point we will use the Nusselt number for the interfacial heat and mass transfer correlation obtained by Lim et al. (1984);

In Lim's paper two correlations can be found; one for a smooth interface, and another one for a wavy interface. 


\section{Correlation 1:}

The correlation that will be used here is the following one obtained by Lim et al. (1984) [37]:

$$
h_{l \text { int }}=\frac{K_{l}}{D_{h l}} \cdot N u_{l \text { int }}=\frac{K_{l}}{D_{h l}} \cdot 0.534 \cdot \operatorname{Re}_{l}{ }^{0.09} \cdot \operatorname{Re}_{g}{ }^{0.58} \cdot \operatorname{Pr}_{l}{ }^{0.3}
$$

As can be seen, the liquid Reynolds number exponent coefficient in this correlation has a small value in equation (7.5) since it has been correlated for a smooth interface.

Therefore, with Lim et al. (1984) [37] correlation we didn't get good results and we are far away from the $313 \mathrm{~K}$ average liquid temperature value for this case.

\section{Correlation 2:}

The correlation that will be used here is the following one obtained by Lim et al. [37] for a wavy interface:

$$
h_{l \text { int }}=\frac{K_{l}}{D_{h l}} \cdot N u_{l \text { int }}=\frac{K_{l}}{D_{h l}} \cdot 0.0291 \cdot \operatorname{Re}^{l^{0.42}} \cdot \operatorname{Re}_{g}{ }^{0.58} \cdot \operatorname{Pr}{ }^{0.3}
$$

We can see here that the multiplier constant is lower than the one of the previous correlation, but the liquid Reynolds exponent is higher.

In the previous table we have the mean temperature of the liquid layer at the probe. Since this correlation was made for a wavy interface, it gives an even higher value for the temperature than the previous smooth one (correlation 1).

It can be seen that we are still far away from getting a good result. 


\section{Correlation 3:}

Because of the poor results of Lim et al. correlation to predict the average temperature, the correlation developed by Kim, Lee and Bankoff (1985) [38], will be implemented in the UPV code to check the average probe results

This correlation is given by the expression:

$$
h_{l \text { int }}=\frac{K_{l}}{D_{h l}} \cdot N u_{l \text { int }}=\frac{K_{l}}{D_{h l}} \cdot 3.2 \cdot 10^{-6} \cdot \operatorname{Re}^{l^{0.95}} \cdot \operatorname{Re}_{g}{ }^{0.78} \cdot \operatorname{Pr} l^{0.95}
$$

With this correlation we have a good result since we are having a $2.5 \%$ of error for the liquid temperature at the probe.

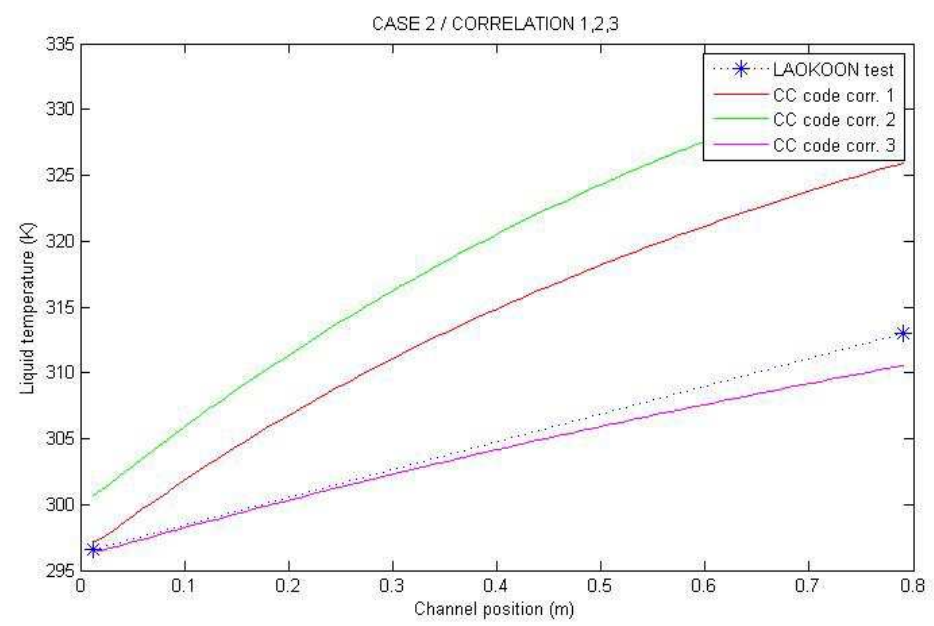

Graph 6.79 Comparison of the water temperature between the LAOKOON test and the UPV code results at the probe point using correlations 1-3 
Table 6.12 Mean water temperature comparison between the LAOKOON experiments and the UPV code with the probe at $790 \mathrm{~mm}$ using correlations 1-3

\begin{tabular}{|c|c|}
\hline & Mean water temperature at the probe $\mathbf{7 9 0} \mathbf{~ m m}$ \\
\hline LAOKOON $\left({ }^{\circ} \mathrm{K}\right)$ & 313.04 \\
\hline $\begin{array}{c}\text { CC code }\left({ }^{\circ} \mathrm{K}\right) \\
\text { Correlation1 }\end{array}$ & 325.94 \\
\hline $\begin{array}{c}\text { CC code }\left({ }^{\circ} \mathrm{K}\right) \\
\text { Correlation 2 }\end{array}$ & 332.94 \\
\hline $\begin{array}{c}\text { CC code }\left({ }^{\circ} \mathrm{K}\right) \\
\text { Correlation 3 }\end{array}$ & 310.54 \\
\hline
\end{tabular}

CASE 3: Countercurrent High steam Reynolds number.

As was told at the beginning of this point, in the LAOCOON test we have 4 cases: two of them (CASES 1 and 2) are for steam-water cocurrent flow, and two of them (CASES 3 and 4) are for steam-water countercurrent flow.

Table 6.13 Flow Regime parameters: low Reynolds number of steam, countercurrent flow

\begin{tabular}{|l|c|}
\hline Inlet flow rate velocity of water & $0.21 \mathrm{~m} / \mathrm{s}$ \\
\hline Outlet flow rate velocity of steam & $0.9 \mathrm{~m} / \mathrm{s}$ \\
\hline Inlet water temperature & $299.85^{\circ} \mathrm{K}$ \\
\hline Mean water temperature at the probe & $333.36^{\circ} \mathrm{K}$ \\
\hline Pressure & $6.98 \mathrm{bar}$ \\
\hline Height of the water layer & $31 \mathrm{~mm}$ \\
\hline
\end{tabular}

\section{Correlation 1:}

In this case, we have data for countercurrent flow. So, we need to find a correlation for countercurrent flow. 
The correlation that will be used here is the following one, which was developed by KyungWon et al. (2006) [134]:

$$
h_{l \text { int }}=\frac{K_{l}}{D_{h l}} \cdot N u_{l \text { int }}=\frac{K_{l}}{D_{h l}} \cdot 1.2 e-7 \cdot \operatorname{Re}_{l}{ }^{0.59} \cdot \operatorname{Re}_{g}^{1.2} \cdot J a^{0.82}
$$

\section{Correlation 2:}

In this case, we have data for countercurrent flow. So, we need to find a correlation for countercurrent flow.

The correlation that will be used here is the following one, which was developed by InCheol et al. (2000) [114]:

$$
h_{l \text { int }}=\frac{K_{l}}{D_{h l}} \cdot N u l \text { int }=\frac{K_{l}}{D_{h l}} \cdot 7.96 e-7 \cdot \operatorname{Re}_{l}{ }^{1.31} \cdot \operatorname{Re}_{g}{ }^{0.51} \cdot \operatorname{Pr}{ }^{1.19}
$$

\section{Correlation 3:}

In this case, we have data for countercurrent flow. So, we need to find a correlation for countercurrent flow.

The correlation that will be used here is the following one, which was developed by Kim et al. (1985) [38]:

$$
h_{l \text { int }}=\frac{K_{l}}{D_{h l}} \cdot N u l \text { int }=\frac{K_{l}}{D_{h l}} \cdot 0.32 e-5 \cdot \operatorname{Re}{ }^{0.95} \cdot \operatorname{Re}_{g}{ }^{0.95} \cdot \operatorname{Pr}^{0.78}
$$

\section{Correlation 4:}

The correlation that will be used here is the following one, which was developed by Lim et al. (1984) for wavy conditions [37]: 


$$
h_{l \text { int }}=\frac{K_{l}}{D_{h l}} \cdot N u l \text { int }=\frac{K_{l}}{D_{h l}} \cdot 0.0291 \cdot \operatorname{Re} l^{0.42} \cdot \operatorname{Re}_{g}{ }^{0.58} \cdot \operatorname{Pr}^{0.3}
$$

Correlation 5:

The correlation that will be used here is the following one, which was developed by Lim et al. (1984) for wavy conditions [37]:

$$
h_{l \text { int }}=\frac{K_{l}}{D_{h l}} \cdot N u l \text { int }=\frac{K_{l}}{D_{h l}} \cdot 0.534 \cdot \operatorname{Re}{ }^{0.09} \cdot \operatorname{Re}_{g}{ }^{0.58} \cdot \operatorname{Pr}{ }^{0.3}
$$

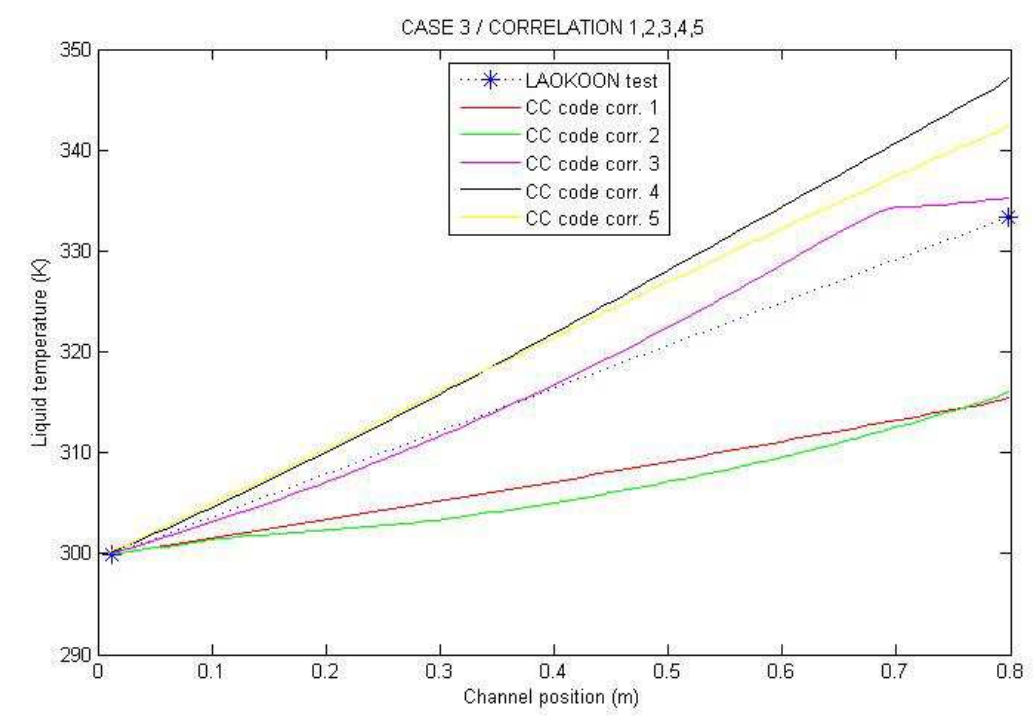

Graph 6.86 Comparison of the water temperature between the LAOKOON test and the UPV code results at the probe point using the correlations 1-5

Table 6.14 Mean water temperature comparison between the LAOKOON experiments and the UPV code at the probe $790 \mathrm{~mm}$

\begin{tabular}{|c|c|}
\hline & Mean water temperature at the probe $790 \mathbf{~ m m}$ \\
\hline LAOKOON $\left({ }^{\circ} \mathrm{K}\right)$ & 333.36 \\
\hline $\begin{array}{c}\text { CC code }\left({ }^{\circ} \mathrm{K}\right) \\
\text { Correlation1 }\end{array}$ & 315.38 \\
\hline
\end{tabular}




\begin{tabular}{|c|c|}
\hline $\begin{array}{l}\text { CC code }\left({ }^{\circ} \mathrm{K}\right) \\
\text { Correlation } 2\end{array}$ & 316.03 \\
\hline $\begin{array}{l}\text { CC code }\left({ }^{\circ} \mathrm{K}\right) \\
\text { Correlation 3 }\end{array}$ & 335.28 \\
\hline CC code $\left({ }^{\circ} \mathrm{K}\right)$ & 347.08 \\
Correlation 4 & 342.50 \\
\hline CC code $\left({ }^{\circ} \mathrm{K}\right)$ & \\
\hline Correlation 5 & \\
\hline
\end{tabular}

CASE 4: Countercurrent low steam Reynolds number.

Table 6.15 Flow Regime parameters: low Reynolds number of steam, countercurrent

\begin{tabular}{|l|c|}
\hline Inlet flow rate velocity of water & $0.25 \mathrm{~m} / \mathrm{s}$ \\
\hline Outlet flow rate velocity of steam & $0.64 \mathrm{~m} / \mathrm{s}$ \\
\hline Inlet water temperature & $299.83^{\circ} \mathrm{K}$ \\
\hline Mean water temperature at the probe & $327.0^{\circ} \mathrm{K}$ \\
\hline Pressure & $7.01 \mathrm{bar}$ \\
\hline Height of the water layer & $31 \mathrm{~mm}$ \\
\hline
\end{tabular}

\section{Correlation 1:}

The correlation that will be used here is the following one, which was developed by KyungWon et al. (2006) [134]:

$$
h_{l \text { int }}=\frac{K_{l}}{D_{h l}} \cdot N u l \text { int }=\frac{K_{l}}{D_{h l}} \cdot 1.2 e-7 \cdot \operatorname{Re}_{l} l^{0.59} \cdot \operatorname{Re}_{g}{ }^{1.2} \cdot J a^{0.82}
$$

It can be appreciated that the liquid temperature prediction at the probe, is pretty far away from the experimental measurement. 
Therefore some other correlations need to be tried in order to obtain more accurate results.

\section{Correlation 2:}

Because of the poor results that we have obtained by using the Kyung-Won et al. (2006) [134] correlation to predict the average temperature, the correlation developed by Kim, Lee and Bankoff (1985) [38], will be implemented in the UPV code to check the average probe results.

This correlation is given by the expression:

$$
h_{l \text { int }}=\frac{K_{l}}{D_{h l}} \cdot N u u_{\text {int }}=\frac{K_{l}}{D_{h l}} \cdot 3.2 \cdot 10^{-6} \cdot \operatorname{Re}_{l}^{0.95} \cdot \operatorname{Re}_{g}{ }^{0.78} \cdot \operatorname{Pr}_{l}{ }^{0.95}
$$

As can be seen in the previous figure, with this correlation the liquid temperature prediction is not as bad as it was with the previous correlation.

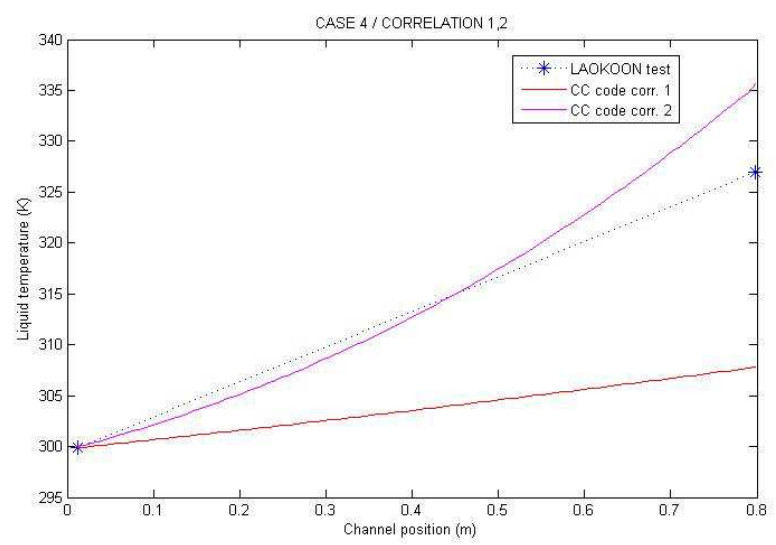

Graph 6.86 Comparison of the water temperature between the LAOKOON test and the UPV code results at the probe point using the correlations 1 and 2 
Table 6.16 Mean water temperature comparison between the LAOKOON experiments and the UPV code at the probe $790 \mathrm{~mm}$

\begin{tabular}{|c|c|}
\hline & Mean water temperature at the probe $\mathbf{7 9 0} \mathbf{~ m m}$ \\
\hline LAOKOON $\left({ }^{\circ} \mathrm{K}\right)$ & 327 \\
\hline $\begin{array}{c}\text { CC code }\left({ }^{\circ} \mathrm{K}\right) \\
\text { Correlation1 }\end{array}$ & 307.82 \\
\hline $\begin{array}{c}\text { CC code }\left({ }^{\circ} \mathrm{K}\right) \\
\text { Correlation 2 }\end{array}$ & 335.64 \\
\hline
\end{tabular}




\section{CHAPTER 7}

\section{CONCLUSIONS AND FUTURE WORK}

\subsection{CONCLUSIONS}

The aim of this final chapter is to state the general conclusions that we have obtained in the work performed in this Thesis.

As was shown in Chapter 6, we proved that our CC code has the capability of modelling a two-phase steam-water countercurrent flow in a duct.

The main milestones which have been undertaken in this Thesis are explained below:

\section{- Chapter 3}

In this chapter an analysis of the ROSA facility test 1.2 with the TRACE code has been made. In the first place, the test 1.2 was described, and then, the steady-state conditions were demonstrated by displaying the graphs which were obtained with the TRACE code model of the ROSA LSTF facility. Finally, the results for the experiment reproduction with the TRACE code and the comparison with the experimental data were presented.

It can be said that it has been reproduced the test 1.2 quite accurately with the TRACE code. Special care was taken when simulating the fluid regime in the hot leg where the break was produced, what directly leads the primary depressurization, and hence the evolution of the rest of main plant variables.

It is very important for this transient the ability of TRACE to predict correctly the fluid regime in the hot leg. At the beginning of the transient the fluid is discharged through the 
break located at the bottom of the hot leg. This fluid is in a liquid state and as a consequence the mass flow rate discharged through the break is very high, and the pressure drop very high during the first seconds of the transient until the beginning of the HPI injection. This behaviour is predicted very well by the TRACE code. Later, the flow at the hot leg becomes biphasic with low void fraction, and the mass flow rate discharged through the break is still high because the TRACE off-take model considers the fact that at the bottom of the hot leg we have liquid. Finally, the flow in the hot leg becomes biphasic with high void fraction and we discharge mainly steam through the break. In this test the contraction of the fluid vein during the steam discharge has an important influence on the depressurization rate during the steam flow regime. A contraction factor of 0.6 has been considered only during the steam regime to take into account this fact. The TRACE code predicts very well the change of regime from biphasic to practically single-phase steam that takes place between time 900 seconds and time 1000 seconds.

The evolution with time of the rest of variables like the pressure in the primary system, mass flow rate through the break, pressure in the secondary, and mass flow rate through the primary are all of them well predicted by the TRACE code through the transient. The pressure in the secondary is well predicted, for instance the maximum pressure attained in the secondary and the cycling of the safety and relief valves are well predicted by the TRACE code. Also well predicted by TRACE is the depressurization rate in the secondary.

As can be seen in the cold leg liquid temperature experimental graphs, a thermal stratification happened in the cold leg where the HPI (high pressure injection) is actuated. At the same time the steam flows countercurrently to the liquid flow. This is the scenario that has been the research issue that we have focused on for the development of this thesis.

At the end it can be concluded at this chapter that we were capable of simulating the test 1.2 scenario with the TRACE code, and give accurate results comparatively to the experimental data. 
- Chapter 4

In this chapter the mathematical model for the steam-water countercurrent flow was developed.

The conservation equations and the premises for the model were presented.

The averaged conservation equations were obtained from the general local instantaneous conservation equations, as it is shown in Appendix A.

The discretized conservation equations were then obtained by integrating the averaged conservation equations over a control volume.

The closure relations, which are needed in order to compensate the loss of information, were also undertaken.

Finally, as the outcome of this chapter it can be said that a $1 \mathrm{D}$ non-linear system of discretized equations was successfully attained.

\section{- Chapter 5}

In this chapter the development of a numerical code in order to mathematically simulate the steam-water countercurrent flow and the thermal stratification which may occur in the cold leg of a nuclear plant during a LOCA (Loss of coolant accident) was presented.

The numerical method for solving the discretized non-linear system of conservation equations is presented. The SIMPLE (Semi-Implicit Method for Pressure Linked Equations) method was used, as it is described in the book "Numerical heat Transfer and fluid flow", 1972 by Suhas V. Patankar.

All the derivatives of the Jacobian matrix are presented, and the way how the method works for obtaining a converged solution is described.

The iterative method that has been used in order to solve the system of equation was the Newton-Raphson, and since it can be seen in chapter 6, it worked properly, without a high computational cost. 
The methods for calculating the advective terms of the conservation equations are described in this chapter, which are the QUICKEST and ULTIMATE methods which are part of the TVD (Total Variation Diminution) strategy for limiting the pressure oscillations of the numerical algorithm.

The iterative method that was followed in order to solve the countercurrent flow regime with our equations is also explained.

The main conclusion that can be drawn out from this chapter is that a robust method for solving our countercurrent non-linear system of equations was presented and described.

\section{- Chapter 6}

In Chapter 6 a validation of our CC code has been made by reproducing with our code some experiments which were performed at different facilities and which resulted in some papers which were published in international reviews.

These are:

Validation 1:

Kyung-Won Lee a, In-Cheol Chu b, Seon-Oh Yu c, Hee Cheon No a, 2006 [134].

In this article, the interfacial condensation heat transfer for a steam-water countercurrent stratified wavy flow in a horizontal and circular pipe was investigated.

In this article four liquid bulk temperature distributions along the pipe can be found. Two of them are for smooth conditions and two for wavy conditions.

These experimental conditions were reproduced with our code, and the bulk liquid temperatures for these four boundary conditions were compared with the graphs which appear in the article.

It can be seen from the graphs in Chapter 6 that our countercurrent code is capable of simulating these conditions and of giving accurate results. We can conclude from this that the models that have been implemented as a way to simulate the physical phenomena which 
occur, i.e. the interfacial heat and mass transfer, the interfacial friction, the heat transfer to the walls of the pipe and the condensation at the steam wall surface are correct and the procedure for solving the non-linear system of equations by using a finite volume method has also been well attained.

\section{Validation 2:}

\section{I.S. Lim, R. S. Tankin, 1984 [37].}

This is a well known experiment when we are dealing with condensation phenomena. In this case the steam-water cocurrent flow condensation is studied

Our CC code was implemented to solve the conservation equations for a countercurrent flow, but since this is a relevant article in this specific field and it is another way to validate the heat and mass transfer models which have been implemented in the code, we modified the code for reproducing a phase stratified steam-water countercurrent flow.

From the five different conditions that were simulated with our code, we can conclude that the steam condensation was well predicted by our code as it can be appreciated in the Chapter 6.

\section{Validation 3:}

The CC code predictions are compared with the data provided by the HZDR (Helmholtz Zentrum Dresden Rossendorf). The data were an outcome from the so called, LAOCON EXPERIMENTS.

In the LAOKOON experiments, four cases were studied. Two of them were for cocurrent steam/water flow, and two of them were for countercurrent flow.

These four experiments were therefore simulated with our code. As can be seen in Chapter 6 , we had to try some different correlations for modelling the interfacial heat and mass transfer, for the code to give an accurate result for the mean liquid bulk temperature at the end of the probe. 
It is to know the important role that the correlation plays which is chosen to model the interfacial mass and heat transfer in order to give accurate predictions for the physical variables distributions. Normally each correlation was developed using a set of experimental data which were obtained for a specific flow conditions which undergo for a particular range for the main variables as the liquid and steam superficial velocities and liquid and steam Reynolds numbers.

It can be concluded from this validation that we can give accurate results by choosing the appropriate correlation for the flow conditions that we want to simulate.

\section{$\underline{\text { Future work }}$}

There is still much to do in order to improve the code and give a better solution for all the phenomenology that is involved in the thermal stratification and PTS (pressurized thermal shock) phenomena.

One point that is pending here is to make an analytical study of the instability of the liquid layer and propose criteria for the transition from a smooth surface to a wavy surface at the steam-liquid interface surface. This may affect the evolution of all the physical variables of this scenario, as we can appreciate in the validation 1 of Chapter 6.

This study has already been started, but there is still much that can be done in order to keep on improving the code.

Another point that would be very interesting and may be a path to continue with in the future is to couple this code with the NRC (National Regulatory Commission) thermalhydraulic code (TRACE). This would be a good improvement for this code in order to being more robust and being more capable when simulating the thermal stratification, the steam-water countercurrent flow and the PTS phenomena. 


\section{REFERENCES}

\section{DIRECT CONTACT CONDENSATION BIBLIOGRAPHIC REVIEW}

- 1913

[1] BLASIUS, P. R. H. 1913. Das Aehnlichkeitsgesetz bei Reibungsvorgangen in

Flüssigk eiten.Forschungsheft 131, 1-41.

- 1916

[2] Nusselt, W. 1916. "Die oberflachenkondensation des Wasser dampfes." Zeitschrift des Vereins deurscher Inginuere 60: 541-575.109

- 1932

[3] NIKURADSE, J. 1932. Gesetzmäßigkeit der turbulenten Strömung in glatten Rohren. Forsch. Arb. Ing.-Wes. N0. 356

- 1935

[4] PRANDTL, L. 1935. The Mechanics of Viscous Fluids. In: W.F, D. (ed.) Aerodynamic Theory III. Berlin: Springer.

- 1940

[5] Taylor, G. I. 1940. "Generation of Ripples by Wind Blowing over a Viscous fluid." The Scientific Works of Sir G. I. Taylor, edited by Batchelor, G. K. Cambridge University Press. 3: 244-254.

- 1949

[6] Bergelin, O. P. and Gazley, C. Ir. 1949. "Cocurrent Gas-liquid Flow- 1. Flow in Horizontal Tubes." Paper presented at the Heat Transfer and Fluid Mechanics Institute, Berkeley, California. Published by American Society of Mechanical Engineers. 5-18.

[7] Lockhart, R. W. and Martinelli, R. C. 1949. "Proposed Correlation of Data for Isothermal Two-Phase, Two-Component Flow in Pipes." Chemical Engineering Progress 45: 39-48.

- 1954

[8] Baker, O. 1954. "Simultaneous Flow of Oil and Gas." Oil and Gas Journal 53: 185-195.

- 1961

[9] Wallis, G.B., 1961. Flooding Velocities for Air and Water in Vertical Tubes. AAEWR123,UKAEA, Harwell, England. 
- 1962

[10] Chato, 1. C. 1962. "Laminar Condensation Inside Horizontal and Inclined Tubes." ASHRAE Journal 4: 52-60.

- 1965

[11] Gradshteyn, I. S. and Ryzhik, I. W. 1965. Table of Integrals, Series and Products. Academic Press. New York. 245-246.

[12] Pletcher, R. H. and McManus, H. N. 1965. "The Fluid Dynamics of Three-dimensional Liquid Films with Free Surface Shear-a Finite Difference Approach." In Proceedings of the 9th Mid-Western Mechanics Conference, Wisconsin.

- 1966

[13] Rufer, C. E. and Kezios S.P. 1966. "Analysis of Stratified Flow with Condensation." Journal of Heat Transfer 88: 265-275.

- 1967

[14] Fortescue, G. E. and Pearson, J. R. A. 1967. On gas absorption into a turbulent liquid. Chemical Engineering Science. 22: 1163-1176.

- 1969

[15] Wallis, G.B., 1969. One-dimensional Two-phase Flow. McGraw Hill, New York.

[16] Woodmansee, D. E. and Hanratty, T. J. 1969. "Mechanisms for the Removal of Droplets from a Liquid Surface by a Parallel Air Flow." Chemical Engineering Science 24: 299-307.

[17] Thorpe, S. A. 1969. Experiments on the instability of stratified shear flows: immiscible fluids. Journal of Fluid Mechanics, 39, 25-48.

- 1970

[18] John H. Linehan, M.M, el-wakil, 1970. The condensation of a saturated vapor on a subcooled film during stratified flow. Chemical Engineering progress symposium series 102, vol. 66 .

- 1972

[19] Alekseev, V.P., Poberezkin, A.E., Gerasimov, P.V., 1972. Determination of flooding rates in regular packings. Heat Transfer Soviet Research (4), 159-163.

[20] Butterworth, D. 1972. "Air-Water Annular Flow in a Horizontal Tube." Progress in Heat and Mass Transfer 6: 235-251.

- 1973

[21] Wallis, G. B. and Dobson J. E. 1973. "The Onset of Slugging in Horizontal Stratified Air-Water Flow." International Journal of Multi phase Flow 1: 173-193.

- 1974 
[22] Mandhane, J. M., Gregory G. A. and Aziz, K. 1974. "A Flow Pattern Map for Gasliquid Flow in Horizontal Pipes." International Journal of Multi phase Flow 1: 537-553.

[23] Tatterson, D. F. 1974. Rates of Atomization and Drop Size in Annular Two-phase Flow. PhD Thesis, University of lllinois.

- 1976

[24] Gnielinski, V., 1976. New equations flow regime heat and mass transfer in turbulent pipe and channel flow. Int. Chem. Eng. 16, 359-368.

[25] Taitel Y., Dukler A. E., 1976. Model for predicting flow regime transitions in horizontal and near horizontal gas-liquid flow. AICHE Journal 22 (1), 47-55.

[26] Boure, 1. A., Fritte, A. A., Giot, M. M. and Reocreux, M. L. 1976. "Highlights of Two-phase Critical Flow - On the Links between Maximum Flow Rates, Sonic Velocities, Propagation and Transfer Phenomena in Single and Two-phase Flows." International Journal of Multiphase Flow 3: 1-22.

[27] Delhaye, I. M. 1976. "Space/time and Time/space Averaged Equations." Proceedings of NATO Advanced Study Institute, Istanbul, Turkey, eds. Kaka , S. and Mayinger, F. Hemisphere. Washington. 108

[28] Finkelstein, Y. and Tamir, A. 1976. Interfacial heat transfer coefficients of various vapors in direct contact condensation. The Chemical Engineering Journal. Vol. 12. pp. 199209.

[29] Taitel, Y. and Dukler A. E. 1976. "A Model for Predicting Flow Regime Transitions in Horizontal and Near Horizontal Gas-Liquid Flow." American Institute of Chemical Engineering Journal 22: 47-55.

- 1977

[30] Tatterson D. F. and Hanratty, T. J. 1977. "Drop Sizes in Annular Gas-liquid Flows." American Institute of Chemical Engineering Journal 23:68-76.

- 1978

[31] Ginoux, J. 1978. Two-phase Flows and Heat Transfer. Hemisphere. Washington.

- 1979

[32] Chen, B. and Saffman, P. G. 1979. "Steady Gravity-Capillary Waves on Deep Water1. Weakly Nonlinear Waves." Studies in Applied Mathematics 60: 183-210.

- 1980

[32] Krolewski, S.M., 1980. Flooding Limits in a Simulated Nuclear Reactor Hot Leg. B.Sc. Thesis of MIT, August 1980.

[33] Mishima K, Ishii M., 1980. Theoretical prediction of onset of horizontal slug flow. Journal of Fluids Engineering-T ASME 102(4), 441-445.

[34] Chen, B. and Saffman, P. G. 1980. "Steady Gravity-Capillary Waves on Deep Water2. Numerical Results for Finite Amplitude." Studies in Applied Mathematics 62: 95-111. 
- 1981

[35] A. Segev, L.J. Flanigan, 1981. Experimental study of Countercurrent steam Condensation. Battelle Columbus Laboratories, 505 King Avenue, Columbus Ohio 43201.

- 1982

[36] Laurinat, J. E. 1982. Studies of the Effect of Pipe Size on Horizontal Annular TwoPhase Flows. Ph.D. Thesis, University of Illinois.

- 1984

[37] I.S. Lim, R. S. Tankin, 1984. Condensation Meassurement of horizontal Cocurrent Steam/Water Flow. Journal of heat transfer, 106 425-432.

- 1985

[38] Kim, H.J., Lee, S.C., Bankoff, S.G., 1985. Heat transfer and interfacial drag in countercurrent steam-water stratified flow. Int. J. Multiphase Flow 11 (5), 593-606.

[39] Bankoff, S.G., Lee, S.C., 1985. A brief review of countercurrent flooding models applicable to PWR geometries. Nuclear Safety 26 (2), 139-152.

[40] Kirchner W., Bankoff S. G., 1985. Condensation effects in reactor transients. Nuclear Science and Engineering 89, 310-321.

- 1986

[41] Celata G. P., Cumo M., Farello G. E.,Focardi G., 1986. Direct contact condensation of steam on slowly moving water. Nuclear Engineering and Design 96, 21-31.

[42] Ardron, K.H., Banerjee, S., 1986. Flooding in an elbow between a vertical and a horizontal or near horizontal pipe. Part I. Theory. International Journal of Multiphase Flow $12,543-558$.

[43] Bankoff, S.G., Lee, S.C., 1986. A critical review of the flooding literature. Multiphase Science and Technology 2, 95-180.

[44] Barnea, D., Ben Yoseph, N., Taitel, Y., 1986. Flooding in inclined pipe: effect of entrance section. The Canadian Journal of Chemical Engineering 64 (2), 177-184.

[45] Ohnuki, A., 1986. Experimental study of countercurrent two-phase flow in horizontal tube connected to inclined riser. Journal of Nuclear Science and Technology 23 (3), 219232.

[46] Siddiqui, H., Banerjee, S., Ardron, K.H., 1986. Flooding in an elbow between a vertical and a horizontal or near horizontal pipe. Part I. Experiments. International Journal of Multiphase Flow 12, 531-541.

[47] Wan, P.T., 1986. Countercurrent steam-water flow in an upright 90。 elbow. In: Proceeding of the Eighth International Heat transfer Conference, San Francisco, CA, USA, pp. 2313-2318. 
- 1987

[48] G.P.Celata, M.Cumo, G.E.Farello, G. Focardi, 1987. Direct contact condensation of steam on a horizontal surface of water. Wärme-und Stoffüberagnung 21, 169-180.

[49] Andritsos, N. and Hanratty, T. 1. 1987. Influence of Interfacial Waves in Stratified Gas-liquid Flows. American Institute of Chemical Engineering Journal 33: 444-454.

[50] Bhatti, M. S. and Shah R. K. 1987. "Turbulent and Transition Flow Convective Heat Transfer in Ducts." In Handbook of Single-phase Convective Heat Transfer, eds. S. Kakac, Shah R. K., and Aung W. Iohn Wiley \& Sons. New York. 4-1-4-166.

[51] Chen, I. Y. and Kocamustafaogullari, G. 1987. "Condensation Heat Transfer Studies for Stratified, Concurrent Two-Phase Flow in Horizontal Tubes." International Journal of Heat and Mass Transfer 30: 1133-1148.

[52] Whalley, P. B. 1987. Boiling, Condensation and Gas-liquid Flows. Clarendon Press. Oxford. White, F. M. 1991. Viscous Fluid Flow. 2nd ed. McGraw-Hill. New York.

- 1988

[53] Ohnuki, A., Adachi, H., Murao, Y., 1988. Scale effects on countercurrent gas-liquid flow in a horizontal tube connected to an inclined riser. Nuclear Engineering and Design 107, 283-294.

[54] Weiss, P.A., Hertlein, R.J., 1988. UPTF test results: first three separate effect tests. Nuclear Engineering and Design 108, 249-263.

- 1989

[55] Celata, G.P., Cumo, N., Farello, G.E., Setaro, T., 1989. The influence of flow obstructions on the flooding phenomenon in vertical channels. International Journal of Multiphase Flow 15 (2), 227-239.

[56] Fukano, T. and Ousaka, A. 1989 .. "Prediction of the Circumferential Distribution of Film Thickness in Horizontal and Near-horizontal Gas-liquid Annular Flows." International Journal of Multi phase Flow 15: 403-419.

- 1990

[57] Tehrani, A.A.K., Patrick, M.A., Wragg, A.A., Gardner, G.C., 1990. Flooding in a scale model of the hot-leg system of a pressurized water reactor. In: Proceeding of the Winter Annual Meeting of the ASME, Dalas, TX, November, pp. 221-228.

[58] Bestion D., 1990 . The physical closure laws in the cathare code, Nuclear Engineering and Design, 124, 229-245.

[59] Chan T.S. , Yuen M. C., 1990. The effect of air on condensation of stratified horizontal concurrent steam water-flow. Journal of heat transfer - T ASME 112 (4), 1092-1095. 576

[60] Jayanti S., Hewitt, G. F. and White, S. P. 1990. "Time-dependent Behaviour of the Liquid Film in Horizontal Annular Flow". International Journal of Multiphase Flow 16: 1097-1116. 
- 1991

[61] Akira Murata, Eiji Hihara and Takamoto Saito, 1991. Prediction of heat transfer by direct contact condensation at a steam-subcooled water interface. International Journal of Heat and Mass Transfer 35 (1), 101-109.

[62] Aya I., Nariai H., 1991. Evaluation of heat-transfer coefficient at direct contact condensation of cold water and steam. Nuclear Engineering and Design 131, 17-24.

[63] Kuo-Shing Liang, 1991. Experimental and analytical study of direct contact condensation of steam in water. Massachusets institute of technology.

[64] Asaka H., Kukita Y., Anoda Y., Nakamura H., Tasaka K., 1991. Improvement of TRAC-PF1 interfacial drag model for analysis of High-Pressure Horizontally-Stratified two-phase flow. Journal of Nuclear Science and Technology 28 (1) 33-44.

[65] Aya I., Nariai H., 1991. Evaluation of heat-transfer coefficient at direct contact condensation of cold water and steam. Nuclear Engineering and Design 131, 17-24.

[66] Akira Murata, Eiji Hihara and Takamoto Saito, 1991. Prediction of heat transfer by direct contact condensation at a steam-subcooled water interface. International Journal of Heat and Mass Transfer 35 (1), 101-109.

[67] Hughes E. D., Duffey R. B., 1991. Direct contact condensation and momentumtransfer in turbulent separated flows. International Journal of Multiphase flow 17 (5), 599619.

[68] Bontozoglou, V. 1991. 'Weakly Nonlinear Kelvin-Helmholtz Waves between Fluids of Finite Depth." International Journal of Multi phase Flow 17: 509-518.

[69] Hanratty, T. J. 1991. "Separated Flow Modelling and Interfacial Phenomena." Applied Scientific Research 48: 353-390.

- 1992

[70] Geweke, M., Beckmann, H., Mewes, D.,1992. Experimental studies of two-phase flow. In: Proceeding of European Two-Phase Flow Group Meeting. Stockholm, June, Paper No. J1.

[71] Glaeser, H., 1992. Downcomer and tie plate countercurrent flow in the upper plenum test facility (UPTF). Nuclear Engineering and Design 133, 259-283.

[72] Ohnuki, A., Akimoto, H., Murao, Y., 1992. Development of interfacial friction model for two-fluid model code against countercurrent gas-liquid flow limitation in PWR hot leg. Journal of Nuclear Science \& Technology 29 (3), 223-232.

[73] Weiss, P., Emmerling, R., Hertlein, R., Liebert, J., 1992. Two-phase flow experiments in full-scale to extend knowledge of PWR LOCA thermal-hydraulics. In: Proceeding of the National Heat Transfer Conference, San Diego, CA, USA, pp. 268-282.

[74] Ohnuki A., Akimoto H., Murao Y., 1992. development of interfacial friction model for two-fluid model code against countercurrent gas-liquid flow limitation in PWR hot leg. Journal of Nuclear Science and Technology 29 (3), 223-232. 
[75] Brauner, N. and Moalem Maron, D. 1992. "Stability Analysis of Stratified Liquidliquid Flow." International Journal of Multiphase Flow 18: 103-121.

[76] Carey, V. P. 1992. Liquid-vapor Phase Change Phenomena. Hemisphere. New York.

[77] Galbiati, L. and Andreini, P. 1992. "The Transition Between Stratified and Annular Regimes for Horizontal Two-Phase Flow in Small Diameter Tubes." International Communications in Heat and Mass Transfer 19: 185-190.

[78] Murata, A., Hihara, E. and Saito, T. 1992. Prediction of Heat Transfer by Direct Contact Condensation at a Steam-subcooled Water Interface. International Journal of Heat and Mass Transfer 31: 101-109.

- 1993

[79] Janicot A., Bestion D., 1993. Condensation eber ri for ECC injection. Nuclear Engineering and Design 145, 37-45.

[80] Glaeser, H., Karwat, H., 1993. The contribution of UPTF experiments to resolve some scale-up uncertainties in countercurrent two phase flow. Nuclear Engineering and Design $145,63-84$.

[81] Lee, S.C., Bankoff, S.G., 1993. Stability of steam water countercurrent flow in an inclined channel: flooding. Journal of Heat Transfer 105, 713-718.

[82] Smits, S.R., Huang, W.D., Razi, J., Kocamustafaogullari, G., 1993. Droplet size modeling in annular flow. In: Proceeding of the $6^{\text {th }}$ International Topical Meeting on Nuclear Reactor Thermal Hydraulics (NURETH-6), Grenoble, France, October 5-8, 1993.

[83] Janicot A., Bestion D., 1993. Condensation modelling for ECC injection. Nuclear Engineering and Design 145, 37-45.

[84] Zhang Q., Hewitt G. F., Leslie D. C., 1993, Nuclear safety code modeling of condensation in stratified flow. Nuclear Engineering and Design 139 (1), 1-15.

- 1994

[85] De Bertodano, M.L., 1994. Countercurrent gas-liquid flow in a pressurized water reactor hot leg. Nuclear Science and Engineering 117, 126-133.

[86] Wongwises, S., 1994. Experimental investigation of two-phase countercurrent flow limitation in a bend between horizontal and inclined pipes. Experimental Thermal and Fluid Science 8, 245-259.

[87] Collier, 1. G. and Thome, 1. R. 1994. Convective Boiling and Condensation. 3rd ed. Clarendon Press. Oxford.

[88] Dobson, M. K. 1994. Heat Transfer and Flow Regimes During Condensation in Horizontal Tubes. PhD Thesis, University of Illinois.

- 1995

[89] J.L.Muñoz-Cobo, L.Herranz, J.Sancho, I.Tkachenko, 1995. Turbulent vapor condensation with noncondensable gases in vertical tubes. International Journal of Heat and Mass Transfer 39 (15), 3249-3260. 
[90] Geffraye, G., Bazin, P., Pichon, P., Bengaouer, A., 1995. CCFL in hot legs and steam generators and its prediction with the CATHARE code. In: Proceeding of the $7^{\text {th }}$ International Meeting on Nuclear Reactor Thermal Hydraulics NURETH-7, New York, USA, pp. 815-826.

[91] Noel, D.G., Shoukri, M., Abdul-Razzak, A., 1994. Two-phase countercurrent flow limitations in complex piping systems. In: Proceeding of $15^{\text {th }}$ Annual Conference of Canadian Nuclear Society, Montreal, Cananda, June.

[92] Stevanovic, V., Studovic, M., 1995. A simple model for vertical annular and horizontal stratified two-phase flows with liquid entrainment and phase transitions: one-dimensional steady-state conditions. Nuclear Engineering and Design 154, 357-379.

[93] Wang, M.J., Mayinger, F., 1995. Simulation and analysis of thermal-hydraulic phenomena in a PWR hot leg related SBLOCA. Nuclear Engineering and Design 155, 643652.

[94] H. Ruile, 1995. Heat transfer by direct contact condensation in stratified two phase flow at high system pressure. Two-Phase Flow Modelling and Experimentation.

[95] J.L. Muñoz-Cobo, L.Herranz, 1995. Turbulent eber condensation with noncondensables gases in vertical tubes. International Journal of Heat and mass transfer vol. 39, $\mathrm{N}^{\mathrm{o}} 15$, pp 3249-3260.

[96] Groenwald, W. and KrOger, D. G. 1995. Effect of Mass Transfer on Turbulent Friction during Condensation Inside Ducts. International Journal of Heat and Mass Transfer 38: 3385-3392.

[97] Heun, M. K. 1995. Performance and Optimization of Microchannel Condensers. PhD Thesis, University of lllinois.

- 1996

[98] Wongwises, S., 1996a. Flooding in a horizontal pipe with bend - brief communication. International Journal of Multiphase Flow 22 (1), 195-201.

[99] C. Tantolin, M. Lallemand, 1997. Film condensation inside horizontal integral-fin tubes of large diameter. Applied thermal engineering, vol. 17, № 2, pp 179-192.

[100] S. Murakami, S. Kato 1996. New low-Reynolds number k- $\varepsilon$ model including damping effect due to buoyancy in a stratified flow field. International Journal of heat and mass transfer 39 (16) 3483-3496.

- 1997

[101] Mikielewicz J., Trela M., Ihnatowicz E., 1997. A theoretical and experimental investigation of direct contact condensation on a liquid layer. Experimental Thermal and fluid Science 15, 221-227.

[102] Luis E.Herranz, Jose L. Muñoz-Cobo, G.Verdu, 1997. Heat transfer modeling in the vertical tubes of the passive containment cooling system of the simplified boiling water Reactor. Nuclear engineering and design 178, 29-44. 
[103] Line A., Lopez D., 1997. Two-fluid model of wavy separated two-phase flow. International Journal of Multiphase flow 23 (6), 1131-1146.

[104] Lorencez C., Nasr-Esfahany, Kawaji M., 1997. Turbulence structure and prediction of interfacial heat and mass transfer in wavy-stratified flow. AIChE Journal 43, 1426-1435.

[105] Mikielewicz J., Trela M., Ihnatowicz E., 1997. A theoretical and experimental investigation of direct contact condensation on a liquid layer. Experimental Thermal and fluid Science 15, 221-227.

[106] Y.J. Yu, S.H. Park, G.H. Sohn, W.J. Bak 1997. Structural evaluation for PWR surge line. Nuclear Engineering and Design 178, 211-220.

- 1998

[107] Tye, P., 1998. Countercurrent and Flooding in Vertical and Horizontal Tubes with and without Obstructions. Ph.D. Thesis. Département de Génie Méchanique Eole Polytechnique de eber ri, Canada.

[108] S. wongwises, W. Khankaew, 1998. Prediction of Liquid Holdup in horizontal Stratified Two-Phase Flow. Thammasa Int. J. Sc. Tech,. Vol.3, No 2.

[109] Jari Tuunanen, Vesa Riikonen, Jyrki Kouhia, Juhani Vihavainen 1998. Analyses of PACTEL passive safety injection experiments GDE-21 thorugh GDE-25. Nuclear Engineering and Design 180, 67-91.

- 1999

[110] Chun, M.H., No, H.C., Kang, S.K., Chu, I.C., 1999. Countercurrent flow limitation in a horizontal pipe connected to an inclined riser. Transactions of the American Nuclear Society 81, 340-341.

[111] Myung Jo Jhung, Youn Won Park, Changheui Jang 1999. Pressurized thermal shock analyses of a reactor pressure vessel using critical crack depth diagrams. International Journal of pressure vessels and piping 76, 813-823.

[112] Klaus W. Bieniussa, Hans Reck 1999. Piping specific analysis of stress due to thermal stratification. Nuclear Engineering and Design 190, 239-249.

- 2000

[113] Moon-Hyun Chun, Seon-Oh Yu, 2000. Effect of steam condensation on countercurrent flow limiting in nearly horizontal two-phase flow. Nuclear Engineering and Design 196, 201-217.

[114] In-Cheol Chu, Moon Ki Chung, 2000. Interfacial condensation heat transfer for countercurrent steam-water stratified flow in a circular pipe. Journal of the Korean Nuclear society 32 (2), 142-156.

[115] Luis E.Herranz, Jose L. Muñoz-Cobo, Maria J. Palomo, 2000. Modeling condensation heat transfer on a horizontal finned tube in the presence of noncondensable gases. Nuclear engineering and design 201, 279-288. 
[116] Zapke, K., Kroger, D.G., 2000. Countercurrent gas-liquid flow in inclined and vertical ducts. II. The validity of the Froude-Ohnesorge number correlation for flooding. International Journal of Multiphase Flow 26, p1457-p1468.

- 2001

[117] J.T.Kwon, Y.C. Ahn, M.H. Kim, 2001. A modeling of in-tube condensation heat transfer for a turbulent annular film flow with liquid entrainment. International journal of multiphase flow (27), 911-928.

[118] K.Ramamurthi, S.Sunil Kumar, 2001. Collapse of vapor locks by condensation over moving subcooled liquid. International Journal of Heat and Mass Transfer 44, 2983-2994.

[119] Il Seok Jeong, Changhuei Jang, Jun-Hyun Park, Sung-Yull Hong 2001. Lessons learned from the plant-specific pressurized thermal shock integrity analysis on an embrittled reactor pressure vessel. International Journal of pressure vessels and piping 78, 99-109.

- 2002

[120] Choi K. Y., Chung H. J., No H. C., 2002. Direct-contact condensation heat transfer model in RELAP5/MOD3.2 with/without noncondensable gases for horizontally stratified flow. Nuclear Engineering and Design 221,139-151.

[121] Hae Yong Jeong, 2002. Prediction of countercurrent flow limitation at hot leg pipe during a small-break LOCA. Annals of Nuclear energy 29, 571-583.

[122] Kim, H.T., No, H.C., 2002. Assessment of RELAP5/MOD3.2.2_ against flooding database in horizontal-to-inclined pipes. Annals of Nuclear Energy 29, 835-850.

[123] H.G. Lele, S.K. Gupta, H.S. Kushwaha, V. Venkat Raj 2002. Modeling of thermal and flow stratification for reactor pressure vessel pressurized thermal shock. Nuclear engineering and design 212, 75-84.

- 2003

[124] Shripad J.Gokhale, Joel L. Plawsky, Peter C. Wayner Jr. 2003. Experimental investigation of contact angle, curvature, and contact line motion in dropwise condensation and evaporation. Journal of Colloid and interphase science 259, 354-366.

[125] A. Cavallini, G. Censi, D. del col, L. Doreti 2003. Condensation inside and outside smooth and enhanced tubes - a review of recent research. International Journal of Refrigeration 26, 373-392.

[126] Park H. S., No H. C., Bang Y. S., 2003. Analysis of experiments for in-tube steam condensation in the presence of noncondensable gases at a low pressure using the RELAP5/MOD3.2 code 577 modified with a non-iterative condensation model. Nuclear Engineering and Design 225 (2-3), 173-190.

[127] Yao W., Coste P., Bestion D., Boucker M., 2003. Two-phase pressurized thermal shock investigations using a 3D two-fluid modeling of stratified flow with condensation. The $10^{\text {th }}$ international Topical Meeting on Nuclear Reactor Thermal Hydraulics (NURETH10). 
- 2004

[128] Gargallo, M., 2004, Countercurrent Flow Limitations in Horizontal Stratified Flows of Air and Water. Dr.-Ing. Dissertation, University of Stuttgart.

[129] Kim Y.-S., Park J.-W., Song C.-H, 2004. Investigation of the steam-water direct contact condensation heat transfer coefficients using interfacial transport models. International Communications in Heat and Mass Transfer 31, 397-408.

- 2005

[30] Berthelsen P.A., Ytrehus T., 2005, Calculations of stratified wavy two-phase flow in pipes. International Journal of Multiphase flow 31 (5), 571-592.

[131] Jose L. Muñoz-Cobo, J. Peña,Luis E.Herranz, A. Perez-Navarro 2005. Steam condensation on finned tubes, in presence of non-condensable gases and aerosols: Influence of impaction, diffusiophoresis and settling on aerosol deposition. Nuclear Engineering and Design 235, 1225-1237.

[132] M. Gargallo, T. Schulenberg, L. Meyer, E. Laurien 2005. Countercurrent flow limitations during hot leg injection in pressurized water reactors. Nuclear Engineering and Design 235, 785-804.

[133] Navarro, M.A., 2005. Study of countercurrent flow limitation in a horizontal pipe connected to an inclined one. Nuclear Engineering and Design 235, 1139-1148.

- 2006

[134] Kyung-Won Lee a, In-Cheol Chu b, Seon-Oh Yu c, Hee Cheon No a, 2006. Interfacial condensation for countercurrent steam-water stratified wavy flow in a horizontal circular pipe. International Journal of Heat and Mass Transfer 49, 3121-3129.

[135] Hua Sheng Wang, John W. Rose 2006. Film condensation in horizontal microchanels: Effect of chanel shape. International Journal of Thermal Sciences 45, 12051212.

- 2007

[136] Claud E. Pugh, B. Richard Bass, Terry L. Dickson 2007. Role of probabilistic analysis in integrity assessments of a reactor pressure vessels exposed to pressurized thermal-shock conditions. Engineering Failure Analyses 14, 501-517.

[137] Changheui Jang 2007. Treatment of the thermal-hydraulic uncertainties in the pressurized thermal shock analysis. Nuclear Engineering and design 237, 143-152.

[138] Ildikó Boros, Attila Aszòdi 2007. Analysis of thermal stratification in the primary circuit of a VVER-440 reactor with the CFX code. Nuclear Engineering and Design.

- 2008

[139] Juan carlos de la rosa, Jose L. Muñoz-cobo, Alberto escriva 2008. Non-iterative model for condensation heat transfer in presence of non-condensable gases inside passive containment cooling vertical tubes. Nuclear Engineering and Design 238, 143-155. 
[140] Deendarlianto, Vallée, C., Lucas, D., Beyer, M., Pietruske, H., Carl, H., 2008. Experimental study on the air/water countercurrent flow limitation in a model of the hot leg of a pressurized water reactor. Nuclear Engineering and Design 238 (12), 3389-3402.

[141] Lucas, D., Vallée, C., Beyer, M., Prasser, H.M., Deendarlianto, 2008. Experiments on the countercurrent flow limitation (CCFL) in a model of a pressurized water reactor hot leg. In: Proceeding of the $5^{\text {th }}$ International Conference on Transport Phenomena in Multiphase Systems, vol. 1, Bialystok, Poland, pp. 325-332.

[142] Minami, N., Nishiwaki, D., Kataoka, H., Tomiyama, A., Hosokawa, S., Murase, M., 2008. Countercurrent gas-liquid flow in a rectangular channel simulating a PWR hot leg (1): flow pattern and CCFL characteristics. Japanese Journal of Multiphase Flow 22 (4), 403-412 (In Japanese).

[143] Solmos, M., Hogan, K.J., Vierow, K., 2008. Flooding experiments and modeling for improved reactor safety. In: Proceeding of U.S. Japan Two Phase Flow Seminar, Sponsored by National Science Foundation, Hosted by UCLA College of Engineering, Santa Monica, CA, September 2008, p. 17.

[144] Vallée, C., Deendarlianto, Lucas, D., M. Beyer, M., Pietruske, H., Carl, H., 2008. Countercurrent flow limitation experiments in a model of the hot leg of a pressurized water reactor. International Journal for Nuclear Power 53 (8/9), 546-549.

[145] Timo Toppila 2008. CFD simulation of Fortum PTS experiment. Nuclear Engineering and Design 238, 514-521.

[146] Jae Dong Chung, Sung Hwan Cho, Choon Seob Tae, Hoseon Yoo 2008. The effect of diffuser configuration on thermal stratification in a rectangular storage tank. Renewable Energy 33, 2236-2245.

- 2009

[147] Hyun-Sik Park a, Sung-Won Choi b, Hee Cheon No, 2009. Direct-contact condensation of pure steam on cocurrent and countercurrent stratified liquid flow in a circular pipe. International Journal of Heat and Mass Transfer 52, 1112-1122.

[148] Höhne, T., 2009. Experiments and numerical simulations of horizontal two-phase flow regimes. In: Proceeding of the Seventh International Conference on CFD in the Minerals and Process Industries, Melbourne, Australia. International Journal of Heat and Mass Transfer 52, 112-1122.

[149] Kinoshita, I., Utanohara, Y., Murase, M., Minami, N., Tomiyama, A., 2009. Numerical calculations on countercurrent gas-liquid flow in a PWR hot leg (2) steamwater flow under PWR plant conditions. In: Proceeding of the $13^{\text {th }}$ International Topical Meeting on Nuclear Reactor Thermal Hydraulics (NURETH-13), Kanazawa City, Japan, September 2009.

[150] Murase, M., Utanohara, Y., Kinoshita, I., Minami, N., Tomiyama, A., 2009. Numerical calculations on countercurrent air-water flow in small-scale models of a PWR hot leg using a VOF model. In: Proceeding of the $17^{\text {th }}$ International Conference on Nuclear Engineering (ICONE 17), Brussels, Belgium, July 2009. 
[151] Utanohara, Y., Kinoshita, I., Murase, M., Minami, N., Tomiyama, A., 2009. Effects of interfacial friction correlations on numerical calculations for countercurrent gas-liquid flow in a PWR hot leg. In: Proceeding of the $13^{\text {th }}$ International Topical Meeting on Nuclear Reactor Thermal Hydraulics (NURETH-13), Kanazawa City, Japan, September 2009.

[152] Vallée, C., Deendarlianto, eber, M., Lucas, D., Carl, H., 2009. Air/water countercurrent flow experiments in a model of the hot leg of a pressurized water reactor. Journal of Engineering for Gas Turbines and Power - Transactions of the ASME 131, 022905 .

- 2010

[153] Luka Strubelj, György Êzsöl, Iztok Tiselj 2010. Direct contact condensation induced transition from stratified to slug flow. Nuclear Engineering and Design 240, 266-274.

[154] Timothy L.Norman, Shripad T. Revankar 2010. Jet-plume condensation of steam-air mixtures in subcooled water, Part-1: Experiments. Nuclear Engineering and Design 240, 524-532.

[155] Timothy L.Norman, Shripad T. Revankar 2010. Jet-plume condensation of steam-air mixtures in subcooled water, Part-2: Code model. Nuclear Engineering and Design 240, 533-537.

[156] Stefano Nebuloni, John R. Thome 2010. Numerical modeling of laminar annular film condensation for different channel shapes. International Journal of Heat and Mass Transfer $53,2615-2627$.

[157] Deendarlianto, Höhne, T., Lucas, D., Vallée, C., 2010. Numerical simulation of airwater countercurrent two-phase flow in a model of the hot-leg of a pressurized water reactor (PWR). In: Proceeding of the $7^{\text {th }}$ International Conference of the Multiphase Flow, ICMF 2010, Tampa, FL, USA.

[158] Nariai, T., Tomiyama, A., Vallee, C., Lucas, D., Murase, M., 2010. Countercurrent flow limitation in a scale-down model of a PWR hot leg. In: Proceeding of the $8^{\text {th }}$ International Topical meeting on Nuclear Thermal-Hydraulics, Operation and Safety (NUTHOS-8), Shanghai, China, October 2010.

[159] Seidel, T., Vallée, C., Lucas, D., eber, M., Deendarlianto, 2010. Two-Phase Flow Experiments in a Model of the Hot Leg of a Pressurised Water Reactor, WissenschaftlichTechnische Berichte/Forschungszentrum Dresden-Rossendorf; FZD-531 2010.

[160] T. Farkas, I. Tóth 2010. Fluent analysis of a Rosa cold leg stratification test. Nuclear Engineering and Design 240, 2169-2175.

[161] Yann Batosiewicz, J.M. seynhaeve, C. Vallé, T. Höhne, J.M. Laviéville 2010. Modeling free surface flows relevant to a scenario: Comparison between experimental data and three RANS based CFD-codes. Comments on the CFD- experiment integration and best practice guideline. Nuclear Engineering and Design 240, 2375-2381.

- 2011 
[162] Richard R.Trewin,2011. One-dimensional three-field model of condensation in horizontal countercurrent flow with supercritical liquid velocity.Nuclear Engineering and Design 241, 2470-2483

[163] Djamel Lakehal, Mathieu Labois 2011. A new modeling strategy for phase-change heat transfer in turbulent interfacial two-phase flow. International Journal of multiphase flow 37, 627-639.

[164] Deendarlianto, Thomas Höhne, Dirk Lucas, Christophe Vallée 2011. CFD studies on the phenomena around countercurrent flow limitations of gas/liquid two-phase flow in a model of a PWR hot leg. Nuclear Engineering and Design 241, 5138-5148.

[165] Yoichi Utanohara, Ikuo Kinoshita, Michio Murase, Noritoshi Minami, Toshifumi Nariai 2011. Numerical simulation using CFD software of countercurrent gas-liquid flow in a PWR hot leg under reflux condensation. Nuclear Engineering and Design 241, 16431655.

[166] Richard R. Trewin 2011. One-dimensional three-field model of condensation in horizontal countercurrent flow with supercritical liquid velocity. Nuclear Engineering and Design 241, 2470-2483.

[167] Höhne, T., Deendarlianto, Dirk Lucas 2011. Numerical simulations of countercurrent two-phase flow experiments in a PWR hot leg model using an interfacial area density model. International Journal of Heat and Fluid Flow 32 (2011) 1047-1056.

- 2012

[168] Christophe Vallée, Tobias Seidel, Dirk Lucas, Matthias Beyer, Horst-Michael Prasser 2012. Countercurrent flow limitation in amodel of the hot leg of a PWR-Comparison between air/water and steam/water experiment. Nuclear Engineering and Design 245, 113 124.

[169] Deendarlianto, Thomas Höhne, Dirk Lucas, Karen Vierow 2012. Gas-liquid countercurrent two-phase flow in a PWR hot leg: A comprehensive research review. Nuclear Engineering and Design 243, 214-233.

[170] DITTUS, P. W., and L. M. K. BOELTER, Univ. Calif. Pub. Eng., Vol. 2, No. 13, pp. 443-461 (1930), reprinted in Int. Comm. Heat Mass Transfer, Vol. 12,pp. 3-22 (1985). 


\section{BOOK' S REFERENCES}

[171] A.F. Mills, Heat Transfer, Second Edition, Prentice Hall, New Jersey, 1999.

[172] Welty, C.E. Wicks, R.E. Wilson, and G.L. Rorrer, Fundamentals of Momentum, Heat, and Mass Transfer, Wiley, New Jersey, 2008.

[173] A.P. Colburn, Trans. AIChE 29, 174-210 (1933).

[174] W. Rohsenow; J. Hartnet; Y. Cho (1998). Handbook of Heat Transfer (3rd edition). McGraw-Hill.

[175] Sir Horace Lamb (first published 1879). Hydrodynamics.

[176] Collier, M.R., 1970. The stability of stratified shear flows. J. Fluid Mech. 42, 367-378.

[177] S. Chandrasekhar, 1961. Hydrodynamic and hydromagnetic stability.

[178] Incropera, F. P. and DeWitt, D. P. 1990. Fundamentals of Heat and Mass Transfer. 3rd ed. John Wiley \& Sons. New York.

[179] Milne-Thomson, L. W. 1955. Theoretical Hydrodynamics. 3rd ed. Macmillan. New York.

[180] Soo, S. L. 1990. Multiphase Fluid Dynamics. Science Press. Beijing. 


\section{APPENDIX A}

\section{VOLUMETRIC AVERAGING OF THE LOCAL AND INSTANTANEOUS BIPHASIC CONSERVATION EQUATIONS}

\section{A.1 INTRODUCTION}

The subject of two or multiphase flow has become increasingly important in a wide variety of engineering systems for their optimum design and safe operations. It is, however, by no means limited to today's modern industrial technology, and multiphase flow phenomena can be observed in a number of biological systems and natural phenomena which require better understandings. Some of the important applications are listed below.

Power Systems

Boiling water and pressurized water nuclear reactors; liquid metal fast breeder nuclear reactors; conventional power plants with boilers and evaporators; Rankine cycle liquid metal space power plants; MHD generators; geothermal energy plants; internal combustion engines; jet engines; liquid or solid propellant rockets; two-phase propellant, etc.

Heat Transfer Systems

Heat exchangers; evaporators; condensers; spray cooling towers; dryers, refrigerators, and electronic cooling systems; cryogenic heat exchangers; film cooling systems; heat pipes; direct contact heat exchangers; heat storage by heat of fusion, etc.

Process Systems

Extraction and distillation units; fluidized beds; chemical reactors; desalination systems; emulsifiers; phase separators; atomizers; scrubbers; absorbers; homogenizers; stirred reactors; porous media, etc. 


\section{Transport Systems}

Air-lift pump; ejectors; pipeline transport of gas and oil mixtures, of slurries, of fibres, of wheat, and of pulverized solid particles; pumps and hydrofoils with cavitations; pneumatic conveyors; highway traffic flows and controls, etc.

Information Systems

Superfluidity of liquid helium: Conducting or charged liquid film; liquid crystals, etc.

\section{Lubrication Systems}

Two-phase flow lubrication: Bearing cooling by cryogenics, etc.

\section{Environmental Control}

Air conditioners: Refrigerators and coolers; dust collectors; sewage treatment plants; pollutant separators; air pollution controls; life support systems for space application, etc.

\section{Geo-Meteorological Phenomena}

Sedimentation: Soil erosion and transport by wind; ocean waves; snow drifts; sand dune formations; formation and motion of rain droplets; ice formations; river floodings, landslides, and snowslides; physics of clouds, rivers or seas covered by drift ice; fallout, etc.

\section{Biological Systems}

Cardiovascular system: Respiratory system; gastrointestinal tract; blood flow; bronchus flow and nasal cavity flow; capillary transport; body temperature control by perspiration, etc.

It can be said that all systems and components listed above are governed by essentially the same physical laws of transport of mass, momentum and energy. It is evident that with our rapid advances in engineering technology, the demands for progressively accurate predictions of the systems of interest have increased. As the size of engineering systems becomes larger and the operational conditions are being pushed to new limits, the precise understanding of the physics governing these multiphase flow systems is indispensable for safe as well as economically sound operations. This means a shift of design methods from 
the ones exclusively based on static experimental correlations to the ones based on mathematical models that can predict dynamical behaviours of systems such as transient responses and stabilities. It is clear that the subject of multiphase flow has immense importance in various engineering technology. The optimum design, the prediction of operational limits and, very often, the safe control of a great number of important systems depend upon the availability of realistic and accurate mathematical models of two-phase flow.

\section{A.2 CHARACTERISTIC OF MULTIPHASE FLOW}

The design of engineering systems and the ability to predict their performance depend upon both the availability of experimental data and of conceptual mathematical models that can be used to describe the physical processes with a required degree of accuracy. It is essential that the various characteristics and physics of two-phase flow should be modelled and formulated on a rational basis and supported by detailed scientific experiments. It is well established in continuum mechanics that the conceptual model for single-phase flow is formulated in terms of field equations describing the conservation laws of mass, momentum, energy, charge, etc. These field equations are then complemented by appropriate constitutive equations for thermodynamic state, stress, energy transfer, chemical reactions, etc. These constitutive equations specify the thermodynamic, transport and chemical properties of a specific constituent material.

It is to be expected, therefore, that the conceptual models for multiphase flow should also be formulated in terms of the appropriate field and constitutive relations. However, the derivation of such equations for multiphase flow is considerably more complicated than for single-phase flow.

The complex nature of two or multiphase flow originates from the existence of multiple, deformable and moving interfaces and attendant significant discontinuities of fluid properties and complicated flow field near the interface. By focusing on the interfacial structure and transfer, it is noticed that many of two-phase systems have a common geometrical structure. It is recalled that single-phase flow can be classified according to the structure of flow into laminar, transitional and turbulent flow. In contrast, two-phase flow 
can be classified according to the structure of interface into several major groups which can be called flow regimes or patterns such as separated flow, transitional or mixed flow and dispersed flow. It can be expected that many of two-phase flow systems should exhibit a certain degree of physical similarity when the flow regimes are the same. However, in general, the concept of two-phase flow regimes is defined based on a macroscopic volume or length scale which is often comparative to the system length scale. This implies that the concept of two-phase flow regimes and a regime dependent model require an introduction of a large length scale and associated limitations. Therefore, regime-dependent models may lead to an analysis that cannot mechanically address the physics and phenomena occurring under the reference length scale.

For most two-phase flow problems, the local instant formulation based on the single-phase flow formulation with explicit moving interfaces encounters insurmountable mathematical and numerical difficulties, and therefore it is not a realistic or practical approach. This leads to the need of a macroscopic formulation based on proper averaging which gives a twophase flow continuum formulation by effectively eliminating the interfacial discontinuities. The essence of the formulation is to take into account the various multi-scale physics by a cascading modelling approach, bringing the micro and meso-scale physics into the macroscopic continuum formulation.

\section{A.3 CLASSIFICATION OF TWO-PHASE FLOW}

There are a variety of two-phase flows depending on combinations of two phases as well as on interface structures. Two-phase mixtures are characterized by the existence of one or several interfaces and discontinuities at the interface. It is easy to classify two-phase mixtures according to the combinations of two phases, since in standard conditions we have only three states of matters and at most four, namely, solid, liquid, and gas phases and possibly plasma (Pai, 1972). Here, we consider only the first three phases, therefore we have: 
1. Gas-solid mixture.

2. Gas-liquid mixture.

3. Liquid-solid mixture.

4. Immiscible-liquid mixture.

It is evident that the fourth group is not a two-phase flow, however, for all practical purposes it can be treated as if it were a two-phase mixture. The second classification based on the interface structures and the topographical distribution of each phase is far more difficult to make, since this interface structure changes occur continuously. Here we follow the standard flow regimes reviewed by Wallis (1969), Hewitt and Hall Taylor (1970), Collier (1972), Govier and Aziz (1972) and the major classification of Zuber (1971), Ishii (1971) and Kocamustafaoguari (1971). The two-phase flow can be classified according to the geometry of the interfaces into three main classes, namely, separated flow, transitional or mixed flow and dispersed flow as shown in Figure A.1. 


\begin{tabular}{|c|c|c|c|c|}
\hline Class & $\begin{array}{l}\text { Typical } \\
\text { regimes }\end{array}$ & Geometry & Configuration & Examples \\
\hline \multirow[t]{3}{*}{$\begin{array}{l}\text { Separated } \\
\text { flows }\end{array}$} & Film flow & & $\begin{array}{l}\text { Liquid film in gas } \\
\text { Gas film in liquid }\end{array}$ & $\begin{array}{l}\text { Film condensation } \\
\text { Film boiling }\end{array}$ \\
\hline & $\begin{array}{l}\text { Annular } \\
\text { flow }\end{array}$ & & $\begin{array}{l}\text { Liquid core and } \\
\text { gas film } \\
\text { Gas core and } \\
\text { liquid film }\end{array}$ & $\begin{array}{l}\text { Film boiling } \\
\text { Boilers }\end{array}$ \\
\hline & Jet flow & & $\begin{array}{l}\text { Liquid jet in gas } \\
\text { Gas jet in liquid }\end{array}$ & $\begin{array}{l}\text { Atomization } \\
\text { Jet condenser }\end{array}$ \\
\hline \multirow[t]{4}{*}{$\begin{array}{l}\text { Mixed or } \\
\text { Transitional } \\
\text { flows }\end{array}$} & $\begin{array}{c}\text { Cap, Slug } \\
\text { or Chum- } \\
\text { turbulent } \\
\text { flow } \\
\end{array}$ & & $\begin{array}{l}\text { Gas pocket in } \\
\text { liquid }\end{array}$ & $\begin{array}{l}\text { Sodium boiling in } \\
\text { forced convection }\end{array}$ \\
\hline & $\begin{array}{l}\text { Bubbly } \\
\text { annular } \\
\text { flow }\end{array}$ & 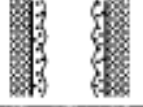 & $\begin{array}{l}\text { Gas bubbles in } \\
\text { liquid film with } \\
\text { gas core }\end{array}$ & $\begin{array}{l}\text { Evaporators with } \\
\text { wall nueleation }\end{array}$ \\
\hline & $\begin{array}{c}\text { Droplet } \\
\text { annular } \\
\text { flow }\end{array}$ & & $\begin{array}{l}\text { Gas core with } \\
\text { droplets and liquid } \\
\text { film }\end{array}$ & Steam generator \\
\hline & $\begin{array}{c}\text { Bubbly } \\
\text { droplet } \\
\text { annular } \\
\text { flow } \\
\end{array}$ & & $\begin{array}{l}\text { Gas core with } \\
\text { droplets and liquid } \\
\text { film with gas } \\
\text { bubbles }\end{array}$ & $\begin{array}{l}\text { Boiling nuclear } \\
\text { reactor channel }\end{array}$ \\
\hline \multirow[t]{3}{*}{$\begin{array}{l}\text { Dispersed } \\
\text { flows }\end{array}$} & $\begin{array}{l}\text { Bubbly } \\
\text { flow }\end{array}$ & 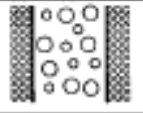 & $\begin{array}{l}\text { Gas bubbles in } \\
\text { liquid }\end{array}$ & Chemical reactors \\
\hline & $\begin{array}{l}\text { Droplet } \\
\text { flow }\end{array}$ & : & $\begin{array}{l}\text { Liquid droplets in } \\
\text { gas }\end{array}$ & Spray cooling \\
\hline & $\begin{array}{l}\text { Particulate } \\
\text { flow }\end{array}$ & & $\begin{array}{l}\text { Solid particles in } \\
\text { gas or liquid }\end{array}$ & $\begin{array}{l}\text { Transportation of } \\
\text { powder }\end{array}$ \\
\hline
\end{tabular}

Figure A.1 Classification of two-phase flow

Depending upon the type of the interface, the class of separated flow can be divided into plane flow and quasi-axis-symmetric flow each of which can be subdivided into two regimes. Thus, the plane flow includes film and stratified flow, whereas the quasi-axissymmetric flow consists of the annular and the jet-flow regimes. The various configurations of the two phases and of the immiscible liquids are shown in Figure A.1. 
At this point we must say that in a multiphasic problem, it is basically impossible to predict the velocity and position of the interfaces. Thence, we must do some kind of averaging to the local and instant governing equations for each phase.

We will hence start by presenting the local and instant conservation equations.

\section{A.4 LOCAL AND INSTANTANEOUS CONSERVATION EQUATIONS}

The equations which have been implemented in the code in order to solve the steam-water countercurrent flow in the hot or cold leg of a PWR reactor are presented here. Since the model is $1 \mathrm{D}$, it won't have the capability to predict axial temperature profiles at the liquid layer. However depending on the interfacial and the wall temperature, below the interface, a liquid temperature profile will be assumed.

The conservation equations are the starting point for biphasic systems analysis. These equations are presented for each phase separately and in cartesian geometry.

We start here by presenting the local and instantaneous conservation equations applied to an infinitesimal volume and an instant of time. These are the governing equations for a viscous fluid flow (in our case, biphasic flow), and they are called local and instantaneous conservation equations. They are expressed in general by using the subscript $\mathrm{k}$, which can represent the liquid $(\mathrm{k}=\mathrm{l})$, or the steam $(\mathrm{k}=\mathrm{g})$.

- $\quad$ Mass conservation Equation

$$
\frac{\partial \rho_{k}}{\partial t}+\vec{\nabla} \cdot\left(\rho_{k} \vec{u}_{k}\right)=0 \quad \mathrm{k}=\mathrm{l}, \mathrm{g}
$$

where $\rho_{k}$ is the density of the phase $\mathrm{k}$, and $\vec{u}_{k}$ is the velocity of the phase $\mathrm{k}$ in the time instant $\mathrm{t}$ and in the considered point. 
As the Equation A.1 is a local and instantaneous equation for each phase at a given point and it is only applicable to open domains in space, there is no mass generation rate per unit volume.

What we just said means that the Equation A.1 is applicable to each phase just up to the interface. Therefore, at the interface, the density, velocity, and energy suffer an abrupt change and it is necessary to specify conservation equations in order to mathematically simulate these singularities at the interface. These equations are called the jump conditions.

We need to introduce here the concept of interface. The interface is an imaginary surface between phases, through which they interchange mass, momentum and energy. By supposing that the interface $A_{I}$ between the steam and the water phases moves with a velocity $\vec{u}_{i}$, which depends on the considered time instant and position, then the mass flow from one phase to the interface, must equal the mass flow from the interface to the other phase. This conservation equation at the interface is expressed as follows:

$$
\sum_{k=l, g} \rho_{k}\left(u_{k}-u_{i}\right) \cdot \hat{n}_{k}=0
$$

Let's notice that the unitary vectors $\hat{n}_{g}$ and $\hat{n}_{l}$ point to opposite directions for the liquid and steam phases.
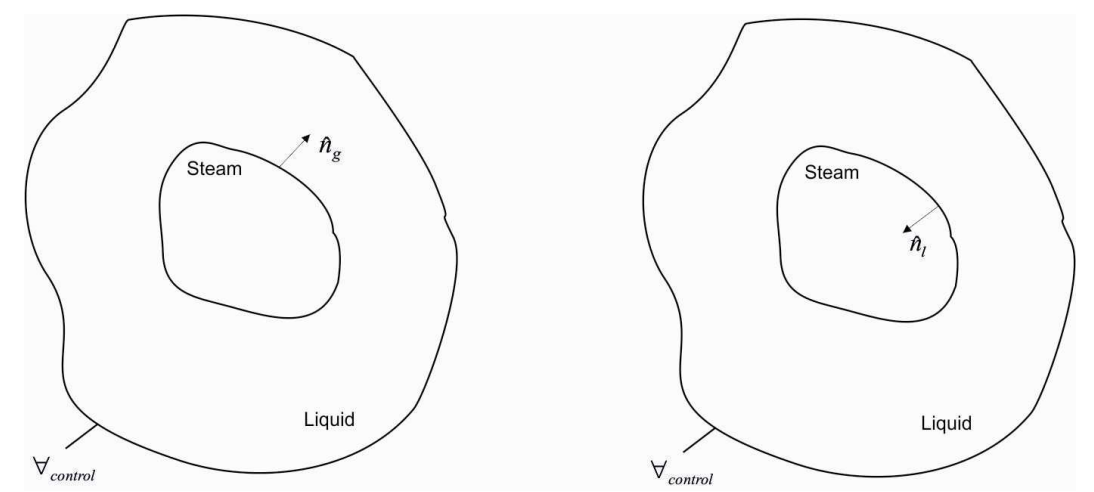

Figure A.1 Unitary vectors $\hat{n}_{g}$ and $\hat{n}_{l}$ in an arbitrary point of the liquid-steam interface 
- Momentum conservation equation

$$
\frac{\partial\left(\rho_{k} \vec{u}_{k}\right)}{\partial t}+\vec{\nabla} \cdot\left(\rho_{k} \vec{u}_{k} \vec{u}_{k}\right)=\rho_{k} \vec{g}+\vec{\nabla} \cdot \vec{T}_{k}
$$

where $\rho_{k} \vec{g}$ is the momentum source due to gravity, and $\vec{T}_{k}$ is the stress tensor due to pressure and the shear stress due to the viscous tension, i.e.:

$$
\vec{T}_{k}=-p \vec{I}+\vec{\tau}_{k}
$$

where $\vec{\tau}_{k}$ is the viscous shear stress tensor of the phase $\mathrm{k}$, where the tension $\vec{t}\left(\hat{n}_{k}\right)$ in an arbitrary point of the interface with unit vector $\hat{n}_{k}$ is given by:

$$
\vec{t}\left(\hat{n}_{k}\right)=\hat{n}_{k} \cdot \vec{T}_{k}=-p_{k} \hat{n}_{k}+\hat{n}_{k} \cdot \vec{\tau}_{k}
$$

In this case, the jump conditions consist of supposing that in every point of the interface, the momentum flow rate from one phase to the interface equals the momentum flow rate from the interface to the other phase plus the exerted tensions by the phases at both sides of the interface. This condition can be expressed as follows:

$$
-\sum_{k=l, g} \rho_{k} u_{k}\left(u_{k}-u_{i}\right) \cdot \hat{n}_{k}+\sum_{k=l, g} \hat{n}_{k} \cdot \vec{T}_{k}=0
$$

Basically, what this means is that when integrating over all the interfacial area, the momentum rate that one phase loses goes to the other.

- Energy conservation equation

$$
\frac{\partial\left(\rho_{k} e_{k}\right)}{\partial t}+\vec{\nabla} \cdot\left(\rho_{k} e_{k} \vec{u}_{k}\right)=-\vec{\nabla} \cdot \vec{q}_{k}^{\prime \prime}+\vec{\nabla} \cdot \vec{T}_{k} \cdot u_{k}+\rho_{k} \vec{g} \cdot \vec{u}_{k}+\dot{q}_{k}^{\prime \prime \prime}
$$

where $\vec{q}_{k}^{\prime \prime}$ is the heat flux received or released through the boundary surfaces, $\vec{\nabla} \cdot \vec{T}_{k} \cdot u_{k}$ is the rate of work done by the pressure and viscous forces, $\rho_{k} \vec{g} \cdot \vec{u}_{k}$ is the rate of work done by the gravity forces, and $\dot{q}_{k}^{\prime \prime \prime}$ is the generated heat rate inside the volume. 
Let's remember that the stored energy per unit mass $(\mathrm{J} / \mathrm{Kg})$ is given by:

$$
e_{k}=e_{k}^{\prime}+\frac{1}{2} u_{k}^{2}+g z
$$

where, $e_{k}^{\prime}$ is the internal specific energy.

In this case, the jump conditions express the fact that the energy transported by convection and the work done, through the interface, that wins or loses one phase equals the energy that the other phase loses or wins respectively. This can be expressed as follows:

$$
-\sum_{k=l, g} \vec{q}_{k}^{\prime \prime} \cdot \hat{n}_{k}+\sum_{k=l, g} \vec{t}\left(\hat{n}_{k}\right) \cdot \vec{u}_{k}-\sum_{k=l, g} e_{k} \rho_{k}\left(\vec{u}_{k}-\vec{u}_{i}\right) \cdot \hat{n}_{k}=0
$$

where $\vec{t}\left(\hat{n}_{k}\right)$ is the stress vector as defined in Hetsroni book, page I-9, see Equation (A.5).

\section{A.5 CONSERVATION EQUATIONS AVERAGING}

Now well, the equations that all the thermal-hydraulic codes use, and which we are going to use in this thesis, are always time and space averaged equations. In these equations, a double space and time average (Ishii 1975) or a space average and an "ensemble average" (Banerjee 1980) is performed on the local and instantaneous equations.

It can be easily shown (Delhaye 1976), that the time and space averaging are commutative, i.e. the result is the same not matter the order we make them.

This averaging will lead us to the so called macroscopic equations.

Let's suppose that we have a volume $\forall$ with two phases, as is shown in Figure A.2. 


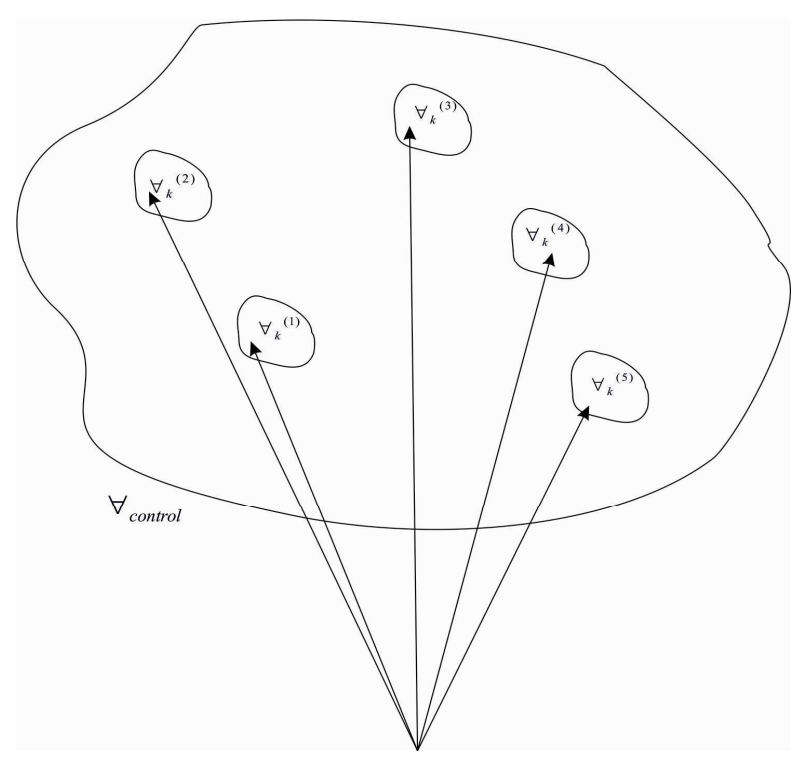

Figure A.2. Occupied volume by phase $\mathbf{k}$ at the time instant $\mathbf{t}$ in the volume element $\forall$

Now, let's consider the characteristic function for phase $\mathrm{k}$, defined as follows:

$$
X_{k}(\vec{r}, t)=\mid \begin{array}{lll}
1 & \text { if } & \vec{r} \in k \\
0 & \text { if } & \vec{r} \notin k
\end{array}
$$

We define the mean volumetric fraction for the phase k, in the volume $\forall$, centred at $\vec{r}$

$$
\left\langle\alpha_{k}(\vec{r}, t)\right\rangle=\frac{1}{V} \int_{V} X_{k}(\vec{r}, t) d V=\frac{1}{V} \int_{V_{k}} d V=\frac{V_{k}(\vec{r}, t)}{V}
$$

Now well, the volume fraction also changes with time, that's why we define the time averaging of the magnitude (A.11) as:

$$
\overline{\left\langle\alpha_{k}(\vec{r}, t)\right\rangle}=\frac{1}{T} \int_{T}\left\langle\alpha_{k}(\vec{r}, t)\right\rangle d t
$$


time $\mathrm{T}$ is a time interval centered in t, i.e.:

$$
\left[t-\frac{T}{2}, t+\frac{T}{2}\right]
$$

We define now the volumetric averaging of a magnitude $f_{k}$ in the phase $\mathrm{k}$ as follows:

$$
\left\langle f_{k}(\vec{r}, t)\right\rangle=\frac{1}{V_{k}(\vec{r}, t)} \int_{V_{k}} f_{k}\left(\vec{r}^{\prime}, t\right) d r^{\prime 3}
$$

We will introduce here a couple of rules that will be continuously used in the averaging process:

$\checkmark$ Leibnitz rule: Applied to the control volume occupied by the phase k, is given by:

$$
\begin{gathered}
\frac{\partial}{\partial t V_{k}(\vec{r}, t)} \int_{V^{\prime}, t} f(\vec{r}, t) d r^{\prime 3}=\int_{V_{k}(\vec{r}, t)} \frac{\partial f(\vec{r}, t)}{\partial t} d r^{3}+\int_{A_{i}(\vec{r}, t)} f(\vec{r}, t) \vec{u}_{i} \cdot \hat{n}_{k} d S+ \\
\sum_{j=1}^{3}\left(\int_{A_{k j}(\vec{r}, t)} f(\vec{r}, t) \vec{u}_{A_{k j 2}} \cdot \hat{n}_{j} d S-\int_{A_{k j 1}(\vec{r}, t)} f\left(\vec{r}^{\prime}, t\right) \vec{u}_{A_{k j 1}} \cdot \hat{n}_{j} d S\right) \\
+\int_{A_{k w}} f(\vec{r}, t) \vec{u}_{A_{k w}} \cdot \hat{n}_{k} d S
\end{gathered}
$$

where as we can see in Figure A.3:

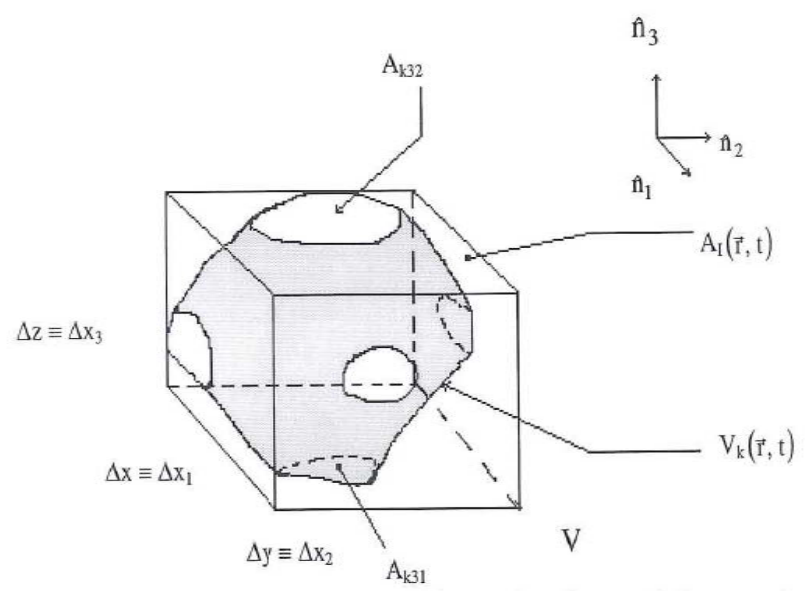


Figure A.3 Control volume where a volume $V_{k}(\vec{r}, t)$ for the phase $\mathbf{k}$ is included. The volume is limited by the planes $x-\frac{\Delta x}{2}, x+\frac{\Delta x}{2}, y-\frac{\Delta y}{2}, y+\frac{\Delta y}{2}, \ldots$

$A_{i}(\vec{r}, t)$ is the interfacial area in the control volume $\forall ; A_{k j 2}(\vec{r}, t)$ and $A_{k j 1}(\vec{r}, t)$ are the intercepted areas by $V_{k}(\vec{r}, t)$ with the planes $\vec{r}+\frac{\Delta x_{j}}{2} \hat{n}_{j}, \vec{r}-\frac{\Delta x_{j}}{2} \hat{n}_{j}$. If $V_{k}$ touches any wall moving at a velocity $\vec{u}_{A k w}$, we should include the last term of the equation (A.14). $\vec{u}_{A k w}$ is the velocity of the surface $A_{k j 2}$ which is normally zero.

\section{Gauss theorem:}

$\int_{V_{k}} \underset{(\vec{r}, t)}{\vec{\nabla}} \cdot B(\vec{r}, t) d r^{3}=\int_{A_{i}(\vec{r}, t)} \hat{n}_{k} \cdot \vec{B} d S+\sum_{j=1}^{3}\left(\int_{A_{k j}(\vec{r}, t)} \hat{n}_{j} \cdot \vec{B} d S-\int_{A_{k j} 1(\vec{r}, t)} \hat{n}_{j} \cdot \vec{B} d S\right)+\int_{A k w} \hat{n}_{k} \cdot \vec{B} d S$

The Equation (A.15) can be written as follows:

$$
\left.\int_{V_{k}} \vec{\nabla}, \vec{\nabla} \cdot t\right) B(\vec{r}, t) d r^{3}=\int_{A_{i}(\vec{r}, t)} \hat{n}_{k} \cdot \vec{B} d S+\sum_{j=1}^{3} \frac{\partial}{\partial x_{j}} \int_{V_{k}(\vec{r}, t)} \vec{B} \cdot \hat{n}_{j} d r^{3}+\int_{A k w} \hat{n}_{k} \cdot \vec{B} d S
$$

\section{A.5.1 VOLUMETRIC AVERAGING OF THE INSTANT AND LOCAL CONSERVATION EQUATIONS}

The local and instant conservation equations for the mass, momentum and energy can be expressed by using the compact notation as follows: 


$$
\frac{\partial\left(\rho_{k} \Psi_{k}\right)}{\partial t}+\vec{\nabla} \cdot\left(\rho_{k} \Psi_{k} \vec{u}_{k}+\vec{J}_{k}\right)=\rho_{k} \phi_{k}
$$

where $\Psi_{k}$ is the magnitude per unit mass in the phase $\mathrm{k}, \vec{J}_{k}$ is the diffusive flux of the conserved magnitude in the phase $\mathrm{k}, \phi_{k}$ is the source term of the magnitude in the phase $\mathrm{k}$.

Comparing Equation (A.18) with the mass, momentum and energy conservation equations, (A.1, A.3 and A.7) we obtain the following equivalence table:

Table A.1 Equivalence terms of the generalized conservation equation

\begin{tabular}{|l|c|c|c|}
\hline Conservation law & $\Psi_{k}$ & $\vec{J}_{k}$ & $\phi_{k}$ \\
\hline Mass equation & 1 & 0 & 0 \\
\hline $\begin{array}{l}\text { Momentum equation } \\
\text { (j-component) }\end{array}$ & $\vec{u}_{k} \cdot \hat{n}_{k}$ & $-\vec{T} \cdot \hat{n}_{j}$ & $\vec{g} \cdot \hat{n}_{j}$ \\
\hline Energy equation & $e_{k}$ & $-\vec{T} \cdot \vec{u}_{k}+\vec{q}_{k}^{\prime \prime}$ & $\vec{g} \cdot \vec{u}_{k}+\dot{q}_{k}^{\prime \prime \prime} / \rho_{k}$ \\
\hline
\end{tabular}

By integrating the local and instant conservation Equation (A.17) in $V_{k}(\vec{r}, t)$, and using the theorems of Leibnitz and Gauss we obtain:

$$
\begin{aligned}
& \frac{\partial}{\partial t} \int_{V_{k}} \rho_{k} \Psi_{k} d r^{3}-\int_{A_{i}(\vec{r}, t)} \rho_{k} \Psi_{k} \vec{u}_{i} \cdot \hat{n}_{k} d S+\int_{A_{i}(\vec{r}, t)}\left(\rho_{k} \Psi_{k} \vec{u}_{k}+\vec{J}_{k}\right) \cdot \hat{n}_{k} d S+ \\
& \sum_{j=1}^{3} \frac{\partial}{\partial x_{j} V_{k}(\vec{r}, t)} \hat{n}_{j} \cdot\left(\rho_{k} \Psi_{k} \vec{u}_{k}+\vec{J}_{k}\right) d r^{3}+\int_{A_{k w}(\vec{r}, t)} \hat{n}_{k} \cdot\left(\rho_{k} \Psi_{k} \vec{u}_{k}+\vec{J}_{k}\right) d S=\int_{V_{k}(\vec{r}, t)} \rho_{k} \phi_{k} d r^{3}
\end{aligned}
$$

Using the volume fraction definition for the phase $\mathrm{k}$ (A.11), and the volumetric averaging definition (A.13), we can rewrite the Equation (A.18) after dividing it by the volume as:

$$
\frac{\partial}{\partial t}\left(\alpha_{k}\left\langle\rho_{k} \Psi_{k}\right\rangle\right)+\vec{\nabla} \cdot\left(\alpha_{k}\left\langle\rho_{k} \Psi_{k} \vec{u}_{k}+\vec{J}_{k}\right\rangle\right)-\alpha_{k}\left\langle\rho_{k} \phi_{k}\right\rangle=S_{k, i}^{c o n v}+S_{k, i}^{J}+S_{k, w}
$$


where the terms at the right side are defined next:

$>S_{k, i}^{c o n v}:$ Term due to the convective flux through the interface:

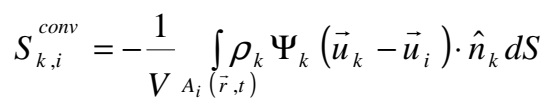

This term represents the transfer rate per unit volume of the conserved magnitude to the phase $\mathrm{k}$ by convective flux through the interface.

$>S_{k, i}^{J}$ : Term due to the $\vec{J}_{k}$ current in the interface.

$$
S_{k, i}^{J}=-\frac{1}{V A_{i}(\vec{r}, t)} \int_{k} \vec{J}_{k} \cdot \hat{n}_{k} d S
$$

This term represents the transfer rate per unit volume of the conserved magnitude to the phase $\mathrm{k}$, due to the current $\vec{J}_{k}$, normally called diffusive current through the interface.

$>\quad S_{k, w}$ : Term due to the current $\vec{J}_{k}$ at the walls.

$$
S_{k, w}=-\frac{1}{V} \int_{A_{k w}} \vec{J}_{k} \cdot \hat{n}_{k} d S
$$

\section{A.6 THE CONSERVATION EQUATIONS AVERAGING AND THEIR JUMP CONDITIONS}

Once the macroscopic equations are obtained, we must perform the time averaging on them. Hence, the mean macroscopic value of any magnitude as for example the volume fraction can be expressed as follows:

$$
\langle\alpha(\vec{r}, t)\rangle=\overline{\langle\alpha(\vec{r}, t)\rangle}+\alpha^{\prime}(\vec{r}, t)
$$


where $\alpha^{\prime}(\vec{r}, t)$ represent the fluctuations in the space averaging of the void fraction. Obviously we have the following mean value of this fluctuation:

$$
\overline{\alpha^{\prime}(\vec{r}, t)}=0
$$

The same happens with the phase velocities, i.e.:

$$
\left\langle u_{k}(\vec{r}, t)\right\rangle=\overline{\left\langle u_{k}(\vec{r}, t)\right\rangle}+u_{k}^{\prime}(\vec{r}, t)
$$

where $u_{k}^{\prime}(\vec{r}, t)$ represent the fluctuations of the velocity.

We will suppose that the following approximation is accomplished:

$$
\langle a b c\rangle=\langle a\rangle\langle b\rangle\langle c\rangle
$$

and we will leave out the volumetric averaging symbol \langle\rangle , which will be understood onwards.

\section{A.6.1 THE MASS CONSERVATION EQUATION AVERAGING AND ITS JUMP CONDITION}

At table A.1, the mass conservation equation, is obtained by taking; $\Psi_{k}=1, \vec{J}_{k}=0$, and $\phi_{k}=0$, in the Equation (A.17), and after making the time averaging, we get:

$$
\frac{\partial\left(\bar{\alpha}_{k} \rho_{k}\right)}{\partial t}+\vec{\nabla} \cdot\left(\rho_{k} \bar{\alpha}_{k} \overline{\vec{u}}_{k}\right)+\vec{\nabla}\left(\rho_{k} \overline{\alpha_{k}^{\prime} u_{k}^{\prime}}\right)=\bar{\Gamma}_{k} \quad \mathrm{k}=1, \mathrm{~g}
$$


where $\bar{\alpha}_{k}$ is the averaged volume fraction of the $\mathrm{k}$ phase, $\rho_{k}$ is the density of the phase $\mathrm{k}$, $\vec{u}_{k}$ is the velocity of the phase $\mathrm{k}$, and the term $\vec{\nabla}\left(\rho_{k} \overline{\alpha_{k}^{\prime} u_{k}^{\prime}}\right)$ is due to the rapid fluctuations of velocity and void fraction. This term, due to turbulence is usually neglected in the codes.

$\bar{\Gamma}_{k}$ is the mass generation rate of the phase k per unit volume and is given by:

$$
\bar{\Gamma}_{k}=-\frac{1}{V} \int_{A_{I}(\vec{r}, t)} \rho_{k}\left(\vec{u}_{k}-\vec{u}_{i}\right) \cdot \hat{n}_{k} d S
$$

If we integrate the jump condition (A.2) all along the interfacial area $A_{I}(\vec{r}, t)$ of the volume V at the time instant $\mathrm{t}$, we get after averaging in space and time and dividing by the volume $\mathrm{V}$ :

$$
\frac{1}{V} \sum_{k=l, g} \overline{\int_{A_{I}(\vec{r}, t)} \rho_{k}\left(\vec{u}_{k}-\vec{u}_{i}\right) \cdot \hat{n}_{k} d S}=0
$$

This can be expressed as:

$$
\bar{\Gamma}_{g}=-\bar{\Gamma}_{l}
$$

In the applications the time averaging symbol is leaved out.

Finally, the averaged 3D mass conservation equations normally used in thermal-hydraulic codes as TRACE are:

\section{- Liquid phase:}

$$
\frac{\partial\left((1-\alpha) \rho_{l}\right)}{\partial t}+\vec{\nabla} \cdot\left(\rho_{l}(1-\alpha) \vec{u}_{l}\right)=\Gamma_{l}
$$

- Steam phase:

$$
\frac{\partial\left(\alpha \rho_{g}\right)}{\partial t}+\vec{\nabla} \cdot\left(\rho_{g} \alpha \vec{u}_{g}\right)=\Gamma_{g}
$$




\section{A.6.2 THE MOMENTUM CONSERVATION EQUATION AVERAGING AND ITS JUMP CONDITION}

In order to obtain the momentum conservation equation, at table A.1, we make:

$$
\Psi_{k}=\vec{u}_{k}, \vec{J}_{k}=\vec{T}_{k} \text { and } \phi_{k}=\vec{g}
$$

and noticing that:

$$
u_{k}(\vec{r}, t)=\overline{u_{k}(\vec{r}, t)}+u_{k}^{\prime}(\vec{r}, t)
$$

Thence, after performing the time averaging and neglecting the less important correlations, we get:

$$
\begin{aligned}
& \frac{\partial\left(\bar{\alpha}_{k} \rho_{k} \vec{u}_{k}\right)}{\partial t}+\vec{\nabla} \cdot\left(\bar{\alpha}_{k} \rho_{k} \vec{u}_{k} \vec{u}_{k}\right)+\vec{\nabla}\left(\bar{\alpha}_{k} \rho_{k}\right)-\vec{\nabla} \cdot V \bar{\alpha}_{k} \vec{\tau}_{k}^{T}+ \\
& \vec{\nabla}\left(\bar{\alpha}_{k} \rho_{k} \overline{\vec{u}_{k} \vec{u}_{k}}\right)-\bar{\alpha}_{k} \rho_{k} \vec{g}=-\frac{1}{V} \int_{A_{i}} \rho_{k} \vec{u}_{k}\left(\vec{u}_{k}-\vec{u}_{i}\right) \cdot \hat{n}_{k} d S-\frac{1}{V} \int_{A_{i}} p_{k} \hat{n}_{k} d S+ \\
&+\frac{\frac{1}{V} \int_{A_{i}} \vec{\tau}_{k} \cdot \hat{n}_{k} d S}{\frac{1}{V} \int_{A_{k w}} \vec{\tau}_{k} \cdot \hat{n}_{k} d S-\frac{1}{V} \int_{A_{k w}} p_{k} \hat{n}_{k} d S}
\end{aligned}
$$

Now well, for a closed surface, the next surface integral is zero:

$$
\int_{A_{i} \cup A_{k w} \cup A_{k}} \hat{n}_{k} d S=0
$$

where $A_{k}$ is the area intersected by $V_{k}$ with the contour of $\mathrm{V}$.

Hence:

$$
+\frac{1}{V} \int_{A_{i}} \hat{n}_{k} d S+\frac{1}{V} \int_{A_{k w}} \hat{n}_{k} d S=-\frac{1}{V} \int_{A_{k}} \hat{n}_{k} d S=-\frac{1}{V} \vec{\nabla} \int_{V_{k}} d V=-\vec{\nabla} \alpha_{k}
$$


So the sum of the terms which contain the pressure under the integral sign, leaving out the time averaging sign result to be equal to:

$$
-\frac{p_{k}}{V}\left\{\int_{A_{i}} \hat{n}_{k} d S+\int_{A_{k w}} \hat{n}_{k} d S\right\}=p_{k} \vec{\nabla} \alpha_{k}
$$

By taking into account Equation (A.38) and leaving out the time averaging sign, we get if the volume is constant, that the momentum conservation Equation (A.35) can be expressed as follows:

$$
\frac{\partial\left(\alpha_{k} \rho_{k} \vec{u}_{k}\right)}{\partial t}+\vec{\nabla} \cdot\left(\alpha_{k} \rho_{k} \vec{u}_{k} \vec{u}_{k}\right)+\alpha_{k} \vec{\nabla} P-\vec{\nabla} \cdot \alpha_{k} \vec{\tau}_{k}{ }^{T}-\alpha_{k} \rho_{k} \vec{g}=\Gamma_{k}\left\langle\vec{u}_{k i}\right\rangle+\vec{F}_{k i}+\vec{F}_{k w}
$$

where $\alpha_{k}$ is the averaged volume fraction of the k phase, $\rho_{k}$ is the density of the phase k, $\vec{u}_{k}$ is the velocity of the phase $\mathrm{k}$, and:

$\vec{\tau}_{k}{ }^{T}$ is the Reynolds viscous shear stress tensor for the $\mathrm{k}$ phase.

$$
\vec{\tau}_{k}^{T}=-\rho_{k} \overline{\vec{u}_{k} \vec{u}_{k}}
$$

$\vec{F}_{k i}$ is the term due to the friction between phases $\vec{F}_{k i}$.

This term is produced due to the fact that the liquid and the steam move at different velocities, what produces a frictional shear stress that causes the steam to be slowed down by the liquid and the liquid dragged by the steam since the steam velocity is higher than the liquid one, and inversely if the liquid velocity is higher than the steam one.

$$
\vec{F}_{k i}=\frac{1}{V} \int_{A_{I}} \vec{\tau}_{k} \cdot \hat{n}_{k} d S
$$

$\vec{F}_{k w}$ is the term due to the friction with the walls $\vec{F}_{k w}$.

$$
\vec{F}_{k w}=\frac{1}{V} \int_{A_{k w}} \vec{\tau}_{k} \cdot \hat{n}_{k} d S
$$


$\Gamma_{k}\left\langle\vec{u}_{k i}\right\rangle$ is the term due to the momentum interchanged due to the phase change.

$$
\Gamma_{k}\left\langle\vec{u}_{k i}\right\rangle=-\frac{1}{V} \int_{A_{I}} \rho_{k} \vec{u}_{k}\left(\vec{u}_{k}-\vec{u}_{i}\right) \cdot \hat{n}_{k} d S
$$

where $\Gamma_{k}$ is the mass generation rate per unit volume of the phase $\mathrm{k}$, and $\left\langle\vec{u}_{k i}\right\rangle$ the mean velocity of the phase $\mathrm{k}$ at the interface.

The integration of the jump condition all along the interfacial area, leads us to the following expression:

$$
\vec{F}_{g i}=-\vec{F}_{l i}
$$

In the momentum equation and also in the following energy equation, we are assuming that $P_{k}=P$. This means that the pressure is the same for both phases. This is because we are supposing that we have a homogeneous flow, i.e. we are analyzing a volume where the phases are mixed and, where we have a volumetric weighted properties for every phase.

Finally, the averaged 3D mass conservation equations normally used in thermal-hydraulic codes are obtained from Equation A.39 taking into account the mass conservation equations.

\section{- Liquid phase:}

$$
\begin{aligned}
\frac{\partial}{\partial t} \vec{u}_{l}+\vec{u}_{l} \cdot \vec{\nabla} \vec{u}_{l}=-\frac{1}{\rho_{l}} & \vec{\nabla} p+\frac{c_{i}}{(1-\alpha) \rho_{l}}\left(\vec{u}_{g}-\vec{u}_{l}\right)\left|\vec{u}_{g}-\vec{u}_{l}\right| \\
& -\frac{\Gamma_{g}^{-}}{(1-\alpha) \rho_{l}}\left(\vec{u}_{g}-\vec{u}_{l}\right)-\frac{c_{w l}}{(1-\alpha) \rho_{l}} \vec{u}_{l}\left|\vec{u}_{l}\right|+\vec{g}
\end{aligned}
$$

\section{- $\underline{\text { Steam phase: }}$}

$$
\frac{\partial}{\partial t} \vec{u}_{g}+\vec{u}_{g} \cdot \vec{\nabla} \vec{u}_{g}=-\frac{1}{\rho_{g}} \vec{\nabla} p-\frac{c_{i}}{\alpha \rho_{g}}\left(\vec{u}_{g}-\vec{u}_{l}\right)\left|\vec{u}_{g}-\vec{u}_{l}\right|
$$




$$
-\frac{\Gamma_{g}^{+}}{\alpha \rho_{g}}\left(\vec{u}_{g}-\vec{u}_{l}\right)-\frac{c_{w g}}{\alpha \rho_{g}} \vec{u}_{g}\left|\vec{u}_{g}\right|+\vec{g}
$$

where;

$$
\begin{aligned}
& \Gamma_{g}^{+}=\max \left[\Gamma_{g}, 0\right] \\
& \Gamma_{g}^{-}=\min \left[-\Gamma_{g}, 0\right]
\end{aligned}
$$

We observe that the interfacial friction term has the opposite sign in both equations. We notice that when evaporation takes place, $\Gamma_{g}>0$, and the steam phase gains an amount of momentum per unit volume and time equal to $\Gamma_{g} \vec{u}_{l}$, the term $-\Gamma_{g} \vec{u}_{g}$ comes from writing the momentum conservation equation in non-conservative form.

\section{A.6.3 THE ENERGY CONSERVATION EQUATION AVERAGING AND ITS JUMP CONDITION}

In order to obtain energy conservation equation, from Figure A.1, we make:

$$
\Psi_{k}=e_{k}, \vec{J}_{k}=-\vec{T} \cdot \vec{u}_{k}+\vec{q}^{\prime \prime} \text { and } \phi_{k}=\vec{g} \cdot \vec{u}_{k}+\dot{q}_{k}^{\prime \prime \prime} / \rho_{k}
$$

and performing the time averaging in equation A.19 yields:

$$
\begin{array}{r}
\frac{\partial\left(\alpha_{k} \rho_{k} e_{k}\right)}{\partial t}+\vec{\nabla} \cdot\left(\alpha_{k} \rho_{k} e_{k} \vec{u}_{k}\right)+\vec{\nabla} \cdot \alpha_{k} p \vec{u}_{k}-\vec{\nabla} \cdot \alpha_{k} \vec{\tau}_{k} \cdot \vec{u}_{k}+\vec{\nabla} \alpha_{k} \vec{q}^{\prime \prime} \\
-\alpha_{k} \rho_{k} \vec{g} \cdot \vec{u}_{k}-\alpha_{k} \dot{q}^{\prime \prime \prime}=S_{k, i}^{c o n v}+S_{k, i}^{J}+S_{k, w}
\end{array}
$$

where the different terms represent:

$\frac{\partial\left(\alpha_{k} \rho_{k} e_{k}\right)}{\partial t}$ : Represents the rate of stored energy in the phase k per unit volume. 
The second and third term give when summing them:

$$
\vec{\nabla} \cdot\left(\alpha_{k} \rho_{k} e_{k} \vec{u}_{k}\right)+\vec{\nabla} \cdot \alpha_{k} p \vec{u}_{k}=\vec{\nabla} \cdot \alpha_{k} \rho_{k}\left(e_{k}+p / \rho_{k}\right) \vec{u}_{k}=\vec{\nabla} \cdot \alpha_{k} \rho_{k} h_{o k} \vec{u}_{k}
$$

where:

$h_{o k}=e_{k}+p / \rho_{k}$, being $h_{o k}$ the stagnation energy.

$>\quad \vec{\nabla} \cdot \alpha_{k} \rho_{k} h_{o k} \vec{u}_{k}:$ Represents the flow of stagnation energy to the phase $\mathrm{k}$.

$>\quad-\vec{\nabla} \cdot \alpha_{k} \vec{\tau}_{k} \cdot \vec{u}_{k}$ : Represents the work done per unit time and volume by the viscous forces.

$>\quad \alpha_{k} \rho_{k} \vec{g} \cdot \vec{u}_{k}$ : Represents the work done per unit time and volume by the gravity forces.

$>\quad \alpha_{k} \dot{q}^{\prime \prime \prime}$ : Represent the energy source per unit volume and time in phase k.

$>S_{k, i}^{c o n v}:$ Represents the energy transfer between phases due to evaporation or condensation.

$$
S_{k, i}^{c o n v}=\frac{1}{V} \int_{A_{i}} \rho_{k} e_{k}\left(\vec{u}_{k}-\vec{u}_{i}\right) \cdot \hat{n}_{k} d S=\Gamma_{k}\left\langle e_{k i}\right\rangle
$$

$S_{k, i}^{J}$ : Represents the energy transfer due to the diffusive flux of energy through the interface:

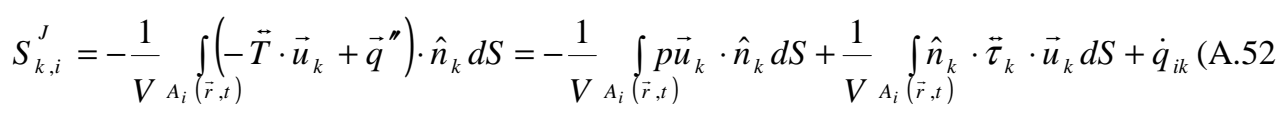

where $\dot{q}_{i k}=-\frac{1}{V} \int_{A_{i}} \vec{q}_{k}^{\prime \prime} \cdot \hat{n}_{k} d S$, represents the heat transfer rate to the phase $\mathrm{k}$ per unit volume through the interface. 
The first term of the right side of Equation (A.52), can be written as:

$$
-\frac{1}{V} \int_{A_{i}(\vec{r}, t)} p \vec{u}_{k} \cdot \hat{n}_{k} d S=-\frac{1}{V} \int_{A_{i}} p\left(\vec{u}_{k}-\vec{u}_{i}\right) \cdot \hat{n}_{k} d S-\frac{1}{V} \int_{A_{i}} p \vec{u}_{i} \cdot \hat{n}_{k} d S
$$

Now well, by applying the Reynolds transport theorem to the magnitude $f_{k}=1$, we get:

$$
\frac{d}{d t V_{k}} \int_{(\vec{r}, t)} f_{k} d V \equiv \frac{\partial}{\partial t} \alpha_{k} V=\int_{A_{i}} \vec{u}_{i} \cdot \hat{n}_{k} d S
$$

where we can express (A.53) as follows:

$$
\left.-\frac{1}{V} \int_{A_{i}} p \vec{u}_{k}, t\right)
$$

$>S_{k, w}$ : The source term due to the walls is given by:

$$
S_{k, w}=-\frac{1}{V} \int_{A_{k w}}-p \vec{u}_{k} \cdot \hat{n}_{k} d S-\frac{1}{V} \int_{A_{k w}} \vec{u}_{k} \cdot \vec{\tau}_{k} \cdot \hat{n}_{k} d S+\dot{q}_{w k}
$$

where:

$\dot{q}_{w k}=-\frac{1}{V} \int_{A_{k w}} \vec{q}_{k}^{\prime \prime} \cdot \hat{n}_{k} d S:$ Represents the heat transfer rate to the phase $\mathrm{k}$ per unit volume through the walls.

The first term of equation (A.56) is:

$W_{k p}=-\frac{1}{V} \int_{A_{k w}}-p \vec{u}_{k} \cdot \hat{n}_{k} d S:$ Power won or lost per unit volume due to the movement of the walls.

By summing Equation (A.51) and the first term of (A.55), we get: 


$$
\Gamma_{k}\left\langle e_{k i}\right\rangle+\Gamma_{k} \frac{p_{k}}{\rho_{k}}=\Gamma_{k}\left(\left\langle e_{k i}\right\rangle+\frac{p_{k}}{\rho_{k}}\right)=h_{o k}^{\prime} \Gamma_{k}
$$

The second term of (A.56) is:

$W_{k w}=-\frac{1}{V} \int_{A_{k w}} \vec{u}_{k} \cdot \vec{\tau}_{k} \cdot \hat{n}_{k} d S:$ Represents the dissipated power by friction with the walls per unit volume.

So, the energy conservation equation can be written as follows:

$$
\begin{array}{r}
\frac{\partial\left(\alpha_{k} \rho_{k} e_{k}\right)}{\partial t}+\vec{\nabla} \cdot\left(\alpha_{k} \rho_{k} e_{k} \vec{u}_{k}\right)=-\vec{\nabla} \cdot \alpha_{k} p \vec{u}_{k}+\alpha_{k} \rho_{k} \vec{g} \cdot \vec{u}_{k}-p \frac{\partial}{\partial t} \alpha_{k}+\Gamma_{k}\left(\left\langle e_{k i}\right\rangle+\frac{p_{k}}{\rho_{k}}\right) \\
+\dot{q}_{i k}+\dot{q}_{w k}+\alpha_{k} \dot{q}_{k}^{\prime \prime \prime}+W_{k p}+W_{k w}-\vec{\nabla} \alpha_{k} \vec{q}_{k}^{\prime \prime}+\vec{\nabla} \cdot\left(\alpha_{k} \vec{\tau}_{k} \cdot \vec{u}_{k}\right) \text { (A.58) }
\end{array}
$$

where the last two terms are normally neglected.

Finally, in order to obtain the internal energy equation, we subtract from Equation (A.58), the kinetic energy equation, and we get:

$$
\begin{array}{r}
\frac{\partial\left(\alpha_{k} \rho_{k} e_{k}^{\prime}\right)}{\partial t}+\vec{\nabla} \cdot\left(\alpha_{k} \rho_{k} e_{k}^{\prime} \vec{u}_{k}\right)=-P \frac{\partial}{\partial t} \alpha_{k}-p \vec{\nabla} \cdot\left(\alpha_{k} \vec{u}_{k}\right)+\Gamma_{k}\left(\left\langle e_{k i}^{\prime}\right\rangle+\frac{p_{k}}{\rho_{k}}\right) \\
+\dot{q}_{i k}+\dot{q}_{w k}+\alpha_{k} \dot{q}_{k}^{\prime \prime \prime}+W_{k p}+W_{k w}-\vec{\nabla} \alpha_{k} \vec{q}_{k}^{\prime \prime}+\vec{\nabla} \cdot\left(\alpha_{k} \vec{\tau}_{k} \cdot \vec{u}_{k}\right)
\end{array}
$$

The last four terms are normally neglected.

where $e_{k}^{\prime}$ is the stored energy per unit mass in the fluid element, and: 
- $\frac{\partial\left(\alpha_{k} \rho_{k} e_{k}^{\prime}\right)}{\partial t}:$ Is the stored energy rate per unit volume $\left(\mathrm{J} / \mathrm{sm}^{3}\right)$ in an arbitrary position and time instant of the domain.

- $\vec{\nabla} \cdot\left(\alpha_{k} \rho_{k} e_{k}^{\prime} \vec{u}_{k}\right)$ : Is the energy flow rate through the fluid element faces.

- $\quad-p \frac{\partial}{\partial t} \alpha_{k}$ : Is the loss of energy per unit volume due to phase expansion.

- $\quad-p \vec{\nabla} \cdot\left(\alpha_{k} u_{k}\right)$ : Is the work done by the pressure due to expansion

- $\Gamma_{k}\left(\left\langle e_{k i}^{\prime}\right\rangle+\frac{p_{k}}{\rho_{k}}\right):$ Is the variation of stored energy due to mass transfer between phases.

- $\dot{q}_{i k}$ : Is the rate of heat per unit volume interchanged between the interface and the phase $\mathrm{k}$.

- $\quad \dot{q}_{w k}$ : Is the rate of heat per unit volume interchanged between the phase $\mathrm{k}$ and the walls.

- $\quad \alpha_{k} \dot{q}_{k}^{\prime \prime \prime}$ : Volumetric source of energy in the fluid element.

By integrating the jump condition of the energy equation, with respect to the interfacial area $A_{I}$ contained in the fluid element volume, we get, neglecting the work done by the viscous forces:

$$
-\int_{A_{I}}\left(\vec{q}_{l}^{\prime \prime} \cdot \hat{n}_{l}+\vec{q}_{g}^{\prime \prime} \cdot \hat{n}_{g}\right) d S-\int_{A_{l}}\left(h_{o g} \dot{m}_{g}+h_{o l} \dot{m}_{l}\right) d S=0
$$

where:

$$
\begin{aligned}
& \dot{m}_{k}=\rho_{k}\left(\vec{u}_{k}-\vec{u}_{i}\right) \cdot \hat{n}_{k} \\
& h_{o k}=e_{k}+p / \rho_{k}
\end{aligned}
$$

Now we are going to introduce the following averaged magnitudes: 


$$
\left[\begin{array}{l}
\text { Mean value of the total } \\
\text { energy of the phase k } \\
\text { at the interface }
\end{array}\right]=\left\langle h_{o k i}\right\rangle=-\frac{\frac{1}{V} \int_{A_{I}} \dot{m}_{k} h_{o k} d S}{\Gamma_{k}}
$$

Hence, we can write the jump condition equation as follows:

$$
\left(\dot{q}_{l i}^{\prime \prime}\right\rangle+\left\langle\dot{q}_{g i}^{\prime \prime}\right) \frac{A_{I}}{V}+\left\langle h_{o l i}\right\rangle \Gamma_{l}+\left\langle h_{o g i}\right\rangle \Gamma_{g}=0
$$

Using the mass jump condition, i.e. $\Gamma_{g}=-\Gamma_{l}$ we can obtain the expression for $\Gamma_{g}$, given by:

$$
\Gamma_{g}=-\frac{\left(\left\langle\dot{q}_{l i}^{\prime \prime}\right\rangle+\left\langle\dot{q}_{g i}^{\prime \prime}\right\rangle\right) A_{I}}{\left(\left\langle h_{\text {ogi }}\right\rangle-\left\langle h_{\text {oli }}\right\rangle\right) V}
$$

Finally, the 3D energy conservation equations as are normally used in the thermal-hydraulic codes is for each phase:

- Liquid phase:

$$
\begin{aligned}
\frac{\partial\left((1-\alpha) \rho_{l} e_{l}^{\prime}\right)}{\partial t}+\vec{\nabla} \cdot\left((1-\alpha) \rho_{l} e_{l}^{\prime} \vec{u}_{l}\right)=-p_{l} \frac{\partial}{\partial t}(1-\alpha)-p \vec{\nabla} \cdot\left((1-\alpha) \vec{u}_{l}\right) & \\
& +\dot{q}_{w l}+\dot{q}_{i l}+\dot{q}_{d l}+\Gamma_{l} h_{l}^{\prime} \text { (A.67) }
\end{aligned}
$$


Appendix A

- Steam phase:

$$
\frac{\partial\left(\alpha \rho_{g} e_{g}^{\prime}\right)}{\partial t}+\vec{\nabla} \cdot\left(\alpha \rho_{g} e_{g l}^{\prime} \vec{u}_{g}\right)=-p_{g} \frac{\partial}{\partial t} \alpha-p \vec{\nabla} \cdot\left(\alpha \vec{u}_{g}\right)+\dot{q}_{w g}+\dot{q}_{i g}+\dot{q}_{d g}+\Gamma_{g} h_{g}^{\prime}
$$




\section{APPENDIX B}

\section{CALCULATION OF THE CONVECTIVE TERMS OF THE CONSERVATION EQUATIONS}

\section{B.1 CONVECTIVE TERMS}

The convective terms which appear in the discretization of the mass and energy conservation equations, were evaluated using the ULTIMATE-SOU (second order upwinding) method. For the momentum equation convective terms, we are using the ULTIMATE-QUICKEST method. These methods are explained here below.

\section{B.2 FIRST ORDER UPWINDING (FOU)}

The upwinding schemes are designed to simulate numerically in a more appropriate way the propagation direction of the flow information. It seems to be obvious that the numerical schemes to solve the flow equations, be consistent with the velocity and direction of the flow with which the information is propagated through the flow field. Strictly talking, the centred differences schemes not always follow the flow information through the flow field. In many cases, the final values fall out of flow field domain. For flow fields which have smooth variations of the flow variables, these schemes don't cause problems. However, when there are discontinuities in the flow, these schemes don't function correctly due to producing oscillations. This problem was the reason why the modern codes of fluid dynamics simulation developed the upwinding schemes. One of the simplest advection problem is the first order upwinding.

Considering the one-dimensional model of a pure advection equation for a scalar $\phi(x, t)$ : 


$$
\frac{\partial \phi}{\partial t}=-u \frac{\partial \phi}{\partial x}
$$

where, $\mathrm{u}$ is the advective velocity which will be supposed as constant. Taking an uniform space-time grid, $(\Delta \mathrm{x}, \Delta \mathrm{t})$, and integrating on $\Delta \mathrm{x}, \Delta \mathrm{t}$, in a centred cell in $\mathrm{x}_{\mathrm{i}}$ we will have:

$$
\int_{n}^{n+1} \frac{\partial \phi}{\partial t} \Delta t \int_{x x-\Delta x / 2}^{x x+\Delta x / 2} \Delta x=-u \int_{n}^{n+1} \Delta t \int_{x x-\Delta x / 2}^{x x+\Delta x / 2} \frac{\partial \phi}{\partial x} \Delta x
$$

Discretizing in a finite volume, we get:

$$
\left(\bar{\phi}_{i}^{n+1}-\bar{\phi}_{i}{ }^{n}\right) \Delta x=-u\left(\phi_{x+\frac{\Delta x}{2}}^{n}-\phi_{x-\frac{\Delta x}{2}}^{n}\right) \Delta t
$$

where $\phi_{x+\frac{\Delta x}{2}}^{n}$ is the averaged value in time at the right face. The averaged value in time for the left face $\phi_{x-\frac{\Delta x}{2}}^{n}$. The bars indicate the spatial averaging at the $\mathrm{i}$ cell between the time steps $n$ and $n+1$.

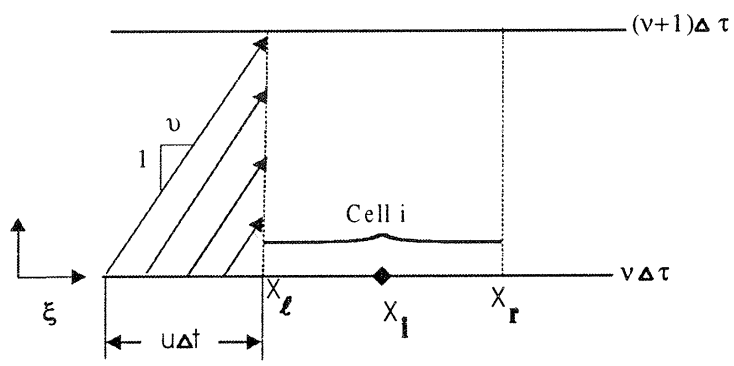

Figure B.1 Space-time gridding showing the convective characteristics inside the left face of the cell I of a finite volume.

As the courant number is $c=\frac{u \Delta t}{\Delta x}$, then the Equation (B.3) results in:

$$
\left(\bar{\phi}_{i}^{n+1}-\bar{\phi}_{i}^{n}\right)=-c\left(\phi_{r}^{n}-\phi_{l}^{n}\right)
$$


At this point, we need to estimate the values at the faces. The temporal average of the Equation (B.4) can be expressed as spatial averaging. For example, the time averaging in the left face is given by:

$$
\phi=\frac{1}{\Delta t} \int_{t n}^{t n+\Delta t} \hat{\phi}_{l}(\tau) d \tau=\frac{1}{c \Delta x} \int_{x i-c \Delta x}^{x} \phi^{n}(\xi) d \xi
$$

where $\hat{\phi}(\tau)$ is the instantaneous value at the right face and $\phi^{n}(\xi)$ the value for $\phi$, in the upstream direction region at the $\mathrm{n}$ time step.

A similar formula is obtained for the right face. Its not necessary to write it because the conservation of the advective flow guaranties that: $\phi_{r}(i)=\phi_{l}(i+1)$.

Different numerical schemes are obtained in function of the election of $\phi^{n}(\xi)$ to estimate the local behaviour. For consistency, $\phi^{n}(\xi)$ must obey the integral restriction:

$$
\frac{1}{\Delta x} \int_{x i-\Delta x / 2}^{x i \Delta x / 2} \phi^{n}(\xi) d \xi=\bar{\phi}_{i}^{n}
$$

In order to get the upwinding scheme, we suppose that $\phi^{n}(\xi)$ is constant for each cell i.

$$
\phi^{n}(\xi) \equiv \bar{\phi}_{i}^{n} \text { for }\left(x_{i}-\frac{\Delta x}{2}\right)<\xi<\left(x_{i}+\frac{\Delta x}{2}\right)
$$

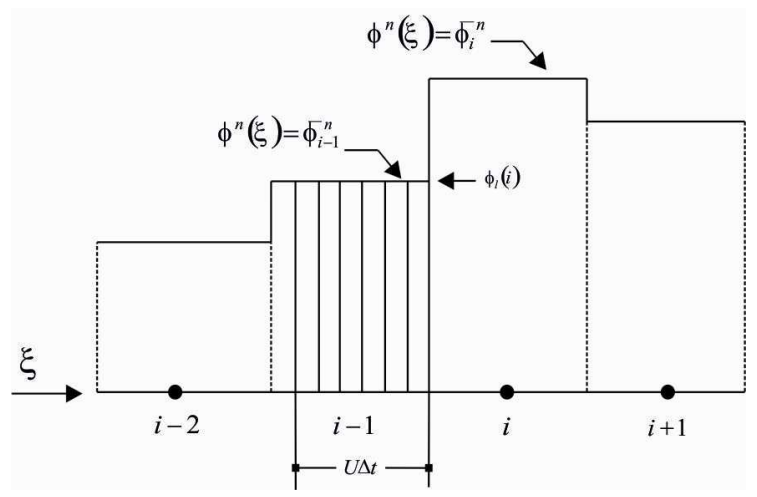

Figure B.2 Gridding for $\phi^{n}(\xi)$ constant at each cell i. 
So, for the Figure B.2 case, we have:

$$
\phi(i)=\phi_{i-1}^{n} \quad \text { for } 0<c \leq 1
$$

and

$$
\phi(i)=\phi_{i}^{n} \text { for } 0<c \leq 1
$$

Finally, the Equation (B.4), results in:

$$
\bar{\phi}_{i}^{n+1}=\bar{\phi}_{i}^{n}-c\left(\phi_{i}^{n}-\phi_{l-1}^{n}\right) \text { for } 0<c \leq 1
$$

In the program PTS, we obtain the convective terms evaluating them at the faces, so, we use the Equation (B.8) to get the interpolation of the terms $\rho_{g} A_{g}$ and $\rho_{l} A_{l}$ of the mass conservation equations for the liquid and the steam, and the terms $e_{g} \rho_{g} A_{g}$ and $e_{l} \rho_{l} A_{l}$ of the energy conservation equation for the liquid and the steam. The first order upwinding scheme was incorporated in four subroutines; FVAP, FLIQUIDN, FEGN and FELN.

\section{B.3 SECOND ORDER UPWINDING (SOU)}

In order to calculate the convective terms of the mass conservation equations $\left(\rho_{g} A_{g}\right.$ and $\left.\rho_{l} A_{l}\right)$, and the energy conservation equations $\left(e_{g} \rho_{g} A_{g}\right.$ and $\left.e_{l} \rho_{l} A_{l}\right)$, a second order upwinding scheme has been used. This scheme is less diffusive than the first order upwinding scheme, but oscillations can even appear. A way to avoid those oscillations is the ULTIMATE strategy.

In order to obtain the second order scheme, a linear interpolation was made, based on the mean values at the upstream cells. 


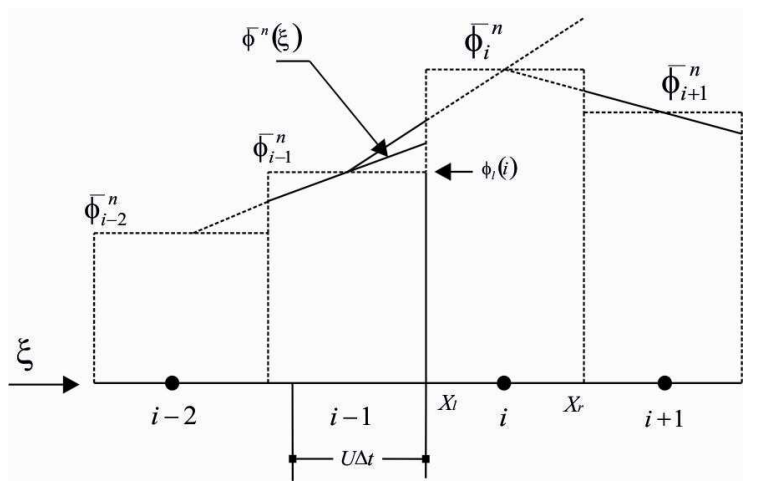

Figure B.3 Second order upwinding

Based on the previous figure, we can get the following equation:

$$
\phi_{i}^{n}(\xi)=\bar{\phi}_{i-1}^{n}+\frac{\bar{\phi}_{i-1}^{n}-\bar{\phi}_{i-2}^{n}}{\Delta x}\left(\xi-X_{l-1}\right) \text { for }\left(X_{l-1}-\frac{\Delta x}{2}\right)<\xi<\left(X_{l-1}+\frac{\Delta x}{2}\right)
$$

The value for $\phi_{l}$ is given by the following equation:

$$
\phi_{l}=\frac{1}{c \Delta x} \int_{x_{i l}-c \Delta x}^{x_{i l}} \phi^{n}(\xi) d \xi
$$

Substitution of Equation B.10 into Equation B.11 yields for the left face;

$$
\phi_{l}=\left(\frac{3-c}{2}\right) \phi_{i-1}-\left(\frac{1-c}{2}\right) \phi_{i-2} \text { for } 0<c \leq 1
$$

Taking the corresponding $\phi_{r}$ value, the updated one when using the second order upwinding method is obtained.

$$
\phi_{i}^{n+1}=\phi_{i}^{n}-c\left[\left(\frac{3-c}{2}\right) \phi_{i}^{n}-(2-c) \phi_{i-1}^{n}+\left(\frac{1-c}{2}\right) \phi_{i-2}^{n}\right]
$$


The second order upwinding scheme was implemented in the PTS code in the subroutines FGAS, FLIQUIDN and FEGLN.

With the intention of diminishing the oscillations of the solution, in the CFD (Computational fluid dynamics) field, new algorithms were developed, and one among them is the QUICKEST method which is explained here next.

\section{B.4 QUICKEST METHOD}

In order to evaluate the convective terms of the steam and water conservation equations, the QUICKEST (Quadratic Upstream Interpolation for Convective Kinematics with Estimated Streaming Terms) method was implemented. For transient flows, this scheme is the canonic form of the third order upwinding for a convection-diffusion equation.

When building this higher order approximation in order to estimate the left face value for $\phi$, a parabola is interpolated as it is seen in the Figure B.4, through getting $\phi_{i-2}^{n}, \phi_{i-1}^{n}, \phi_{i}^{n}$, if $u>0$. This interpolation does not generally satisfy the integral condition of the Equation (B.5) due to its curvature. By introducing an additional constant, we can express upstream value for $\phi^{n}(\xi)$ as follows:

$$
\phi^{n}=C_{1}+\phi_{i-1}^{n}+\left[\frac{\bar{\phi}_{i}^{n}-\bar{\phi}_{i-2}^{n}}{2 \Delta x}\right]\left(\xi-X_{i-1}\right)+\left[\frac{\bar{\phi}_{i}^{n}-2 \bar{\phi}_{i-1}^{n}+\bar{\phi}_{i-2}^{n}}{2 \Delta x^{2}}\right]\left(\xi-X_{i-1}\right)^{2}
$$

Substitution of Equation (B.14) into Equation (B.5) yields the value for the constant $\mathrm{C}_{1}$ :

$$
C_{1}=-\frac{\bar{\phi}_{i}^{n}}{24}-\frac{\bar{\phi}_{i-1}^{n}}{12}-\frac{\bar{\phi}_{i-2}^{n}}{24}
$$

Therefore, we have for the left face, by substituting into Equation (B.4):

$$
\phi_{l}=\frac{1}{2}\left(\bar{\phi}_{i}^{n}+\bar{\phi}_{i-1}^{n}\right)-\frac{c}{2}\left(\bar{\phi}_{i}^{n}+\bar{\phi}_{i-1}^{n}\right)-\left(\frac{1-c^{2}}{6}\right)\left(\bar{\phi}_{i}^{n}-2 \bar{\phi}_{i-1}^{n}+\bar{\phi}_{i-2}^{n}\right)
$$




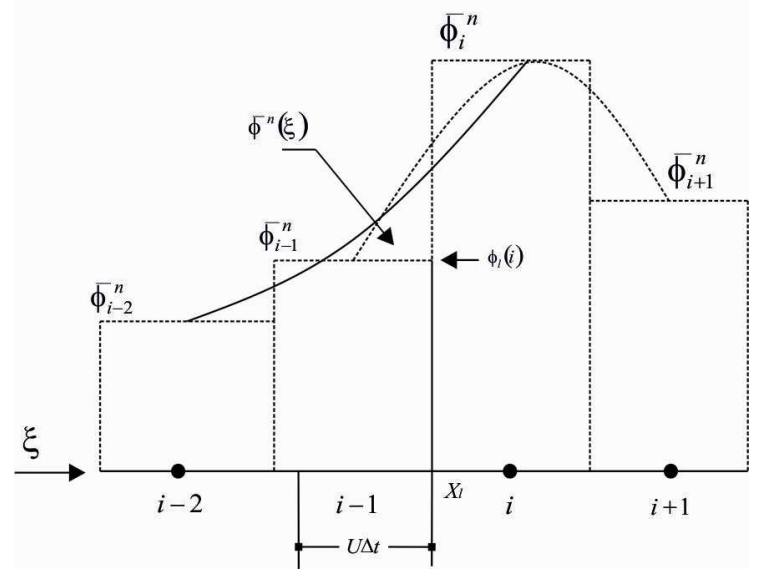

Figure B.4 Third order interpolation

In a similar way, we get $\phi_{r}$. The updating equation that results is:

$$
\begin{aligned}
\bar{\phi}_{i}^{n+1}=\bar{\phi}_{i}^{n}-\frac{c}{2}\left(\bar{\phi}_{i+1}^{n}+\bar{\phi}_{i-1}^{n}\right)+ & \frac{c^{2}}{2}\left(\bar{\phi}_{i+1}^{n}-2 \bar{\phi}_{i}^{n}+\bar{\phi}_{i-1}^{n}\right) \\
& +\left(\frac{1-c^{2}}{6}\right)\left(\bar{\phi}_{i+1}^{n}-3 \bar{\phi}_{i}^{n}+3 \bar{\phi}_{i-1}^{n}-\bar{\phi}_{i-2}^{n}\right)
\end{aligned}
$$

Here we note that the value for $\phi_{i-1}$ is given by Equation B.14, particularized in $\xi=X_{i-1}$ :

$$
\phi_{i-1}=\phi^{n}\left(\xi=X_{i-1}\right)=C_{1}+\bar{\phi}_{i-1}^{n}
$$

Thence:

$$
\phi_{i-1}^{n}=\bar{\phi}_{i-1}^{n}-\frac{\left(\bar{\phi}_{i}^{n}-2 \bar{\phi}_{i-1}^{n}+\bar{\phi}_{i-2}^{n}\right)}{24}
$$




$$
\phi_{i}^{n}=\bar{\phi}_{i}^{n}-\frac{\left(\bar{\phi}_{i+1}^{n}-2 \bar{\phi}_{i}^{n}+\bar{\phi}_{i-1}^{n}\right)}{24} \forall i
$$

Hence, we obtain in this way, the relations between the values in the nodes and the mean values. If we express now the mean values as function of the values in the nodes, we find the following relation:

$$
\begin{aligned}
\bar{\phi}_{i}^{n+1}=\bar{\phi}_{i}^{n}-\frac{c}{2}\left(\bar{\phi}_{i+1}^{n}+\bar{\phi}_{i-1}^{n}\right)+ & \frac{c^{2}}{2}\left(\bar{\phi}_{i+1}^{n}-2 \bar{\phi}_{i}^{n}+\bar{\phi}_{i-1}^{n}\right) \\
& +\left(\frac{1-c^{2}}{6}\right)\left(\bar{\phi}_{i+1}^{n}-3 \bar{\phi}_{i}^{n}+3 \bar{\phi}_{i-1}^{n}-\bar{\phi}_{i-2}^{n}\right) \text { for } 0<c \leq 1
\end{aligned}
$$

This method is used combined with the ULTIMATE method, in the subroutine VEFICL and VEFICV in order to get the convective terms of the momentum conservation equation. As every explicit algorithm, the QUICKEST method is constrained to certain restrictions in the time step, depending on the cell size, the convective velocity and the diffusion coefficient. This analysis is commonly made by the Von Neumann analysis. In Appendix G this stability method is presented.

\section{B.5 ULTIMATE}

The interpolation schemes previously detailed were incorporated to the CC code in combination with the ULTIMATE strategy. The ULTIMATE strategy belongs to the TVD (Total-Variation-Diminution).

To explain the TVD strategy, let's take the following equation as an example:

$$
\frac{\partial u}{\partial t}+\frac{\partial f}{\partial x}=0
$$

where $f=f(u)$ 
Visualizing the variation of $\mathrm{u}$ with respect to $\mathrm{x}$ in a $\mathrm{n}$ time step, in some point at the $\mathrm{x}$ axis, both, $\mathrm{u}$ and its derivative are known. An important property of the physical solutions for the Equation (B.23) is that $\left|\frac{\partial u}{\partial x}\right|$, integrated on all the $\mathrm{x}$ axis domain doesn't increase with time. This integrated quantity is called total variation (TV):

$$
T V(u)=\int\left|\frac{\partial u}{\partial x}\right| d x
$$

For a physically own solution, TV doesn't increment with time. In terms of a numerical solution, the Equation (B.23) is discretized with $\left(u_{i+1}-u_{i}\right) / \Delta t$, so that the Equation (B.24) can be written as:

$$
T V(u)=\sum_{i}\left|u_{i+1}-u_{i}\right|
$$

The Equation (B.25) defines the total variation in $\mathrm{x}$ of one discretized numerical solution. If $T V\left(u^{n+1}\right)$ and $T V\left(u^{n}\right)$ represent the Equation (B.25) evaluated at the time steps $\mathrm{n}+1$ and $\mathrm{n}$, respectively, and if:

$$
T V\left(u^{n+1}\right) \leq T V\left(u^{n}\right)
$$

Then the numerical algorithm is called TVD (Total-Variation-Diminution).

When the TVD is incorporated to a differences scheme, the induced numerical oscillations are simply avoided. This is because of the nature of the basic differentiation problem where the TVD is incorporated.

The ULTIMATE strategy is based on an explicit formulation that uses a Universal Limitator. This strategy, expressed by B.P. Leonard, has one simple universal limitator, which can be applied to a differences scheme without an order restriction. This limitator makes the oscillations to vanish without affecting the hoped for exactitude of the scheme.

The strategy used in our problem uses normalized variables. Figure B.5 shows a onedimensional control volume paying attention to the left face. In order to determine the effective value of the left side, $\phi$, the more influencing nodes are the two nodes neighbor of the face and the closest one upstream. These depend on the direction of the velocity. 
These three nodes receive the name of $\phi_{D}($ downstream $), \phi_{U}($ upstream $)$ and $\phi_{C}($ centrally-localized $)$, as is shown in Figure B.5.

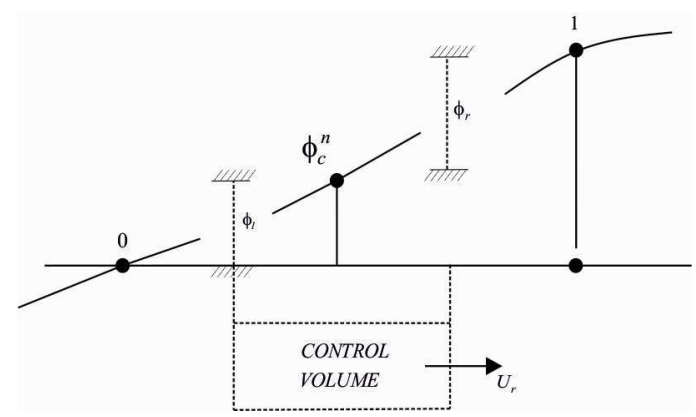

Figure B.5 Value of the normalized nodes in the case of monotonic behaviour

In terms of the original variables, there are many cases to consider: positive or negative combination $u_{l}$, positive or negative $\phi$ and positive or negative values of the gradient or the curvature. The sign variations and flow direction can be normalized defining the normalized variable in each point as follows:

$$
\bar{\phi}(x, t)=\frac{\left|\phi(x, t)-\phi_{U}^{n}\right|}{\left(\phi_{D}^{n}-\phi_{U}^{n}\right)}
$$

where $\phi$ is a function of $\phi_{D}^{n}, \phi_{C}^{n}, \phi_{U}^{n}$ and the courant number; the normalized value at the face is only function of the value at the adjacent upstream node and the courant number.
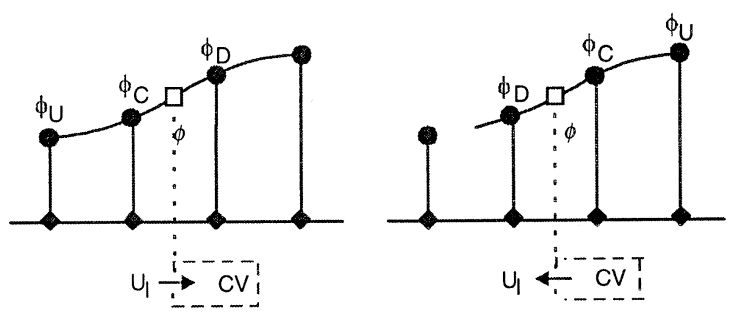

Figure B.6 Definition of the upstream, downstream and centred nodes,

$$
\text { depending on the velocity }{ }^{u_{l}} \text { sign }
$$




$$
\bar{\phi}_{l=f}\left(\bar{\phi}_{C}^{n}\right)
$$

As the normalized nodes are constant: $\phi_{D}^{n}=1$ and $\phi_{U}^{n}=0$

For monoticity, and as Figure B.5 suggests:

$$
\bar{\phi}_{C}^{n} \leq \bar{\phi}_{r}^{n} \leq 1
$$

The value at the upstream face $\bar{\phi}_{l}$, must accomplish:

$$
0 \leq \bar{\phi}_{C}^{n} \leq \bar{\phi}_{l}
$$

Integrating $\frac{\partial \phi}{\partial t}=-u \frac{\partial \phi}{\partial x}$, and with normalized variables we have:

$$
\bar{\phi}_{C}^{n+1}=\bar{\phi}_{C}^{n}-c\left(\bar{\phi}_{r}-\bar{\phi}_{l}\right)
$$

To maintain the monoticity, the new value for $\bar{\phi}_{C}$ must accomplish:

$$
\bar{\phi}_{U}^{n+1} \leq \bar{\phi}_{C}^{n+1} \leq \bar{\phi}_{D}^{n+1}
$$

For pure advection, the right side of the inequality is less restrictive than $\bar{\phi}_{C}^{n} \leq \bar{\phi}_{r}$, but the left side one leads us to:

$$
\bar{\phi}_{U}^{n+1} \leq \bar{\phi}_{C}^{n+1}-c\left(\bar{\phi}_{r}-\bar{\phi}_{l}\right)
$$

So,

$$
\bar{\phi}_{r} \leq \bar{\phi}_{l}+\frac{1}{c}\left(\bar{\phi}_{C}^{n}-\bar{\phi}_{U}^{n+1}\right)
$$

As $\bar{\phi}_{l} \geq 0$ and $\bar{\phi}_{U} \leq 0$, the more limiting case will be when $\bar{\phi}_{l}=\bar{\phi}_{U}^{n+1}=0$, i.e. when:

$$
\bar{\phi}_{r} \leq \frac{1}{c}\left(\bar{\phi}_{C}^{n}\right) \text { for } 0<\bar{\phi}_{C}^{n} \leq 1
$$

For the case of $\bar{\phi}_{C}^{n}<0$, or $\bar{\phi}_{C}^{n}>1$, the following condition has given good results as has been proved in simple numerical experimentation: 


$$
\bar{\phi}_{r}=\bar{\phi}_{C}^{n} \text { for } \bar{\phi}_{C}^{n}<0 \text { or } \bar{\phi}_{C}^{n}>1
$$

The universal limitator is shown schematically in Figure B.5. the borders depend on the courant number. If $\mathrm{c}$ tends to 0 (dashed line) and if $\mathrm{c}$ tends to 1 it tends to the bisectrix.

For a better comprehension of the strategy, we show the steps that we followed when applying this methodology. Firstly, depending on the velocity, we name the neighbor nodes as: Upstream (U), Downstream (D), and centred (C). The second step is to calculate Del:

$$
D e l=\phi_{D}^{n}-\phi_{U}^{n}
$$

If $|D e l|<10^{-5}$, then $\phi_{r}=\phi_{c}$, and we continue with the next face.

The next step is made if the previous conditions are not accomplished:

$$
\bar{\phi}_{C}^{n}=\left(\phi_{C}^{n}-\phi_{U}^{n}\right) / D e l
$$

If this equation is less than 0 , or bigger than 1 , then we say $\phi_{r}=\phi_{c}$ and we continue to the next face. If not, we do the next step:

$$
\bar{\phi}_{r}^{n}=\left(\phi_{r}-\phi_{l}\right) / D e l
$$

where we calculate the convective terms of the mass and energy equations with the first order upwinding scheme.

Afterwards, we get $\phi_{r}$ by making the following considerations:

If $\bar{\phi}_{r}<\bar{\phi}_{C}^{n}$, we apply the inferior limitator $\bar{\phi}_{r}=\bar{\phi}_{C}^{n}$.

If $\bar{\phi}_{r}>\bar{\phi}_{C}^{n} / c$, we apply the superior limitator $\bar{\phi}_{r}=\bar{\phi}_{C}^{n} / c$

If $\bar{\phi}_{r}>1$, we apply the absolute superior limitator $\bar{\phi}_{r}=1$ 


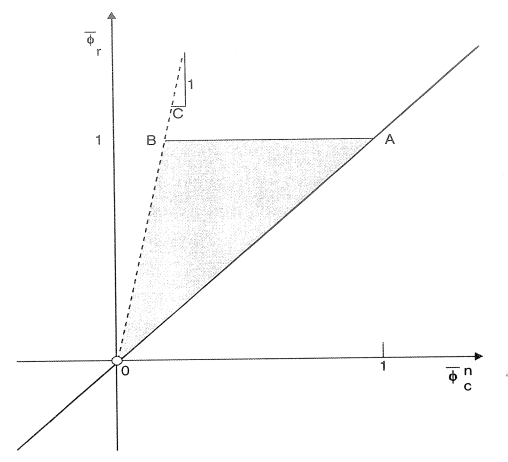

Figure B.7 Universal limitator diagram border.

Finally we do:

$$
\bar{\phi}_{r}=\bar{\phi}_{r} D e l+\phi_{U}
$$

The stability of the method is guaranteed because of the fact that the monoticity of the system is preserved.

This strategy is incorporated to the subroutines FVAP, FLIQUIDN, FEGN, FELN, CALCGR and CALCLR. 


\title{
APPENDIX C
}

\section{INTERFACIAL AND THROUGH THE WALLS HEAT TRANSFER AND ITS DERIVATIVES}

\begin{abstract}
When solving the system of conservation equations, as it was explained in Chapter 5, we need the heat transfer to the wall and the interfacial heat transfer. We also need the derivatives of the heat transfer with respect to the pressure, temperature and the pressures difference.
\end{abstract}

The heat transferred through the walls and at the interface is calculated with different correlations which depend on some dimensionless numbers. These dimensionless numbers will be derived with respect to the pressure, temperature and the pressures difference since these derivatives are needed in the numerical algorithm when solving the system of equations.

It is mandatory to define here the dimensionless numbers which will be needed later in the definitions of the heat transfer coefficients:

$$
\begin{aligned}
& \operatorname{Re}_{k}=\left(\frac{\rho_{k} u_{k} D_{h k}}{\mu_{k}}\right), \quad \text { for each k phase } \\
& G r_{l}=\frac{9.81 \beta_{l}\left|T_{l j}-T_{w l j}\right| \rho_{l}^{2} D_{h l}^{3}}{\mu_{l}^{2}} \\
& J a=\left(\frac{C p_{l} \rho_{l}\left(T_{g}-T_{l}\right)}{\rho_{g} h_{f g}}\right)
\end{aligned}
$$




$$
\operatorname{Pr}_{k}=\left(\frac{C p_{k} \mu_{k}}{C_{k}}\right), \quad \text { for each } \mathrm{k} \text { phase }
$$

Below the heat transferred from each phase with the interface and the derivatives for each phase separately are presented.

\section{C.1 LIQUID PHASE}

The equations that will be used to calculate the heat interchanged at the interface and with the wall are:

$$
\begin{aligned}
& Q_{i l}{ }^{t+\Delta t}=A_{l i j}{ }^{t} h_{l i j}{ }^{t+\Delta t}\left(T_{\text {sati }}-T_{l}\right)_{j}^{t+\Delta t} \Delta t \\
& Q_{w l}{ }^{t+\Delta t}=A_{l w j}{ }^{t} h_{l w j}{ }^{t+\Delta t}\left(T_{l w}-T_{l}\right)_{j}^{t+\Delta t} \Delta t
\end{aligned}
$$

The correlations used to calculate the heat transfer coefficients, depend on the fluid regime for the convection to the wall, and for the interfacial heat transfer there are several different correlations in several books and publications deduced from some experimental investigation.

Two different correlations will be used for calculating the convective heat interchanged with the wall; these are, the Dittus-Boelter, and the Grashof correlations. The Dittus-Boelter correlation is applicable when forced convection is the only heat transfer mode. The Grashof correlation is used when natural convection is the heat transfer mode. [A.F. Mills, Heat Transfer, Second Edition, Prentice Hall, New Jersey, 1999].

Our CC code will use the one that gives us the higher value for the conditions that we are simulating.

$$
\begin{cases}h_{l w}=h_{D B}=\frac{K_{l}}{D_{h l}} N u_{D B}=\frac{K_{l}}{D_{h l}} 0.023 \operatorname{Re}_{l}^{0.8} \operatorname{Pr}_{l}^{0.4} & \text { Dittus-Boelter } \\ h_{l w}=h_{G r}=\frac{K_{l}}{D_{h l}} N u_{G r}=\frac{K_{l}}{D_{h l}} 0.59 G r_{l}^{0.25} \operatorname{Pr}_{l}^{0.25} & \text { Grashof }\end{cases}
$$

For the interfacial condensation and heat transfer, we will use a correlation like the following one: 


$$
h_{l \mathrm{int}}=\frac{K_{l}}{D_{h l}} N u l_{\mathrm{int}}=\frac{K_{l}}{D_{h l}} c t_{1} \operatorname{Re}_{l}{ }^{c t_{2}} \operatorname{Re}_{g}{ }^{c t_{3}} J a{ }^{c t_{4}} \operatorname{Pr}_{l}{ }^{c t_{5}}
$$

In this equation it can be seen that we have five different parameters $\left(c t_{1}-c t_{5}\right)$, which are the exponents of the dimensionless numbers and one first constant that multiplies all of them. These constants have different values for the different correlations that can be chosen.

There are several different correlations which come from some studies made for cocurrent or countercurrent steam-water condensation phenomena in pipes as was explained in Chapter 2.

Now, the equations for the derivatives for the different heat transfers are being defined, and in order to make it more general, the exponents as $\left(c t_{1}-c t_{5}\right)$ will be kept in the equations. Introducing the definitions for the dimensionless numbers into the convective heat transfer coefficients, for one cell $j$ and one specific time step, we obtain:

$$
\begin{aligned}
& h_{l \text { int } j}^{t+\Delta t}=\frac{K_{l j}^{t+\Delta t}}{D_{h l j}^{t}} c t_{1}\left(\left(\frac{\rho_{l} D_{h l}}{\mu_{l}}\right)_{j}^{t+\Delta t}\left(\frac{u_{l j-1 / 2}+u_{l j+1 / 2}}{2}\right)^{t+\Delta t}\right)^{c t_{2}} . \\
& \left(( \frac { \rho _ { g } D _ { h g } } { \mu _ { g } } ) _ { j } ^ { t + \Delta t } \left(\frac{u_{g}}{2}+u_{g-1 / 2}\right.\right. \\
& \left(\left(\frac{C p_{l} \rho_{l}\left(T_{g}-T_{l}\right.}{\rho_{g} h_{f g}}\right)_{j}^{t+\Delta t}\right)^{c t_{3}} \cdot\left(\left(\frac{C p_{l} \mu_{l}}{k_{l}}\right)_{j}^{t+\Delta t}\right)^{c t_{5}}
\end{aligned}
$$




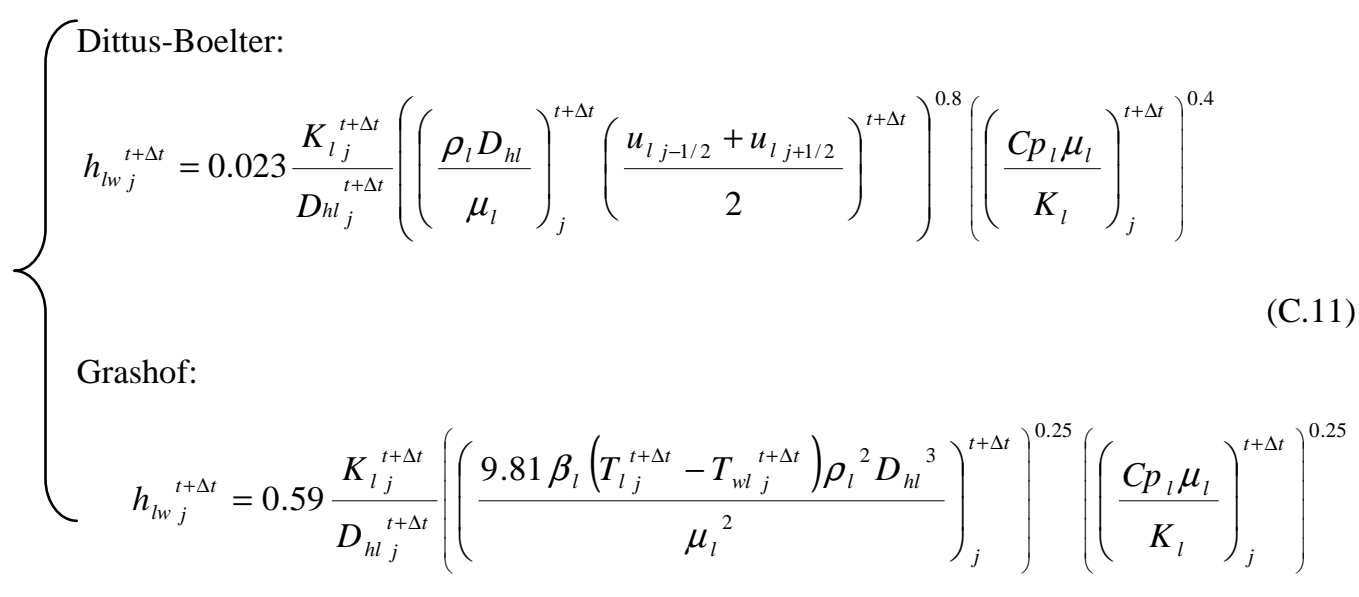

For the sake of simplicity, we start defining the following expressions for the interfacial heat transfer during one time step and through the interfacial area of one node of length $\Delta x:$

$$
\begin{aligned}
& a=\frac{c t_{1} K_{l j}^{t+\Delta t}}{D_{h l_{j}}^{t+\Delta t} P_{\text {int } e \text { f }} \Delta x \Delta t\left(T_{\text {sati } j}{ }^{t+\Delta t}-T_{l j}^{t+\Delta t}\right)} \\
& b=\left(\left(\frac{\rho_{l} D_{h l}}{\mu_{l}}\right)_{j}^{t+\Delta t}\left(\frac{u_{l j-1 / 2}+u_{l j+1 / 2}}{2}\right)^{t+\Delta t}\right)^{c t_{2}} \\
& c=\left(\left(\frac{\rho_{g} D_{h g}}{\mu_{g}}\right)_{j}^{t+\Delta t}\left(\frac{u_{g}{ }_{j-1 / 2}+u_{g_{j+1 / 2}}}{2}\right)^{t+\Delta t}\right)^{c t_{3}} \\
& d=\left(\left(\frac{C p_{l} \rho_{l}\left(T_{g}-T_{l}\right)}{\rho_{g} h_{f g}}\right)_{j}^{t+\Delta t}\right)^{c t_{4}} \\
& e=\left(\left(\frac{C p_{l} \mu_{l}}{k_{l}}\right)_{j}^{t+\Delta t}\right)^{c t_{5}}
\end{aligned}
$$


The interfacial convective heat transferred during one time step can be defined as a function of the previous expressions:

$$
Q_{i l}{ }^{t+\Delta t}=a b c d e
$$

Below the derivative of the interfacial heat transfer with respect to the liquid pressure is shown:

$$
\begin{aligned}
& \frac{\partial Q_{i l}{ }^{t+\Delta t}}{\partial P_{l j}^{t+\Delta t}}=A_{l i j}{ }^{t}\left(T_{\text {sati }}-T_{l}\right)_{j}^{t+\Delta t} \Delta t c t_{1} \frac{1}{D_{h l_{j}}^{t+\Delta t}} \frac{\partial K_{l j}^{t+\Delta t}}{\partial P_{l j}^{t+\Delta t}} b c d e \\
& +\operatorname{acdect}_{2}\left(\left(\frac{D_{h l}}{\mu_{l}}\right)_{j}^{t+\Delta t}\left(\frac{u_{l j-1 / 2}+u_{l j+1 / 2}}{2}\right)^{t+\Delta t}\right)^{c t_{2}}\left(\rho_{l_{j}}^{t+\Delta t}\right)^{c 2-1} \frac{\partial \rho_{l j}^{t+\Delta t}}{\partial P_{l j}^{t+\Delta t}} \\
& -\operatorname{acdect}_{2}\left(\left(\rho_{l} D_{h l}\right)_{j}^{t+\Delta t}\left(\frac{u_{l j-1 / 2}+u_{l j+1 / 2}}{2}\right)^{t+\Delta t}\right)^{c t_{2}}\left(\mu_{l j}^{t+\Delta t}\right)^{-c 2-1} \frac{\partial \mu_{l j}^{t+\Delta t}}{\partial P_{l j}^{t+\Delta t}} \\
& + \text { abcect }_{4}\left(\left(\frac{C p_{l}\left(T_{g}-T_{l}\right)}{\rho_{g} h_{f g}}\right)_{j}^{t+\Delta t}\right)^{c t_{4}}\left(\rho_{l j}^{t+\Delta t}\right)^{c t_{4^{-1}}} \frac{\partial \rho_{l_{j}}^{t+\Delta t}}{\partial P_{l j}^{t+\Delta t}} \\
& - \text { abcect }_{4}\left(\left(\frac{C p_{l} \rho_{l}\left(T_{g}-T_{l}\right)}{\rho_{g}}\right)_{j}^{t+\Delta t}\right)^{c t_{4}}\left(h_{f g_{j}}{ }^{t+\Delta t}\right)^{-c t_{4}-1} \frac{\partial h_{f g_{j}}^{t+\Delta t}}{\partial P_{l j}^{t+\Delta t}} \\
& + \text { abcect }_{4}\left(\left(\frac{\rho_{l}\left(T_{g}-T_{l}\right)}{\rho_{g} h_{f g}}\right)_{j}^{t+\Delta t}\right)^{c t_{4}}\left(C p_{l_{j}}^{t+\Delta t}\right)^{c t_{4-1}} \frac{\partial C p_{l_{j}}^{t+\Delta t}}{\partial P_{l j}^{t+\Delta t}}
\end{aligned}
$$


$+a b c d c t_{5}\left(\left(\frac{\mu_{l}}{k_{l}}\right)_{j}^{t+\Delta t}\right)^{c t_{5}}\left(C p_{l_{j}}^{t+\Delta t}\right)^{c t_{5}-1} \frac{\partial C p_{l_{j}}^{t+\Delta t}}{\partial P_{l_{j}}^{t+\Delta t}}$

$+a b c d c t_{5}\left(\left(\frac{C p_{l}}{k_{l}}\right)_{j}^{t+\Delta t}\right)^{c t_{5}}\left(\mu_{l_{j}}^{t+\Delta t}\right)^{c t_{5-1}} \frac{\partial \mu_{l_{j}}^{t+\Delta t}}{\partial P_{l_{j}}^{t+\Delta t}}$

$-a b c d c t_{5}\left(\left(C p_{l} \mu_{l}\right)_{j}^{t+\Delta t}\right)^{c t_{5}}\left(k_{l j}^{t+\Delta t}\right)^{-c t_{5^{-1}}} \frac{\partial k_{l j}^{t+\Delta t}}{\partial P_{l j}^{t+\Delta t}}$

For the derivative of the interfacial heat transfer with respect to the liquid temperature we have:

$$
\begin{aligned}
& \frac{\partial Q_{i l}{ }^{t+\Delta t}}{\partial T_{l j}^{t+\Delta t}}=-A_{l i j}{ }^{t} h_{l i j}{ }^{t+\Delta t} \Delta t+A_{l i j}{ }^{t}\left(T_{\text {sati }}-T_{l}\right)_{j}^{t+\Delta t} \Delta t c t_{1} \frac{1}{D_{h l j}{ }^{t+\Delta t}} \frac{\partial K_{l j}^{t+\Delta t}}{\partial T_{l j}^{t+\Delta t}} b c d e \\
& +\operatorname{acdect}_{2}\left(\left(\frac{D_{h l}}{\mu_{l}}\right)_{j}^{t+\Delta t}\left(\frac{u_{l j-1 / 2}+u_{l j+1 / 2}}{2}\right)^{t+\Delta t}\right)^{c t_{2}}\left(\rho_{l_{j}}^{t+\Delta t}\right)^{c t_{2}-1} \frac{\partial \rho_{l_{j}}^{t+\Delta t}}{\partial T_{l_{j}}^{t+\Delta t}} \\
& -\operatorname{acdect}_{2}\left(\left(D_{h l} \rho_{l}\right)_{j}^{t+\Delta t}\left(\frac{u_{l j-1 / 2}+u_{l j+1 / 2}}{2}\right)^{t+\Delta t}\right)^{c t_{2}}\left(\mu_{l_{j}}^{t+\Delta t}\right)^{-c t_{2-1}} \frac{\partial \mu_{l_{j}}^{t+\Delta t}}{\partial T_{l_{j}}^{t+\Delta t}} \\
& + \text { abcect }_{4}\left(\left(\frac{C p_{l}\left(T_{g}-T_{l}\right)}{\rho_{g} h_{f g}}\right)_{j}^{t+\Delta t}\right)^{c t_{4}}\left(\rho_{l j}^{t+\Delta t}\right)^{c t_{4^{-1}}} \frac{\partial \rho_{l j}^{t+\Delta t}}{\partial T_{l j}^{t+\Delta t}} \\
& + \text { abcect }_{4}\left(\left(\frac{\rho_{l}\left(T_{g}-T_{l}\right)}{\rho_{g} h_{f g}}\right)_{j}^{t+\Delta t}\right)^{c t_{4}}\left(C p_{l_{j}}^{t+\Delta t}\right)^{c t_{4^{-1}}} \frac{\partial C p_{l_{j}}^{t+\Delta t}}{\partial T_{l_{j}}^{t+\Delta t}}
\end{aligned}
$$


- abcect $_{4}\left(\left(T_{g}-T_{l}\right)_{j}^{t+\Delta t}\right) c t_{4^{-1}}\left(\left(\frac{C p_{l} \rho_{l}}{\rho_{g} h_{f g}}\right)_{j}^{t+\Delta t}\right)^{c t_{4}}$

$-\operatorname{abcect}_{4}\left(\left(\frac{C p_{l} \rho_{l}\left(T_{g}-T_{l}\right)}{\rho_{g}}\right)_{j}^{t+\Delta t}\right)^{c t_{4}}\left(h_{f g_{j}}{ }^{t+\Delta t}\right)^{-c t_{4}-1} \frac{\partial h_{f g_{j}}{ }^{t+\Delta t}}{\partial T_{l_{j}}{ }^{t+\Delta t}}$

$+\operatorname{abcdect} t_{5}\left(\left(\frac{\mu_{l}}{k_{l}}\right)_{j}^{t+\Delta t}\right)^{c t_{5}}\left(C p_{l_{j}}{ }^{t+\Delta t}\right) c t_{5^{-1}} \frac{\partial C p_{l_{j}}{ }^{t+\Delta t}}{\partial T_{l j}{ }^{t+\Delta t}}$

$+\operatorname{abcdect}_{5}\left(\left(\frac{C p_{l}}{k_{l}}\right)_{j}^{t+\Delta t}\right)^{c t_{5}}\left(\mu_{l_{j}}^{t+\Delta t}\right)^{c t_{5-1}} \frac{\partial \mu_{l_{j}}^{t+\Delta t}}{\partial T_{l_{j}}^{t+\Delta t}}$

For the derivative of the interfacial heat transfer with respect to the liquid pressure differences we have:

$$
\begin{gathered}
\frac{\partial Q_{i l}{ }^{t+\Delta t}}{\partial\left(P_{l j+1}-P_{l j}\right)^{t+\Delta t}}=+\operatorname{acdect}_{2}\left(\left(\frac{\rho_{l} D_{h l}}{\mu_{l}}\right)_{j}^{t+\Delta t}\right)^{c t_{2}}\left(\left(u_{l_{j+1 / 2}}\right)^{t+\Delta t}\right)^{c t_{2}-1} \frac{\partial u_{l_{j+1 / 2}}^{t+\Delta t}}{\partial\left(P_{l j+1}-P_{l j}\right)^{t+\Delta t}}(\mathrm{C} .21 \\
\frac{\partial Q_{i l}{ }^{t+\Delta t}}{\partial\left(P_{l j}-P_{l j-1}\right)^{t+\Delta t}}=+\operatorname{acdect}_{2}\left(\left(\frac{\rho_{l} D_{h l}}{\mu_{l}}\right)_{j}^{t+\Delta t}\right)^{c t_{2}}\left(\left(u_{l j-1 / 2}\right)^{t+\Delta t}\right)^{c t_{2}-1} \frac{\partial u_{l_{j-1 / 2}}{ }^{t+\Delta t}}{\partial\left(P_{l j}-P_{l j-1}\right)^{t+\Delta t}}(\mathrm{C} .22
\end{gathered}
$$

Next the following constants for the heat transfer to the wall equation are defined:

$$
a_{2}=A_{l w j}{ }^{t}\left(T_{w l}-T_{l}\right)_{j}^{t+\Delta t} \Delta t 0.023 \frac{K_{l j}^{t+\Delta t}}{D_{h l_{j}}^{t}}
$$




$$
\begin{aligned}
& b_{2}=\left(\left(\frac{\rho_{l} D_{h l}}{\mu_{l}}\right)_{j}^{t+\Delta t}\left(\frac{u_{l j-1 / 2}+u_{l j+1 / 2}}{2}\right)^{t+\Delta t}\right)^{0.8} \\
& c_{2}=\left(\left(\frac{C p_{l} \mu_{l}}{K_{l}}\right)_{j}^{t+\Delta t}\right)^{0.4} \\
& a_{3}=A_{l w j}^{t}\left(T_{w l}-T_{l}\right)_{j}^{t+\Delta t} \Delta t 0.59 \frac{K_{l j}^{t+\Delta t}}{D_{h l j}^{t+\Delta t}} \\
& b_{3}=\left(\left(\frac{9.81 \beta_{l}\left|T_{l j}^{t+\Delta t}-T_{w l j}{ }^{t+\Delta t}\right| \rho_{l}^{2} D_{h l}{ }^{3}}{\mu_{l}^{2}}\right)_{j}^{t+\Delta t}\right)^{0.25} \\
& c_{3}=\left(\left(\frac{C p_{l} \mu_{l}}{K_{l}}\right)_{j}^{t+\Delta t}\right)^{0.25}
\end{aligned}
$$

Hence, the heat transferred with the wall from the liquid as a function of the previous constants is defined as:

$$
\begin{aligned}
q_{w l}{ }^{t+\Delta t} & =a_{2} b_{2} c_{2} & & \text { Dittus-Boelter } \\
q_{w l}{ }^{t+\Delta t} & =a_{3} b_{3} c_{3} & & \text { Grashof }
\end{aligned}
$$

So, the partial derivative of the heat transferred with the wall with respect to the liquid pressure is:

\section{- FOR THE DITTUS -BOELTER CORRELATION WE MAY WRITE:}

$\frac{\partial Q_{w l}{ }^{t+\Delta t}}{\partial P_{l j}^{t+\Delta t}}=a_{2} c_{2} 0.8\left(\left(\frac{D_{h l}}{\mu_{l}}\right)_{j}^{t+\Delta t}\left(\frac{u_{l j-1 / 2}+u_{l j+1 / 2}}{2}\right)^{t+\Delta t}\right)^{0.8}\left(\rho_{l_{j}}^{t+\Delta t}\right)^{-0.2} \frac{\partial \rho_{l_{j}}^{t+\Delta t}}{\partial P_{l j}^{t+\Delta t}}$ 


$$
\begin{aligned}
& -a_{2} c_{2} 0.8\left(\left(\rho_{l} D_{h l}\right)_{j}^{t+\Delta t}\left(\frac{u_{l j-1 / 2}+u_{l j+1 / 2}}{2}\right)^{t+\Delta t}\right)^{0.8}\left(\mu_{l j}^{t+\Delta t}\right)^{-1.8} \frac{\partial \mu_{l j}^{t+\Delta t}}{\partial P_{l j}^{t+\Delta t}} \\
& +a_{2} b_{2} 0.4\left(\left(\frac{C p_{l}}{K_{l}}\right)_{j}^{t+\Delta t}\right)^{0.4}\left(\mu_{l j}^{t+\Delta t}\right)^{-0.6} \frac{\partial \mu_{l j}^{t+\Delta t}}{\partial P_{l j}^{t+\Delta t}}+a_{2} b_{2} 0.4\left(\left(\frac{\mu_{l}}{K_{l}}\right)_{j}^{t+\Delta t}\right)^{0.4}\left(C p_{l j}^{t+\Delta t}\right)^{-0.6} \frac{\partial C p_{l j}^{t+\Delta t}}{\partial P_{l j}^{t+\Delta t}} \\
& -a_{2} b_{2} 0.4\left(\left(\mu_{l} C p_{l}\right)_{j}^{t+\Delta t}\right)^{0.4}\left(K_{l j}^{t+\Delta t}\right)^{-1.4} \frac{\partial K_{l j}^{t+\Delta t}}{\partial P_{l_{j}}^{t+\Delta t}}
\end{aligned}
$$

- FOR THE GRASHOF CORRELATION WE MAY WRITE:

$$
\begin{aligned}
& \frac{\partial Q_{w l}{ }^{t+\Delta t}}{\partial P_{l j}^{t+\Delta t}}=a_{3} c_{3} 0.5\left(\left(\frac{9.81 \beta_{l}\left|T_{l j}^{t+\Delta t}-T_{w l j}{ }^{t+\Delta t}\right| D_{h l}{ }^{3}}{\mu_{l}^{2}}\right)_{j}^{t+\Delta t}\right)^{0.25}\left(\rho_{l j}^{t+\Delta t}\right)^{-0.5} \frac{\partial \rho_{l j}^{t+\Delta t}}{\partial P_{l j}^{t+\Delta t}}+ \\
& -a_{3} c_{3} 0.5\left(\left(9.81 \beta_{l}\left|T_{l_{j}}^{t+\Delta t}-T_{w l j}{ }^{t+\Delta t}\right| \rho_{l}{ }^{2} D_{h l}{ }^{3}\right)_{j}^{t+\Delta t}\right)^{0.25}\left(\mu_{l_{j}}^{t+\Delta t}\right)^{-1.5} \frac{\partial \mu_{l j}^{t+\Delta t}}{\partial P_{l j}^{t+\Delta t}} \\
& +a_{3} b_{3} 0.25\left(\left(\frac{C p_{l}}{K_{l}}\right)_{j}^{t+\Delta t}\right)^{0.25}\left(\mu_{l_{j}}^{t+\Delta t}\right)^{-0.75} \frac{\partial \mu_{l j}^{t+\Delta t}}{\partial P_{l j}^{t+\Delta t}} \\
& +a_{2} b_{2} 0.25\left(\left(\frac{\mu_{l}}{K_{l}}\right)_{j}^{t+\Delta t}\right)^{0.25}\left(C p_{l j}^{t+\Delta t}\right)^{-0.75} \frac{\partial C_{l_{j}}^{t+\Delta t}}{\partial P_{l j}^{t+\Delta t}} \\
& -a_{2} b_{2} 0.25\left(\left(C p_{l} \mu_{l}\right)_{j}^{t+\Delta t}\right)^{0.25}\left(K_{l_{j}}^{t+\Delta t}\right)^{-1.25} \frac{\partial K_{l_{j}}^{t+\Delta t}}{\partial P_{l_{j}}^{t+\Delta t}}
\end{aligned}
$$

Now the derivative of the heat interchanged with the wall with respect to the liquid temperature is shown: 
- FOR THE DITTUS -BOELTER CORRELATION WE MAY WRITE:

$\frac{\partial Q_{w l}{ }^{t+\Delta t}}{\partial T_{l j}^{t+\Delta t}}=-A_{l w j}{ }^{t} h_{l w j}{ }^{t+\Delta t} \Delta t+A_{l w j}{ }^{t}\left(T_{w l}-T_{l}\right)_{j}^{t+\Delta t} \Delta t 0.023 \frac{1}{D_{h l j}{ }^{t+\Delta t}} \frac{\partial K_{l j}^{t+\Delta t}}{\partial T_{l j}^{t+\Delta t}} b_{2} c_{2}$

$+a_{2} c_{2} 0.8\left(\left(\frac{D_{h l}}{\mu_{l}}\right)_{j}^{t+\Delta t}\left(\frac{u_{l j-1 / 2}+u_{l j+1 / 2}}{2}\right)^{t+\Delta t}\right)^{0.8}\left(\rho_{l j}^{t+\Delta t}\right)^{-0.2} \frac{\partial \rho_{l j}^{t+\Delta t}}{\partial T_{l j}^{t+\Delta t}}$

$-a_{2} c_{2} 0.8\left(\left(\rho_{l} D_{h l}\right)_{j}^{t+\Delta t}\left(\frac{u_{l j-1 / 2}+u_{l j+1 / 2}}{2}\right)^{t+\Delta t}\right)^{0.8}\left(\mu_{l j}^{t+\Delta t}\right)^{-1.8} \frac{\partial \mu_{l j}^{t+\Delta t}}{\partial T_{l j}^{t+\Delta t}}$

$+a_{2} b_{2} 0.4\left(\left(\frac{\mu_{l}}{K_{l}}\right)_{j}^{t+\Delta t}\right)^{0.4}\left(C p_{l j}^{t+\Delta t}\right)^{-0.6} \frac{\partial C p_{l j}^{t+\Delta t}}{\partial T_{l j}^{t+\Delta t}}$

$+a_{2} b_{2} 0.4\left(\left(\frac{C p_{l}}{K_{l}}\right)_{j}^{t+\Delta t}\right)^{0.4}\left(\mu_{l j}^{t+\Delta t}\right)^{-0.6} \frac{\partial \mu_{l j}^{t+\Delta t}}{\partial T_{l_{j}}^{t+\Delta t}}$

$-a_{2} b_{2} 0.4\left(\left(C p_{l} \mu_{l}\right)_{j}^{t+\Delta t}\right)^{0.4}\left(K_{l_{j}}^{t+\Delta t}\right)^{-1.4} \frac{\partial K_{l j}^{t+\Delta t}}{\partial T_{l_{j}}^{t+\Delta t}}$

- FOR THE GRASHOF CORRELATION WE MAY WRITE:

$\frac{\partial Q_{w l}{ }^{t+\Delta t}}{\partial T_{l j}^{t+\Delta t}}=-A_{l w j}{ }^{t} h_{l w j}{ }^{t+\Delta t} \Delta t+A_{l w j}{ }^{t}\left(T_{w l}-T_{l}\right)_{j}^{t+\Delta t} \Delta t 0.59 \frac{1}{D_{h l j}{ }^{t+\Delta t}} \frac{\partial K_{l j}{ }^{t+\Delta t}}{\partial T_{l j}{ }^{t+\Delta t}} b_{3} c_{3}$

C_10 
$+a_{3} c_{3} 0.5\left(\left(\frac{9.81 \beta_{l}\left|T_{l_{j}}^{t+\Delta t}-T_{w l j}{ }^{t+\Delta t}\right| D_{h l}{ }^{3}}{\mu_{l}{ }^{2}}\right)_{j}^{t+\Delta t}\right)^{0.25}\left(\rho_{l j}^{t+\Delta t}\right)^{-0.5} \frac{\partial \rho_{l_{j}}^{t+\Delta t}}{\partial T_{l j}^{t+\Delta t}}$

$+a_{3} c_{3} 0.25\left(\left(\frac{9.81 \rho_{l}^{2} \beta_{l} D_{h l}^{3}}{\mu_{l}{ }^{2}}\right)_{j}^{t+\Delta t} \int^{0.25}\left(T_{l j}^{t+\Delta t}-T_{w l j}{ }^{t+\Delta t}\right)^{-0.75}\right.$

$-a_{3} c_{3} 0.5\left(\left(9.81 \beta_{l}\left(T_{l j}^{t+\Delta t}-T_{g_{j}}^{t+\Delta t}\right) \rho_{l}{ }^{2} D_{h l}{ }^{3}\right)_{j}^{t+\Delta t}\right)^{0.25}\left(\mu_{l j}^{t+\Delta t}\right)^{-1.5} \frac{\partial \mu_{l j}^{t+\Delta t}}{\partial T_{l j}^{t+\Delta t}}$

$+a_{3} b_{3} 0.25\left(\left(\frac{\mu_{l}}{K_{l}}\right)_{j}^{t+\Delta t}\right)^{0.25}\left(C p_{l j}^{t+\Delta t}\right)^{-0.75} \frac{\partial C p_{l_{j}}^{t+\Delta t}}{\partial T_{l j}^{t+\Delta t}}$

$+a_{3} b_{3} 0.25\left(\left(\frac{C p_{l}}{K_{l}}\right)_{j}^{t+\Delta t}\right)^{0.25}\left(\mu_{l j}^{t+\Delta t}\right)^{-0.75} \frac{\partial \mu_{l j}^{t+\Delta t}}{\partial T_{l j}^{t+\Delta t}}$

$-a_{3} b_{3} 0.25\left(\left(C p_{l} \mu_{l}\right)_{j}^{t+\Delta t}\right)^{0.25}\left(K_{l j}^{t+\Delta t}\right)^{-1.25} \frac{\partial K_{l j}^{t+\Delta t}}{\partial T_{l_{j}}^{t+\Delta t}}$

\section{C.2 STEAM PHASE}

The equations that will be used to calculate the convective interfacial and the heat transferred with the wall are:

$$
\begin{aligned}
& Q_{i g}{ }^{t+\Delta t}=A_{l i j}{ }^{t} h_{l i j}{ }^{t+\Delta t}\left(T_{\text {sati }}-T_{g}\right)_{j}{ }^{t+\Delta t} \Delta t \\
& Q_{w g}{ }^{t+\Delta t}=A_{g w_{j}}{ }^{t} h_{g w_{j}}{ }^{t+\Delta t}\left(T_{g w}-T_{g}\right)_{j}^{t+\Delta t} \Delta t
\end{aligned}
$$


The correlations used to calculate the heat transfer coefficients, depend on the fluid regime for the convection to the wall, and for the interfacial mass and heat transfer there are several different correlations in books and publications deduced from several experimental researches.

Two different correlations will be used for the convection to the wall; these are, the DittusBoelter, and the Grashof correlations. The Dittus-boelter correlation is applicable when forced convection is the only heat transfer mode. The Grashof correlation is used when natural convection is the heat transfer mode. [A.F. Mills, Heat Transfer, Second Edition, Prentice Hall, New Jersey, 1999].

It will be taken in our CC code, the one that gives us the higher value for the conditions that we are simulating.

$$
\left\{\begin{array}{l}
h_{g w}=h_{D B}=\frac{K_{g}}{D_{h g}} N u_{D B}=\frac{K_{g}}{D_{h g}} 0.023 \operatorname{Re}_{g}{ }^{0.8} \operatorname{Pr}_{g}{ }^{0.4} \text { Dittus-Boelter } \\
h_{g w}=h_{G r}=\frac{K_{g}}{D_{h g}} N u_{G r}=\frac{K_{g}}{D_{h g}} 0.59 G r_{g}{ }^{0.25} \operatorname{Pr}_{g}{ }^{0.25} \quad \text { Grashof }
\end{array}\right.
$$

For the interfacial condensation and heat transfer between the steam phase and the interface, a correlation like the following one will be used:

$$
h_{g \text { int }}=\frac{K_{g}}{D_{h g}} \quad N u_{g t \text { int }}=\frac{K_{g}}{D_{h g}} \quad 0.023 \operatorname{Re}_{g}{ }^{0.8} \operatorname{Pr}_{g}^{0.4}
$$

It is assumed that the steam flow regime is a fully developed turbulent flow and the main heat transfer mode is forced convection, hence, we are taking the Dittus-Boelter correlation for the convective heat transfer from the steam to the interface.

Introducing the definitions of the dimensionless numbers and for one cell $(j)$ and at one specific time:

$h_{g_{\text {int }}{ }_{j}}{ }^{+\Delta t}=\frac{K_{g_{j}}{ }^{t+\Delta t}}{D_{h g_{j}}{ }^{t}} 0.023\left(\left(\frac{\rho_{g} D_{h g}}{\mu_{g}}\right)_{j}^{t+\Delta t}\left(\frac{u_{g_{j-1 / 2}}+u_{g_{j+1 / 2}}}{2}\right)^{t+\Delta t}\right)^{0.8}$. 


$$
\left(\left(\frac{C p_{g} \mu_{g}}{k_{g}}\right)_{j}^{t+\Delta t}\right)^{0.4}
$$

\section{Dittus-Boelter:}

$$
h_{g_{w j}}{ }^{t+\Delta t}=0.023 \frac{K_{g_{j}}{ }^{t+\Delta t}}{D_{h g_{j}}{ }^{t+\Delta t}}\left(\left(\frac{\rho_{g} D_{h g}}{\mu_{g}}\right)_{j}^{t+\Delta t}\left(\frac{u_{g_{j-1 / 2}}+u_{g_{j+1 / 2}}}{2}\right)^{t+\Delta t}\right)^{0.8}\left(\left(\frac{C p_{g} \mu_{g}}{K_{g}}\right)_{j}^{t+\Delta t}\right)_{\text {C.41) }}^{0.4}(
$$

Grashof:

$$
h_{g w_{j}}{ }^{t+\Delta t}=0.59 \frac{K_{g_{j}}{ }^{t+\Delta t}}{D_{h g_{j}}{ }^{t+\Delta t}}\left(\left(\frac{9.81 \beta_{v}\left(T_{g_{j}}{ }^{t+\Delta t}-T_{w g_{j}}{ }^{t+\Delta t}\right) \rho_{g}{ }^{2} D_{h g}{ }^{3}}{\mu_{g}{ }^{2}}\right)_{j}^{t+\Delta t}\right)^{0.25}\left(\left(\frac{C p_{g} \mu_{g}}{K_{g}}\right)_{j}^{t+\Delta t}\right)^{0.25}
$$

At first the following constants for the interfacial heat transfer are defined hereafter:

$$
\begin{aligned}
& a=\frac{0.023 \cdot K_{l_{j}}^{t+\Delta t}}{D_{h l j}{ }^{t+\Delta t}} P_{\text {interf }} \Delta x \Delta t\left(T_{\text {sati } j}{ }^{t+\Delta t}-T_{g_{j}}^{t+\Delta t}\right) \\
& b=\left(\left(\frac{\rho_{g} D_{h g}}{\mu_{g}}\right)_{j}^{t+\Delta t}\left(\frac{u_{g_{j-1 / 2}}+u_{g_{j+1 / 2}}}{2}\right)^{t+\Delta t}\right)^{0.8} \\
& c=\left(\left(\frac{C p_{g} \mu_{g}}{k_{g}}\right)_{j}^{t+\Delta t}\right)^{0.4}
\end{aligned}
$$

Therefore the interfacial convective heat transfer as function of the previous expressions can be defined as follows:

$$
Q_{i g}{ }^{t+\Delta t}=a b c
$$


Now the derivative of the interfacial heat transfer with respect to the steam pressure is shown:

$$
\begin{aligned}
& \frac{\partial Q_{i g}{ }^{t+\Delta t}}{\partial P_{g_{j}}{ }^{t+\Delta t}}= \\
& 0.8 a c\left(\left(\frac{D_{h g}}{\mu_{g}}\right)_{j}^{t+\Delta t}\left(\frac{u_{g_{j-1 / 2}}+u_{g_{j+1 / 2}}}{2}\right)^{t+\Delta t}\right)^{0.8}\left(\rho_{g_{j}}{ }^{t+\Delta t}\right)^{0.8-1} \frac{\partial \rho_{g_{j}}{ }^{t+\Delta t}}{\partial P_{g_{j}}{ }^{t+\Delta t}} \\
& -0.8 a c\left(\left(\rho_{g} D_{h g}\right)_{j}^{t+\Delta t}\left(\frac{u_{g_{j-1 / 2}}+u_{g_{j}+1 / 2}}{2}\right)^{t+\Delta t}\right)^{0.8}\left(\mu_{g_{j}}{ }^{t+\Delta t}\right)^{-0.8-1} \frac{\partial \mu_{g_{j}}{ }^{t+\Delta t}}{\partial P_{g_{j}}{ }^{t+\Delta t}} \\
& +0.4 a b\left(\left(\frac{C p_{g}}{k_{g}}\right)_{j}^{t+\Delta t}\right)^{0.4}\left(\mu_{g_{j}}{ }^{t+\Delta t}\right)^{-0.4-1} \frac{\partial \mu_{g_{j}}{ }^{t+\Delta t}}{\partial P_{g_{j}}{ }^{t+\Delta t}} \\
& +0.4 a b\left(\left(\frac{\mu_{g}}{K_{g}}\right)_{j}^{t+\Delta t}\right)^{0.4}\left(C p_{g_{j}}{ }^{t+\Delta t}\right)^{-0.6} \frac{\partial C p_{g_{j}}{ }^{t+\Delta t}}{\partial P_{g_{j}}^{t+\Delta t}} \\
& \quad-0.4 a b\left(\left(C p_{g} \mu_{g}\right)_{j}^{t+\Delta t}\right)^{0.4}\left(K_{g_{j}}{ }^{t+\Delta t}\right)^{-1.4} \frac{\partial K_{g_{j}}{ }^{t+\Delta t}}{\partial P_{g_{j}}{ }^{t+\Delta t}}
\end{aligned}
$$

For the derivative of the interfacial heat transfer with respect to the steam temperature we have:

$$
\begin{aligned}
& \frac{\partial Q_{i g}{ }^{t+\Delta t}}{\partial T_{g_{j}}{ }^{t+\Delta t}}= \\
& A_{g i_{j}}{ }^{t} h_{g i_{j}}{ }^{t+\Delta t} \Delta t+A_{g i_{j}}{ }^{i}\left(T_{s a t}-T_{g}\right)_{j}^{t+\Delta t} \Delta t \frac{\partial h_{g i_{j}}{ }^{t+\Delta t}}{\partial T_{g_{j}}{ }^{t+\Delta t}}=A_{g i_{j}}{ }^{t}{ }_{g i_{j}}{ }^{t+\Delta t} \Delta t
\end{aligned}
$$




$$
\begin{aligned}
& +0.8 a c\left(\left(\frac{D_{h g}}{\mu_{g}}\right)_{j}^{t+\Delta t}\left(\frac{u_{g_{j-1 / 2}}+u_{g_{j+1 / 2}}}{2}\right)^{t+\Delta t}\right)^{0.8}\left(\rho_{g_{j}}^{t+\Delta t}\right)^{0.8-1} \frac{\partial \rho_{g_{j}}^{t+\Delta t}}{\partial T_{g_{j}}{ }^{t+\Delta t}} \\
& -0.8 a c\left(\left(\left(\frac{u_{g_{j-1 / 2}}+u_{g_{j+1 / 2}}}{2}\right)^{t+\Delta t} D_{h g} \rho_{g}\right)_{j}^{t+\Delta t}\right)^{0.8}\left(\mu_{g_{j}}{ }^{t+\Delta t}\right)^{-0.8-1} \frac{\partial \mu_{g_{j}}{ }^{t+\Delta t}}{\partial T_{g_{j}}^{t+\Delta t}} \\
& +0.4 a b\left(\left(\frac{C p_{g}}{k_{g}}\right)_{j}^{t+\Delta t}\right)^{0.4}\left(\mu_{g_{j}}{ }^{t+\Delta t}\right)^{-0.4-1} \frac{\partial \mu_{g_{j}}^{t+\Delta t}}{\partial T_{g_{j}}^{t+\Delta t}} \\
& +0.4 a b\left(\left(\frac{\mu_{g}}{K_{g}}\right)_{j}^{t+\Delta t}\right)^{0.4}\left(C p_{g_{j}}{ }^{t+\Delta t}\right)^{-0.6} \frac{\partial C p_{g_{j}}{ }^{t+\Delta t}}{\partial T_{g_{j}}^{t+\Delta t}} \\
& -0.4 a b\left(\left(C p_{g} \mu_{g}\right)_{j}^{t+\Delta t}\right)^{0.4}\left(K_{g_{j}}{ }^{t+\Delta t}\right)^{-1.4} \frac{\partial K_{g_{j}}{ }^{t+\Delta t}}{\partial T_{g_{j}}{ }^{t+\Delta t}}
\end{aligned}
$$

For the derivative of the interfacial heat transfer with respect to the liquid pressure differences we have:

$$
\begin{aligned}
& \frac{\partial Q_{i g}{ }^{t+\Delta t}}{\partial\left(P_{g_{j+1}}-P_{g_{j}}\right)^{t+\Delta t}}=+\operatorname{acdect}_{2}\left(\left(\frac{\rho_{g} D_{h g}}{\mu_{g}}\right)_{j}^{t+\Delta t}\right)^{c t_{2}}\left(\left(u_{g_{j+1 / 2}}\right)^{t+\Delta t}\right)^{c t_{2}-1} \frac{\partial u_{g_{j+1 / 2}}^{t+\Delta t}}{\partial\left(P_{g_{j+1}}-P_{g_{j}}\right)^{t+\Delta t}} \\
& \text { (C.49) } \\
& \frac{\partial Q_{i g}{ }^{t+\Delta t}}{\partial\left(P_{g_{j}}-P_{g_{j-1}}\right)^{t+\Delta t}}=+ \text { acdect }_{2}\left(\left(\frac{\rho_{g} D_{h g}}{\mu_{g}}\right)_{j}^{t+\Delta t}\right)^{c t_{2}}\left(\left(u_{g_{j-1 / 2}}\right)^{t+\Delta t}\right)^{c t_{2}-1} \frac{\partial u_{g_{j-1 / 2}}{ }^{t+\Delta t}}{\partial\left(P_{g_{j}}-P_{g_{j-1}}\right)^{t+\Delta t}}
\end{aligned}
$$

The following expressions for the heat transfer to the wall are defined hereafter: 


$$
\begin{aligned}
& a_{2}=A_{g w_{j}}{ }^{t}\left(T_{w g}-T_{w}\right)_{j}^{t+\Delta t} \Delta t 0.023 \frac{K_{g_{j}}{ }^{t+\Delta t}}{D_{h_{g}{ }_{j}}{ }^{t}} \\
& b_{2}=\left(\left(\frac{D_{h g}}{\mu_{g}}\right)_{j}^{t+\Delta t}\left(\frac{u_{g_{j-1 / 2}}+u_{g_{j+1 / 2}}}{2}\right)^{t+\Delta t}\right)^{0.8} \\
& c_{2}=\left(\left(\frac{C p_{g} \mu_{g}}{K_{g}}\right)_{j}^{t+\Delta t}\right)^{0.4} \\
& a_{3}=A_{g w_{j}}{ }^{t}\left(T_{w g}-T_{g}\right)_{j}^{t+\Delta t} \Delta t 0.59 \frac{K_{g_{j}}{ }^{t+\Delta t}}{D_{h g_{j}}{ }^{t+\Delta t}} \\
& b_{3}=\left(\left(\frac{9.81 \beta_{g}\left(T_{g_{j}}{ }^{t+\Delta t}-T_{w g}{ }^{t+\Delta t}\right) \rho_{g}{ }^{2} D_{h g}{ }^{3}}{\mu_{g}{ }^{2}}\right)_{j}^{t+\Delta t}\right)^{0.25} \\
& c_{3}=\left(\left(\frac{C p_{g} \mu_{g}}{K_{g}}\right)_{j}^{t+\Delta t}\right)^{0.25}
\end{aligned}
$$

The convective heat interchaned with the wall can be defined now as a function of the previous constants:

$$
\begin{aligned}
& q_{w g}{ }^{t+\Delta t}=a_{2} b_{2} c_{2} \quad \text { Dittus-Boelter } \\
& q_{w g}{ }^{t+\Delta t}=a_{3} b_{3} c_{3} \quad \text { Grashof }
\end{aligned}
$$

So, the derivative of the heat transferred with the wall with respect to the steam pressure is: 
- FOR THE DITTUS -BOELTER CORRELATION WE MAY WRITE:

$$
\begin{aligned}
& \frac{\partial Q_{w g}{ }^{t+\Delta t}}{\partial P_{g_{j}}{ }^{t+\Delta t}}= \\
& a_{2} c_{2} 0.8\left(\left(\frac{D_{h g}}{\mu_{g}}\right)_{j}^{t+\Delta t}\left(\frac{u_{g_{j-1 / 2}}+u_{g_{j+1 / 2}}}{2}\right)^{t+\Delta t}\right)^{0.8}\left(\rho_{g_{j}}{ }_{j}\right)^{-0.2} \frac{\partial \rho_{g_{j}}^{t+\Delta t}}{\partial P_{g_{j}}{ }^{t+\Delta t}} \\
& -a_{2} c_{2} 0.8\left(\left(\rho_{g} D_{h g}\right)_{j}^{t+\Delta t}\left(\frac{u_{g_{j-1 / 2}}+u_{g_{j+1 / 2}}}{2}\right)^{t+\Delta t}\right)^{0.8}\left(\mu_{g_{j}}^{t+\Delta t}\right)^{-1.8} \frac{\partial \mu_{g_{j}}^{t+\Delta t}}{\partial P_{g_{j}}{ }^{t+\Delta t}} \\
& \left.+a_{2} b_{2} 0.4\left(\frac{C p_{g}}{K_{g}}\right)_{j}^{t+\Delta t}\right)^{0.4}\left(\mu_{g_{j}}^{t+\Delta t}\right)^{-0.6} \frac{\partial \mu_{g_{j}}^{t+\Delta t}}{\partial P_{g_{j}}{ }^{t+\Delta t}} \\
& +a_{2} b_{2} 0.4\left(\left(\frac{\mu_{g}}{K_{g}}\right)_{j}^{t+\Delta t}\right)^{0.4}\left(C p_{g_{j}}{ }^{t+\Delta t}\right)^{-0.6} \frac{\partial C p_{g_{j}}{ }^{t+\Delta t}}{\partial P_{g_{j}}{ }^{t+\Delta t}} \\
& -a_{2} b_{2} 0.4\left(\left(C p_{g} \mu_{g}\right)_{j}^{t+\Delta t}\right)^{0.4}\left(K_{g_{j}}{ }^{t+\Delta t}\right)^{-1.4} \frac{\partial K_{g_{j}}{ }^{t+\Delta t}}{\partial P_{g_{j}}{ }^{t+\Delta t}}
\end{aligned}
$$

- FOR THE GRASHOF CORRELATION WE MAY WRITE:

$\frac{\partial Q_{w g}{ }^{t+\Delta t}}{\partial P_{g_{j}}{ }^{t+\Delta t}}=$ 
$a_{3} c_{3} 0.5\left(\left(\frac{9.81 \beta_{g}\left(T_{g_{j}}{ }^{t+\Delta t}-T_{w g}{ }^{t+\Delta t}\right) D_{h l}{ }^{3}}{\mu_{g}{ }^{2}}\right)_{j}^{t+\Delta t}\right)^{0.25}\left(\rho_{g_{j}}{ }^{t+\Delta t}\right)^{-0.5} \frac{\partial \rho_{g_{j}}{ }^{t+\Delta t}}{\partial P_{g_{j}}{ }^{t+\Delta t}}+$

$-a_{3} c_{3} 0.5\left(\left(9.81 \beta_{g}\left(T_{g_{j}}^{t+\Delta t}-T_{w g_{j}}{ }^{t+\Delta t}\right) \rho_{g}{ }^{2} D_{h g}{ }^{3}\right)_{j}^{t+\Delta t}\right)^{0.25}\left(\mu_{g_{j}}{ }^{t+\Delta t}\right)^{-1.5} \frac{\partial \mu_{g_{j}}^{t+\Delta t}}{\partial P_{g_{j}}^{t+\Delta t}}$

$+a_{3} c_{3} 0.25\left(\left(\frac{9.81 \rho_{g}{ }^{2} \beta_{g} D_{h g}{ }^{3}}{\mu_{g}{ }^{2}}\right)_{j}^{t+\Delta t}\right]^{0.25}\left(T_{g_{j}}{ }^{t+\Delta t}-T_{w g_{j}}{ }^{t+\Delta t}\right)^{-0.75}$

$+a_{3} b_{3} 0.25\left(\left(\frac{C p_{g}}{K_{g}}\right)_{j}^{t+\Delta t}\right)^{0.25}\left(\mu_{g_{j}}{ }^{t+\Delta t}\right)^{-0.75} \frac{\partial \mu_{g_{j}}{ }^{t+\Delta t}}{\partial P_{g_{j}}{ }^{t+\Delta t}}$

$+a_{3} b_{3} 0.25\left(\left(\frac{\mu_{g}}{K_{g}}\right)_{j}^{t+\Delta t}\right)^{0.25}\left(C p_{g_{j}}{ }^{t+\Delta t}\right)^{-0.75} \frac{\partial C p_{g_{j}}{ }^{t+\Delta t}}{\partial P_{g_{j}}{ }^{t+\Delta t}}$

$$
-a_{3} b_{3} 0.4\left(\left(C p_{g} \mu_{g}\right)_{j}^{t+\Delta t}\right) 0.25\left(K_{g_{j}}{ }^{t+\Delta t}\right)^{-1.25} \frac{\partial K_{g_{j}}{ }^{t+\Delta t}}{\partial P_{g_{j}}{ }^{t+\Delta t}}
$$

The derivative of the heat transferred with the wall with respect to the steam temperature is shown next, for the Dittus-Boelter and for the Grashof correlation:

\section{- FOR THE DITTUS -BOELTER CORRELATION WE MAY WRITE:}

$$
\frac{\partial Q_{w g}{ }^{t+\Delta t}}{\partial T_{g_{j}}{ }^{t+\Delta t}}=
$$




$$
\begin{aligned}
& A_{g w_{j}}{ }^{t} h_{g w_{j}}{ }^{t+\Delta t} \Delta t+A_{g w_{j}}{ }^{t}\left(T_{g}-T_{w g}\right){ }_{j}^{t+\Delta t} \Delta t 0.023 \frac{1}{D_{h g_{j}}{ }^{t+\Delta t}} \frac{\partial K_{g_{j}}^{t+\Delta t}}{\partial T_{g_{j}}{ }^{t+\Delta t}} b_{2} c_{2} \\
& +a_{2} c_{2} 0.8\left(\left(\frac{D_{h g}}{\mu_{g}}\right)_{j}^{t+\Delta t}\left(\frac{u_{g_{j-1 / 2}}+u_{g_{j+1 / 2}}}{2}\right)^{t+\Delta t}\right)^{0.8}\left(\rho_{g_{j}}^{t+\Delta t}\right)^{-0.2} \frac{\partial \rho_{g_{j}}{ }^{t+\Delta t}}{\partial T_{g_{j}}{ }^{t+\Delta t}} \\
& \left.-a_{2} c_{2} 0.8\left(\rho_{g} D_{h g}\right)_{j}^{t+\Delta t}\left(\frac{u_{g_{j-1 / 2}}+u_{g_{j+1 / 2}}}{2}\right)^{t+\Delta t}\right)^{0.8}\left(\mu_{g_{j}}{ }^{t+\Delta t}\right)^{-1.8} \frac{\partial \mu_{g_{j}}{ }^{t+\Delta t}}{\partial T_{g_{j}}{ }^{t+\Delta t}} \\
& +a_{2} b_{2} 0.4\left(\left(\frac{\mu_{g}}{K_{g}}\right)_{j}^{t+\Delta t}\right)^{0.4}\left(C p_{g_{j}}{ }^{t+\Delta t}\right)^{-0.6} \frac{\partial C p_{g_{j}}{ }^{t+\Delta t}}{\partial T_{g_{j}}{ }^{t+\Delta t}} \\
& +a_{2} b_{2} 0.4\left(\left(\frac{C p_{g}}{K_{g}}\right)_{j}^{t+\Delta t}\right)^{0.4}\left(\mu_{g_{j}}{ }^{t+\Delta t}\right)^{-0.6} \frac{\partial \mu_{g_{j}}{ }^{t+\Delta t}}{\partial T_{g_{j}}{ }^{t+\Delta t}} \\
& -a_{2} b_{2} 0.4\left(\left(C p_{g} \mu_{g}\right)_{j}^{t+\Delta t}\right)^{0.4}\left(K_{g_{j}}{ }_{j}+\Delta t\right)^{-1.4} \frac{\partial K_{g_{j}}{ }^{t+\Delta t}}{\partial T_{g_{j}}{ }_{j}+\Delta t}
\end{aligned}
$$

- FOR THE GRASHOF CORRELATION WE MAY WRITE:

$$
\begin{aligned}
& \frac{\partial Q_{w g}{ }^{t+\Delta t}}{\partial T_{g_{j}}{ }^{t+\Delta t}}= \\
& A_{g w_{j}}{ }^{t} h_{g w_{j}}{ }^{t+\Delta t} \Delta t+A_{g w_{j}}{ }_{j}\left(T_{g}-T_{w g}\right)_{j}^{t+\Delta t} \Delta t 0.59 \frac{1}{D_{h_{j}}{ }_{j}+\Delta t} \frac{\partial K_{g_{j}}{ }^{t+\Delta t}}{\partial T_{g_{j}}{ }^{t+\Delta t}} b_{3} c_{3}
\end{aligned}
$$




$$
\begin{aligned}
& a_{3} c_{3} 0.5\left(\left(\frac{9.81 \beta_{g}\left(T_{g_{j}}{ }^{t+\Delta t}-T_{w g_{j}}{ }^{t+\Delta t}\right) D_{h g}{ }^{3}}{\mu_{g}{ }^{2}}\right)_{j}^{t+\Delta t}\right)^{0.25}\left(\rho_{g_{j}}{ }^{t+\Delta t}\right)^{-0.5} \frac{\partial \rho_{g_{j}}{ }^{t+\Delta t}}{\partial T_{g_{j}}{ }^{t+\Delta t}} \\
& -a_{3} c_{3} 0.5\left(\left(9.81 \beta_{g}\left(T_{g_{j}}{ }^{t+\Delta t}-T_{w g_{j}}{ }^{t+\Delta t}\right) \rho_{g}{ }^{2} D_{h_{g}}{ }^{3}\right)_{j}^{t+\Delta t}\right)^{0.25}\left(\mu_{g_{j}}{ }^{t+\Delta t}\right)^{-0.5} \frac{\partial \mu_{g_{j}}{ }^{t+\Delta t}}{\partial T_{g_{j}}{ }^{t+\Delta t}} \\
& +a_{3} b_{3} 0.25\left(\left(\frac{\mu_{g}}{K_{g}}\right)_{j}^{t+\Delta t}\right)^{0.25}\left(C p_{g_{j}}{ }^{t+\Delta t}\right)^{-0.75} \frac{\partial C p_{g_{j}}{ }^{t+\Delta t}}{\partial T_{g_{j}}{ }^{t+\Delta t}} \\
& +a_{3} b_{3} 0.25\left(\left(\frac{C p_{g}}{K_{g}}\right)_{j}^{t+\Delta t}\right)^{0.25}\left(\mu_{g_{j}}{ }^{t+\Delta t}\right)^{-0.75} \frac{\partial \mu_{g_{j}}{ }^{t+\Delta t}}{\partial T_{g_{j}}{ }^{t+\Delta t}} \\
& -a_{3} b_{3} 0.25\left(\left(C p_{g} \cdot \mu_{g}\right)_{j}^{t+\Delta t}\right)^{0.25}\left(K_{g_{j}}{ }^{t+\Delta t}\right)^{-1.25} \frac{\partial K_{g_{j}}{ }^{t+\Delta t}}{\partial T_{g_{j}}{ }^{t+\Delta t}}
\end{aligned}
$$




\section{APPENDIX D}

\section{CALCULATION OF THE INTERFACIAL CONDENSATION AND ITS DERIVATIVES}

In this appendix it is shown how we are going to calculate the condensed mass at one certain time step and its derivatives which we need to solve our thermal-hydraulic problem, for each phase.

In our countercurrent problem the biphasic field is solved separately and an update of the relations between both fields is considered at the end of each time step. This means that we need to calculate the condensation and its derivatives, for one time step, and for each phase, as we are calculating two fields. Once time for the steam and once for the liquid phase.

Next, these definitions will be shown for each phase separately:

\section{D.1 LIQUID PHASE}

The condensation equation that will be used for the liquid phase is the following one, based on the assumption that both phases interchange heat with the interface [TRACE manual, "Interfacial heat transfer models "].

$$
\Phi_{l j}{ }_{l+\Delta t}(K g)=\frac{Q_{i l j}{ }^{t+\Delta t}+Q_{i g_{j}}{ }^{t+\Delta t}}{h_{g i_{j}}{ }^{t+\Delta t}-h_{l i j}{ }^{t+\Delta t}}
$$

It can be observed that the condensation mass is defined in $\mathrm{Kg}$. This is the amount of steam mass which is condensed in one time step, at the time step $t$ at a given node $j$.

As we saw before in Appendix A, the expression for the liquid interfacial convective heat transfer due to condensation is:

$$
Q_{l i j}^{t+\Delta t}=A_{i j}^{t} \cdot h_{l \text { int } j}^{t+\Delta t}\left(T_{\text {sati }}-T_{l}\right)_{j}^{t+\Delta t} \Delta t \quad(\mathrm{~J})
$$


The expression for the steam interfacial convective heat transfer is as follows:

$$
Q_{g i j}{ }^{t+\Delta t}=A_{i j}^{t} \cdot h_{g \text { int }}{ }_{j}^{t+\Delta t}\left(T_{\text {sati }}-T_{g}\right)_{j}^{t+\Delta t} \Delta t(\mathrm{~J})
$$

where $T_{g}$ is the steam temperature $(\mathrm{K})$ at the corresponding pressure, $\mathrm{T}_{1}$ the liquid temperature $(\mathrm{K})$ in the centre of the node, $T_{\text {sati }}$ is the interface temperature which is saturated at the steam pressure.

As can be seen in the Equation (D.1), we are using the amount of heat which is transferred between phases to evaluate how much mass is condensed from the steam phase to liquid phase.

For the interfacial heat transfer we will use different correlations to calculate the liquid and the steam condensation rate.

For calculating the heat transfer from the steam to the interface the well known DittusBoelter correlation [112] is used, since a fully developed turbulent flow and a forced convection heat transfer mode is supposed for the steam:

$$
h_{g \text { int }}=\frac{K_{g}}{D_{h g}} \quad N u_{g t \text { int }}=\frac{K_{g}}{D_{h g}} \quad 0.023 \operatorname{Re}_{g}{ }^{0.8} \operatorname{Pr}_{g}^{0.4}
$$

For calculating the heat transfer from the liquid to the interface different correlations are used, depending on the flow regime that we are modelling, which have the following pattern:

$$
h_{l \mathrm{int}}=\frac{K_{l}}{D_{h l}} N u_{l \mathrm{int}}=\frac{K_{l}}{D_{h l}} c_{1} \operatorname{Re}_{l}{ }^{c 2} \operatorname{Re}_{g}{ }^{c 3} J a^{c 4} \operatorname{Pr}_{l}{ }^{c 5}
$$

where $h_{\text {lint }}$ is the liquid interfacial heat transfer coefficient $\left(W / \mathrm{Km}^{2}\right), h_{g \text { int }}$ is the steam interfacial heat transfer coefficient $\left(W / \mathrm{Km}^{2}\right), \mathrm{K}_{\mathrm{l}}$ is the liquid conductivity $\left(\mathrm{W} / \mathrm{Km}^{2}\right), \mathrm{K}_{\mathrm{g}}$ is the conductivity of the steam ( $W / K m), \mathrm{Dh}_{\mathrm{l}}$ is the liquid hydraulic diameter $(m), \mathrm{Dh}_{\mathrm{g}}$ is 
the steam hydraulic diameter $(m)$, Re is the Reynolds number, Ja is the Jakob number, and Pr is Prandtl number.

For calculating the interfacial heat transfer form the liquid to the interface different correlations are used, where c1, c2, c3, c4, c5, are different constants which change depending on the flow regime that we are studying, the pipe inclination, etc.

We are defining now some constants, just to make the derivative equations more legible.

These are:

$$
\begin{aligned}
& a=\frac{c_{1} K_{l j}^{t+\Delta t}}{D_{h l_{j}}{ }^{t+\Delta t} h_{f g_{j}}{ }^{t+\Delta t}} P_{\text {int } e r f} \Delta x \Delta t\left(T_{\text {sati } j}{ }^{t+\Delta t}-T_{l j}^{t+\Delta t}\right) \\
& b=\left(\left(\frac{\rho_{l} D_{h l}}{\mu_{l}}\right)_{j}^{t+\Delta t}\left(\frac{u_{l j-1 / 2}+u_{l j+1 / 2}}{2}\right)^{t+\Delta t}\right)^{C_{2}} \\
& c=\left(\left(\frac{\rho_{g} D_{h g}}{\mu_{g}}\right)_{j}^{t+\Delta t}\left(\frac{u_{g_{j-1 / 2}}+u_{g_{j+1 / 2}}}{2}\right)^{t+\Delta t}\right)^{C_{3}} \\
& d=\left(\left(\frac{C p_{l} \rho_{l}\left(T_{g}-T_{l}\right)}{\rho_{g} h_{f g}}\right)_{j}^{t+\Delta t}\right)^{c_{4}} \\
& e=\left(\left(\frac{C p_{l} \mu_{l}}{k_{l}}\right)_{j}^{t+\Delta t}\right)^{C 5}
\end{aligned}
$$

We express now the liquid condensation during one time step at the interface of node $\mathrm{j}$ as a function of the previous constants;

$$
\Phi_{l}\left(K_{g}\right)=a b c d e+\frac{Q_{i g_{j}}{ }^{t+\Delta t}}{h_{g i j}{ }^{t+\Delta t}-h_{l i j}{ }^{t+\Delta t}}
$$




\section{D.1.1 DERIVATIVE OF THE LIQUID CONDENSATION WITH RESPECT TO THE LIQUID PRESSURE}

$$
\begin{aligned}
& \frac{\partial \Phi_{l j}^{t+\Delta t}}{\partial P_{l j}^{t+\Delta t}}=-h_{l \text { int } j}{ }^{t+\Delta t}\left(T_{\text {sati } j}{ }^{t+\Delta t}-T_{l_{j}}^{t+\Delta t}\right) P_{\text {int erf }} \Delta x \Delta t \cdot\left(h_{f g_{j}}{ }^{t+\Delta t}\right)^{-2} \frac{\partial h_{f g_{j}}^{t+\Delta t}}{\partial P_{l j}^{t+\Delta t}} \\
& +\operatorname{acdec}_{2}\left(\left(\frac{D_{h l}}{\mu_{l}}\right)_{j}^{t+\Delta t}\left(\frac{u_{l j-1 / 2}+u_{l j+1 / 2}}{2}\right)^{t+\Delta t}\right)^{C 2}\left(\rho_{l_{j}}^{t+\Delta t}\right)^{C 2-1} \frac{\partial \rho_{l_{j}}^{t+\Delta t}}{\partial P_{l_{j}}^{t+\Delta t}} \\
& -\operatorname{acde} C_{2}\left(\left(\rho_{l} D_{h l}\right)_{j}^{t+\Delta t}\left(\frac{u_{l j-1 / 2}+u_{l j+1 / 2}}{2}\right)^{t+\Delta t}\right)^{C 2}\left(\mu_{l_{j}}^{t+\Delta t}\right)^{C 2-1} \frac{\partial \mu_{l j}^{t+\Delta t}}{\partial P_{l j}^{t+\Delta t}} \\
& -a b c e \cdot C_{4}\left(\left(\frac{C p_{l}\left(T_{g}-T_{l}\right)}{\rho_{g} h_{f g}}\right)_{j}^{t+\Delta t}\right)^{C 4}\left(\rho_{l_{j}}^{t+\Delta t}\right)^{C 4-1} \frac{\partial \rho_{l j}^{t+\Delta t}}{\partial P_{l_{j}}^{t+\Delta t}} \\
& -a b c e \cdot C_{4}\left(\left(\frac{C p_{l} \rho_{l}\left(T_{g}-T_{l}\right)}{\rho_{g}}\right)_{j}^{t+\Delta t}\right)^{C 4}\left(h_{f g}{ }^{t+\Delta t}\right)^{-C 4-1} \frac{\partial h_{f g}{ }_{j}{ }^{t+\Delta t}}{\partial P_{l_{j}}^{t+\Delta t}} \\
& +\operatorname{abcec}_{4}\left(\left(\frac{\rho_{l}\left(T_{g}-T_{l}\right)}{\rho_{g} h_{f g}}\right)_{j}^{t+\Delta t}\right)^{C 4}\left(C p_{l_{j}}^{t+\Delta t}\right)^{C 4-1} \frac{\partial C p_{l_{j}}^{t+\Delta t}}{\partial P_{l_{j}}^{t+\Delta t}} \\
& +\operatorname{abcd} C_{5}\left(\left(\frac{\mu_{l}}{k_{l}}\right)_{j}^{t+\Delta t}\right)^{C 5}\left(C p_{l_{j}}^{t+\Delta t}\right)^{C s-1} \frac{\partial C p_{l_{j}}^{t+\Delta t}}{\partial P_{l_{j}}^{t+\Delta t}} \\
& +\operatorname{abcd} C_{5}\left(\left(\frac{C p_{l}}{k_{l}}\right)_{j}^{t+\Delta t}\right)^{C 5}\left(\mu_{l j}^{t+\Delta t}\right)^{C s-1} \frac{\partial \mu_{l j}^{t+\Delta t}}{\partial P_{l j}^{t+\Delta t}}
\end{aligned}
$$


$-\operatorname{abcd} C_{5}\left(\left(C p_{l} \mu_{l}\right)_{j}^{t+\Delta t}\right)^{C 5}\left(k_{l j}^{t+\Delta t}\right)^{-C 5-1} \frac{\partial k_{l j}^{t+\Delta t}}{\partial P_{l j}^{t+\Delta t}}$

\section{D.1.2 DERIVATIVE OF THE LIQUID CONDENSATION WITH} RESPECT TO THE LIQUID PRESSURE DIFFERENCES

$$
\begin{aligned}
& \frac{\partial \Phi_{l j}^{t+\Delta t}}{\partial\left(P_{l j}-P_{l j-1}\right)^{t+\Delta t}}=\operatorname{acdeC} 2\left(\left(\frac{\rho_{l} D_{h l}}{2 \mu_{l}}\right)_{j}^{t+\Delta t}\right)^{C 2}\left(u_{l j-1 / 2}^{t+\Delta t}+u_{l j+1 / 2}^{t+\Delta t}\right)^{c 2-1} \frac{\partial u_{l j-1 / 2}^{t+\Delta t}}{\partial\left(P_{l j}-P_{l j-1}\right)^{t+\Delta t}}( \\
& \frac{\partial \Phi_{l j}^{t+\Delta t}}{\partial\left(P_{l j+1}-P_{l j}\right)^{t+\Delta t}}=\operatorname{acdeC}_{2}\left(\left(\frac{\rho_{l} D_{h l}}{2 \mu_{l}}\right)_{j}^{t+\Delta t}\right)^{C 2}\left(u_{l j-1 / 2}^{t+\Delta t}+u_{l j+1 / 2}^{t+\Delta t}\right)^{C 2-1} \frac{\partial u_{l_{j+1 / 2}^{t+\Delta t}}}{\partial\left(P_{l j+1}-P_{l j}\right)^{t+\Delta t}}(\mathrm{D} .1
\end{aligned}
$$

\section{D.1.3 DERIVATIVE OF THE LIQUID CONDENSATION WITH RESPECT TO THE LIQUID TEMPERATURE}

$$
\begin{aligned}
& \frac{\partial \Phi_{l j}^{t+\Delta t}}{\partial T_{l j}^{t+\Delta t}}=\frac{h_{l \text { int } j}{ }^{t+\Delta t}}{h_{f g}^{\prime}} P_{\text {int }{ }_{e r f}} \Delta x \Delta t \\
& -h_{l \text { int } j}{ }^{t+\Delta t}\left(T_{\text {sati } j}{ }^{t+\Delta t}-T_{l j}^{t+\Delta t}\right) P_{\text {int } e r f} \Delta x \Delta t\left(h_{f g_{j}}{ }^{t+\Delta t}\right)^{-2} \frac{\partial h_{f g_{j}}{ }^{t+\Delta t}}{\partial T_{l_{j}}^{t+\Delta t}} \\
& +\frac{1.2 e-7}{D_{h l_{j}}^{t+\Delta t} h_{f_{j}}{ }^{t+\Delta t}} P_{\text {interf }} \Delta x \Delta t\left(T_{g_{j}}{ }^{t+\Delta t}-T_{l_{j}}^{t+\Delta t}\right) b c d e \frac{\partial K_{l j}^{t+\Delta t}}{\partial T_{l_{j}}^{t+\Delta t}} \\
& +\operatorname{acde} 1.32\left(\left(\frac{D_{h l}}{\mu_{l}}\right)_{j}^{t+\Delta t}\left(\frac{u_{l j-1 / 2}+u_{l j+1 / 2}}{2}\right)^{t+\Delta t}\right)^{1.32}\left(\rho_{l j}^{t+\Delta t}\right)^{0.32} \frac{\partial \rho_{l j}^{t+\Delta t}}{\partial T_{l j}^{t+\Delta t}}
\end{aligned}
$$




$$
\begin{aligned}
& \left.-a c d e \cdot C_{2}\left(\left(\frac{u_{l j-1 / 2}+u_{l j+1 / 2}}{2}\right)^{t+\Delta t} \rho_{l} D_{h l}\right)_{j}^{t+\Delta t}\right)^{C 2}\left(\mu_{l_{j}}^{t+\Delta t}\right)^{-C 2-1} \frac{\partial \mu_{l_{j}}^{t+\Delta t}}{\partial T_{l_{j}}^{t+\Delta t}} \\
& +\operatorname{abce} C_{4}\left(\left(\frac{C p_{l}\left(T_{g}-T_{l}\right)}{\rho_{g} h_{f g}}\right)_{j}^{t+\Delta t}\right)^{C 4}\left(\rho_{l j}^{t+\Delta t}\right)^{C 4-1} \frac{\partial \rho_{l_{j}}^{t+\Delta t}}{\partial T_{l_{j}}^{t+\Delta t}} \\
& -\operatorname{abce} C_{4}\left(\left(\frac{C p_{l} \rho_{l}\left(T_{g}-T_{l}\right)}{\rho_{g}}\right)_{j}^{t+\Delta t}\right)^{C 4}\left(h_{f g}{ }_{j}{ }^{t+\Delta t}\right)^{-C 4-1} \frac{\partial h_{f g_{j}}{ }^{t+\Delta t}}{\partial T_{l j}^{t+\Delta t}} \\
& +\operatorname{abce} C_{4}\left(\left(\frac{\rho_{l}\left(T_{g}-T_{l}\right)}{\rho_{g} h_{f g}}\right)_{j}^{t+\Delta t}\right)^{C 4}\left(C p_{l j}{ }_{l+\Delta t}\right)^{C 4-1} \frac{\partial C p_{l j}{ }_{l+\Delta t}}{\partial T_{l j}^{t+\Delta t}} \\
& -\operatorname{abcec}_{4}\left(\left(\frac{C p_{l} \rho_{l}}{\rho_{g} h_{f g}}\right)_{j}^{t+\Delta t}\right)^{C 4}\left(\left(T_{g}-T_{l}\right)_{j}^{t+\Delta t}\right)^{C 4-1} \\
& +a b c d C_{5}\left(\left(\frac{\mu_{l}}{k_{l}}\right)_{j}^{t+\Delta t}\right)^{C 5}\left(C p_{l_{j}}^{t+\Delta t}\right)^{C 5-1} \frac{\partial C p_{l_{j}}{ }^{t+\Delta t}}{\partial T_{l j}^{t+\Delta t}} \\
& +\operatorname{abcd} C_{5}\left(\left(\frac{C p_{l}}{k_{l}}\right)_{j}^{t+\Delta t}\right)^{C 5}\left(\mu_{l j}^{t+\Delta t}\right)^{C 5-1} \frac{\partial \mu_{l j}^{t+\Delta t}}{\partial T_{l j}^{t+\Delta t}} \\
& +a b c d C_{5}\left(\left(\frac{C p_{l}}{k_{l}}\right)_{j}^{t+\Delta t}\right)^{C 5}\left(\mu_{l_{j}}^{t+\Delta t}\right)^{C 5-1} \frac{\partial \mu_{l_{j}}^{t+\Delta t}}{\partial P_{l_{j}}^{t+\Delta t}} \\
& -\operatorname{abcd} C 5\left(\left(C p_{l} \mu_{l}\right)_{j}^{t+\Delta t}\right)^{C 5}\left(k_{l j}^{t+\Delta t}\right)^{-C 5-1} \frac{\partial k_{l j}^{t+\Delta t}}{\partial T_{l j}^{t+\Delta t}}
\end{aligned}
$$




\section{D.2 STEAM PHASE}

The condensation equation that will be used for the steam phase is the following one, based on the assumption that both phases interchange heat with the interface [TRACE manual, "Interfacial heat transfer models "].

$$
\Phi_{g_{j}}{ }^{t+\Delta t}(K g)=-\frac{Q_{i j_{j}}{ }^{t+\Delta t}+Q_{i g_{j}}{ }^{t+\Delta t}}{h_{g i j}{ }^{t+\Delta t}-h_{l i j}{ }^{t+\Delta t}}
$$

It can be observed that the condensation mass is defined in $\mathrm{Kg}$. This is the amount of steam mass which is condensed in one time step, at the time step $t$ at a given node $\mathrm{j}$.

As we saw before in Appendix A, the expression for the liquid interfacial convective heat transfer due to condensation is:

$$
Q_{l i j}{ }^{t+\Delta t}=A_{i j}^{t} \cdot h_{l \text { int } j}{ }^{t+\Delta t}\left(T_{\text {sati }}-T_{l}\right)_{j}^{t+\Delta t} \Delta t \quad(\mathrm{~J})
$$

The expression for the steam interfacial convective heat transfer is as follows:

$$
Q_{g i j}{ }^{t+\Delta t}=A_{i j}^{t} \cdot h_{g \text { int }{ }_{j}}{ }^{++\Delta t}\left(T_{\text {sati }}-T_{g}\right)_{j}^{t+\Delta t} \Delta t(\mathrm{~J})
$$

where $T_{g}$ is the steam temperature $(\mathrm{K})$ at the corresponding pressure, $\mathrm{T}_{1}$ the liquid temperature $(\mathrm{K})$ in the centre of the node, $T_{\text {sati }}$ is the interface temperature which is saturated at the steam pressure.

As can be seen in the Equation (D.16), is being used the amount of heat which is transferred between phases to evaluate how much mass is condensed from the steam phase to liquid phase.

For the interfacial heat transfer different correlations are used to calculate the liquid and the steam condensation.

For calculating the heat transfer from the steam to the interface the well known DittusBoelter correlation [112] is used since it is supposed a fully developed turbulent flow and a forced convection heat transfer mode for the steam: 


$$
h_{g \text { int }}=\frac{K_{g}}{D_{h g}} \quad N u_{g t \text { int }}=\frac{K_{g}}{D_{h g}} \quad 0.023 \operatorname{Re}_{g}^{0.8} \operatorname{Pr}_{g}^{0.4}
$$

For the heat transfer from the liquid to the interface, we use different correlations depending on the flow regime we are modelling, which have the following pattern:

$$
h_{l \text { int }}=\frac{K_{l}}{D_{h l}} N u_{l \text { int }}=\frac{K_{l}}{D_{h l}} c t_{1} \operatorname{Re}_{l}{ }^{c t_{2}} \operatorname{Re}_{g}{ }^{c t_{3}} J a{ }^{c t_{4}} \operatorname{Pr}_{l} c t_{5}
$$

where $h_{\text {lint }}$ is the liquid interfacial heat transfer coefficient $\left(W / \mathrm{Km}^{2}\right), h_{g \text { int }}$ is the steam interfacial heat transfer coefficient $\left(W / \mathrm{Km}^{2}\right), \mathrm{K}_{\mathrm{l}}$ is the liquid conductivity $\left(\mathrm{W} / \mathrm{Km}^{2}\right), \mathrm{K}_{\mathrm{g}}$ is the conductivity of the steam ( $W / K m), \mathrm{Dh}_{\mathrm{l}}$ is the liquid hydraulic diameter $(m), \mathrm{Dh}_{\mathrm{g}}$ is the steam hydraulic diameter $(m)$, Re is the Reynolds number, Ja is the Jakob number, and Pr is Prandtl number.

For calculating the interfacial heat transfer form the liquid to the interface different correlations can be used, where $\mathrm{c} 1, \mathrm{c} 2, \mathrm{c} 3, \mathrm{c} 4, \mathrm{c} 5$, are different constants which change depending on the flow regime that we are studying, the pipe inclination, etc.

There are being defined now some constants, just to make the derivative equations more legible. These are:

$$
\begin{aligned}
& a=\frac{c_{1} K_{l_{j}}^{t+\Delta t}}{D_{h l j}{ }^{t+\Delta t} h_{f_{j}}{ }^{t+\Delta t}} P_{\text {interf }} \Delta x \Delta t\left(T_{\text {sati }}{ }^{t+\Delta t}-T_{g_{j}}^{t+\Delta t}\right) \\
& b=\left(\left(\frac{\rho_{l} D_{h l}}{\mu_{l}}\right)_{j}^{t+\Delta t}\left(\frac{u_{l j-1 / 2}+u_{l j+1 / 2}}{2}\right)^{t+\Delta t}\right)^{c t_{2}} \\
& c=\left(\left(\frac{\rho_{g} D_{h g}}{\mu_{g}}\right)_{j}^{t+\Delta t}\left(\frac{u_{g_{j-1 / 2}}+u_{g_{j+1 / 2}}}{2}\right)^{t+\Delta t}\right)^{c t_{3}}
\end{aligned}
$$




$$
\begin{aligned}
& d=\left(\left(\frac{C p_{l} \rho_{l}\left(T_{g}-T_{l}\right)}{\rho_{g} h_{f g}}\right)_{j}^{t+\Delta t}\right)^{c t_{4}} \\
& e=\left(\left(\frac{C p_{l} \mu_{l}}{k_{l}}\right)_{j}^{t+\Delta t}\right)^{c t_{5}} \\
& a_{g}=\frac{0.023 K_{g_{j}}{ }^{t+\Delta t}}{D_{h g_{j}}{ }^{t+\Delta t} h_{g_{g_{j}}}{ }^{t+\Delta t}} P_{\text {int } e r f} \Delta x \Delta t\left(T_{\text {sati } j}{ }^{t+\Delta t}-T_{g_{j}}{ }^{t+\Delta t}\right) \\
& b_{g}=\left(\left(\frac{\rho_{g} D_{h g}}{\mu_{g}}\right)_{j}^{t+\Delta t}\left(\frac{u_{g_{j-1 / 2}}+u_{g_{j+1 / 2}}}{2}\right)^{t+\Delta t}\right)^{0.8} \\
& c_{g}=\left(\left(\frac{C p_{g} \mu_{g}}{k_{g}}\right)_{j}^{t+\Delta t}\right)^{0.4}
\end{aligned}
$$

The steam condensation at one time step and at the interface of node $\mathrm{j}$ is expressed now as function of the previous constants;

$$
\Phi_{g}\left(K_{g}\right)=-a b c d e-\frac{Q_{i g_{j}}{ }^{t+\Delta t}}{h_{g i j}{ }^{t+\Delta t}-h_{l i j}{ }^{t+\Delta t}}
$$

\section{D.2.1 DERIVATIVE OF THE STEAM CONDENSATION DERIVATIVE WITH RESPECT TO THE STEAM PRESSURE}

$$
\frac{\partial \Phi_{g_{j}}{ }^{t+\Delta t}}{\partial P_{g_{j}}{ }_{j}+\Delta t}=h_{l \text { int } j}{ }^{t+\Delta t}\left(T_{\text {sati } j}{ }^{t+\Delta t}-T_{g_{j}}{ }^{t+\Delta t}\right) P_{\text {int } e r f} \Delta x \Delta t\left(h_{f g_{j}}{ }^{t+\Delta t}\right)-2 \frac{\partial h_{f g_{j}}{ }^{t+\Delta t}}{\partial P_{g_{j}}{ }^{t+\Delta t}}
$$




$$
\begin{aligned}
& -\operatorname{abdect}_{3}\left(\left(\frac{D_{h g}}{\mu_{g}}\right)_{j}^{t+\Delta t}\left(\frac{u_{g_{j-1 / 2}}+u_{g_{j+1 / 2}}}{2}\right)^{t+\Delta t}\right)^{c t_{3}}\left(\rho_{g_{j}}{ }^{t+\Delta t}\right) \frac{\partial t_{3}-1}{\partial \rho_{g_{j}}{ }^{t+\Delta t}} \frac{\partial P_{g_{j}}{ }^{t+\Delta t}}{} \\
& +\operatorname{abdect}_{3}\left(\left(\rho_{g} D_{h g}\right)_{j}^{t+\Delta t}\left(\frac{u_{g_{j-1 / 2}}+u_{g_{j+1 / 2}}}{2}\right)^{t+\Delta t}\right)^{c t_{3}}\left(\mu_{g_{j}}{ }^{t+\Delta t}\right)^{-c t_{3}-1} \frac{\partial \mu_{g_{j}}{ }^{t+\Delta t}}{\partial P_{g_{j}}{ }^{t+\Delta t}} \\
& + \text { abcect }_{3}\left(\left(\frac{C p_{l} \rho_{l}\left(T_{g}-T_{l}\right)}{\rho_{g}}\right)_{j}^{t+\Delta t}\right)^{c t_{3}}\left(h_{f g_{j}}{ }^{t+\Delta t}\right)^{-c t_{3}-1} \frac{\partial h_{f g_{j}}{ }^{t+\Delta t}}{\partial P_{g_{j}}{ }^{t+\Delta t}} \\
& + \text { abcect }_{3}\left(\left(\frac{C p_{l} \rho_{l}\left(T_{g}-T_{l}\right)}{h_{f g}}\right)_{j}^{t+\Delta t}\right)^{c t 3}\left(\rho_{g_{j}}{ }^{t+\Delta t}\right)^{-c t_{3}-1} \frac{\partial \rho_{g_{j}}{ }^{t+\Delta t}}{\partial P_{g_{j}}{ }^{t+\Delta t}} \\
& -\frac{K_{g_{j}}{ }^{t+\Delta t}}{D_{h g_{j}{ }^{t+\Delta t} h_{g_{j}}{ }^{t+\Delta t}}} P_{\text {int } e r f} \Delta x \Delta t\left(T_{\text {sati } j}{ }^{t+\Delta t}-T_{g_{j}}{ }^{t+\Delta t}\right) 0.023 b_{g} c_{g}\left(K_{g_{j}}{ }^{t+\Delta t}\right)^{-2} \frac{\partial K_{g_{j}}{ }^{t+\Delta t}}{\partial P_{g_{j}}{ }^{t+\Delta t}} \\
& -0.8 a_{g} c_{g}\left(\left(\frac{D_{h g}}{\mu_{g}}\right)_{j}^{t+\Delta t}\left(\frac{u_{g_{j-1 / 2}}+u_{g_{j+1 / 2}}}{2}\right)^{t+\Delta t}\right)^{0.8}\left(\rho_{g_{j}}{ }^{t+\Delta t}\right)^{0.8-1} \frac{\partial \rho_{g_{j}}{ }^{t+\Delta t}}{\partial P_{g_{j}}{ }^{t+\Delta t}} \\
& \left.+0.8 a_{g} c_{g}\left(\rho_{g} D_{h g}\right)_{j}^{t+\Delta t}\left(\frac{u_{g_{j-1 / 2}}+u_{g_{j+1 / 2}}}{2}\right)^{t+\Delta t}\right)^{0.8}\left(\mu_{g_{j}}{ }^{t+\Delta t}\right)^{-0.8-1} \frac{\partial \mu_{g_{j}}{ }^{t+\Delta t}}{\partial P_{g_{j}}{ }^{t+\Delta t}} \\
& -0.4 a_{g} b_{g}\left(\left(\frac{C p_{g}}{k_{g}}\right)_{j}^{t+\Delta t}\right)^{0.4}\left(\mu_{g_{j}}{ }^{t+\Delta t}\right)^{-0.4-1} \frac{\partial \mu_{g_{j}}{ }^{t+\Delta t}}{\partial P_{g_{j}}{ }^{t+\Delta t}} \\
& -0.4 a_{g} b_{g}\left(\left(\frac{\mu_{g}}{K_{g}}\right)_{j}^{t+\Delta t}\right)^{0.4}\left(C p_{g_{j}}{ }^{t+\Delta t}\right)^{-0.6} \frac{\partial C p_{g_{j}}{ }^{t+\Delta t}}{\partial P_{g_{j}}{ }^{t+\Delta t}}
\end{aligned}
$$




$$
+0.4 a_{g} b_{g}\left(\left(C p_{g} \mu_{g}\right)_{j}^{t+\Delta t}\right)^{0.4}\left(K_{g_{j}}{ }^{t+\Delta t}\right)^{-1.4} \frac{\partial K_{g_{j}}{ }^{t+\Delta t}}{\partial P_{g_{j}}{ }^{t+\Delta t}}
$$

\section{D.1.2 DERIVATIVE OF THE STEAM CONDENSATION WITH} RESPECT TO THE STEAM PRESSURE DIFFERENCES

$$
\begin{aligned}
& \frac{\partial \Phi_{g_{j}}{ }^{t+\Delta t}}{\partial\left(P_{g_{j}}-P_{g_{j-1}}\right)^{t+\Delta t}}=-\operatorname{abdect}_{3}\left(\left(\frac{\rho_{g} D_{h g}}{2 \mu_{g}}\right)_{j}^{t+\Delta t}\right)^{c t_{3}}\left(u_{g_{j-1 / 2}}{ }^{t+\Delta t}+u_{g_{j+1 / 2}}^{t+\Delta t}\right){ }^{c t_{3}-1} \frac{\partial u_{g_{j-1 / 2}}{ }^{t+\Delta t}}{\partial\left(P_{g_{j}}-P_{g_{j-1}}\right)^{t+\Delta t}} \\
& -a_{g} c_{g} c t_{3}\left(\left(\frac{\rho_{g} D_{h g}}{2 \mu_{g}}\right)_{j}^{t+\Delta t}\right)^{c t_{3}}\left(u_{g_{j-1 / 2}}^{t+\Delta t}+u_{g_{j+1 / 2}}^{t+\Delta t}\right)^{c t_{3}-1} \frac{\partial u_{g_{j-1 / 2}}^{t+\Delta t}}{\partial\left(P_{g_{j}}-P_{g_{j-1}}\right)^{t+\Delta t}} \text { (D.24) } \\
& \frac{\partial \Phi_{g_{j}}^{t+\Delta t}}{\partial\left(P_{g_{j+1}}-P_{g_{j}}\right)^{t+\Delta t}}=-\operatorname{abdect}_{3}\left(\left(\frac{\rho_{g} D_{h g}}{2 \mu_{g}}\right)_{j}^{t+\Delta t}\right)^{c t_{3}}\left(u_{g_{j-1 / 2}+\Delta t}+u_{g_{j+1 / 2}}^{t+\Delta t}\right)^{c t_{3}-1} \frac{\partial u_{g_{j+1 / 2}+\Delta t}^{t+2}}{\partial\left(P_{g_{j+1}}-P_{g_{j}}\right)^{t+\Delta t}} \\
& -a_{g} c_{g} c t_{3}\left(\left(\frac{\rho_{g} D_{h g}}{2 \mu_{g}}\right)_{j}^{t+\Delta t}\right)^{c t_{3}}\left(u_{g_{j-1 / 2}}^{t+\Delta t}+u_{g_{j+1 / 2}}^{t+\Delta t}\right)^{c t_{3}-1} \frac{\partial u_{g_{j+1 / 2}}^{t+\Delta t}}{\partial\left(P_{g_{j+1}}-P_{g_{j}}\right)^{t+\Delta t}} \text { (D.25) }
\end{aligned}
$$

\section{D.1.3 DERIVATIVE OF THE STEAM CONDENSATION WITH} RESPECT TO THE STEAM TEMPERATURE

$$
\frac{\partial \Phi_{g_{j}}^{t+\Delta t}}{\partial T_{g_{j}}^{t+\Delta t}}=-\frac{h_{l \text { int } j}{ }_{j}^{t+\Delta t} P_{\text {int } t \text { erf }} \Delta x \Delta t}{h_{f g}^{\prime}}
$$




$$
\begin{aligned}
& +h_{l \text { int } j}{ }^{t+\Delta t}\left(T_{\text {sati } j}{ }^{t+\Delta t}-T_{g_{j}}{ }^{t+\Delta t}\right) P_{\text {int } e r f} \Delta x \Delta t\left(h_{f g_{j}}{ }^{t+\Delta t}\right)^{-2} \frac{\partial h_{f g_{j}}{ }^{t+\Delta t}}{\partial T_{g_{j}}^{t+\Delta t}} \\
& -\operatorname{abdect}_{3}\left(\left(\frac{D_{h g}}{\mu_{g}}\right)_{j}^{t+\Delta t}\left(\frac{u_{g_{j-1 / 2}}+u_{g_{j+1 / 2}}}{2}\right)^{t+\Delta t}\right)^{c t_{3}}\left(\rho_{g_{j}}{ }^{t+\Delta t}\right)^{-0.47} \frac{\partial \rho_{g_{j}}{ }^{t+\Delta t}}{\partial T_{g_{j}}{ }^{t+\Delta t}} \\
& +\operatorname{abdect}_{3}\left(\left(\rho_{g} D_{h g}\right)_{j}^{t+\Delta t}\left(\frac{u_{g_{j-1 / 2}}+u_{g_{j+1 / 2}}}{2}\right)^{t+\Delta t}\right)^{c t_{3}}\left(\mu_{g_{j}}{ }^{t+\Delta t}\right)^{-C 3-1} \frac{\partial \mu_{g_{j}}{ }^{t+\Delta t}}{\partial T_{g_{j}}{ }^{t+\Delta t}} \\
& +\operatorname{abcect}_{4}\left(\left(\frac{C p_{l} \rho_{l}\left(T_{g}-T_{l}\right)}{h_{f g}}\right)_{j}^{t+\Delta t}\right)^{c t_{4}}\left(\rho_{g_{j}}{ }^{t+\Delta t}\right)-c t_{4}-\frac{\partial \rho_{g_{j}}{ }^{t+\Delta t}}{\partial T_{g_{j}}{ }^{t+\Delta t}} \\
& +\operatorname{abcect}_{4}\left(\left(\frac{C p_{l} \rho_{l}\left(T_{g}-T_{l}\right)}{\rho_{g}}\right)_{j}^{t+\Delta t}\right)^{c t_{4}}\left(h_{f g_{j}}{ }^{t+\Delta t}\right)^{-c t_{4}-1} \frac{\partial h_{f g_{j}}{ }^{t+\Delta t}}{\partial T_{g_{j}}{ }^{t+\Delta t}} \\
& - \text { abcect }_{4}\left(\left(\frac{C p_{l} \rho_{l}}{\rho_{g} h_{f g}}\right)_{j}^{t+\Delta t}\right)^{c t_{4}}\left(\left(T_{g}-T_{l}\right)_{j}^{t+\Delta t}\right) c t_{4}^{-1} \\
& + \text { abcect }_{3}\left(\left(\frac{C p_{l} \rho_{l}\left(T_{g}-T_{l}\right)}{h_{f g}}\right)_{j}^{t+\Delta t}\right)^{c t_{3}}\left(\rho_{g_{j}}{ }^{t+\Delta t}\right)^{-c t_{3}-1} \frac{\partial \rho_{g_{j}}{ }^{t+\Delta t}}{\partial P_{g_{j}}{ }^{t+\Delta t}} \\
& -\frac{K_{g_{j}}{ }^{t+\Delta t}}{D_{h g_{j}}{ }^{t+\Delta t} h_{f_{g_{j}}}{ }^{t+\Delta t}} P_{\text {int } e r f} \Delta x \Delta t\left(T_{\text {sati } j}{ }^{t+\Delta t}-T_{g_{j}}{ }^{t+\Delta t}\right) 0.023 b_{g} c_{g}\left(K_{g_{j}}{ }^{t+\Delta t}\right)^{-2} \frac{\partial K_{g_{j}}{ }^{t+\Delta t}}{\partial T_{g_{j}}{ }^{t+\Delta t}} \\
& -0.8 a_{g} c_{g}\left(\left(\frac{D_{h g}}{\mu_{g}}\right)_{j}^{t+\Delta t}\left(\frac{u_{g_{j-1 / 2}}+u_{g_{j+1 / 2}}}{2}\right)^{t+\Delta t}\right)^{0.8}\left(\rho_{g_{j}}{ }^{t+\Delta t}\right)^{0.8-1} \frac{\partial \rho_{g_{j}}{ }^{t+\Delta t}}{\partial T_{g_{j}}{ }^{t+\Delta t}}
\end{aligned}
$$




$$
\begin{aligned}
& +0.8 a_{g} c_{g}\left(\left(\rho_{g} D_{h g}\right)_{j}^{t+\Delta t}\left(\frac{u_{g_{j-1 / 2}}+u_{g_{j+1 / 2}}}{2}\right)^{t+\Delta t}\right)^{0.8}\left(\mu_{g_{j}}{ }^{t+\Delta t}\right)^{-0.8-1} \frac{\partial \mu_{g_{j}}{ }^{t+\Delta t}}{\partial T_{g_{j}}{ }^{t+\Delta t}} \\
& -0.4 a_{g} b_{g}\left(\left(\frac{C p_{g}}{k_{g}}\right)_{j}^{t+\Delta t}\right)^{0.4}\left(\mu_{g_{j}}{ }^{t+\Delta t}\right)^{-0.4-1} \frac{\partial \mu_{g_{j}}{ }^{t+\Delta t}}{\partial T_{g_{j}}{ }^{t+\Delta t}} \\
& -0.4 a_{g} b_{g}\left(\left(\frac{\mu_{g}}{K_{g}}\right)_{j}^{t+\Delta t}\right)^{0.4}\left(C p_{g_{j}}{ }^{t+\Delta t}\right)^{-0.6} \frac{\partial C p_{g_{j}}{ }^{t+\Delta t}}{\partial T_{g_{j}}{ }^{t+\Delta t}} \\
& +0.4 a_{g} b_{g}\left(\left(C p_{g} \mu_{g}\right)_{j}^{t+\Delta t}\right)^{0.4}\left(K_{g_{j}}{ }^{t+\Delta t}\right)^{-1.4} \frac{\partial K_{g_{j}}{ }^{t+\Delta t}}{\partial T_{g_{j}}{ }^{t+\Delta t}}
\end{aligned}
$$




\section{APPENDIX E}

\section{CALCULATION OF THE WALL HEAT TRANSFER AND CONDENSATION}

In this chapter the condensation at the wall of a horizontal and circular pipe will be studied in more detail.

In the literature there is not too much information about wall condensation for a circular surface at the inside of a horizontal pipe. In the Heat Transfer [Mills, 2009] book, we may find a brief description of what we should do in order to obtain the local heat transfer coefficient as well as the condensation rate and the condensate film thickness as functions of the angle.

It is more common to find the Nusselt study of the condensation for a falling film on a vertical plate, as we see below:

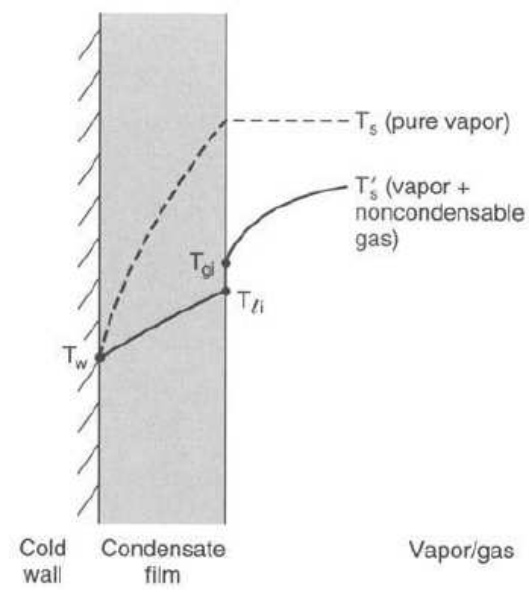

Figure E.1 Temperature distributions during film condensation on a vertical plate 
The balances which are made at an elementary element of condensate volume are shown in the figure below. These are, the momentum in $\mathrm{z}$ and $\mathrm{y}$ directions (vertical and horizontal), and the energy balance in the y direction, as shown in Figure E.2.

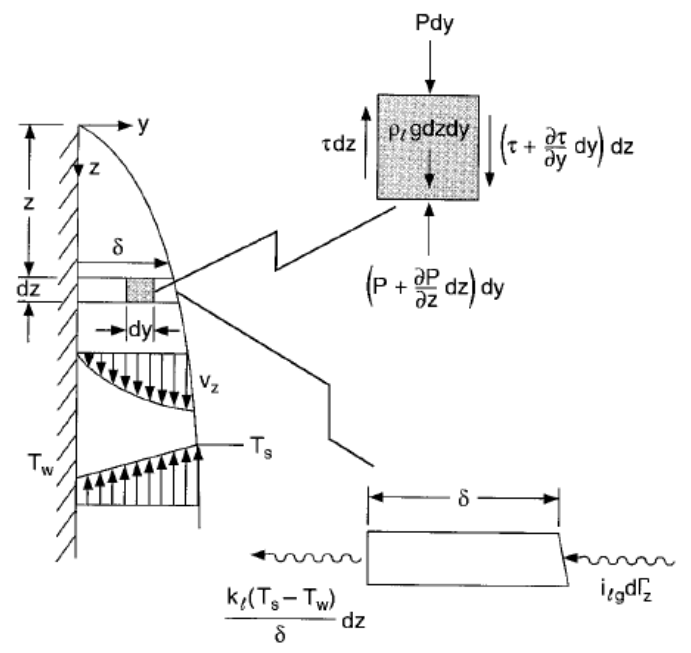

Figure E.2. Model of laminar film condensation on a vertical plate

We first assume in this case that, the steam is at a saturation temperature $T_{\text {sat }}$, the plate surface temperature is $T_{w}$, and we have a laminar free convection. We first make a momentum balance in $\mathrm{z}$ direction:

$$
\frac{\partial \tau}{\partial y}-\frac{\partial P}{\partial z}+\rho_{l} g=0
$$

where $\tau$ is the shear stress, $P$ is the film pressure, $\rho_{l}$ is the liquid film density, and $g$ is the gravity acceleration.

A similar momentum balance in the y direction gives $\frac{\partial P}{\partial y}=0$, so that:

$$
\frac{\partial P}{\partial z}=\frac{d P_{g}}{d z}=\rho_{g} g
$$


Substituting Equation (E.2) into (E.1), integrating from $y$ to $\delta$ with the assumption that all fluid properties are constant, yields the shear stress distribution in the film:

$$
\tau=\mu_{l} \frac{\partial u_{z}}{\partial y}=\left(\rho_{l}-\rho_{g}\right) g(\delta-y)
$$

where $u_{z}$ is the velocity in the $\mathrm{z}$ direction and $\delta$ is the film thickness.

The shear stress at $y=\delta$ has been assumed to be zero. With $u_{z}=0$ at $y=0$, the condensate velocity distribution is:

$$
u_{z}=\frac{\left(\rho_{l}-\rho_{g}\right) g}{\mu_{l}}\left(\delta y-y^{2} / 2\right)
$$

The local liquid flow rate (per unit depth) in the film can be calculated:

$$
\Gamma_{z}=\int_{0}^{\delta} \rho_{z} u_{z} d z=\frac{\rho_{l}\left(\rho_{l}-\rho_{g}\right) g \delta^{3}}{3 \mu_{l}}
$$

Neglecting the convection effects in the film, and making an energy balance on a differential slice of condensate of width dz (Figure E.1) gives:

$$
\frac{d \Gamma_{z}}{d z}=\frac{k_{l}\left(T_{s}-T_{w}\right)}{i_{f g} \delta}
$$

where $i_{f g}$ is the enthalpy due to the phase change.

Combining Equation (E.6) with Equation (E.5), and assuming that the wall temperature remains constant, yields the local heat transfer coefficient:

$$
h_{z}=\frac{q^{\prime \prime}}{\left(T_{s}-T_{w}\right)}=\frac{k_{l}}{\delta}=\left[\frac{\rho_{l}\left(\rho_{l}-\rho_{g}\right) g i_{f g} k_{l}^{3}}{4 \mu_{l}\left(T_{s a t}-T_{w}\right) z}\right]^{1 / 4}
$$

We can get the mean heat transfer coefficient for a vertical plate by integrating Equation (E.7) between $z=0$ and $L$ : 


$$
\bar{h}_{m}=\frac{1}{L} \int_{0}^{L} h_{z} \cdot d z=0.943\left[\frac{\rho_{l}\left(\rho_{l}-\rho_{g}\right) g i_{f g} k_{l}^{3}}{\mu_{l}\left(T_{s a t}-T_{w}\right) L}\right]^{1 / 4}
$$

From now on, we are going to do something similar in order to obtain the mean heat transfer coefficient and the condensation rate at the wall of an horizontal and circular pipe wall.

In Figure (E.3) we can see the flow configuration that we have. This is, we have water at the bottom of the pipe, interfacial condensation, and steam condensation at the pipe wall with liquid condensate falling from along the pipe wall to the liquid bulk.

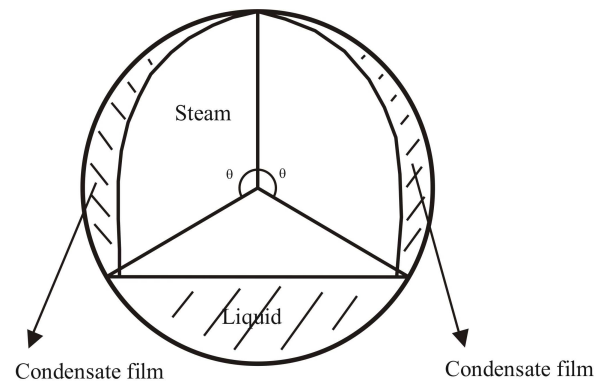

Figure E.3. Axial cut of the pipe. Configuration of the problem

An elementary volume is being considered as can be seen in Figure A.4:

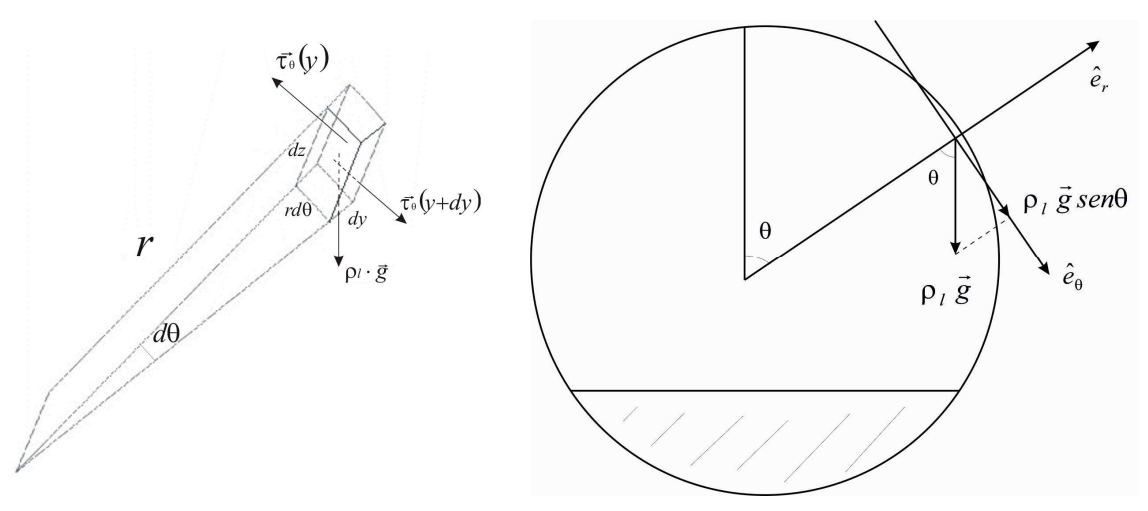

Figure E.4. Momentum balance at an elementary volume of the condensate film of the wall 
Firstly it will be performed a momentum balance in the $\hat{e}_{\theta}$ direction. So we get:

$$
\begin{aligned}
\left\{\rho_{l} g \operatorname{sen} \theta \cdot r d \theta d r d z\right\} \hat{e}_{\theta} & +\left\{\tau_{\theta}(r) d \theta d z-\left(r \tau_{\theta}+\frac{\partial}{\partial r}\left(r \tau_{\theta}\right) d r\right)\right\} d \theta d z \hat{e}_{\theta}+ \\
& +\left[P d r d z-\left(P+\frac{\partial P}{\partial \theta} d \theta\right) d r d z\right] \hat{e}_{\theta}=0
\end{aligned}
$$

Clearing, we get; $\rightarrow \rho_{l} g \operatorname{sen} \theta r-\frac{\partial}{\partial r}\left(r \tau_{\theta}\right)-\frac{\partial P}{\partial \theta}=0$

As we have a volume of liquid immersed in steam, we will have a buoyancy force due to the steam. We can say this equals:

$$
\frac{1}{r} \frac{\partial P}{\partial \theta}=\rho_{g}^{*} g \operatorname{sen} \theta
$$

Taking $r=R-y$ and $d r=-d y$ :

$$
\frac{\partial}{\partial r}\left(r \tau_{\theta}\right)=r\left(\rho_{l}-\rho_{g}\right) g \operatorname{sen}(\theta) \rightarrow-\frac{\partial}{\partial y}\left((R-y) \tau_{\theta}\right)=(R-y)\left(\rho_{l}-\rho_{g}\right) g \operatorname{sen}(\theta)
$$

As we now, $\tau_{\theta}=-\mu \frac{\partial u_{l}}{\partial y}$ and as $r=R-y$ and $d r=-d y$,

$$
\rightarrow \frac{\partial}{\partial y}=\frac{\partial}{\partial r} \frac{\partial r}{\partial y}=-\frac{\partial}{\partial r}
$$

Hence: 


$$
-\frac{\partial}{\partial y}\left((R-y) \mu \frac{\partial u_{l}}{\partial y}\right)=(R-y)\left(\rho_{l}-\rho_{g}\right) g \operatorname{sen} \theta
$$

Note 1:

$$
\int_{0}^{y} y \frac{\left(R-\frac{y}{2}\right)}{R-y} d y=\frac{1}{R} \int_{0}^{y} y \frac{\left(R-\frac{y}{2}\right)}{\left(1-\frac{y}{R}\right)} y d y=\frac{1}{R} \int_{0}^{y} y\left(R-\frac{y}{2}\right)\left(1+\frac{y}{R}\right) d y
$$

on account that $\mathrm{y}<<\mathrm{R}$, we can expand the denominator in Taylor series to get:

$$
\begin{aligned}
& \approx \frac{1}{R} \int_{0}^{y} y\left(R y-\frac{y^{2}}{2}\right)\left(1+\frac{y}{R}\right) d y=\frac{1}{R} \int_{0}^{y}\left(R y+\frac{y^{2}}{2}-\frac{y^{3}}{2 R}\right) d y=\frac{y^{2}}{2}+\frac{y^{3}}{6 R}-\frac{y^{4}}{8 R^{2}} \\
& -\int \frac{y^{2}}{2(R-y)} d y=-\frac{1}{2 R} \int y^{2}\left(1+\frac{y}{R}\right) d y=\frac{-y^{3}}{6 R}+\frac{y^{4}}{8 R^{2}} \approx \frac{-y^{3}}{6 R}
\end{aligned}
$$

We integrate between $y$ and $\delta$, with the boundary conditions;

$\tau_{i}(y=\delta)=\left.0 \Rightarrow \frac{\partial u_{l}}{\partial y}\right|_{y=\delta}=0$, and $u_{l}(y=0)=0$ :

$-\int_{y}^{\delta} \frac{\partial}{\partial y}\left((R-y) \mu \frac{\partial u_{l}}{\partial y}\right) d y=\int(R-y)\left(\rho_{l}-\rho_{g}\right) \operatorname{gsen}(\theta) d y$

Next we use the boundary condition at $y=\delta$ :

$[R-y] \mu \frac{\partial u_{l}}{\partial y}=\left[R \delta-\frac{\delta^{2}}{2}-R y+\frac{y^{2}}{2}\right]\left(\rho_{l}-\rho_{g}^{*}\right) g \operatorname{sen}(\theta)$ 


$$
\frac{\partial u_{l}}{\partial y}=\frac{1}{\mu} \frac{\left[R \delta-\frac{\delta^{2}}{2}-R y+\frac{y^{2}}{2}\right]}{[R-y]}\left(\rho_{l}-\rho_{g}^{*}\right) g \operatorname{sen}(\theta)
$$

So, integrating between 0 and $y$, and on account of the boundary condition at $y=0$ :

$$
\begin{gathered}
u_{l}(y)=-\frac{g \operatorname{sen} \theta}{\mu}\left(\rho_{l}-\rho_{g}^{*}\right) g\left(R \delta-\frac{\delta^{2}}{2}\right)[\ln (R-y)]_{0}^{y}-\frac{\left(\rho_{l}-\rho_{g}\right) g \operatorname{sen} \theta}{\mu} \int_{0}^{y} y \frac{\left(R-\frac{y}{2}\right)}{(R-y)} d y \\
u_{l}(y)=-\frac{g \operatorname{sen} \theta}{\mu}\left(\rho_{l}-\rho_{g}^{*}\right)\left(R \delta-\frac{\delta^{2}}{2}\right) \ln \left(1-\frac{y}{R}\right)-\frac{\left(\rho_{l}-\rho_{g}^{*}\right) g \operatorname{sen} \theta y^{2}}{\mu} . \\
\left(\frac{1}{2}+\frac{1}{6}\left(\frac{y}{R}\right)-\frac{1}{8}\left(\frac{y}{R}\right)^{2}\right)=-\frac{g \operatorname{sen} \theta}{\mu}\left(\rho_{l}-\rho_{g}^{*}\right)\left(R \delta-\frac{\delta^{2}}{2}\right) \ln \left(1-\frac{y}{R}\right)- \\
\frac{\left(\rho_{l}-\rho_{g}^{*}\right) g \operatorname{sen} \theta}{\mu}\left(\frac{2}{2}+\frac{1}{6}\left(\frac{y}{R}\right)-\frac{1}{8}\left(\frac{y^{2}}{R^{2}}\right)\right)
\end{gathered}
$$

Here we approximate lineally the logarithm using the Taylor series expansion to the two first terms:

$$
\ln \left(1-\frac{y}{R}\right) \approx-\frac{y}{R}-\frac{y^{2}}{2 R^{2}}
$$

Note 2:

$$
\ln (1-x)=\ln 1+\left[\frac{-1}{1-x}\right]_{x=0} x+\frac{1}{2}\left[\frac{-1}{(1-x)^{2}}\right]_{x=0} x^{2}=0-x-\frac{x^{2}}{2}
$$


So, we get:

$$
u_{l}(y)=-\frac{g \operatorname{sen} \theta}{\mu}\left(\rho_{l}-\rho_{g}^{*}\right)\left[\left(R \delta-\frac{\delta^{2}}{2}\right)\left(-\frac{y}{R}+\frac{y^{2}}{R^{2}}\right)+\frac{y^{2}}{2}+\frac{1}{6}\left(\frac{y^{3}}{R}\right)-\frac{1}{8}\left(\frac{y^{4}}{R^{2}}\right)\right]
$$

Neglecting the terms in $1 / R^{2}$, we have the velocities profile for the condensate film as a function of the angle.

$$
\begin{gathered}
u_{l}(y)=-\frac{g \operatorname{sen} \theta}{\mu}\left(\rho_{l}-\rho_{g}^{*}\right)\left[\delta y-\frac{y^{2}}{2}-\frac{\delta^{2}}{2 R}+\frac{\delta^{2} y}{2 R}-\frac{\delta^{2} y^{2}}{4 R^{2}}-\frac{1}{6} \frac{y^{3}}{R}+\frac{1}{8}\left(\frac{y^{4}}{R^{2}}\right)\right] \\
\approx \frac{g \operatorname{sen} \theta}{\mu}\left(\rho_{l}-\rho_{g}^{*}\right)\left\{\delta \mathrm{y}-\frac{y^{2}}{2}+\frac{\delta^{2}}{2 R}-\frac{\delta^{2} y}{2 R}-\frac{\delta^{2} y^{2}}{4 R^{2}}-\frac{1}{6} \frac{y^{3}}{R}\right\} \\
\mathrm{u}_{1}(\mathrm{y})=\frac{\operatorname{gsen} \theta}{\mu}\left(\rho_{1}-\rho_{\mathrm{g}}^{*}\right)\left\{\delta \mathrm{y}-\frac{\mathrm{y}^{2}}{2}+\frac{\delta \mathrm{y}}{2 \mathrm{R}}-\frac{\delta^{2} \mathrm{y}}{2 \mathrm{R}}-\frac{\delta^{2} \mathrm{y}^{2}}{4 \mathrm{R}^{2}}-\frac{1}{6} \frac{\mathrm{y}^{3}}{\mathrm{R}}\right\}
\end{gathered}
$$

Equation (E.18). Condensate liquid velocity profile

We will calculate now the mass condensation rate per unit length at the wall, by using the velocity profile obtained before:

$$
\Gamma(\theta)=\int_{0}^{\delta(\theta)} \rho_{1} \mathrm{u}_{1 \theta}(\theta) \mathrm{dy}=\frac{\rho_{\mathrm{l}}\left(\rho_{1}-\rho_{\mathrm{g}}^{*}\right) \mathrm{gsen} \theta}{\mu}\left\{\frac{\delta^{3}}{2}-\frac{\delta^{3}}{6}+\frac{\delta^{4}}{6 \mathrm{R}}-\frac{\delta^{4}}{4 \mathrm{R}}-\frac{1}{24} \frac{\delta^{4}}{\mathrm{R}}\right\}
$$




$$
\begin{gathered}
=\frac{\rho_{l}\left(\rho_{l}-\rho_{g}^{*}\right) g \operatorname{sen} \theta}{\mu}\left\{\frac{\delta^{3}}{3}-\frac{(4+6+1)}{24} \frac{\delta^{4}}{R}\right\} \\
=\frac{\rho_{l}\left(\rho_{l}-\rho_{g}^{*}\right) g \operatorname{sen} \theta}{\mu}\left\{\frac{\delta^{3}}{3}-\frac{3}{24} \frac{\delta^{4}}{R}\right\} \\
=\frac{\rho_{l}\left(\rho_{l}-\rho_{g}^{*}\right) g \operatorname{sen} \theta}{\mu} \frac{\delta^{3}}{3}\left\{1-\frac{3}{8} \frac{\delta}{R}\right\} \\
\Gamma(\theta)=\frac{\rho_{l}\left(\rho_{l}-\rho_{g}^{*}\right) g \operatorname{sen} \theta}{\mu} \frac{\delta^{3}}{3}\left\{1-\frac{3}{8} \frac{\delta}{R}\right\}
\end{gathered}
$$

Equation (E.20). Mass condensation rate

Now we introduce the film Reynolds number, which is:

$$
\operatorname{Re}(\theta)=\frac{\rho \bar{v} D_{h}}{\mu}=\frac{\Gamma 4 \delta}{\delta \mu}=\frac{4 \Gamma(\theta)}{\mu}
$$

The hydraulic diameter is, $D_{h}=\frac{4 A}{P_{\text {mojado }}}=\frac{4 x 1 x \delta}{1}=4 \delta$

So, we get:

$$
\operatorname{Re}(\theta)=\frac{4 \rho_{l}\left(\rho_{l}-\rho_{g}^{*}\right) g \operatorname{sen} \theta}{\mu^{2}} \frac{\delta^{3}}{3}\left(1-\frac{3}{8} \frac{\delta}{R}\right)
$$

As we want to clear $\delta$, we assume that, $\frac{3}{8} \frac{\delta}{R} \approx \frac{3}{8} \frac{\delta_{\mathrm{N}}}{R}$, where $\delta_{\mathrm{N}}$ is the Nusselt thickness:

$$
\operatorname{Re}(\theta)=\frac{4 \rho_{l}\left(\rho_{l}-\rho_{g}^{*}\right) g \operatorname{sen} \theta}{\mu^{2}} \frac{\delta^{3}}{3}\left(1-\frac{3}{8} \frac{\delta_{\mathrm{v}}}{R}\right)
$$


and clearing $\delta$ :

$$
\delta=\frac{\left[\frac{3 \mu^{2} \operatorname{Re}(\theta)}{4 \rho_{l}\left(\rho_{l}-\rho_{g}^{*}\right) g \operatorname{sen}(\theta)}\right]^{1 / 3}}{\left[1-\frac{3}{8} \frac{\delta_{\mathrm{v}}}{R}\right]^{1 / 3}} \approx \frac{\delta_{\mathrm{v}}(\theta)}{\left[1-3 \frac{\delta_{\mathrm{v}}}{R}\right]^{1 / 3}}
$$

Equation (E.24) For the condensate film thickness

Note 3:

Neglecting the term $\delta_{N} / R$, we get the Nusselt expression for the condensation on

cylindrical pipes:

$$
\operatorname{Re}_{N}(\theta)=\frac{4 \rho_{l}\left(\rho_{l}-\rho_{g}^{*}\right) g \operatorname{sen} \theta}{\mu^{2}} \frac{\delta_{N}^{3}}{3} \text { Hence } \delta_{N}=\left[\frac{3 \mu^{2} \operatorname{Re}_{N}(\theta)}{4 \rho_{l}\left(\rho_{l}-\rho_{g}^{*}\right) g \operatorname{sen}(\theta)}\right]^{1 / 3}
$$

We are going to make an energy balance in the condensate film:

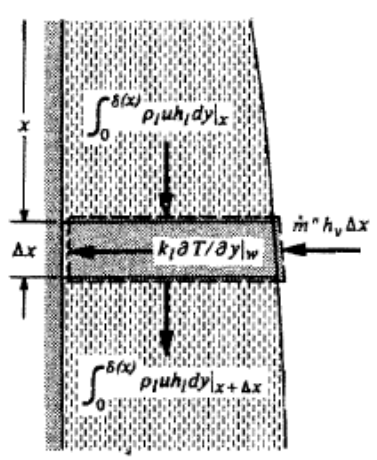

Figure E.5 Elementary volume for the condensate falling film 
Let's consider firstly, and for simplicity, a condensate film on a vertical plate. Here we have next the energy balance:

$$
\begin{aligned}
\rho_{l} C p \frac{\partial T_{l}}{\partial t}=\vec{\nabla}\left(K \cdot \vec{\nabla} T_{l}\right)+q^{\prime \prime \prime} \\
\rightarrow \rho_{l} C p \frac{\partial T_{l}}{\partial t}=\vec{\nabla}\left(\frac{\partial^{2} T_{l}}{\partial x^{2}}+\frac{\partial^{2} T_{l}}{\partial y^{2}}+\frac{\partial^{2} T_{l}}{\partial z^{2}}\right)+q^{\prime \prime \prime}
\end{aligned}
$$

being $T_{l}$ the liquid temperature at the layer.

Considering, the $\mathrm{x}$ direction, steady state condition, and that there is no volumetric heat source, we get:

$$
\frac{\partial^{2} T_{l}}{\partial x^{2}}=0
$$

We solve now this differential equation at the falling film, with the next boundary conditions:

$y=0 \rightarrow T_{l}=T_{w}$

$y=\delta \rightarrow T_{l}=T_{\text {sat }}$

$$
\text { Hence, } \quad T_{l}=\frac{T_{s a t}-T_{w}}{\delta} y+T_{w}
$$

Now, we want to get the value for the local heat transfer coefficient. For this, we make an energy flux balance for the liquid condensate film. This is:

$$
\left\{\begin{array}{l}
\dot{q}^{\prime \prime}=h \cdot\left(T_{w}-T_{\text {sat }}\right) \\
\dot{q}^{\prime \prime}=-K \cdot \vec{\nabla} T
\end{array}\right.
$$


We equate both equations, and we clear the heat transfer coefficient, and so we obtain;

$$
\bar{h}=\frac{\left[-K_{l} \cdot \frac{\partial T_{l}}{\partial y}\right]_{y=0}}{T_{w}-T_{s a t}}
$$

Now, from Equation (E.28), $\frac{\partial T_{l}}{\partial y}=\frac{T_{s a t}-T_{w}}{\delta}$, and, hence, the local heat transfers is:

$$
\begin{gathered}
\bar{h}=\frac{-K_{l} \cdot \frac{\partial T_{l}}{\partial y}}{T_{w}-T_{\text {sat }}}=\frac{-K_{l} \cdot \frac{T_{\text {sat }}-T_{w}}{\delta}}{T_{w}-T_{\text {sat }}}=\frac{K_{l}}{\delta} \\
\bar{h}=\frac{K_{l}}{\delta}
\end{gathered}
$$

Equation (E.33). Local heat transfer coefficient

Making an energy balance, as we se in Figure E.5, so computing the energy balance due to the phase change, is in absolute value:

$$
\dot{q}^{\prime \prime}=K_{l} \cdot \frac{T_{s a t}-T_{w}}{\delta}=h_{f g}^{\prime} \frac{d \Gamma}{d x}
$$

In our case, we have a curved surface, because we are trying to obtain the mass condensation rate for the inner wall of a circular and horizontal pipe. So, using Equation (E.34) and, $x=R \cdot \theta \rightarrow d x=R d \theta:$

$K_{l} \frac{T_{s a t}-T_{w}}{\delta}=h_{f g}^{\prime} \frac{d \Gamma}{d x}=h_{f g}^{\prime} \frac{d \Gamma}{d \theta} \frac{d \theta}{d x}=\frac{h_{f g}^{\prime}}{R} \frac{d \Gamma}{d \theta}$, so: 


$$
\frac{d \Gamma}{d \theta}=\frac{R K_{l}\left(T_{s a t}-T_{w}\right)}{h_{f g}^{\prime} \delta(\theta)}
$$

Here, we might say that we are solving the problem for an isothermal wall surface.

As, $\operatorname{Re}(\theta)=\frac{4 \Gamma(\theta)}{\mu}$, then $\frac{d \Gamma(\theta)}{d \theta}=\frac{\mu}{4} \frac{d \operatorname{Re}(\theta)}{d \theta}$ and so;

$$
\frac{\mu}{4} \frac{d \operatorname{Re}(\theta)}{d \theta}=\frac{R K_{l}\left(T_{s a t}-T_{w}\right)}{h_{f g}^{\prime} \cdot \delta}
$$

From Equation (E.24),

$$
\delta(\theta)=\frac{\delta \mathrm{N}(\theta)}{\left[1-\frac{3}{8} \frac{\delta}{\mathrm{R}}\right]^{1 / 3}}=\frac{\left[\frac{3 \mu^{2}}{4 \rho_{1}\left(\rho_{1}-\rho_{\mathrm{g}}^{*}\right) \mathrm{g}}\right]^{1 / 3} \frac{\operatorname{Re}_{\mathrm{N}}^{1 / 3}(\theta)}{\operatorname{sen}^{1 / 3} \theta}}{\left[1-\frac{3}{8}\left[\frac{3 \mu^{2}}{4 \rho_{1}\left(\rho_{1}-\rho_{\mathrm{g}}\right) \mathrm{g}}\right]^{1 / 3} \frac{\operatorname{Re}_{\mathrm{N}}^{1 / 3}(\theta)}{\operatorname{Rsen}^{1 / 3} \theta}\right]^{1 / 3}}=\frac{\mathrm{C}_{1} \frac{\operatorname{Re}_{\mathrm{N}}^{1 / 3}(\theta)}{\operatorname{sen}^{1 / 3} \theta}}{\left[1-\frac{3}{8} \mathrm{C}_{1} \frac{\operatorname{Re}_{\mathrm{N}}^{1 / 3}(\theta)}{\operatorname{Rsen}^{1 / 3} \theta}\right]^{1 / 3}}
$$

Where,

$$
C_{1}=\left[\frac{3 \mu^{2}}{4 \rho_{l}\left(\rho_{l}-\rho_{g}^{*}\right) g}\right]
$$

Substituting of $\delta(\theta)$ into Equation (E.35) yields:

$$
d \theta=\frac{h_{f g}^{\prime}}{R K_{l} \Delta T} \frac{\mu}{4} C_{1} \frac{R_{e}^{1 / 3}(\theta)}{\operatorname{sen}^{1 / 3} \theta} d \operatorname{Re} \frac{1}{\left[1-\frac{3}{8} C_{1} \frac{R_{e}{ }^{1 / 3}(\theta)}{\operatorname{Rsen}^{1 / 3} \theta}\right]^{1 / 3}}
$$

By neglecting the term, $\frac{3}{8} C_{1} \frac{\operatorname{Re}^{1 / 3}(\theta)}{\operatorname{Rsen}^{1 / 3} \theta}$, we get:

$$
\operatorname{sen}^{1 / 3}(\theta) d \theta=\frac{h_{f g}^{\prime} \mu C_{1}}{4 K \Delta T R} \operatorname{Re}_{N}^{1 / 3} d \operatorname{Re}_{N}
$$


Now, we integrate this equation:

$$
\int_{0}^{\theta_{i}} \operatorname{sen}^{1 / 3}(\theta) d \theta=F\left(\theta_{i}\right)=\frac{h_{f g}^{\prime} \mu}{4 R K \Delta T}\left[\frac{3 \mu^{2}}{4 \rho_{l}\left(\rho_{l}-\rho_{g}{ }^{*}\right) g}\right]^{1 / 3} \frac{\left[\operatorname{Re}_{N}\left(\theta_{i}\right)\right]^{4 / 3}}{4 / 3}
$$

Hence, we get the Reynolds number as a function of the angle $\theta_{i}$ :

$$
\begin{aligned}
\operatorname{Re}_{N}\left(\theta_{i}\right)= & {\left[\frac{4}{3} F\left(\theta_{i}\right) \frac{4 R K \Delta T}{h_{f g}^{\prime} \mu_{l}}\left(\frac{4 \rho_{l}\left(\rho_{l}-\rho_{g}{ }^{*}\right) g}{3 \mu_{l}{ }^{2}}\right)^{1 / 3}\right]^{3 / 4}=} \\
& =\left[\frac{8 D K \Delta T}{3 h_{f g}^{\prime} \mu}\right]^{3 / 4}\left[\frac{4 \rho_{l}\left(\rho_{l}-\rho_{g}^{*}\right) g}{3 \mu_{l}^{2}}\right]^{1 / 4}\left(F\left(\theta_{i}\right)\right)^{3 / 4}
\end{aligned}
$$

where; $F\left(\theta_{i}\right)=\int_{0}^{\theta_{i}} \operatorname{sen}^{1 / 3}(\theta) d \theta$

$$
\operatorname{Re}_{N}\left(\theta_{i}\right)=\left[\frac{8 D K \Delta T}{3 h_{f g}^{\prime} \mu_{l}}\right]^{3 / 4}\left[\frac{4 \rho_{l}\left(\rho_{l}-\rho_{g}^{*}\right) g}{3 \mu_{l}^{2}}\right]^{1 / 4}\left(F\left(\theta_{i}\right)\right)^{3 / 4}
$$

\section{Equation (E.43). Reynolds number in the approach}

Once we have the $\operatorname{Re}_{N}\left(\theta_{i}\right)$, we get the equation for the thickness in the Nusselt approximation $\delta_{N}\left(\theta_{i}\right)$ :

Defining the constants; $A=\frac{8 D K_{l} \Delta T}{3 h_{f g}^{\prime} \mu_{l}}, B=\frac{4 \rho_{l}\left(\rho_{l}-\rho_{g}^{*}\right) g}{3 \mu_{l}^{2}}$, we have: 


$$
\begin{gathered}
\delta_{\mathrm{N}}=\left[\frac{3 \mu^{2}\left[\frac{8 D K_{l} \Delta T}{3 h_{f g}^{\prime} \mu_{l}}\right]^{3 / 4}\left[\frac{4 \rho_{l}\left(\rho_{l}-\rho_{g}^{*}\right) g}{3 \mu_{l}{ }^{2}}\right]^{1 / 4}\left(F\left(\theta_{i}\right)\right)^{3 / 4}}{4 \rho_{l}\left(\rho_{l}-\rho_{g}{ }^{*}\right) \operatorname{sen}\left(\theta_{i}\right)}\right]^{1 / 3}= \\
=\left[\frac{A^{1 / 4} B^{1 / 12} F^{1 / 4}\left(\theta_{i}\right)}{B^{1 / 3} \operatorname{sen}^{1 / 3}\left(\theta_{i}\right)}\right]=\frac{A^{1 / 4} B^{-1 / 4} F^{1 / 4}\left(\theta_{i}\right)}{\operatorname{sen}^{1 / 3}\left(\theta_{i}\right)}=\frac{A^{1 / 4} F^{1 / 4}\left(\theta_{i}\right)}{B^{1 / 4} \operatorname{sen}^{1 / 3}\left(\theta_{i}\right)}
\end{gathered}
$$

Now that we have $\delta_{N}\left(\theta_{i}\right)$, we substitute it in Equation (E.24):

$$
\delta \approx \frac{\delta_{\mathrm{N}}\left(\theta_{i}\right)}{\left[1-\frac{3}{8} \frac{\delta_{\mathrm{N}}\left(\theta_{i}\right)}{R}\right]^{1 / 3}}=\frac{\frac{A^{1 / 4} F^{1 / 4}\left(\theta_{l}\right)}{B^{1 / 4} \operatorname{sen}^{1 / 3}\left(\theta_{l}\right)}}{\left[1-\frac{3}{8} \frac{\left(\frac{A^{1 / 4} F^{1 / 4}\left(\theta_{l}\right)}{B^{1 / 4} \operatorname{sen}^{1 / 3}\left(\theta_{l}\right)}\right)}{R}\right]^{1 / 3}}
$$

In order to obtain the local heat transfer coefficient, we substitute the Equation (E.45) in Equation (E.33):

$$
\mathrm{h}\left(\theta_{1}\right)=\frac{\mathrm{K}_{1}}{\delta}=\frac{\mathrm{K}_{1}}{\delta_{\mathrm{N}}\left(\theta_{\mathrm{i}}\right)}\left(1-\frac{3}{8} \frac{\delta_{\mathrm{N}}\left(\theta_{\mathrm{i}}\right)}{\mathrm{R}}\right)^{1 / 3}=\frac{\mathrm{B}^{1 / 4} \operatorname{sen}^{1 / 3}\left(\theta_{\mathrm{i}}\right) \mathrm{K}_{1}}{\mathrm{~A}^{1 / 4}\left(\mathrm{~F}\left(\theta_{\mathrm{i}}\right)\right)^{1 / 4}}\left(1-\frac{3}{8} \frac{\mathrm{A}^{1 / 4}\left(\mathrm{~F}\left(\theta_{\mathrm{i}}\right)\right)^{1 / 4}}{\mathrm{RB}^{1 / 4} \operatorname{sen}^{1 / 3}\left(\theta_{\mathrm{i}}\right)}\right)^{1 / 3}
$$

So, the mean heat transfer coefficient is:

$$
\bar{h}\left(\theta_{i}\right)=\frac{1}{\theta_{i}} \int_{0}^{\theta_{i}} h(\theta) d \theta=\frac{1}{\theta} \int_{0}^{\theta_{v}} \frac{B^{1 / 4} \operatorname{sen}^{1 / 3}(\theta) K_{l}}{A^{1 / 4}(F(\theta))^{1 / 4}}\left(1-\frac{3}{8} \frac{A^{1 / 4}(F(\theta))^{1 / 4}}{R^{1 / 4} \operatorname{sen}^{1 / 3}(\theta)}\right)^{1 / 3} d \theta
$$




$$
\bar{h}\left(\theta_{i}\right)=\frac{B^{1 / 4} K_{l}}{A^{1 / 4}} \frac{1}{\theta_{i}} \int_{0}^{\theta_{i}} \frac{\operatorname{sen}^{1 / 3}(\theta)}{(F(\theta))^{1 / 4}}\left(1-\frac{3}{8} \frac{A^{1 / 4}(F(\theta))^{1 / 4}}{R^{1 / 4} \operatorname{sen}^{1 / 3}(\theta)}\right)^{1 / 3} d \theta
$$

\section{Equation (E.47). Mean condensation heat transfer coefficient}

As we will need the derivatives of the this coefficient with respect to the steam temperature and pressure:

E.1 Derivative of $\bar{h}\left(\theta_{i}\right)$ with respect to the steam pressure:

$$
\begin{aligned}
& \frac{\partial \bar{h}\left(\theta_{i}\right)}{\partial P_{g}}= \\
& -\frac{1}{4} B^{-3 / 4} \frac{K_{l}}{A^{1 / 4}}\left[\frac{1}{\theta_{i}} \int_{0}^{\theta_{i}} \frac{\operatorname{sen}^{1 / 3}(\theta)}{(F(\theta))^{1 / 4}}\left(1-3 \frac{A^{1 / 4}(F(\theta))^{1 / 4}}{R B^{1 / 4} \operatorname{sen}^{1 / 3}(\theta)}\right)^{1 / 3} d \theta\right] \frac{4 \rho_{l} g}{3 \mu_{l}^{2}} \frac{d \rho_{g}}{d P_{g}} \\
& -\frac{1}{4} A^{-5 / 4} B^{1 / 4} K_{l}\left[\frac{1}{\theta_{i}} \int_{0}^{\theta_{i}} \frac{\operatorname{sen}^{1 / 3}(\theta)}{(F(\theta))^{1 / 4}}\left(1-\frac{3}{8} \frac{A^{1 / 4}(F(\theta))^{1 / 4}}{R B^{1 / 4} \operatorname{sen}^{1 / 3}(\theta)}\right)^{1 / 3} d \theta\right] . \\
& \cdot \frac{3 h_{f g}^{\prime} \mu}{8 D K_{l}}\left(T_{s a t}-T_{w}\right)^{-5 / 4} \frac{d T_{s a t}}{d P_{g}}
\end{aligned}
$$

E.2 Derivative of $\bar{h}\left(\theta_{i}\right)$ with respect to the steam temperature: 
Appendix E

$$
\begin{aligned}
\frac{\partial \bar{h}\left(\theta_{i}\right)}{\partial T_{g}} & = \\
& -\frac{1}{4} B^{-3 / 4} \frac{K_{l}}{A^{1 / 4}}\left[\frac{1}{\theta_{i}} \int_{0}^{\theta_{i}} \frac{\operatorname{sen}^{1 / 3}(\theta)}{(F(\theta))^{1 / 4}}\left(1-\frac{3}{8} \frac{A^{1 / 4}(F(\theta))^{1 / 4}}{R B^{1 / 4} \operatorname{sen}^{1 / 3}(\theta)}\right)^{1 / 3} d \theta\right] \frac{4 \rho_{l} g}{3 \mu_{l}^{2}} \frac{d \rho_{g}}{d T_{g}} \text { (E.49) }
\end{aligned}
$$




\section{APPENDIX F}

\section{CALCULATION OF THE AXIAL LIQUID TEMPERATURE PROFILE}

As we are trying to study the thermal stratification in the cold leg due to a small break in the hot leg, we need to get the vertical liquid temperature profile in the liquid phase at the lower part of the cold leg.

With our two-phase1D CC code we obtain a mean bulk liquid temperature at the liquid layer. So we will have to determine the liquid temperature profile by assuming a parabolic shape in the liquid, as follows:

$$
T_{l}(\xi)=T_{0}+b \xi+c \xi^{2}
$$

In Figure F.1 how we are assuming the axis and how the profile looks like is shown:

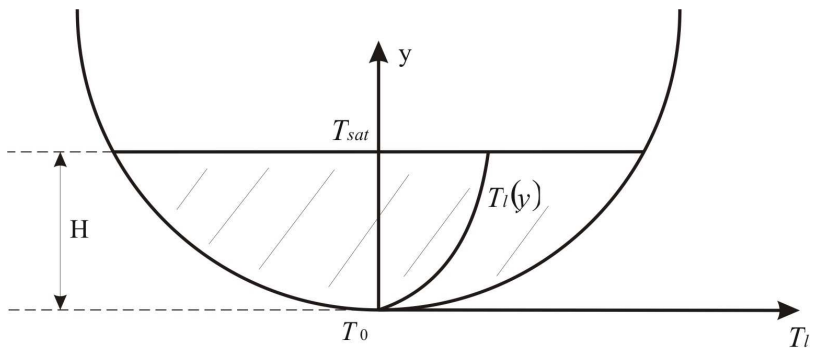

Figure F.1 Liquid temperature profile

As we see in the Equation F.1, we have three unknown constants. Hence we will need three conditions that we will have to impose to the equation in order to obtain the profile. Here below we are going to explain the method to obtain them: 


\section{CONDITION 1:}

First we define $\xi$ as $\xi=\frac{y}{H}$, where $\mathrm{y} \in[0, \mathrm{H}]$

Hence,

$y=0 \rightarrow \xi=0$

$y=H \rightarrow \xi=1$, and $\xi \in[0,1]$.

So, this first condition fixes the liquid temperature at the interfacial surface at $T_{\text {sat }}$. Hence we get:

$$
\begin{gathered}
\xi=1 \Rightarrow T_{l}(1)=T_{\text {sat }}=T_{0}+b+c \\
T_{\text {sat }}=T_{0}+b+c
\end{gathered}
$$

Equation (F.2)

\section{CONDITION 2:}

The second condition refers to the mean liquid temperature at the liquid layer. With our CC code, we get a bulk temperature for the liquid and the steam phase, as it is a 1D code. So, the mean value for the liquid temperature with the Equation F.1 has to equal the value for the temperature given by the CC code $T_{l m}$.

$$
\begin{gathered}
T_{l m}=\int_{0}^{1} T_{l}(\xi) d \xi \\
\int_{0}^{1} T_{l}(\xi) d \xi=\left[T_{0} \xi+\frac{1}{2} b \xi^{2}+\frac{1}{3} c \xi^{3}\right]_{0}^{1}=\left(T_{0}+\frac{1}{2} b+\frac{1}{3} c\right) \\
T_{l m}=T_{0}+\frac{1}{2} b+\frac{1}{3} c
\end{gathered}
$$

Equation (F.5) 


\section{CONDITION 3:}

Here we will equal the heat transfer at the liquid wall. This is, we will equal the conduction heat transfer with the convective heat transfer from the liquid to the wall.

$$
\begin{gathered}
\left.\dot{q}^{\prime \prime}\right|_{w}=-\left.K_{l} \frac{\partial T_{l}}{\partial \xi}\right|_{\xi=0}=h_{w l}\left(T_{w}-T_{l m}\right) \\
\left.\frac{\partial T_{l}}{\partial \xi}\right|_{\xi=0}=b \\
\Rightarrow b=-\frac{h_{w l}\left(T_{w}-T_{l m}\right)}{K_{l}}
\end{gathered}
$$

Now, we can substitute b in Equations F.2 and F.5. So, solving the system of two equations, we get the values for $T_{0}$ an c:

$$
\begin{aligned}
& c=-\frac{3}{2}\left[\left(T_{l m}-T_{\text {sat }}\right)+\frac{1}{2} \frac{h_{w l}\left(T_{l m}-T_{w}\right)}{K_{l}}\right] \\
& T_{0}=\frac{3}{2} T_{l m}-\frac{1}{2} T_{\text {sat }}-\frac{1}{2} \frac{h_{w l}\left(T_{l m}-T_{w}\right)}{K_{l}}
\end{aligned}
$$

Now, we have the three constants that we need, to get the Equation F.1, and by substituting we get:

$$
\begin{aligned}
& T_{l}(\xi)=\frac{3}{2} T_{l m}-\frac{1}{2} T_{s a t}-\frac{1}{2} \frac{h_{w l}\left(T_{l m}-T_{w}\right)}{K_{l}}-\frac{h_{w l}\left(T_{w}-T_{l m}\right)}{K_{l}} \cdot \xi \\
& -\frac{3}{2}\left[\left(T_{l m}-T_{s a t}\right)+\frac{1}{2} \frac{h_{w l}\left(T_{l m}-T_{w}\right)}{K_{l}}\right] \xi^{2}
\end{aligned}
$$


In the beginning, the idea was to study the thermal stratification in the cold leg of the Rosa facility, and simulate test 1.2 , which was explained in Chapter 3. So a liquid temperature distribution in an axial cut of the pipe would be needed. Here we have obtained a temperature distribution for the centre of the liquid layer, but we would need a temperature distribution for more points in order to compare the results with the thermal stratification data from the ROSA facility test.

In order to have this, we will suppose here a similitude solution. This means that the temperature distribution in different parts of the liquid layer has the same shape (parabolic), and the boundary conditions are the same. So, the only thing that changes is the value for the liquid depth $\mathrm{H}$, which depends on where we are trying to get the temperature profile, as it is illustrated in the next figure:

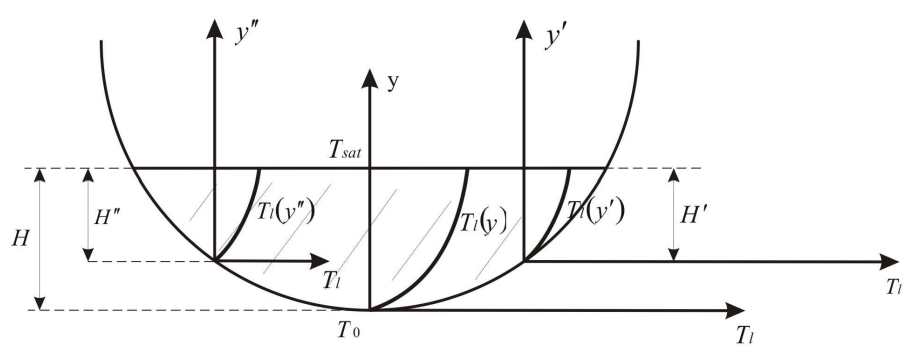

Figure (F.2). Liquid temperature profile at different points

The limitations of the 1D CC code that we have developed, made it complicated to obtain a profitable and accurate result for the axial liquid temperature distribution, and in the results chapter a fully comparative study of the test 1.2 in comparison with our CC code results has not been included. 


\section{APPENDIX G}

\section{VON NEUMANN STABILITY ANALYSIS}

Several methods have been developed for making a stability analysis, almost all of them limited to linear problems. Even though with this restriction a complete stability investigation for problems with initial and boundary conditions can be extremely complicated, particularly with boundary conditions and its numerical representation.

The question of the stability for a linear problem with constant coefficients is now well known when the influence of the boundaries can be neglected or removed. In this case even for an infinite domain or for periodic conditions in an finite domain. In the last case we consider that the domain in the $\mathrm{x}$ axis of length $\mathrm{L}$ is repeated periodically and hence all the quantities, the solution, so as the errors, can be developed in Fourier series over the domain 2L. This development in the frequencies domain forms the basis of the Von Neumann stability method.

Considering an simple harmonic $E_{j}^{n} e^{l i \phi}$, its evolution time is determined by the same numerical scheme than the complete solution of $u_{i}{ }^{n}$, where $\mathrm{n}$ indicates the time level and $i$ the cell node in the grid. Inserting a representation of this shape in the errors equation:

$$
\frac{\varepsilon_{i}^{n+1}-\varepsilon_{i}^{n}}{\Delta t}=-\frac{a}{2 \Delta x}\left(\varepsilon_{i+1}^{n}-\varepsilon_{i-1}^{n}\right)
$$

Taking out the $j$ subscript, we get: 


$$
E^{n+1}-E^{n}=-\frac{\sigma}{2} E^{n}\left(e^{l \phi}-e^{-l \phi}\right)
$$

where $\sigma=\frac{a \Delta t}{\Delta x}$. The stability condition $\lim _{n \rightarrow \infty}\left|\varepsilon_{i}^{n}\right| \leq K$ for a fixed $\Delta t$ is satisfied if the amplitude of any harmonic $E^{n}$ doesn't grow with time, i.e. if the radius:

$$
|G|=\left|\frac{E^{n+1}}{E^{n}}\right| \leq 1 \text { for every } \phi
$$

The quantity $\mathrm{G}$, defined as:

$$
G=\frac{E^{n+1}}{E^{n}}
$$

is the amplification factor and it is a function of the time step $\Delta t$, the frequency and size of the grid. In this case, from Equation (G.2), we get:

$$
G-1+\frac{\sigma}{2} \cdot 2 I \sin \phi=0
$$

Thence:

$$
G=1-\frac{\sigma}{2} \cdot 2 I \sin \phi=1-\sigma I \sin \phi
$$

The stability condition $(\mathrm{G} .3)$ requires the module of $\mathrm{G}$ to be less or equal to 1 . 
For this case we have that this condition is never satisfied. This is why the centered differences scheme $\frac{u_{i}^{n+1}-u_{i}^{n}}{\Delta t}=\frac{a}{2 \Delta x}\left(u_{i+1}^{n}-u_{i-1}^{n}\right)$ is unconditionally unstable.

Now we will insert the harmonic $E_{j}^{n} e^{l i \phi}$ in the first order Upwinding scheme:

$$
\frac{u_{i}^{n+1}-u_{i}^{n}}{\Delta t}=\frac{a}{\Delta x}\left(u_{i+1}^{n}-u_{i-1}^{n}\right)
$$

This way we have the written equation for the errors:

$$
\left(E^{n+1}-E^{n}\right) e^{l \phi}+\sigma E^{n}\left(e^{l \phi}-e^{-l(i-1) \phi}\right)=0
$$

Dividing by $e^{l \phi}$ and $E^{n}$ :

$$
G=1-\sigma+\sigma e^{-l \phi}=1-\frac{2 \sigma \sin ^{2} \phi}{2}-\sigma I \sin \phi
$$

For analyzing the stability of the First order Upwinding scheme, i.e. in the regions where the module of the amplification factor $\mathrm{G}$ is less than one, it is convenient to make a representation in the complex plane. If we consider that $\xi$ and $\eta$ are the real and the imaginary part respectively of $\mathrm{G}$, we get:

$$
\xi=1-2 \sigma \sin ^{2} \phi / 2=(1-\sigma)+\sigma \cos \phi
$$

and 


$$
\eta=-\sigma \sin \phi
$$

Which are considered as the parametric equations of $\mathrm{G}$ with $\phi$ as a parameter.

We recognise the parametric equations of a circle centered on the real axis $\varepsilon$ in $(1-\sigma)$ with radius $\sigma$.

In the complex plane of $\mathrm{G}$ the stability condition establishes that the curve that represents to $\mathrm{G}$ for al the values of $\phi=k \Delta x$ must remain in an unity circle, see Figure G.1. In this figure it is seen clearly that the scheme is stable for:

$$
0<\sigma \leq 1
$$

This is why the first order Upwinding scheme is conditionally stable, and the condition (G.9) is known as the Courant-Friedrichs-Lewy (CFL). The parameter $\sigma$ is called the Courant number. This condition was firstly introduced by Courant et al. in 1928 .

Following now the Leonard [B.P. Leonard] notation we have that considering the pure advection onedimensional model for a scalar $\phi(x, t)$ :

$$
\frac{\partial \phi}{\partial t}=-u \frac{\partial \phi}{\partial x}
$$

where $\mathrm{u}$ is a constant advective velocity. Taking a time and space uniform grid $(\Delta x, \Delta t)$ and integrating the Equation (G.13) over a finite volume we get:

$$
\bar{\phi}_{i}^{n+1}+\bar{\phi}_{i}^{n}=-u \Delta t / \Delta x\left(\phi_{r}-\phi_{l}\right)
$$

where the bars indicate the space averaging over the cell $i$ at the time steps $\mathrm{n}$ and $\mathrm{n}+1$, and the time averaged values for the right (r) and left (l) faces of the cell. In this case the Courant number is given by:

$$
c=u \Delta t / \Delta x
$$


Substitution of Equation (G.15) into (G.14) yields:

$$
\bar{\phi}_{i}^{n+1}=\bar{\phi}_{i}^{n}-c\left(\phi_{r}-\phi_{l}\right)
$$

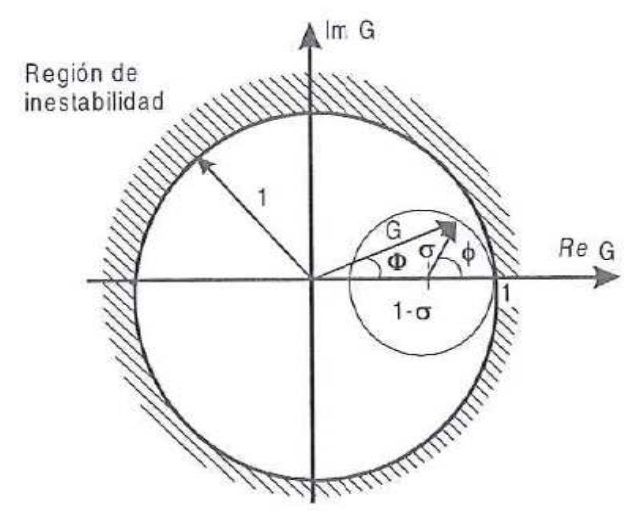

Figure G.1 Image of $G(\phi)$

For making the von Neumann analysis we write $\phi(x, t)$ as a wave:

$$
\phi(x, t)=A(t) e^{i k x}
$$

where $\mathrm{k}$ is the wave number and $i$ represents the imaginary unity $\sqrt{-1}$. when this is substituted inside the Equation (G.13) it is obtained:

$$
A(t)=A(0) e^{-i k u t}
$$

Thence the exact solution is:

$$
\phi(x, t)=A(0) e^{i k(x-u t)}
$$


Which corresponds to a wave traveling with $\phi=$ cte through the characteristics $(x=u t)$. the relation of amplitudes is then:

$$
G=\frac{\phi(x, t+\Delta t)}{\phi(x, t)}=\frac{e^{i k t(x-u(t+\Delta t))}}{e^{i k t(x-u t)}}
$$

Thence:

$$
G_{\text {exact }}=e^{i c \theta}
$$

where $\theta$ is the nondimensional number of a wave:

$$
\theta=k \Delta x
$$

If $c>1$ then we can say $c=N+\Delta c$, and we have:

$$
G_{\text {exact }}=\exp (-i N \theta) \exp (-i \Delta c \theta)
$$

The spatially averaged exact values are:

$$
\begin{aligned}
& \bar{\phi}_{i}^{n}=\frac{1}{\Delta x} \int_{x_{i}-\frac{\Delta x}{2}}^{x_{i}} A(0) e^{i k(x-u \Delta t)} d x \\
& \bar{\phi}_{i}^{n}=\frac{A(0)}{\Delta x} e^{-i k u \Delta t}\left[\frac{e^{i k x}}{i k}\right]_{x_{i}-\frac{\Delta x}{2}}^{x_{i}+\frac{\Delta x}{2}}
\end{aligned}
$$




$$
\bar{\phi}_{i}^{n}=A(0) e^{-i k u \Delta t}\left[\frac{e^{i k x_{i}}\left(e^{i k \frac{\Delta x}{2}}-e^{-i k \frac{\Delta x}{2}}\right)}{i k}\right]
$$

$$
\bar{\phi}_{i}^{n}=A(0) e^{-i k u \Delta t+i k x_{i}}\left[\frac{\operatorname{sen}\left(\frac{\theta}{2}\right)}{\frac{\theta}{2}}\right]
$$

Finally we get:

$$
\bar{\phi}_{i}^{n}=A(0) e^{i k\left(x_{i}-u \Delta t\right)}\left[\frac{\operatorname{sen}\left(\frac{\theta}{2}\right)}{\frac{\theta}{2}}\right]
$$

and

$$
\bar{\phi}_{i}^{n+1}=A(0) e^{i k\left(x_{i}-u(t+\Delta t)\right)}\left[\frac{\operatorname{sen}\left(\frac{\theta}{2}\right)}{\frac{\theta}{2}}\right]
$$

Then the exact relation of amplitudes is: 


$$
\bar{G}_{\text {exact }}=\frac{\bar{\phi}_{i}^{n+1}}{\bar{\phi}_{i}^{n}}=G_{\text {exact }}=\exp (-i k u \Delta t)=\exp (-i k \Delta x c)=\exp (-i c \theta)
$$

$$
\bar{G}_{\text {exact }}=G_{\text {exact }}=\exp (-i N \theta) \exp (i \Delta x c \theta)
$$

Making a Taylor expansion we have.

$$
=G_{\text {exact }}=1+\frac{c^{2}}{2} \theta^{2}+O\left(\theta^{4}\right)-i\left[c \theta-\frac{c^{3}}{6} \theta^{3}+O\left(\theta^{5}\right)\right]
$$

Applying the Von Neumann analysis to the second order Upwinding scheme we get:

$$
\begin{gathered}
\bar{\phi}_{i}^{n}=A(0) e^{i k\left(x_{i}-u \Delta t\right)}\left[\frac{\operatorname{sen}\left(\frac{\theta}{2}\right)}{\left.\frac{\theta}{2}\right]} \quad\right. \text { (G.33) } \\
\bar{\phi}_{i-1}^{n}=A(0) e^{i k\left(x_{-1 i}-u(t+\Delta t)\right)}\left[\frac{\operatorname{sen}\left(\frac{\theta}{2}\right)}{\frac{\theta}{2}}\right] \\
\bar{\phi}_{i-1}^{n}=A(0) e^{i k u \Delta t}\left\{\frac{\operatorname{sen}\left(\frac{\theta}{2}\right)}{\frac{\theta}{2}}\right\}\left\{e^{i k x_{i}}-c\left(\frac{3-c}{2}\right) e^{i k x_{i}}-(2-c) e^{i k x_{i}-1}+\left(\frac{1-c}{2}\right) e^{i k x_{i}-2}\right\} \text { (G.35) }
\end{gathered}
$$


From here we have that the relation of amplitudes is:

$$
G_{2 U}=\frac{\bar{\phi}_{i}^{n+1}}{\bar{\phi}_{i}^{n}}=1-c\left[\left(\frac{3-c}{2}\right)-(2-c) e^{-i \theta}+\frac{(1-c)}{2} \operatorname{sen} 2 \theta\right]
$$

Hence, the complex relation of amplitudes is:

$$
G_{2 U}=\frac{\bar{\phi}_{i}^{n+1}}{\bar{\phi}_{i}^{n}}=1-c\left(\frac{3-c}{2}\right)+c(2-c) \cos \theta-c\left(\frac{1-c}{2}\right) \cos 2 \theta-i\left[c(2-c) \operatorname{sen} \theta-c\left(\frac{1-c}{2}\right) \operatorname{sen} 2 \theta\right]
$$

Making a Taylor expansion:

$$
G_{2 U}=1+\frac{c^{2}}{2} \theta^{2}+O\left(\theta^{4}\right)-i\left[c \theta-\left(\frac{3 c^{2}-2 c}{6}\right) \theta^{3}+O\left(\theta^{5}\right)\right]
$$

If $c=1$ we have:

$$
G_{2 U}=\cos \theta-i \operatorname{sen} \theta
$$

and if $c=2$ :

$$
G_{2 U}=\cos 2 \theta-i \operatorname{sen} 2 \theta
$$


In fact the second order Upwinding scheme is stable for the range:

$$
\left|G_{2 U}\right| \leq 1 \text { for } 0 \leq c \leq 2
$$

In the case of the QUICKEST method we have, by Leonard:

$$
\begin{aligned}
& G_{Q}=1-c^{2}(1-\cos \theta)-c\left(\frac{1-c^{2}}{3}\right)(1-\cos \theta)^{2} \\
& i\left[\operatorname{csen} \theta+c\left(\frac{1-c^{2}}{3}\right) \operatorname{sen} \theta(1-\cos \theta)\right]
\end{aligned}
$$

Hence the Taylor expansion is:

$$
G_{Q}=1-c^{2} \theta^{2}+O\left(\theta^{4}\right)-i\left[c \theta-\left(\frac{c^{3}}{6}\right) \theta^{3}+O\left(\theta^{5}\right)\right]
$$

It can be observed that $G_{Q}$ is the same as $G_{\text {exact }}$ until $\theta^{3}$ for what QUICKEST is third order in time and space. 